Florida International University FIU Digital Commons

\title{
Jewish Women's Transracial Epistemological Networks: Representations of Black Women in the African Diaspora, 1930-1980
}

Abby S. Gondek

Florida International University, agond002@fiu.edu

DOI: 10.25148 /etd.FIDC004069

Follow this and additional works at: https://digitalcommons.fiu.edu/etd

Part of the African History Commons, African Languages and Societies Commons, African

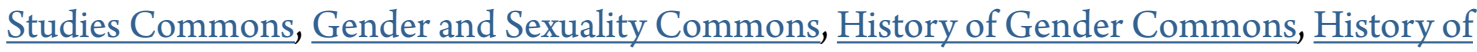
$\underline{\text { Religion Commons, History of Science, Technology, and Medicine Commons, Inequality and }}$

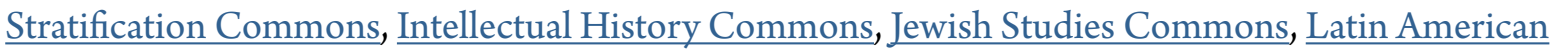
History Commons, Latin American Studies Commons, Migration Studies Commons, Quantitative, Qualitative, Comparative, and Historical Methodologies Commons, Race and Ethnicity Commons, Race, Ethnicity and Post-Colonial Studies Commons, Social and Cultural Anthropology Commons, Theory, Knowledge and Science Commons, Urban Studies and Planning Commons, Women's History Commons, and the Women's Studies Commons

\section{Recommended Citation}

Gondek, Abby S., "Jewish Women’s Transracial Epistemological Networks: Representations of Black Women in the African Diaspora, 1930-1980" (2018). FIU Electronic Theses and Dissertations. 3575.

https://digitalcommons.fiu.edu/etd/3575

This work is brought to you for free and open access by the University Graduate School at FIU Digital Commons. It has been accepted for inclusion in FIU Electronic Theses and Dissertations by an authorized administrator of FIU Digital Commons. For more information, please contact dcc@fiu.edu. 


\section{FLORIDA INTERNATIONAL UNIVERSITY}

Miami, Florida

\section{JEWISH WOMEN'S TRANSRACIAL EPISTEMOLOGICAL NETWORKS: REPRESENTATIONS OF BLACK WOMEN IN THE AFRICAN DIASPORA, $1930-1980$}

A dissertation submitted in partial fulfillment of the requirements for the degree of DOCTOR OF PHILOSOPHY

in

GLOBAL AND SOCIO-CULTURAL STUDIES

by

Abby Suzanne Gondek 
To: Dean John F. Stack, Jr.

Green School of International and Public Affairs

This dissertation, written by Abby Suzanne Gondek, and entitled Jewish Women's Transracial Epistemological Networks: Representations of Black Women in the African Diaspora, 1930-1980, having been approved in respect to style and intellectual content, is referred to you for judgment.

We have read this dissertation and recommend that it be approved.

$\begin{array}{r}\hline \text { Andrea Queeley } \\ \hline \text { Guillermo Grenier } \\ \hline \text { Alexandra Cornelius } \\ \hline \text { Vrushali Patil, Major Professor }\end{array}$

Date of Defense: March 21, 2018

The dissertation of Abby Suzanne Gondek is approved.

Dean John F. Stack, Jr. Green School of International and Public Affairs

Andrés G. Gil Vice President for Research and Economic Development and Dean of the University Graduate School

Florida International University, 2018 
(C) Copyright 2018 by Abby Suzanne Gondek

All rights reserved. 


\section{DEDICATION}

For Ruth Schlossberg Landes, who inspired my investigation into the lives of Jewish women in the history of anthropology and sociology. Without Ruth, this dissertation would not exist.

For the women who inspire me: Rosie Rosenzweig, Martha Browne-Ahokas,

Luzia do Sacramento, Sulamita Auster Portnoi, Catia Anita Nascimento, Nana Betty, my mom and my sister. 


\section{ACKNOWLEDGMENTS}

This project was made possible by grants from the Ruth Landes Memorial Research Fund, a program of the Reed Foundation as well as a Dissertation Year Fellowship through the University Graduate School at Florida International University. I wish to acknowledge all of the librarians, archivists, museum professionals, scholars and family members of the women in this project with whom I consulted for this project; without their support and assistance this project would have been impossible. More information about each individual is provided in the Appendix. I received permission from each archive to reproduce images and to quote from archival materials. I also received permission from those I interviewed in order to quote from our interviews.

I would like to thank Dr. Vrushali Patil, my dissertation advisor, for her constant encouragement of my ideas, and her praise for my creativity. Without her support, I likely would have been discouraged from completing this dissertation. I would also like to thank the members of my dissertation committee, Dr. Andrea Queeley, Dr. Alexandra Cornelius, and Dr. Guillermo Grenier. Dr. Queeley introduced me to writings about Ruth Landes in her class African Diaspora Studies Theory in my first semester at FIU (which I elaborate on in Chapter 1). Dr. Cornelius was the graduate advisor during my time in the African and African Diaspora Studies M.A. program. She also supported me as a member of my M.A. Exit Paper committee, through which she encouraged me to analyze the female theoretical influences on Ruth Landes and not just the impact of male theorists like Edison Carneiro and E. Franklin Frazier. Thus, she inspired my interest in women's epistemological networks, especially the section in Chapter 3 on the connection between Zora Neale Hurston and Ruth Landes. Dr. Grenier was the graduate program director in 
GSS during the time I applied to attend FIU, and without him, I may never have come here to Miami. Dr. Maya Boutaghou (now at the University of Virginia), who was formerly on my committee, inspired my focus on textual analysis; she encouraged me to analyze not only what these women authors wrote, but also how they wrote. I would also like to thank Dr. Okezi Otovo, who was a member of my M.A. Exit Paper committee; she taught me how to use the tracing the footnotes strategy that I used frequently and discuss in Chapter 1. Dr. Otovo also nurtured my interest in writing a final paper in her class about the intersections between Ruth Landes' theorizing and her Jewish identity, which formed the foundation for Chapter 3. I would especially like to acknowledge Dr. Jean Muteba Rahier, the chair of my M.A. Exit Paper committee. Much of the information presented in Chapter 3 regarding Ruth Landes' theories about what she considered black matriarchy and her interactions with Melville Herskovits, Arthur Ramos and Edison Carneiro emerged through the research for that Exit Paper. I would also like to acknowledge my advisor in my Women's Studies M.A. program at San Diego State, Esther Rothblum, who continues to support my academic pursuits.

I immensely appreciate the assistance and support of Pim van Bree and Geert Kessels of Lab1 100 who created the digital research platform called nodegoat that I utilized to create the social network visualizations in this dissertation; Pim and Geert answered my questions graciously, which enabled me to include these visualizations.

I want to recognize my friends and colleagues in the GSS program who supported me through the most challenging times when I thought I might not continue and who have shown me the various paths where GSS can lead: Masonya Bennett, Aysha Preston, Angelica Hill, Alexander Fernandez, Martin Tsang, Rayna Rusenko, Kemar Mcintosh, 
Mariama Jaiteh, Eric Van Vleet, Alyssa Edwards, Renata Bozzetto, Maria Barbero, Mamyrah Prosper, LaToya Eaves, and Oceane Jasor.

Thank you to my mom for providing me with access to an extensive Jewish education, my Papa Larry for encouraging me to stand up to him and to argue with him about my feminist beliefs, and my Nana Betty for telling me stories that crafted me into a feminist historian. Without Robson, I never would have continued returning to Brazil for research and would not have been drawn to doing research about Ruth Landes. Finally, I wish to acknowledge my newest supporter, Greg Whitley. 


\begin{abstract}
OF THE DISSERTATION
JEWISH WOMEN'S TRANSRACIAL EPISTEMOLOGICAL NETWORKS: REPRESENTATIONS OF BLACK WOMEN IN THE AFRICAN DIASPORA, $1930-1980$

by
\end{abstract}

Abby Suzanne Gondek

Florida International University, 2018

Miami, Florida

Professor Vrushali Patil, Major Professor

This dissertation investigates how Jewish women social scientists relationally established their gendered-racialized subjectivities and theories about race-gendersexuality-class through their portrayals of black women's sexuality and family structures in the African Diaspora: the U.S., Brazil, South Africa, Swaziland, and the U.K. The central women in this study: Ellen Hellmann, Ruth Landes, Hilda Kuper, and Ruth Glass, were part of the same political generation, born in 1908-1912, coming of age when Jews of European descent experienced an ambivalent and conditional assimilation into whiteness, a form of internal colonization. I demonstrate how each woman's familial origin point in Europe, parental class and political orientations, were important factors influencing her later personal/professional networks and social science theorizing about women of color. However, other important factors included the national racial context, the political affiliations of her partners, her marital status and her transracial fieldwork experiences. One of the main problems my work addresses is how the internal colonization process in differing nations within the Jewish diaspora differently affected 
and positioned Jewish social scientists from divergent class and political affiliations. Gendering Aamir Mufti's primarily male-oriented argument, I demonstrate how Jewish internal divergences serve as an example that highlights the lack of uniformity within any identity group, and the ways that minority groups, like Jews, use measures of so-called abnormal gender and sexuality, to create internal exiled minorities in order to try to assimilate into the majority colonizing culture. My dissertation addresses three problems within previous studies of Jewish social scientists by creating a gendered analysis of the history of Jews in social science, an analysis of Jewish subjectivity within histories of women (who were Jewish) in social science, and a critique of the either-or assumption that Jewishness necessarily equated with a radical anti-racist approach or a colonizing stance toward black communities. The data collection followed a mixed methods approach, incorporating archival research, ethnographic object analysis, site visits in Brazil and South Africa, consultations with library, archive and museum professionals, and interviews with scholars connected to the core women in the study. 


\section{TABLE OF CONTENTS}

CHAPTER

PAGE

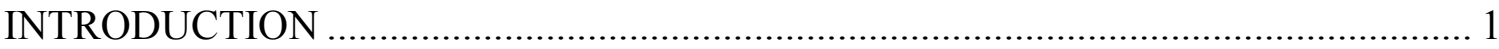

Racialization as an historically and geographically contingent process ....................... 5

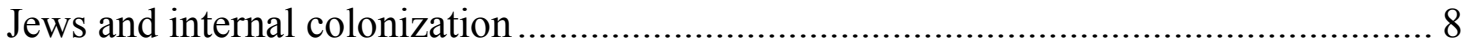

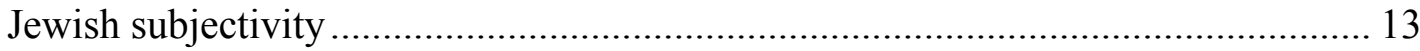

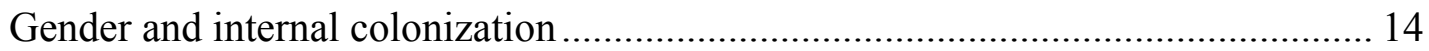

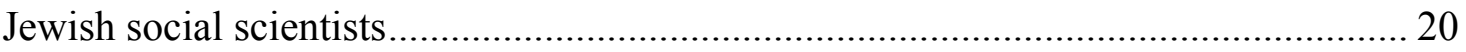

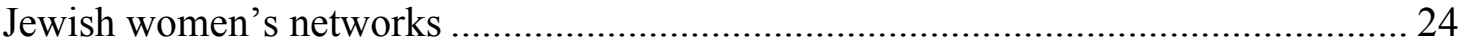

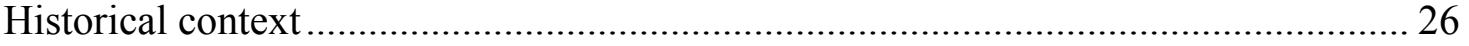

Anti-colonial and global anti-racist movements ........................................... 27

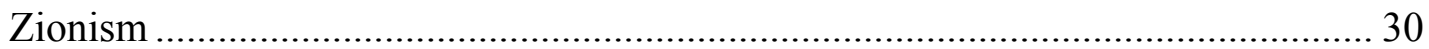

Turning point for women's involvement in nationalism and imperialism .............. 33

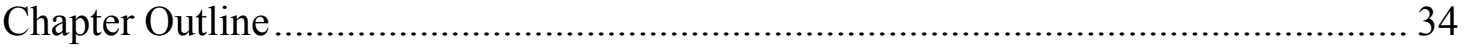

CHAPTER 1 METHODOLOGIES: REFLEXIVITY AND RECIPROCAL

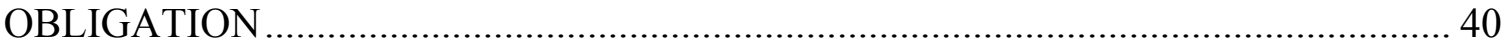

I. My gendered and racialized Jewish subjectivity formation ................................. 44

The Roots and Routes of This Project .................................................................... 52

II. Sampling Strategy and Comparative Biographies ......................................... 57

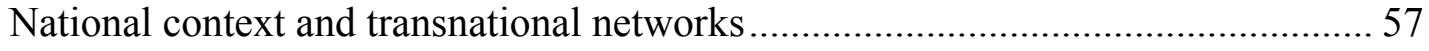

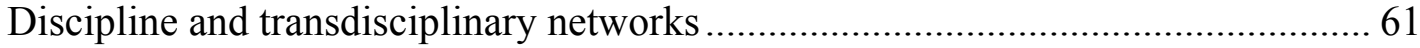

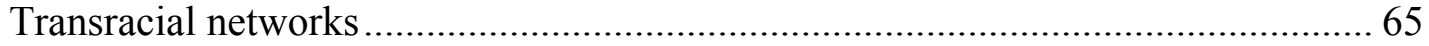

Jewish subjectivity and theorizing about race, gender, sexuality, class, nation ....... 79

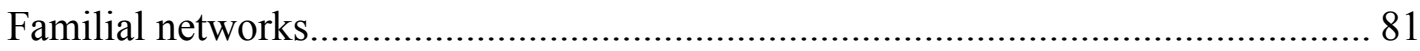

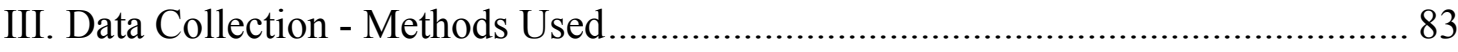

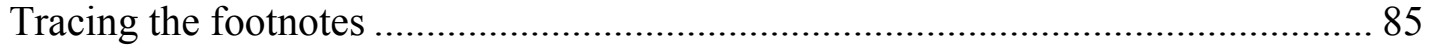

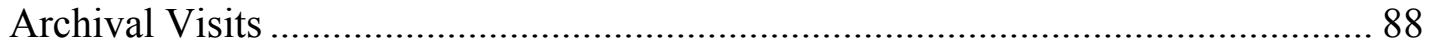

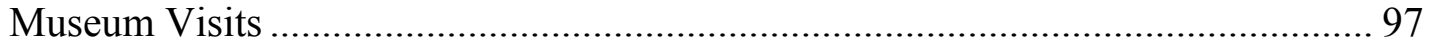

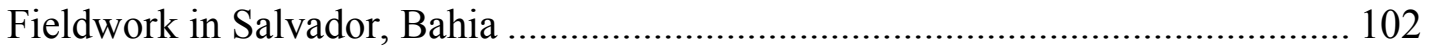

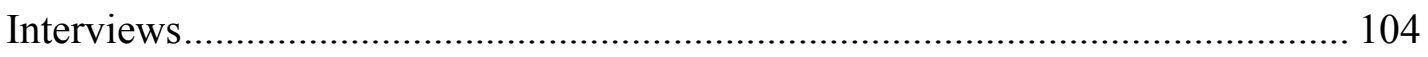




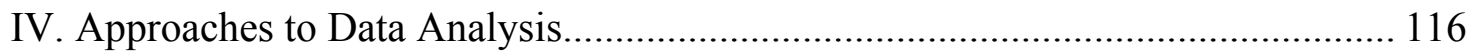

Grounded theory methodology: Textual analysis for themes ................................. 117

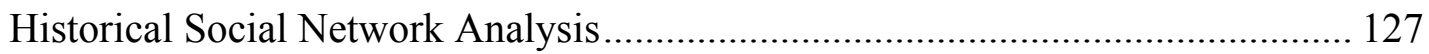

Affective entanglements and their theoretical effects......................................... 128

CHAPTER 2 DE YEKE, ELLEN HELLMANN: GERMAN JEWISH BELONGING IN WHITENESS, AND MORALISTIC REPRESENTATIONS OF BLACK WOMEN'S SEXUALITY IN JOHANNESBURG...

Part I: Jewish family backgrounds and Jewish subjectivity in relation to whiteness/blackness

Ellen Hellmann's German Jewish Family ......................................................... 136

I started out through a sense of guilt: Hellmann's involvement in Jewish community organizations

De Yeke, The German One: Eastern Jews v. Western Jews and Jewish whiteness in South Africa

Hellmann's differing approach to Jewish and Black South Africans ..................... 151

Closing for Part I........................................................................................ 168

Part II Theorizing about Black Women and Professional and Personal Networks .... 170

Gender role conformity as a form of assimilation into whiteness .......................... 175

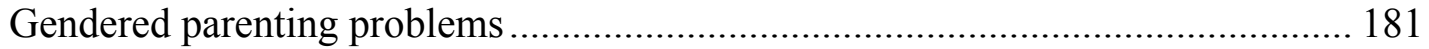

Instability of marital unions, laxness of sexual morality ........................................ 187

Prostitution and sexually transmitted diseases....................................................... 191

CHAPTER 3 I TOO BELONG IN THE STRANGE ABSTRACTION OF THE

DAMNED: RUTH LANDES, GENDERED INTERNAL COLONIZATION AND

BLACK SEXUALITY AS POWER

Part I: Jewish family backgrounds and Jewish subjectivity in relation to

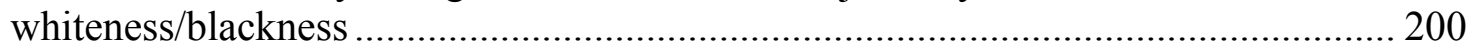

Ruth Landes' Eastern European Jewish socialist origins ....................................... 200

Ruth Landes' perception of her family's and her own whiteness............................ 211

Exposure to black intellectuals and activists ........................................................... 214

Similarities between Yiddish newspapers and Landes' writings/Communist associations

Part II: Theorizing about Black women and Professional and Personal Networks .... 228

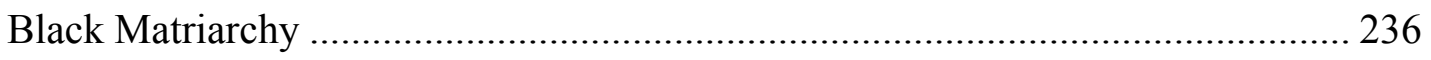

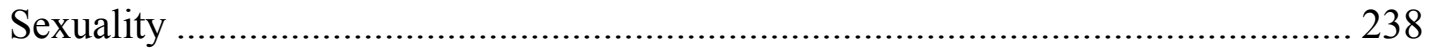


Black women as financial providers ............................................................... 242

Modernization and women's loss of power ................................................. 246

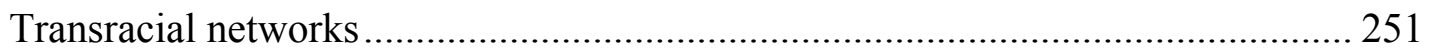

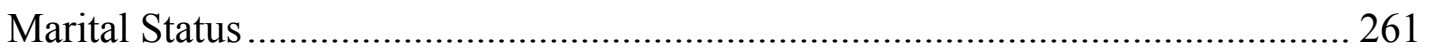

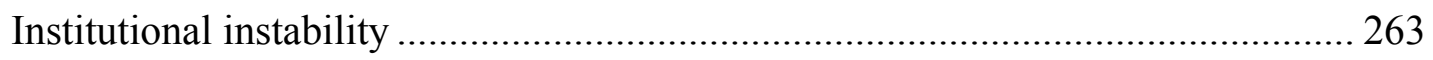

CHAPTER 4 MORE SWAZI THAN AMERICAN: HILDA KUPER - SIMILAR TRAINING, BUT DISTINCTIVE OUTCOMES ................................................... 277

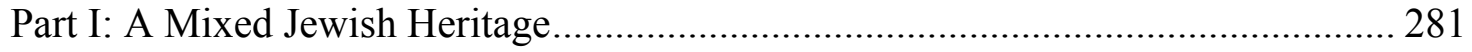

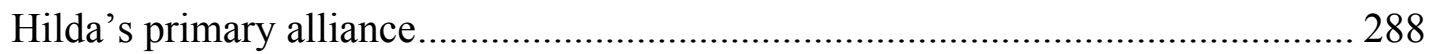

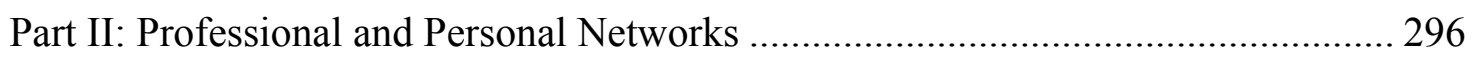

Institutional Affiliations: The differential influence of Winifred Hoernlé and SAIRR on Kuper and Hellmann ................................................................ 296

Political orientations and marital status ......................................................... 311

Divergent Political Beliefs - Ellen Hellmann, the Progressive Party and the

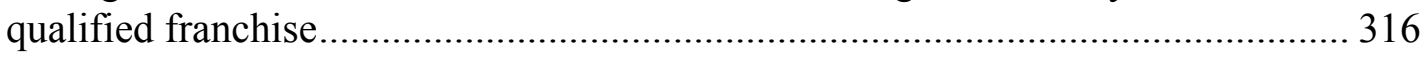

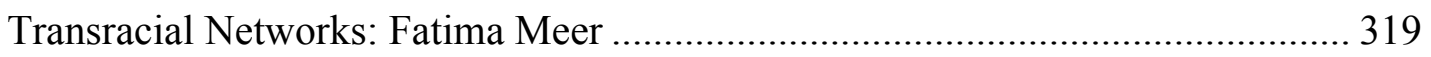

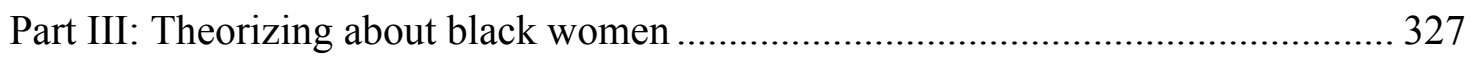

Lobola and stability of marriage in Western Native Township, a contrast to

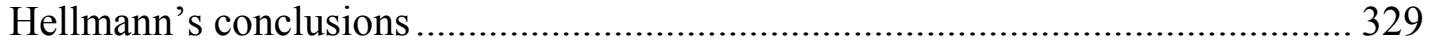

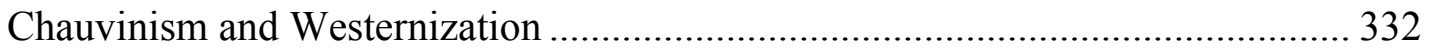

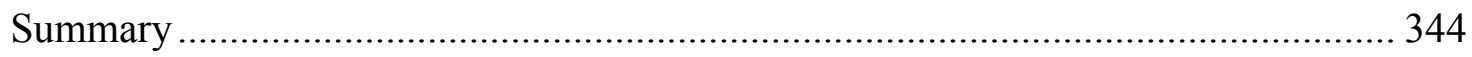

CHAPTER 5 THE CRITIQUE OF COLOUR CALCULUS: RUTH GLASS AND GERMAN JEWISH OPPOSING VIEWS OF BLACK URBAN MIGRATION .......... 347

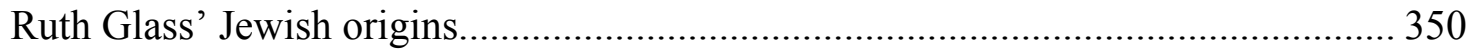

Ruth Glass' analogies between anti-Semitism and anti-black racism ..................... 353

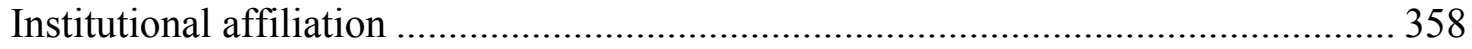

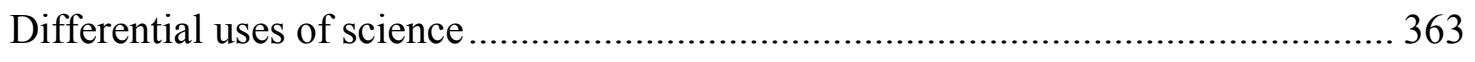

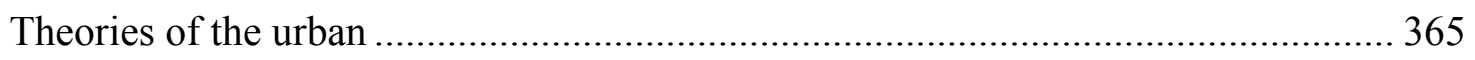

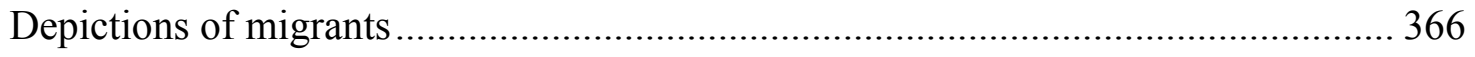

Representations of black women within race relations social science -1950 s............ 368

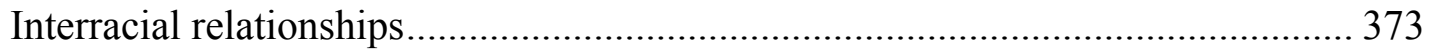

Images of illegitimacy, instability and matri-central black families.................... 380

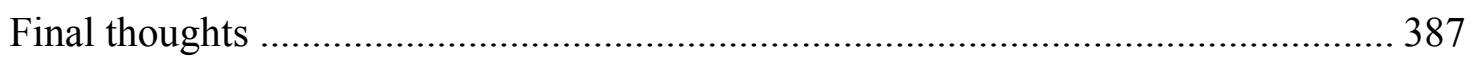


CHAPTER 6: DISCUSSION/CONCLUSION

White supremacist views of concealed Jewish control and links to anti-racism and communism

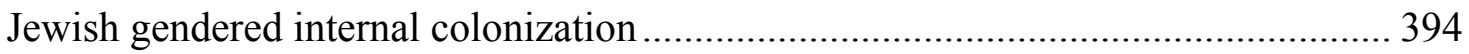

Questioning canonical theoretical dichotomies ........................................................ 396

Argument was the spice of life: A closer examination of the diverse positionalities and perspectives of Jewish women social scientists in relation to their theories about black women's sexuality

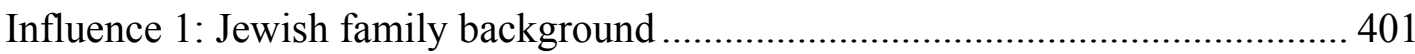

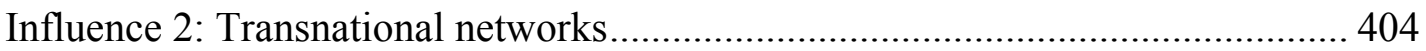

Influence 3: Political and institutional affiliations.................................................... 407

Influence 4: Marital/romantic relationships..................................................... 410

Influence 5: Transracial networks and theorizing about black women ................... 412

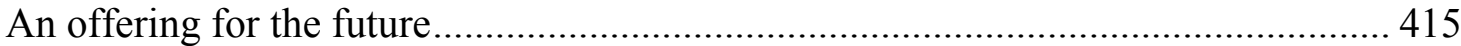

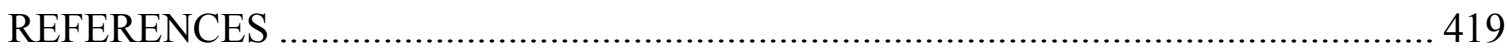

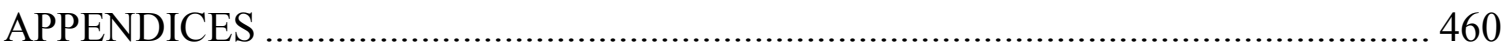

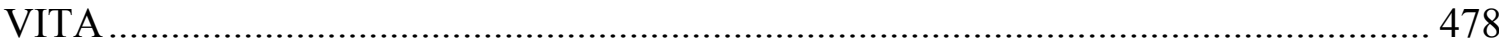


Table 1: Parental information for each of the four women: country of origin, class,

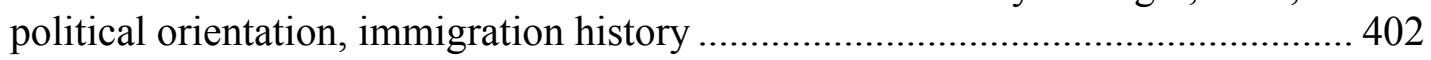

Table 2. Relationship between each woman and her parents ......................................... 403

Table 3. Self- information regarding birth place, and transnational immigration .......... 405

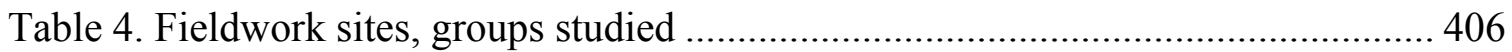

Table 5. Political and institutional affiliations, disciplinary training............................... 407

Table 6. Marital and other romantic relationships: marital status, class, race, politics and Jewish subjectivity of partners .................................................................. 410

Table 7. Transracial networks and theorizing black women's sexuality.......................... 413 


\section{LIST OF FIGURES}

FIGURE

PAGE

Figure 1. My mom (pregnant with me), dad and maternal grandfather in 1982 „............ 45

Figure 2. Abby with Jair at his front door, Cachoeira, Bahia, Brazil, June 2003 ............ 48

Figure 3. Abby with Papa Larry, 1984 (age 2) ....................................................... 50

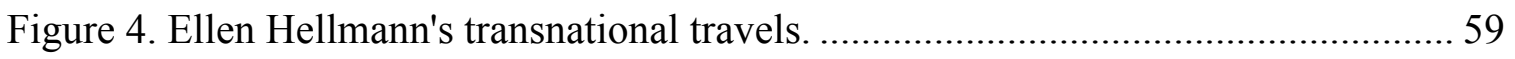

Figure 5. Ruth Glass' transnational places of residence included Berlin (until 1932), Prague, Geneva, and Wien in the mid-1930s, London (1935-1940), New York City (1940-42), and various locations in India including Durgapur, where she advised on the building of a new steel town in 1961 .

Figure 6. Hilda Kuper's transnational residences and fieldwork locations including Bulawayo, Rhodesia (now Zimbabwe) where she was born; Johannesburg (1917-32, 1941-46) and Durban (1952-58, 1959-61), South Africa; Chapel Hill, North Carolina (1947-49), and Los Angeles, California (1961-1992); and London (1932-1934), Birmingham (1950-52) and Manchester (1958-59), in the U.K.

Figure 7. Ruth Landes' transnational fieldwork locations and places of residence.

Figure 8. Social network visualization of the four core women's disciplinary training. Note that Hellmann, Landes and Kuper were trained in anthropology, while Landes, Hellmann and Glass were trained in or connected to sociology.

Figure 9. Social network visualization of the four core women's institutional affiliations.

Figure 10. Ruth Landes transracial romantic relationships, including type of relationship and research themes/topics they shared.

Figure 11. The transracial publication networks between Hilda Kuper, Fatima Meer and Thoko Ginindza.

Figure 12. The impact of Ruth Landes' transracial female relationships on her publications.

Figure 13. Noatsi and Setlogelo, photo by Ellen Hellmann, November 1937 in Alexandra Township. Item 20, File 31, Subseries 8.1.1, Ellen Hellmann Papers, Historical Papers Archive, ZA HPRA A1419-8-8.1-8.1.1-20 .

Figure 14. Hellmann's reliance upon transracial networks in her publications about black urban life in Johannesburg. 72

Figure 15. Ellen Hellmann's white colleague networks. 75 
Figure 16. Ruth Glass' transracial colleague networks. Glass shared her political beliefs with Krishna Menon, Dharma Kumar and Nigel Harris; she shared her association with the London School of Economics with Menon and Harris. 78

Figure 17. The racial/ethnic/national identities (including Jewish familial backgrounds) of the four core women in the study.

Figure 18. Ellen Hellmann's house. I took this photo when I visited the site with Jill Weintroub on February 26, 2017.

Figure 19. Ruth Landes Ethnographic Object Collection in the storage room of the National Museum of Natural History, Museum Support Center, Suitland, Maryland. Control No. 1048265, Location: A1 Row 607:003, photo taken by author, June 27, 2014

Figure 20. Abby with Alcione Amos, Curator at Anacostia Community Museum, with bahiana doll in the collection of Lorenzo Dow Turner. Catalog no. ACM 2003.0032.0371, July 2014, in Washington, D.C. Photo taken by Suzanne Ingalsbe

Figure 21. Abby at UCLA Fowler Museum with Teresa Thoko Ginindza Swazi collection. November 2016, photo taken by Erica P. Jones, Assistant Curator of African Art.

Figure 22. Thoko Ginindza with Hilda Kuper at UCLA, 1984/1985, from Mary Kuper's personal collection, used with Mary's permission. Unfortunately, neither of Kuper's daughters nor any of her students knew the reason behind this meeting.

Figure 23. Beth Rosen-Prinz and Dawn Chatty at a party for Hilda's graduate students at Hilda's home in Los Angeles, 1974, photo from Dawn Chatty's personal collection, used with Dawn's permission.

Figure 24. Ruth Landes with Louise (Masha/Mazhi) Nocktonick, one of her informants during her 1935 and 1936 fieldwork among the Prairie Potawatomi in Mayetta Kansas.

Figure 25. Ellen Hellmann, undated. Ellen Hellmann Papers, Subseries 8.3, Personal File, Historical Papers Archive, University of Witwatersrand, ZA HPRA A1419-8-8.3

Figure 26. Ellen Hellmann family photograph at a public swimming pool in Johannesburg. Bernard and Chlothilde Kaumheimer with their daughters, Ellen (left, aged 14) and Inez (right, aged 10), Ellen Hellmann Papers, Historical Papers Archive, University of Witwatersrand, Series 8.1.2, Item 7, ZA HPRA A1419-8-8.1-8.1.2-7

Figure 27. The South African organizations with which Hellmann worked.

Figure 28. Rooiyard in 1935. Photo taken by Ellen Hellmann, Ellen Hellmann Papers, Historical Papers Archive, File 35, Subseries 8.2, ZA HPRA A1419-8-8.2-13 ..... 158 
Figure 29. Ellen Hellmann's presidential address to SAIRR in Cape Town, January 24, 1955. Ellen Hellmann Box of Clippings, Jewish Board of Deputies Archive, Beyachad Community Center, Johannesburg.

Figure 30. Thematic/issue focus for Hellmann's organizations.

Figure 31. 90 Justinas, 50 Mandlas, Sixty bursaries for Native Applicants, December 26, 1961. The Star, Ellen Hellmann Box of Clippings, Jewish Board of Deputies Archive, Beyachad Community Center....

Figure 32. Ellen received a Royal Africa Society medal in 1970 for her service to Africa. This photograph was part of a tribute to Hellmann upon her death in the Race Relations News, Vol. 44, No. 9, Dec. 1982, Ellen Hellmann Box of Clippings, Jewish Board of Deputies Archive, Beyachad Community Center

Figure 33. Drinking on Fields Round Pimville, December 1937. Photograph by Ellen Hellmann, photo 1.16 on page 29 in Series 8, photograph album 31.1, Ellen Hellmann Papers, Historical Papers Archive.

Figure 34. The Tshabalalas in Orlando Location, January 1938. Photograph by Ellen Hellmann, page 33, Series 8, photograph album 31.1, Ellen Hellmann Papers, Historical Papers Archive, University of Witwatersrand

Figure 35. Lena Napumulo was one of the women Ellen interviewed as part of her research in Pimville in 1938 for Problems of Urban Bantu Youth. This photo was taken by Ellen Hellmann and is in Series 8, photo album 31.1, page 48, in the Ellen Hellmann Papers at the Historical Papers Archive.

Figure 36. John Chawafambera, 1935, from Rooiyard. Photo taken by Ellen Hellmann. Ellen Hellmann Papers, Subseries 8.2, File 35, ZA HPRA A1419-8-8.2-16.

Figure 37. Ruth Landes in Salvador, Bahia, 1938-1939. Image ID: landes_photo_brazil_91-4_0137, Brazil: Bahian blacks and candomblé [3 of 3], Box 62, Ruth Landes Papers, National Anthropological Archives, Smithsonian Institution

Figure 38. Joseph and Anna Schlossberg are on the left. Adele and David Pinski, Anna's aunt and uncle are on the right. Photograph is from the Museum of Family History Website.

Figure 39. Ignacio López, Landes' second husband, 1958 in either Mexico or Oregon. Image ID: landes_35mm_mexico_oregon_16, Box 62, Ruth Landes Papers.

Figure 40. The connections between Landes' father, Joseph Schlossberg, her great uncle, David Pinski, her second husband, Ignacio L. López, and E. Franklin Frazier, a sociologist she often cited.

Figure 41. Resembles my mother in her going-away dress about 1904 and facial type, Landes wrote at the bottom of this drawing by Charles Dana Gibson. Box 60, Ruth Landes Papers. 
Figure 42. Ruth Landes' black intellectual networks, facilitated through her connections with her father, Joseph Schlossberg, and her teacher, Franz Boas. .... 216

Figure 43. Edison Carneiro, photo taken by Ruth Landes in Bahia on a boat trip they took together, November 21, 1938. Image ID: landes_photo_brazil 91-4_0224, Box 62, Ruth Landes Papers

Figure 44. Ruth and Edison Carneiro in Salvador, September 14, 1938. Image ID: ruth_landes_02, Box 63, Ruth Landes Papers

Figure 45. Elmer S. Imes on his lawn at Fisk University, 1937. Handwritten on verso by Ruth Landes: at Fisk on his lawn before my tow time in 1937. Image ID: landes_photo_family_friends_es_imes_07, Friends and Family: E.S. Imes, Box 62, Ruth Landes Papers, National Anthropological Archives, Smithsonian Institution

Figure 46. The intersections between Ruth Landes' father and her transracial romantic relationships.

Figure 47. Capoeira musicians, 1938, Salvador, Bahia, Brazil. Image ID: landes_photo_brazil_91-4_0059, Box 62, Ruth Landes Papers

Figure 48. Mãe Menininha, Candomblé priestess of the terreiro called Gantois, in Salvador, Bahia with filhas do santo (daughters of the saint), September 1938. Image ID: landes_photo_brazil_91-4_0126 in Box 62 of RLP...

Figure 49. Ruth Landes' correspondence network with her teacher Ruth Benedict in 1938, while Landes was at Fisk and then in Brazil. This visualization reveals the content of Landes' letters including the people, themes, and racial/ethnic groups she discussed, as well as the institutions from which the letters were sent and received.

Figure 50. Ruth Landes' professional/institutional instability, represented through her multiple moves across the U.S. and Canada.

Figure 51. Maria Julia, the most ancient priestess of her cult, said to be over 100 years of age. Lavagem do Bonfim (washing of the Bonfim church), Jan. 12, 1939. Photo ID: landes_photo_brazil_91-4_0001, Box 62, Ruth Landes Papers.

Figure 52. Men in front of the Ogum house (Ogum is one of the orixás, a warrior god) at Engenho Velho, one of the oldest Candomblé terreiros in Salvador, October 24, 1938. Photo ID: landes_photo_brazil_91-4_0577, Box 62, RLP

Figure 53. The connections between Landes' writings about Jewish and black families.

Figure 54. Ruth Landes with Martiniano Eliseu do Bonfim at his home in Salvador, Bahia, August 1938. Martiniano was a Babalorixá (Father of the Orixás), an Ifá diviner who received training in Lagos, Nigeria. Photo was taken by Edison. Photo ID: landes_photo_brazil_91-4_0315, Box 62, Ruth Landes Papers

Figure 55. Maggie Wilson in front of her house in Manitou Rapids, near Emo, Ontario in 1933-4. Image ID: landes_photo_chippewa_people_09, Box 62, RLP 251 
Figure 56. The highly interconnected thematic networks between Landes' unpublished works Ethos of the Negro in the New World (1939) and Chronicle of Bloods (1960) and Zora Neale Hurston's Mules and Men (1935) and Tell My Horse (1938).

Figure 57. Landes school/work affiliations, 1928-1965 264

Figure 58. The white old boys' transnational network that circulated gossip and negative evaluations of Landes' research in Brazil, leading to her thirty-year institutional instability. 266

Figure 59. Hilda Kuper at her home in Los Angeles, 1974, at a party organized for her students, photo taken by Dawn Chatty and used with Dawn's permission.

Figure 60. Hilda Kuper, Ellen Hellmann, and their teacher, Winifred Hoernlé: The intersections between their disciplinary training, institutional affiliations, racial/ethnic affiliations, and the people who influenced them.

Figure 61. Hilda Kuper's Jewish South African network......................................... 284

Figure 62. Hilda Kuper's London School of Economics network, 1932 ..................... 286

Figure 63. Hilda with the two wives of Prince Makhosini, the first Prime Minister of Swaziland: La Nldangamandla and La Mkhonta, 1974. Hilda Kuper Papers, Box 45, Folder 8 .

Figure 64. Ligcebesha Swazi necklaces in the Thoko Ginindza Collection at the UCLA Fowler Museum. Catalogue nos. X76.336, 340, 344, an everyday accessory worn by adults of both genders and children.

Figure 65. Swazi necklaces made from porcupine quills and umsinsi seeds in the Thoko Ginindza collection at the UCLA Fowler Museum. Catalogue no. X76.369.

Figure 66. Winifred Hoernlé's network including A.R. Radcliffe-Brown, W.H.R. Rivers, A.C. Haddon, J.D. Rheinallt Jones, and Winifred's husband Alfred Hoernlé. This visualization includes shared institutional affiliations, advisors and advisees, and disciplinary training.

Figure 67. Thoko Ginindza with her son, Sibongo, at his 8th grade graduation, May 20, 1977, when he was 12 years old. From Box 45, Folder 20, HKP. Sibongo wrote letters to Hilda (January 6, 1974, Box 24, Folder 20, HKP)

Figure 68. Hilda Kuper (center) with Sobhuza II (left) in September 1934. Photo likely taken by Leo Kuper before Hilda's departure for three-month tour of Swaziland. Hilda's assistant (right) is unnamed in the photo, but in African Aristocracy (1961) she said his name was Umnyakaza. Car's license plate was from Transvaal, Johannesburg (TJ). Hilda Kuper Papers, Box 60, Folder 2

Figure 69. Kuper's publications about Swaziland, connections with Swazi royalty, and

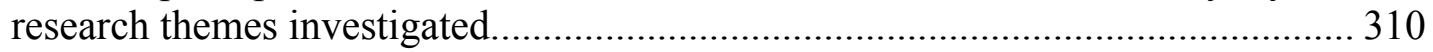

Figure 70. The institutional associations that Hilda Kuper and Leo Kuper shared........ 313 
Figure 71. Hilda Kuper (center) with Leo Kuper (behind) and Max Gluckman (right) at Watts Towers, Los Angeles. Hilda Kuper Papers, Box 45, Folder 20.

Figure 72. People Ransack Their Attics: Ellen Hellmann fundraising for the Treason Trial Art Auction. Hellmann is pictured with Irma Stern painting, February 19, 1959, The Star. Ellen Hellmann Box of Clippings, Jewish Board of Deputies Archives, Beyachad Community Center.

Figure 73. Hilda Kuper with Fatima Meer and Gisele Maquet, in front of Hilda's home on Warner Ave. in Los Angeles, 1984/5. Mary Kuper personal collection. Fatima's daughter, Shamim, posited that Fatima must have come to visit Hilda during 1985 when Fatima was a Visiting Lecturer at Swarthmore. Gisele Maquet's husband Jacques Maquet was an anthropologist at UCLA (with Hilda). 321

Figure 74. Hansi Pollak pictured with Ellen Hellman (sic) regarding their work with SAIRR, January 19, 1967. Ellen Hellmann Box of Clippings, Jewish Board of Deputies Archive, Beyachad Community Center

Figure 75. Fatima Meer and Ellen Hellmann Debate, September 4, 1975, The Star. Ellen Hellmann Box of Clippings, Jewish Board of Deputies Archive, Beyachad Community Center.

Figure 76. Ruth Glass and the cover for her book, London: Aspects of Change (1964). This image comes from the following site: https://www.brownstoner.com/brooklyn-life/what-is-gentrification-definitioncauses-effects/......

Figure 77. Ruth Glass' Institutional Affiliations, 1932-1986. 359

Figure 78. London's Newcomers (1960) and the publications in its network (including the female authors) 


\section{ABBREVIATIONS AND ACRONYMS}

BK

Bodo Koch

CAA Council on African Affairs

DG David Glass

EC Edison Carneiro

EH Ellen Hellmann

EHP Ellen Hellmann Papers

EI Elmer Imes

GTM Grounded Theory Methodology

HD Henry Durant

HK Hilda Kuper

HKP Hilda Kuper Papers

IL Ignacio López

JBD Jewish Board of Deputies

JH Joseph Hellmann

LK Leo Kuper

LSE London School of Economics

NAA National Anthropological Archives

NNC National Negro Congress

NMNH National Museum of Natural History

RL Ruth Landes

RLP Ruth Landes Papers 


$\begin{array}{ll}\text { RG } & \text { Ruth Glass } \\ \text { SAIRR } & \text { South African Institute of Race Relations } \\ \text { SNA } & \text { Social Network Analysis } \\ \text { UCL } & \text { University College London } \\ \text { UCLA } & \text { University of California Los Angeles } \\ \text { VL } & \text { Victor Landes } \\ \text { Wits } & \text { University of Witwatersrand }\end{array}$




\section{INTRODUCTION}

In this dissertation, I analyze dynamics of internal colonization, Jewish subjectivity, and the intersections of gender, sexuality, race, class and nation through the experiences of Jewish women social scientists. One of my primary aims is to explore how Jewish anthropologists/sociologists became a "semi-modern colonized elite," an oppressed group with the potential to marginalize others, both internal and external to their own groups, in order to establish their disciplinary and colonial authority and status within whiteness. Thus, I bring post-colonial historical studies into conversation with the Jewish historical experience of being simultaneously colonizer and colonized.

Studying Jewish subjectivity complicates the colonizer/colonized dichotomy, but it also questions liberal conceptions of a unified or uniform identity. Jewishness disrupts "the category of identity" and represents a "crisis for modern, liberal subjectivity" (Mufti 2007:7, 31). Jewish existence contests the assumption that a "uniform," "tolerant," "national," and unified citizenry or subjectivity is possible. Jewishness underscores the simultaneity and tensions within modern, liberal, secular nationalism. This is because Jews embody the supposed dichotomies inherent within that modern nationalism: on one side - the particular, "narrow," "ritualistic," "irrational" - and on the other - the "universal," "transnational," "homeless," and "abstract" (8, 11-13, 38-39). Through their bodies Jews challenge the liberal division between public and private. Jewish experience can never be completely displaced from the state to civil society and into the patriarchal bourgeois "private" sphere $(5,51-52)$. Jewish assimilation into the majority can never be complete and the figure of the Jew represents the inherent contradictions within the 
liberal, modern, secular, national project, which by its nature disrupts and unsettles, creating exilic minorities like Jews, rather than a universal unified subject (Mufti 2007:2, $7,11,13,53,55)$.

As Eric Goldstein explains, Jews were a "racial conundrum," an ambiguous racial group, unable to be pinned into either the "white" or "black" racial categories in the preWorld War II era in the U.S. Even when Jews tried to conform to the requirements of whiteness, their self-identification as a distinctive minority oppressed group created conflicts and tension in fully embracing whiteness. They were unable to fully "reject or embrace the racial conventions of white America" (1-3). Rather than seeing Jews as already having "become" white (an implicit reference to Karen Brodkin's work), or as “choosing” whiteness (a reference to David Roediger ${ }^{1}$ ), Goldstein emphasizes that the Jewish struggle between "coercion" into whiteness and a distinctive minority status has never ended and continues into the present. Thus he critiques the idea that Jews have already become uncontestably white, as well as the concept that Jews freely chose or choose whiteness (Goldstein 2006:5). Goldstein also provides a link between studies of the Jewish relationship to whiteness and processes of internal colonization (without using that terminology): "While American Jews were often buoyed by their ability to move

\footnotetext{
${ }^{1}$ Inspired by James Baldwin's quote that European immigrants became white "by deciding that they were white," David Roediger contends that, "White ethnics, while they lived under conditions not of their own choosing, by and large chose whiteness, and even struggled to be recognized as white" (Baldwin 1984; Roediger 1994:185).
} 
freely in white America, their entry into that world resulted in alienation, communal breakdown, and psychic pain," all markers of internal colonization (6, my emphasis).

A key reason for my emphasis on a dis-unified, conflicted and ambivalent European-descended Jewish subjectivity, which embodies the simultaneity of colonizer and colonized or particular and universal, is that this approach is a theory and a methodology that tries to avoid essentialization of the "the Big Bad West" (or in this case the "racist white Jewish woman"). I also underscore internal divisions within other racially oppressed groups (in addition to Jews) that the four core women in my study researched, especially highlighting class divisions that are marked by assertions of sexual normality/abnormality. I do this to avoid re-colonizing "Third World others" by only portraying them as "mirrors" or "backdrops" who reflect the West back to itself (Narayan 1997:136-40). In other words, I emphasize how the women presented here studied the ambivalence and disunity within other racially marginalized groups, which like Jews, could and can oftentimes be presented as monolithic groups.

The central Jewish women in my study - Ellen Hellmann, Ruth Landes, Hilda Kuper and Ruth Glass - were part of the same "political generation," born in 1908-1912, coming of age when European diasporic Jews experienced an ambivalent and conditional assimilation into whiteness, a form of internal colonization. They studied Jewish, indigenous and black women living under internal colonial systems, oftentimes immigrants, in urban settings in Brazil, the United States, the United Kingdom, South Africa and Swaziland (Celarent 2012; Elazar 2002; Glass and Pollins 1960; Hellmann 1948c; Kuper 1993; Landes 1933, 1947, 1985a). 
This dissertation investigates how Jewish women relationally established their "modern" and "civilized" gendered and racialized subjectivities and disciplinary authority through their sometimes "colonizing" portrayals of black and indigenous female research participants. Viola Klein (1908-1973), a Jewish Viennese refugee sociologist, explained that even though individuals from "out-groups" including Jews, blacks and women could promote a democratic, humanitarian and anti-discrimination perspective, they could also unconsciously adopt majority standards and become self-critical and self-hating, unable to tolerate inhabiting space with others of their "kind": "It is as if they would see their own grimace reflected from a multiple distorting mirror" (1946:172-174). For example, Ellen Hellmann (1908-1982), a South African public anthropologist and one of the core women in this dissertation, expressed that Jews should promote and protect themselves as a group, yet that blacks should not do so, because this would be "divisive," fueling separatism. Instead, she maintained that "Africans"/"non-Europeans"/“natives" should assimilate into whiteness as elite Jews were doing (Hellmann 1961b, 1964).

I examine how Jewish women (like Ellen Hellmann) sometimes established their modernity and civility by theorizing about the supposedly "unstable" and "illegitimate" families of working-class black women. I show how each Jewish woman's upbringing, including her family's origin point in Europe, familial class background and political orientations, were important factors influencing her later personal and professional networks and social science theorizing about women of color. However, other important factors included the national racial context, her marital status and the political affiliations of her partners, and her transracial fieldwork experiences. Assumptions that Central European Jews were more assimilationist and politically conservative, and that Eastern 
European Jews were more "radical," are too simplistic to explain the multi-dimensional context that influenced Jewish women's social science theorizing about women of color.

Previous studies of Jewish social scientists tend to de-emphasize analysis of gender and sexuality, focusing on men (Frank 2001; Hart 1999; Lewis 2008, 2013; Messer 1986; Morris-Reich 2008), while studies of women social scientists, who were Jewish, de-emphasize the potential Jewishness of their theorizing and the intricacies of gendered and racialized Jewishness (Cole 2003; Lyon 2007; du Toit 2005). Though Andrew Bank analyzes Ellen Hellmann's Jewish identity, he assumes a causal connection between her Jewish subjectivity and her supposedly "radical" anti-apartheid "activist" research with black populations (Bank 2016:150). My dissertation intervenes at the intersections of these three literatures in order to provide (1) a gendered analysis of the history of Jews in social science, (2) an analysis of Jewish subjectivity within histories of women (who were Jewish) in social science, and (3) a critique of the either-or assumption that Jewishness necessarily equated with a "radical"/“activist" anti-racist approach or a "colonizing" stance toward black communities.

\section{Racialization as an historically and geographically contingent process}

This dissertation approaches racial processes as unstable, contingent, and subject to historical context; race is a relationship, and not a thing, not innate or unchanging; this way of thinking about race applies not only to blackness, but also to whiteness, and any other racial formation including Jewishness (Tabili 2013:126-28). Historical processes of racial formation, at the macro level, in the "West," have generally produced a hierarchy of whiteness over blackness (Phillips 2013:379-380), with Jewishness defined 
relationally and located somewhere in the middle, closer to (or overlapping with) one pole or another depending on historical and national context (Sherman 2000:505-10; Slabodsky 2014:60-62). Definitions of "whiteness" and blackness" are based upon hierarchies of gender and sexuality performance; so that whiteness is defined by sexual purity, maternity, civility and national belonging in contrast to the sexual degeneracy, vulgarities and physical "abnormalities" (fatness, dirtiness) that are associated with blackness and undesirability (Bloul 2013:8; Carby 1992; Palmer 1989; Phillips 2013:387-88, 393; Rollins 1985) threatening the core of the nation-state (Williams 1989:436)

A group that at one time is perceived as closer to blackness, can become closer to whiteness during a different time, for example the Irish in the U.S. and England (Garner 2004; Phillips 2013:385, 394-95, 397). Groups reproduce these racialization processes both externally and internally - so that those who have been identified as closer to blackness disassociate from this link and establish their proximity to whiteness and national belonging by positing another group's blackness. Eastern European, primarily Lithuanian, working-class Jews, in South Africa at the turn of the $20^{\text {th }}$ century, employed in eating houses ("kaffireatniks") serving black mine workers, could access economic and social power by adopting the racist system in which they were positioned above the “despised black laborer" (Sherman 2000:505-506, 510). In an example of internal reproduction of these racialization processes, Russian Jews in the mid-1990s in Moscow utilized the same Jewish stereotypes that had been historically targeted at Eastern European Jews and mobilized them against an internal minority - the "Mountain Jews" - 
in order to establish Russian Jewish belonging as citizens of the Russian state (Goluboff 2001:290-93).

However, a different strategy has often been utilized by members of racially ambiguous groups: claiming solidarity with blackness by re-envisioning the stereotypes that have traditionally been applied to them to "subvert coloniality's structures of domination" (Slabodsky 2014:62, 67). For example, Albert Memmi, a Tunisian Jew inspired by Africana thinkers such as Cesaire and Senghor, identified himself as: "a Jew in an anti-Semitic world," "a native in a colonial country," and an "African in a world dominated by Europe" (Slabodsky 2014:115).

Informed by Omi and Winant (1986), Jemima Pierre (2004) illustrates the necessity for maintaining an analysis of racialization processes that impact an entire society (white supremacy) rather than only looking at intra-racial differentiation or "ethnicity" (Omi and Winant 2014; Pierre 2004:161). Ethnicity is a problematic theoretical construct (Pierre refers to Glazer and Moynihan 1963) because it was historically applied to European immigrant groups (like Jews and Irish) who were able to "effectively" assimilate, but black people have been theorized as incapable of successful assimilation because of their "culture of poverty" and "ethnic family structure" (code for female-centered family, one of the central tropes I analyze in this dissertation). Ethnicity theories have failed to evaluate how their hierarchical conceptualization of assimilation "success" is predicated on white supremacy, inherently unequal access to assimilation (Pierre 2004:146-148) and the positionality of some groups (classified as "ethnic") as temporarily inferior with the possibility of belonging inside the nation, and others as "racial" - outside of the nation and ineligible for belonging (Goluboff 2001:285). 
Fanon (1967) argued that Jews can pass but Blacks cannot, so Jews will never reach similar levels of "shame, self-contempt and nausea" that Blacks do and that Jews (unlike Blacks) can remain unknown in their Jewishness (Fanon 1967:115). Rachel Bloul (2013) articulates how Jews and other groups which are not necessarily visibly physically different from the assumed white norm, can still experience the affective and embodied effects of racialization processes because racialization operates by "focusing the victim's consciousness on specific parts of the body," causing the interruption of integrated embodiment; Jews can still perceive their bodies through racialized stereotypes even if their bodies are not actually different $(5,13-14)$.

By looking at this group of Jewish women scholars and their representations of women of color in this particular time period, I focus on how gender and sexuality performances mattered for the navigation of their positionalities within broader racialization processes and hierarchies. Importantly, analyzing these women gives us a privileged entry point into typically neglected processes of racial and gendered selfmaking.

\section{Jews and internal colonization}

Colonizers create their modern subjectivities by positing the non-modern, uncivilized, hypersexual, and racialized subjectivities of colonized people and by developing a semi-modern colonized elite to regulate the colonized (Bacchetta 2010:55961; Steinmetz 2014:80-81). Thus it is the hierarchies of race, gender, class, sexuality and nation that create modern, semi-modern and non-modern identities (Fanon 2003; Few 2007; Schmidt 2015; Sebastiani 2005; Wilson 2003). “Oppressed” or minority groups, 
such as Jews (but not limited to Jews), can perpetuate internal colonization on another marginalized group, or an "internal minority" within their group, in order to establish their superiority as civilizers, saviors, or pioneers and their belonging and modernity within the nation (Bacchetta, El-Tayeb, and Haritaworn 2015:770-74; Mufti 1995:85, 93, 1998:123). Thus, semi-modern elites (like Jewish social scientists) create internal minorities using classifications of race, class, gender and sexuality in order to establish their own disciplinary authority and national belonging within whiteness.

The concept of internal colonization draws attention to the processes of economic and political exploitation of a subjugated group by a dominant group that occurs within a polity rather than across national borders. The dominant group typically uses race, religion or ethnicity to differentiate and exploit colonized labor for capital. By showing how colonialism occurs within "the nation," and that "foreign" and "domestic" are relative terms, depending on which subjects use them and for what purposes, the concept of internal colonialism questions the centrality of "the nation" in studies of power (Gordon 2005:1-6). Internal colonization can also be defined as: "forced assimilation, internalized self-rejection, political cooptation, social conformism... and creative transcendence" (Shohat 1992:110).

In Britain in the first half of the $20^{\text {th }}$ century, Jews were objects of the processes of internal colonization that occurred within the domestic sphere. In mixed marriages between English citizens and Jewish immigrants, the English partner would try to "kill off any signs of Jewishness" in the Jewish partner and the mixed race children (Feinstein 2005:340-41). Jewish assimilation and social mobility to positions of power and privilege upon arrival from Eastern Europe in the 1880 s to 1890 s endangered the imperial 
hierarchy. Jews were examined as scientific objects as part of the new "civil" imperialist cause (similar to the process in India) to prevent the Jewish "invasion" from reversing the imperial order (Trubowitz 2012:104, 110-11, 215). John Cuddihy called Jews an "internal colony" to the West and viewed the imposition of "modernity" or civility as a form of anti-Semitism and trauma for underclass, ethnic outsiders (Cuddihy 1974:9, 46). Within Jewish postcolonial studies, Jewishness is portrayed as the experience of being colonized in Europe but colonizer in Israel/Palestine (Hesse 2014:882, 885). However, this dichotomy is too simplistic in all of these geographic regions. In both the U.S. and Europe, Jewish social scientists served the colonial agendas of their nations through their research and administrative duties. Aamir Mufti refers to the normalization of Jews as "colonizing people" in the Israeli-Palestinian context and Karen Brodkin to Americanization through white superiority in the U.S. (Brodkin 1998b:19; Mufti 1998:123).

Karen Brodkin (similarly to Eric Goldstein) describes the "ambivalence" American Jews felt about modernization and assimilation into whiteness because it cost "meaningful Jewish community, cultural identity, and the loss of an authentic Jewish soul"; they experienced "a conflict between Jewishness and whiteness and between white Jewishness and blackness" and that this revealed the ambivalence that is inherent within the construct of whiteness. In order for assimilation into whiteness to be attractive, there had to be a negative valence to blackness. Conversely, for assimilation into whiteness to be portrayed negatively there had to be a corresponding romantic representation of blackness. Brodkin uses the example of 1960s feminists who critiqued "feminine dependency and institutional sexism" by creating images of "invulnerable, autonomous 
black women" (Brodkin 1998a:182-83). Anthropologist Ruth Landes (1908-1991) used this exact type of theorizing in her descriptions of Afro-Brazilian Candomblé priestesses in Salvador, Bahia.

In addition, Eastern European Jews became an internal minority to Central European Jewish communities because of racialization and class stratification. Central European Jews were the "semi-modern" elite; they considered themselves more civilized and modern than the Eastern European Jews, whom Central European Jews considered poor, backward and prone to criminality (Brown 2014; Pinski 1999:4, 185). The wealthy German Uptown Jews of New York City were ashamed of the behavior, language, appearance, and political ideologies of Russian Jews: "aghast at their political ideologies, and terrified lest the world crumble by the mad act of a Jewish radical" (Lewis 2013:548). A similar pattern developed in both Europe and South Africa: the British government granted Western European Jews emancipatory citizenship rights, but for Russian Jews "secularization was not accompanied by assimilation or acculturation." Russian Jews wanted to create a distinct secular Jewish culture and national autonomy that was separate from and in addition to political, economic and religious freedom (Krut 1984:141).

Gideon Shimoni argues that the disproportionate involvement of radical Jews in the anti-apartheid movement in South Africa can be explained by Jewish "social marginality" among segments of the Eastern European Jewish population. These Jews were "outsiders in relation to the vested interests of society's established state authorities, social classes, and dominant ethnic group or groups" and their "alienation" triggered the adoption of "counter-normative ideologies" (Shimoni 2000:166-68), what Aamir Mufti 
calls “oppositional culture” (2007:7). These radical Leftist Jews were not only marginal in relation to the dominant white Afrikaner society but also to the "upwardly mobile Jewish community of Johannesburg and its norms of religious and Zionist identification" (167-169). Social anthropologist Ellen Hellmann (1908-1982) is a perfect representation of the "upwardly mobile Jewish community" through her involvement in the Jewish Board of Deputies, which refused to admit that there was a "collective Jewish imperative to oppose apartheid" (Shimoni 2000:171).

Shimoni's "marginality theory" explicitly repudiates what he calls the "Jewish values theory" advocated by Immanuel Suttner. "Jewish values theory" uses historical Jewish religious stories, ideas and values as an explanation for Jews" "solidarity with the underdog" (Suttner 1997:602-5). Shimoni argues that "Jewish values theory" falsely assumes that all Jewish radicals were religious or were exposed to these Jewish religious precepts. Shimoni also contends that the "Jewish values theory" neglects to consider the fact that the more religious a Jew was the less likely s/he was to be radical politically (2000:164-165).

This dissertation emphasizes divergences within Jewish diasporic populations based upon their placement within national racial classificatory systems. Constructs such as gender, sexuality, race and class established Central European Jews as the "semimodern elite" who vied for belonging in whiteness based upon their adherence to white middle and upper-class gender-sexuality norms, and Eastern European Jews as the internal minorities, seen as threatening Central European Jews' acceptance within whiteness. 


\section{Jewish subjectivity}

I conceptualize subjectivity as relational, dependent upon context, and a negotiation with power (Braidotti 2014; Hall 2001; Hancock 2016). As Ange-Marie Hancock elaborates in her work on intersectionality, oppressor and oppressed identities are not mutually exclusive (2016: 86-91). Also, one cannot assume individuals who are part of the same "identity" group (in this case, Jews) experience the world identically (Hancock 2016:156). "Jewishness" is a multifarious term that could signify a bio-racial definition of Jewish identity (Hart 1999:279). From a "blood-and-descent" perspective Jewishness is the "core" of a Jew's identity (Behar 2009:254-55). Karen Brodkin explicates both the differences and the connection between the "ethnoracial identity" aspect of Jewishness and "ethnoracial assignment" $(3,21)$. Assignment to Jewishness can often mean the documentation of racialized stereotypes, emphasizing the embodied stigma of degeneracy, criminality, (and for women especially) fatness and ugliness associated with Jewish bodily appearance. It has been called an "affliction," a problem to be eradicated, a "stain" to be purged, a "racialized corporeal schema" that becomes embedded at the somatic level, resistant to any evidence that the Jewish body is actually not different (Behar 2009:254-55; Bloul 2013:5-6, 13-14; Feinstein 2005:341-42). Jewishness can mean a "social condition and artistic impulse" (Feinstein 2005: 336), or a form or style of expression (Damon 1996:492-93, 495-96). It can express an experience of irony or paradox because of competing loyalties between "Western" scientific principles and "traditional Judaism," between social activism and security, between assimilation into whiteness and the devastating consequences of that assimilation (King 2000:3). Jewishness is a way of being and theorizing based upon the experience of being 
a Jew in a specific historical (anti-Semitic and/or emancipatory) context (King 2000:viiviii, 2-3). Harvey Goldberg asserts that to understand the specific "Jewishness" of a historical figure, one must know the "internal details of the varieties of Jewish life" at the time the individual lived (Goldberg 1995:57).

Gendering Mufti's oftentimes male-centered argument about Jews in Europe, I demonstrate how Jewish internal divergences serve as an example that highlights the lack of uniformity within any "identity" group, and the ways that minority groups, like Jews, exile internal minorities using measures of "abnormal" gender and sexuality, in order to try to assimilate into the majority colonizing culture. Evelyn Brooks Higginbotham developed the term "politics of respectability" to describe the process through which African American middle-class women employ behavioral and self-definitional strategies to "uplift the race" by utilizing an adherence to and promotion of "proper," "restrained" and "conservative," gender and sexuality norms and appearance, and traditional family structures, in order to counteract racist assumptions about black hyper-sexuality and immorality associated with lower class black communities (Meyer 2012:626; Simmons 2012:433). Therefore, I examine how gender and sexuality, in their intersections with race and class, are primary methods for creating internal minorities within a nation and marking their difference from the majority and the "universal" and "uniform" subject.

\section{Gender and internal colonization}

The traditional "internal colonialism theory" did not theorize the "intimate, social and cultural aspects of domination" and either ignored gender or treated it "like race, as an artifact of independent economic imperatives." It did not attend to "household and 
reproductive labor and failed to examine the circulation of resources and power among kinfolk. It thus missed vital dimensions of domination and control" (Gordon 2005:8-9). Internal colonization occurred in intimate private spaces, demanding that colonized subjects adopt colonial gender roles and that colonized women become victims of sexual violation and submit to male authority (Fanon 2003:49; Gordon 2005:15; Mbembe 1992:4; Spencer-Wood 2011:11; Stoler 2002:6, 43). The bodies and sexual practices of colonized women were used as a barometer of assimilation into white European civilization or the inability to progress from barbarity (Gordon 1998:46-51; Schmidt 2015; Sebastiani 2005:76; Wilson 2003:179). I apply these concepts about gendered internal colonization to the experiences of Jewish women.

Assimilation or belonging in whiteness can be defined based upon distinctions that rely upon a separation or distancing from "abnormal" gender and sexuality performance, that are associated with lower-class status, and non-whiteness. Thus, definitions of whiteness depend upon definitions of non-whiteness. As Karen Brodkin illustrates, the features of Eastern European Jewishness, and whiteness in contrast, included residential patterns, employment, politics, and familial structures, which were all inflected with class-based, gender and sexuality norms. Thus, Jewishness was associated with extended families living in ghettos in which women worked to financially support their families, girls were "brainy and assertive," and grandmothers lived with their children and grandchildren in homes in which privacy was not a priority or value. In contrast, "whiteness" meant living in white-dominated suburbs where couples lived far from their parents and raised their children without their parents' constant supervision and assistance. White women were supposed to be submissive wives and stay-at-home 
mothers rather than career women and children were permitted privacy, autonomy, and separation from their parents (Brodkin 1998:2-15). Giovanna P. Del Negro emphasizes how the comedic performances of Jewish women, such as Belle Barth and Pearl Williams, articulated a working-class, Yiddish-based, aggressive, "zaftig," (full-figured) sexual bawdiness and raunchiness in the 1950 s and ' 60 s, which enabled assimilating Jewish suburbanites to re-connect with their working-class Jewish roots $(145,147,154)$. Del Negro explicates that while these Jewish women advocated anti-assimilationist messages and transgressed gender and sexuality norms, non-Jews perceived them as "exotic" females whose performances could only be allowed in liminal spaces such nightclubs or underground record labels, while Jewish men could "tame" their image and become part of the white mainstream (153-155). Belle (Salzman) Barth (born 1911 in New York City) critiqued "upwardly mobile Jews" who had "eagerly abandoned their immigrant past" (Del Negro 2010:147). Thus, Barth underscored what Eric Goldstein calls the "emotional costs" of whiteness and critiqued the "abandonment of cultural distinctiveness" among wealthy, assimilating Jews (236).

Pearl (Wolfe) Williams (born in 1914 on the Lower East Side of Manhattan) often made husbands the butt of her jokes: for example, in one comedic anecdote, a man asked his wife why she was ironing her bra since, "You don't have anything to put in it." The wife replied, “I iron your shorts, don't I?” Williams also often incorporated jokes about oral sex or stories about Jewish characters with thick Yiddish accents who refused to capitulate to white norms of relational decorum. For example, in another Pearl Williams joke, when a white Texan stole a Jewish traveling salesman's hotel room, the Jewish man placed a manhole cover on the Texan's chest as he slept. Only after the Texan threw the 
manhole cover out the window upon waking did he notice the note that the Jewish man had left on the bed: "And now, you big bastard, you have fifteen seconds to untie the cord that's attached to your beardzall [testicles]" (Del Negro 2010:149). These types of bawdy, aggressive jokes performed by Jewish comediennes highlight the association between a working class Eastern European Jewish culture and women's outspokenness about sexuality; these gendered performances stood in stark contrast to the definitions of white middle class femininity.

Jewish men have historically responded to their experiences of marginalization by further marginalizing Jewish women (Kamel 2014:131). Brodkin emphasizes that Jewish women were the “prime scapegoats for men's and women's ambivalence about whiteness" (183). Schwadron adds that the scapegoating of Jewish women was also classed, since assimilation into whiteness involved gendered shifts in class status (15). The sexualization of "undomesticated" Jewish women scholars (Landes 1970a:133), was a result of Jewish male scholars' desire to assert their whiteness and modernity in juxtaposition to these "loose" Jewish women. Jewish women scholars' radical stances were viewed as threatening, whereas Jewish male scholars could express similar positions without fear of reprisals (Frank 1997:739).

In Freud's Vienna, the Jewish male body was recognized as "black." Freud's male Jewish identity emerged from an outside perception that he was unable to discuss so

${ }^{2}$ Sander Gilman (1993) explains that from Freud's perspective Jewishness meant "being seen as different, as diseased, as incomplete" (16). Freud was labeled as a "black" Jew in a period (the late $19^{\text {th }}$ century) in which "the male Jew and the male African are seen as equivalent dangers to the "white' races" (19, figure 1). Franz Kafka (a Czech Jew) wrote in 1920 to the non-Jewish Czech journalist Milena Jesenká that her father lumped Kafka 
he transferred it onto the Jewish female body (Mohanram 1999:43-44). Similarly, Viola Klein maintained that Jewish Austrian philosopher, Otto Weininger, asserted his dominance over women in compensation for his sense of inferiority as a Jew (Klein 1946:59-60).

In response to this gendered internal colonization, Jewish women writers like Gertrude Stein (1874-1946), “affirmed a kind of Jewishness that eschewed fixed categories and unilinear ways of thinking," expressing an "oppositional culture," a form of decolonization (Damon 1996:495; Mufti 2007:7). Viola Klein explained that those from marginal "out-groups" such as women, blacks and Jews share a "vital interest in the promotion of a humanitarian, universalist outlook, in the abolition of discrimination against people on account of their race, creed, sex or nationality and in a legal order that puts rights before might," thus becoming a "progressive element" advocating for democracy and internationalism (Klein 1946:174). Ruth Landes wrote about her disappointment with the racial situation in Canada where Jews and Blacks who were "ordinarily... the two most vocal groups in the world" were not speaking out against racism (Landes 1987a).

Despite this potential for Jewish women's activism against racism, internal colonialism theory - in its intersectional analysis of hierarchies of gender, race and class reveals the ways that elite white women (including Jewish women) defended "their

and Jesenká's Jewish husband together, since "to the European we [Jews] both have the same Negro face." Jesenká wrote in 1938 that Jews were "the Negroes of Europe" (Gilman 1993:20, 210 n. 40-41). Jews' "black" or at least "swarthy" skin was linked to their supposed dirtiness, lack of bodily hygiene, and status as disease-carriers and "mongrels" who "interbred with Africans" (Gilman 1993:20-21). 
dominion over underdeveloped populations as a necessary historical process of female emancipation and uplift" (Gordon 2005:19). Thus white feminists in imperialist projects and national struggles from the end of the $19^{\text {th }}$ century until World War II proved their nationalist-imperialist belonging, citizenship and "modern" subjectivities by portraying themselves as the saviors of their "helpless" Indian "sisters" (Brodkin 1998a; Burton 1994:7; Mufti 1998; Woollacott 2006:104). This “softer” form of paternalism emerged from kinship-like notions of colonized subjects' supposed child-like, dependent and underdeveloped position in relation to their advanced, beneficent parental colonizers, who could guide and tutor them into improved well-being and development (Patil 2008:3, 28, 95-96). Gordon's argument that elite women depended upon the cheap domestic labor of colonized women to enable their own leisure is directly applicable to the writings of Ellen Hellmann who argued in 1963 that there should not be restrictions on black workers' movements in white areas because white women needed black women to work for them as servants, so that white women would not have to do their own "dreary chores" (Gordon 2005:20; Hellmann 1963a).

Thus, Jewish women became an internal minority to Jewish men; they used this position in divergent ways, sometimes taking an "oppositional" decolonization approach, advocating against racial discrimination, but other times they replicated oppressions, making the women of color they worked with into internal minorities as a way to produce their own imperial modernity and belonging in whiteness. 


\section{Jewish social scientists}

The predominance of Jews within histories of social science and the influence of Jewish subjectivity on the theorizing of Jewish social scientists are well-established ideas. Thus anthropology and sociology have been called "Jewish" sciences, and the Jewish subaltern experience of "double consciousness" has supposedly made Jewish social scientists into "born ethnologists" or "marginal intellectuals," who were uniquely positioned to apply their experiences of anti-Semitism to their theorizing about racism (Collins 1986:S15; Frank 1997:732, 735, 740; Gewald 2007:467; Goldberg 2012:201-2; Hyatt 1990:34, 98; Lewis 2008:187; Nava 2013:11). Despite the existence of these literatures, Jewish subjectivity's influence on the development of sociology and anthropology is still under-analyzed because of the process of internal colonization that forces assimilation and whitening and triggers fear that drawing attention to social scientists' Jewishness would discredit their research (Brodkin 1998a; Frank 1997:731). Asserting one's Jewishness has been perceived as too "subjective" and unanthropological (Frank 1997:732; Hyatt 1990:34, 98), since Jews did not fit into the Boasian concept of culture; they were multi-lingual and linguistically assimilated yet remained socially separate (Morris-Reich 2008:29).

${ }^{3}$ W.E.B. DuBois used the term "double consciousness" in order to describe the African American experience of "always looking at one's self through the eyes of others, of measuring one's soul by the tape of a world that looks on in amused contempt and pity. One ever feels his two-ness - an American, a Negro; two souls, two thoughts, two unreconciled strivings; two warring ideals in one dark body, whose dogged strength alone keeps it from being torn asunder" (Du Bois 1994:2). 
It is common for scholars to argue that Jewish social scientists in three specific national and disciplinary contexts - Boasian anthropologists trained at Columbia University in New York City in the 1930s (Ruth Landes), sociologists studying gendered racial relations in Britain post-WWII (Ruth Glass), and social anthropologists at the University of Witwatersrand in Johannesburg, South Africa in the 1930s (Ellen Hellmann and Hilda Kuper), advocated for political and economic justice for other racially marginalized peoples (Frank 1997:732, 735, 740; Gewald 2007:467; Goldberg 2012:2012; Hyatt 1990:34, 98; Lewis 2008:187; Nava 2013:11). A common hypothesis is that Jewish theorists addressed anti-Semitism through "remote control," examining their own otherness by investigating "the most other" (Berger 2010:24; Damon 1996:491; Frank 1997:735; Lewis 2013:555).

Though the conflict between Eastern and Western European Jews, because of class and political affiliations, has often been discussed in scholarship on Jewish history (Diner 1995; Krut 1984; Lewis 2013), this literature has not been utilized to explain the conflicts between different Jewish social scientists and their divergent theoretical approaches to research with black and indigenous populations. For example, though the conflicted relationship between Melville Herskovits (American Jew of Central European heritage) and Ruth Landes (American Jew of Eastern European heritage) has been discussed, and Herskovits' Jewish subjectivity has been examined (Frank 2001; Price and Price 2003; Yelvington 2006), their different Jewish positionalities have not been analyzed as a potential source of the conflict between them.

Categorizations like colonizer/colonized, upwardly mobile/counter-normative, Central European/Eastern European assume that Jewish social scientists had a unified 
way to understand their own Jewishness and they fit into one category but not another. It also presumes that individual Jewish social scientists displayed only one kind of relationship between Jews as a group and other racialized and oppressed peoples. One of the main problems my work addresses is how the internal colonization process in differing nations within the Jewish diaspora differently affected and positioned Jewish social scientists from divergent class and political affiliations, and how gender and sexuality were used as indications of degrees of (forced) assimilation into whiteness and heterosexual "normality."

Theories of Jewish marginality do not leave space for the possibility that Jewish female social scientists displayed multiple forms of relationships with black and indigenous research participants and collaborators. Based upon my archival research, Jewish women social scientists did not necessarily advocate for political and economic justice or address anti-Semitism through "remote control." For example, Ellen Hellmann and others in her network, did not fight for full racial justice and equality but rather an incomplete access to citizenship rights for black people that required "proof" of sufficient "civilization" and ensured that the white minority in South Africa could have easy access to "productive" and "efficient" black workers (Deputies 1976:4; Hellmann 1945e:9; Mitchell 1962; Party 1959). In addition, rather than fighting anti-Semitism by "remote control" she focused on protecting and promoting the Jews as a white group in a country with increasing "Afrikanerisation," yet she believed that "black nationalism," which she viewed as a rejection of Western assimilation, would further divide South African society (Deputies 1950; Hellmann 1961b, 1964:16). 
I also found that contradictory behaviors or statements were possible, so that for example, Ruth Landes could clearly advocate against racism, and simultaneously extol her own blondness and Jews' whiteness and bemoan her inclusion in the Negro's Who's Who or the fact that black Southerners, like Elmer Imes, a black physicist at Fisk, considered Jews to be non-white (Landes 1985d, 1985e, 1986e, 1986f, 1990).

Informed by symbolic interactionism and grounded theory methodology, I searched for specific textual analogies that elaborated what Jewishness meant to each woman (and why) in relation to other marginalized women and how these selfperceptions and representations changed over time (Blumer 1969; Strauss and Corbin 1998). I found Jewishness to be a state of in-between-ness: a conflict between assimilation into the white norm, versus affirmation of difference from that norm. I investigate how racialized Jewish stereotypes impacted Jewish women social scientists' self-understandings, their gendered/sexualized experiences and performances of Jewishness and whiteness, and how they (in some cases) tried to de-emphasize their Jewishness (Behar 2009; Bloul 2013; Feinstein 2005; King 2000; Schwadron 2013). Utilizing an intersectional perspective, I examine how "internal colonization" processes differently affected Jewish women social scientists based not only on their familial origin point in Europe, and parental class and political affiliations, but also their national racial context, institutional and political party affiliations, marital status (and the class/politics of the men they engaged in relationships with), and their transracial professional networks. These dynamics influenced their Jewish subjectivities and social science theorizing in distinct ways. 


\section{Jewish women's networks}

I demonstrate how Jewish women's personal/familial and professional (including transracial and transnational) networks influenced their relational subjectivity formation and theorizing. I reveal how each Jewish woman's familial origin point in Europe (either Central or Eastern Europe) cannot be the sole factor used to establish her "counternormativity" or "upward mobility." I concentrate on women's networks because typically women are remembered as the "daughters" of a prominent male figure like Franz Boas rather than being theoretically connected to other women scholars (Parezo 1993:12). I center on women's theorizing in order to challenge the assumption that what "counts" as “theory" are "male" domains: public, macro, and institutional (Albert 2014). My goal is to bring the women in this study into anthropology and sociology canons in order to change what counts as canonical and re-configure theoretical concepts and assumptions (Bhambra 2007:879, 881 n. 8). Through a post-colonial feminist approach I question the theoretical divisions between social/identity and structure, non-modern and modern, and West and non-West (Bhambra 2007:876-77) by analyzing Jewish women's transracial and transnational social science networks.

Histories of anthropology and sociology (including feminist versions) ignore or de-emphasize racial and gendered colonial hierarchies. Postcolonial feminist sociology addresses this gap by analyzing how these colonial conceptual juxtapositions enable the development of modern Western subjectivity (Puri 2015:64-65). I contribute to the body of feminist social science literature that continues to break the assumed theoretical dichotomies between the realm of the micro, private, social, cultural (often gendered 
female and associated with racial identity) and the realm of macro, public, institutional, and structural - gendered male, and coded as "theory" (Bhambra 2007:876-77; Gacs et al. 1989:xiii; Laslett and Thorne 1997:8, 15, 21; McDowell 1993:173; Thorne 2006:476).

Histories of anthropology and sociology (including feminist interventions) tend to display three primary problems in their approach and implementation. (1) They study individual women in isolation from each other or racially segregate groups of women instead of exploring transracial relationships (Aldridge 2009; Behar 1995; Gacs et al. 1989; Harrison and Harrison 1999; McClaurin 2001; Parezo 1993). (2) They examine the history of the disciplines in isolation rather than investigating transdisciplinary histories.

(3) They study scholars within one national context rather than in transnational conversations (Blasi 2005; Calhoun 2007; Harley and Wickham 2014; Patel 2011; Steinmetz 2013). An exclusive focus on isolated women, only on white women's networks, or solely on anthropology in the U.S. would not enable the analysis of hierarchical racialized colonial and transracial relationships, and Jewish women scholars' "in-between" position within them, as both colonizer and colonized.

Instead of looking at individual "heroines," perpetuating the myth of the "Lone Ranger" anthropologist (Bhaskaran 2004:17), I use a feminist post-colonial approach to social network analysis to investigate the transracial networks between women theorists. I follow the example of Lyn Schumaker (2001) who contends that fieldwork networks generate collaborative data collection, theory development, and the re-formation of subjectivities (Schumaker 2001:36, 41, 86-92). Using a "connected histories" approach by studying transracial, transdisciplinary and transnational networks reveals how the concept of the "non-modern" facilitated the emergence of contrasting "modern" 
subjectivities and theorizing (Behar 1995; Bhambra 2007, 2010; Chakrabarty 2000; Cole 2003; Hier and Kemp 2002; McClaurin 2009; Subrahmanyam 1997). By taking a transnational approach, I break the assumed separation between nation-states and "cultures" in supposedly different geographic "areas" (Rodríguez, Boatca, and Costa 2010:15; Subrahmanyam 1997:745). The conceptualization of diaspora as networks, routes, and mobility (Chivallon 2002:360), connecting diasporic people across racial and national lines (Patterson and Kelley 2000:26), is useful for my understanding of some Jewish women scholars' transnational/transracial networks. The central women in my study were less oriented toward Israel in their research, than toward other marginalized and internally colonized women, who had also experienced historical displacement and suffering (in response to internal colonial contexts) and demonstrated resistance. However, each Jewish woman social scientist's attitude toward the issue of "resistance" and what forms it should be allowed to take (or if it was even a possibility) differed depending upon social location: her national context, marital (sexual) status, class position, political stance, and types of transracial networks.

\section{Historical context}

The inter-war and post-World War II period is an ideal time to study the experience of Jews as simultaneously colonized and colonizer and gender/sexuality as a marker of this struggle. Anti-colonial and global anti-racist movements, including transnational black movements and Zionism gained momentum. This was a period when Jews adopted colonial practices as a way to gain power and assimilate into whiteness. Many of the Jewish women scholars in this study made analogies between Zionism and 
other nationalist, including Black Nationalist, movements. Women became increasingly involved as citizens in nationalist, imperialist and anti-colonialist movements and by the 1960s entered tenure track university positions after decades of exclusion. The primary training, publishing, teaching, and working years of the cohort of women in this study took place during the 1930s-1980s.

\section{Anti-colonial and global anti-racist movements}

The First World War was a defining moment enabling the colonized elite to appropriate philosophies of self-determination, self-government and democracy, promoting their agency (Adas 2004:98; Barraclough 2004:120). WEB Du Bois, a black American sociologist excluded from canonical (white) sociology (Deegan 2005:189) organized Pan-African Congresses in the 1920s in order to create a black united front to attack global racism that stemmed from capitalism, colonization and the industrial revolution (Morris 2007:523-24). The international Négritude movement is another example of the African diasporic networks occurring during this time period, and AfroCaribbean women like Paulette Nardal (1896-1985) and her sister Jane (d. 1993) were especially foundational as network facilitators (Edwards 2003:122). The "long civil rights movement" began in the 1930s, extended post-World War II, was tied to the New Deal and was not confined to the South (Hall 2005:1235). Von Eschen articulates that in the 1940s African Americans connected their fight against racism with the anti-colonial struggles of African people and other oppressed peoples whom they had met during WWII (Von Eschen 1997:2), though these transnational anti-colonial and anti-racism struggles began before the 1940s. 
The Jewish women in this study reveal the connections between Jews of European descent and these global anti-racist movements. From 1929-1932, Ruth Landes conducted fieldwork with Garvey-inspired "negro cults claiming Hebraic blood" in Harlem; she found that these "cults" arouse out of specific sociological and political conditions including racial housing segregation and the denial of voting rights to black citizens of the South (2-3); she articulated how Garvey's philosophies were influential because they gave black people pride and a sense of roots - "national rehabilitation" $(1933: 5,22)$. The specific "cult" that Landes investigated was called the Congregation of the House of the Sons of Abraham (Beth B'Nai Abraham or BBA). Landes demonstrated how the BBA connected Garveyism with the belief that white culture was indebted to black Hebrews. Through this methodology, congregants of BBA were able to transform themselves from "black waifs" into "scions of noble lineage" (5, 16 n. 3). However, Landes critiqued the "sex lure" that the BBA church leaders employed in order to attract female members' financial support $(20,26)$ as well as the leaders' self-aggrandizement and exploitation of their members (8-9). She also expressed distaste for what she considered the disingenuous claims to Jewish ancestry $(10,12)$. She maintained that the primary motivator for the BBA leadership was financial advancement. She quoted a father whose black Jewish child attended a white Jewish school for Hebrew instruction in Harlem. He ardently believed that if he were a Jew, his family would be lifted up: "Look how far they have gone, in spite of persecution. They own all the money in the country. If their religion could do that for them, maybe it can do that for us. We want to be Jewish and get in with the Jews so they can give us jobs and money and help lift us up. Jews should help one another" (21). 
Based upon J.D. Rheinallt Jones' connections with African American activists and intellectuals through his directorship of the South African Institute of Race Relations (SAIRR), Ellen Hellmann journeyed to the U.S. in 1944-5 to attend the World Jewish Congress, fundraise for the SAIRR and observe the contrasts between "race relations" in the states versus South Africa. While in New York City and Washington D.C., she interacted with organizations such as the National Negro Congress (NNC) and the Council on African Affairs (CAA). CAA was a U.S. based organization that supported anti-colonial and anti-apartheid struggles in Africa. The NNC was affiliated with the Communist Party and established a global coalition of religious, labor and civic leaders in order to fight racial discrimination and the deportation of black immigrants. Through this visit, Hellmann met Max Yergan ${ }^{4}$ (a leader/founder in both the NNC and CAA) when she addressed a reception organized by CAA; she also mentioned Paul Robeson and A. Philip Randolph in her report to Rheinallt Jones. Hellmann seemed to prefer the more "moderate" National Urban League because it was "similar to our Joint Councils in setup" through its focus on "problems affecting employment and social services" (Hellmann 1945d).

\footnotetext{
${ }^{4}$ Max Yergan and Z.K. Matthews became close when Max was working as a missionary with the YMCA in Fort Hare from 1922-1936; by the time ZK and Frieda Bokwe visited the U.S. in 1952, Max had disassociated from his previous radical communist politics, but he still was a key connector between African American and black South African activists/intellectuals (Grant 2014:83). Z.K. Matthews (1901-1968) and his wife Frieda Bokwe were anti-racism black intellectuals, educators and African National Congress activists (Gewald 2007:464-66). Z.K. Matthews was a professor of social anthropology at Fort Hare University and spent a year studying with Malinowski at LSE like Hilda Kuper. Matthews and Hellmann were at LSE at the same time in the fall of 1934 (Bank 2016:57). Both Matthews and Ellen Hellmann were allied with the SAIRR (Grant 2014:82).
} 
Then in 1960, Ruth Glass thanked Claudia Jones (1915-1964), of the West Indian Gazette in Brixton for her assistance with London's Newcomers. Harold Pollins (2017) argues that Ruth Glass never met Claudia Jones or any other West Indian women, though he did as the primary researcher and writer for this book. Jones expressed "an internationalist ideology that encompassed feminism, black nationalism, and Marxism” (Lynn 2014:1). Jones was deported from the U.S. in 1955 because of her communist organizing and she immigrated to England. Through the West Indian Gazette Jones advocated a "West Indian consciousness" in Britain (Cantres 2014:268).

Connectedly, as part of the Jewish elite assimilation process in the years before and after World War II, some European Jews became colonizers rather than (and in addition to) being colonized. In the U.S. context, Jewish women gave up their Jewishness for whiteness, using racial superiority over black domestic workers to become "modern" female subjects (Brodkin 1998b:4; Mufti 1998:104, 122-23).

Zionism

Harriet Freidenreich portrays Zionist involvement as a rare exception among her sample of Jewish Central European university women who were of the same generation as the women in my study (39). Most of the women in her sample were highly attached to German culture so that Jewish nationalism seemed "absurd" or "almost inconceivable." Those in the minority who were committed Zionists were part of the group that Freidenreich calls "Jewish Jews" (40). This group "actively affirmed their Jewishness" becoming involved in Jewish voluntary organizations and acknowledging a Jewish nationality. Identifying with Zionism often created a more "positive and modern 
identification as Jews" for "Jewish Jews" that was an exception to the norm for Jewish Central European university women (Freidenreich 2002:144).

Though none of the women in my study was primarily interested in Israel or Zionism as research topics, they made analogies between Zionism and other nationalistic movements. For example, the director of the Research Institute of the Study of Man, Vera D. Rubin, wrote in 1960 that while the Zionist leader, Herzl, re-found his Judaism within Zionism, the West Indian did not rediscover his Africanism through West Indian nationalism. Thus, Rubin contrasted Zionists' reclaiming of their Jewish subjectivity with the absence of African pride in West Indians. Importantly, in this analogy Jewishness is not religious, but rather ethnic or national pride since the comparison is between Africanism and Judaism (Rubin 1960:17).

Ruth Landes made analogies between Afrikaner nationalists' relationship with the Afrikaans language and Zionists' relationship with Israel, stating that South African Nationalists made such comparisons and "admire Israel" because of their shared belief in "separateness" under "Chosen" leadership, even though Nationalists were anti-Semitic (Landes 1970c:3, 1980:25). In a letter to Charles S. Johnson, Landes critiqued "the ease with which even Zionist Jews speak of themselves as a 'race"' because they used it in the Nazi sense (Landes 1944:2).

Though Ellen Hellmann was active in the Zionist Socialist Party from the 1930s1948 , her focus was less on Israel than on the socialist ideal of the inclusion of the "masses" in "organized Jewish life" as well as fighting anti-Semitism through her leadership in the Committee for Rescue from Nazi Terror, reviving the "positive aspects of Jewish life" (Hellmann 1944b:6). Hellmann said that upon the establishment of the 
state of Israel 1948, "I resigned from the Zionists because ...I could see no reason for having Zionist political parties outside of Israel, since I reckoned that was a function that should play itself out inside Israel; they do it rather excessively" (Hellmann and Krut 1982)! In 1955, Ellen Hellmann spoke to the Cape Zionist Club, using Israel as an example of a country where "individuals with thousands of years' divergence in civilization" would in a few generations "be adapted to Israel's way of life" (E. Hellmann 1955b). From her perspective, this assimilation could be a template for middle-class Africans who were adopting Western lifestyles.

In contrast to the arguments presented by Blumen and Elazar, the women in my study did not represent Zionism as a subjugation of women into passive roles (Blumen 2002:557; Elazar 2002:378). When they did discuss the intersection of Zionism with gender (which was not that often), the women in this study portrayed Zionism for the most part as creating equality between men and women. However, it is extremely important to note that both Landes and Hellmann were referring to Labor Zionism or the Zionist Socialists rather than to a "generic" Zionist movement. Landes emphasized the gender segregation within Orthodox religious groups, but argued that the Labor Federation for Israel (Histadrut, of which her father was a primary leader) included both men and women "and one of its female members is also Israeli Minister of Labor" (5). Israel emphasized emotional "hardiness" for both men and women (7). "For the first time in history, Jewish women serve equally with men in the Israeli forces...the women are as equal and independent - in theory, and slowly but growingly in practice - in other spheres of Israeli life; they compose ten percent of the Parliament" (Landes 1951:9). 
Ellen Hellmann said that within the Zionist Socialist movement men and women carried equal responsibilities since there was no analogous socialist and Zionist Pioneer Women organization (which existed in the U.S.) in South Africa (Hellmann 1944b:6). Looking at this time period allows analysis of the analogies Jewish women made between Zionism and other nationalist and decolonization movements.

\section{Turning point for women's involvement in nationalism and imperialism}

Many scholars argue that the women's movement took a hiatus after women won the right to vote in the 1920s, only returning as the Second Wave in the 1960s (Crooks and Moreno-Black 2012:14). In the British Empire this time period was a turning point for women's economic and political citizenship; through their military, nationalist and imperial involvements women could prove they were worthy citizens (Burton 1994:7; Woollacott 2006:104). Female social scientists finally began receiving tenure track or permanent positions at universities in the mid 1960s. For example, Ruth Landes moved to Hamilton, Ontario in 1965 for a tenure track position at McMaster University (Glenn and Wang 2010:9; Landes 1986g:3). Viola Klein gained a full time academic position as a lecturer in sociology at Reading University in 1967, twenty years after the publication of her thesis at the London School of Economics (Lyon 2007:838). I concentrate on the period between the so-called first and second waves in order to emphasize Leela Fernandes' non-linear feminist history that breaks from the teleological wave approach (Fernandes 2013:175). This time period is interesting because while feminist activism may not have been as visible as it was in the earlier part of the $20^{\text {th }}$ century and as it would be starting in the 1960s, women, at least in the British Empire, were able to gain 
prestige through their involvement in colonial projects. Thinking about the historical continuities between women's organizing, anti-colonial and anti-racism movements is useful in considering the transracial, transnational and transdisciplinary conversations between diasporic women scholars who worked in colonized contexts and who theorized about race, class, gender and sexuality.

In the chapters that follow I evaluate not only how Jewish women's "in-betweenness" produced subversive stances toward the colonial contexts where they conducted fieldwork, but also how their position in relation to gender, sexuality, race, and class norms influenced their assumption of colonial hierarchies and categorizations as a method to become "authentic" social scientists or "forces for progress" (Puri 2004:69-70, 234 n. 13). I demonstrate how Jewish women's familial networks in combination with their racialized national context, and their personal and professional (including transracial) networks influenced their social science theorizing about women of color.

\section{Chapter Outline}

The first chapter, Methodologies: Reflexivity and Reciprocal Obligation, directly follows this Introduction. Historical studies often do not include a methods or methodologies chapter, but based upon the assistance and interventions I received from librarians, archivists, museum professionals, scholars, religious practitioners, and family members/students of the women in my study, it is necessary to describe the process of my historical research. Additionally, the inclusion of an extended methodologies chapter is an intervention in the typical approach to historical materials as non-active. Viewing 
historical materials as inert neglects the political agency of nonhuman things (Bennett 2010; Latour 1990) and the power of human-nonhuman entanglements in knowledge production (Hodder 2014). I begin the chapter with a reflection on how my gendered and racialized Jewish subjectivity formation and my transracial networks influenced my relationships with historical research subjects and my theorizing about them. This heuristic and self-ethnographic approach emphasizes the anthropologist's embodied experience as knowledge production. Next, the chapter provides brief bios of each historical woman, in order to set up theoretical comparisons between them based upon the sampling approach. Then, I explain when, where and how I collected data and how data collection influenced the re-formulation of research questions and theorizing, as part of the grounded theory methodology process. Finally, I justify my choices for my three approaches to data analysis: grounded theory methodology, historical social network analysis and an exploration of affective entanglements and their theoretical effects.

In Chapter 2, I introduce Ellen Hellmann, who was the most "conservative" Jewish woman in this study. Hellmann's wealthy class background, marriage to two Jewish men, and forty-year institutional stability at the South African Institute of Race Relations, guaranteed that her professional networks were primarily with elite white men/women and black men, who worked as her "assistants" during her master's and doctoral research. She labored to preserve, protect and promote Jewish specialness while also ensuring Jewish rightful belonging in whiteness in South Africa and advocated black assimilation into "Westernized" and "civilized" white middle-class modes of behavior. Subsequently, her views of black women's sexuality were paternalistic and moralizing, attributing working class black women's "immorality" and familial "instability" as the 
primary causes of juvenile delinquency. Chapter 2 creates a baseline for comparison in the subsequent chapters, which use Hellmann as a counter-point.

Chapter 3 introduces Ruth Landes, who often made analogies between Jews and Blacks as similarly oppressed groups. She simultaneously asserted her own white identity despite being assigned as non-white by colleagues. Inspired by her working class and socialist Eastern European Jewish familial origins, she engaged in interracial relationships, which impacted not only her theorizing but also her access to institutional stability. In contrast to Hellmann, Landes' theories about black women celebrated the relationship between sexuality and power, and black women's authority and leadership in the African Diaspora. This chapter contrasts Ruth Landes with Ellen Hellmann in order to evaluate the divergences between anthropologists of Eastern European and Central European Jewish descent in terms of how they thought about the intersections of Jewish and Black communities in South Africa, Brazil, and the U.S. The chapter explores how and why these two women theorized inversely about black women's sexuality and family structures based on differences in each woman's class origins, political associations, marital status, institutional affiliations and professional networks. The chapter emphasizes their differential placement in relation to whiteness and how the gendered internal colonization process sexualized and racialized certain Jewish women social scientists, like Ruth Landes, who did not conform to middle and upper-class white gendered sexual norms. It explores how Jewish women used representations of black women to reflect their own racial subjectivity and relationship to whiteness.

Chapter 4 introduces Hilda Kuper, born in Rhodesia, but who like Ellen Hellmann, grew up in Johannesburg, and trained with Winifred Hoernlé at the University 
of Witwatersrand. While Hilda Kuper and Ellen Hellmann both began with research about the impact of liquor laws on black women in Johannesburg, Kuper's research sites expanded to Swaziland and later, Durban in Natal, South Africa, where she formed lifelong friendships and research partnerships because of her immersion in her field sites. Additionally, because of Hilda's marriage to Leo Kuper she became involved in nonviolent apartheid protests as one of the founders of the Liberal Party and was forced to leave South Africa. In her theorizing about black women, Hilda took a "Swazi point of view," arguing that Westernization weakened women's position. She portrayed Swazi women and Indian South African women as the victims of colonization as well as patriarchal indigenous systems. In contrast, Ellen Hellmann took a white elite point of view, depicting black women in Johannesburg as the "problem" and cause of juvenile delinquency, and arguing that they should become more Western, white and middle-class in their familial structures. Through Hellmann's involvement in the Progressive Party she advocated the qualified franchise, requiring voters to prove their "civilization" through property-ownership, wealth and education. This chapter demonstrates that not all Jewish social scientists in South Africa were necessarily "radical" in their anthropological studies of black communities.

Chapters 3 and 4 emphasize how transracial networks between women impacted the theorizing of Jewish women social scientists, as part of the effort to desegregate the history of the social sciences (Bhambra 2014:486). I aim to directly counteract the tendency to portray black women scholars as being receivers of white women's wisdom (Deegan 2005:193, 198-99) and instead demonstrate how women of color's theories about their worlds directly influenced the theorizing of Jewish women. I also emphasize 
that the lack of transracial networks, or networks with only black elite men and not with women of color, tended to lead to more conservative, "upwardly mobile," and assimilationist theorizations about black women (as evidenced by the life and work of Ellen Hellmann).

Chapter 5 introduces Ruth Glass, a German Jewish refugee sociologist who fled the Nazis and conducted research about West Indian migrants to London in the 1950s and '60s. Glass mobilized her research to activate policy changes, while Hellmann interpreted "objectivity" to be the opposite of impassioned social activism. Glass critiqued the clichés associated with urban growth espoused by writers like Ellen Hellmann. Glass also condemned "native" white Londoners, who used Nazi-like tropes regarding the increasing migration of West Indian migrants to the city. In contrast, Hellmann placed the onus of responsibility on black migrants to adapt "civilized" white modes of behavior. Glass portrayed West Indian women migrants primarily as workers and did not discuss their sexuality or family structures, in contrast with the other women in this study as well as other race studies scholars in the U.K. at the time. Chapter 5 intervenes on the assumption that German Jews were necessarily assimilationist and conservative as compared to Eastern European Jews. This chapter reveals how the Jewish position in relation to whiteness within specific national racial contexts impacted social scientists' theorizations of urbanization and migration of racialized/marginalized peoples.

Chapter 6 is the final chapter and articulates the larger significance of the dissertation. It includes a discussion of the primary themes and findings of this dissertation. It provides a few select examples of these themes from each of the previous chapters as a method of "recapping" and also compares and contrasts all of the women in 
one place using five key influences on Jewish women's theorizing: Jewish family background, transnational networks, political and institutional affiliations, marital/romantic relationships, and transracial networks. Finally, this chapter elaborates some future directions for the research. 


\section{CHAPTER 1 METHODOLOGIES: REFLEXIVITY AND RECIPROCAL}

\section{OBLIGATION}

"It does not seem to me that we understand the laws governing the return of the past, but I feel more and more as if time did not exist at all, only various spaces between which the living can move back and forth as they like, and the longer I think about it the more it seems to me that we who are still alive are unreal in the eyes of the dead, and that only occasionally, in certain lights and atmospheric conditions, do we appear in their field of vision." -W.G. Sebald, Austerlitz (a novel), cited by Carolyn Steedman

While analyzing documents, photographs and ethnographic objects that had once been in the hands of the women in this study, I felt that "time did not exist at all" and that these physical objects connected me with the women. By touching, reading and scrutinizing their archival objects, I was "communing with the dead" (Steedman 2008:5). Carolyn Steedman in "Romance in the Archive" writes (influenced by Jules Michelet, a French historian) that "history-writing" is a form of "making the dead walk and talk." She articulates the power of the historian to emphasize certain narratives and deemphasize, hide or erase others (Steedman 2008:5-6). I want to reveal the aspects of my social location which impact the kinds of stories I choose to tell about the women in this study. However, I also wish to underscore how alive the objects felt to me, how powerful, how much I perceived them to tie me to the women they once belonged to. Bob Sillar explains that "things engage our emotions and evoke memories, ideas and meanings" but that they also "have a degree of intentionality of their own" (2009:368). As I worked in the archives, and also when I spoke to other academics who were students of the women in my study, I sensed the presence of these female Jewish ancestors. Sillar discusses the ritual "tie of obligation between the animate entity and the devotee making the [ancestral] offering" and the "contagious magic" (a Frazerian concept from 1915) through which 
things previously in physical contact maintain their link despite their subsequent distance (Sillar 2009:370, 373). In this chapter I intervene in these conversations by applying theories about human and non-human dependence (Hodder 2014:32) and "reciprocal obligation" (Sillar 2009:367) to my relationships with non-human archival and ethnographic objects which once belonged to living female social scientists. The "ties of obligation" I feel for the women I studied continue into the present, despite my physical distance from their archives and objects. Their archival objects enabled me to perform this project (thus I am dependent upon them), and by analyzing their lives and work through their objects I promote potential further research about them (thus they in some ways depend upon me). Subsequently, I view this dissertation and especially this methodologies chapter as my "offering" to them; even when I critique them, I still bring potential further attention to their theoretical contributions to the social sciences.

To emulate the reflexive approach of Jewish and Black women anthropologists, like Ruth Landes and Zora Neale Hurston (Hurston 1935; Landes 1947), in this chapter I am contemplative about my subjective engagement with archival materials, using a selfethnographic style, which understands the anthropologist's embodied experience as knowledge production. I do this by analyzing the intersections between subjectivity (including my personal experiences and motivations), disciplinary theory-making, and global-historical-political processes (Bhaskaran 2004:3-4, 29-33; Okely and Callaway 1992; Prahlad 2005; Shalin 2010). This "self-search, self-dialogue, and self-discovery" is the "heuristic process," which requires that "the investigator must have had a direct, personal encounter with the phenomenon being investigated" as I do with Jewish gendered subjectivity, processes of internal colonization, and transracial social science 
networks (Moustakas 1990:10, 14). "Reflexivity" requires vulnerability, the embrace of subjectivity and introspection, an interrogation of one's epistemologies, and social formations. It requires social scientists to tell the stories they have been unwilling to tell (Behar 1996; Probyn 1993). The first section of this chapter is a reflexive account that mirrors the questioning process I utilized with the core women in this study. I turn the questions on myself, revealing how my Jewish gendered subjectivity formation, experiences of internal colonization based on my familial history, and my transracial networks, influenced my theorizing about the women in this study.

Section Two describes my theoretical sampling strategy and sets up "theoretical comparisons" or "axial coding" between the four core women using brief comparative biographies. "Theoretical comparisons" reveal the relationships between the "properties and dimensions" of categories: properties describe the characteristics of a category, while dimensions explain the variation within the category (Saldaña 2013:209, 218). In this project, the "categories" were national context, disciplinary training, transracial networks, and Jewish subjectivity. Examples of the "properties" I used to describe the category “Jewish subjectivity" are: explicit statements about each woman's Jewish identity and analogies between anti-Semitism and other forms of racial discrimination. "Dimensions" are the variations between the women within each property, for example I explore how the women differently expressed their Jewish identities.

Section Three explores when, where and how I collected data and how data collection influenced the re-formulation of research questions and theorizing, as part of the grounded theory methodology process. I provide information about which archives and museums I physically visited or gathered materials from digitally with the help of 
special collections librarians and archivists. I also include information about the interviews and consultations I conducted with scholars, students and family members of the core women in my study.

In this project, I intertwined data collection and analysis, thus practicing an iterative, grounded theory methodology (GTM). Systematic and close textual analysis, of what and how (word choices, analogies) historical subjects wrote about their subjective experiences and those of their research participants, informed the reformulation of research questions and theme-theory construction (Brondo et al. 2009; Maor 2012; Strauss and Corbin 1998). One of my initial and central hypotheses in my proposal was that Jewish female social scientists fought anti-Semitism by "remote control," taking an anti-racist and pro-political/economic justice stance to understand their otherness through "the most other" (Berger 2010; Damon 1996; Diner 1995; Lewis 2008, 2013). Through the use of grounded theory methodology, I found this hypothesis to be untrue and instead uncovered the differences between the theorizing of different Jewish women in my study based upon their national affiliation, class background, political orientation, marital status and transracial networks.

The fourth section explicates my methodological interventions in typical histories of social science by using three innovative approaches to data analysis for historical studies: grounded theory methodology, historical social network analysis and an exploration of affective entanglements and their theoretical effects. In order to clarify this process, I include examples of each of these data analysis approaches. 


\section{My gendered and racialized Jewish subjectivity formation}

Growing up, my Jewish mom often told my sister and me that she married my dad, who was not Jewish, so that we would not look Jewish or have a Jewish last name. My mom, who was born in the mid-1950s, was teased for her "Jewish" appearance (skin complexion, hair, and body shape) and subjected to anti-Semitic jokes in a primarily nonJewish Los Angeles neighborhood. She also felt alien among the Jewish kids because her father, my grandfather, went into the produce business unlike the lawyer and doctor fathers of the Jewish kids my mom knew. Papa Larry's parents were Eastern European Jews who had escaped pogroms in Russia; his mother ran a corner-store while his father (who died when Larry was 17) was a house-painter who did not speak English. My mom, my grandfather and my dad are pictured in Figure 1. As Karen Brodkin explains, historical experiences of anti-Semitism become engrained in the communal memory of Jewish families (Brodkin 1998a:3). Anna Denejkina uses the term "exoautoethnography" to articulate how her father's (war-based) trauma impacted her "by proxy" through "transgenerational trauma transmission" (Denejkina 2017). Though my mom clearly hoped for my sister and I to pass into whiteness as a way to try to escape her fear of persecution (based on her familial experiences of anti-Semitism), she also paradoxically ensured our active involvement in the Jewish Reform movement, through religious and Hebrew school, summer camp and youth group, which all required financial, as well as time and energy commitments for her and my dad. She told us she wanted us to have the Jewish upbringing she was not given access to. She came of age before Reform Jewish girls were able to become bat mitzvah, "daughter of the 
commandment." I spent several days each week at synagogue (we called it "temple") and three weeks to two months at Reform Jewish camp (called Camp Swig) each summer starting in fourth grade through high school. I worked as a camp counselor at the same Jewish camp throughout college and later worked for the Foundation for Jewish Camp advising camp counselors and their supervisors to increase the Jewish content in their educational programming. Through my deep and prolonged Jewish education, I developed what I consider a strong Jewish identity that aligns with Brodkin's description: politically liberal, invested in social justice and identified with other marginalized groups (3). My Reform Jewish social justice-oriented youth group led me to enroll at Brandeis University, founded in 1948 for Jews and other subaltern groups who were denied entrance into the Ivy Leagues (Lapkin 2015; Shapiro 1992:71-76).

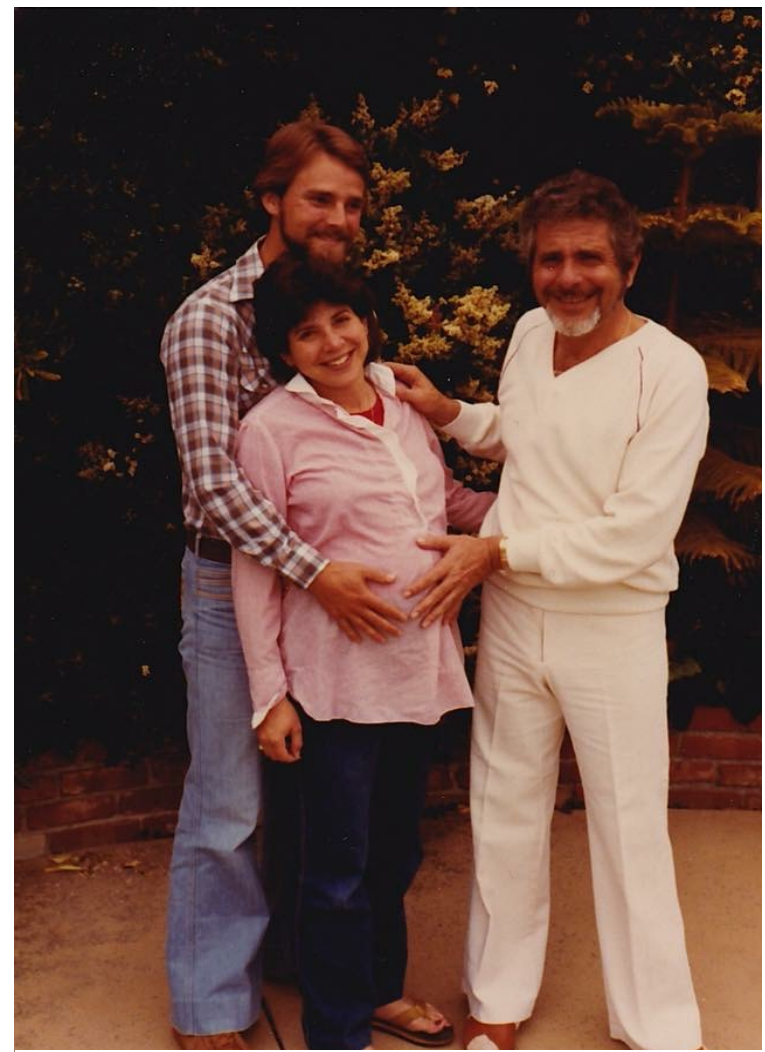

Figure 1. My mom (pregnant with me), dad and maternal grandfather in 1982 
Despite this pride in being Jewish, I still felt ashamed of my fatness, which I learned from Jewish female relatives, who expressed "concern" for my big belly and who insisted that I diet even as a young child. Jewish women have historically been portrayed as fat, immoral, lustful, dirty, vulgar and disgusting, characteristics which link them with blackness and subsequently the absence of femininity (Bloul 2013:6-7; Brown Lavitt 1999:253; Schiff 2003:91-92; Trubowitz 2012:1-2). Consequently, Jewish women actively worked to physically assimilate into whiteness through plastic surgery and food restriction, in an attempt to escape what Rachel Bloul calls the "racialized disgust" that "contaminates its victims to the bone," invading and structuring their "corporeal schemas" (Bloul 2013:18). Jewish women's body modification and their enforcement of these practices upon their daughters is part of the internal colonization process (Brodkin 1998a:17; Maor 2012:6-7). Ruth Landes argued that this hypercritical gaze was a strategy for Jewish mothers to maintain dominance over their daughters within a patriarchal family structure (Landes and Zborowski 1950:456-57). Landes' mother was hypercritical of her, reminding her to wash her "greasy" face (A. Schlossberg 1959b:2). Landes admired Afro-Brazilian Candomblé priestesses because, unlike her mother, they "did not care about being dainty. Their concern was to lay claim to where they sat" (Landes 1947:83). The criticisms Landes received from her mother, and her perception that the black female religious leaders in her research were not held to the same appearance requirements, connected with my own experiences and caused me to be even more interested in studying her personal and professional trajectory.

Bodily memories construct our experiences of subjectivity (Fuchs 2012:9). Because of my experience of corporeal otherness triggered by familial reactions to my 
“fat" body, white boys' taunts and abuses through adolescence, and my experience of bodily "recognition" through my relationships with some Black men, especially Jair Santos (a pseudonym, my first boyfriend, an Afro-Brazilian Portuguese student and teacher), I came to associate blackness with "self-recognition" and whiteness with "misrecognition" and shame (see figure 2, a photograph of me with Jair). Percy Hintzen and Jean M. Rahier explicate how white supremacy creates "black abjection, exclusion and erasure" through an assumed naturalization of "black inferiority, inhumanity" (x-xi); thus, white supremacy coordinates a profound "black misrecognition" through which black subjects experience what Du Bois identifies as "double consciousness" - the process of looking at oneself through the state's racist ideologies (xi). Stuart Hall, alluding to Franz Fanon, calls this practice a complicity in "an objectification of oneself that is a profound misrecognition of one's own identity" (Hall 2001:31). Though I am not black, my Jewish body's failure to adhere to contemporary white middle-class female beauty standards led me to feel this "misrecognition" - a perception of myself as inferior and abject because I internalized the racist/sexist body ideologies of white supremacy.

Hintzen and Rahier reveal how the metaphor of "diaspora" formulates a "space of collective self-recognition" (my emphasis) that often inhabits "subliminal levels of black consciousness" that were previously "rendered invisible by distortion, misrecognition and miscognition" (Hintzen and Rahier 2010:xi). Thus, diaspora calls these formerly incomprehensible feelings into awareness through "mutual recognition across difference" (xiv). I experienced this "self-recognition" through my relationships with specific members of the African diaspora, through which we could collectively access subliminal feelings of acceptance "across difference" (my emphasis). 
My experience of bodily "recognition" within specific black communities, mirrors the experience of other white women with high body mass indexes (BMI) who Kivan Polimis (2012) found were more likely than white women with lower body mass indexes to date black men. Polimis does not provide information on the ethnicity of these white women, for example, if any of them were Jewish. Polimis explained his findings partially by arguing that black male adolescents preferred "thicker" women while white male teens preferred thinner women. Black children perceived the "ideal body" as larger than white children did (Polimis 2012:8-10).

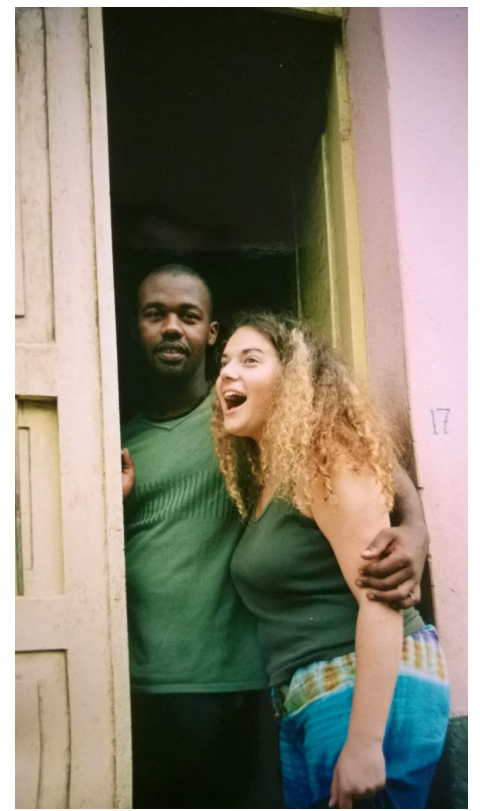

Figure 2. Abby with Jair at his front door, Cachoeira, Bahia, Brazil, June 2003

Eduardo Bonilla-Silva points out that BMI is a purportedly "universal" but racist measure. ${ }^{5}$ In 1871, Dr. Paul Broca aimed to scientifically prove white elite men's

\footnotetext{
${ }^{5}$ Thank you to Imani Wadud for the recommendation to look into this article by BonillaSilva regarding critiques of BMI.
} 
superiority by creating a body "ideal" that categorized black bodies, which were heavier and more muscular, as outside of the "norm" or "ideal" (Bonilla-Silva 2012:2-3). My experience of "recognition" in Jair's community and other specific black spaces potentially stems from the black challenge to normative white beauty and body standards (Bonilla-Silva 2012:11).

In mostly white spaces, I was a fat Jewish girl. In some black spaces, I did not experience the same kind of verbal attacks, and in fact, Jair called me "the blackest white woman," [a branca mais negra] including me into his Brazilian conception of blackness (facebook communication, September 20, 2013). In 2014, he explained what this term meant to him: "My neguinha [using a racialized term of endearment], the blackest white woman means that you embrace black culture, even more strongly than many black people. The skin is a mere detail...you are a black woman of culture and soul and a Jewish woman of heart." Jair demonstrates the Afro-Bahian black activist definition of "negro" as "not a matter of pigmentation, but a result of a mental attitude." If one thinks critically about race and racism, one can be "negro" even if one is not dark skinned or "preto" [black] (Silva 2012:14-16).

My alliance with black communities (in both my research and my relationships) troubled the tendency for some Jews to assimilate into whiteness as a form of protection against anti-Semitism. I followed the pattern of Jewish identification with other racially marginalized communities. Though I often feel like an anomaly in my family because of my dating and research patterns, my mom has also expressed pride in my accomplishments and the fact that I "dance to my own beat" and "don't follow the crowd, you follow your heart." 
Though my Papa Larry expressed his classification of Jews as white, and criticized my “communist" views, he also encouraged our debates, strengthening my feminism. "I don't care who you date as long as you remember you are White, Jewish and American," he expressed in 2003 in reference to my relationship with Jair. He clearly identified Jews as white, a process that was already underway when he was born in 1933 but accelerated after World War II. His statement is somewhat surprising considering that many Jews who grew up before WWII do not identify as white (Brodkin 1998a). Papa Larry also frequently called me a "communist" during dinner debates in which I challenged his sexist perspectives. Jews who sought assimilation often distanced themselves from "radical" political views like communism. Violaine Junod (1952) found that the "communist bogy" was associated with all sorts of causes in the early 1950s in the U.K. (the site of Ruth Glass' study London's Newcomers) including interracial dating, and demands for self-governance in the British colonies (Banton 1960:152). Thus, it is

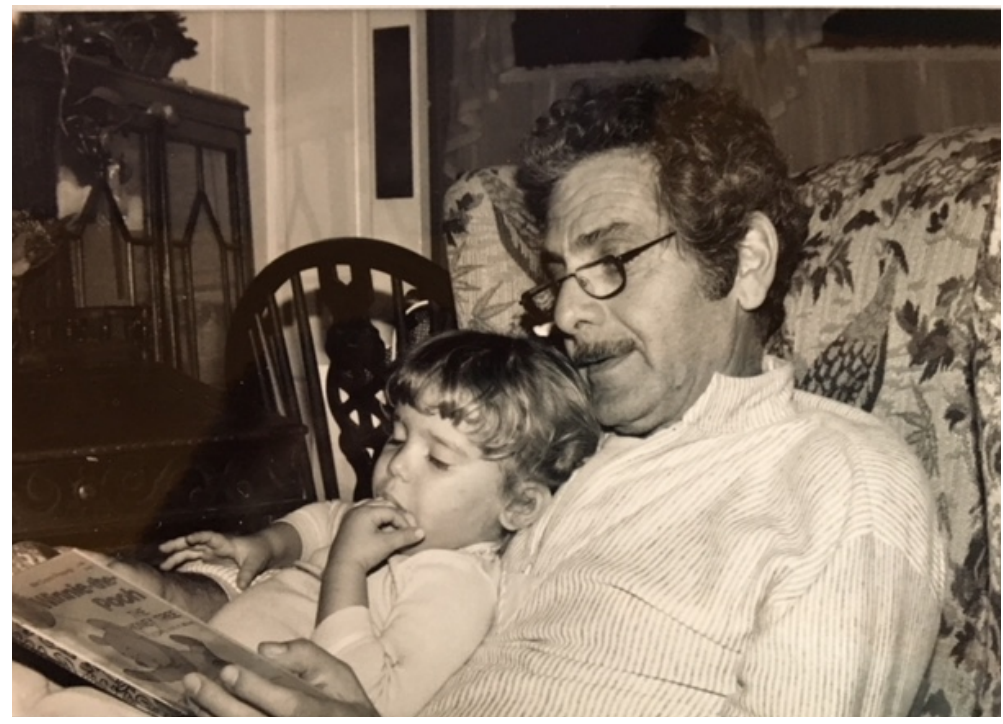

Figure 3. Abby with Papa Larry, 1984 (age 2) 
unsurprising that my feminist, anti-racist views and my interracial relationships would lead Papa Larry to categorize me as a "communist."

Papa Larry never shut down our debates by silencing me, which encouraged me to continue to contest his perspectives, fortified my feminism and confidence to speak up, especially to my elders. For a photograph of me with my grandfather, see Figure 3. Similarly, Landes' approach toward those in authority mirrored the Eastern European Jewish belief that leaders were not immune to critique. They had to prove their capability through their performance; their power was not taken for granted (Landes 1951:5). The ambivalence displayed by my Jewish relatives, the messages that I should blend into white normality, yet simultaneously that I should remain "different" and outspoken, is the crux of the dilemma of being a Jew of Ashkenazi/European descent within an internal colonial context.

Ruth Landes was criticized by Margaret Mead both for her lack of gender conformity (Mead called her "unladylike"), but also for her "bi-racial interests," which Mead found "neurotic" (Cole 2003:x, 13, 201; Landes 1986d:1). I began this research project because I wanted to understand why Jewish women (like me) who experienced forced assimilation, and were products of the Jewish diaspora from Europe, might have identified with black communities. I wondered if their research in black communities permitted an access point for self-decolonization, finding recognition where there had previously been "depersonalization," a feeling of detachment from one's body triggered by trauma (Shusta 1994:23). But I also wondered if Jewish women responded to antiSemitism through gendered and racialized self-hatred and a distancing from blackness in order to become white, an inability to be in the same space with others of their "kind" or 
other minority groups (Klein 1946:172-73). Schwadron reveals that Jewish performers (blackface actors and also dance choreographers in the 1930s) appropriated or "borrowed" black vernaculars in order to emphasize Jewish difference; Gertrude Stein is a Jewish woman writer who used these strategies in the early $20^{\text {th }}$ century (Damon 1996). Thus Jewishness could be conceptualized as incorporating blackness both as "sympathetic identification" but also as a process of racial privilege, guilt and exploitation (Schwadron 2013:36-37). This accentuates the intersection of Jewish experiences of diaspora and internal colonization and Jewish perpetuation of colonization processes upon other diasporic peoples.

\section{The Roots and Routes of This Project}

The homophones "roots" and "routes" refer to two different conceptualizations of diaspora. Within the "classical" or "roots" view of diaspora, also called "A Series time," Jews are seen as coming from one ancestral "home" and longing to return to that place if not physically, then symbolically (Safran 1991). The second and newer version, uses the analogy of "routes" or "B series time," conveying a "hybrid" and decentered view of diaspora (Clifford 1994), emphasizing "traveling cultures," mobility, networks, and exchanges between locations within the diaspora instead of permanence and one singular homeland (Chivallon 2002:360; Gilroy 2003). My work as a Jewish white American woman with Jewish women of color in Brazil (during my Women's Studies M.A. thesis, 2007-8) and with no-longer living Jewish women social scientists and the women of color they collaborated with in the $20^{\text {th }}$ century, could be seen as part of the "decentered, lateral" kind of Diaspora studies in which we do not focus on a homeland, but instead our 
possibly common journeys toward self-determination and self-recognition (Patterson and Kelley 2000:15).

Below I include a description of the process by which I came to do this dissertation project because I want to emphasize the importance of $m y$ transracial networks to my theorizing about other Jewish women's transracial networks. This dissertation is not only a product of my Jewish subjectivity formation, but also the relationships with scholars and members of the African diaspora that my Jewish diaspora background led me to. By describing the process in depth, I reveal my epistemologies about Jewish disaporic women and use my embodied experience as knowledge production. I analyze the intersections of my motivations, my networks with disciplinary theory makers (my teachers and the writers they exposed me to), and global-historicalpolitical processes like the racialized sexualization of women scholars that impacted their career trajectories, women's transgression of sexual norms, "outlaw" status and "erotic autonomy."

The seeds for this project emerged from two African Diaspora Studies courses I took in my first semester (Fall 2013) of the combined Ph.D. in Global and Socio-cultural Studies and M.A. in African and African Diaspora Studies at Florida International University. In a course entitled, “African Diaspora Studies Theory” taught by Dr. Andrea Queeley, we read several texts that referred to Ruth Landes in the context of her contested relationship with anthropologist Melville Herskovits (Price and Price 2003:8485; Yelvington 2006:75). As a creative option for the second mid-term exam, I wrote a short play in which the different scholars we had been reading were characters at a party. I created a cameo role for Ruth Landes in the final scene of my play which I tellingly 
entitled "Scene 6: Ruth changes everything." I include a brief discussion of my play here because it not only illustrates my initial interest in Ruth Landes that eventually led to this dissertation project, but also points to the teachers and writers who influenced my theorizing. My interpretation of Ruth's personality and behavior also reveals why I was so attracted to her as a historical figure. Sally Cole, Landes' biographer, explains the tendency for anthropologists (like Ruth Landes) to both find and present informants who mirror the anthropologist's own traits. In both Landes' and my case, we wanted research subjects who mirrored our strong-minded, stubborn and individualistic characteristics (Cole 2003:11).

In the final scene of my play, Ruth calls the home of Manning Marable where the party is being held, since she was not invited to the gathering, and asks to be put on speaker phone so that she can critique Sally Price's portrayal of the mati work (black women's relationships with women) in Suriname as non-sexual (Price 1993:17, 201). I purposely positioned Ruth Landes in the play as an outsider who was not invited to the party to emphasize her marginalization from the anthropological establishment for three decades from the mid-1930s to the mid-1960s because of gossip spread by a transnational network of white male scholars including Melville Herskovits, Arthur Ramos and Rüdiger Bilden (discussed in Chapter 3). Even though she died before Sally Price's work was published, I made her character critique Price because I thought that Ruth would likely argue (as Gloria Wekker did) for the importance of sexuality in its intersections with gender, race and class in the mati work (Wekker 1999). Sexuality, including both hetero- and homosexuality, was an important element of Landes' theorizing in City of Women (1947) regarding her interpretations of Candomblé matriarchy. Her academic 
marginalization was a result of her emphasis on homosexuality in her theorizing of Candomblé, and her own sexuality with men of color (deemed "abnormal"). My knowledge of Gloria Wekker and Sally Price's writings about Suriname and the mati work emerged through two seminars I took in the Women's Studies program at San Diego State (2006-2008), one focused on sexualities taught by Dr. Esther Rothblum, and the other on gender in the African diaspora taught by Dr. Betsy Colwill, who has written about heterosexuality, monogamy and sexual control of women as the proof of citizenship status in Haiti (Colwill 1998). ${ }^{6}$

My play ended with Ruth taking center stage with her voice, if not through her body, since I gave her the last line of dialogue: “we can’t forget about the people who are the most marginalized, like women and non-heterosexuals." The way I wrote Landes' character in my play reveals my interest in her transgression of sexual norms, both in her personal life (because of her interracial relationships both within and outside of the institution of marriage) but also in her research interests. These paralleled my previous relationships and research history. Also, my desire for her to "take center stage" and to have the last word emphasizes my interest in creating a space, this dissertation, where Ruth Landes and women social scientists like her would get the attention I think they deserve, even if the attention comes in the form of critique.

\footnotetext{
${ }^{6}$ Dr. Vrushali Patil introduced me to this article by Betsy Colwill in Patil's Fall 2015 course exploring the connections between gender, race, sexuality and the history of colonialism.
} 
$\underline{\text { An outlaw space }}$

The other root/route for this dissertation came from an African Diaspora Studies Colloquium, which was taught as a proposal-writing course during my first semester of the combined M.A./Ph.D. program. My intention was to continue my Women's Studies M.A. thesis research with Afro-Brazilian Jewish women (Gondek 2008). During that course we read Jacqui Alexander's Pedagogies of Crossing, which asks whether women should be ladylike daughters, defined by their relationships to men or if they have sexual agency and "erotic autonomy" (Alexander 2006:22). This erotic autonomy challenges the nation, which wants to control women's sexuality, making women who break these rules into "outlaws." When I spoke with Jewish women of color during my thesis research, I felt we were in an "outlaw" space together, since I perceived myself as a rebel and they described themselves as "exceptions to the rule." I was interested in exploring how the fieldwork space might be a site of the proliferation of this "outlaw" identity and strengthening of "erotic autonomy." Though I wrote my proposal for the colloquium about my relationship with living research participants in Brazil, my questions about the transformative nature of relationships during fieldwork still applies. Lyn Schumaker's Africanizing Anthropology (which I read in Dr. Queeley's class) illustrates how the crossracial relationships, practices and experiences in the field shape the theories created (Schumaker 2001:5-7).

The male professor who taught that Colloquium exclaimed exasperatedly in response to my proposal: "It's not about you!" because he thought I was focusing too much on myself rather than on the Black Jewish women I proposed to research. I realized that I was interested in studying myself as part of a group of diasporic Jewish women of 
European descent, who had undergone the historical process of forced assimilation, a form of internal colonization, into whiteness, and who chose to study black communities, as I had done in Brazil. In this chapter, I examine my affective relationships with nolonger living Jewish women social scientists, and in Chapters 2-5 I investigate the relationships between Jewish women and their female research participants and collaborators.

\section{Sampling Strategy and Comparative Biographies}

I chose the core women in this study using a theoretical sampling strategy (Padilla 2013:7) ensuring I investigated Jewish women from different national and disciplinary contexts who were engaged in transracial, transdisciplinary and transnational scholarly networks especially with women, and who reflected upon Jewish subjectivity in a way that enabled me to make comparisons to their theorizing about race, gender, sexuality, class and nation. Thus, this section explains why and how I chose the women in this study, and provides brief overviews for each of them before delving deeper in Chapters $2-5$.

\section{National context and transnational networks}

Ellen Hellmann grew up, attended school, and conducted research primarily in Johannesburg, South Africa. However, she also visited other South African cities such as Cape Town, Port Elizabeth and Umtata in the Transkei (E. Hellmann 1955b; Hellmann 1943; Pitman 1962; Writer 1955; Writer and Jewish Board of Deputies Archive 1967). She attended the London School of Economics to study with Malinowski for a brief 
period in the fall of 1934, and traveled on behalf of the South African Institute of Race Relations to the Congo, French Equatorial and West Africa (including Dakar, Senegal), Trinidad and Tobago, and New York in 1944-45 (Bank 2016:121; Hellmann 1944a). She visited Nairobi, Kenya with J.D. Rheinallt Jones in February 1947 to form a Kenyan Institute of Race Relations (Hellmann 1947). In September-October 1954, Hellmann represented SAIRR at an UNESCO conference for social scientists in Abidjan, Ivory Coast, and stopped in Accra, Ghana at the beginning of her trip (Staff writer 1954; UNESCO 1954; Writer 1954a, 1954b). She visited England often once her daughter Ruth began to have children (Ruth started at Cambridge in 1956/7). Ellen came to Oxford in June 1959 for an urbanization conference at Nuffield College, at which she interacted with Ruth Glass (Hellmann, Glass, and Myrdal 1959). For a visual representation of Hellmann's transnational trips see Figure 4. 


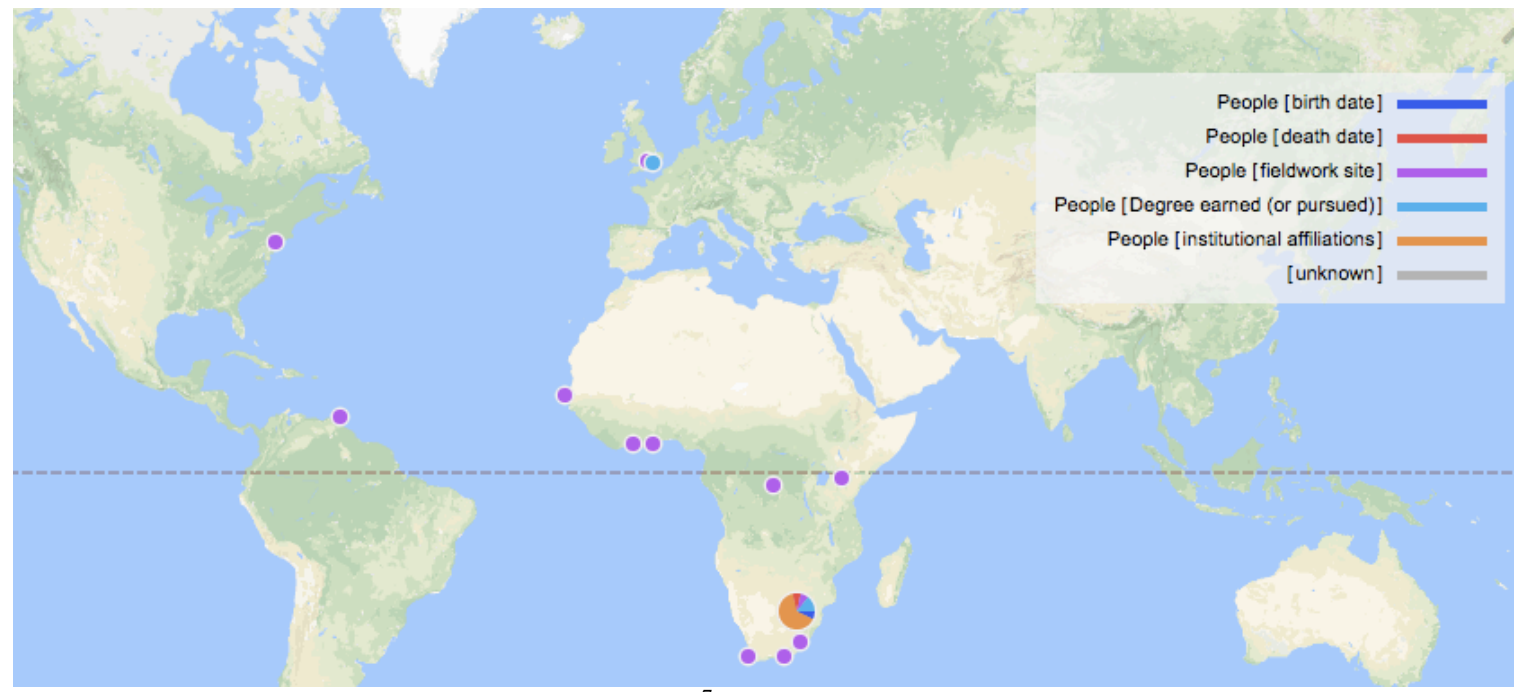

Figure 4. Ellen Hellmann's transnational travels. ${ }^{7}$

Ruth Glass was born in Germany but immigrated to Prague, Geneva, and Wien,

Austria, and the U.K. and conducted research about racism toward West Indian migrants

to London, thus providing a transnational perspective on both the Caribbean and the U.K.

(Glass and Pollins 1960). She lived in the New York City from 1940-1942 and attended

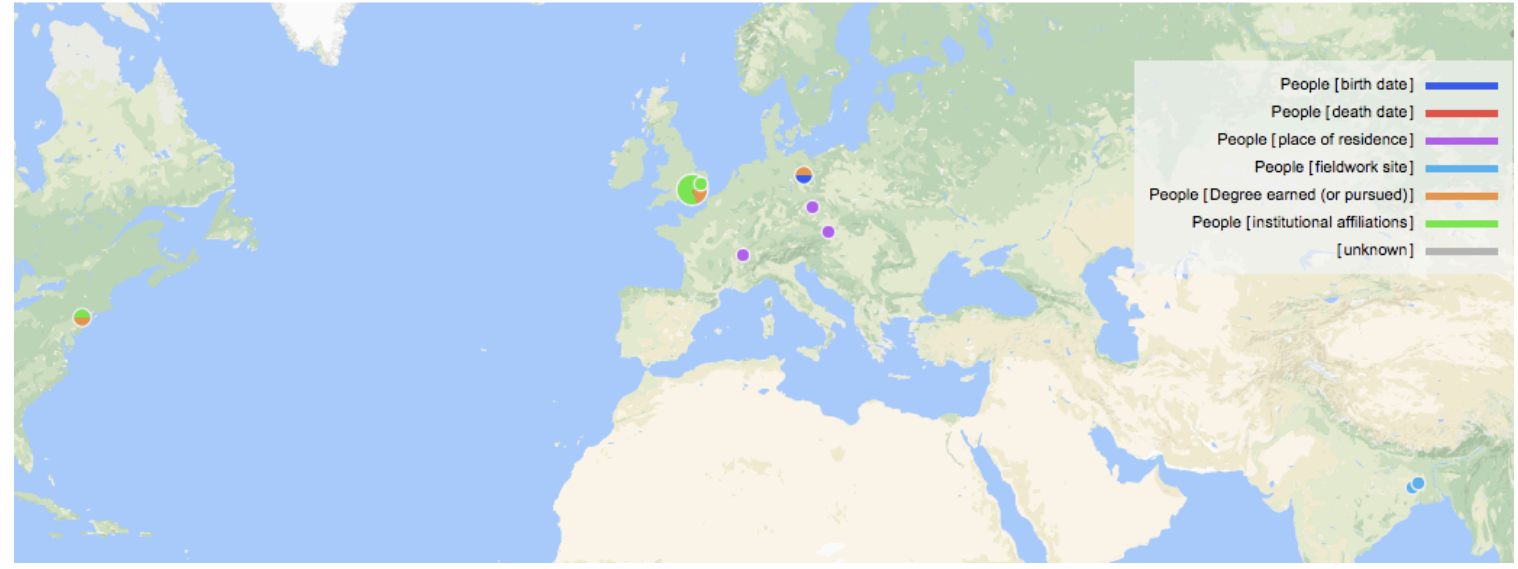

Figure 5. Ruth Glass' transnational places of residence included Berlin (until 1932), Prague, Geneva, and Wien in the mid-1930s, London (1935-1940), New York City (1940-42), and various locations in India including Durgapur, where she advised on the building of a new steel town in 1961.

${ }^{7}$ I created this image (and subsequent visualizations) using a web-based data management, network analysis \& visualization environment called "nodegoat." 
Columbia University. She also visited India every year for two months after 1958. For a visual representation of Ruth Glass' places of residence, see Figure 5.

Hilda Kuper was from Bulawayo, Rhodesia, but migrated to Johannesburg at age six, living in various cities in England (London, Birmingham/Coventry, and Manchester) but also in the U.S. in Chapel Hill, North Carolina and Los Angeles, California (Bank 2016:192-93, 196, 216-17, 222, 229). Her primary research was in Swaziland, but also in Durban, Natal in South Africa with Indian South African communities (Kuper 1947, 1960, 1961). A visualization of Hilda's transnational residences and fieldwork locations is pictured in Figure 6 .

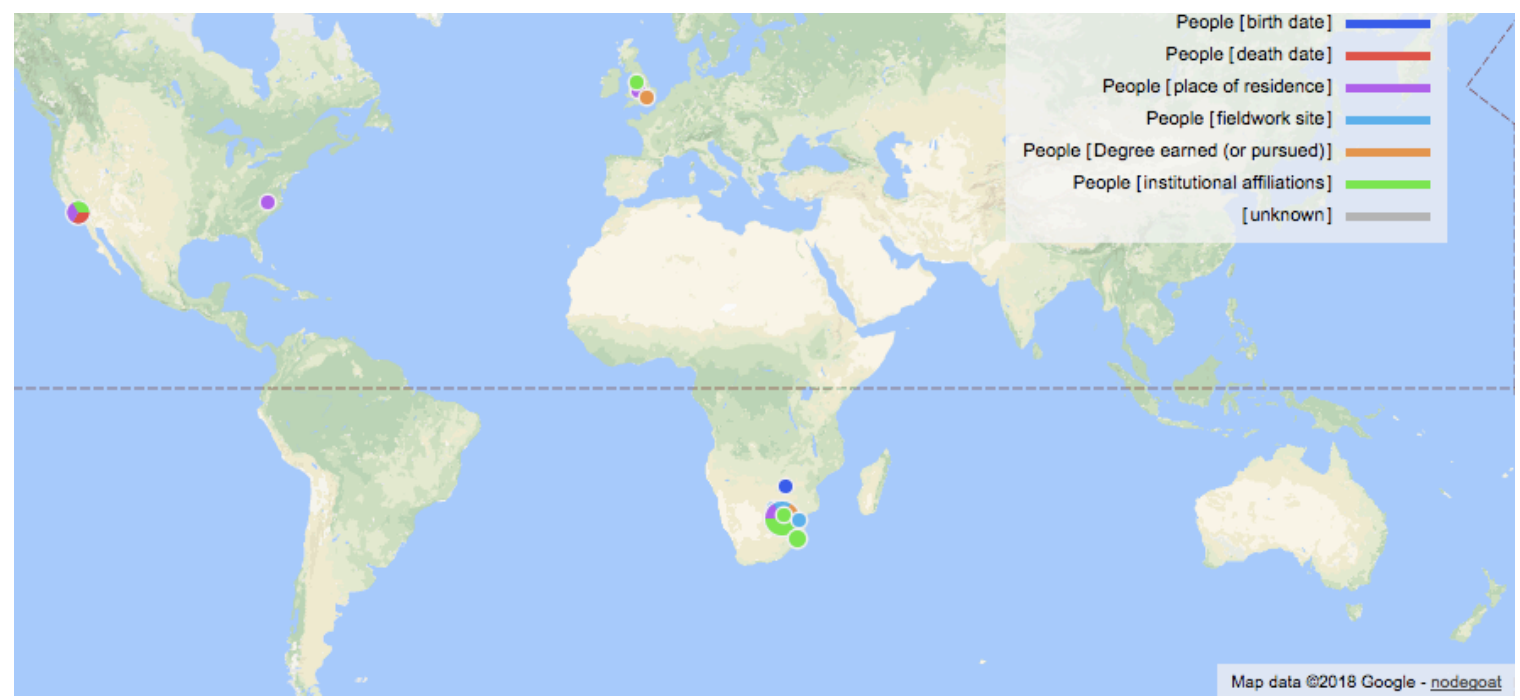

Figure 6. Hilda Kuper's transnational residences and fieldwork locations including Bulawayo, Rhodesia (now Zimbabwe) where she was born; Johannesburg (1917-32, 1941-46) and Durban (1952-58, 1959-61), South Africa; Chapel Hill, North Carolina (1947-49), and Los Angeles, California (1961-1992); and London (1932-1934), Birmingham (1950-52) and Manchester (1958-59), in the U.K.

Ruth Landes moved even more than Hilda Kuper did, caused by her exclusion from stable academic posts. Landes' home base was New York City, but she lived and/or conducted fieldwork in Minnesota, Kansas, Tennessee, Louisiana, and California in the U.S., Salvador and Rio de Janeiro in Brazil, Edinburgh, Scotland, and South Africa (and 
other countries too). She moved to Ontario, Canada for a tenure track position in 1965, where she had previously conducted research with the Ojibwa in the 1930s (Glenn and Wang 2010:4-5). Landes was the most "transnational" because of the number of different countries and world regions where she conducted research (see Figure 7). ${ }^{8}$

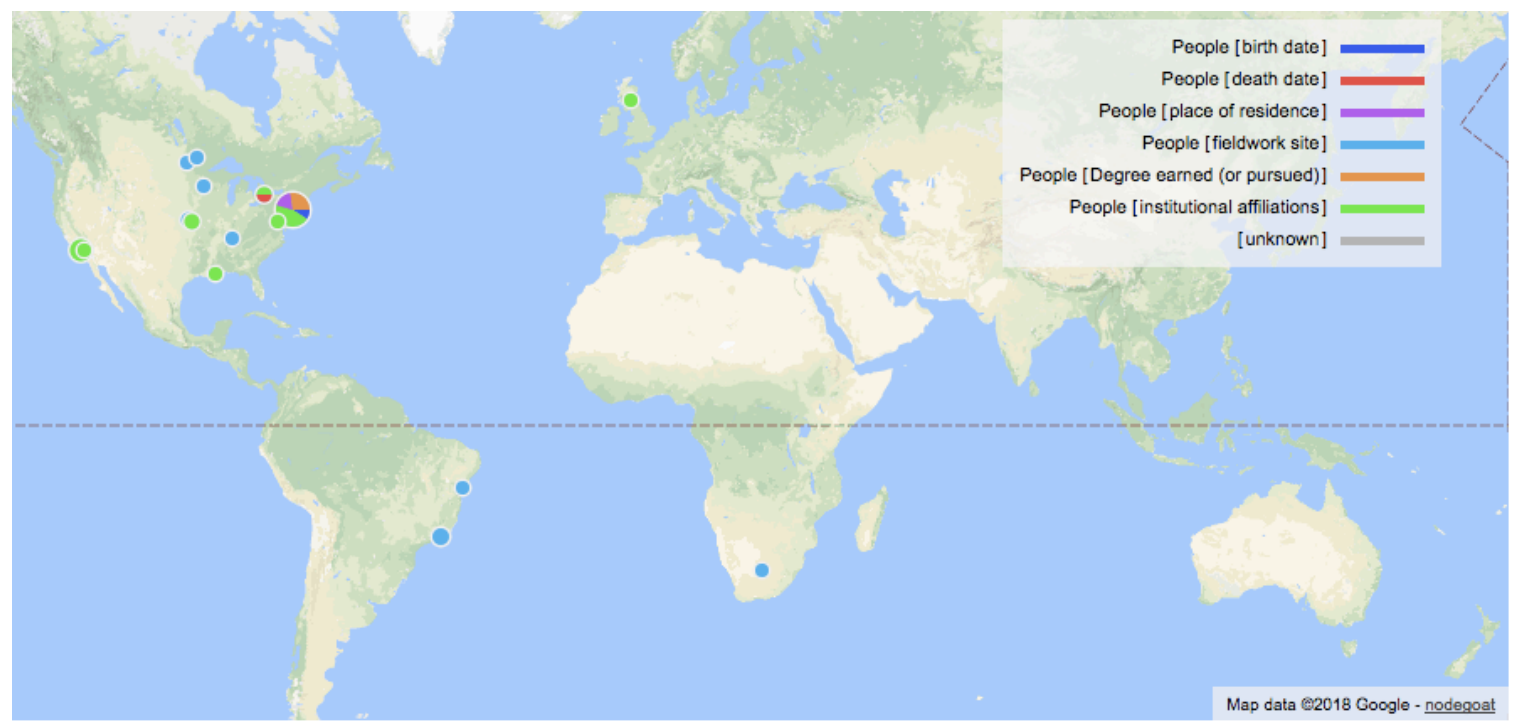

Figure 7. Ruth Landes' transnational fieldwork locations and places of residence.

\section{Discipline and transdisciplinary networks}

Ruth Glass was trained as an urban planner and sociologist at the London School of Economics and previously at the University of Berlin. From 1940 to 1942 she was a senior research officer at the Bureau of Applied Social Research at Columbia University

\footnotetext{
${ }^{8}$ In addition to fieldwork in Salvador, Bahia, and Rio de Janeiro in Brazil (1938-1939, 1966), Edinburgh, U.K. (1951-1952), and South Africa (1970), Landes conducted fieldwork and lived in various U.S. and Canadian cities including Manitou Rapids (193236) and Hamilton (1965-1991), Ontario; New York City; Red Lake (1932-1935) and Red Wing (1935), Minnesota; Mayetta (1935-36, 1964) and Lawrence (1957), Kansas; Nashville, Tennessee (1937-38); Washington, D.C. (1941-45); Los Angeles, California (1946-47, 1955-65); and New Orleans (1964).
} 
in New York and was awarded a M.A. (Pimlott Baker 2004). She often crossed disciplinary boundaries; she invited historians, epidemiologists, demographers, urban planners and public health engineers to speak at her Centre for Urban Studies at University College London (Edwards 2012). She is the only social scientist in this study who can clearly be defined as a sociologist.

The other women received graduate training in anthropology, but Landes majored in sociology as an undergraduate and received a Master's degree in social work before undergoing anthropological training by Ruth Benedict and Franz Boas at Columbia University (Glenn and Wang 2010:4). Hellmann's urban anthropological studies of rural black women migrants to Johannesburg, under the supervision of Winifred Hoernlé, at the University of Witwatersrand, allied her to both metropolitan sociology and the sociology of migration, especially the study of migrant proletarian labor, connecting her to sociologist W.I. Thomas (1927), who studied Polish peasants in Europe and America (Celarent 2012:278). Figure 8 displays the intersections between the four core women's disciplinary training. Hilda Kuper was a social anthropologist trained by Winifred Hoernlé at the University of Witwatersrand and also by Malinowski at the London School of Economics (Ellen Hellmann shared the same advisors, though she only worked with Malinowski for a brief period in the fall of 1934. Ruth Glass also attended LSE, from 1935-1940.) Hilda's initial interests in law, acting, languages and history, morphed into her career as a legal and political anthropologist, novelist and playwright (Kuper 1984:193). Durkheim and French sociology were also highly influential, as both Hilda and her research assistant, sociologist Fatima Meer wrote about suicide and women of color in South Africa (Kuper 1957, 1984:195; Meer 1976). Thus, though Kuper, 

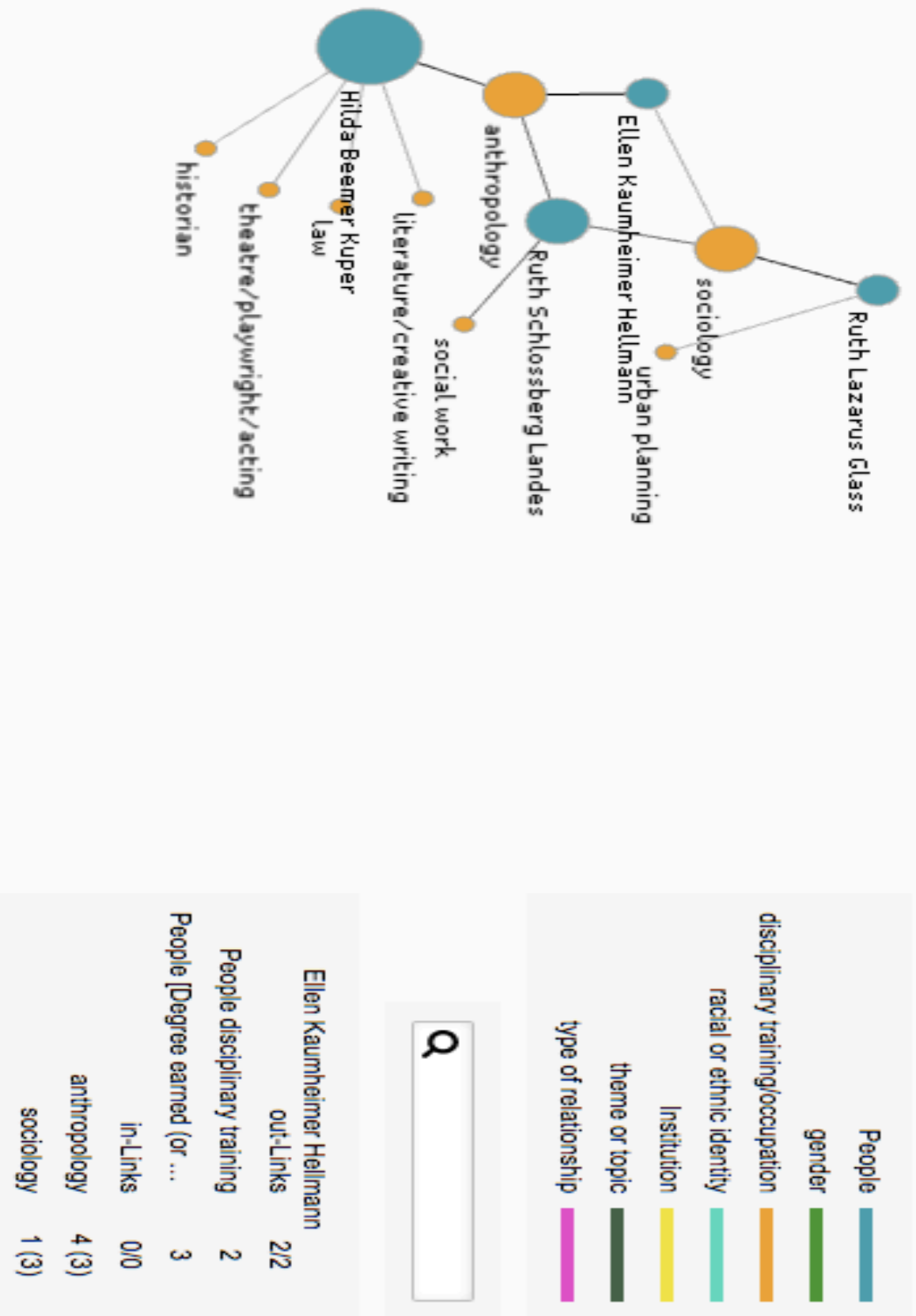

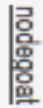

Figure 8. Social network visualization of the four core women's disciplinary training. Note that Hellmann, Landes and Kuper were trained in anthropology, while Landes, Hellmann and Glass were trained in or connected to sociology. 
Hellmann and Landes were trained as anthropologists, they were also influenced by or demonstrated links to sociological theories and approaches. A social network visualization of all four women's institutional connections is pictured in Figure 9. ${ }^{9}$

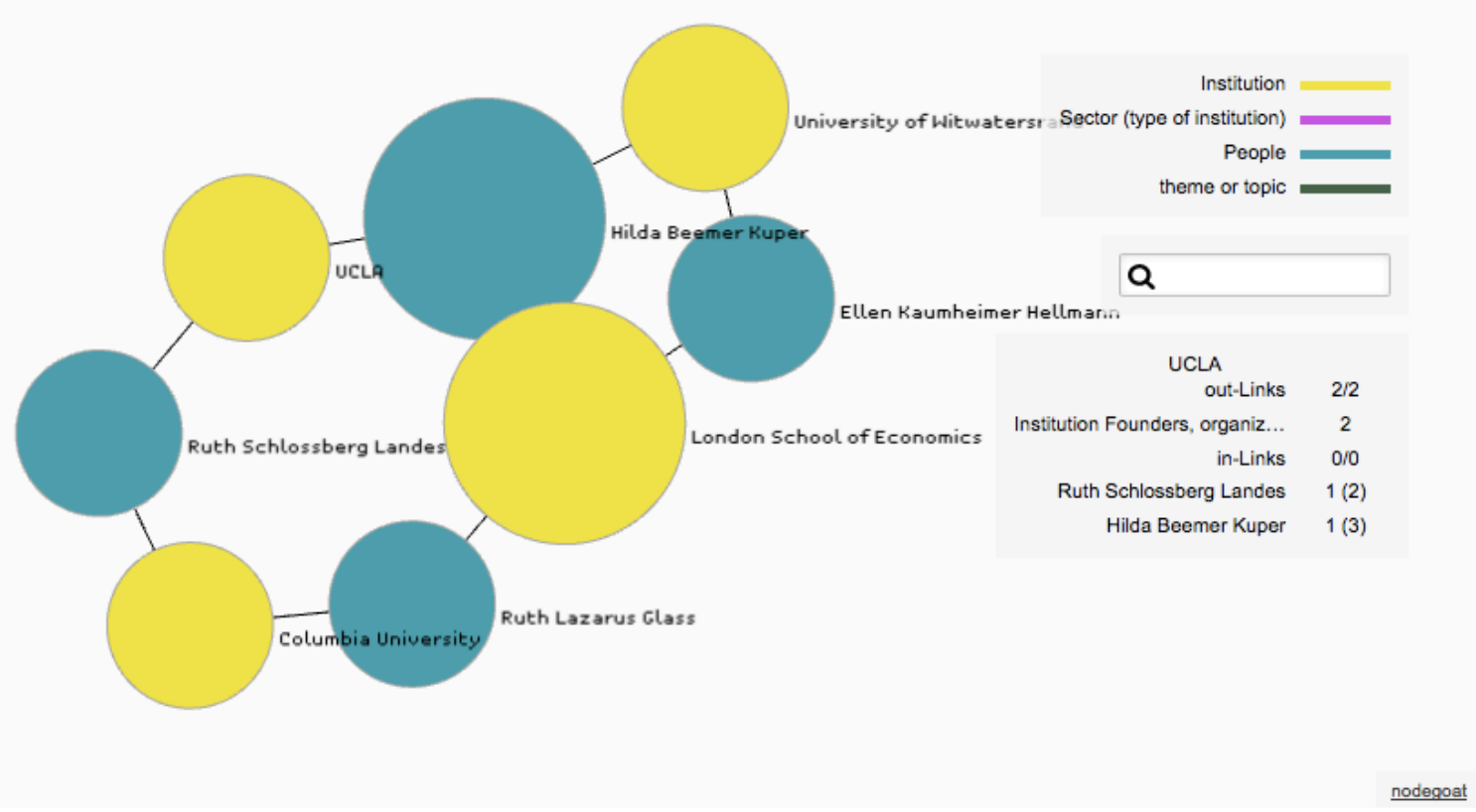

Figure 9. Social network visualization of the four core women's institutional affiliations.

\footnotetext{
${ }^{9}$ Notice that Ruth Glass and Ruth Landes were students at Columbia University, though in different departments (Glass from 1940-1942 and Landes from 1929-1935). Landes and Kuper both worked at UCLA though Landes was an extension lecturer in 1962, while Kuper worked full time in the anthropology department from 1963-1977. Kuper and Hellmann attended the University of Witwatersrand at the same time (1929-1932). Glass, Kuper and Hellmann were students at the London School of Economics (Kuper from 1932-1934, Hellmann in the fall of 1934, and Glass from approximately 1935-1940).
} 
Transracial networks

Ruth Landes displayed the greatest diversity in her transracial networks, including in her romantic relationships (Figure 10). ${ }^{10}$ She was the only woman in this study who engaged in interracial intimate relationships; all the other women married Jewish men. Landes' second husband, Ignacio López, was a Mexican American activist journalist and her research partner in Brazil, Afro-Brazilian journalist Edison Carneiro, was also her significant other (Carneiro 1946; Landes 1967).

Hilda Kuper and Landes were highly influenced by the research and experiences of women of color. Hilda collaborated with Fatima Meer, a Muslim Indian South African sociologist, on a project about Indian South Africans in Durban, Natal (Kuper and Meer 1956). Kuper also collaborated with Teresa Thoko Ginindza on research regarding Swazi material culture and gender roles (Ginindza 1971; Kuper 1973). Figure 11 reveals the connections between the publications of Hilda Kuper, Fatima Meer, and Thoko Ginindza. ${ }^{11}$

\footnotetext{
${ }^{10}$ Landes shared a "romantic" relationship with both Elmer Imes and Edison Carneiro. She was married to Ignacio López. Edison Carneiro was also her research colleague, in addition to being a romantic partner. With all three of these relationships, Landes shared her research interests in race and class. With Carneiro and López she shared an interest in fighting racial discrimination and police brutality. Elmer Imes was opposed to the condescension of "racial uplift" and instead he believed that black college students ought to be taught the value of hard work, rather than an emphasis on race (Landes 1985a:33, 65-66).

${ }^{11}$ At the top right of this visualization are publications written by Hilda Kuper and Fatima Meer. "Indian Elites in Natal" (1956), co-authored by Kuper and Meer, shared a thematic focus on Indian South Africans and protest with Hilda's book Indian People in Natal (1960), for which Fatima Meer acted as a research assistant. "Indian Elites" also shared an emphasis on Indian ethnic groups, such as Tamil and Hindustani, with Hilda's play The Decision (1957). All three of these works, contrasted the "African" (meaning
} 


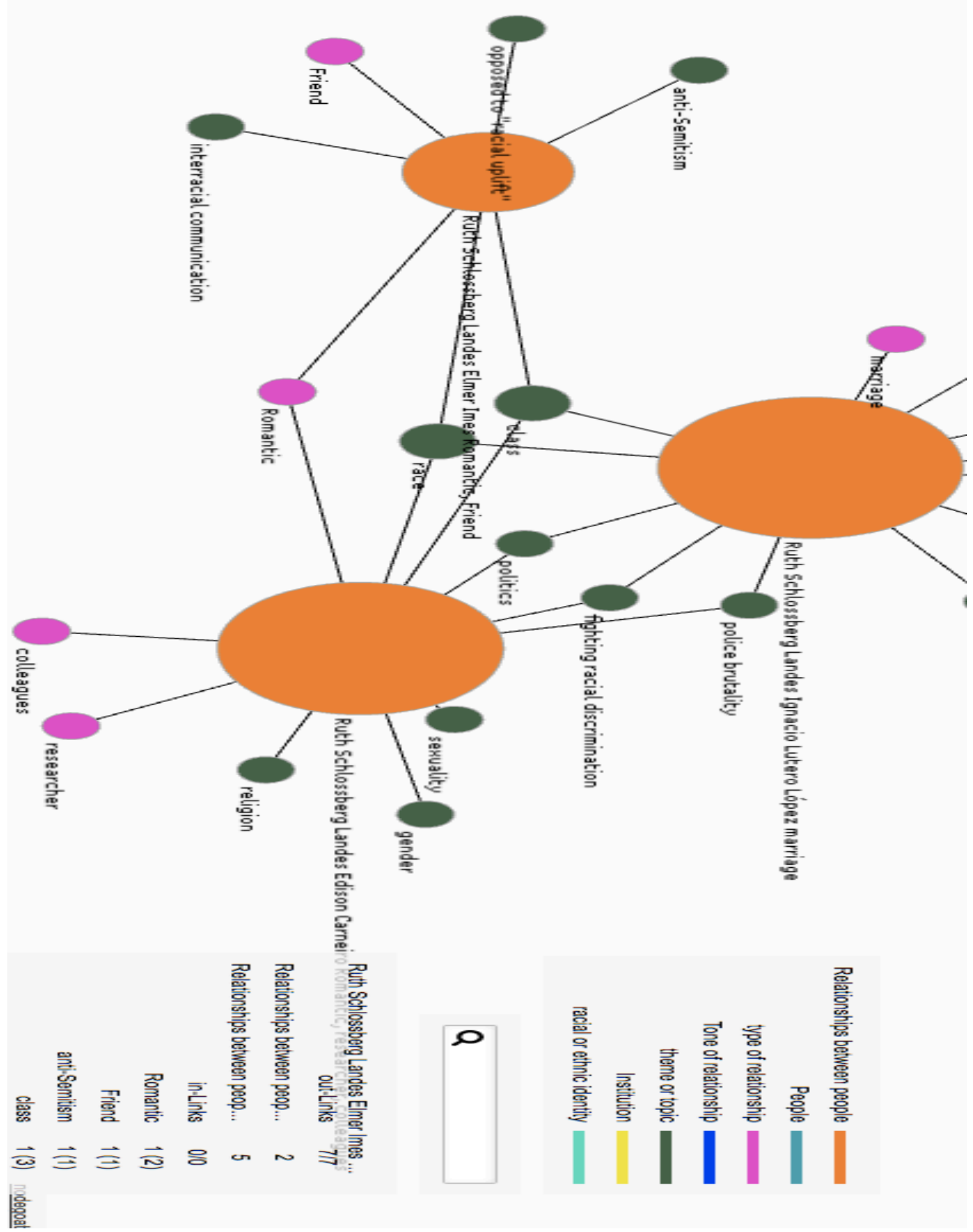

Figure 10. Ruth Landes transracial romantic relationships, including type of relationship and research themes/topics they shared.

black) and Indian South African populations. Ginindza's "Dress in Swaziland" (1971) was influential for Kuper's "Costume and Identity" (1973), about Swazi material culture and gender roles, for which Ginindza was listed as an assistant. The thematic connections between these works have been omitted in this visualization for simplicity. 


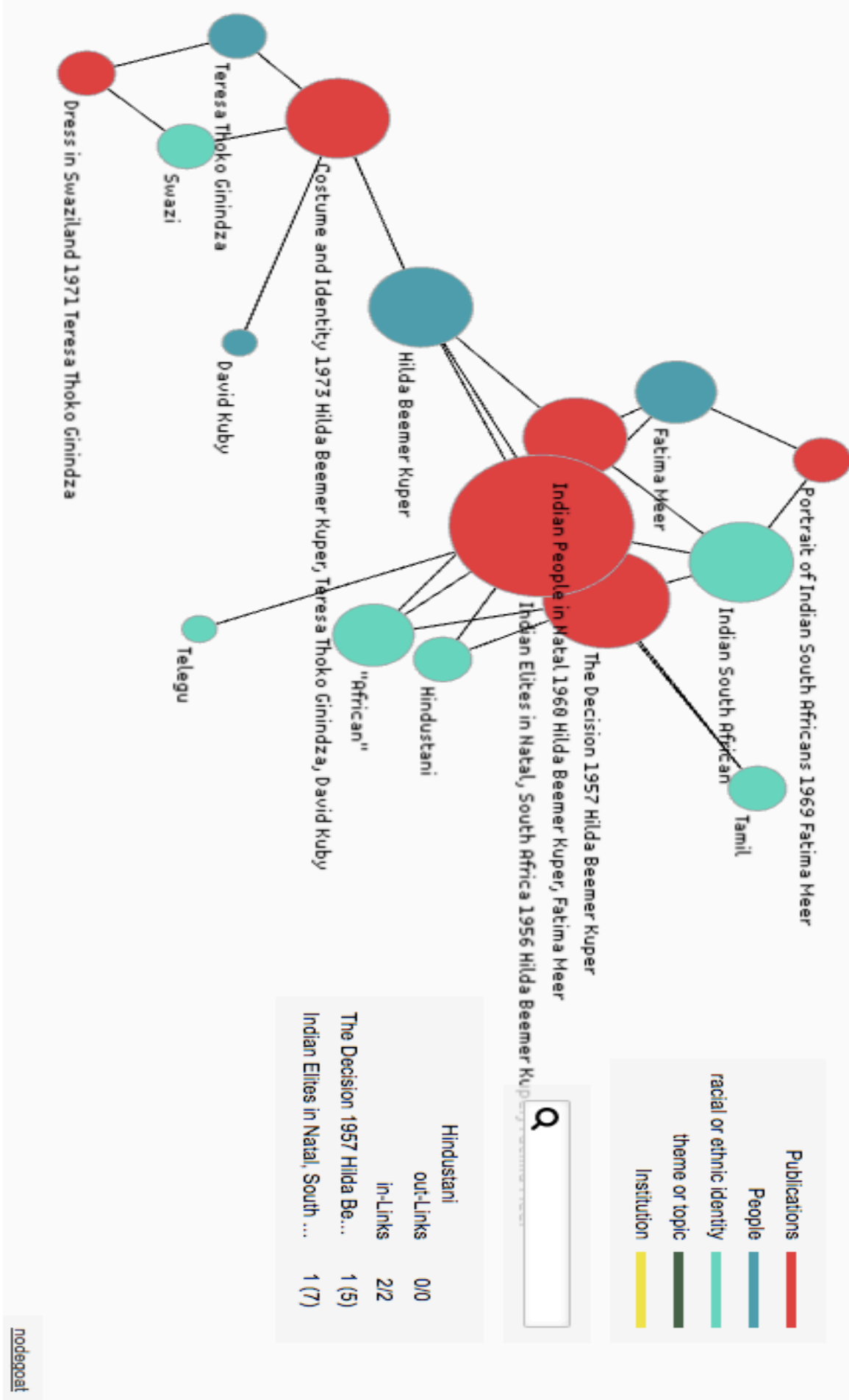

Figure 11. The transracial publication networks between Hilda Kuper, Fatima Meer and Thoko Ginindza. 
Ruth Landes was highly influenced by Native American research collaborators like Maggie Wilson (Scott/Cree), Louise Nocktonick (Potawatomi), and Anishinaabeg scholar, Keewaydinoquay Peschel (Cole 2009; Nocktonick 1966; Peschel 1988). Zora Neale Hurston's work was influential for Landes' writings about the African diaspora (Landes 1939g). Landes' writings about Brazil were shaped by priestesses of Candomblé in Salvador, Bahia, like Mãe Menininha (Landes 1947). ${ }^{12}$ See Figure 12 for an illustration of the impact of Landes' female transracial networks on her publications. ${ }^{13}$

\footnotetext{
${ }^{12}$ Her relationship with Mãe Menininha did not emerge through her working relationship with Edison, since Menininha supposedly resented Edison for political reasons related to the União de Seitas Afro-Brasileiras - Union of Afro-Brazilian Cults (Andreson 2014:48, n. 33; Landes 1947:72-73). Thus, Landes met Menininha through Eustácio da Lima, not Edison. Landes described da Lima as an aristocratic médico-legista (forensic doctor); she was appalled when he showed her the decapitated heads of Lampeão (a caboclo bandit) and his girlfriend Maria Bonita, which he had stored in jars filled with formaldehyde (1947:73).

${ }^{13}$ This network visualization displays Zora Neale Hurston's influence on Landes' unpublished Ethos of the Negro in the New World (1939). Afro-Brazilian mãe do santo, Menininha, was a central figure in Landes' City of Women (1947). Maggie Wilson and Louise Nocktonick advised Landes during her fieldwork with the Ojibwa and Potawatomi, leading to the books Ojibwa Woman (1938) and The Prairie Potawatomi (1970).
} 


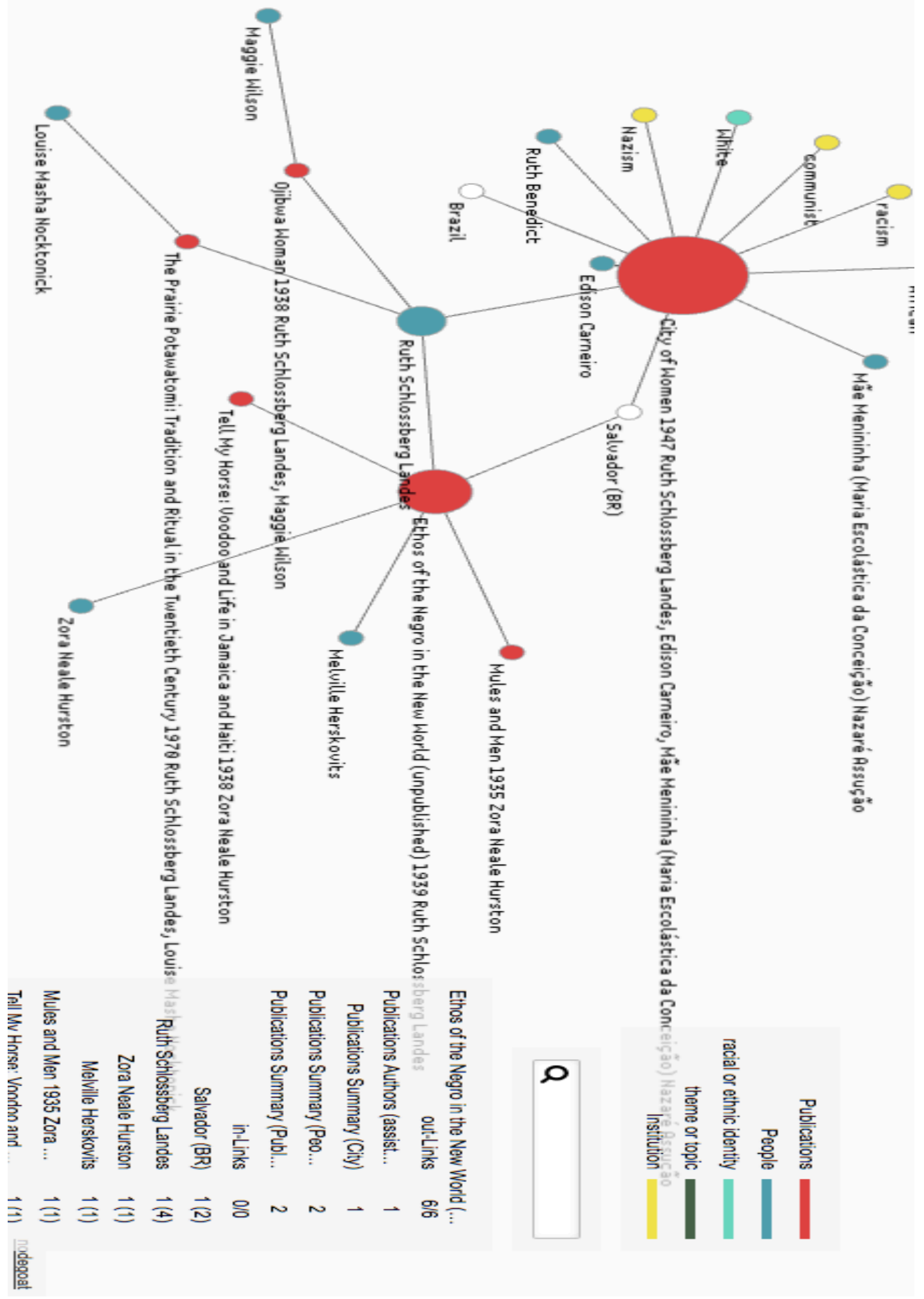

Figure 12. The impact of Ruth Landes' transracial female relationships on her publications. 
Ellen Hellmann cited black male scholars in some of her work on the black middle class (like Z.K. Matthews, Nimrod Mkele, St. Clair Drake, and Horace R. Cayton) and she collaborated with Alfred Xuma on the Joint Council of Europeans and Africans (E. Hellmann 1955a:11-12; Hellmann 1948c:115, 1964; Hellmann and Xuma 1940). Hellmann also relied upon the assistance of two black African male informants and research assistants for both her master's thesis research in the Rooiyard slum yard (193334) and dissertation research (1937-1938), which became Problems of Urban Bantu Youth (Hellmann 1940e:v). Her informant and assistant in Rooiyard was John Chawafambera ${ }^{14}$, a Manyika diviner, who attended a missionary school (1913-1915) and night school in Johannesburg (1927-1930), where he became proficient in English (Hellmann 1948c:118-19). According to Wulf Sachs, an Eastern European Jewish psychoanalyst, who interviewed John over a period of two and a half years, Ellen Hellmann "very naturally relied more and more upon [John Chavafambira] in her difficult task of collecting information from the hostile women in the yard. She helped him financially, and he accepted her help freely, realizing very well what motives were behind her generosity" (125).

${ }^{14}$ John's surname was also spelled "Chavafambira"; he was the central figure in Black Hamlet by Wulf Sachs (1947). Sachs met John through Ellen Hellmann (5). 


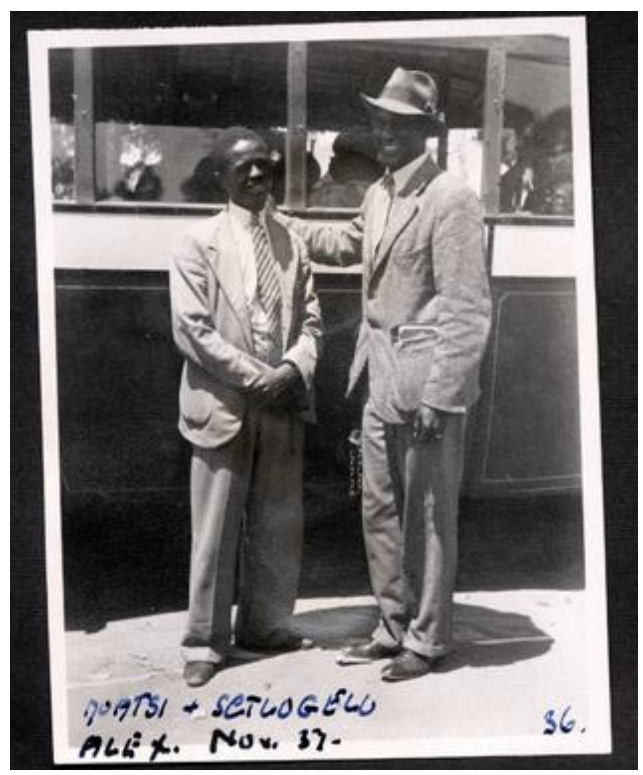

Figure 13. Noatsi and Setlogelo, photo by Ellen Hellmann, November 1937 in Alexandra Township. Item 20, File 31, Subseries 8.1.1, Ellen Hellmann Papers, Historical Papers Archive, ZA HPRA A1419-8-8.1-8.1.1-20

Her second primary assistant was Conference Setlogelo (Figure 13), a Morolong "with a good knowledge of Bantu languages as well as fluency in English and Afrikaans" who was her interpreter, assistant and informant for her dissertation research; however, she only elaborated on the extent of his contributions to the project in the Original Report on Causes of Early School Leaving and Occupational Opportunities for Juveniles, 19381939. "He matriculated and had one year's academic training in Edinburgh. For two and a half months he accompanied me daily in the course of my home visits in the Western Area and in Orlando." After this initial training period Setlogelo conducted independent family investigations without Hellmann (Hellmann 1939:6-7). Figure 14 provides a 
social network visualization of the transracial networks Hellmann relied upon for her writings about black urban experiences in Johannesburg. ${ }^{15}$

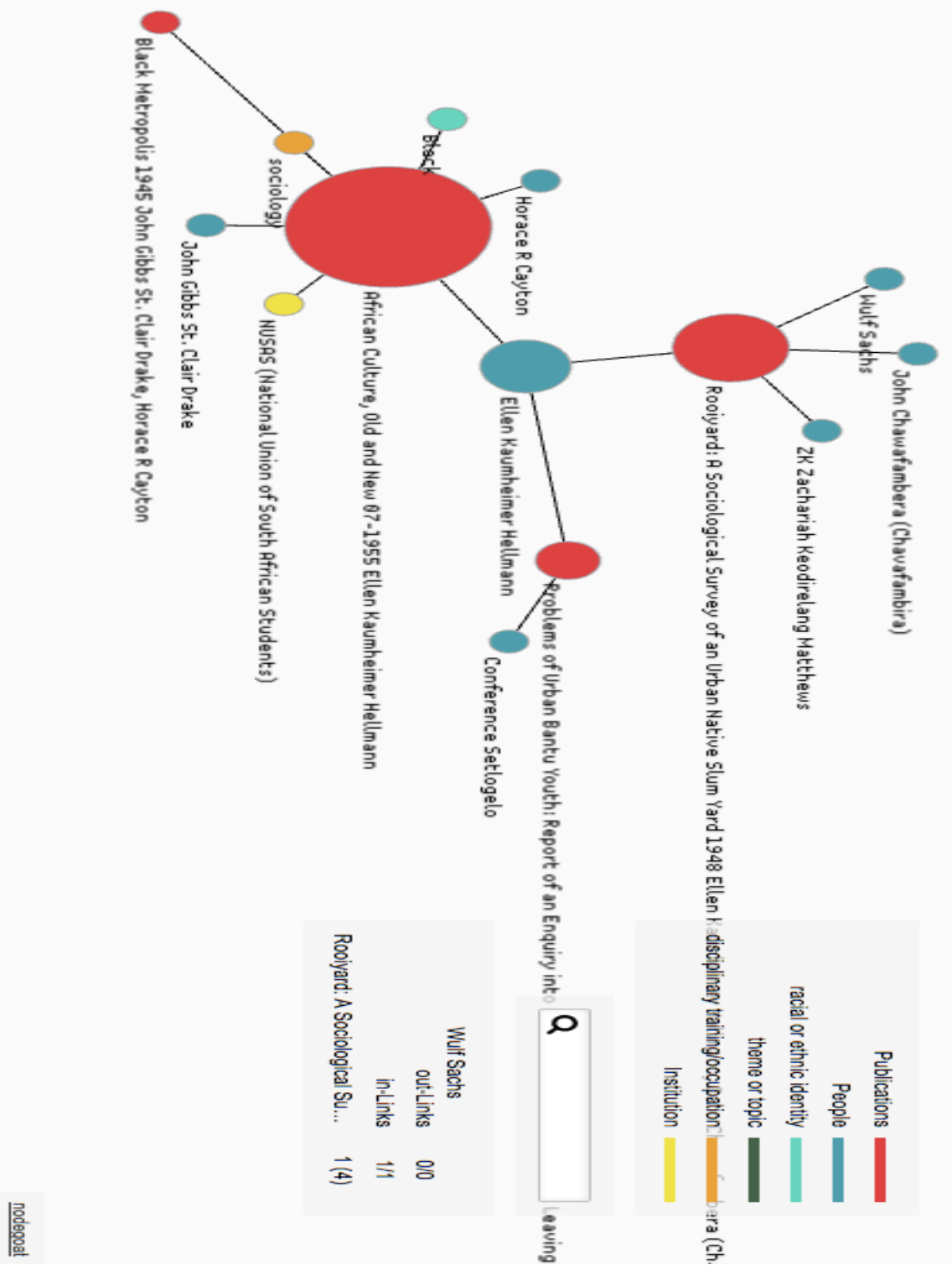

Figure 14. Hellmann's reliance upon transracial networks in her publications about black urban life in Johannesburg.

${ }^{15}$ This network visualization reveals the black men whom Hellmann cited and whom she worked with as "assistants." Conference Setlogelo worked with Hellmann on Problems of Urban Bantu Youth (1940). John Chawafambera assisted Hellmann with Rooiyard (1948) and Hellmann connected Chawafambera to Wulf Sachs. Hellmann cited Z.K. Matthews in Rooiyard. Horace R. Cayton and St. Clair Drake's Black Metropolis (1945) featured in Hellmann's “African Culture, Old and New” (1955). 
As Lynn Thomas and Lyn Schumaker argue, white (and Jewish) anthropologists in South Africa and Northern Rhodesia often relied upon educated black African men as research assistants. Schumaker points out that this group of men also had experience travelling internationally because of World War II (Schumaker 2001:103, 118, 194-95). Lynn Thomas explicates that white anthropologists' knowledge was shaped by the views of these "learned and relatively well-off young [black] men" (Thomas 2009:34-35). ${ }^{16}$ It is concerning that Ellen Hellmann relied upon black male assistants but did not elaborate on how they facilitated her research except in the unpublished original report of her doctoral dissertation. Yet, Ruth Landes considered Edison Carneiro her research partner and her ethnography, City of Women, clearly elaborated his centrality to her research and findings, even though Edison himself thought Landes had actually given him too much credit (Carneiro 1947). ${ }^{17}$ In addition, she not only engaged in a romantic relationship with him, but they maintained a life-long friendship and research relationship.

Ellen's professional networks were primarily made up of white men from the South African Institute of Race Relations where she worked in a leadership capacity for

16 Thank you to Mariama Jaiteh for recommending the chapter by Lynn Thomas.

${ }^{17}$ On July 28, 1947 upon receiving a copy of her book City of Women, Edison wrote to Ruth: "I think you said very little about your own studies and put to my credit many of your own findings. That is not loyal to you. In my opinion you made an honest, real, good, intelligent book and, although I'm not satisfied with my portrait, as in the case of my aristocracy, it amuses me (or in Portuguese, eu acho graça) to read the things you recall. I cannot accustom myself with the idea that you could not make the book you would have written - a scientific one. But I am grateful to you for not letting that year die, for reviving those incidents of our daily life among the blacks of Bahia, for upholding the dreamy, the one-thousand nighty tale of our friendly partnership" (Carneiro 1947). 
forty years; these men included J.D. Rheinallt Jones, Quintin Whyte and Fred Van Wyk (Hellmann 1945d, 1967, 1973b). She was also connected to white female politicians and public figures like Margaret Ballinger, Helen Suzman, and Hansi Pollak (Hellmann 1945c; Jewish Board of Deputies Archive 1954; Writer and Jewish Board of Deputies Archive 1967). Figure 15 demonstrates Hellmann's white colleague networks. ${ }^{18}$

${ }^{18}$ This network visualization emphasizes Hellmann's connections to white South African male and female colleagues whom she worked with through the South African Institute of Race Relations, Progressive Party, and the Johannesburg Joint Council. 


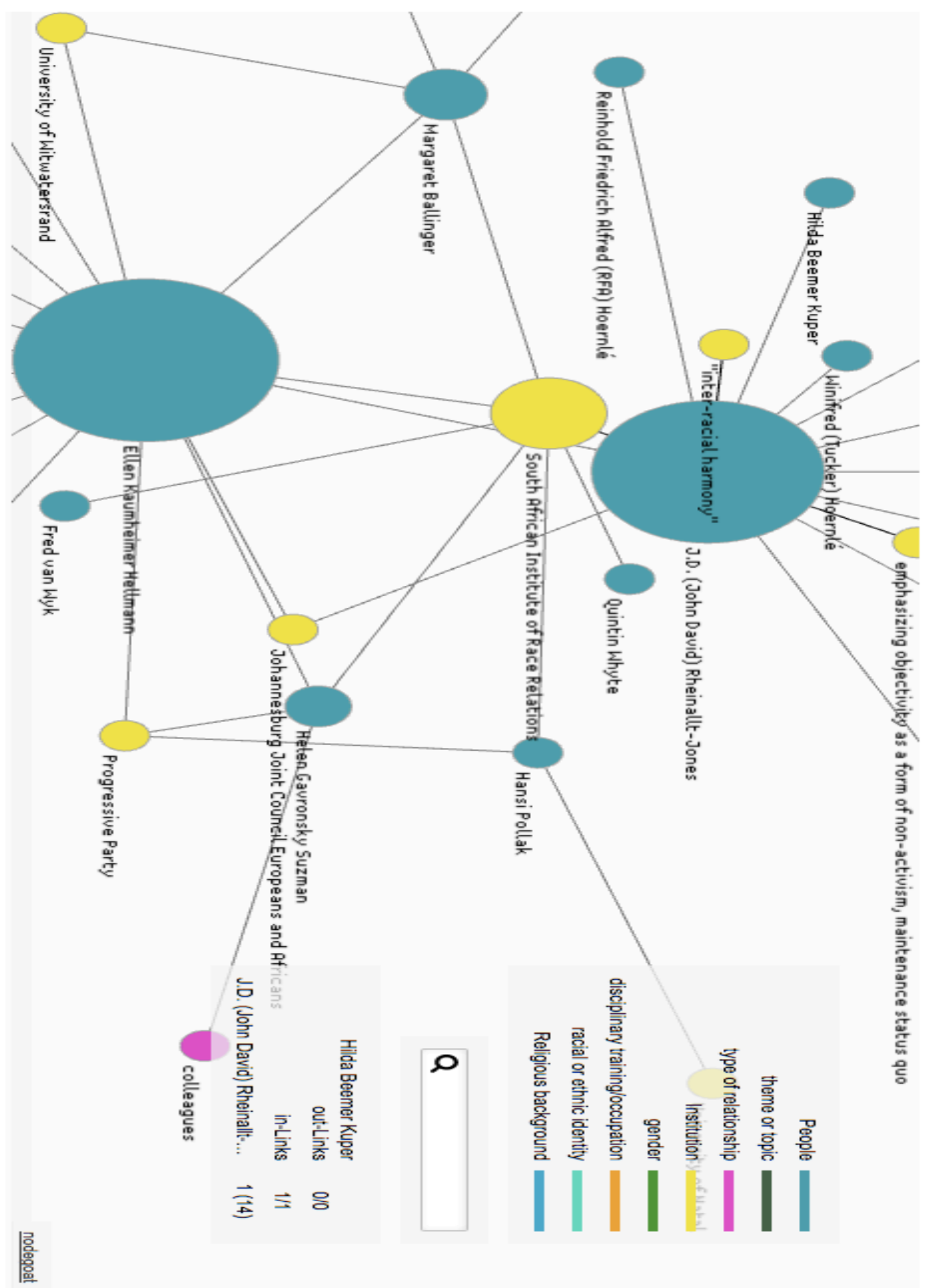

Figure 15. Ellen Hellmann's white colleague networks.

Her interactions with black women were limited to the researcher-research participant relationship; the women in Rooiyard associated Hellmann with police raids 
for beer brewing, triggering suspicion, "resentment and antagonism" (Hellmann 1935:3637, 1948c:2; du Toit 2005:609). Hellmann adamantly opposed Fatima Meer's views that violence might be necessary to defeat apartheid, instead emphasizing the gradual improvements that had been made for black South Africans (Hellmann and Meer 1975). In contrast, Hilda Kuper praised and supported Meer's work, like her book Portrait of Indian South Africans (1969), and encouraged Meer to submit the manuscript for a doctoral degree (Kuper 1970).

Since there are no Ruth Glass Papers, I was not able to analyze her correspondence. Apparently, she worked with many students from the "Third World" in her role as director of the Centre for Urban Studies. She had strong ties to India where she frequently visited - after 1958, she spent two months every year there (Oxford Dictionary of National Biography 2004); her interest in the Indian anti-colonial movement began in the 1930s inspired by Krishna Menon (Edwards 2012; Hobsbawn 1990). In fact, according to Nigel Harris, an urban economist who worked with Ruth Glass at the Centre from 1967-1971, "Sadly, after David [Glass'] death [in 1978], Ruth became obsessed by India (even while I was at the Centre) and insisted, despite strong advice to the contrary on going in the hot season, failed to drink enough water and was, suffering from dehydration forcibly invalided out of India by her sponsor, the British council." When I asked Nigel to explain what he meant by "obsessed by India" he explained how she was well-respected there: "I think she was treated with great respect as a famous intellectual and town planner (and regularly sponsored by the British Council) she advised on the 1961 census, on the planning of the British Steel New Town, Durgapur, and the re-planning of the Old Steel Town, Jamshedpur." 
Nigel also told me, "Ruth had a good friend in Delhi, Dharma Kumar (a distinguished historian) and Tirril [Nigel's wife] thinks she contacted us to check on Ruth who was ill [in the early 1980s]" (Gondek, Harris, and Harris 2017). Dharma Kumar (1928-2001) was an economic historian trained in Bombay and Cambridge in the 1940s and '50s. ${ }^{19}$ Figure 16 demonstrates Ruth Glass' transracial networks.

${ }^{19}$ Dharma Kumar wrote about land, caste, and agricultural labor in the $19^{\text {th }}$ century. Kumar contended (in contrast to canonical forms of thinking at the time) that landless workers had come into existence before the colonial period and that it was not solely British colonialism that was to blame (Subrahmanyam 2001:4251). 


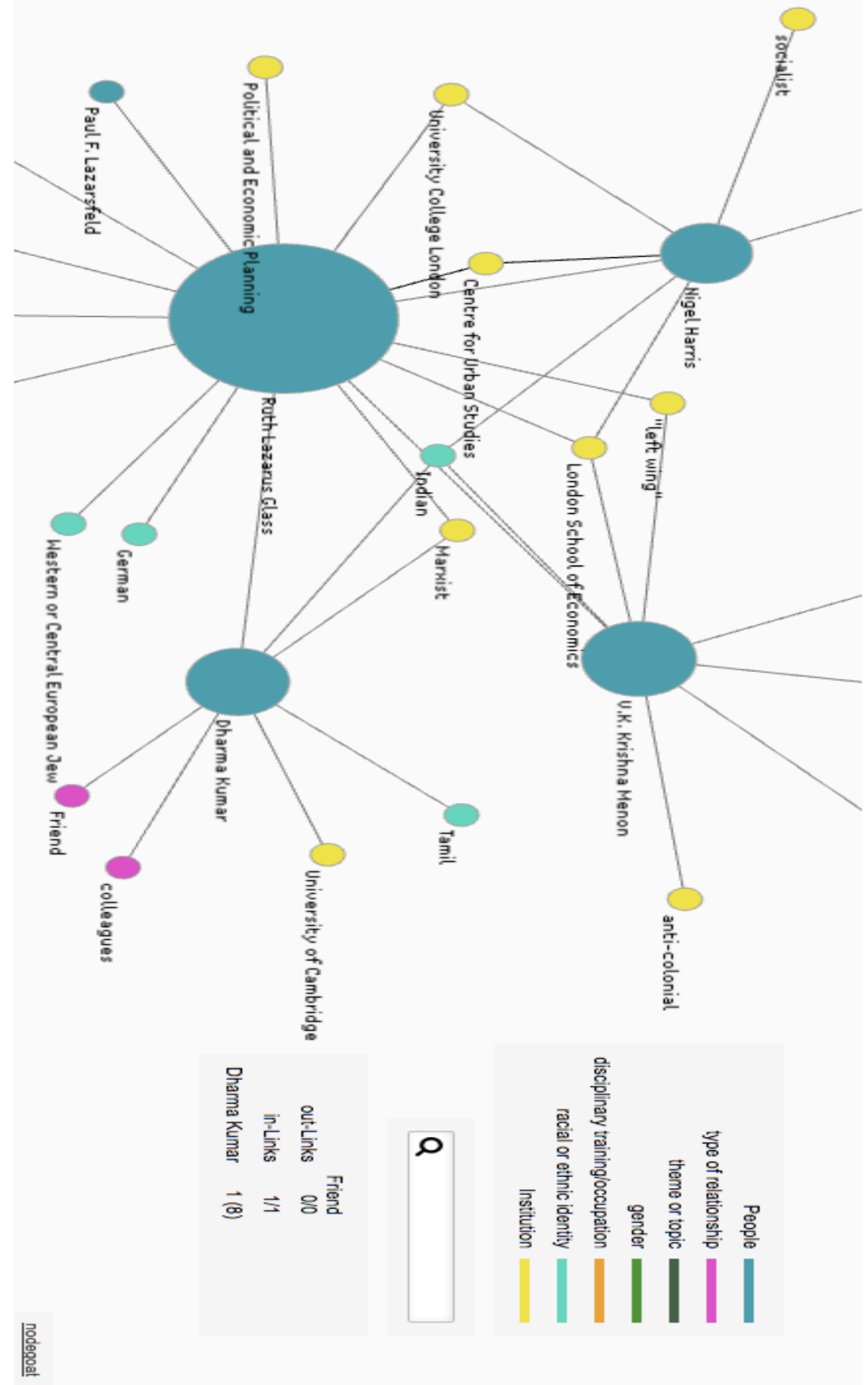

Figure 16. Ruth Glass' transracial colleague networks. Glass shared her political beliefs with Krishna Menon, Dharma Kumar and Nigel Harris; she shared her association with the London School of Economics with Menon and Harris. 


\section{Jewish subjectivity and theorizing about race, gender, sexuality, class, nation}

In 1962 Ruth Glass compared discrimination against Jews to racism against East Indians in Africa and the Caribbean, calling them 'classic' and 'hidden' minorities who could not expect to remain hidden because in times of social stress they could become easily re-stigmatized (Glass 1989a:226). She also compared Jews in pre-Hitler Germany and Indians in parts of Africa who were not solely associated with their occupations, but who frequently received their social status through their occupations, which were limited based upon their ethnicity. Thus, those occupations came to be regarded derogatorily with their ethnicities (Glass 1989a:218, n. 1). Glass emphasized that German middle-class Jews were "super-Germans" while black middle-class Americans were "superAmericans" as part of her point that middle-class minorities tended to be the most loyal and patriotic members of their host societies (1989:230).

Hilda Kuper also made comparisons between Jews and Indians: "Like Jews...the Indians in South Africa can be, and have been used as a scapegoat by other national groups. Sufficiently wealthy to serve as bait for greed, too few to be feared, and, in the main, ideologically opposed to counter aggression with physical violence, their ethnic difference and cultural diversity serve as excuses for discrimination and oppression" (Bank 2016:219; Kuper 1960:271). Though Hilda hardly ever wrote about her own Jewish subjectivity, she did describe her cohort at the University of Witwatersrand: "several of us were non-orthodox Jews struggling to achieve a nonethnocentric ethical perspective" (Kuper 1984:193-94). Hilda's graduate student David Kuby explained how he perceived Hilda's Jewishness: 
Her Judaism was centered in sharing the fullness of the humanity of others with a deep concern for empowering those who had been disempowered, loving broadly, deeply and authentically. To me this is the true spirit of Judaism, which transcends all forms with an embracive mystical intuition of our essential atonement in the great Maker of the Universe. Hilda believed in a God, sought to honor this God with courage and diligent work to make the world a more just and loving place... She was also quite British in her sensibilities. I found that out when I honked at a wayward motorist and Hilda was horrified. Jewish, British and African are quite a combination of values not easily put into one neat box and there was a comfortable, very human dimension of Hilda that was humble and nonjudgmental that made one feel very accepted in our imperfections despite Hilda's high standards for scholarship and social justice work (Kuby and Gondek 2017).

Both Ruth Landes and Ellen Hellmann often wrote about Jewish topics, though in different ways in relation to how they wrote about black communities. Landes expressed pride in her Jewishness and associated her female rebelliousness with her Jewish subjectivity: "I as a she-maverick would choose to be a Jew if I were not already one" (Landes 1977). She researched Jews explicitly in her master's thesis in 1933 about a black Jewish group in Harlem, and again in 1950-1951 regarding the Eastern European Jewish family and Jewish National Character (Landes 1933, 1951; Landes and Zborowski 1950). During the last decade of her life, she became interested in reading the Russian and Yiddish novels of Eastern European Jews in translation and reflected upon her early familial exposure to Yiddish creative writing (Landes 1983). Landes viewed Jews and Blacks as the "two most vocal groups in the world" and was disturbed that neither black nor Jewish Canadians spoke out against racism (Landes 1987a:1). She also felt that both Jewish and black women lost power through Westernization, modernization and class mobility (Landes 1947:196-201, 1986g:2).

Ellen Hellmann was part of the German Jewish community in Johannesburg, which viewed itself as superior to, and more "civilized" than "Eastern Jews" which they 
associated with "Non-Europeans" (Hellmann and Krut 1982:4). She identified with the white South African community and she took a philanthropic/social reform approach to working with black communities, utilizing a patronizing and moralizing tone (Hellmann 1940e:9). Her work with the Jewish community emerged with the rise of Hitlerism and her sense of "guilt" that she was not working with her "own people" (Hellmann and Krut 1982:5-6). While she believed in self-promotion and protection of the Jewish community in order to guarantee access to white citizenship rights (Hellmann 1961b), she expressed antipathy toward black self-promotion and protection through black consciousness ideologies such as "black identity" or "Black is beautiful." Instead, she advocated African assimilation into Western and white gendered modes of behavior (Hellmann 1964:16). This included the adoption of middle class "stable" family structures which she believed had less incidence of "illegitimacy," thus providing the foundation for South African economic development (Hellmann 1963b:10).

\section{Familial networks}

Through my use of grounded theory methodology, I found that the women could be categorized by familial origin point in Europe (see Figure 17). Ruth Landes was of Eastern European descent. Two of the women were of Central European (German) descent: Ellen Hellmann and Ruth Glass. One woman was a mixture of the two: Hilda Kuper because her father was Lithuanian while her mother was from Vienna, Austria. Jewish familial origin, class background and political affiliations will be discussed in the beginning of Chapters 2-5. 

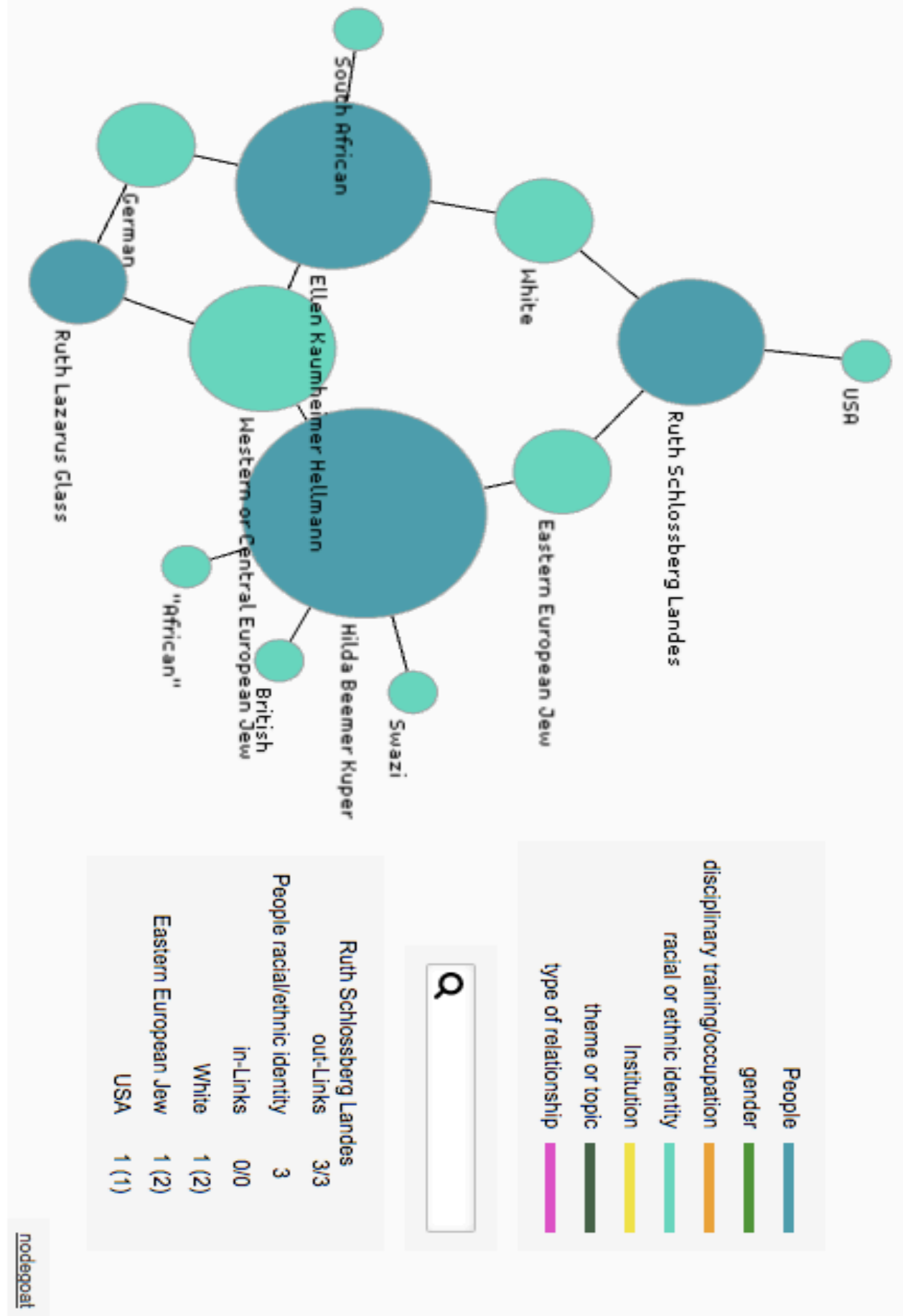

Figure 17. The racial/ethnic/national identities (including Jewish familial backgrounds) of the four core women in the study. 


\section{Data Collection - Methods Used}

Using archival materials was important to this study because many historical studies of social scientists do not use archival sources at all, but instead a combination of secondary sources about the social scientist and primary published texts by the social scientist (Broschart 2005; Desai 2010; Frank 1997, 2001; Goldberg 2012; Jansen 2000; Magubane 2014; Yue 2012). Solely analyzing published sources would not allow access to "private" correspondence, unpublished manuscripts and field notes that provide a more deep and nuanced understanding of subjectivities as well as network influences on theorizing. Feminist historian of empire, Antoinette Burton, explicates that women's “personal" archives unite "history," assumed to be "public," with "home," assumed to be "private" (Burton 2003:5-6). Not all the women had "private" materials in their archives (Ellen Hellmann did not), but still the materials in archives provide information that cannot be accessed through published sources alone. A preliminary step to the archival visits I took was tracing the footnotes I found in published sources about the core women in this study. The footnotes of other scholars provided alternative archival sources that I would not have known about otherwise. Footnotes also gave me information about other researchers who had studied the same women.

Archival visits were usually in-person, but I also accessed archival documents digitally with the assistance of archivists and librarians. In addition, archivists sometimes intervened by suggesting materials I was not previously aware of. In this Data Collection section I describe the types of archival materials I accessed for each of the women in the study in order to demonstrate the differences between the collections of each of the 
women, for example, whether or not there was personal correspondence, and who they corresponded with in a personal or professional capacity. I emphasize whether they had significant transracial connections, especially with women of color.

As previously stated, I used a mixed-methods approach including archival data collection, from fifteen different collections, and six physical archival visits in Maryland, Los Angeles, and New York City, in the U.S., and Johannesburg in South Africa. I also utilized ethnographic object analysis at six museums in Maryland and Los Angeles, in the U.S.; Salvador, Bahia in Brazil; and Johannesburg in South Africa. I consulted with fifteen special collections librarians and archivists, and twelve museum professionals. I engaged in fieldwork in Salvador, Bahia, Brazil with nine academics and practitioners of the Afro-Brazilian religion, Candomblé, and visited the former home of Ellen Hellmann in Johannesburg. I also performed thirty-three interviews or consultations with scholars who studied the core women in my study or with students or family members of the women in my study.

I discuss these methods in this section to emphasize the crucial contributions of museum professionals, academics, Candomblé practitioners, students and family members of the women in my study, to my research process and ultimate conclusions. Ethnographic objects served as the physical evidence of transracial and transnational networks between Jewish women anthropologists and women of color who were research assistants and participants/collaborators. Consultations with librarians, archivists and museum professionals provided more in-depth information and hidden sources that I could not find through my online searches of finding aids. Field site visits enabled me to see and interact with the spaces where Jewish women anthropologists lived and 
conducted research as well as understand each woman's contemporary relevance and impact. For example, my fieldwork in Salvador, Bahia, Brazil led me to experience the contemporary and historical workings of the old white boys' network within the field of Afro-Brazilian Studies and how this network contributed to the academic marginalization of Ruth Landes.

Interviews with individuals with knowledge of the Jewish women in this dissertation emphasized the multi-faceted and complex nature of each Jewish woman's subjectivity, networks and theorizing. Interviews and consultations also highlighted how different researchers interacting with the same set of archival materials often have completely divergent affective reactions and conclusions based upon their social locations. I witnessed the tendency to focus on the "personal" rather than "theoretical" when scholars critique women's writings. These interviews and conversations additionally drew my attention to specific archival documents and taught me the importance of using doubt and disbelief when analyzing the narratives of historical speakers. I provide examples throughout this section to illustrate the activities I engaged in and how they impacted my iterative data collection/analysis process as part of my application of grounded theory methodology.

\section{Tracing the footnotes}

Before beginning each archival trip, I read published articles and books about the core women in my study as well as books and articles they had written themselves. An unexpected benefit of this preliminary reading was that I discovered archival collections 
that I was not yet aware of, but that would prove useful for my project, in the footnotes of the writings of other scholars. ${ }^{20}$

I used this "tracing the footnotes" strategy while reading Andrew Bank's collective biography, Pioneers of the field: South Africa's women anthropologists (2016), which includes chapters on Ellen Hellmann and Hilda Kuper. Since this book was newly published I only heard about it through Sondra Hale, one of Kuper's graduate students, because Bank interviewed her for his chapter on Kuper (Bank 2016). Bank’s footnotes led me to many other articles written by Hellmann and her teacher at the University of Witwatersrand, Winifred Hoernlé. Bank's chapter also introduced me to social historians who had cited Hellmann's work. Even though I eventually disagreed with most of Bank's conclusions about Hellmann (after visiting her papers in Johannesburg) his chapter still provided an important foundation for understanding the breadth of her body of work and ways that more contemporary scholars had used her historical depictions of black working-class life in the 1930s and '40s.

A key archive that I learned about through the footnotes of Andrew Bank's book was the Jewish Board of Deputies Archive. However, it was unclear where I could find this archive based upon the information provided in the footnote: "The information in this paragraph is taken from Johannesburg Public, Library of the Jewish Board of Deputies, ARCH 809, Relations Committee Minutes 1944-1950, File on Ellen Hellmann. Thanks to

\footnotetext{
${ }^{20}$ Using footnotes to trace primary sources is a strategy I learned from Dr. Okezi Otovo in a class on race and nationalism in Latin American history in the fall of 2014.
} 
Jill Weintroub for this information from the Jewish Board Library" (Bank 2016:136, n. 95). Luckily, this footnote provided the name of a researcher, Jill Weintroub, who I searched for using google. Jill directed me to the South African Zionist Federation offices in Raedene, Gauteng, which I later discovered was part of the Beyachad Community Center.

Jill also met with me when I first got to Johannesburg and showed me the house where Ellen Hellmann had lived in Houghton, an extremely wealthy neighborhood in the northern suburbs of Johannesburg (see Figure 18). The posh-ness of Hellmann's home and neighborhood contributed to my conclusions about her positionality in relation to black communities.

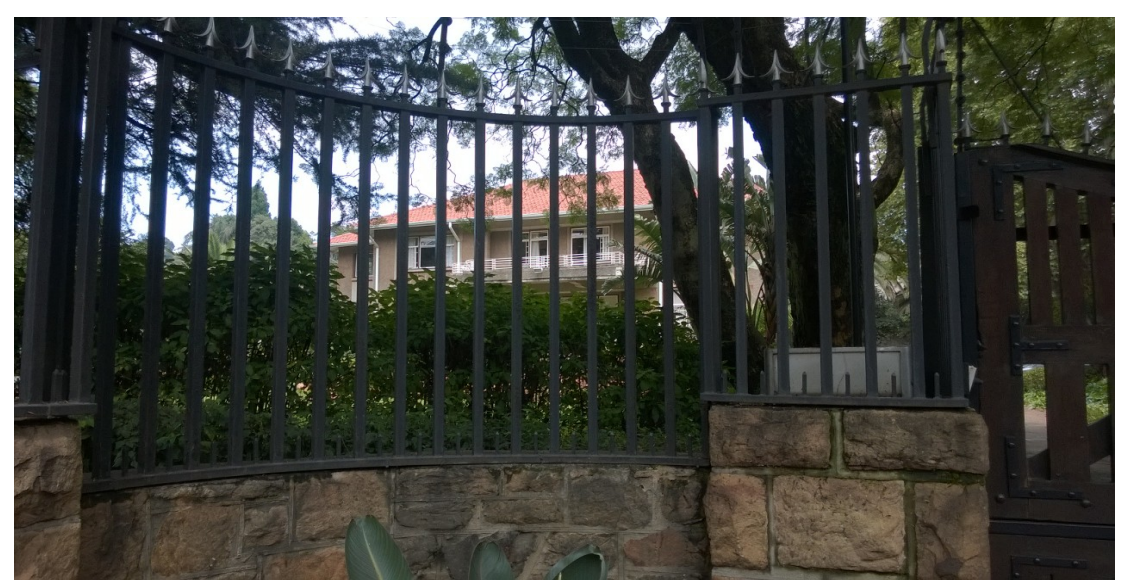

Figure 18. Ellen Hellmann's house. I took this photo when I visited the site with Jill Weintroub on February 26, 2017.

The Jewish Board of Deputies (JBD) Archive only had two sets of resources regarding Ellen Hellmann, a book of minutes from the Public Relations Committee 19441950 (Hellmann was the Chair of this committee from 1947-1949), and a box of newspaper clippings regarding Ellen Hellmann. Both proved to be exceptionally useful in understanding Hellmann's perspectives about the Jewish community in contrast to her 
views about black communities. There were many articles in this box of clippings about how she was viewed as "ultra-conservative" or part of the "old-guard" of the South African Institute of Race Relations by the 1970s (Hellmann 1974; Laurence 1973). The archivist at the JBD Archive was Naomi Musiker whom I only saw once, but I read through the materials in the Isie Maisels library, run by Maxine Fine, who told me stories about her memories of the South African Jewish community and her mother's involvement in the Black Sash. ${ }^{21}$ I would not have known about these Hellmann resources held at Beyachad, and the JBD Archive without Andrew Bank's chapter on Hellmann, or Jill Weintroub's previous research with those materials.

\section{Archival Visits}

I began archival visits in the summer of 2014, but they occurred primarily in the year between the summer of 2016 and the spring of 2017. I visited six different archives in person, two of which were at UCLA - the Hilda Kuper Papers, and Sondra Hale's personal collection of Hilda Kuper's creative writing - and two in Johannesburg, South Africa -the Jewish Board of Deputies Archives at the Beyachad Community Center and the Ellen Hellmann Papers and other collections with Hellmann materials at the Historical Papers Archive at the University of Witwatersrand. I visited Suitland,

${ }^{21}$ Hilda Kuper thought protests should be "dignified" like the Black Sash movement (Hale and Gondek 2016). Sondra wrote: "We saw [Hilda] as having enormous courage to be a part of the Black Sash Movement in South Africa and to engage in liberal politicsthough only 'liberal,' could still be dangerous in the apartheid days" (Gondek and Hale 2016). Ellen Hellmann was also member of Black Sash (Celarent 2012:274). 
Maryland on two different trips to see the Ruth Landes Papers at the National Anthropological Archives. I also took two trips to New York City to see the Vera D. Rubin Papers as well as Ruth Landes materials from outside of the Landes Papers held at the Reed Foundation. These archival visits gave me access to twelve different collections. Additionally, I accessed another three collections at two different university libraries (University of Cape Town and Northwestern University) through digital communication with special collections librarians and archivists. Vera D. Rubin is not discussed in detail within Chapters 2-5, so I have omitted detailed descriptions of her archival collection in this chapter. Appendix A summarizes my archival visits.

Consultations with fifteen librarians, archivists, and directors guided these visits. When I knew the specific sources I needed, these consultations involved me asking the librarian or archivist for the materials and they in turn looking for and bringing the boxes from the storage area, and when I was not physically present, digitizing the needed materials and e-mailing them to me free of charge.

$\underline{\text { Digital archival materials }}$

An example of this type of electronic/digital consultation was my interaction with Clive Kirkwood, the Special Collections Librarian at the University of Cape Town (UCT). I identified the sources held at UCT utilizing the extensive footnotes of Andrew Bank's (2016) chapter on Ellen Hellmann. One of the cited sources was a digitized taperecorded interview with Ellen Hellmann by historian Riva Krut, conducted June 3, 1982 only a few months before Ellen's death in November 1982. This item (number BC 949) was originally held at the Kaplan Centre Archive but is now held by UCT. Clive not only 
sent me the digitized audio, but also a transcript of "Side A" of the interview.

Unfortunately, Clive was not able to find a transcript for "Side B." When I transcribed portions of Side B I found that this piece of audio provided key data for my analysis of Ellen's upbringing as a "Western Jew" in contrast with "Eastern Jews." Andrew Bank also cited correspondence between Colin Legum (a Jewish anti-apartheid journalist) and Ellen Hellmann as well as Colin Legum's journal entries regarding Ellen Hellmann and her second husband, Bodo Koch, a German Jewish refugee. Clive Kirkwood sent me digital images of these archival materials from the Colin Legum Papers. I later found a tie between Colin Legum and Hellmann in the Jewish Board of Deputies Public Relations Committee Minutes from 1944-1950 (held at the Jewish Board of Deputies Archive at the Beyachad Community Center in Johannesburg).

$\underline{\text { Archivist Interventions }}$

In other cases, when the archivists thought I might benefit from looking at collections or specific materials that I was not aware of, they either brought the materials to me or instructed me on how to search for them in digital finding aids. This was the case with Gabriele Mohale, Zofia Sulej (Historical Papers Archive at Wits) and Lorain Wang (Ruth Landes Papers).

The two expert archivists at the Historical Papers Archive, Gabriele Mohale and Zofia Sulej, helped me do a system wide search for any materials related to Ellen Hellmann, so I could access items that were not included in the Ellen Hellmann Papers. This was how I learned about and utilized several other collections at the Historical Papers Archive: AD 1158 South African Institute of Race Relations, Series B: History of 
the Institute; AD 843 RJ Records of the South African Institute of Race Relations Part II; and AD 1433 Joint Council of Europeans and Africans.

During my first trip to the National Anthropological Archives (NAA) and the National Museum of Natural History (NMNH) Museum Support Center in Suitland, Maryland as part of my participation in the Smithsonian Institute in Museum Anthropology in the summer of 2014, I learned about a small Ruth Landes ethnographic object collection housed in the Collections' lab area awaiting cataloguing. These nine objects were part of a larger collection of over 71 objects from her fieldwork that Landes intended to donate to the Smithsonian that were lost between February 26, 1991 and September 18, 1991 either during or after transfer from her apartment in Hamilton, Ontario to the Smithsonian's NMNH (Landes 2010). Lorain Wang was the Processing Archivist at the NAA who re-organized the Ruth Landes Papers and revised the "Register to the Landes Papers" in 2010. When I told her that I was interested in figuring out what happened to the lost objects, she requested permission from her supervisor to show me the Ruth Landes accession file for the Ruth Landes Papers held at the NAA (this is separate from the accession file for the Ruth Landes objects held at the NMNH). On July 30, 2014, she showed me a memo that James Glenn, the former Head Archivist, had written about his February 25, 1991 visit to Landes' apartment to collect her papers and objects (Glenn 1991). Lorain's crucial intervention and assistance allowed me to piece together an explanation of who was responsible for the loss and why the loss might have occurred, which was connected to the devaluation of Landes as a scholar. 
$\underline{\text { Types of archival materials }}$

Ideally, I wanted to find correspondence between each of the core women in my study and other female scholars, research collaborators, assistants and key informants, especially women of color. I also hoped to find personal writings including correspondence that would illuminate how each woman thought about her gendered Jewish subjectivity and the connections between her personal relationships and her social science research and theorizing. I thought this would be possible based on my preliminary research with the Ruth Landes Papers in the summer of 2014. However, I quickly discovered that the Ruth Landes Papers are an exception.

The Ruth Landes Papers

Landes kept highly "personal” letters in her collection including probably hundreds of letters from her parents, Joseph and Anna Schlossberg (I read and took notes on a total of 39 letters: 22 written from 1955-1965, and 17 written from 1970-1973) as well as love letters from Edison Carneiro, her Afro-Brazilian research partner, Elmer Imes, a black physics professor at Fisk University, and Herbert Baldus, a German Brazilian anthropologist. I felt closer to her because of the content of these letters. (I will discuss the theoretical importance of affective reactions to archival materials under "Approaches to Data Analysis" the last section in this chapter). None of the other women's archives included love letters, and thus I did not have the opportunity to connect with them in the way I did with Ruth Landes.

Not only did Landes include personal letters in her collection, but also she often included self-analyses of the connections between her private experiences and 
professional research interests, something I have not seen in the archives of any of the other women. This is ideal for my project since I am interested in the intersections of social science theorizing and subjectivity formation. For example, Landes made a very revealing comment in a July 10, 1967 letter to Ruth Sawtell Wallis (a Boasian physical anthropologist) about why she thought she married Ignacio López, her second husband. "I have an idea, especially after doing my CULTURE and SOUTHWEST books that I married my husband, this second one, because of an undying affair with Spanish and frontier history" (Landes 1967). Her personal and professional correspondence from the 1980s, in the last ten years of her life, revealed detailed self-reflection on her lifetime of research (Landes 1984d, 1990). During this time, she returned to work on a fictionalized memoir about her time at Fisk in 1937-1938 and her relationship with Elmer Imes. The various versions of this memoir and her letters to black scholars inquiring about the reason for the gender discrepancy in enrollment at Fisk, reveal her prevailing interests in the intersections of race, gender and class hierarchies as well as her personal experiences with an interracial relationship in the segregated South (Landes 1960, 1985a, 1985c, 1987d).

Thirdly, Landes wrote in the margins of her letters, as if to explain their contents to a future reader, drawing the researcher closer and into the midst of Landes' stories. Olívia Maria Gomes da Cunha argues that these marginalia serve to direct future readings of Landes' work and translate key pieces of information that might not be understood otherwise. Da Cunha contends that Landes wanted readers to have the tools to fully comprehend her career and biography (da Cunha 2006:14-15). 
The Landes papers also contain significant correspondence with Landes' Native American key informants, research collaborators, and colleagues, like Maggie Wilson, whose stories enabled Landes to write The Ojibwa Woman, Louise Nocktonick, a key Potawatomi informant who made several of the items in Landes' intended ethnographic object collection, and Kee (Keewaydinoquay) Peschel, an Anishinaabeg ethnobotanist who both admired and critiqued Landes (Landes and Cole 1997; Masha 1936; Nocktonick 1966; Peschel 1988).

\section{Collections related to Ellen Hellmann}

The Ellen Hellmann Papers at the Historical Papers Archive at the University of Witwatersrand contained no personal or professional letters. These papers were made up of published and unpublished manuscripts, conference papers and newspaper clippings organized alphabetically by research theme. Thus, there is more archival material available regarding her theoretical positions than about her connections with people. Since there was no correspondence available in her papers, I looked at whom she cited in her articles and conference talks, and with whom she was associated or placed in opposition to in newspaper articles.

In her position as the Honorary Secretary, Vice Chairman (1940-1944) and Chairman (1945-1948) of the Johannesburg Joint Council of Europeans and Africans (this collection is held at the Historical Papers Archive, no. AD1433) she wrote letters to city government officials lobbying on behalf of the Joint Council for improved social services for "natives" including food, labor, restroom facilities, train transportation, and health care. For example, she requested reduction in costs for commuter train fares to 
better meet the needs of African workers. She said that the "Council" made these requests to "give some relief to the residents of Orlando, without requesting any fundamental changes in the system at present operative" (Hellmann 1940b:2). This archival collection enabled me to see how the Joint Council and Hellmann as its spokesperson worked within the apartheid system rather than radically challenging the system of segregation.

The (unorganized) box of newspaper clippings relating to Ellen Hellmann held at the Jewish Board of Deputies Archive in the Beyachad building in Johannesburg was the source of information that gave me the strong impression that by the 1970s Hellmann was considered extremely conservative in her race and gender perspectives by younger members of the South African Institute of Race Relations (Laurence 1973).

\section{Collections related to Hilda Kuper}

Though Hilda Kuper's papers do not include the type of personal materials that I found in the Ruth Landes Papers, Hilda did keep correspondence with her graduate students/research assistants, which in some cases revealed personal information about her but also demonstrated Hilda's transracial collaborative relationships with Teresa Thoko Ginindza and Fatima Meer. Unfortunately, the Hilda Kuper Papers are highly disorganized with letters from the same student, like Beth Rosen-Prinz, separated into widely different boxes - Boxes 23,41 and 53 . Also the names of Kuper's students are misspelled within the finding aid to the Kuper Papers as well as on the folders, for example Teresa Thoko Ginindza is referred to as "T. Ghinza" and David Kuby as "Kaby I" in the finding aid (Cubé and Hatayama 2011). Also, letters were incorrectly placed in the wrong folder. For example, I found a letter from David Kuby signed "Gumbi" in the 
midst of letters from Beth Rosen Prinz in Box 41, folder 3 (Rosen-Prinz 1978). This was confusing and made it difficult to access the entirety of Hilda's correspondence with each of her students, as I had to look in multiple places. This contrasts with the Ruth Landes Papers in which letters from each correspondent are separated and alphabetized, making it easy to track correspondence with each person over time.

I learned of the collaboration between Hilda and Teresa Thoko Ginindza during my first trip to the Hilda Kuper Papers in May 2016. I came across letters between Hilda and Thoko in which Hilda asked Thoko to collect Swazi artifacts to form an object collection at the ethnology museum at UCLA (Kuper and Ginindza 1976). Also, in the same folder as the correspondence between them, is Thoko's statement of purpose for her admission to UCLA. This reveals Thoko's interest in the impact of colonization as well as the traditional aristocracy on women's roles in Swaziland and women's attitudes in the post-colonial era (Ginindza 1974). Thoko developed the theme of gender in Swazi culture that Hilda would only address in her creative writing (Ginindza 1989; Kuper 1965; Kuper and Institute 1970).

Also during my trips to the Hilda Kuper Papers in both the summer and winter of 2016, I looked through Fatima Meer's fieldwork notebooks (Box 14 is full of them) in which she detailed the effect of Indian immigration to South Africa upon caste affiliation, marriage traditions, legally required medical care, and labor strikes. Meer also tracked and summarized the ship logs by sex, age, caste, religion, village, and marriage status (Kuper et al. 1953). Additionally, I found a limited correspondence between Hilda and Fatima in Hilda's papers. 
In November and December 2016, I met with Sondra Hale, a retired Women's Studies professor at UCLA, who was one of Hilda Kuper's students at UCLA and who also knew Teresa Thoko Ginindza during graduate school. Sondra is the dissertation advisor for one of my close friends from my Women's Studies program at San Diego State from 2006-2008, Dalal Alfares, who recently competed her Ph.D. at UCLA in the Women's Studies program. I interviewed Sondra about her experience as Hilda's student and Sondra gave me access to a personal box of Hilda's creative writing, that Sondra, Beth Rosen-Prinz and Dawn Chatty (two of Hilda's other graduate students) were going to use for a festschrift for Hilda after her death. Unfortunately, because of the lack of email in the early 1990s (Hilda died in 1992) and Sondra, Beth and Dawn's spatial dispersal across the globe, this collaborative project never realized. This personal box of various short stories, poems, and essays also included a draft of a play called The Decision. This play shows the influence of Fatima Meer's research assistance and collaboration on Hilda's work about Indian South Africans (Kuper 1957). There is only a summary of the play in a 1993 collection of Hilda's creative writing edited by Nancy Schmidt and the endings differ (Kuper 1993).

\section{Museum Visits}

In addition to archival data collection, I visited six museums, four relating to my research regarding the Ruth Landes ethnographic object collection, specifically the black cloth bahiana dolls (made by Candomblé priestesses) she collected in Salvador, Bahia in 1938-1939 and donated to the Natural Museum of Natural History (NMNH). Two 
museum visits related to my research about Hilda Kuper and her students/assistants Teresa Thoko Ginindza and Fatima Meer. Appendix B summarizes my museum visits.

During the Summer of 2014, I analyzed Landes' small ethnographic object collection and her accession file at the National Museum of Natural History (NMNH). I gained access to the Landes object collection because of Candace Greene, the Director of the Smithsonian Institute in Museum Anthropology (SIMA). Candace told me about a few Ruth Landes objects housed in the Collections' lab area awaiting cataloguing. These nine objects were part of a larger collection Landes intended to donate to the Smithsonian that were lost (as I previously mentioned). Candace suggested I talk to Susan Crawford, the Registrar, who showed me both Landes' NMNH accession file as well as the drawer where the Landes objects are stored in the "lab" area of the Collections offices (personal communication, June 27, 2014). For a photograph of the Ruth Landes collection, see Figure 19.

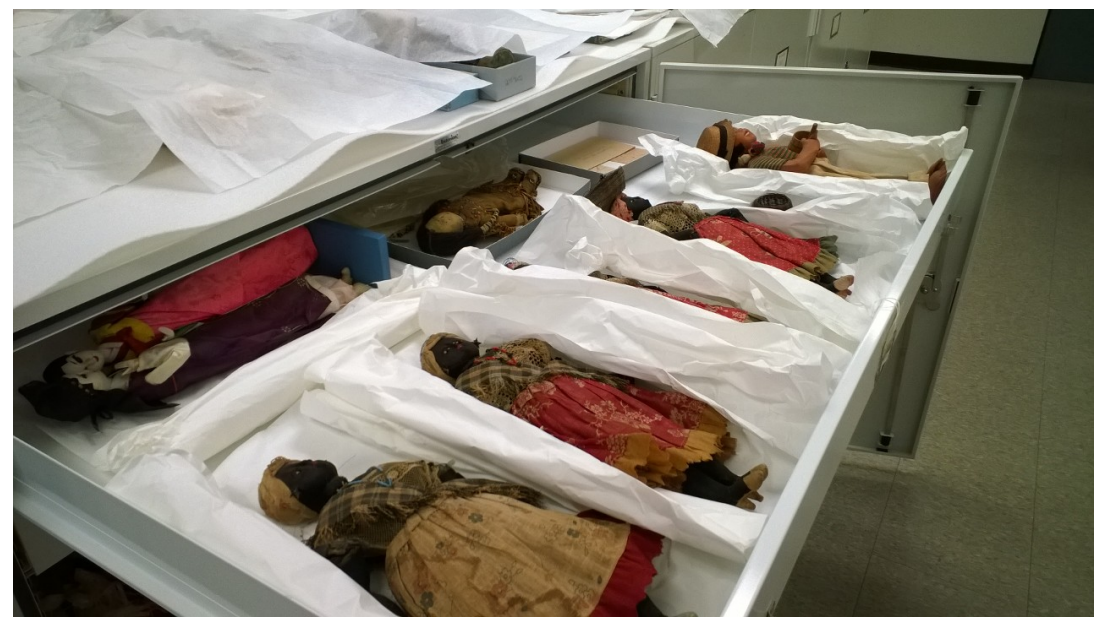

Figure 19. Ruth Landes Ethnographic Object Collection in the storage room of the National Museum of Natural History, Museum Support Center, Suitland, Maryland. Control No. 1048265, Location: A1 Row 607:003, photo taken by author, June 27, 2014 
The bahiana dolls are important to my study of Landes' networks with black women because they are physical evidence of the relationships Landes formed in Brazil in 1938-1939. Afro-Brazilian priestesses crafted them from the same clothing they wore on a daily basis. The dolls also wear jewelry that is color coded to specific orixas (goddesses), thus making it possible that they are representations of specific women Landes interacted with and wrote about in her ethnography City of Women (1947). Landes' repudiated the common assumption that black matriarchs represented a black "problem." She believed that because of their lower class standing, Candomblé women were sexually and spiritually empowered (1947:148). Perhaps influenced by her experience of Eastern European Jewish women's financial support of their families

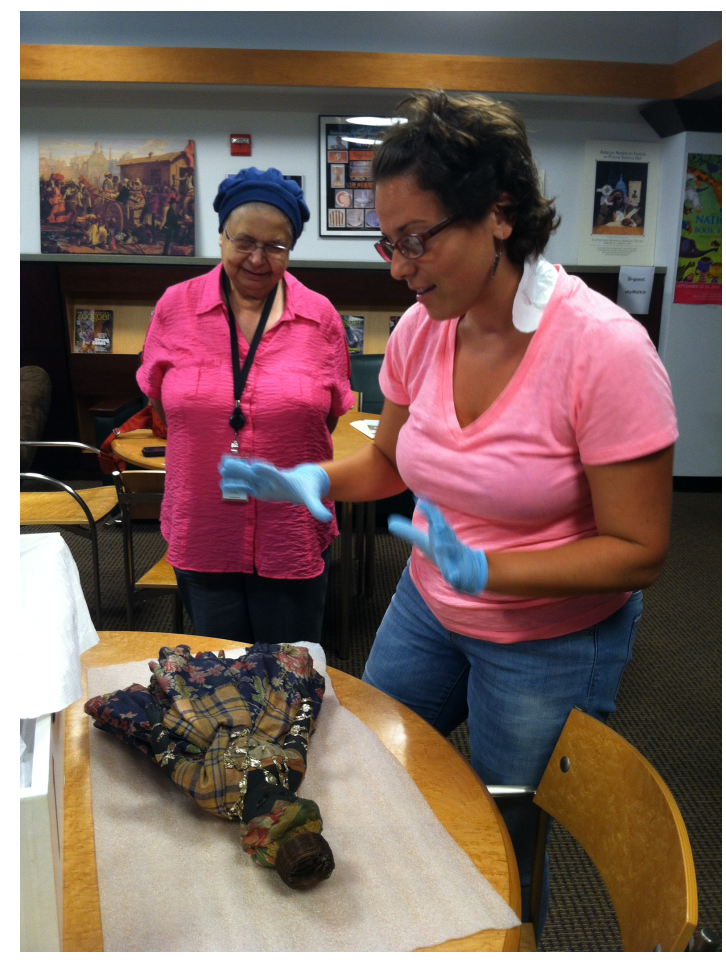

Figure 20. Abby with Alcione Amos, Curator at Anacostia Community Museum, with bahiana doll in the collection of Lorenzo Dow Turner. Catalog no. ACM 2003.0032.0371, July 2014, in Washington, D.C. Photo taken by Suzanne Ingalsbe 
(Landes and Zborowski 1950:449-50), she also contended that Afro-Bahian women were the economic saviors of their communities (Landes 1947:146-47).

The museum visits to the Anacostia Community Museum (in Anacostia, Maryland, see Figure 20), the Popular Art Museum in the Feminine Institute of Bahia, and the Museu Afro-Brasileiro of the Federal University of Bahia were to compare the bahiana and orixa dolls in their collections with the ones Ruth Landes collected in order to note any unique elements of the Ruth Landes dolls, since Landes said that they were "handmade for me" and to try to find out exactly who made the bahiana dolls in the Ruth Landes collection. Landes never stated the exact names of the women who made the dolls only that these women were "cult daughters" and that the dolls were made on the property of a Candomblé house, but since Landes completed fieldwork in at least five different houses this is still quite a broad statement (Landes 2010). 


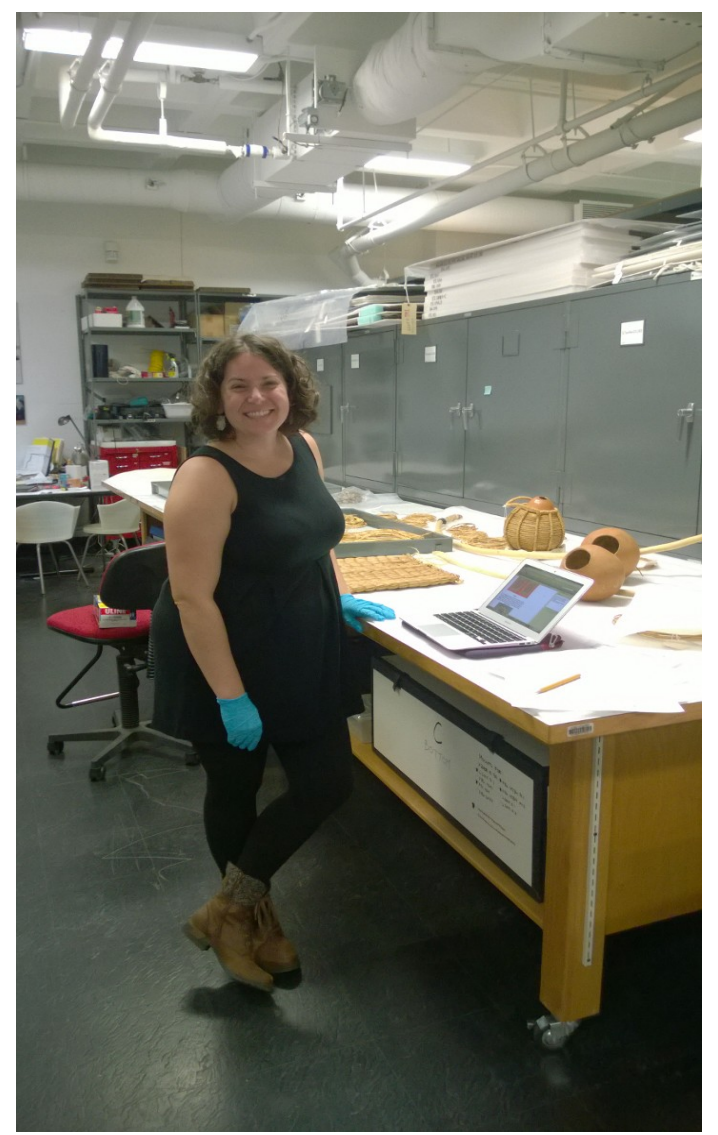

Figure 21. Abby at UCLA Fowler Museum with Teresa Thoko Ginindza Swazi collection. November 2016, photo taken by Erica P. Jones, Assistant Curator of African Art

After reading correspondence between Hilda Kuper and Teresa Thoko Ginindza in the Hilda Kuper Papers in which Hilda asked Thoko to collect Swazi artifacts and Thoko reported on which types of objects she managed to find (Kuper and Ginindza 1975), I contacted the African Art curator, Erica P. Jones, at the Fowler Museum on the UCLA campus in July 2016, to inquire if a Swazi ethnographic object collection existed. Indeed, there was a collection (see Figure 21), though the documentation listed Thoko as a man! There was a visual index of the materials and I set up a time in November 2016 to go to the Fowler to see and photograph the Swazi objects that Teresa Thoko Ginindza had collected and sent to Hilda Kuper in 1976-1977 (Fowler Museum 1976). I was 
interested in what the objects revealed about how Kuper's transracial and transnational relationship with Thoko (see Figure 22) enabled Kuper's theorizing about Swazi material culture, especially women's clothing and adornment (Ginindza 1971; Kuper 1973).

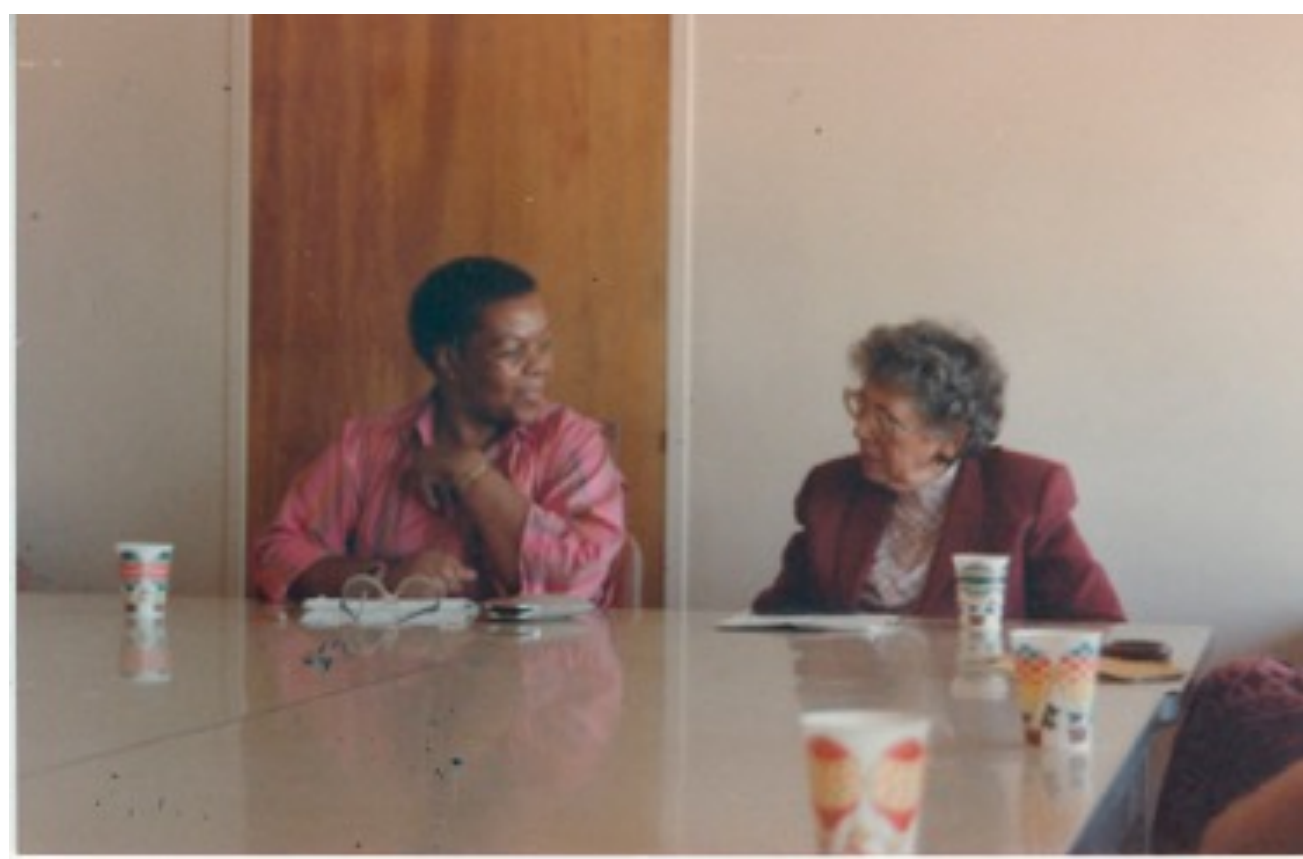

Figure 22. Thoko Ginindza with Hilda Kuper at UCLA, 1984/1985, from Mary Kuper's personal collection, used with Mary's permission. Unfortunately, neither of Kuper's daughters nor any of her students knew the reason behind this meeting.

Fieldwork in Salvador, Bahia

I conducted preliminary fieldwork in Salvador, Bahia in December 2014 and January 2015, using the "Afro-Brazilian Studies Center" (a pseudonym) at a prominent public university in Salvador as one of my primary fieldwork sites. ${ }^{22}$ I wanted to

${ }^{22}$ IRB protocol exemption number: IRB-14-0315, as of 10/29/2014, TOPAZ reference number 102994 
understand the contemporary impact of the 1938-1939 fieldwork relationships between Ruth Landes, Edison Carneiro and Candomblé priestesses. I consulted with five faculty members and administrators; "consultations" involved brief conversations or interactions either in person, over the phone or via e-mail. One of the administrators I consulted with was a filha do santo ("daughter of the saint") at Gantois, one of the central houses portrayed in City of Women. These conversations were brief because the individuals felt they did not have much to tell me regarding Ruth Landes, they did not think Ruth Landes was worthy of in depth study and/or they did not feel she had a significant impact on contemporary Candomblé communities, namely Gantois. I engaged in two informal interviews with a faculty member/museum director and an administrator who was also a filha do santo at Casa do Cobre ("House of the Snake"), the house that Landes wrote about in Chapter 18 of City of Women when she described the women's dress and comportment at a "modern" "social dance." My "informal interviews" were longer inperson conversations, at least forty-five minutes to an hour or more in length, in which the individual provided substantial information regarding Ruth Landes, her fieldwork interactions with other scholars and Candomblé practitioners in 1938-1939, and her contemporary impact on specific Candomblé communities like Casa do Cobre. I conducted more extended interviews (approximately two hours long) with two members of Candomblé houses where Landes conducted fieldwork: Ilê Axé Opô Afonjá and Casa Branca. These extended interviews helped me understand how City of Women was reintroduced into specific Candomblé communities as well as contextual information about how doll-making would have happened in the late 1930s in Salvador among Candomblé priestesses. In total, four of the people I spoke to were members of Candomblé houses 
where Landes conducted research in 1938-1939. Appendix C summarizes my interviews and consultations.

I found that Ruth Landes is not well known or well-remembered within the Candomblé houses where she did research in 1938-1939. Individuals who are part of both the academic community, especially the Afro-Brazilian Studies Center at the public university in Salvador, and also a Candomblé house, seem to be the reason that Ruth Landes might be known within a specific house. I found that the old white boys' network was still utilized to value white male historical scholars while excluding non-white and non-male historical figures, as well as marginalizing the contemporary researchers who study these non-canonical figures. This fieldwork helped me understand the processes that contributed to Landes' academic marginalization.

\section{Interviews}

The final method I employed was interviews, conversations or consultations with scholars who have also researched the women in my study or who were students of Hilda Kuper or worked with Ruth Glass. I used a "snowball method" to find individuals to interview. In the last part of this section on Interviews I describe several interviews and consultations with researchers who have also utilized the Ruth Landes Papers in order to emphasize the divergent affective reactions to the same set of archival sources, based upon social location and research motivations and how these affective responses impacted theorizing. ${ }^{23}$

\footnotetext{
${ }^{23}$ IRB protocol exemption no. IRB-16-0153, IRB exemption date: 4/26/16, Topaz Reference No. 104671
} 
$\underline{\text { Hilda Kuper's graduate students }}$

I interviewed four of Hilda Kuper's graduate students from UCLA (three inperson and one via Skype) and consulted via e-mail with another student of Kuper as well as Kuper's daughter Jenny. These interviews occurred during the winter of 2016-2017 and the summer of 2017 and focused on themes such as Hilda's differing relationships with her graduate students, her influence on their research, Hilda's approach to gender and feminism and how it impacted the research of her students, her relationship with her husband, Leo Kuper, and her Jewish subjectivity. I also consulted via e-mail or in-person (in Johannesburg) with three scholars who are familiar with Hilda's work (JanuaryMarch 2017). I spoke to Fatima Meer's daughter briefly on the phone to ask if there were any references to Hilda Kuper in her mother's recently published autobiography (Meer 2017). Appendix C provides more detailed information about these interviews.

$\underline{\text { Snowball method }}$

Finding individuals to interview typically involved a snowball method. After interviewing Sondra Hale in November 2016, she put me into contact with Beth RosenPrinz, another graduate student of Hilda Kuper, whom I also interviewed, in Beth's home in Los Angeles in December 2016 (Rosen-Prinz and Gondek 2016). Beth gave me the contact information for other graduate students of Hilda's like David Kuby, who e-mailed me about Hilda's Jewish subjectivity (Kuby and Gondek 2017). Beth gave me the contact info for Dawn Chatty whom I interviewed via Skype in July 2017 (Gondek and Chatty 2017). For a photograph of Beth and Dawn together at Hilda's home, see Figure 23. Beth also suggested I contact Gelya Frank, a graduate student who had interviewed Hilda 
about the process of doing life-history research when Hilda had been writing a biography of the Swazi King Sobhuza II (Kuper 1978); I had seen a transcript of this interview in the Hilda Kuper Papers (Frank and Kuper 1979). The interview eventually made it into a book: Lives: An Anthropological Approach to Biography (Langness and Frank 1981). I interviewed Gelya Frank on August 6, 2017 in her home in Santa Monica, CA (Frank and Gondek 2017).

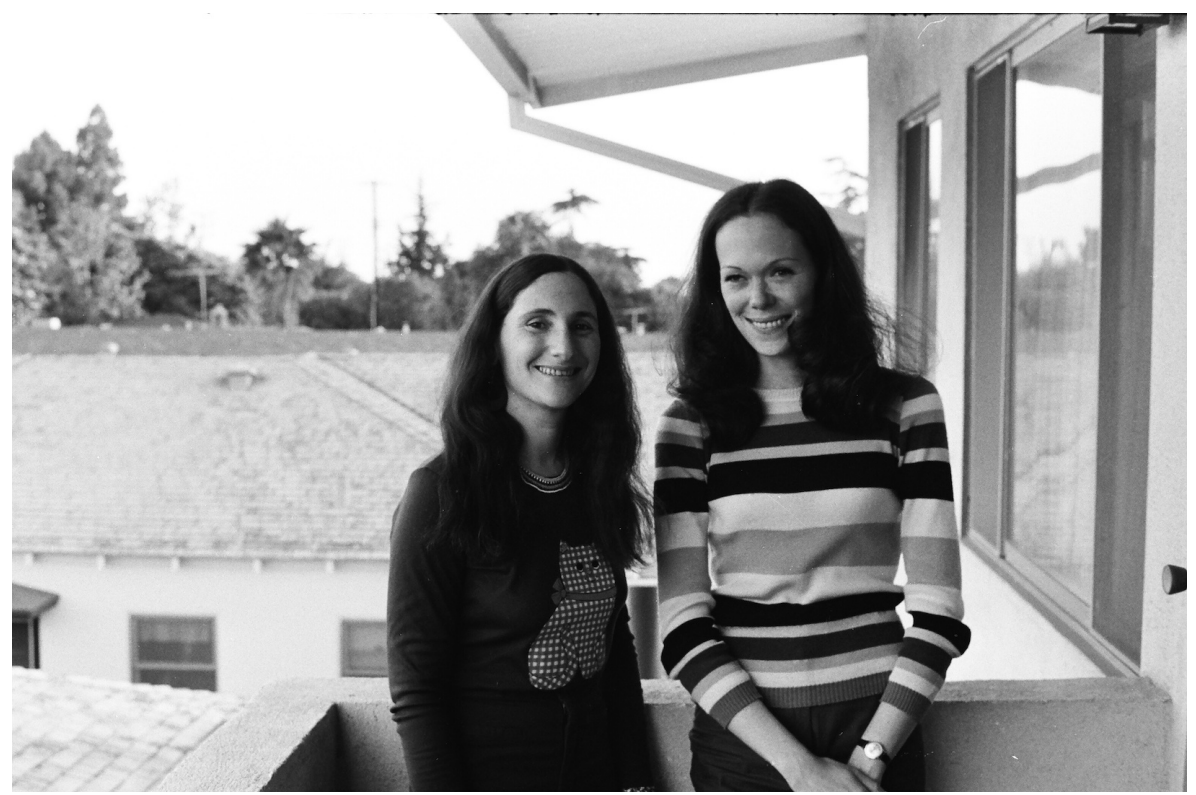

Figure 23. Beth Rosen-Prinz and Dawn Chatty at a party for Hilda's graduate students at Hilda's home in Los Angeles, 1974, photo from Dawn Chatty's personal collection, used with Dawn's permission.

Before going to Johannesburg, I e-mailed Sharad Chari, a geographer who was working at the University of Witwatersrand in Johannesburg in the Center for Indian Studies. I thought he might know about Fatima Meer because of his research about Indian South Africans. Sharad told me about Shamim Meer (Fatima's daughter) who had recently edited and published her mother's autobiography (Meer 2017). I purchased 
Fatima's autobiography while I was in Johannesburg. Shamim told me that her mother mentioned Hilda Kuper in her autobiography, but more as a "family friend."24

Sharad also directed me to talk to Kelly Gillespie, Chair of the Anthropology Department at Wits and Shireen Hassim, at WISER: Wits Institute for Social and Economic Research. Kelly made suggestions for readings in the history of South African anthropology especially regarding Ellen Hellmann and Hilda Kuper's teacher, Winifred Hoernlé, and the split between British and Afrikaner anthropological approaches in South Africa (Gillespie 2011). Shireen Hassim told me about several Jewish leftist women in the history of South African anti-apartheid activism, which gave me ideas for how I could contrast more radical Jewish South African perspectives with those of Ellen Hellmann.

\section{Divergent Affective Entanglements}

Regarding Ruth Landes, I consulted with three scholars via e-mail between February 2014 and February 2015, recorded an interview with Mica Nava via Skype (February 2015) and engaged in informal interviews with Linda Perkins in person (May 2015) and Ron Mickens via phone (June-July 2017). Through my conversations with Nava, Perkins and Mickens, I learned that different researchers interacting with the same

\footnotetext{
${ }^{24}$ After reading parts of Fatima's autobiography in April 2017, while finishing my "Interim Report" to the Ruth Landes Fund, I discovered that Fatima did not have as much Jewish ancestry as I had originally thought since Fatima's mother was only half-Jewish on her father's side. Also, I learned that Fatima considered Hilda and Leo Kuper to be her "most constant friends" during the 1956 Treason Trials (2017:169). This was the same year that the Kupers "solicited a loan" and "stood guarantor" for Fatima and her husband Ismail Meer, so that they could get the capital to build their house, since non-whites could not get loans at that time (163).
} 
set of archival materials (in this case, the Ruth Landes Papers) often have completely different affective reactions and conclusions based upon their social locations. Mica Nava, Emeritus Professor of Cultural Studies at the University of East London, expressed this idea in her report to the Ruth Landes Fund:

In all cases, our standpoints, our personal biographies and politics, inform what and whom we choose to research and how we interpret our findings. This inevitably makes for complex relationships with the people we engage with in the archives. Sometimes we grow to admire them and sometimes the obverse happens, as it did, regrettably, for me, with Ruth Landes (Nava 2013a:8).

In my interview with Nava, she called Landes' research about British race relations “appalling” (Gondek and Nava 2015). Mica thought Ruth Glass was more "radical” and “open-minded” than Landes because of Glass' German refugee status giving her a special relationship with other migrants to Britain (Gondek and Nava 2015). I learned about Ruth Glass through reading Nava's comparison of the two scholars. Nava maintained that Ruth Glass' research on the same population, West Indian migrants, was more "solid," portraying more "investment and commitment than Landes" (2013a:32). Glass' study London's Newcomers (discussed in detail in Chapter 5) was a quantitative study that also included ethnographic details while Landes' unpublished work was strictly ethnographic and narrative-based (Glass and Pollins 1960; Landes 1954). Nava expressed her "loss of respect for Landes as a person and writer" (8), arguing that Landes was "opportunistic and intuitive rather than scholarly" (18) and "exasperatingly impressionistic and anecdotal" (Nava 2013:26). Nava pointed to Landes' extremely small sample size Landes used only two families, one her host family, social anthropologist Kenneth Little and his Jamaican wife, Iris, to inform her findings, which Nava called "audacious" and “astonishingly presumptuous” because of Landes' psychoanalysis of her hosts (16). 
Landes' reliance upon the life histories of a limited number of key informants with whom she also had a personal relationship was her typical methodology; she used this technique in Brazil with her research partner, Edison Carneiro, and in her Native American fieldwork, with Louise Nocktonick and Louise's mother, Gunogwe Masha, for Landes' Potawatomi book, and Maggie Wilson for The Ojibwa Woman (Landes 1947, 1970d; Landes and Cole 1997).

Nava preferred Ruth Glass because she was more optimistic than Landes about Britain as a "multicultural and multiracial society" (33). Nava sought female social scientists to prove that Britain was becoming a more progressive and less racist society in the 1950s. Landes' perspective that West Indian migrants and "half-caste" children were always seen as "foreign visitors" and not Britons (Landes 1954:5), contradicted the main argument that Nava wished to make about "the relative openness" of some Britons which Nava argued was a "harbinger of a better, more progressive, less racist, society" (Nava 2013a:28). The differences in perspective between Mica Nava and myself demonstrate my interest, less in arguing how things "really were," and more in analyzing each woman's writings for what they show about who she was and what issues preoccupied her.

Another example of the differences in perspective between researchers studying the same individual is that when I told Mica that I wanted to focus on Landes' Jewishness, which I found to be extremely prominent, and that I thought did not get enough attention in Sally Cole's biography (2003), Mica said she did not see Landes' family as that "Jewish" because they were not "religious"; this showed me that we had different perspectives on what counted as "Jewish." Mica is Jewish on her father's side 
but “very secular" (Nava 2007:139). For Mica, Landes' Jewishness only emerged as it related to Landes' identification with "difference"; Mica observed that Jewish women researchers in the post WWII years were often interested in race relations (Gondek and Nava 2015). Similarly, my focus on Jewish subjectivity in the interviews I did with Hilda Kuper's students was often met with comments that Hilda did not talk about her Jewishness much. This caused me to question whether my focus on Jewishness in some cases comes more from my own interest and background than from the explicit statements of the women in my study. Ruth Landes, Ruth Glass and Ellen Hellmann often mentioned Jews, Jewish identity or anti-Semitism. Landes, Glass and Kuper developed analogies between anti-Semitism and anti-black racism and other forms of discrimination, however, Hilda Kuper made these references to Jews and analogies less frequently.

My conversations with Linda Perkins, Associate Professor of Education, Women's Studies and History at Claremont Graduate University and Ronald E. Mickens, Callaway Professor of Physics at Clark Atlanta University, revealed that scholars who research Ruth Landes tend to focus on her "personal" life, also common with writings about Zora Neale Hurston and Ruth Benedict. While historians keep men's personal and professional lives separate, in histories of women the personal tends to be the focus (Parezo 1993:15). Exclusive attention to black women's "personal" lives or writing "style" diminishes the power of their political theorizing, as is the case with Zora Neale Hurston's ethnographies (Marshall 2008:182). This is one of the primary reasons I chose to emphasize the relationships between women's theorizing and their "personal" experiences. 
In addition to their focus on Landes' "personal life" both Perkins and Mickens demonstrate the importance of approaching archival materials with doubt and disbelief and treating the historical figure under study as an "unreliable narrator." Their sense of doubt about the truthfulness of Landes' accounts of her relationship with Elmer Imes, a black physics professor, at Fisk University in 1937-1938, led me to question whether Landes indeed lied or exaggerated and also to ponder why she would do this (Perkins 2011:7). I also started to think about why contemporary scholars would conclude that historical figures were lying and why multiple scholars have accused Landes of lying. ${ }^{25}$ It is possible that she misinterpreted what she observed or described lived realities in a way that fit her theorizations (Lovisek, Holzkamm, and Waisberg 1997:134-37). It is also possible that her theorizations and descriptions of reality challenged dominant gendered norms or emphasized subaltern perceptions of reality that she heard from her key informants who were often marginal to the dominant society, just as she was (Cole 2003:85, 88-89; Landes and Cole 1997:xi).

In one of her e-mails to me Linda Perkins said that Landes had "sexual fantasies about black men" (Gondek and Perkins 2015). In a different e-mail, Perkins wrote:

She may have slept with [Imes] but his marriage broke up over his affair with another white woman who was on the staff at Fisk [Ethel Gilbert]. This was widely reported in all of the Black newspapers and his divorce to renown[ed] Black writer Nella Larsen was well known. Landes' name was never mentioned (or even hinted) in the many articles about Imes and his extra-marital activities. In fact, I spoke with Imes biographer [Ron Mickens] and he said Landes was lying... (Perkins, Cole, and Nava 2013).

\footnotetext{
${ }^{25}$ White Brazilian anthropologist Arthur Ramos argued that Landes was not scientifically honest, made "dangerous generalizations" and errors of observation, falsified concepts and created a untrue picture of black religion in Brazil (Ramos 1942:186, 189-90)
} 
Another reason that Perkins thought Landes was lying about her relationship with Elmer Imes was that Landes said she destroyed ${ }^{26}$ all the letters from Elmer; this seemed suspicious since Landes kept all of Carneiro's letters. There are a few letters signed "Tony"/"Toni" (Landes' nickname for Elmer, according to Landes) in the Elmer Imes folder in the Ruth Landes Papers in which he calls Ruth "Little Darling" and asks her, “Do write me. I shall feel very much alone if you don't write often" (Imes and Landes 1940). Both Perkins and Elmer Imes' biographer, Ronald Mickens, told me they had not seen these letters. Even after I assisted Dr. Mickens to access these letters from "Tony" to Ruth Landes (held at the NAA), which are written on letterhead from Imes' home on Hermosa Street in Nashville Tennessee, Mickens insisted (personal communication, June $14,2017)$ that the letters were "fake" and Landes wrote them herself (Imes, Imes, and Landes 1941). In a more recent exchange Ron explicitly wrote to me: "I am 99 percent certain that the letter from EI to RL are fake!" This is because of the different spellings of Tony/Toni, what Ron viewed as two different styles of handwriting in the two letters supposedly from Elmer Imes to Ruth Landes, and also the lack of mention of Landes in any writings or conversations Ron has had about Elmer Imes or Nella Larsen with their contemporaries; Ron finds it doubtful that Nella Larsen would not have known about

\footnotetext{
${ }^{26}$ On the bottom of an October 1940 letter from Elmer Imes, signed "Tony," Landes wrote: "I tore up the letters that followed this as I did all those in Brazil. Why? Because I thought I had no place for them. They were loving, passionate, full of promise for the future, full of details, and I knew there would 'always' be another. How could he let his [Ethel] Gilbert violate this and I suppose she asks a similar question..." (Imes and Landes 1940).
} 
Landes, if she fully knew about Imes' affair with Ethel Gilbert, who is discussed in detail in Larsen's biographies (Hutchinson 2006; Mickens 2017).

Landes seemed to love Elmer Imes, “...this man I loved, as prayerful souls love God, was a man not of my color ...He is dead, of cancer that started in his throat...He had been a man until the end, never fearful, never uncertain, never yielding" (Landes 1985a:3). But my conversations with Mickens and Perkins caused me to question whether Landes and Imes had been romantically involved with each other.

Linda Perkins and I differed in our responses to Ruth Landes because of our differing positionalities and research purposes. Perkins felt offended at what she perceived as Landes' lies and "harsh and negative" portrayals of Charles S. Johnson stemming from what Perkins understood as Johnson's rebukes of Landes' overtures. Perkins greatly admired Johnson's mentorship of black professional women whom he helped bring onto the faculty and staff at Fisk (Perkins 2011:5; Perkins et al. 2013). Perkins did not provide any specific evidence of Landes' "lies" about Johnson except to write that Landes never acknowledged the employment assistance Johnson provided. Also Perkins argued that Landes resented that Johnson never made time for her when he visited New York (Johnson and Landes 1946; Perkins 2011:6-7). I realized how important specific archival document references are for future researchers. Perkins' statements caused me to dig deeper for Landes' references to Charles S. Johnson, and to access the correspondence between Landes and Johnson from the Fisk Archives, copies of which I found at the Reed Foundation in New York City. The fact that C.S. Johnson kept making excuses not to meet with her in New York in 1944-45 illustrates the possible uneasiness some Black male scholars, like C.S. Johnson, felt around Landes after the 
rumors about her interracial sexual relationships spread by Rüdiger Bilden at Fisk University in 1937. I began to wonder if Johnson was concerned that Landes' "loose" reputation would be applied to him (or that rumors would begin that he was involved with her sexually) and so he actively tried to avoid meeting her in person even if he provided recommendations for her. In contrast to Perkins' findings, I identified multiple times that Landes acknowledged Charles S. Johnson's support for her work, including personally coming to her parents' apartment to invite her to Fisk to learn "how Negroes really live" under Jim Crow before her trip to Brazil (Landes 1985c, 1986a:2). Johnson also urged her to apply to the Fulbright to study the migration of "colored colonials" to Britain and then she was invited by Kenneth Little to study at the University of Edinburgh (Landes 1965:6, 1987c). Charles S. Johnson was one of Landes' recommenders (Nava 2013:22). In one of the versions of Landes' unpublished fictionalized memoir, she wrote of Johnson's character positively: "his intelligence and poise impressed one immediately." He had a sly wit, and a "rare smile" which illumined his talk (Landes 1985a:4).

There are several potential explanations for Perkins' assessment of Landes' antipathy toward Johnson. Landes described a rivalry between her friend (and possible lover) Elmer Imes and C.S. Johnson (Landes 1986a:3, 1987b). She was baffled by Johnson's "weird London behavior" when he bolted from the house of her upper-class English friend [Sally Chilver?] in London in early 1955 when Landes asked "Wouldn't Walter White rejoice over the Supreme Court (1954) decision?" referring to Brown v. 
Board of Education. ${ }^{27}$ Ruth wrote that Johnson never talked with her much but always looked at her "as if amazed." Landes also hypothesized that perhaps Johnson felt that her host behaved snobbishly toward him (Landes 1987c:1). Or perhaps Perkins took issue with Landes' statement that Charles S. Johnson "excludes women by silence" because Landes felt he did not discuss women enough considering "in ALL folk black worlds, women are the nurses, midwives, witches, doctors in Africa, West Indies, USA and Brazil” (Landes 1986g:1-2).

My conversations with Linda Perkins and Ron Mickens about Landes' "lies" pushed me to search for further evidence of whether or not Landes could have had a relationship with Elmer Imes, leading me to an extremely important archival find in the papers of Melville Herskovits in a letter from Rüdiger Bilden ${ }^{28}$, which had been briefly referred to in the chapter by Kevin Yelvington where I originally read about Ruth Landes

${ }^{27}$ In a different letter, Landes wondered about why Johnson was opposed to Brown v. Board of Education. She had read an article Johnson had written in the New York Times Magazine in which he had explained his position related to the "recalcitrance of local whites" (Landes 1986e). Landes explained that Johnson emphasized education for all Americans, not just "Negroes" in "A Southern Negro's View of the South" published September 23, 1956 (Johnson 1957). From reading his 1956 article, it seems he was not opposed to the Court's 1954 decision, but instead, described Southern whites' resistance to desegregation and whites' refusal to comply with the Court's decision (5).

Additionally, he did not believe in "gradual" or "cautious" integration (Johnson 1957:78).

${ }^{28}$ Rüdiger Bilden was a German (non-Jewish) immigrant and an "expert" on race in Brazil who exchanged ideas with his Brazilian, Columbia University friend Gilberto Freyre. Through a 1929 article called "Brazil: A Laboratory for Civilization," Rüdiger Bilden provided many of the foundational ideas upon which Gilberto Freyre based his book Casa Grande e Senzala in 1933 (Pallares-Burke 2012:349-50). Bilden knew about Landes' relationship with black physicist Elmer Imes at Fisk because Bilden informally trained Landes in New York and at Fisk before she went to Brazil (Yelvington 2006:74). 
(Bilden 1937; Yelvington 2006:74). Bilden wrote to Herskovits regarding Bilden's negative opinion of Landes, based on his contact with her at Fisk: "Landes is a damn fool and a disgrace to the Department of Anthrop. As far as I can see, she has done little or no Brazilian preparation here or anything else, except getting herself sexually involved with colored members of the faculty. Sex seems to be her forte, particularly in its practical aspects..." (Bilden 1937). This letter provides outside corroboration that Landes was possibly (rumored to be) involved with at least one black faculty member at Fisk, in addition to revealing the sexualized and racialized gossip spread about Landes by an "old white boys network" that negatively impacted her career.

This example demonstrates the importance of a mixed method approach, incorporating both footnote tracing and interviews with other scholars, in order to narrow archival searches but also to strengthen the relevance of and highlight specific archival materials for future debate. Also, my conversations with Nava, Perkins and Mickens demonstrate how important the interview/consultation method is for developing and maintaining an approach of doubt or disbelief toward historical figures, which pushed me to seek out different primary sources in order to answer the questions that had been posed in the interviews.

\section{Approaches to Data Analysis}

I selected my modes of data analysis based upon three methodological problems with many histories of social science. 


\section{Grounded theory methodology: Textual analysis for themes}

The first methodological problem is that historians of social science tend not to use a systematic textual analysis process to find themes. Instead their depictions of social scientists are more descriptive or explanatory than analytical of the meanings of the women's written texts (Broschart 2005; Goodwin and O’Connor 2015). For example, Kay Richards Broschart (2005) provides brief biographical information and summaries of the "sociological contributions" of each of the Southern foremothers of sociology, who were all Black women. Broschart states that Ida B. Wells-Barnett was a leader for "Black civil rights and woman's suffrage" without providing excerpts from Wells-Barnett's body of work that would reveal how she integrated race and gender in her sociological analyses (Broschart 2005:63).

John Goodwin and Henrietta O’Connor (2015) profile the methodological innovations, which would later be called "feminist," of Pearl Jephcott, a British woman sociologist who studied themes of youth, class, gender, and race in Britain in the 1940s1970s (Goodwin and O’Connor 2015:144-145, 150). Jephcott commissioned visual data like photographs and drawings and asked respondents to write their autobiographies, which she included in her books (Goodwin and O'Connor 2015:144, 147-48). The authors state that they collected Jephcott's material from various archives, but the citations include only Jephcott's published work. The structure of the paper follows a common pattern for histories of women social scientists: her biography, innovative methodology, research focus, and academic marginalization. Goodwin and O'Connor use quotations from Jephcott's work, but only to serve their argument about her methodological innovation, rather than to analyze the themes evoked through her word 
selection. For example they quote from Jephcott's published book, A Troubled Area:

Notes on Notting Hill (1964), “"though the unfamiliar colour of their skin causes them to be classed together, they are far from being a group racially or socially"' but their explication of the quote is that her statement reveals how she was "ahead of her time" in regards to the debates about "difference" in Britain; she thought in terms of heterogeneity within groups, while homogeneity within groups was the dominant assumption (Goodwin and O'Connor 2015:150; Jephcott 1964:80). The authors do not provide an in-depth analysis of what Jephcott might have meant by her statement, how she came to that conclusion, how she felt about her findings or how her assessment of heterogeneity within racial groups might have related to her reflections on her own positionality.

Goodwin and O'Conner completely omitted Jephcott's reliance upon predominant stereotypes about West Indian women, that were common among social science writers at that time in England (which Ruth Glass did not employ). Thus, Jephcott was the opposite of "ahead of her time" since her approach epitomized that of many social science writers of her time. For example, Jephcott mobilized images of unmarried West Indian mothers, with various children with different fathers, who relied upon the national assistance programs to care for their children, and who refused to marry the fathers of their children (90-92). Jephcott also reproduced racist and classist accusations against West Indian residents in Notting Dale such as:

There are authenticated tales of migrant landlords who, to drive out a white tenant, have smeared feces on a door handle, thrown sanitary towels from an upper window into the white tenant's yard, and deliberately allowed water to overflow. Unpleasant habits which most English working-class families have now discarded- filthy dust bins, blocked lavatories, spitting-may still seem pernickerty matters to up-country Caribbean villagers (91). 
Thus, an in-depth analysis of themes based upon word choice is an essential methodological approach to analysis of histories of social science. Without this kind of approach, important aspects of a writer's theorizing would be glossed over or invisibilized and false conclusions could be made about a researcher's "forward thinking."

Grounded theory methodology (GTM) is not typically used with historical data but it served my goal by focusing on author's word selections and analogies. GTM allows the researcher to alter her focus based upon emerging themes from the spoken or written articulations of subjects (Brondo et al. 2009; Maor 2012). Maya Maor explains her iterative grounded theory process in her interviews with Jewish-Israeli self-identified fat women: "I noticed that when participants recall their experiences related to fat identity, they talk about their relationships with their mothers and their daughters" (100). Grounded theory caused her to reassess her research focus, to "conceptualize motherdaughter relationship as the organizing theme of the study" (100). One of the quotes that Maor uses reveals how girls learn from their mothers how to relate to their bodies and the connection between a "flawed self and body": "I remember [that] as a really young child... she [used to] stand naked in front of the mirror before getting dressed and was disgusted at herself and her body because she had put on weight" (102). Grounded theory methodology permits entry into subjective experience through close analysis of what and how historical subjects wrote. 
Brief examples of my application of grounded theory methodology

While conducting data collection with Ellen Hellmann's materials, the word "civilization" seemed to predominate. This became especially clear and troubling for me when I read about her advocacy of the qualified franchise, one of the principle tenets of Hellmann's Progressive Party: "to enable suitably qualified citizens of a defined degree of civilisation belonging to any population group to participate in the government of the country..." (Party 1959). Coinciding with this theme of "civilization" was her use of the dichotomy between "European" (whites) and "non-European"/“African"/“native.” She never used the word "African" to describe white South Africans. She maintained that South Africa needed both the "initiative and resourcefulness of the European and the labour of the Non-European" (Hellmann 1948a:9). Though she thought that Europeans depended on African labor, she clearly posited that they had different capabilities, and that Europeans provided the intelligence while Non-Europeans provided the physical power. Though she claimed to not believe in separate development advocated by the Afrikaner government, she did contend that white and black groups were physically and socially distinct. "I am not concerned with social Jim Crowism...No one disputes that European and African will remain physically separate racial groups" (Hellmann 1956:4).

While reading the creative writing of Hilda Kuper a theme that emerged was her portrayal of women as the primary victims (through death or exile) of gender and racial inequalities. Women's lives were the ones taken because of the hierarchies and the obligations of both patriarchal families and racist colonialism. As I will discuss in Chapter 4, Hilda's main characters were exiled because of witchcraft assumptions, rejected as marriage partners because of interracial relationships, developed venereal 
infections and died, sometimes by suicide. After reading multiple stories in which the main female character died or was exiled, the "women as victims" theme became extremely apparent.

\section{Coding}

The coding process began by taking extensive notes in a word document on the archive I was working with, noting the collection, the box and folder number. I also took photographs and eventually used a scanning app I downloaded on my phone called "Handyscan" making sure to correctly label images by collection, box and folder number. (I learned these skills from the Smithsonian Institute in Museum Anthropology, directed by Candace Greene). I added to these notes every day I was at the archive, highlighting or bold printing words or phrases that stood out to me as recurring themes or "codes." I used these themes when writing the "Interim Reports" I submitted to the Ruth Landes Memorial Fund, administered by the Reed Foundation. I applied "open" or "eclectic" coding (Saldaña 2013: 188) to the primary source materials written/collected by the core women. "Eclectic" refers to the use of multiple types of coding at once.

"Structural coding" applies conceptual phrases related to the research question in order to categorize data and examine relationships (Saldaña 2013:84). I used this type of coding when I looked for words like "Jewish," or "Zionism" in the archives. The results of "structural coding" can be seen in the Introduction when I discuss Zionism and Jewish subjectivity. "Matrix coding" finds pieces of text that have been coded for multiple (overlapping) "nodes" or key themes. This type of coding could also be considered "word co-occurrence" (Ryan and Bernard 2003:97). I used this type of coding with the materials 
relating to Ellen Hellmann to find articles in which she talked about both Jewish and black communities in order to compare her perspectives. This led to my conclusion that while she believed in self-promotion and protection of the Jewish community in order to guarantee access to white citizenship rights, she expressed antipathy toward black selfpromotion and protection through black consciousness ideologies such as "black identity" or "Black is beautiful."

"Emotion coding" tracks "emotional journ[ies]" and establishes contextual effects on emotional intensity (Saldaña 2013: 107-108). This type of coding was useful when I encountered emotions such as anger, for example, in a 1975 letter from Louise Nocktonick to Ruth Landes after the publication of Landes' Prairie Potawatomi (1970). Ruth and Louise reunited in 1964, thirty years after Landes' initial research in Mayetta, Kansas (see Figure 24). ${ }^{29}$ Louise felt betrayed because Landes had included what Louise considered "private" letters in the text of her book without Louise's permission. Landes' book caused Louise to be ostracized from her community because other Potawatomi accused her of being a gossip (Nocktonick and Landes 1975). Landes did tell Louise in 1957 that she was going to be working on a book but not that she would be using Louise's exact words and Louise's name (Landes 1957).

\footnotetext{
${ }^{29}$ Handwritten on verso of this photograph by Landes: "30 yrs later. July 1964. (Potawatomi) Pow-wow on Fair Grounds on Pot. reservation, Mayetta, Kansas. taken by Jas A. Clifton, Anthro Dept, Univ. of Kans. Louise Nocktonick, Ruth Landes (great hair). IV" landes_photo_ruth_landes_15, Box 63, Ruth Landes Papers
} 


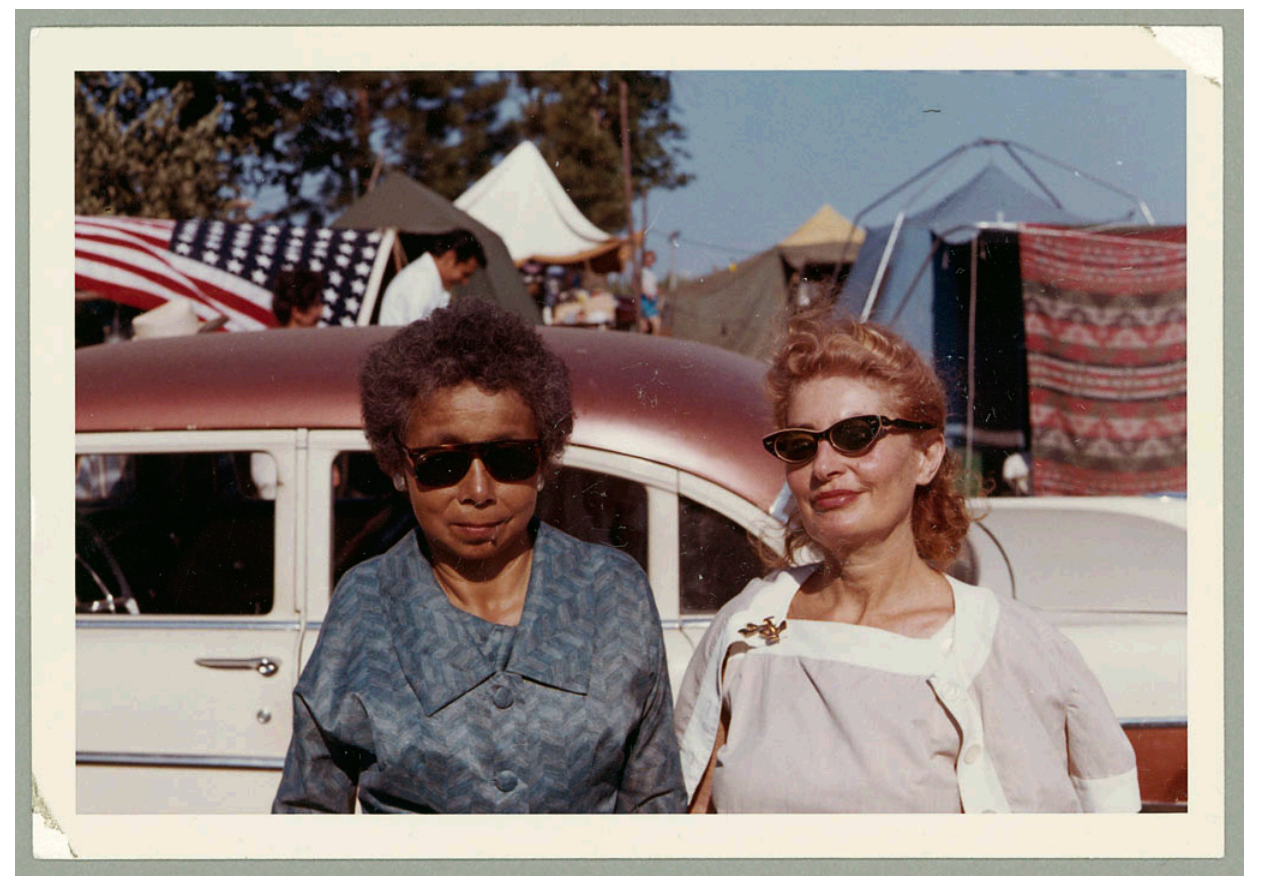

Figure 24. Ruth Landes with Louise (Masha/Mazhi) Nocktonick, one of her informants during her 1935 and 1936 fieldwork among the Prairie Potawatomi in Mayetta Kansas.

"Magnitude coding" assesses intensity, frequency, or direction (Saldaña 2013:72).

I utilized this type of coding when I summed the number of letters from different correspondents in order to judge closeness in relationships. For example, I counted 50 letters from Sally Chilver, Landes' colleague and close friend in Britain. The only other people who wrote her so many letters (at least that she kept and that I read) were her parents and Edison Carneiro (who wrote 62 letters). Some of the people she was least close to based upon letters received were Monica Wilson (only 3 letters), Eileen Krige (4 letters) and Ellen Hellmann (6 letters), also women who Landes expressed antipathy toward in letters she wrote to Audrey Richards (Landes 1970c). 
I also judged intensity by the quantitative use of emotionally intense words, which could be divided into either a positive or a negative charge, or a combination of both. I also noted emotionally neutral words. Then I could sum the numbers of each type in a letter. This gave me a sense for the intimacy between correspondents, the amount of "professional" formality or even hostility between them. For example, in a letter to Audrey Richards, Landes critiqued Monica Wilson for her tunnel-vision patronage of "her tribal societies" and Eileen Krige for not speaking Afrikaans or discussing Afrikaans matters (Landes 1970c).

"Versus coding" contrasts emotions and "values coding" explicates participants' worldviews (Saldaña 2013: 108, 110-111, 115). I incorporated "versus coding" when comparing the emotional tone of letters between Hilda Kuper and her students, Beth Rosen-Prinz and Teresa Thoko Ginindza. Based on the types of words used, I found that Beth seemed emotionally closer to Hilda, while Thoko maintained a professional distance. For example, in December 1972, Beth wrote from Swaziland to Hilda to express her sadness to hear of Hilda's sister's death "I know how close you were to her and how difficult it can be to 'carry on.' My love flies to you to comfort you as much as possible" (Rosen-Prinz 1972). In contrast, in a letter from Thoko to Hilda in November 1973, Thoko expressed frustration that Hilda had told others in Swaziland that she had not been doing the work that she had in fact been doing. "I am very upset to be told that I haven't done the work when I have tried my best to do it" - the issue was that Thoko's work was not arriving in time by mail (Ginindza 1973). In my interview with Beth she explained that she considered Hilda to be like her mother, thus supporting the evaluation I made based upon their letters (Rosen-Prinz and Gondek 2016). 
I employed "values coding” when I assessed Ellen Hellmann's judgments toward unmarried black mothers in Johannesburg. Hellmann's “moralizing” can be detected within her analysis of the "instability" of home life and her negative evaluation of the "veritable progression of fathers" as women went from one relationship to the next (Hellmann 1940e:14). Words like "veritable progression," "laxness of sexual morality" and "instability," connote value judgments.

"Evaluation coding" can assess how scholars interpret the significance of each other's work (Saldaña 2013:119-121). Keewaydinoquay (Kee) Peschel, a medicine woman, an ethnobotanist, and a teacher of anishinaabe knowledge, made sure that Landes knew that she liked her even if Kee disliked what Landes had written about "us." Kee wrote: "First off, when I met you, I liked you right away" which actually surprised Kee since "I had not liked very much some of the things you had written about us-even if they were true!" Kee liked and admired Landes because Landes knew "so much about my people and my religion" and also because "I recognized your particular brand of loneliness only too well" (Peschel 1978). This form of coding enabled me to determine how each woman assessed the work of other women scholars in her network.

"Longitudinal coding" can track the theory development timeline within the network (Saldaña 2013:209, 236-237). I used this type of coding, when I tracked Teresa Thoko Ginindza's influence on Hilda Kuper's writing about Swazi adornment. Thus, longitudinal coding allowed me to track chronological trajectories of influence. 
Memo-writing

In addition to coding, I engaged in reflective and analytical memo writing.

Reflective memos revealed how meanings emerged from my subjective interactions with archival documents and ethnographic objects (Sanjek 1990:108). Typically, I wrote reflective memos within the notes I took for each archival visit. I marked these reflections upon my subjective reactions using brackets. Other times, these reflections emerged within the "Interim Reports" I sent to the Ruth Landes Memorial Fund. For example, in my report (May 2017) on my research with the collections related to Ellen Hellmann, I wrote:

The negative evaluations made by Ellen Hellmann and Vera D. Rubin regarding female-headed households upset me deeply and I wondered why Ruth Landes approached female-led families so differently. My point of view is definitely affected by the fact that I grew up with a strong Jewish mother, who often repeated the mantra: 'never depend on a man for anything.' This was important to her because her mother, my Nana Nessa (b. 1935), married very young, never had a career, and mentally fell apart after her divorce from my grandfather, Papa Larry, when my mother was in college... Because of the kind of family, I grew up in, I bristle at the type of hetero-sexist principles that Hellmann and Rubin promoted, that valued women as stay-at-home mothers as an ideal or that critiqued strong women figures as deviant, because they supposedly raised underdeveloped men.

I used analytical memos to connect emerging themes or "codes" to craft an "evolving theoretical scheme" (Emerson, Fretz, and Shaw 1995:143; Saldaña 2013:190, 206; Strauss and Corbin 1998). Writing the interim reports I submitted to the Ruth Landes Memorial Fund required me to sift through the data I collected, organize it into themes, which connected to my initial three fields of analysis - internal colonization, women's networks, and Jewish subjectivity. These reports also triggered the reconsideration of my 
initial hypotheses as new theoretical schemas began to emerge based upon the new data I encountered in the various archives.

\section{Historical Social Network Analysis}

The second methodological problem is that histories of social science (because of the influence of historical methodologies) tell linear, biographical narratives that do not evoke enough relational comparisons or network interactions (Franzosi and Mohr 1997:143, 145). Historical social network analysis permits a complex non-linear representation of social life that is constructed based upon relationships and focuses on "broader social institutions" rather than solely the mindset of individuals (Franzosi and Mohr 1997:143-48). Bonnie Erickson explains that historical social network analysis has tended towards "whole network" approaches that are more comprehensive and structural than “ego-centric network” approaches (Erickson 1997:150-51). Charles Wetherell (1998) explicates that historians have tended not to use social network analysis because they are unfamiliar with social science methods including quantitative methods (125). Ego-centric network analysis requires diaries and personal correspondence and has not yet been used in a systematic way to track "affection and social support" (Wetherell 1998:130). I intervene in this literature by using ego-centric network analysis that tracks affective connections, which I argue are simultaneously "structural."

Social network analysis (SNA) enables "multi-modal” inquiry investigating relationships between individuals and social structure at simultaneous levels (Hanneman and Riddle 2005:5). SNA is a way to implement Vrushali Patil's historical feminist sociological concept of "webbed connectivities," to analyze how "cross-border colonial 
...circuits ... shape racialized notions of sex, gender and sexuality” (Patil 2016). I apply her concept by analyzing how colonial "connectivities" influenced the formulation of Jewish women's theorizing of race, gender and sexuality but also their own conceptions of their raced, gender and sexualized subjectivities. Social network analysis allowed me to visualize the structure of the network, and quantitatively track the frequency, intensity, and content of the relationships between individuals (Hanneman and Riddle 2005:37-44), but also between individuals, organizations and nation-states. I utilized a web-based data management, network analysis \& visualization environment called "nodegoat" in order to both geographically and chronologically represent these network relationships.

\section{Affective entanglements and their theoretical effects}

The third methodological problem is that historians of social science do not analyze their affective entanglements with the archival materials/ethnographic collections of their subjects and the subsequent impact upon their theory generation (Cole 2003; French 2005; Bell 2009; Hviding and Berg 2014; Stocking 1992; da Cunha 2006; Stoler 2009). Archival documents and ethnographic objects in the hands of researchers are often seen as passive and inert material. This approach neglects the political agency of nonhuman things (Bennett 2010; Latour 1990) and the power of human-nonhuman entanglements in knowledge production (Hodder 2014). Scholars who write about the process of archive creation focus on telling the story of the historical figure's life, research trajectory or the intentional archival interventions this historical figure made by citing data from the archive (da Cunha 2006; Stoler 2009). Even if the writer knew the historical figure personally, the tendency is to describe the historical anthropologist's 
biography or research trajectory without a focus on the writer's own affective experiences (Brettell 1997; Scheper-Hughes 1991). These writers rarely talk about their embodied experience with specific items in the archive or with the archive as a whole and how this impacted the theoretical conclusions they reached. If researchers discuss their affective experiences with archives, it tends to be generalized, so that the text describes the "universal" experience of archival work. Also these texts may center on governmental archives, not personal papers of individual social scientists (Farge 2013; Steedman 2002). These works do not investigate how the subjectivity of the researcher impacts the relationship with the archival materials. If co-production of knowledge and positionality is so imperative in ethnographic studies with other humans (Harden 2011; Schumaker 2001), why do these issues cease to be important when conducting archival or museum work? My method intervenes in this theoretical gap because I analyze my relationships with the objects (archival materials) and how this influenced my theoretical emphases and findings.

During preliminary research in Summer 2014 with the Ruth Landes Papers and ethnographic object collection amassed during her fifty-year career in anthropology (1930s-1980s), I experienced a sense of “reciprocal obligation," a need to find Landes' lost objects, an embodied approach, and a personal interest in why Landes wrote several versions of a fictionalized ethnographic memoir about her research and teaching at Fisk University (1937-1938). Each of her things brought me closer to the historical moment in which she created or collected it (Gordon 2006; Sillar 2009). This "embodied approach" is informed by the idea that people, places and things remain in communication even after physical separation, creating an ongoing commitment to care for each other (Sillar 
2009). Beverly Gordon (2006) demonstrates how social location (gender) impacts the objects one is drawn to, how one interacts with them and what about the object one is most interested in understanding. I intervene in Gordon's approach by analyzing how my racialized Jewishness, sexuality, national origin in addition to my gender identity influenced my interface with archival materials and ethnographic objects. Reflexivity about my own subjectivity and my affective engagement with each woman's archival materials, enables a simultaneous empathy and critique of each woman's theories and methods, as if she were a colleague I was constructively evaluating "face to face," rather than looking up or down at her (Narayan 1997:156).

I'll provide a few examples of this here. My different affective reaction to Ruth Landes and her materials compared to any of the other women in this study is a result of several factors. First, as has already been mentioned, Landes kept her personal letters in the papers she donated to the National Anthropological Archives. For example, during the time that Landes lived in Claremont, California and was married to Ignacio L. López, her mother, Anna Schlossberg, in April 1959, wrote both criticism of Landes' appearance and a warning about Ignacio's domestic violence. "Actually you are in the prime of life, please don't forget that. You are beautiful, even your good friend [RL wrote "Ignacio" in pencil above this] knows it, and don't spoil your looks by neglecting your appearance... There is no need of going around with a greasy face all the time..." (A. Schlossberg 1959b:2). Then Anna recounted a story of domestic abuse, in which a wellknown Amalgamated Clothing Workers official, Mr. [Joseph] Salerno, an Italian immigrant, "an intellectual ... and a big shot," beat his Jewish wife almost to the point of death. Anna said she was telling this story because of her own memories and Ruth wrote 
"of Ignacio" in pencil above. Anna continued "to hell with these people who haven't the decency to control their tempers. Don't be a naïve child and know they never change..." (3-5). The inclusion of personal letters in Landes' archive allows researchers access to intimate aspects of her subjectivity that are not available in the archives of the other women under investigation. Subsequently, I felt closer to Ruth Landes and was able to get a more in depth understanding of her perspectives and the possible explanations for her positions. I felt empathy with her experiences because my mom has also been critical of my appearance and oftentimes expressed concern about my interracial relationships.

Similarly, Edison Carneiro's love letters to Ruth Landes reminded me of Jair's quixotic words (like Edison, Jair is Afro-Brazilian). On June 8, 1939 Edison wrote:

In these ten months we lived together, working and amusing ourselves I learnt to love you and to appreciate your qualities: you are the woman I want. In a book I gave to you (you left it with me again) I wrote these Castro Alves' verses: 'Teu amor na treva é um astro, no silencio - uma canção...' [translation: Your love in the darkness is a star, in the silence, a song] We quarreled all the time, it's true, but if it happened it was not my fault: always I was not sure about you, because we were in an uncivilized country. You told me sometimes about my cruelty. You were not right. It was my love always protecting and guarding you -but probably you did not know it except its tyrannical form. Pardon me and my crazy love. You know I like to work with you, and except when you're asking and asking me, I like to take contact with your clear intelligence...(Carneiro 1939b)

Just as Jair has had a profound impact on my academic and professional interests, Edison and Landes maintained a life-long correspondence (28 letters between 1938-40, 8 letters between 1946-51, and 22 letters between 1961-72) until Edison's death in 1972. Landes returned to Brazil in 1966; he translated and edited the Portuguese version of her book, Cidade das Mulheres, and got it published in Brazil in 1967 (Carneiro 1968). 
Thirdly, Landes wrote in the margins of her letters, as if to explain their contents to a future reader, drawing the researcher closer and into the midst of Landes' stories. Her insertions of "Ignacio" as discussed above, are an example of this strategy that positions Landes as storyteller and me as her audience as co-participants in a dialogue (Sparkes 2002:210,218). My role as a "reader" of her archive is as important as her role as teller, because she envisioned her archive as being read, seen and re-told (da Cunha 2004). Landes' marginalia in a letter from Anna Schlossberg alerted me to the conflict between Landes and Hellmann (Schlossberg 1970). Her frequent insertions of "Ignacio" in the margins of letters she received from her parents helped to clarify her marital problems with her second husband, Ignacio López, as well as his alcoholism and abuse (A. Schlossberg and Schlossberg 1959; Schlossberg and Schlossberg 1958a). Her mother's tone in the letters that refer to Ignacio reminded me of my mother's disapproval of my marriage to an Afro-Caribbean musician, Cotter Hamilton (pseudonym), from 20102015. When Cotter had a manic episode, was forcibly hospitalized and diagnosed with bipolar disorder in 2012 during a visit to my family in California, my parents confronted me, telling me I should get divorced immediately. I could not help but think of my relationship with Cotter when I read Landes' holiday card to her friend Luz in 1958: "Ignacio has behaved atrociously again after I'd built up hopes of his learning better...I am relieved to be alone again. He needs attention - psychiatric? Severely...He's in quite a bad way and soon he will be 51 . Why does he hate so? He seems to detest his own self" (Landes 1958). Anna Schlosberg wrote to her daughter in July 1959: "your description of Ignacio's condition is pathetic. I had a suspicion for a long time that he is mentally sick. I think you will be lucky to get out of this mess whole" (J. Schlossberg and Schlossberg 
1959). Landes underlined the phrase above, another instance of her marking up or commenting upon the content of letters for future readers.

These three methodological concerns with typical histories of social scientists justify my use of grounded theory methodology, social network analysis and a reflexive approach to my engagement with archival materials. 
CHAPTER 2 DE YEKE, ELLEN HELLMANN: GERMAN JEWISH BELONGING IN

WHITENESS, AND MORALISTIC REPRESENTATIONS OF BLACK WOMEN'S

SEXUALITY IN JOHANNESBURG

"When the others [Eastern Jews] were in prison we used to call them the non-Europeans (laughing), because they shared so many of the traits with the non- Europeans, they were unpunctual, they couldn't keep to time, they exaggerated, well I mean this was goodnatured, not malicious, but we were very aware of the difference between us. They called me a 'yeke,' which wasn't a complimentary term." -Ellen Hellmann, in an interview with Riva Krut, 1982

Part I: Jewish family backgrounds and Jewish subjectivity in relation to whiteness/blackness

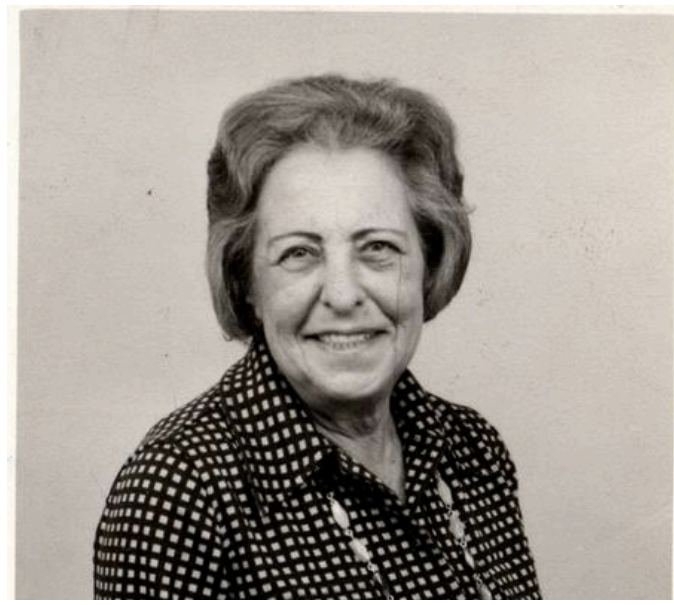

Figure 25. Ellen Hellmann, undated. Ellen Hellmann Papers, Subseries 8.3, Personal File, Historical Papers Archive, University of Witwatersrand, ZA HPRA A1419-8-8.3

Ellen Hellmann (1908-1982) was a public anthropologist and a public servant, a leader in the Progressive Party (1959-71), South African Institute of Race Relations 
(1932-74), and Johannesburg Joint Council of Europeans and Africans (1940-48); her research attempted to improve the basic living conditions of "African"/“NonEuropean"/"native" people (Figure 25). Thus, rather than directly attacking the structural foundations of racism and classism within the apartheid system, she focused on social services to ameliorate but not radically alter "non-European" status, such as food, housing, health care, education and transportation.

Hellmann was a leader of the German Jewish community in Johannesburg, which viewed itself as superior to, and more "civilized" than "Eastern Jews" which they associated with "Non-Europeans." She identified with the white South African community and she took a philanthropic/social reform approach to working with black communities, utilizing a paternalistic and moralizing tone, motivated by an obligation she felt to help those whom she perceived to be less privileged.

Her work with the Jewish community from 1933-1950 (Zionist Socialists, then the Jewish Board of Deputies) emerged with the rise of Hitlerism and her sense of "guilt" that she was not working with her "own people." While she believed in self-promotion and protection of the Jewish community in order to guarantee access to white citizenship rights, she expressed antipathy toward black self-promotion and protection through black consciousness ideologies such as "black identity" or "Black is beautiful." She advocated African assimilation into Western and white modes of behavior.

Even if Hellmann's work might have seemed "radical" in the 1930s because of the general lack of concern with black communities, by the 1970 s, she was perceived by younger anti-apartheid activists as "ultra conservative" and part of the "old guard" at the 
South African Institute of Race Relations. In her desire to create one "South African community" she actually hindered black agency, pride and self-preservation/promotion.

\section{Ellen Hellmann's German Jewish Family}

Ellen Hellmann grew up "well off" as part of the "privileged minority" (Hellmann and Krut 1982:2). She was born in August 1908, in Berea, a wealthy suburb of Johannesburg. Her father, Bernard Kaumheimer (b. 1878), was an extremely poor sixteen-year-old orphan immigrant from a town near Nunberg, Germany and worked with Johannesburg cousins in the retail industry, upon his arrival in 1894. Hellmann explained that though she did not know much about her father's background, she knew that his family had been "small traders," and that her father had not had much schooling. She remembered he used to remark how lucky she and her sister were to be able to eat an egg every day, since he got one egg, only once a year at his birthday (Hellmann and Krut 1982:3-4). Ruth Runciman, Ellen's daughter, added that her grandfather, Bernard Kaumheimer had been a "messenger boy on a donkey" (Gondek and Runciman 2018).

After twelve years of acquiring enough funds, he followed the custom among German Jews and returned to Germany to find a wife. Chlothilde Theilheimer was his "exceptionally beautiful" selection, and her parents were "terribly opposed" to her "marrying down" and they feared Africa, which they perceived as a "wild place" (Bank

2016:109-110). ${ }^{30}$ Hellmann further explained (which was not typed into the transcript)

\footnotetext{
${ }^{30}$ Interestingly, in the interview transcript between Hellmann and Riva Krut, the sentence is typed as "they kept telling her it was not necessary to go to this one-eyed place, Africa" (1982:1). But after listening to the actual interview recording, it sounds to me more like
} 
that her grandparents were in a "line of 'petit-bourgeoisie,' certainly not from a posherline than that...they were not very well up on things... who knew anything about South Africa in nineteen hundred and six?" (Hellmann and Krut 1982:1). Hellmann's mother received restitution after WWII because of the confiscation of her father's (Ellen's grandfather's) farm property in Munich (Graczyk, Heimrath, and Eisen 2013; Online 2015).

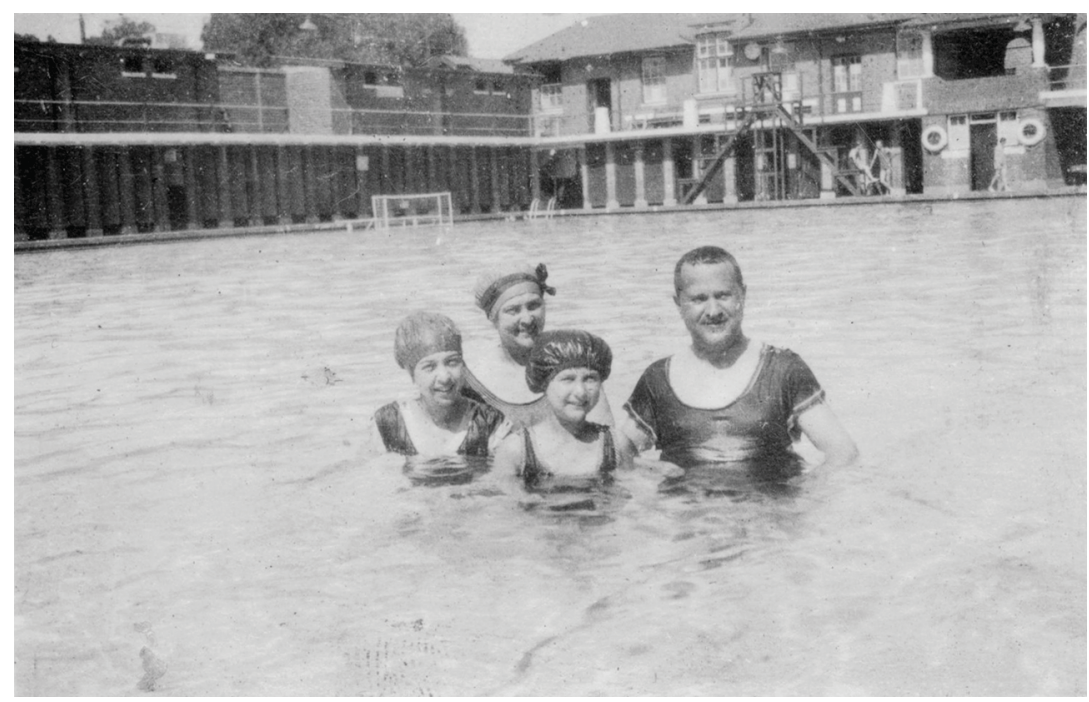

Figure 26. Ellen Hellmann family photograph at a public swimming pool in Johannesburg. Bernard and Chlothilde Kaumheimer with their daughters, Ellen (left, aged 14) and Inez (right, aged 10), Ellen Hellmann Papers, Historical Papers Archive, University of Witwatersrand, Series 8.1.2, Item 7, ZA HPRA A1419-8-8.1-8.1.2-7

Thus, Ellen grew up in a materially privileged environment (Figure 26) with a sense of the major class differences between her parents, at least in the beginning of their relationship. She also had a sense that she was living in a supposedly "way-out" place, South Africa, viewed by her maternal relatives as wild, since as she said in her interview with Riva Krut, her maternal grandparents worried that her mother would be "mauled by

\footnotetext{
"way out place, Africa." Andrew Bank interpreted this part of the recording as "wild place."
} 
tigers or lions" (2). Upon seeing the house where Ellen lived, it becomes extremely ironic that Ellen's maternal grandparents thought of Africa as a "way out" place considering the opulence of Hellmann's upbringing and adult living environment. This house is a heritage site in Johannesburg that Swiss architect Theophile Schaerer built for Ellen's father, Bernard Kaumheimer, in 1936. In a letter from Hellmann to Ruth Landes in December 1956, Ellen said that she and her husband sold their "small, but rather charming home" [in Dunkeld] and moved into "the parental mansion so that my Mother could keep the home she likes and the occupations of looking after it which she needs now more than ever" (Hellmann 1968). Ellen lived there between 1946-7, since she listed her address at 14 First Ave. Lower Houghton, in the Joint Council of Europeans and Africans materials in 1946 (Africans 1946). Runciman verified that she lived with her mother and grandparents at 14 First Ave. during this brief period (1946-47) and then again after her grandfather's death in 1956.

"A Stubborn Little Girl"

Hellmann described her parents as very strict, in the Victorian style. She and her father, Bernard Kaumheimer, fought constantly. While her parents thought children should be seen and not heard, Hellmann remarked, "I said argument was the spice of life" and "I was a very, very stubborn little girl, very difficult." Her father favored Ellen's younger sister, Inez [Gordon], causing Ellen to feel like "simply the ugly duckling in this family of lovely girls" (Hellmann and Krut 1982:2). Her father remarked, “I don't know how you come into this family of beautiful women" (Bank 2016:110). At the end of her life, Ellen remarked that her father had once asked her "why do all my friends think 
you're such a communist?" Yet at the same time, Ellen's daughter had told her she was too much of a "liberal" and not radical enough (Schwartz 1981). Pat Schwartz remarked that Hellmann was known for her steadfastness to "unpopular views." At one time, she was a young person critiquing her elders, but by 1981 , Hellmann remarked that the young people were "looking down" at her; but she insisted that she just could not agree with their perspectives. ${ }^{31}$ Hellmann's experience with her father could be at least a partial explanation for why she was so opposed to a strict disciplinarian style of parenting, especially on the part of fathers. She argued it was the sternness of African parents in the urban setting that was to blame for young people's disobedience (Hellmann 1940e:10).

${ }^{31}$ This statement reminded me of Hellmann's views regarding the Schlebusch Commission's request that the SAIRR provide testimony in the apartheid government's investigation into interracial organizations. Her public reflection on the Schlebusch Commission in a report she submitted to the SAIRR stated: "As an avowed member of the 'Old Guard' in the Institute, and as one who would have been only too glad to be subpoena-ed by the Commission to give evidence and thereby be afforded the opportunity to set out what prompted me to give forty years of service to this particular institution and why I consider its work of national value, I am unregenerate in my belief that we need the accession of younger members of differing viewpoints if that fruitful tension created by opposing views sincerely held is to be maintained. For without this, the danger of becoming static and sterile is great" (Hellmann 1974:2). One of the young resistors to the "old guard" within the SAIRR was Clive Nettleton, who was the leader of the Institute's youth program. He pointed out that because the SAIRR was dominated by “...white, middle class, academic values it cannot hope to attract either young or black people in any significant way... there is more to the elimination of prejudice and discrimination than objective fact finding..." Nettleton argued that there were few black people involved in the IRR because the Institute failed to do "anything that is relevant to the needs of black people in their own situations" (Nettleton 1973). In a private letter to H.W. van der Merwe, Hellmann presented her antagonism toward Clive Nettleton: "I must admit a personal bias about Clive - I have for more than two years felt that he is lacking in everyday competence, is woolly-headed, and simply not suitable"; she wanted to force him to resign but she feared that the "articulate minority" who viewed him as a "hero" would stir another "crisis" for the Institute while the majority within the IRR remained silent (Hellmann 1973a). 


\section{I started out through a sense of guilt: Hellmann's involvement in Jewish community}

organizations

Ellen Hellmann's early childhood experiences of discrimination seemed to be more related to her German identity in an anti-German World War I environment than to her Jewishness. She was bullied for being German at the age of six: a group of children forced open her gym dress so she was left "standing in the playground in my bloomers, which in 1914 was a very terrible thing to happen to one. This was a very improper thing." They also taunted her with names like "Hun.” Even though she had relatives fighting on both sides of the war, Ellen felt "very aware that I was different and wrong because I was German” (Bank 2016:110; Hellmann and Krut 1982:1).

Even in the Jewish community in Johannesburg, there was anti-German sentiment during the First World War, when solely the Jews on the non-German side received prayers from the congregation; this led to her family's departure from the Wolmaransstad synagogue. Because of this separation from the synagogue community, Ellen did not grow up being religious, "we had no Jewish religion at all." Though she insisted she knew she was Jewish when she was growing up, she associated her memories of antiSemitism, her assumption of a Jewish identity and her involvement in the Jewish community with Hitler's ascension to power in 1933 (Hellmann and Krut 1982:5-6), when Hellmann was at the University of Witwatersrand, conducting her master's research in Rooiyard, a Johannesburg slum yard (Hellmann 1948c).

I was not too bit interested in the Jewish community, and the only reason I became interested in the Jewish community was the ascension of Hitler, and when Hitler took over Germany, when Hitler came to light, I started feeling guilty. I never wanted to deny that I was Jewish, never, I was Jewish, I knew I was Jewish, but we weren't in the least religious (Hellmann and Krut 1982:5-6). 
There was a sharp rise in public anti-Semitism, anti-communism and segregation in the 1930s in South Africa. The University of Witwatersrand (where both Hellmann and Kuper attended) was one third Jewish, and the eventual apartheid Prime Minister H.F. Verwoerd dubbed Wits "a Jewish university with an appendage of Indian and native students" (Bank 2016:110-113). It is key to note that in the year that Ellen began studying at Wits in 1929, the Afrikaner-dominated National Party defeated the more moderate South African Party, leading to a revitalization of white supremacist ethnic mobilization and racial segregation. Upon winning the election, General Hertzog cut government funds for African Studies (Bank 2016:50).

Hellmann's "sense of guilt" emerged because "You can't only be interested in black people [my emphasis]. Your own people are in trouble and you have got to do something. There was also the anti-Semitism, which worried me very much, not personally, but generally" (Hellmann and Krut 1982:Side B, 13 min 52 sec). Hellmann's father helped refugee German Jews and then Polish Jews (who were fleeing from the Nazis) resettle in South Africa. Both Ellen and her sister, Inez, became involved in this effort. Ellen instilled the importance of maintaining a Jewish religious practice in her daughter, Ruth, who recalled that her mother "urged" her to attend Saturday morning Shabbat services every weekend, until the age of 15 , when Ruth managed to effectively develop a rational argument for why she should be able to cease attendance; however, Ellen and Ruth's grandparents never accompanied her to the synagogue, except if it was a special occasion (Gondek and Runciman 2018). 
$\underline{\text { Spokesperson for "problems" of "Africans"; establishing favorable relation with }}$

Afrikaners by fighting anti-Semitism

Hellmann explained how she became involved in the Jewish Board of Deputies as the representative of the Zionist Socialists (she was a German Jew in a mostly Eastern European Jewish socialist organization), as well as when she stopped her involvement upon the establishment of the State of Israel.

It was only when Hitler came that I became aware of my Jewishness and then I joined Jewish organizations. I joined the Zionist Socialists and then became their representative on the Board of Deputies. In 1948, the moment Israel was safely established, I resigned from the Zionists because ...I could see no reason for having Zionist political parties outside of Israel, since I reckoned that was a function that should play itself out inside Israel; they do it rather excessively! (Hellmann and Krut 1982:Side B, $12 \mathrm{~min} 36 \mathrm{sec}$ )

Then she laughed, giving a hint into what she might have thought about Israel's "excessiveness." Interestingly, her sister Inez became the President of the Women's Zionist Organization of South Africa and eventually immigrated to Israel in the mid1950s (Bank 2016:137). Ruth Runciman confirmed that Ellen was at least "slightly less" enthusiastic and more "skeptical" of Zionism and the state of Israel than her sister, Inez, especially once Israel became a "passionately nationalistic state." However, their views were not vastly different, and the sisters were "very close" and lived right next to each other on Tyson Road in Parkview, a northern well-off neighborhood in Johannesburg. Garry Runciman, Ruth Runciman's husband, and a Cambridge historical sociologist, wrote of Ellen: "Her reservations about Zionism were not in contradiction with pride in her Jewishness" (March 7, 2018). 
Ellen's work with the Jewish Board of Deputies and other Jewish organizations involved being a spokesperson for the "problems" of "Africans" in South Africa. ${ }^{32}$ One of her central concerns was that "non-Europeans" did not have proper representation in recognized white trade unions. For example, in Pioneer Woman (1945), a publication of the Women's Labor Zionist Organization of America, she explained that though "nonEuropeans" provided South Africa with un-skilled labor, their unions were unrecognized and they lacked political representation (Hellmann 1945e). In 1976 she remarked to the Jewish Board of Deputies that after the 1973 unrest in Durban, black workers could strike but their trade unions still lacked legal status, and blacks were not permitted to join recognized [white] trade unions (Deputies 1976:2). However, she prioritized the Jewish community's need to establish favorable relations with the dominant Afrikaner population by addressing anti-Semitism.

As part of her work on the Public Relations Committee of the Jewish Board of Deputies, Ellen agreed in 1944 to be part of an advisory committee related to the increase of anti-Semitism in South Africa (Deputies 1944). One of the Committee's primary interests was anti-Semitism within "African" (black) communities as well as within the Afrikaner Party. She tried to bring the awareness of the Board of Deputies to "the conditions in which Africans in the Union lived" that led to their anti-European (including anti-Jewish) sentiment. Ellen's comment stemmed from the committee's discussion of the widespread Afrikaner Nationalist Party propaganda that accused Jews

\footnotetext{
${ }^{32}$ Hellmann was an executive member of the South African Jewish Board of Deputies from 1940-1950. She served as the Chairman of the Public Relations Committee of this Board from 1947-1949 (Deputies 1949).
} 
of communist recruitment among black populations. The Jewish Board of Deputies had already protested this type of association between Jews and bolshevism in 1919 which was related to the desire for German Jewish assimilation into white society and distancing from "radical” Eastern European Jews (Shain 1994:88, n. 41). ${ }^{33}$ Hellmann was interested in the actual "racial composition" of the Communist Party membership (Deputies 1945b). Ellen found that anti-Semitism among Africans in the Free State was rising because Africans were refused trading licenses that Jews were allowed (Deputies 1945a).

By 1950, Ellen was part of a sub-committee of the Public Relations Committee regarding "inter-group relations"; however, the PR committee decided that "inter-group relations" would have to "be secondary to our programs specifically directed at the English and Afrikaans-speaking groups." This was because of the "present trend in South African society, which is crystalizing out into distinct racial blocks -English, Afrikaans, Bantu, Coloured and Indian." Hellmann's sub-committee felt that "developing a 'philosophy' of Jewish group identity within the South Africa framework" as well as "inter-cultural education" would have to yield to a greater focus on targeting the Afrikaans-speaking population because of the increasing 'Afrikanerisation' of South African society (Deputies 1950). Thus, rather than Jewish relations with other minority

${ }^{33}$ The link between Jews and bolshevism in South Africa arose because of white South African fear of "rising worker consciousness and socialist rhetoric" that would spread to black workers. The triggers of these suspicions were the Bolshevist Revolution in Russia, the assumed role Jews played in the overthrow of the Tsar in 1917, Russian Jewish immigration to South Africa and the supposed large numbers of Russian Jews who were "mischievous Bolshevist agitators" in 1919 (Shain 1994:78, 83-84). 
groups, the primary target had to be Afrikaners because of their increasing dominance over the British group in South Africa.

In 1951, Hellmann wrote about the pervasive anti-Semitism within the Afrikaner Party, which prevented Jews from membership and published anti-Semitic material in its weekly publication, Die $O B$. Specifically, Ellen mentioned a stereotype of a greedy, capitalistic, cosmopolitan Jewish financier, called the "Hoggenheimer caricature" (Hellmann 1951:9). ${ }^{34}$ Even though Hellmann emphasized anti-Semitism in the Afrikaner party in 1951, by 1953 the Prime Minister, D.F. Malan would praise the "Jewish People" after visiting Israel. Milton Shain and Richard Mendelsohn write that the apartheid government appropriated Jews as whites, "anti-Semitism receded rapidly," and Jews came to have a "rightful and welcome place" (Shain and Mendelsohn 2000:10-11).

\section{De Yeke, The German One: Eastern Jews v. Western Jews and Jewish whiteness in \\ South Africa}

Ellen Hellmann described the divide between Eastern and Western European Jews. Ellen's family, as well as the entire German Jewish community, looked down on

\footnotetext{
${ }^{34}$ The Hoggenheimer caricature emerged in 1903 when Jewish Witwatersrand mining magnates seemed to dominate South African politics and businesses; there was a strong animosity toward immigrant Jews who were seen as a threat to the whiteness of South Africa. The image originated in a London-based musical called "The Girl from Kay's," which parodied an American Jewish financier (Max Hoggenheimer) seduced by a dancer; this character was adapted to the South African context by cartoonist and avid theatergoer D.C. Boonzaier. In 1922, when Jewish mine owners upgraded black workers, white workers rebelled, accusing the Jewish owners of bolshevism. At the same time, Harry Oppenheimer, the anti-apartheid head of the De Beers empire, became associated with the Hoggenheimer stereotype (because of the similarity of their names and economic positions) bolstering the caricature (Brockman 2006; Shain 2016; Shimoni 1996).
} 
Eastern European Jews and felt themselves superior. Hellmann explained to Riva Krut, "It meant that you selected your friends amongst German Jews, you didn't associate much with Eastern Jews...” Hellmann called this separation, "prejudice": "I mean how does prejudice assert itself if you don't have any laws to help you, [especially] in this country..." (Hellmann and Krut 1982:4).

Riva Krut analyzed these German-Russian divisions within the Jewish community in Europe and in South Africa. Western European Jews under the British government were granted emancipatory citizenship rights, but for Russian Jews "secularization was not accompanied by assimilation or acculturation"; thus, for Russian Jews the goal was to create a distinct secular Jewish culture and national autonomy that was separate from and in addition to political, economic and religious freedom. This was different from the acceptance of Western “emancipation” that German Jews desired (Krut 1984:141). Ellen's family began to associate with "Eastern Jews" (as Hellmann called them) when her father became friends with Wulf Uhlman, an Eastern European immigrant who was raising funds to save a Jewish orphanage during Ellen's teen years (Bank 2016:111112). Ellen also came into contact with the Eastern European Jewish community through her "mixed" marriage to a Lithuanian Jewish lawyer, Joseph Hellmann, in 1932 (Bank 2016:113). Ellen explicated, “...one of the troubles, not the sole one, about my first marriage, was that he was an Eastern Jew, [she emphasized the word Eastern] a Jew of 
Eastern Jewish descent" and this was considered "not good" (Hellmann and Krut $1982: 4) .^{35}$

When Ellen worked for the Zionist Socialists in the 1930s, they called her "de yeke" ${ }^{36}$ which Hellmann interpreted as "the German one," another piece of evidence of how the two groups perceived themselves as separate and how she was seen as an outsider within this Eastern European Jewish socialist movement (Hellmann and Krut 1982:5). After she discussed German Jews' sense of their own superiority, she described the white professional preference for "Western Jews": "it would be very difficult for you to describe in action how anti-Semitism displays itself amongst the white community here"; Hellmann believed that employers preferred Western Jews to Eastern Jews, but that firms would never advertise this (Hellmann and Krut 1982:5). ${ }^{37}$

It seems clear that Hellmann saw Western Jews as part of the white group. For example, in a 1970 address to the Union of Jewish Women of South Africa, she stated "within the white community" age distribution and social structure modifications required shifts in community service and that the Union of Jewish Women "perceptively

\footnotetext{
${ }^{35}$ Unfortunately, Ruth Runciman, Ellen's daughter, cannot remember much about her father or her parents' relationship, since she was only 5 when her father, Joseph Hellmann, committed suicide (January 29, 2018 interview).

${ }^{36}$ Yiddish speaking Jews from Eastern Europe used this humorous and slightly derogatory term to refer to German or Western Ashkenazi Jews (Gold 1981:57).

${ }^{37}$ It is unclear (because she did not elucidate what she meant by "white community") if she was referring to internalized anti-Semitism that Western Jewish employers felt toward Eastern Jews, or whether she meant that non-Jewish whites preferred Western Jews since they were more "western."
} 
recognized" this need; to me this triggered the implication that she placed Jews in the realm of the "white community" (Hellmann 1970).

Riva Krut demonstrated how the Jewish bourgeoisie needed to take control of the South African Jewish community away from the Eastern European socialist Zionists in order to establish Jews as part of the South African white and British nationalist movement in the early 1900s; the South African Jewish Board of Deputies (of which Hellmann was an executive member) was part of this effort by middle class Jewish men to establish Jewish assimilation into the whiteness of South African nationalism (Krut 1984:143, 145-46, 148-49). The Jewish Board of Deputies gave itself the role of policing and controlling the "correct" Jewish image projected to the South African public; the Board members were "self-appointed community watchdogs" (Krut 1984: 148, 150-151). A 1905 article in the South African Jewish Chronicle declared, "The raw Russian Jew, is of all Europeans, the one who has the least of the European and the most of the Oriental about him" (Krut 1984:150-151, n. 53) - a sentiment that would be echoed by Ellen Hellmann in her interview with Riva Krut. The Jewish Board of Deputies aimed to “"Anglicize' the 'aliens"” so that all Jews could be considered white South Africans (Krut 1984:151).

Because of Ellen Hellmann's elite class privilege, German-ness, and Westernness, she was not associated with non-Europeans (or Africans) in the way that Eastern European Jews were. Interestingly, lower class, Russian immigrant Jewish women were associated with prostitution and illegal liquor dealing (as black African women were in Ellen Hellmann's writings). The Jewish Board of Deputies in the first decade of the $20^{\text {th }}$ century set up committees to monitor prostitution and liquor dealing cases. They 
scrutinized the arrival of all unaccompanied Jewish women and they publicized liquor cases in which Jews had been "falsely trapped" because Russian Jews did not understand the laws, or because of corrupt police officers. Riva Krut emphasizes that the Board only agreed to help those who were "respectable" and "deserved" their assistance. For example, Krut details the case of Hannah Woolf (1907) who embarrassed the Board when she was found guilty of illegal liquor dealing. The Board wrote to Woolf chastising her: "We exist for the purpose of helping in deserving [my emphasis] cases, not to assist offenders against the Law" (Krut 1984:152, 159, n. 60-62). This emphasis on helping only "respectable" and "deserving" women is echoed in the discussion about women employees in "Native" municipal beer halls from Hellmann's Joint Council for Europeans and Africans. The Council was concerned that the "worst" type of woman (with criminal records) was being employed in the municipal beer halls. The Council requested that the Municipal Native Affairs Department give preference to the employment of "respectable married women" and that they should be paid an "adequate weekly or monthly wage" that would never be "much greater than [wages] which can be earned in domestic service, or the income obtained from washing, since it is undesirable to make the selling of liquor the most profitable employment open to women" (J. C. of E. and Africans 1939).

When discussing her work with the Zionist Socialists in her interview with Riva Krut, Hellmann revealed how Western Jews compared Eastern Jews to non-Europeans (see the quote that began this chapter). She depicted both "Eastern Jews" and "nonEuropeans" as "unpunctual," and "exaggerated" in their mannerisms. She also emphasized that she was an outsider within this group because they called her a "yeke," a 
German, in a primarily Eastern European Jewish organization. Hellmann made a joke out of her comparison of Eastern Jews to non-Europeans, but I find this parallel extremely revealing because it shows how she distanced herself, as other German Jews did, from Eastern European Jews, whom German Jews perceived as being non-European, more similar to Africans, than to Western Jews. ${ }^{38}$

In 1971, Ellen again brought up the hierarchy between Eastern Jews and German Jews through using the term "yekke" and associating "yekkes" with organizational skills that non-Europeans and Eastern Jews supposedly lacked. In her letter to Colin Legum, anti-apartheid journalist, and fellow Zionist, whom she had worked with on the Public Relations Committee of the Jewish Board of Deputies, she wrote: "Remember how you and Louis used to scorn what you called Yekkes in the old days [German Jews, she was one of them]. Well I wish there were a few yekkes floating around in the African community to do the organizational jobs required" (Koch and Legum 1971).

\footnotetext{
${ }^{38}$ The association between Eastern European Jews and "kaffirs" or black non-Europeans in South Africa was commonly used. For example, Jewish South African novelist Nadine Gordimer (b. 1923) fictionalized the experiences of her father, an Eastern European Jew who immigrated to South Africa. He initially identified with black miners who were also migrants like himself, but he was criticized by his wife, a more assimilated Englishspeaking Jew for his uncivilized, supposedly low-class behaviors: sleeping like an animal, "stinking of garlic," rarely bathing. Subsequently, the father character recoils against the association his wife develops between him and the "kaffir"; thus he repeats this oppression when he verbally abuses his black male employee (Davis 2009:49; Leveson 2000:70-71). This internal colonization process occurring within the intimate space of the South African Jewish home reminds me of the 1930s unfinished autobiographical novel Goy Israels by Mina Loy (1882-1966) in which the British Christian mother aims to "colonize the alien attributes" of her Jewish husband and halfJewish children, one of the children being Mina herself (Feinstein 2005:340).
} 


\section{Hellmann's differing approach to Jewish and Black South Africans}

"Ellen was fundamentally conservative in her temperament and attitudes, but both moderately and pragmatically so. She detested apartheid, but was neither a socialist nor an egalitarian." - Garry Runciman, March 7, 2018

Ellen Hellmann's Jewishness was not necessarily a motivation for her work in black South African communities, since her work in black communities was from a "charity" or "philanthropic" approach, and her involvement in the Jewish community evolved afterward with the rise of Nazism from a "sense of guilt" (as she explained in her interview with Riva Krut). Her Jewish communal work was a form of community promotion and protection with the ultimate aim of Jewish assimilation into South African society as a legitimate part of the "white" group. Ellen did not associate herself as a Jew with being similar to black people; in contrast, she perceived herself as being socially obligated to help them since they were an underprivileged group whereas she publicly contended that Jews belonged in the "white" group. This contrasts with my initial hypothesis that the anti-racist and pro-political/economic justice stance taken by Jewish female social scientists was a way to fight anti-Semitism by "remote control," to try to understand their otherness through "the most other" (Berger 2010; Damon 1996; Diner 1995; Lewis 2008, 2013). Hellmann's fight against anti-Semitism was direct (rather than indirect and by "remote control") and separate from her work with black communities. Her social service work with black communities could be conceptualized as an extension of the philanthropic work of certain segments of the Jewish elite community in Johannesburg, however it was not in the vein of "we are all oppressed, let's fight together." Upon learning more about Ellen Hellmann's position, I would not classify her explicit political stance as radically "anti-racist" or "pro-political or economic justice." 
Even if she privately believed in "social justice" and the "absolute rights of black people" the political actions and rhetoric she used were "conservative with a small 'c" or "liberal with a small ' 1 "” in order to achieve "pragmatic," "realistic" and "measured" steps toward "progress" in South Africa (Gondek and Runciman 2018). Hellmann's organizations that worked with Jewish and black populations in South Africa are pictured in Figure 27. ${ }^{39}$

${ }^{39}$ This network visualization focuses on the organizations, demonstrating Ellen Hellmann's (in the center) connections to the Joint Council, SAIRR, the Progressive Party, the Zionist Socialists and the Jewish Board of Deputies. This visual also demonstrates the colleagues Hellmann was connected to via these organizations and the types of work (social service, research, political party) each institution performed. It is important to note that Hilda and Leo Kuper were involved with the Jewish Board of Deputies in 1946; Hilda agreed to review a "Race Prejudice" pamphlet that Hellmann suggested and the PR committee agreed should be a "popular exposition of modern theories on race prejudice, outlining how prejudices arise, and illustrating the theory throughout with concrete examples from the South African racial situation." Leo was "co-opted" into the PR committee in September 1946; he contended that, "Sympathy for the Jewish cause could be enlisted by acquainting the public with the facts about the Palestine issue. He suggested the arrangement of a series of lectures to various organizations and clubs and the planning of a number of well-illustrated publications" (S. A. J. B. of Deputies 1946). Both Hilda and Winifred Hoernlé paid membership dues to the Joint Council of Europeans and Africans in 1945-6 (Africans 1947). In August 1939, H. Kuper received a letter from the Joint Council inviting her to attend a meeting of the Council's Executive Committee at the Bantu Men's Social Centre, to discuss "the sale of beer by African Women at Western Native Township Municipal Beer Hall" (J. J. C. of E. and Africans 1939). 


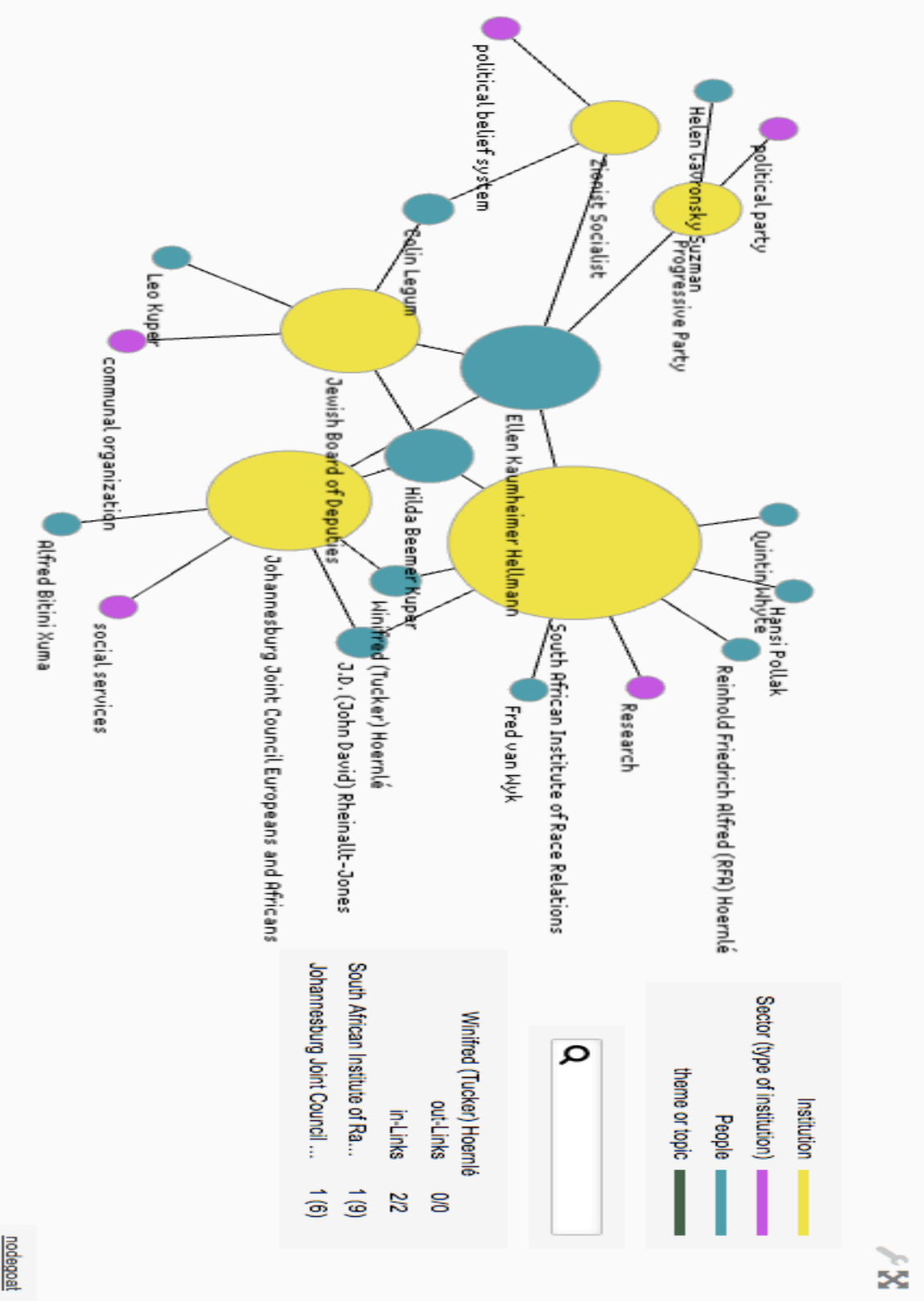

Figure 27. The South African organizations with which Hellmann worked. 
Hellmann's approach to the Jewish community in South Africa was one of protection, preservation and promotion. In a speech to the new National Executive of Jewish women's organizations in 1961, Hellmann argued: "We must preserve our Jewish background, no matter how it is expressed, religiously or otherwise. Our Jewishness is part of our personality, and is expressed in our activities, whether we play our part in Jewish or in other spheres..." She advocated for the importance of the Jewish Board of Deputies, which she described as an "instrument" of the Jewish community's needs: "whether it be working against anti-Semitism, helping the police in its probe into the bombing of the Great synagogue, or seeing that legislation of the proper kind is tabled in Parliament" (Hellmann 1961b). This illustrates her view that the Jewish Board of Deputies served to protect and promote Jewish rights to be included into whiteness. As Dr. Andrea Queeley explains, the pattern of the intermediary group agitating for full inclusion, often based upon their cultural, familial and racial ties to the dominant group rather than any interest in challenging the subjugation of those relegated to the margins is a familiar one in histories of the African Diaspora ${ }^{40}$; this underscores how Ellen

\footnotetext{
${ }^{40}$ The distancing from the lower-class group often depended upon replications of gendered and racialized stereotypes that associated blackness with hypersexuality, barbarism, and witchcraft. For example, De La Fuentes discusses the shame middle class black Cubans felt (in the first quarter of the $20^{\text {th }}$ century) toward "low" blacks, represented by "immoral" black and mulata women who had many "illegitimate" children and engaged in prostitution (Fuentes 2001:loc. 3402-3423). Aline Helg contends that in post-independence Cuba, when middle class Afro-Cubans fought for full equality, they were reminded of the specter of the black male witch that triggered associations with lower-class blackness, migrants from Haiti, and African "barbarism" and "inferiority" (Helg 2000:583-84). In the Brazilian context, the black middle class criticized black women's leadership roles in families because of illegitimate births, and the supposed
} 
Hellmann and the elite German Jewish community in Johannesburg were not unique in their strategies in relation to the powerful white Afrikaner minority and the disenfranchised black majority.

She maintained, "that South African Jews could not separate" Jewish "problems" from "those concerning all South Africans, regardless of colour or creed." She argued that, "Jewish South Africans needed to be more aware of the necessity for engagement with the actual conditions prevailing in South Africa" (Online 2015).

It seems to me unreasonable to expect the Jew-or, for that matter a member of any minority and hence vulnerable group - to be able to divide the problems that concern him as a Jew and those that concern him as a South African into separate compartments...There are not only inter-racial cleavages but a deep and seemingly growing, gulf separates the two main sections of the White group (Hellmann 1951).

Thus, her belief was that the Jewish Board of Deputies should "stimulate awareness of every Jew" and to ensure Jewish "active participation in the various responsibilities of citizenship" (Hellmann 1951:9-10). These statements demonstrate her emphasis on Jewish assimilation into White South Africa and her concern with the divides within the White group (between British and Afrikaner), which affected Jews.

Her advocacy for Jewish assimilation into South African culture can be further seen in her belief that Jews should neither solely strengthen their in-group affiliations,

absence of male providers. George Reid Andrews also points to the associations middle class Afro-Brazilians created between poverty, blackness and prostitution. For example, middle class blacks described the Rua Direita in São Paulo, where working class blacks congregated in the 1930s and 1940s, as connected to "ill-bred black dancers" and "cheap prostitution" (Andrews 1991:80, 180). 
nor evolve a "third culture" for Jewish South Africans (Hellmann 1950:4). She acknowledged that there were defining features of the Jewish culture in South African society (the preservation of Jewish background as part of Jews' personality) but she did not think that in practice these elements took precedence over South African culture, "which is itself a sub-culture of the near-pervasive Western culture of today." One of these unique cultural aspects was the Jewish emphasis on learning and education, a trait she felt was not held by all South Africans (1950:5).

Approach to Black South Africans

Her letters as the Honorary Secretary, Vice Chairman (1940-1944) and Chairman (1945-1948) for the Johannesburg Joint Council of Europeans and Africans advocated for basic needs and social services for "Africans" or "Non-Europeans" such as poverty alleviation, clean neighborhoods and adequate housing, transportation, food, and education (Hellmann 1940a, 1940b, 1940c, 1940d, 1948b). Along with the topics she discussed, which did not underscore racism (though Ruth Runciman clearly stated that Hellmann "loathed racism of any kind"), I perceived Hellmann's tone toward Black South Africans to be patronizing, another clue to her moralistic social improvement/charity angle rather than an explicitly social justice position that focused on a radical approach to fighting racism. In contrast, Runciman contends that her mother clearly believed in "social justice" (including a fairer society, the redistribution of wealth, and rights to proper education) and the "absolute rights of black people, passionately," but that this could never be achieved quickly, and so one must take a step-by-step approach, in order to achieve "some degree of progress." 
Her paternalistic position is evident in her doctoral dissertation turned report, Problems of Urban Bantu Youth (published in 1940, researched in 1937-1938) when she discussed a presentation she gave to an African women's organization about improved parenting styles. She said the women bemoaned their "naughty children" but that they had only tried punishment as a disciplinary strategy, which only caused their children to become more disobedient. Hellmann stated that the women were interested and sympathetic to Hellmann's suggestions of winning the children over with care and consideration (Hellmann 1940e:9). At the end of her 1940 report, she recommended that African women be encouraged to attend "women's clubs" where they would learn about "housekeeping, child-welfare, and the problems which arise in the upbringing of children" leading to "a more satisfactory adjustment in family relationships" (Hellmann 1940e:91).

Relatedly, as part of her Rooiyard fieldwork (her master's thesis research in 19331934, see figure 28) she taught the women she interviewed to keep household budgets and included the budgets in the published manuscript Rooiyard (Hellmann 1948c:24-25, 29-37, n.d.). One of her goals was to understand the economic conditions of "native" African workers in the yard, but she also imposed a specific kind of household maintenance strategy upon her female informants. Intriguingly, in a 1935 publication about her Rooiyard research, she mentioned that "the more hostile elements in the yard" were suspicious of her requests to track her informants' budgets and they blamed the increased vigor and frequency of police beer-raids on her presence in the yard (Hellmann 1935:37-38). Wulf Sachs quoted John Chavafambira's initial assessment of Ellen Hellmann: 
A rich young woman who comes here in her grand motor car and looks at you as if she didn't see you properly. They say she is a spy working for the police. They are all talking about it. She questions all the time; silly questions about what we eat, how many children we have, what money we earn, and so on (1947:123).

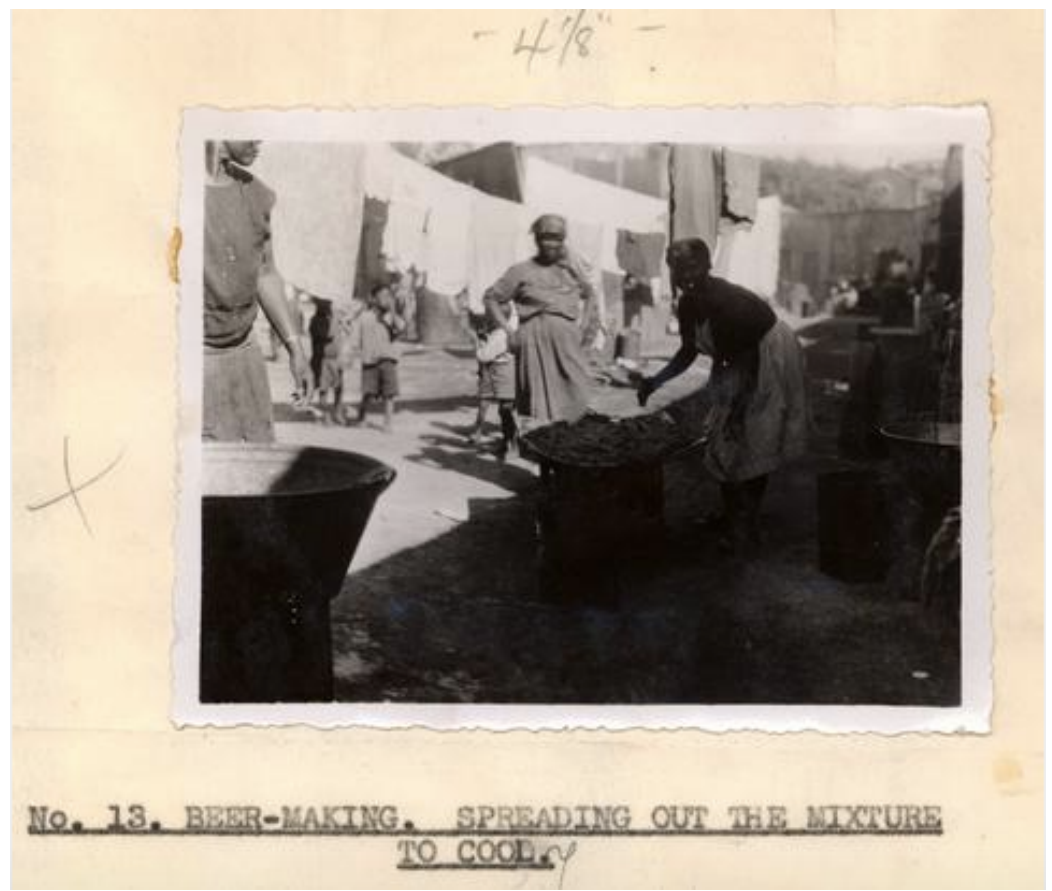

Figure 28. Rooiyard in 1935. Photo taken by Ellen Hellmann, Ellen Hellmann Papers, Historical Papers Archive, File 35, Subseries 8.2, ZA HPRA A1419-8-8.2-13

The Connection between Westernization and Economic Development In Rooiyard (1948) she clearly adopted the belief that European culture represented "higher civilization," an ideal to be attained. She critiqued the effects of the colonial system on "native" Africans including poverty and unsanitary living conditions (1948:7-9), yet her goal was for them to "adopt such elements of European culture as may enable them to an ordered and economically secure social life" (1935:61). She cited Z.K. Matthews in order to explain the "synthesis" of "Native" and "European" cultures, how "Native culture" was incorporating consumer elements of "European culture" and "modifying them... to create a new composite culture." Hellmann said that according to 
Matthews, this process was most successful in the families of "educated Natives" $(1948: 115)$.

Ellen Hellmann perceived Westernization as being connected to national economic development, a central focus for her work with SAIRR (see Figure 29). ${ }^{41}$ It was "necessary for Africans" to become westernized in order that they could "make the fullest contribution" and expand "productivity"; this would enable South Africa to "develop its natural resources and offer its peoples the higher standard of living and the expanded

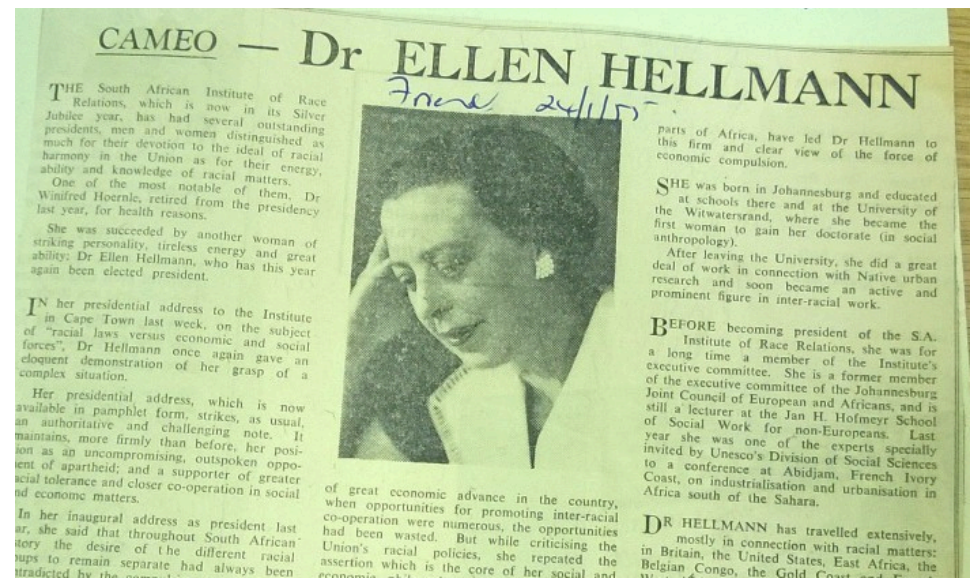

Figure 29. Ellen Hellmann's presidential address to SAIRR in Cape Town, January 24, 1955. Ellen Hellmann Box of Clippings, Jewish Board of Deputies Archive, Beyachad Community Center, Johannesburg.

services this country could support" (Hellmann 1962a:11). Hellmann praised Margaret Ballinger, a white Native Representative in the Cape Eastern Circle (there were only three Native Representatives in a house of 153), for her concordance with the idea that discrimination against "natives" economically threatened "Europeans" (Hellmann

\footnotetext{
${ }^{41}$ She argued in her presidential address to the SAIRR, featured in this article, that "economic development in the Union, economic progress in Africa generally and the trend of world events would eventually knit the peoples of South Africa irreversibly into one."
} 
1945c:14-15). Hellmann believed that the racial system of South Africa created an embarrassing image to outside nations, making South African seem uncivilized (Hellmann 1962b). Thus, her arguments against apartheid were often based on the underlying assumption that apartheid was "bad" because it negatively affected South Africa's economy and made the country look "backward" in the international arena.

Her solution to the "racial-caste society" in which the Afrikaner Nationalist group played on white fears by exaggerating the "black bogey" and preaching in "rabid antiAsiatic, anti-Native, anti-Semitic propaganda an all out segregation policy ${ }^{, 42}$ was "economic productivity"; this required "efficient labour and production" - workers had to have proper education, nourishment, health care and housing (Hellmann 1945e:9). The gist of her argument was that the government must provide basic needs to the "Africans" so that they could be productive workers in order to benefit the South African economy; she did not stress eliminating discrimination based upon race or fighting for equal rights. In fact, she accentuated the cultural differences between the "European and African" stating that she was not "concerned with social Jim Crowism. The cultural disparity between European and African is at the present stage still so marked, the white fear of being engulfed by a black flood so great..." (Hellmann 1945e:8). She admired Margaret Ballinger for avoidance of the "starry-eyed idealist" approach that would expect Europeans to be philanthropic do-gooders ${ }^{43}$, instead Ballinger used a "realistic" strategy

\footnotetext{
${ }^{42}$ This statement is one of the only places where Hellmann discussed "anti-Native" and "anti-Semitic" propaganda together as if they were connected issues.

${ }^{43}$ Though Ballinger and Hellmann might not have promoted the philanthropic do-gooder approach with whites in the political realm, they did employ this method with "Africans"
} 
(which Hellmann highly valued) that rhetorically underlined the negative impact of racial discrimination on the "whole population" i.e. the white "Europeans" (Hellmann 1945c). Thus, like Ballinger, Hellmann decided that the most pragmatic tactic was to appeal to white concerns about the South African economy rather than to expect white citizens to be interested or invested in the wrongs of racism. Figure 30 compares the topics/issues that were central for the organizations with which Hellmann worked. ${ }^{44}$

by co-founding the Margaret Ballinger Convalescent Home for African Children (Jewish Board of Deputies Archive 1954).

${ }^{44}$ This visualization provides information about the connections between Hellmann's organizations and other "institutions"/belief systems such as Nazism, bolshevism and socialism; for example, both the JBD and Zionist Socialists fought Nazism, while the Zionist Socialists were affiliated with socialism and the JBD wished to de-link bolshevism from Jews. The visualization also depicts the racial or ethnic identity of the Jewish organizations; the Zionist Socialists tended to be made up of Eastern European Jews while the Jewish Board of Deputies was dominated by Western/Central European Jews who wanted to make Eastern European Jews more "civilized" and assimilated into South African whiteness. 


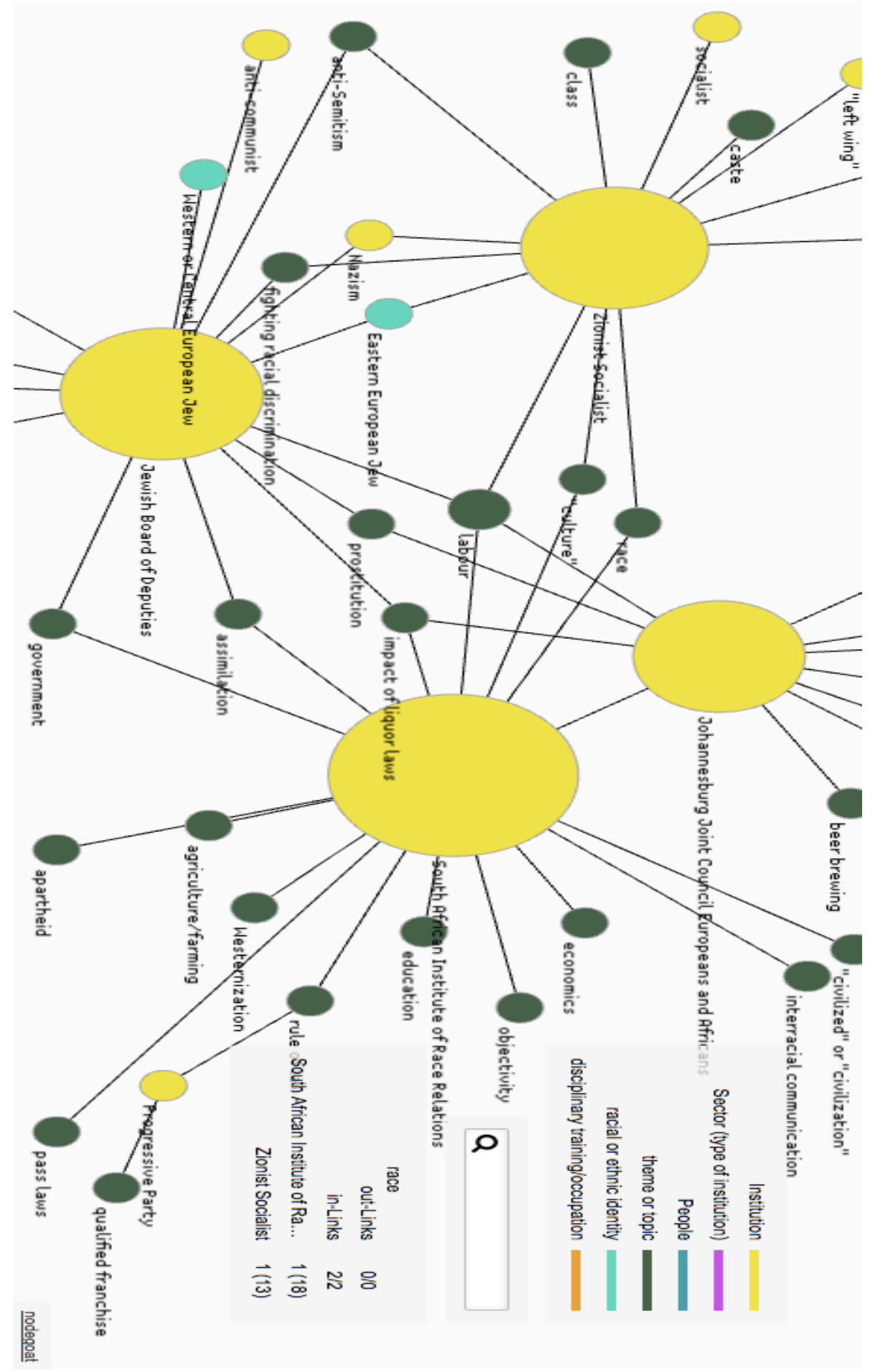

Figure 30. Thematic/issue focus for Hellmann's organizations. 
Education as assimilation and conformity

Hellmann felt that Africans (like Jews) formed a "sub-culture" within South

Africa but that their "cultural development" was toward the "dominant Western culture";

She argued that assimilation was a positive form of cultural development: "It is a matter

for neither cultural shame nor cultural pride that the most potent cause of cultural

development on a global scale has been through the enriching process of borrowing and assimilation" (Hellmann 1964:15). However by 1981 she did not think it possible for this acculturation to occur within one generation (Schwartz 1981). ${ }^{45}$

\footnotetext{
${ }^{45}$ Though she clearly did not believe in separate development, she did believe that white and black groups were quite distant from each other physically and socially. For example she critiqued Mr. Wennie du Plessis, Secretary for Information, who believed in the "basic differences between people" and that those who "belong together" should be kept together and should "develop separately... according to their own inherent capacities" (Hellmann 1962a:4). Yet, in 1956 she wrote: "No one disputes that European and African will remain physically separate racial groups" (Hellmann 1956:4). Though she believed that Bantu traditions and values were westernizing, a development she encouraged (1956:6).
} 
According to Professor John Dugard, "For Ellen, research and education were inextricably linked. She believed that if South Africa were to become a decent society, it would be through education." Hellmann taught African social workers at the Jan Hofmeyr School, and organized scholarships (bursaries, see figure 31) for young Africans (Schwartz 1982). ${ }^{46}$

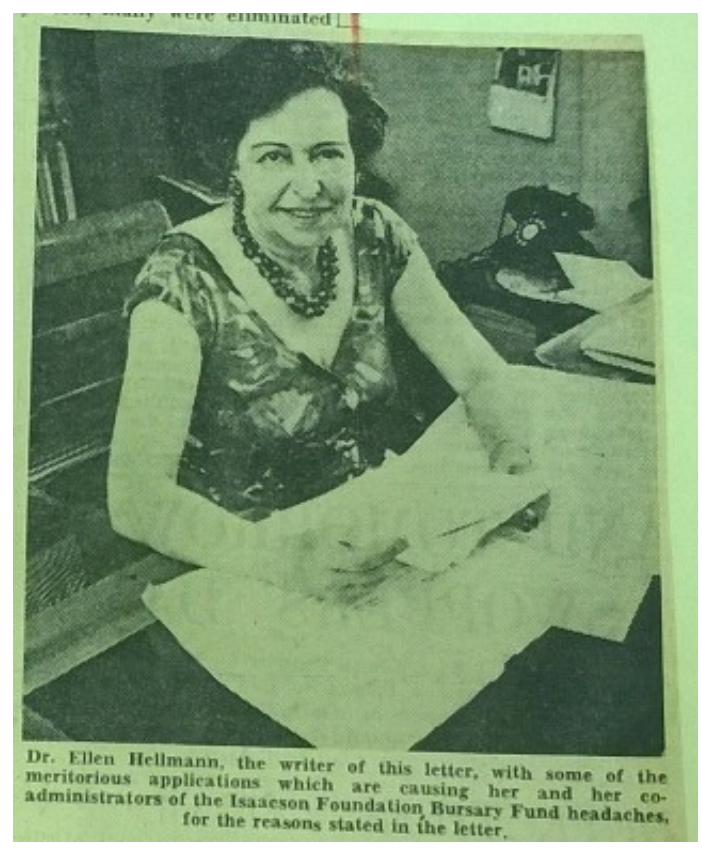

Figure 31. 90 Justinas, 50 Mandlas, Sixty bursaries for Native Applicants, December 26, 1961. The Star, Ellen Hellmann Box of Clippings, Jewish Board of Deputies Archive, Beyachad Community Center

Ellen Hellmann's fervent belief in free and compulsory education for Bantu youth in order to counter "idleness," "delinquency" and criminality, and produce "valuable," "law-abiding" "citizens" was an application of middle-class Jewish and Black beliefs about the power of education as a path to assimilation into Western standards in the pre-

\footnotetext{
${ }^{46}$ Hellmann worked to provide bursaries for African students as part of the Isaacson Foundation Bursary Fund (Hellmann 1961a).
} 
WWII period (Hellmann 1940e:17, 50, 85-87; Lewis 2013:550, 556). In 1962, she

described education as creating conforming, law-abiding, and "responsible" citizens:

The end aim [of the educational system] is to produce not only an individual whose innate abilities have been developed to their maximum capacity, but also a responsible citizen. And this presupposes common values, for unless there is consensus on certain fundamentals, agreement as to what is mainly important to a society, divergent concepts of what constitutes responsible citizenship will develop and there will be a divided nation (Hellmann 1962a:2).

In 1964, she wrote that the major problem of urban living was of "social control" which involved "defining certain approved standards of behavior and ensuring their observance...there must be sanctions which will operate to promote conformity" (Hellmann 1964:12). While the "rule of Law" in the U.S. protected the rights of racial minorities, in South Africa the "rule of Law" prevented the rights of "natives" who were the racial majority (Hellmann 1945a:310). Ellen Hellmann avidly supported the concept of "rule of Law" and subsequently supported the obeisance to apartheid laws because they were governmentally mandated even if she critiqued the logic behind the laws. ${ }^{47}$

${ }^{47}$ In 1973 Ellen Hellmann was considered one of the older, conservative, stalwarts, of the South African Institute of Race Relations (SAIRR), who believed that the organization had a legal duty to comply with the governmental investigation, called the Schlebusch Commission of Inquiry, into several multi-racial organizations (including SAIRR).

Younger members of SAIRR felt that SAIRR should refuse to provide evidence or testify before the Commission of Inquiry, yet Hellmann argued that "if it is to maintain its integrity and uphold the principle of objective inquiry and its commitments to the rational, as opposed to the emotional approach, the Institute cannot, as a body, refuse to testify before a statutorily appointed commission." Hellmann felt that the SAIRR could not "put itself outside of the law or refuse to obey the law" even though it felt "dismay" at the banning of eight NUSAS (National Union of South African Students) leaders and the banning and house arrest of eight black leaders of the South African Student Organisation (Pringle 1973). Ellen's response and position on this issue reveals again her ardent belief in the "rule of Law" and how it led her to take conservative positions especially by the 1970 s in relation to apartheid policies and governmental commissions. 
Garry Runciman, Ellen's son-in-law, and a historical sociologist at Cambridge, wrote of Ellen: "She was entirely comfortable with the workings of capitalism provided that they are subject to the rule of law, and admired men like her father who rose to riches from rags" (March 7, 2018). The Progressive Party, of which she was an Executive Member, held the "rule of Law" as one of its primary tenets (Party 1959). In a 1964 talk to the Interdenominational African Ministers' Association of Southern Africa she explained that "influx control, location regulations, pass laws, prohibition of the right to strike" are not publicly accepted, and "undermine the respect for law and order." She did not like this lack of respect for law and order because it led to the tendency to "blur the distinction between statutory offences and crime" causing legal prohibitions to "lose their moral force" and make "law breaking or law evasion a positive value" (Hellmann 1964:13). Hellmann did not question the authority of police or teachers to inculcate European values about appropriate citizenship. Instead she praised education as a way to teach norms and conformity.

Hellmann did not seem open to the possibility that Black South Africans would need to engage in the same kind of self-preservation or self-promotion work that the South African Jewish community did. Because of the rise of Black Consciousness in the 1960s, she feared there was a danger that "Africans" would be prevented from accepting Westernization and instead would be led to adopt "African culture" as a "nationalist" strategy. She worried that the continuation of a separate Bantu culture would increase divisiveness in South African society, which she perceived as an "interdependent whole." She could not conceptualize the possibility that Black Africans might chose to embrace a separate "African culture" rather than a white "Western" one (Hellmann 1964:16). 
Hellmann argued a similar point in 1970 in her presentation to the Union of Jewish Women of South Africa, critiquing assertions of "black identity" and "a withdrawal and a turning away from whites, their institutions and way of life": she cited as examples of this the saying "Black is beautiful," the formation of SASO (South African Student Organization) "as a racially exclusive Black national students' organization in opposition to the multi-racial NUSAS" [National Union of South African Students] and the "request that 'Black' be used instead of 'African'" (Hellmann 1970:7). This position strikes me as ironic and hypocritical considering her point in 1961 that Jewishness should be preserved and expressed as part of one's personality. Despite Hellmann's contestation of black consciousness and the fact that SAIRR failed to do "anything that is relevant to the needs of black people in their own situations" (Nettleton 1973), Hellmann was still awarded the Royal Africa Society medal in 1970 (Figure 32) and SAIRR Director John Rees (in 1982) said, "she left her mark on all that we do from research to practical help for the underprivileged" (Coggin 1982). 


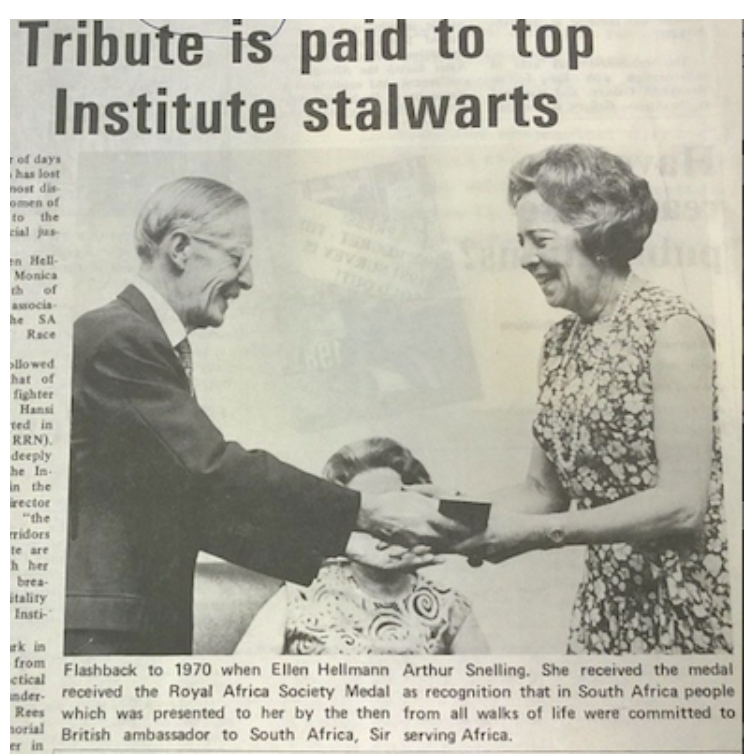

Figure 32. Ellen received a Royal Africa Society medal in 1970 for her service to Africa. This photograph was part of a tribute to Hellmann upon her death in the Race Relations News, Vol. 44, No. 9, Dec. 1982, Ellen Hellmann Box of Clippings, Jewish Board of Deputies Archive, Beyachad Community Center

\section{Closing for Part I}

Hellmann contended that Jews had a rightful place in white South African society and that black people should assimilate westernized values and behaviors, though she felt that black and Europeans were both physically and socially separate. She also maintained that Jews could and should maintain a certain level of uniqueness that she effectively denied to black people. Her work with black communities was not an extension of her effort to fight anti-Semitism or to understand her own otherness because she did not see herself as being an "other." Even though she became involved in Jewish communal promotion work with the rise of anti-Semitism in South Africa, she distinguished herself from "Eastern Jews" whom she compared to "non-Europeans." Because of the way that the South African apartheid system divided whites from blacks, and assigned Jews to the white category, upper class German Jews (like Ellen) did not need to associate with black 
people in order to fight for their rights as South African citizens. They were already considered far superior to (black) Africans that allying with them could serve no political purpose. This was directly opposed to the U.S. context where Jews found that aligning with black groups could draw attention to "the most conspicuous failure of the American way of life" which was the denial of "not only the freedom to be different, but also the untrammeled right to economic, political and social equality" (Hellmann 1945a:310). This was because in the U.S. context, "to improve race relations means opposing discrimination against all minority groups, the two most vulnerable groups being the Jews and the Negroes." After Hellmann's visits to anti-racist organizations in New York and Washington D.C. in 1944-5, she clearly understood that unlike the racial situation in South Africa, in the U.S. "the starting off point" was that "all men are born equal" thus inequalities and discriminations could be branded as "un-American" (Hellmann 1945d:1).

Also speaking about the U.S. context, Hasia Diner (1995) discusses the Eastern European Yiddish belief that their "special concern" for black Americans "set them apart" from whites, making them the "truest and best" Americans (237). Though living in a different national context than Ellen Hellmann, Melville Herskovits, an American Jewish anthropologist of Central European heritage, wrote for apolitical, non-socialist Jewish English language magazines that were uninterested in either Yiddish culture or advocating desegregation of public facilities or political enfranchisement of black people. Like Ellen Hellmann, middle class Jews in the U.S. context wished to retain the "specialness" of Jewish culture while being accepted into elite institutions of middle class white American society (Diner 1995:90-91, 100-103, 106-8). Thus, it is imperative to analyze not only the placement of Jews within the national racial hierarchy in a specific 
historical moment, but also the diversity of Jewish positionalities within each national context based upon European origin point, class-background and political orientations. In this way, the apparent contradictions or double standards expressed by specific Jewish social scientists in their writings about people of color can be clarified with historical and geographic perspective.

\section{Part II Theorizing about Black Women and Professional and Personal Networks}

Solely based upon her public writings and talks, Ellen Hellmann seemed to view herself and her moral standard as superior to the women she researched. Privately though, Hellmann suffered from long-term depression (Gondek and Runciman 2018) and selfdoubts about her "standing in the scientific world" because she perceived herself to be a "jack of all trades and most definitely not a master of any" (Hellmann 1968). Garry Runciman, Ellen's son-in-law, and Ruth Runciman's husband, said of Ellen: "She was excessively modest about her own career and achievements, and would have been astonished to see a photograph of herself reproduced in the pages of The Times Literary Supplement in a review about women anthropologists including herself." Hellmann expressed to Ruth Landes a potential explanation for her depression and self-doubt: "A diet of futile opposition isn't always v. heartening! ... I thrive selfishly and often with a sense of inevitable guilt on the compensations that our country offers those who have the right skin colour" (Hellmann 1968:2). Thus, Ellen expressed an affective reaction of guilt that motivated her work with not only the Jewish community (in her interview with Riva Krut) but also that seemed to inform her work with black communities. Ruth Runciman emphasized her mother's influential teaching that “one 'owed people' given one's own 
privileges"; Ellen's "philanthropic" approach could be interpreted as stemming from the sense of guilt that she expressed in her letter to Ruth Landes. Given what Runciman shared about her mother's dedication to "social justice" and "absolute rights" for black communities in South Africa and Hellmann's avid desire to rid South Africa of apartheid, I felt confused by Hellmann's theoretical writings in which she seemed to negatively evaluate what she considered to be the morally inferior sexual practices of black women. Garry Runciman explained: "[Ellen] was a firm believer in the conventional European norms of marriage and childrearing, but equally firmly believed that the failure of the black population to conform to them was due not to their innate psychology but to sociological influences beyond their control." Hellmann's theoretical stance regarding black women's sexualities and family structures emerged not only from her wealthy upbringing in a German Jewish immigrant family in Johannesburg in which "Western Jews" perceived themselves as superior to "Eastern Jews" and "non-Europeans," but also her allegiance with the conservative/moderate South African Institute of Race Relations $(\mathrm{SAIRR})^{48}$, Jewish Board of Deputies, and Progressive Party. She was also married to two Jewish men, Joseph Hellmann, a lawyer and Bodo Koch, a surgeon, which enabled her financial stability. According to Ruth Runciman, Koch was not a politically-oriented

\footnotetext{
${ }^{48}$ Ruth Runciman wishes to emphasize that SAIRR was a "moderate" and not a "conservative" organization. "The SAIRR was an important part of my mother's life, especially when she was President. Also, she oversaw their Annual Survey of Race Relations which was an important and probably unique source of information on race relations for a number of years" (March 10, 2018).
} 
man, and dedicated himself exclusively to his medical practice. ${ }^{49}$ It is important to point out that her second husband was a German Jew, like Ellen, while her first husband, Joseph Hellmann, had been an "Eastern Jew" which she explicitly stated created difficulty for her. She mostly worked with prominent white men and women through the SAIRR and Progressive Party. The few transracial connections she had were with welleducated black men whom she cited in her writings about the black middle class or whom she worked with as assistants and interpreters. Also, her primary research site was Johannesburg (because she began research when she was already married to Joseph Hellmann) and she lived in Johannesburg throughout her life (even though she traveled for short-term trips related to her SAIRR advocacy), unlike the other women in this study who either moved frequently, or were themselves immigrants or refugees.

One of my primary arguments is that Ellen Hellmann saw the heterosexual "stable" married family as the foundation to national "development" and "progress" in South Africa. Because of her emphasis on a "pragmatic" and "realistic" approach to South African political improvement, she highly valued the family structure which she believed was the most likely to contribute to this "progress." Thus, she depicted the ideal family structure for black families as a working father who financially provided for his

${ }^{49}$ Ellen told Colin Legum something similar in a letter dated November 3, 1953: "Bodo keeps getting busier and busier and working harder and harder. I don't know where it is leading or what purpose this mad involvement in practice serves. The whole question should really have been discussed, but there wasn't time and I have practically forgotten how to discuss personal matters. Tragic example of the muzzling effects of the committee technique! I've often wished someone would do my political thinking for me - now it appears I need my other thinking done for me too" (Koch 1953). 
wife, who only took care of her children and did not work outside the home. Through this stance she adhered to the Jewish adoption of middle class white norms regarding the seclusion and domination of women in the domestic realm. However, this familial ideal did not account for the fact that white women would "require" black women to work for them as domestic servants, contradicting her argument that black women should not work outside of their homes. Her publicly stated views on gender role conformity were in line with the views of the Afrikaner government.

One of the specific "problems" that Ellen Hellmann saw with black women's relationships in Johannesburg was that they were supposedly "unstable" leading to "illegitimate" children. She saw this as contributing to the inability to appropriately (from her point of view) discipline their children, leading to increased criminality in black urban areas, a "problem" that impacted South Africa's ability to "progress" and "develop." She was by no means alone in these depictions of black women and black families; both the white and black elite perceived changing gender roles and women's increased independence as leading to the "insecurity" of family life.

At the end of this chapter, I discuss Hellmann's sometimes judgmental perceptions of prostitution and syphilis infection, as well as her observations that the transition of lobola (bride payment) from cattle exchange to a monetary exchange contributed to increasing "illegitimacy" and family instability, since many black men in the cities could not afford to pay their girlfriends' families the high lobola cost.

One of Hellmann's themes was the issue of "shame" -whether or not the women participating in unions "in the Johannesburg way" felt "shame"; Hellmann seemed offended that women engaging in non-legal unions did not feel shame. This demonstrates 
how she negatively judged their different cultural and moral standards regarding gendered and sexual behavior based upon her own white middle/upper-class status and hierarchies of "civilization."

According to Marijke du Toit (2005), Hellmann did not perpetuate the typical 1920s portrayal of black poor women who had migrated to urban environments as "Skokiaan queens," criminalizing them for beer brewing and prostitution (du Toit 2005: 602-604). Du Toit contends that Hellmann portrayed women in Rooiyard as "breadwinners" along with men, clarifying that women worked hard to support their families and demonstrating the need for social welfare (du Toit 2005:604). According to du Toit: "Hellmann refigured Rooiyard as a domesticated space of arduous female labour for survival... presented women neither as idealised carriers of tribal identity nor as prostitutes and beer brewers at the immoral centre of slum living" (604, n. 30; Hellmann 1948:40). In contrast, I argue that both in her book Rooiyard, 1948, which du Toit uses as a central source, and in Hellmann's 1935 article, "Native Life in a Johannesburg Slum Yard" completed in the year directly following her research in Rooiyard, Hellmann represented Rooiyard as a site of illicit beer brewing where a "criminal population" or "criminal class" lived, whose "whole endeavor is to outwit the police" (Hellmann $1935: 36,61 ; 1948: 46)$. She was critical of the lack of "social stigma" related to "arrest and conviction for beer brewing" which led to the "evasion and dodging of the police" (1948:47). She did acknowledge that beer-brewing and prostitution were necessities for economic survival, but she underscored that "prostitution is exceedingly common" even if the women in the yard often did not admit to it publicly (Hellmann 1935:36; 1948:46, 


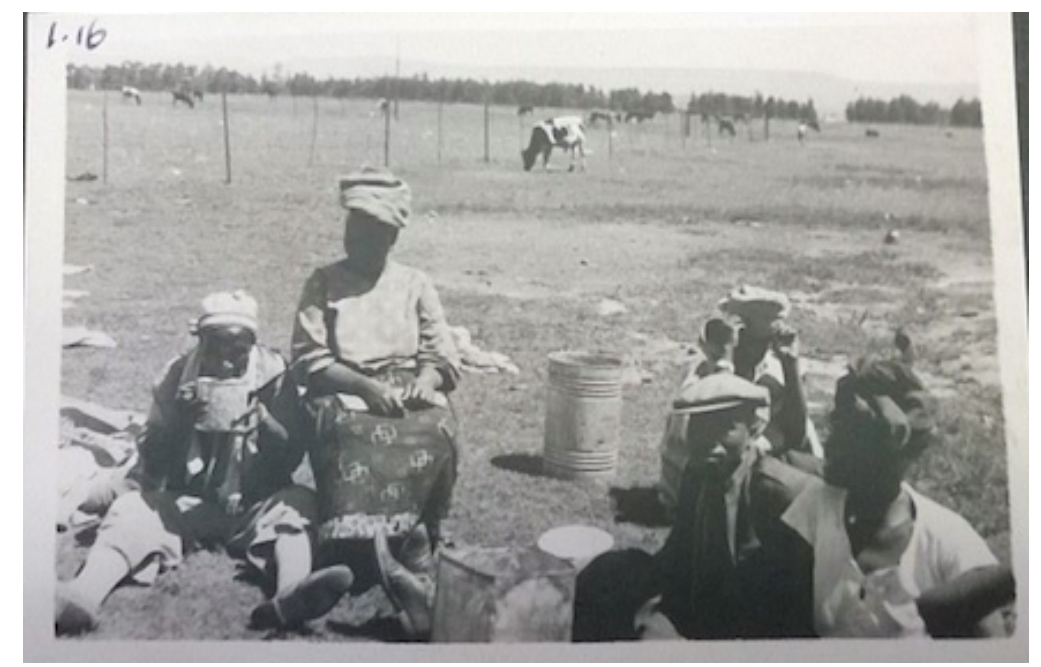

Figure 33. Drinking on Fields Round Pimville, December 1937. Photograph by Ellen Hellmann, photo 1.16 on page 29 in Series 8, photograph album 31.1, Ellen Hellmann Papers, Historical Papers Archive

50). She was critical of women's beer brewing, because it not only exposed them to arrest, but also it took them away from caring for their children, which she viewed as of primary importance (see figure 33). Thus beer brewing led to the "division of the family" (Hellmann 1935:45).

In an environment where adultery, illegitimacy, prostitution, even if not completely condoned, are accepted as social norms, and where lobola is regarded as payment, the foundations of marriage must inevitably totter; it is a logical conclusion to an unfortunate concatenation of circumstances in which economic pressure is of great importance, to find extreme disruption in family life (Hellmann 1948:88).

\section{Gender role conformity as a form of assimilation into whiteness}

In the Johannesburg Jewish population in 1928-1948, sixty percent of Jewish women were housewives, while only 2.5 percent worked in the professions. More Jewish women were housewives than among the white female population in Johannesburg and half as many Jewish women as white women worked in professions. In stark contrast, half of Jewish men in Johannesburg worked in commercial or financial industries, double 
the general white population. Andrew Bank notes the "clear divide" between the "public world of Jewish men and the private world of Jewish women" (Bank 2016:112). ${ }^{50}$

From my analysis of Hellmann's writings of the 1940s, based on research completed in the 1930s, she clearly contended that black South Africans should adopt the hyper-assimilation undertaken by Jewish South Africans that involved women's obedience to extreme separation between private and public realms. Hellmann maintained that the ideal family structure for "native" South Africans was for the husband to work outside the home, and receive a livable wage to support his family, and for his wife to be a stay-at-home mother. According to Hellmann: "Above all, in the interest of creating an integrated and stable family life, the mother of the family must be freed from her dual role of wage-earner and housewife and enabled to give all her attention to her children and her home" (Hellmann 1940:89). In Rooiyard (1948) she conceived of the "family" in a traditional way including father, mother and children and excluding widows, widowers, bachelors and unmarried women (13). In her economic analysis she explicated that women living in Rooiyard had to work because their husbands did not make enough on their own, thus re-enforcing the expectation that men should be the primary breadwinners (Hellmann 1948c:37-39). In contrast to my conclusions based on reading Hellmann's theorizations, Ruth Runciman, Hellmann's daughter, underscored that Hellmann was "much more open-minded" than that, and was not “dogmatic" about women's roles (Gondek and Runciman 2018). However, even if

\footnotetext{
${ }^{50}$ It is interesting that Bank includes Jews into the "white" group without mentioning if they were ever considered non-white as they were in other national contexts at this time.
} 
Hellmann might have thought that women ought to be able to "have any chance they could," she developed these arguments about the best place for women because of her underlying emphasis on "an integrated and stable family life" which was intricately interwoven with her commitment to South Africa's "national development" and "progress."

I found that Hellmann's advocacy for black women as stay-at-home mothers, conflicted with her public argument that black women were needed as domestic servants for white women (like herself). In 1963, she argued that there should not be restrictions on black workers' movements in white areas because white women needed black women to work for them as servants, so that white women would not have to do their own “dreary chores." She deplored the fact that [white] women with outside jobs had to "waste" their energy on housework or that their [white] husbands would have to take out the garbage, wash up or perform odd jobs around the house. Her argument was that if there was high unemployment among Africans, why should they be denied jobs as domestics: "while this unemployment persists, there is no justification whatsoever for calling for a reduction of domestic servants" (Hellmann 1963a). Garry Runciman wrote to me: "[Ellen] had no reservations about the employment of domestic servants by welloff private employers, but deplored that restrictions imposed on them under apartheid and their effect on their family lives" (March 7, 2018). It is unclear if Hellmann fully believed these arguments, or if she deployed them because she thought they may be persuasive for those whites who were promoting pass laws for non-European women. On the surface, it seems that in this article Hellmann did not consider that black women also might find housework "dreary" or how the apartheid system prevented black people from advancing 
educationally or professionally because it kept them in servant-type professions. It appeared to me initially that Hellmann failed to see the contradictions within her own arguments. However, after my interview with Ruth Runciman, I began to wonder if newspaper articles like these were part of Hellmann's "pragmatic" and "realistic" stepby-step plan to progressively dismantle apartheid by appealing to those who might not otherwise listen.

Hellmann's theorizations regarding women's proper place reminded me of how men in the colonies could only prove their worth as national citizens if they engaged in Westernized gendered family practices in which women must be secluded within the domestic sphere as "patriotic helpmeets and model mothers" (Colwill 1998:212). Hellmann's stance on the importance of women remaining in the domestic sphere in order to create "stability" bears similarity to the Afrikaner nationalistic emphasis on white women's motherhood. In 1938 the Afrikaner "Second Trek" or "Centenary" celebrated the Boers' first mutinous Great Trek away from British laws. It also commemorated the opposition to the emancipation of slavery and the massacre of Zulus. Nine replicas of the original trek's wagons were built, each was named after a Voortrekker hero and one wagon was given the generic name "Wife and Mother." The icon of the nation was a mother "volksmoeder" (mother of the nation). This trek celebrated the white patriarch, the enslavement of black people, and the purity of white women (McClintock 1991:107). This was all an invention, creating a "zombification" of collective identity through the staging of a spectacle, inculcating a "master code" that overpowered all other alternative meanings, becoming common sense, non-negotiable, and non-debatable (Mbembe 1992:3-4). There was a clear link between this trek, the 
Broederbond (white brotherhood that spearheaded the Afrikaner nationalist movement) and Nazism. The Broederbond sent Afrikaner students to German universities, and these same men became the architects of apartheid. Men were the political-economic agents while women were supposed to be the keepers of its tradition and spiritual mission in the "private" domestic realm; this was also the case in the Indian nationalist context (Chatterjee 1993:120-26; McClintock 1991:108). Hellmann echoed these types of nationalistic and colonial values and thinking; however, it is now unclear to me whether she fully believed them or if she was utilizing them as a political measure to achieve her "measured" progress strategy.

In contrast to Hellmann's position on women and labor, Viola Klein, a feminist sociologist of knowledge and refugee from Vienna and Prague born in 1908 (in the same age cohort as Hellmann and also a Central European Jew), argued that women should be able to work beyond their forties, as was common for refugee women and in times of war (Lyon 2007:836). Klein herself had been a domestic worker when she first arrived in London in 1938 (Lyon 2007: 831-832). In 1960, Klein argued that women's "dual role" was not new, since women combined domestic and economic production in all nonindustrial economies. Klein contended that the "problem" of married working women was not a universal one, since in "emergent countries" it was unremarkable that women worked at home and in the fields (Klein 1960:255). In 1946, before Klein began her studies of married working women, she already expressed interest in the conflict women felt between "individual achievement" and "family duties" and how women's "emancipation" had not yet reached "the emotional side of family life" (Klein 1946:157). She maintained that the "emancipation of women" had to be followed by the 
“'emancipation of men,' from their notion of a dependent, domesticated and receptive wife" (1946:158).

Klein's theorizations about working wives demonstrate that not all Central European Jewish women social scientists writing in the mid- $20^{\text {th }}$ century theorized in the same ways as Ellen Hellmann about gender norm conformity and assimilation; this was at least partially a result of different racial contexts in South Africa and the U.K. Operating in the South African environment, Hellmann likely felt her arguments that (a) black women should be full time mothers (in an emulation of white middle class Afrikaner mores) or (b) black women should be allowed freedom of movement (without pass laws) so that white women could have easily available domestic labor and not have to engage in household labor themselves, would be more politically viable and effective platforms. However, it is also possible that Hellmann advocated these policies because she fit into the category of elite white women for whom she was speaking; in contrast, Viola Klein was a refugee Jewish woman who had to work for pay, initially as a domestic worker upon her arrival in England, and later as a paid translator for the British Foreign Office, journalist on issues of women and education, and lecturer in sociology at Reading University and she was critical of women-related gatherings that excluded working-class women (Lyon 2007:834, 838). Thus, the racialized national context and Jewish women theorists' class positionalities intersect to influence their theorizing about gender role conformity. 


\section{Gendered parenting problems}

Many "literate older-generation Africans, welfarists, and governmental officials" believed that rural-urban dichotomy was a primary explanation for the "problems" of parenting that led to "urban African juvenile delinquency" (Glaser 2000:22). Hellmann took up this common argument; for example, she maintained that in rural areas, the tribal system for child rearing was balanced because the entire extended family raised the children and maternal relatives tempered the severity of the paternal relatives in patrilineal cultures. In contrast, in urban areas it was almost impossible for whole extended families to live close together, causing an imbalance and leading to the "problems of urban Bantu youth" such as early school leaving, mentioned in the title of Hellmann's report (1940e:5-6). In Rooiyard (1948), Hellmann explained that women increasingly migrated to urban centers after 1921 because of land and food shortages in the kraal (rural regions), overcrowding and the lack of funds to meet the rising cost of industrial living standards, resulting from contact with "higher civilization" (Hellmann 1948:5).

Hellmann clearly underlined the gendered parenting processes that led to children's increasing insubordination and unruliness around the ages of ten to twelve within the urban environment. From Hellmann's perspective, this problem did not just

affect Bantu families, but European ones as well, citing the "revolt of modern youth" and the generational conflict she termed "weltanschauung" using a German concept meaning a shared worldview (Hellmann 1940e:8-9).

Hellmann described how (in the urban context) Bantu fathers sought leisure away from their children on their time off from work, while Bantu mothers did not show 
interest in their children's affairs (1940e:7). Hellmann traced this distant relationship in the city setting to the traditional emphasis in Bantu families on children's obedience to their parents, rather than familiarity with their parents. Hellmann cited Mrs. H. Henderson, a "social welfare worker in the Municipal Department of Native Affairs" to explain that the Southern Sotho child must think his parents hate him otherwise he will think he is their equal $(4$, note 2$){ }^{51}$

Hellmann criticized the average mother in the towns for not engaging in discussions with her children to try to understand their problems. The rare women who did were "exceptional...greatly advanced and incomprehensible to the average town dweller" (1940e:7). Though Hellmann explicitly stated that she would try to remain unbiased and separate herself from the values of her own childhood (5, note 3), her tone emerges as quite judgmental of Bantu parenting practices (especially of mothers) in the urban environment.

${ }^{51}$ Hellmann knew Mrs. Henderson from Ellen's work as Vice Chair of the Joint Council of Europeans and Africans in Johannesburg. In a letter from the Honorary Secretary of the Joint Council to the Manager of the Native Affairs Department, "African assistants" were requested for Mrs. Henderson to aid her work "in the four municipal native townships" (Secretary 1940). 


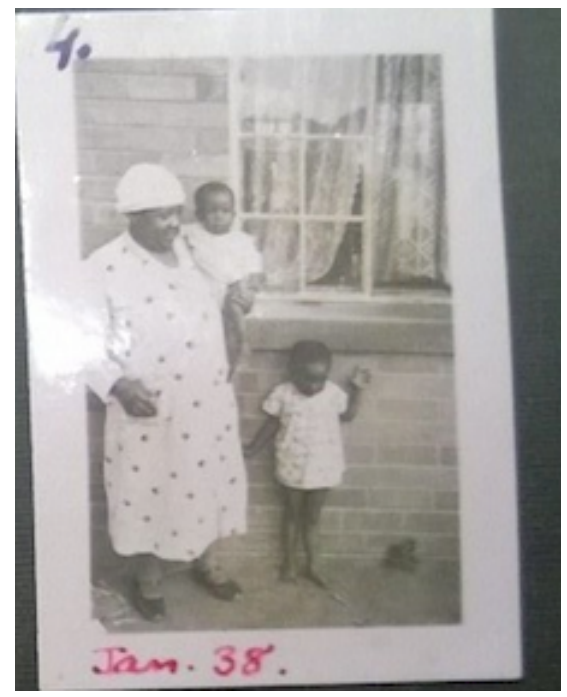

Figure 34. The Tshabalalas in Orlando Location, January 1938. Photograph by Ellen Hellmann, page 33, Series 8, photograph album 31.1, Ellen Hellmann Papers, Historical Papers Archive, University of Witwatersrand

Her judgment of Bantu mothers becomes especially clear when Hellmann noted how the parents' neglect of children led to maternal grandmothers becoming the sole caretakers (see Figure 34 of a grandmother with her grandchildren in Orlando Location). She argued that they overly indulged their grandchildren, leading to a loss of control; "many informants have pointed out to me the bad effects on the child of a grandmother's upbringing" (1940e:8). This preoccupation with the absence of mothers from the home environment was commonly expressed at the time in newspapers, by social welfare organization reports (like the SAIRR), and local Johannesburg administrative documents. The common view was that because males did not earn enough, women had to work outside the home and this led to negative influences upon children, especially males, who often got involved in youth gangs (Glaser 2000:27, 42 note 23). 
$\underline{\text { Hellmann's marital and working status }}$

I initially found it ironic that Ellen Hellmann valued families in which women/wives did not work, since I thought of her as a working researcher. Her marriage to Joseph Hellmann (1932) required her to stay close to home, in Johannesburg; this is why she did not conduct rural fieldwork as was typical at that time (Schwartz 1981). I had assumed that Ellen was paid for her work at the South African Institute of Race Relations, but became doubtful when I read a letter of introduction from the Institute's Director J.D. Rheinallt Jones to Emory Ross of the Foreign Missionary Conference in New York regarding Ellen's upcoming trip to attend the World Jewish Congress in 1944. Part of the motivation for Ellen's trip was to seek funding for the SAIRR on behalf of Rheinallt Jones. He called Hellmann a "voluntary worker" who "gives freely of her time to this institute"; so I wondered if all of her work and leadership positions were actually voluntary and not paid (Rheinallt Jones 1944).

With her father's earnings, and her two husbands' employment, she was not only free to participate in philanthropic pursuits, but she also felt that this was something she ought to do, and that it would be wrong to be a salaried worker. Ruth Runciman explained that as a "privileged person," Ellen wished to be "philanthropic"; she was not seeking a job, or a career, and she likely felt that it would not be "right" if she had accepted pay or a salary. According to Ruth, her mother believed (and instilled in Ruth) that as a "very privileged person" one "owed it to those who were not privileged to give something back." Perhaps, her experience as a philanthropist and volunteer and not a mother who worked for pay could explain why she consistently critiqued the existence of black working mothers, since she felt women should care for children while men earned 
an income for the family in order to achieve a "stable" family structure, and thus economic development for South Africa.

Her critiques of single or "unmarried" mothers also struck me as somehow hypocritical since I assumed that she was a single mother between 1941 and 1948. Her first husband Joseph Hellmann (a lawyer) killed himself in 1941 while serving in the South African military in North Africa. ${ }^{52}$ She married Bodo Koch, a German Jewish refugee surgeon, in 1948 (Bank 2016:134, 137). ${ }^{53}$ Ellen's daughter, Ruth, was born in 1936, so I thought Ellen raised Ruth as a single mother from the time Ruth was five until she was twelve (1941-1948). Yet, from a journal entry written by Colin Legum, I learned that Hellmann already was romantically involved with Bodo Koch at least in November 1946 (Legum 1946). Thus, I decided Ellen was really only a "single" mother for the war years. However, Ruth Runciman explained that she lived with her aunt Inez for approximately a year when her mom traveled to the U.S. in 1944-5 to attend the World

\footnotetext{
${ }^{52}$ Ruth Runciman has only one memory of her father's suicide (when Ruth was five); she overheard a "black servant” saying "poor Miss Ruth" (Gondek and Runciman 2018).

${ }^{53}$ From Colin Legum's November 9-10 diary entries I learned that Bodo Koch was born in Germany to a German father and a Jewish mother, had an "unhappy childhood" and an "expensive and thorough medical training." He was imprisoned because of the rise of Hitlerism, tortured and received a permanent scar on his forehead. When he was released he escaped to Austria and then to South Africa. He went to medical school for three years and served as a surgeon during WWII in Madagascar. Because of a severe eye disease, he had to give up surgery and so as of 1946 was practicing as a General Practitioner in a "poor area, mostly Indians" in Johannesburg. "Ellen says doctoring is a passion, surgery his deep love." At the time, Bodo had just heard news from Austria that his mother had been shot two days before Austria's release from the Nazis, but Bodo's father was alive (at $90 \mathrm{lbs}$ ) and had gone to England to be with his daughter; Bodo was saving money to bring his father to South Africa. Needless to say, Bodo was "so desperately unhappy" and had "built a great wall" about him (Legum 1946).
} 
Jewish Congress (Hellmann 1945d). Ellen's sister Inez lived right next door to Ellen on Tyson Road in Parkview, an upscale Northern Johannesburg neighborhood. The following year (1946-7) Ruth lived with her mother and grandparents at 14 First Ave. in Houghton (the mansion that I visited) before Ellen and Bodo married in 1948. In addition, Ruth attended a "grand school" called Roedean (an all girls' day/boarding school) in Johannesburg where she was one of only three Jewish students. Ruth stayed with her grandparents at 14 First Ave. during the year 1948-49, while attending as a day student, and then during 1949-1953 she became a boarding student at Roedean, meaning she lived at the school, until she went to the University of Witwatersrand for college (Gondek and Runciman 2018).

Thus, Ellen was never really "alone" in raising her daughter, since she had her sister Inez, her parents, her second husband, Bodo, as well as the "grand" Roedean school to contribute to the child-rearing process. My assumptions that Ellen was a "working" and "single" mother turned out to be untrue. Subsequently, my hypothesis that she should have been able to "relate" to the women she studied also revealed itself to be an erroneous assumption, leading me to see a potentially even wider class/culture divide between Ellen Hellmann and the black women she worked with in Johannesburg. Even though Ellen was not paid for her work, her "philanthropy" and "liberal" conviction ("with a small 'l"), that one "owed" the people who had less privilege and who were "particularly disadvantaged" (Gondek and Runciman 2018), still created an environment where her daughter was oftentimes raised by a community of others. This seems contradictory to Hellmann's expressed principle that mothers ought to stay at home to raise their children in order to create a stable family structure. 


\section{Instability of marital unions, laxness of sexual morality}

Hellmann praised the traditional African moral code (my emphasis), which typically, even in the city, included an emphasis on chastity, condemnation of extramarital relations and also prevention of pre-marital childbearing. Yet she established that the problem was the inability to practically enforce these moral statutes within the urban setting, highlighting her thesis that urban migration led to imbalances in the traditional rural patterns (1940e:5, 14). Hellmann agreed with the Bantu Juvenile Delinquency Conference that the dearth of legal or formal marital unions among "native" Africans was another leading cause of the problem of undisciplined black youth (1940e:14, note 13). She was not alone in this opinion; as Clive Glaser notes, "the high rate of illegitimacy in the Rand townships tended to be linked uncritically to family instability" (26). Hellmann's "moralizing" can be detected within her analysis of the "instability" of home life and her negative evaluation of the "veritable progression of fathers" since she perceived women to quickly go from one relationship to another. The percentage of unmarried parents did not rise above $15 \%$ in any of Hellmann's three sample groups in her dissertation study (researched in 1937-1938): group 1 was made up of 216 "school leavers" and their families; group 2, the "sample group," came from four different parts of the Orlando location in Johannesburg; and group 3, the "economically better," came from two mine compound married quarters, as well as Alexandra Township (1940e:2, $14) .^{54}$

\footnotetext{
${ }^{54}$ There are more details about these groups, their exact locations and the names of the schools where she conducted her research in Appendix \#3 of the "Original report on
} 
However, Hellmann contended that these low statistical rates were not a "true reflection of the laxness of sexual morality in the urban Native community" (my emphasis, 14). Thus, even though the statistics showed that the large majority of "native" African parents were in fact married, she firmly articulated that "native" Africans did not maintain a high level of sexual morality. She explained that it was not "sexual morality per se" that concerned her, but the effect it had, which was the women's inability to appropriately (according to her standards) discipline their children.

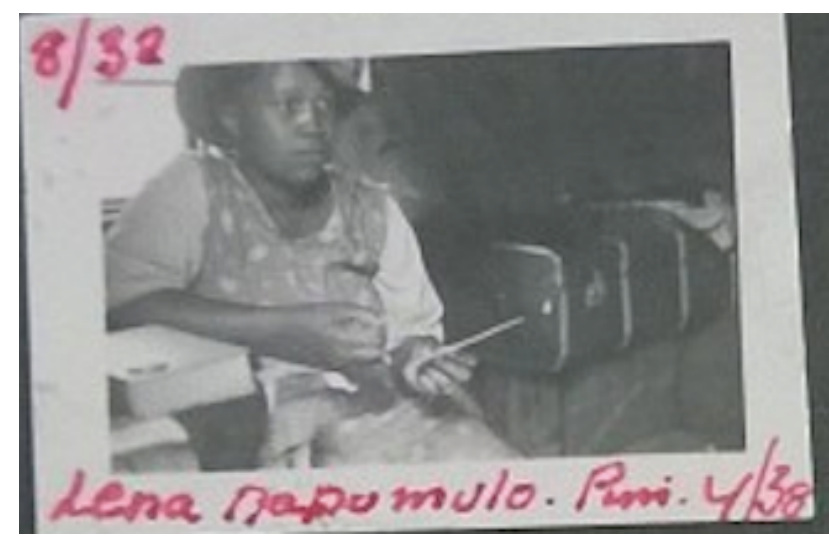

Figure 35. Lena Napumulo was one of the women Ellen interviewed as part of her research in Pimville in 1938 for Problems of Urban Bantu Youth. This photo was taken by Ellen Hellmann and is in Series 8, photo album 31.1, page 48, in the Ellen Hellmann Papers at the Historical Papers Archive.

Hellmann seemed to blame African mothers for urban "problems" rather than assigning blame to the colonial system itself. For a photograph of one of the women Hellmann interviewed in Pimville, see figure 35. Interestingly, Hellmann selected an excerpt from a letter written to Bantu World, December 3, 1938 from A.D. Petersen, which blamed the lack of formal marriage on women's "looseness" -"the terrible

Causes of Early School Leaving and Occupational Opportunities for Juveniles, 19381939" (Hellmann 1939). 
weakness of our womenfolk" for keeping lovers as husbands (1940e:14-15, note 15). Clive Glaser notes that Bantu World was run by African journalists, and represented the views of the African elite, but was financed by conservative white mining houses (Glaser 2000:21). Independent African women's supposed "looseness" was rhetorically connected to their engagement in illegal beer brewing and prostitution. All of these factors were not only causally linked with family "instability" but with the overall "problem" of "juvenile delinquency." The argument was that women's "immoral" practices such as beer-brewing exposed children to illegal acts from a young age, gave women too much independence, and thus caused instability in family formations (Glaser 2000:27, 42 notes 24, 25). Clive Glaser cites an editorial in the Bantu World from October 29, 1938 in which the author claimed that women's belief in their equality with men was connected to children's rebellion against parental control: “...Women have discovered that by selling liquor they can become economically independent of men's controls" - the author associated this independence with familial quarrels leading to the insecurity of family life (Glaser 2000:28, 42, note 26). Glaser importantly notes that both white policy makers and elite black African males used these types of statements about black African women. White lawmakers wished to restrict African migration to urban centers, while elite African males wanted to reassert patriarchal "traditional" values (28). Thus, it becomes clear that Hellmann followed the typical approach among not only whites but also black elite males that blamed black women for the "problems" of urban life including law-breaking, family instability and youth rebellion. 
Class status, family "stability" and assimilation

It seems that the "economically better" group in Hellmann's dissertation study did not display the "problems" to the same extent as the poorer Bantu groups. The wealthier group was half as likely to have unmarried parents and the "school-leavers" group was 3.5 times as likely to have "illegitimate" children as the "economically better" group (1940e:15). She made the same point in 1963 in her essay "The Impact of City Life on Africans" that middle class families tended to be more "stable" and have less “illegitimacy" (Hellmann 1963b:10). Hellmann often mentioned the work of black male researchers when she discussed the African middle class. In this 1963 essay she cited Dr. Nimrod Mkele who was the "best known analyst of the emerging African middle class, its behaviour and values, [he] states that a pattern of 'conspicuous reserve' is beginning to appear" among elite Africans so that they were not buying large American cars, but small or medium British ones (5). She discussed the changes of status for the "African townswoman" who had gained "new authority" and a "more democratic type of relationship" with her husband in which husband and wife shared recreational activities and made decisions together, which freed her from "subordination and submission"; however, she cited Mkele to include the fact that this was not necessarily true in the younger generation of married men who did not take their wives with them for recreational outings (1963b:8).

In 1955, she cited black male sociologists St. Clair Drake and Horace Cayton, the authors of Black Metropolis (1945), in order to support her contention that "middle class status and family stability go together" and that Black middle class norms for behavior, "respectability," and "morality," are those of the white middle class (Drake and Cayton 
1962). Her purpose with this argument was to critique those who would say that African advances would undermine "Western civilization"; in contrast she clarified that the African middle class was becoming more Westernized and European (E. Hellmann 1955a:11-12).

\section{Prostitution and sexually transmitted diseases}

Ellen Hellmann discussed the practice of "back door lovers" in Rooiyard (1948:50) and in her article "Native Life in a Johannesburg Slum Yard" (1935) published one year after she completed her master's thesis research. Even though Marijke du Toit portrays Hellmann as not criminalizing the women in Rooiyard, I found that she did pathologize them with the use of statistics to demonstrate that the high rates of miscarriage and child mortality were related to the high rates of syphilis infection (Hellmann 1948:14, 120-123). Forty percent of the 26 women tested had syphilis, yet Hellmann did not elaborate on the causes such as the colonial situation, lack of health care access or frequent labor migration that caused husbands and wives to not be able to live together $(119,121)$. She did describe the constant migration between rural and urban environments $(20,118-120)$ but did not utilize this as a cause of the high syphilis rates. She also did not connect syphilis with the frequency of prostitution in the yard. She did not seem disapproving of the practice of prostitution, explaining that it was a way for women (even married women) to supplement their beer brewing income by establishing economic-sexual exchange relationships with existing customers called "back door husbands." Illicit forms of financial sustenance enabled women, especially widows and deserted wives, to gain economic autonomy (1948:51). Her tone became disparaging, 
though, when she described a "class of dissolute women" who went from man to man or mothers who pimped their daughters $(1948: 50) .{ }^{55}$

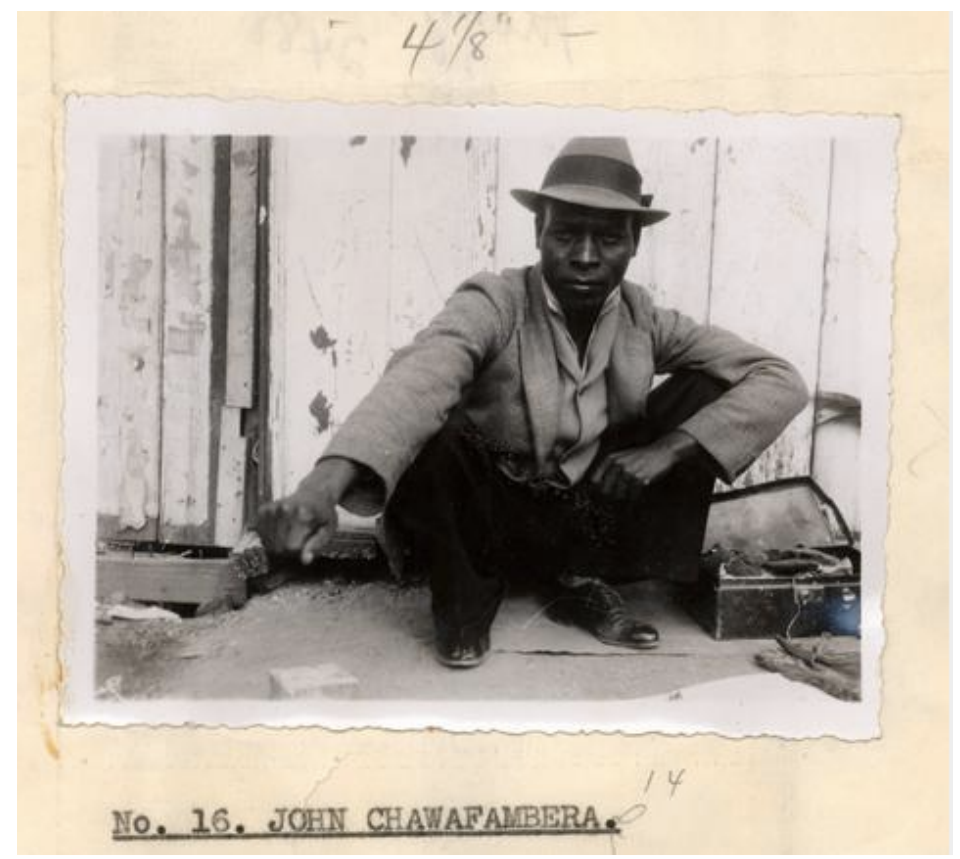

Figure 36. John Chawafambera, 1935, from Rooiyard. Photo taken by Ellen Hellmann. Ellen Hellmann Papers, Subseries 8.2, File 35, ZA HPRA A1419-8-8.2-16

55 The Joint Council of Europeans and Africans used the research of Hellmann and Eileen Krige to argue that beer brewing and selling was how "a great many respectable women supplemented their inadequate family incomes." Yet the Council, of which Hellmann was a leader, was concerned that the "worst" type of woman (with criminal records) was being employed in the municipal beer halls. The Council requested that the Municipal Native Affairs Department give preference to the employment of "respectable married women" and that they should be paid an "adequate weekly or monthly wage" that would never be "much greater than [wages] which can be earned in domestic service, or the income obtained from washing, since it is undesirable to make the selling of liquor the most profitable employment open to women." Also the Council felt that the women beer sellers at the beer halls should not be allowed to run individual kiosks because they thought this would encourage prostitution because it would identify individual women with specific groups of clientele (J. C. of E. and Africans 1939). 
Hellmann's conservative views were influenced by black educated men like John Chawafambera (Figure 36), a Manyika "reliable" informant, who explained the pattern of "back door lovers" to her: "All the women make a business of it. Nobody tells the husbands. Many women are married by lobola only, no court. ${ }^{156}$ Hellmann utilized this statement to argue: "in an environment where adultery, illegitimacy and prostitution, even if not completely condoned, are accepted as social norms, and where lobola is regarded as payment, the foundations of marriage must inevitably totter" (Hellmann 1935:56). By 1960 she would argue that the continuance of lobola led to the delay of marriage and the increase in "illegitimacy" (Hellmann 1960:1-2). This was because black working class men could not afford the lobola payments that girls' families demanded (Gutsche 1952).

Hellmann used the term "illegitimacy" and measured its incidence; she defined illegitimate children as those of unmarried daughters or of other unmarried relatives (usually the wife's sister). Hellmann uncritically posited illegitimacy as a problem and differentiated children in the household based upon these criteria, which may not have matched the evaluations of the household members (1940:15). She even remarked that the women she interviewed rarely, if ever, voiced any "shame or embarrassment" regarding their marital status, since even if they were not formally or legally married either through Western or African customs of lobola (cattle exchange), from their

\footnotetext{
${ }^{56}$ According to Wulf Sachs, John had previously experienced infidelity from a girlfriend (Maggie) when he had been away. Maggie had relied upon "back-door husbands" for economic sustenance, and this likely impacted Chawafambera's views about "back-door husbands" (Sachs 1947:114).
} 
perspective they were married "in the Johannesburg way" (1940:80). Yet from Hellmann's point of view, this was "illegitimate" and "unstable" partnership.

Ellen Hellmann's colonizing portrayals of the "uncivilized" sexual practices of black women was a method to establish white civilized "normal" heterosexual practices ("morality") through women's bodies. Her perspectives demonstrate the continuity of European values from the Scottish enlightenment period. For example, John Millar (1806) believed that a lack of sexual restraint must be met with shame, remorse, aversion, and contempt in order to regulate sexual desire. More "advanced" societies had shame, while "savages" did not (Moloney 2005:242). Millar contended that it was women's position in a society that indicated the society's level of civilization (259-261). Lord Kames (1788) argued that a sign of civilization was for men's sexual appetite to be limited to one female partner otherwise the sexual passion would be diluted and exhausted as happened in "savage" societies (Moloney 2005:256). What made a society "savage" was indiscriminate desire that was not concentrated on one specific woman (239); in contrast "refined" societies placed high importance on desire for one exclusive woman (262). This is an example of how some Jewish women reinforced colonial beliefs and practices that distanced themselves from black and indigenous women while establishing themselves in a position of "civilized" white heterosexuality. As Linda Gordon (2005) explicates, elite women (in this case, elite Jewish women) constructed their own "uplift" through the defense of the "dominion over underdeveloped populations" (19). Thus, Hellmann's case illustrates the ways that Jewish women acted as semi-modern colonial elites who created internal and external minorities based upon race and class hierarchies that were defined by gender and sexuality conformity. However, 
Ellen's history also underscores the disunity created by Jewish subjectivity and experiences of internal colonization. She clearly elucidates evidence of internal colonization, as defined by Ella Shohat: social conformism, forced assimilation, political cooptation, and internalized self-rejection. Hellmann's father's criticisms began when she was a girl, causing her to feel like an "ugly duckling." She also demonstrated evidence of psychic pain, and alienation (through her experience of long-term depression), which Eric Goldstein argues are signs of the Jewish conflict between coercion into whiteness and self-identification as an oppressed minority group. Her articulation of guilt as a motivating emotion for working with both the Jewish community (with the rise of Nazism) and black communities because of her sense that she "owed" those who were "disadvantaged" in a national context in which her skin color automatically gave her privileges, indicates the emotional and psychological effects of the internal colonization process. Even if she privately may have "loathed racism of any kind" and "believed in the absolute rights of black people, passionately," in her public stances, she affiliated with conservative "liberal" bodies that did not advocate a radical reconstruction of South African society but rather a step-by-step pragmatic approach that attempted to achieve gradual progress. Her political positions were also highly connected with her class status and German Jewish heritage, which led her to see herself as belonging in South African whiteness (even if that came with the feeling of guilt) but simultaneously to advocate for Jewish uniqueness (as long as it did not interfere with belonging in whiteness). 


\section{CHAPTER 3 I TOO BELONG IN THE STRANGE ABSTRACTION OF THE}

\section{DAMNED: RUTH LANDES, GENDERED INTERNAL COLONIZATION AND}

\section{BLACK SEXUALITY AS POWER}

"Landes is a damn fool and a disgrace to the Department of Anthrop. As far as I can see, she has done little or no Brazilian preparation here or anything else, except getting herself sexually involved with colored members of the faculty. Sex seems to be her forte, particularly in its practical aspects." -Rüdiger Bilden (at Fisk University) to Melville Herskovits, December 6, 1937

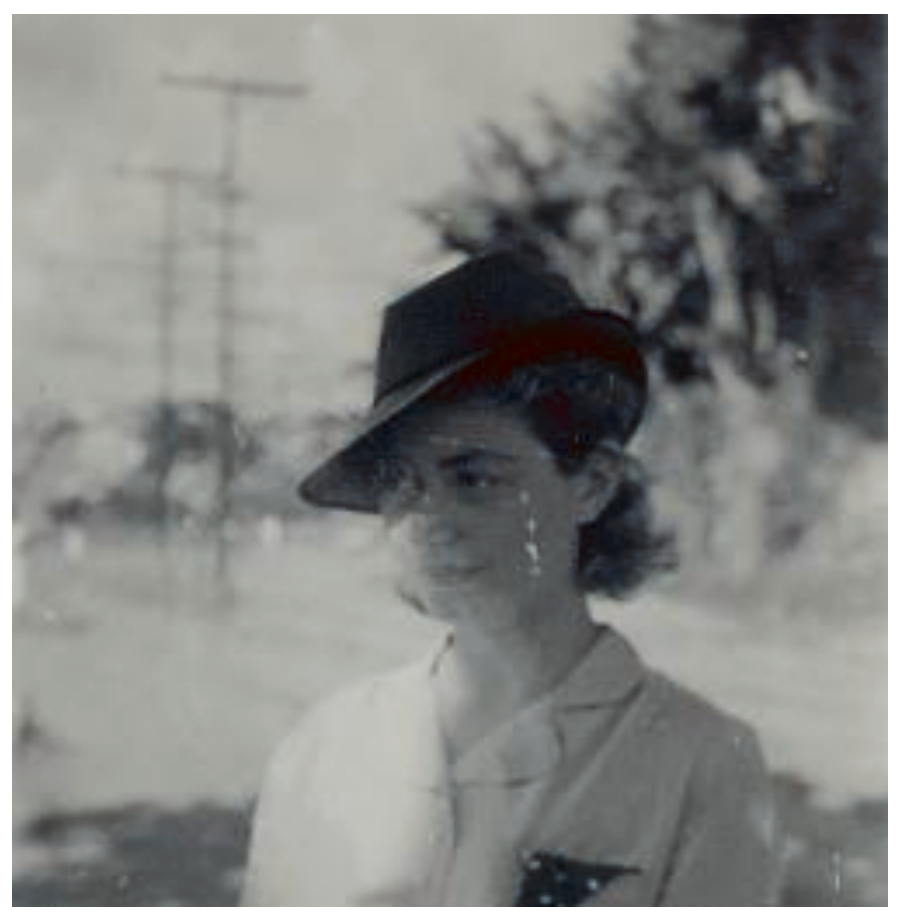

Figure 37. Ruth Landes in Salvador, Bahia, 1938-1939. Image ID: landes_photo_brazil_91-4_0137, Brazil: Bahian blacks and candomblé [3 of 3], Box 62, Ruth Landes Papers, National Anthropological Archives, Smithsonian Institution

As I discussed in the Introduction, historically Eastern European Jews were portrayed as being more politically "radical," working-class, "criminal," and interested in maintaining a separate secular Jewish culture than Western/Central European (including German) Jews who were considered more refined, civilized, cultured and apt to prefer 
assimilation into their host cultures. Also, Western/Central European Jews used Eastern European Jews as an internal minority in order to establish their own belonging within whiteness.

Ruth Landes' working class, socialist family exposed her to the intellectual work of black activists and scholars. Because of these networks, black scholars' theorizing was highly important to her, and she engaged in interracial relationships (both personally and professionally). Landes regarded Edison Carneiro, an Afro-Brazilian journalist and scholar, as her research partner, never her "assistant," and she strongly emphasized his central role in her research in her letters to her teacher, Ruth Benedict, in 1938-1939, in her published ethnography City of Women (1947) and in later reflections (1970) upon her gendered experiences in anthropology in Brazil. A photograph of Landes in Salvador, Bahia, Brazil begins this chapter (Figure 37). Landes' transracial networks strongly impacted her writing as well as her access to institutional stability, thus revealing how "private" or "personal" embodied experiences are necessarily also "public," influencing theory-development and positionality within hierarchies of power. Landes was coded as non-white or black by both black and white academics because of her transracial associations and her controversial theorizing about black women's centrality and power within Candomblé, an Afro-Brazilian religion. ${ }^{57}$ Inversely, Hellmann viewed women-led

\footnotetext{
${ }^{57}$ This conclusion is based on the argument of Mariza Corrêa (2003) as well as Landes' comments upon being included in the Negro's Who's Who and her remembrances of Elmer Imes' statements about Jewish non-whiteness, all of which will be discussed within this chapter.
} 
families as the opposite of development into "civilization" and blamed "immoral" unmarried mothers for the "problems" of "juvenile delinquency."

Ruth Landes' relationships to whiteness and blackness were more ambivalent than Hellmann's. Landes expressed pride in her family's whiteness and often explicitly identified herself as "white," even if both whites and blacks called her whiteness into question (as will be elaborated further in this chapter). This challenges the assumption that Eastern European Jews necessarily worked for separation from the dominant "white" culture rather than assimilation into it. Additionally, when colleagues associated her with blackness, she felt offended; her rejection of the label "black" contests the assumption that an Eastern European Jewish "radical" anti-assimilationist stance in relation to "white" culture, necessarily translated into a desire to be "black" or to be considered "black."

At other times Landes incorporated an empathetic identification or alliance with black women who were in some ways similarly positioned, marginalized, and disadvantaged within gendered and racialized internal colonial contexts. For example, she perceived modernization as negatively impacting both black and Jewish women's freedom of movement, while Ellen Hellmann viewed modernization and adoption of "civilization" as requisites for "Non-Europeans" in order to promote South African economic development. Subsequently, Landes questioned the traditional theoretical dichotomies between modern and non-modern and West and non-West through her explicit identification with Candomblé priestesses in Bahia. Hellmann reproduced these established conceptual divisions. 
Ruth Landes complicates the typical representation of Eastern European Jewish working-class radicalism, while Ellen Hellmann's wealth, “civilized” German Jewish identity, marriage to Jewish men and three-decade tenure at the South African Institute of Race Relations, created a more typical Western or Central European Jewish approach to assimilation. While Herskovits accused Landes of becoming too close to her research participants in Brazil, Hellmann maintained an "objective" distance from black communities, and especially black women. In contrast to Landes' representation of Edison Carneiro, Hellmann referred to John Chawafambera and Conference Setlogelo as her research assistants, informants or translators.

In Part I, I discuss the class and political affiliations of Landes' parents, and how these initial orientations impacted the ways that she discussed her own Jewish subjectivity in relation to whiteness and blackness and how she made analogies between anti-Semitism and anti-black racism. The first part of this chapter underscores the dissonance between Landes' desire to be seen as white and the pain and alienation she felt upon discovering that others (both black and white) did not see her or Jews in general as white. In Part II, I emphasize how her theorizing about women of color emerged out of her familial origins and the personal and professional networks those origins facilitated. Thus, this chapter illustrates the impact of transracial networks on Ruth Landes' theorizations about women of color and her Jewish subjectivity. It also reveals the process through which Jewish elite men of Central European descent (like Melville Herskovits) marginalized Jewish women as a response to the experience of internal colonization. 
Part I: Jewish family backgrounds and Jewish subjectivity in relation to

whiteness/blackness

\section{Ruth Landes' Eastern European Jewish socialist origins}

Great Artists: David Pinski, Yiddish Playwright

The Pinskis and Schlossbergs in Israel

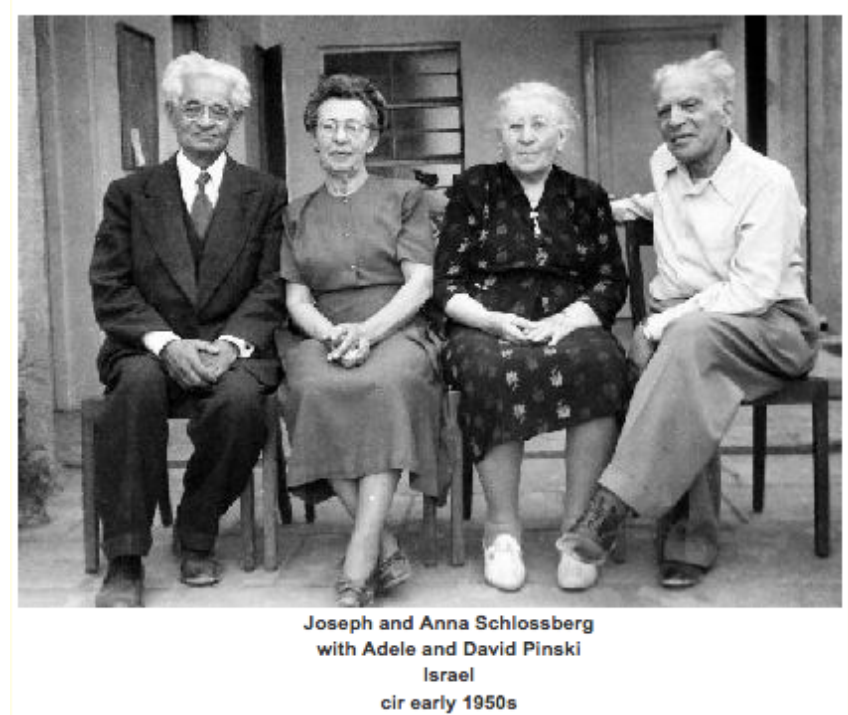

Figure 38. Joseph and Anna Schlossberg are on the left. Adele and David Pinski, Anna's aunt and uncle are on the right. Photograph is from the Museum of Family History Website.

Landes' father, Joseph Schlossberg (1875-1971), was born in the Jewish Pale of Settlement ${ }^{58}$ in Czarist Russia in a small town called Koidanov, now called Dzerzhinzk. Born into a poor family, his father was a tailor (and a Talmudic scholar) and his mother a

${ }^{58}$ Immanuel Suttner defines the Jewish Pale of Settlement as "a Jewish 'bantustan' in which Jews were forced to live by the Tsarist Russian government." Thus Suttner makes an analogy between the territorial segregation experienced by Eastern European Jews and the homelands where black South Africans were forced to live by the Afrikaner government (Suttner 1997:632). 
domestic worker (Cole 2003:22-23). In contrast, Anna Grossman Schlossberg (18811976), Landes' mother, was from a well-off and educated Bundist family in Russia. ${ }^{59}$ Joseph Schlossberg became a socialist Yiddish journalist, trade union organizer and Labor Zionist (Cole 2003:22-26; Schlossberg 1935a, 1935b, 1942, 1947:x-xi, 1948). Anna Schlossberg became a leader in the Pioneer Women's Organization (Na'amat), which was a division of the National Committee for Labor Palestine (Schlossberg and Schlossberg 1956, 1958a).

When her mother died, Anna Grossman went to Berlin with her maternal aunt Adele Koiffman and Adele's husband David Pinski (1872-1959), a Yiddish leftist playwright and journalist, who became a central figure in Anna's adolescence (Cole 2003:20, 21, 253-54 n.3; Pinski 1999:21). A photograph of the Schlossbergs and the Pinskis began this section (Figure 38). In 1900, Anna Grossman moved with the Pinskis to New York where David Pinski attended Columbia. David Pinski was fleeing Russian persecution because of his radical politics, which were Bundist and then Labor Zionist (McGee 2004). In 1905, Anna met her future husband, Joseph Schlossberg, through one of her uncle David's open houses for artists and political radicals. Adele financially supported David, and Anna (Grossman) Schlossberg offered to support Joseph through her work in her aunt Adele's medical massage practice (Cole 2003:22-23).

\footnotetext{
${ }^{59}$ Bundism was based in Marxism and involved devotion to Yiddish and secular Jewish nationalism within Eastern Europe. Bundists were opposed to Zionism and other global Jewish identities (Cole 2003:20, 253-254 n.3). Joseph Schlossberg explained that the Bundist influence on Russian immigrants, who came to the U.S. after 1905, caused trade unions to be anti-Palestine (Schlossberg 1947:xv-xvii).
} 
David Pinki's plays were about the Jewish working class, conflicts within Jewish communities, internalized anti-Semitism and self-hatred, and Jewish leadership. They were not sentimental and were more pessimistic and realistic than those of Sholom Aleichem, whose plays were known for their nostalgia for the old country (Pinski 1918, 1999). Pinski depicted working class people who sought upward mobility but "found themselves beaten by powers greater than their own" (Pinski 1918:vi). In his 1899 play, Isaac Sheftel, Pinski portrayed the hopeless despair of poverty, the betrayal of working class Jews by wealthier business-owning Jews, the belief that God has abandoned the poor and the sense that "I can't accomplish what I feel in me- chains fetter my hands, heavy weights oppress my mind" (Pinski 1918:76). Pinski critiqued the lack of consensus within Jewish communities, which divided assimilationists, Zionists, socialists, pious Jews and those who wished to convert to Christianity. He believed that the Jewish people should "throw off the yoke of the old religion and become a modern secular nation" (McBee 2004). Ruth Landes' shared her great uncle Pinski's interest in intra-group class differences and conflicts (Landes 1947, 1949:5, 1960:11, 1965:294, 1985a:20).

For example, in her unpublished fictional manuscript, $A$ Chronicle of Bloods, based on her year at Fisk University (1937-1938), Landes portrayed the divisions within black communities based on class and color; similarly, black sociologist E. Franklin Frazier (whose writings Landes cited in her 1933 master's thesis Negro Jews in Harlem) believed that there was a large gulf between black elites and folk people that could not be bridged, even with race consciousness (Matsumoto 2005:57). In "The Black Matriarchate" Frazier briefly discussed colorism between Southern blacks and mulattos; he wrote that mulatto women would rather be white men's concubines than a "nigger's 
wife" (Frazier 1939:129). In A Chronicle of Bloods, Landes portrayed a wealthy lightskinned black family from Washington D.C. The mother, Mrs. Crowe, seemed sure that her white-looking daughter, Hortense, could tell the difference between "white" and "us" and "black trash" (Landes 1960:4).

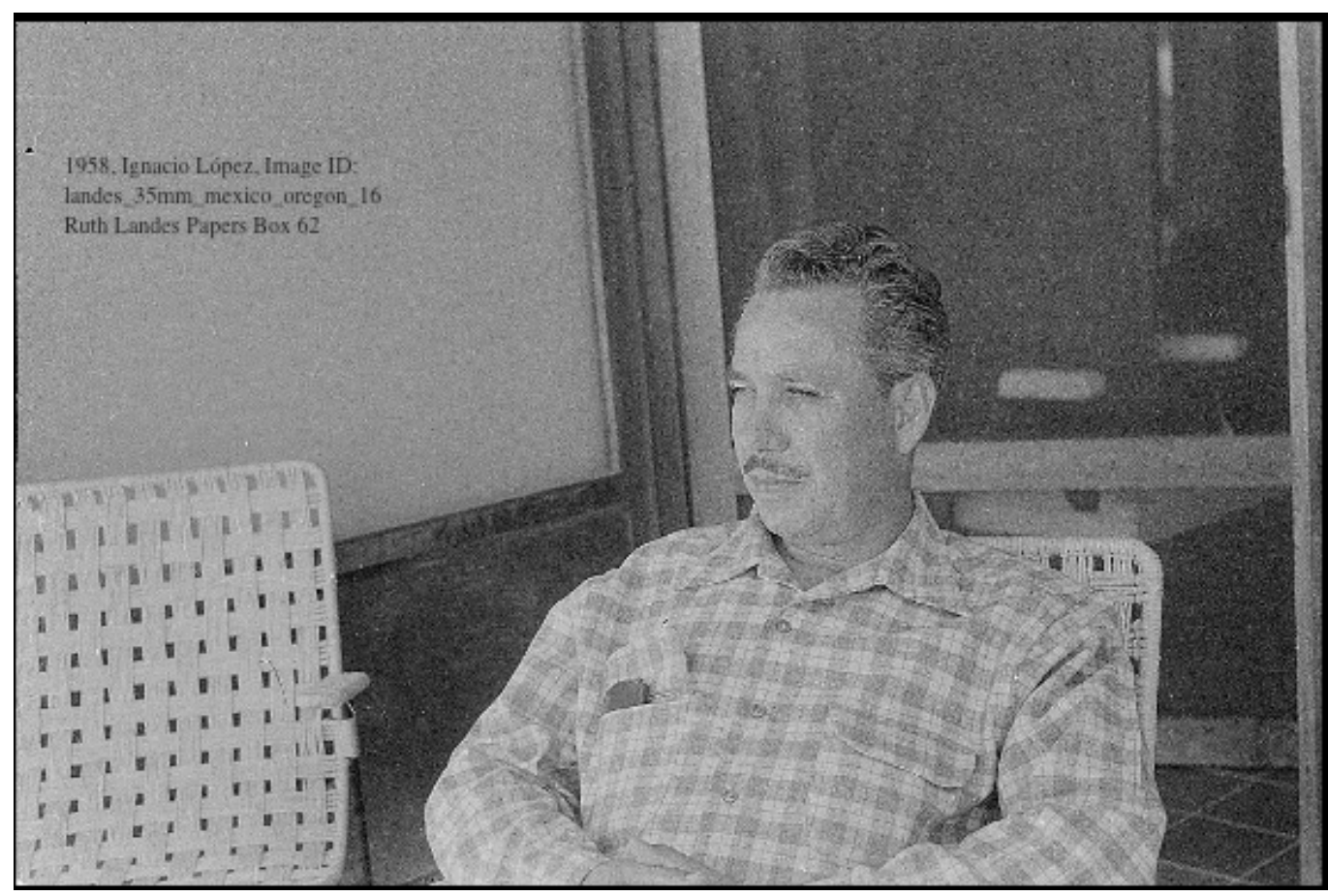

Figure 39. Ignacio López, Landes' second husband, 1958 in either Mexico or Oregon. Image ID: landes_35mm_mexico_oregon_16, Box 62, Ruth Landes Papers

In another example, both Ignacio López (Landes' second husband, figure 39) and Landes were interested in the splits within Mexican communities between braceros, poor Mexican immigrants who came to the U.S. for work, and "zootsuiters" who were young Mexican American youth. López described these youth as "pachuco miscreants" who reflected poorly on the Mexican American community, while Landes argued that pachucos enabled young Mexican Americans to express frustration, experience camaraderie and become leaders. Yet both Landes and López contended that the causes 
of the youth gangs lay in economic and social discrimination experienced by minorities because of dominant groups (Garcia 2001:181-82, 230; Landes 1949:2-3). Figure 40 reveals the intersections between the research interests (themes), disciplinary training, and institutional affiliations between López, E.F. Frazier, and Landes' father and uncle. ${ }^{60}$

${ }^{60}$ I have chosen to exclude data about Ruth Landes in this visualization in order to simplify, and emphasize the connections between the men (Jewish, Mexican and Black) who were influential for her theorizing. 


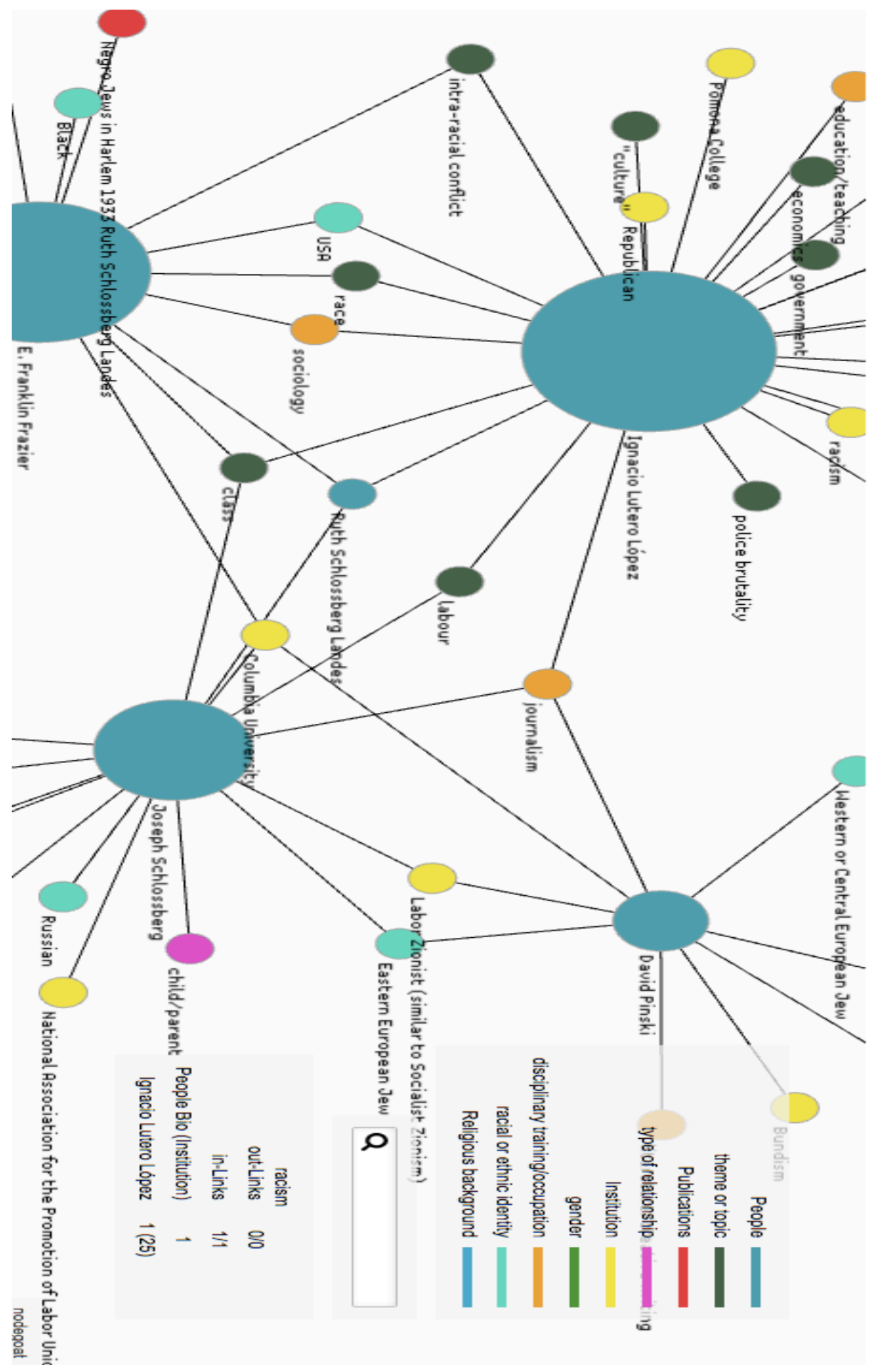

Figure 40. The connections between Landes' father, Joseph Schlossberg, her great uncle, David Pinski, her second husband, Ignacio L. López, and E. Franklin Frazier, a sociologist she often cited. 
Landes' father grew up in a working-class Jewish environment in both Russia and New York City. Joseph Schlossberg and his family immigrated to the U.S. in 1888 because of pogroms, but upon arrival Schlossberg elucidated, "we lived in a new ghetto, separated from the American people by a thousand invisible walls" (Schlossberg 1935b:159, 161). Joseph was only able to attend public school (PS 2 at Henry and Pike Street) from 1888-1889 before he had to go to work in a sweatshop at the age of fourteen, since he was the eldest child and needed to provide for his family (Schlossberg 1935b:161). In a letter to Ruth, her father explained that his year at PS 2 "was the only happy year in my childhood, in Russia and here" and called the sweatshop "hell" (Schlossberg 1959). There was a socialist boarder in his family's house to help pay the rent; this boarder took Joseph to his first socialist meeting. In Russia, Joseph had feared socialism for its associations with nihilism, and killing the Czar and public officials. He joined the labor movement out of frustration when he was forced to leave school to work in the sweatshop; it felt like a vanished promise (Schlossberg 1935b:159, 162).

Joseph Schlossberg considered himself a socialist; he received labor movement schooling in the Socialist Labor Party under the teaching of Daniel de Leon, but Joseph was expelled from the movement in 1917 because of his belief in a united Socialist Party, considered heresy at that time. He argued that factionalism within the labor movement led to fascism in Europe (Schlossberg 1935b:168, 188-189). He was the editor for AbendBlatt, a Yiddish newspaper, from 1899-1902 and then worked for Der Arbeiter, a Socialist Labor Party weekly paper, from 1904-1911 (Cole 2003: 23). From 1905-1907, 
right before Ruth's birth, he attended lectures at Columbia University in Political Science (Schlossberg 1935b:188-189).

Schlossberg compared Marx to Moses and called Marx's Capital the "labor Bible"; he argued that just as Moses taught the slaves to be free and led them through the wilderness to the Promised Land, Marx taught workers how to be free (1935b:166). He believed passionately that the labor movement created workers who were spiritually and intellectually free, without exploitation, but that the labor movement had to be selfsufficient. He maintained that "labor conquers all things" and that "an enlightened and organized working class will make the world free" (Schlossberg 1935b:224). He led citizenship education for fellow workers so that they would able to vote the socialist ticket (167). He advocated against child labor during the depression (Schlossberg 1935b:220). He was anti-militarism and war; he also was outspoken against dictators of any kind and critiqued Soviet attacks on Israel (Schlossberg 1935b:212; Joseph Schlossberg 1959b).

In 1918, Schlossberg became the chair of the U.S. National Committee for the Jewish Labor movement in Palestine, Histadrut. Schlossberg contended that the Americanization of Jews led to increased support for Palestine and a Jewish State (Schlossberg 1947:xiv-xvii). In 1930, Joseph took his first trip to Palestine and he said that the labor movement in Palestine was the only instance in history of an organized working class building up a nation, a "neglected and wasted land." Schlossberg contended that the Jewish labor movement in Palestine had the highest percentage of organized workers in the world, above eighty percent (Schlossberg 1935b:222). He argued that the Jewish people have an "indomitable will to survive" that emerged out of 
their history of "persecution, degradation and massacre." He commended Jews for "entering voluntarily upon a life of great hardship and danger in order to restore to life the virtually dead land and make it again a national home for the people which has been nearly 2,000 years without a home" (Schlossberg 1947:x-xi).

Joseph believed that Jewish socialism created a "pioneering... Moses spirit" that simultaneously built the Nation of Israel and taught "young nations in Asia and Africa how to build a democratic society - a new kind of internationalism" (Joseph Schlossberg 1959c:6). Schlossberg saw a link between Zionism and other post-colonial liberation movements.

In a letter to George and Alice Park, Landes described her father:

...beautifully mannered, genteel, gracious, etc. And when he retired from the NY [Board] of Higher Education, I listened to the chairman (a scholar, can't recall his name) address my then 80-year-old father, 'Joe, to know you is to love you.' Had you meant to contrast him with the Teamsters? I recall his telling us at home that some anti-union thugs had come into his office (Secretary-Treasurer), laid pistols on his desk, and delivered ultimata. But he was unmoved, as ever (Landes 1985d).

Joseph Schlossberg and Hellmann's father, Bernard Kaumheimer may have both come from poverty, but Kaumheimer was a German Jew who built wealth from trading and continued to work in the retail/trading industry, eventually accumulating enough wealth to build a mansion in the upscale Houghton neighborhood of Johannesburg in 1936. In stark contrast, Schlossberg was a Russian Jew born in the Pale of Settlement who worked in sweatshops and continued to advocate for workers as one of the founders of the Amalgamated Clothing Workers of America. He considered himself a socialist, while Bernard Kaumheimer criticized his daughter Ellen for her "radical" views. Landes and 
Hellmann also differed markedly in their relationships to their fathers. Landes clearly admired her father, using words such as "genteel" and "gracious" to describe him, while Hellmann portrayed her father as emotional abusive, telling her she did not belong in their family of beautiful women.

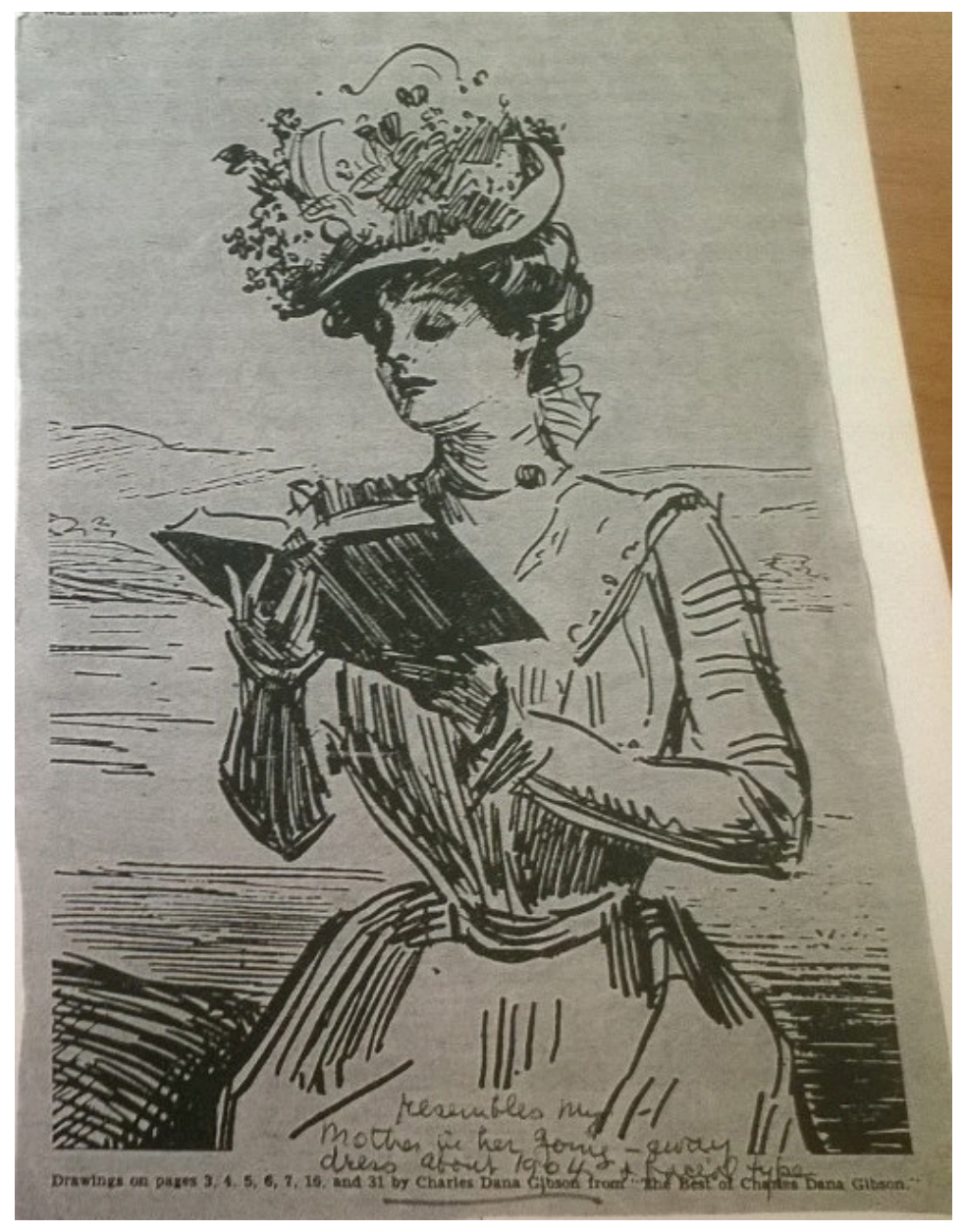

Figure 41. Resembles my mother in her going-away dress about 1904 and facial type, Landes wrote at the bottom of this drawing by Charles Dana Gibson. Box 60, Ruth Landes Papers

However, there are similarities in the way that Hellmann and Landes depicted their mothers. Hellmann described her maternal grandparents as being concerned that 
their daughter Chlothilde Theilheimer was "marrying down." Landes perceived her mother as a refined, Victorian-style lady. In a folder of clippings, Landes wrote a comment about her mother on the bottom of a drawing by Charles Dana Gibson: "resembles my mother in her going-away dress about 1904 and facial type" (Figure 41). The illustration is probably of the "The Gibson Girl" who set the standard for beauty and proper feminine behavior from the 1890s until World War I (Gibson n.d.; Library of Congress 2013).

Ruth's mother did not seem to feel any desire to remember the Lower East Side, where working class Jews lived.

We have freed ourselves of the vulgarities of the East side and I am not interested in going back five decades. I never lived nor observed the East side but I heard enough about it. It may all be of great interest to Adlai Stevenson and others like him; I know how much your father suffered. He may have developed a certain personality but it took out of him the joy of life. He could never correct that; until this day he does not know how to enjoy things or be happy. Of course it reflects on me - he is still going strong here, speech-making (A. Schlossberg 1959a:1-2).

Anna Grossman Schlossberg's condescension and reproach for working class Eastern European Jewish communities could have stemmed from her experience growing up with her uncle David Pinski, since he was born (1872) in the Belorussian town of Mohilev to a wealthy family who had business connections in the non-Jewish world, and lived outside of the Jewish Pale of Settlement which allowed David to study at Moscow University (Cole 2003:21). David's father was a supplier to the Czar's army and so the family was privileged enough that his father could take David to the theater. Pinski lived in Switzerland, Vienna and Berlin and was part of the modern intelligentsia, editing left wing and literary journals (Pinski 1999:21). In 1896, David and her maternal aunt Adele took Anna Grossman (later Schlossberg) with them to Berlin for David's studies, thus 
Anna would have been exposed to German Jewish intellectual life, an experience that Joseph Schlossberg did not have.

\section{Ruth Landes' perception of her family's and her own whiteness}

Landes perceived Jews as white and was proud of her blondness and what she considered her family's Western European appearance.

I cannot resist declaring that my kinsmen, both sides, were strikingly handsome remaining so until death. My mother's side were blonde and blue-grey eyed in the Russian coloring (but none looked Slavic, but very W. European). My father was an arresting brunette/magnificent head and face; his five surviving brothers and sisters had colorings that ranged from red-head (like his father Matthias) to blonde and chestnut, all but one blue-eyed. (Mendelian ratio?) (Landes 1985d).

Landes emphasized that her mother's side had "W. European" "Russian coloring" not "Slavic." This is reminiscent of Hellmann's emphasis that she was a "Western Jew" and not an "Eastern Jew." Ruth expressed dismay that Black folks, like her significant other at Fisk, Elmer Imes, believed that Jews were non-white (Landes 1985e, 1986f). Referring to her fictionalized memoir about Fisk University, she explained:

The story is told from the outside, I being the chief White Northern outsider character (then aged 27, but there were important involvements with Blacks in this curious American concentration camp ${ }^{61}$ ). The Black middle-class (socioculturally the 'upper-class' in education and income) is ultra-secretive about itself (not like middle-class Jews who of course are White, though denied so by Blacks)

${ }^{61}$ Landes referred to Fisk University, a Historically Black University as a "concentration camp." Although she did not explain this analogy explicitly, she did describe her perceptions of Fisk during the time period she was there (1937-38) to Julian Bach, "just preceding the Nazi war, and immense changes in US race relations. Having re-read a portion of my MS [manuscript] (A CHRONICLE OF BLOODS), I see that the action holds middle-class Negro-White relations, Southern-Northern ones, Black anti-Semitism, Aryan-German anti-Nazis and Jews, German and American Jews, Walter White's internationalism, Negro-White love affairs - all these penned-up on this segregated Jim Crow campus, ringed around by rednecks, KKK, the police and the abolitionist Congregational Church, consequences of Black suicide, rape, etc." 
so I cannot risk approaching a Black University press and EBONY magazine is out of the question (Landes 1985e:2).

In another letter, she told Joe Richardson, who was a historian of Fisk University, "ESI [Elmer S. Imes] told me gleefully that blacks did not consider Jews 'white' so people could spit on them! And Fisk was profiting from [Julius] Rosenwald!"(Landes 1986f) ${ }^{62}$ She interpreted Elmer's joke as an "anti-Semite slur." She also revealed that black faculty both resented Jewish attempts to express "brotherhood" with black people and felt that the Jewish presence at Fisk was indicative of Jews' inferior status. Lewis Jones 'tried bullying us with his 'Communist' line: 'If you were any good, you wouldn't be at a Negro school. I don't believe in your 'brotherhood"” (Landes 1986a:3).

Landes was offended when she was named in the "Negro Who's Who" edited by Paula Harris, while she was working for the Fair Employment Practices Committee (FEPC) as a Representative for Negro and Mexican Affairs from 1941-1945 (Glenn and Wang 2010:7; Landes 1986e:2, 1986h:2). She considered this an offense and an act of what she called "reversed discrimination" and clearly identified herself as the "only white" within the FEPC at the time. "Blacks, of course do a fine job of reversed discrimination. I learnt this when I worked at FDR's FEPC, during the first year the only

\footnotetext{
${ }^{62}$ Like the Yiddish newspapers, she found black anti-Semitism at Fisk ironic considering the financial support from Julius Rosenwald, a German Jewish philanthropist who funded almost one half of black education in the south, operating out of Booker T. Washington's black self-help philosophy. Of course, Rosenwald was part of the social-academic circle Joseph Schlossberg enabled Landes to access. Rosenwald frequently conducted fundraising campaigns for Fisk University in Chicago, the home of the well-known white sociologist, Robert E. Park, who trained E. F. Frazier and who had been Booker T. Washington's secretary (Diner 1995:78-80, 168, 174-75; Landes 1986a:2, 1986g:3; Magubane 2014).
} 
white (by Brig. General Sarnoff's appointment and Walter White's proposal). Still my name appeared in the Negro Who's Who prepared by Paula --? and WW [Walter White] said I could get \$10,000 compensation for that offense..." (Landes 1986d:2).

Landes felt "sick and shocked" when she discovered the existence of antiSemitism in Brazil directed against one of her Jewish colleagues from Columbia University stationed in Rio de Janeiro at the same time as her, William Lipkind. "Dona Heloisa" Torres, the Director of the National Museum, told Landes that Torres did not want to hire Lipkind because of rising anti-Semitism particularly in the military, which Lipkind would suffer from, and so Dona Heloisa "refused to add unnecessarily to my complications" by hiring a Jew (Lipkind). Landes named two other women (Mrs. [Kate] De Pierri and Maria Julia [Pourchet]) who associated Lipkind's unlikeable traits - he was "self-important and self-seeking" - with his Jewishness. Landes remarked to her teacher Ruth Benedict: "what the hell, it is an ugly situation and I can't help feeling sick and shocked over it." Landes hid her Jewishness from these Brazilians: "neither [Dona Heloisa Torres] nor anyone else imagines that I too am a 'semite' and the effect on me has worn so deep that I have to remind myself as they talk, including me with them and excluding the 'others,' that I too belong in the strange abstraction of the damned" (Landes 1939d:1).

Though Landes self-identified as white, she was shocked at the contrasting perceptions of her racial assignment and that of other Jews as non-white. Mariza Corrêa writes that Landes'

affinities, also explicit because of her love affairs with black men, first at Fisk, afterward in Bahia [a northeastern Brazilian state], deserve more attention to explain her long period of unemployment than the attack by Ramos and 
Herskovits... Landes was 'racialized' ... in the North American anthropological context of that era and her trajectory was more similar to Zora Neale Hurston than to her white colleagues, descendants of the Boasian tradition (Correa 2003:176).

Exposure to black intellectuals and activists

Through her father's organizing, Ruth Landes grew up interacting with black activists. In her chapter “A Woman Anthropologist in Brazil,” Landes positioned herself as a black ally. "I was in the avant-garde, with my parents' encouragement, of those who had social relations with Negro peers" (Landes 1970a:119). She mentioned the names of several Black leaders of the "Negro Renaissance" whom her familial contacts gave her access to: Zora Neale Hurston, Alain Locke, W.E.B. Du Bois, James Weldon Johnson, Walter White, Abram L. Harris, Charles S. Johnson, and Aaron Douglas (Landes 1965:vi, 3-6, 1970a). Yiddish newspapers (for which her father wrote for), reported on the "heroic" black community organizing of James Weldon Johnson, W.E.B. Du Bois and A. Philip Randolph. In addition, Joseph Schlossberg collaborated with Randolph and Chandler Owens on the advisory board for the National Association for the Promotion of Labor Unionism among Negroes (Diner 1995:51-53, 202-3, 222-28).

Landes cited Yiddish newspaper articles and the scholarly work of Black male intellectuals and leaders like E. Franklin Frazier, Wilfred Adolphus Domingo, Sterling Spero, Charles S. Johnson, Ira De Augustine Reid, Edgar Grey and E.K. Jones in her ethnographic work, Negro Jews in Harlem (Landes 1933). She utilized the work of Charles S. Johnson, E.K. Jones, and E.F. Frazier to discuss Marcus Garvey’s movement in response to racial discrimination and the black community's sense of betrayal when they experienced "contempt, viciousness and exploitation" and "increased race prejudice" after wartime promises like, “"Make the world safe for democracy' and 'Safeguard the 
rights of minorities."' She explained that black migrants to New York City came from all over the U.S., the British West Indies, Latin America and West Africa, but they shared an experience of residential segregation and ostracism from whites. She cited W.A.

Domingo to elaborate the differences between the racial context in the Caribbean compared to that in the U.S.; in the Caribbean there was a "colored" group in addition to black and white, and class privilege affected perceptions of racial group placement (Landes 1933:4-6).

She was able to go to Fisk University and Brazil because of the networks she was exposed to through her father. Schlossberg connected his daughter with Franz Boas (Landes 1965:v), who linked her to well-known white sociologist, Robert E. Park, who trained E. F. Frazier and Charles S. Johnson and who had been Booker T. Washington's secretary. Boas and Park met through a lawyer friend from the Julius Rosenwald Fund (Rosenwald was a prominent Jewish philanthropist for Black education in the South). According to Landes, Robert Park sent Charles S. Johnson to the Schlossberg home in New York City and then Park and C.S. Johnson arranged for Landes to work at Fisk "to see how Negroes live" as a preparation for her year of research in Brazil (Landes 1986a:1-2; Magubane 2014). ${ }^{63}$ Figure 42 reveals the highly interconnected networks

\footnotetext{
${ }^{63}$ Landes' Brazil study was part of Park's plan to prove that Brazilian race relations were more peaceable than those of the segregated United States and thus could serve as an example for what the U.S. could become (Healey 1998:96).
} 


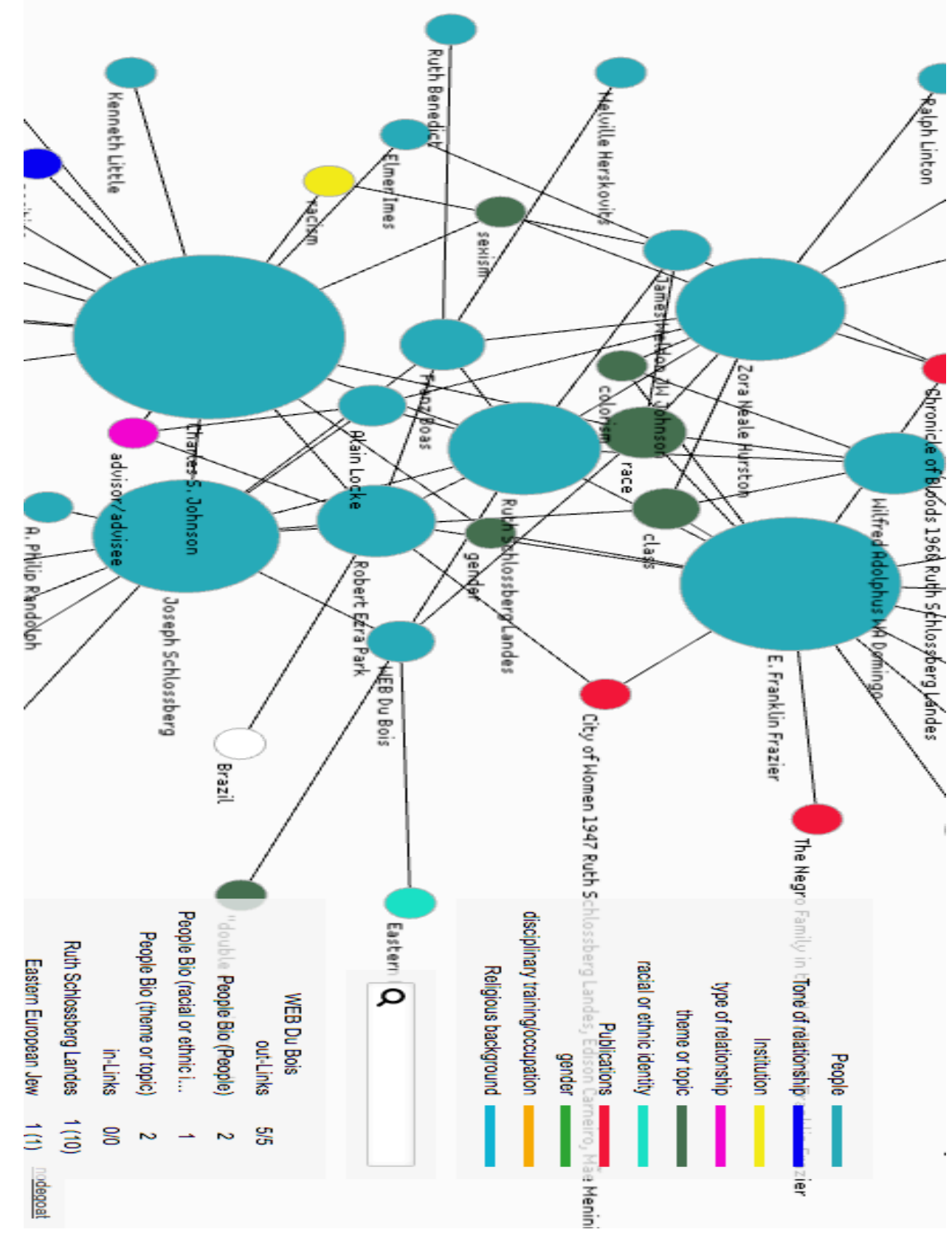

Figure 42. Ruth Landes' black intellectual networks, facilitated through her connections with her father, Joseph Schlossberg, and her teacher, Franz Boas.

between Landes, her father, Joseph Schlossberg, her teacher, Franz Boas, and the black scholars and activists discussed in this section. ${ }^{64}$ 


\section{Similarities between Yiddish newspapers and Landes' writings/Communist}

associations

Landes commented on the influence of Yiddish writers, like her great uncle (David Pinski), on her development as an anthropologist:

From childhood, and since early in my anthropological career, I've known Yiddish language poets and playwrights and story-tellers in English print and personally (e.g. Sholem Aleichem, Singer brothers, Hirschbein, 2 uncles who were early writers in the Yiddish vulgate in Russia (Moscow) and Poland (Warsaw), etc. not to mention the Forwards Bintel Brief [Yiddish advice column] that were translated for me)...(Landes 1983).

This statement uncovers Landes' late-life reflections on the importance of Yiddishkeit (Yiddish/Eastern European Jewish culture) and Yiddish artists and intellectuals on her upbringing and intellectual development as a writer and a thinker; Landes defined "yiddishkeit" as "traditionally prescribed standard of respectability and integrity" required for both men and women, otherwise known as "our own way of life" (Landes and Zborowski 1950:451-452).

Unlike Ellen Hellmann, who used separate strategies to discuss Jewish and Black communities in South Africa, Landes adopted a Yiddish journalistic strategy, which was to make analogies between anti-black racism in the U.S. and anti-Semitism in Europe. Landes was also politically affiliated with socialism (through her father) and communism (through Edison Carneiro). Also in contrast with Hellmann, Landes valued resistance to oppression and challenges to norms, views she held in common with the Yiddish papers, her father, Edison Carneiro and her second husband, Ignacio López.

Yiddish journalists like Joseph Schlossberg drew attention to segregation in labor unions and public facilities and black exclusion from political processes (Diner 1995:45- 
51; Schlossberg 1942). Yiddish newspapers depicted black folks as "America's Jews" and used analogies between the Eastern European Jewish experience of oppression and anti-black racism in the U.S. context. For example, in Yiddish newspapers, white riots became "pogroms," and lynchings were called "autos da fé" in reference to the Spanish Inquisition (Diner 1995:75-76). Landes used this strategy when she called Native American reservations and Fisk University "concentration camps" (Landes 1965:3, 1985e:2). Though "concentration camp" may seem a strange and inaccurate analogy to make with a Historical Black University, Landes seemed to be responding to the "segregated Jim Crow campus, ringed around by rednecks, KKK, the police and the abolitionist Congregational Church, consequences of Black suicide, rape, etc." (Landes 1985e). The Yiddish Press made analogies between the Eastern European Jewish experience of oppression and anti-black racism in order to condemn inequalities within U.S. society, revealing the country's failure to live up to its promises of democracy. Jews believed that their special concern for black Americans "set them apart" from white Americans, and proved that Jews were the truest and best Americans (Diner 1995:28, 43, 75-76, 97, 237). Deploring and condemning cases of racial or religious discrimination was the third most cited issue in Yiddish presses between 1912 and 1920, after rebuilding Palestine and aiding brethren abroad (Soltes 1969:89-90, 95).

In her ethnography City of Women (1947), Landes intertwined a description of the anti-democratic, anti-communist, Getúlio Vargas dictatorship with depictions of German and Brazilian anti-Semitism and anti-black statements upon her arrival to Brazil in 1938. She described the Vargas take-over and the erasure of democratic institutions; any persons who opposed him were denounced as "communists" (2). A government minister 
told her that Brazil's political backwardness was due to "Negro blood" and that subsequently there was a need for the "whitening of the Brazilian race"; this left her feeling "confused and disturbed" (6). Then she provided several examples of how others depicted the northeastern state of Bahia as "African" and dangerous for a white woman. She wrote that in Rio de Janeiro people laughed at Bahians' "African ways"; an American from Georgia told her "You know what those blacks will do" and her teacher in Rio feared for Landes' safety as a white woman alone in Bahia (8). Then directly after this commentary about anti-black statements, Landes depicted the presence of Nazis in Brazil. On the German ship she took to Bahia, she heard "Heil Hitler!" and discussions of pushing Jews out of Germany. She saw portraits of Hitler and the purser on the boat said, "I feel for you, stuck up there in Bahia with all those blacks!" Then he told her: "we need fine people like you" (9-10). Landes did not mention her Jewishness within this opening to City of Women, though the fact that she included her experiences of anti-Semitic and anti-black statements within the beginning section of her ethnography emphasizes her standpoint that the experiences of Jews and Afro-Brazilians were intertwined within that historical moment and geographic location.

However, as was commonplace in that era, she argued that Brazil was free from the racial prejudice and discrimination found in the U.S. and South Africa (Landes 1947:vi, 1954:2-3). However, she highlighted police surveillance by the Bahian government. Secret police followed Landes 24-hours a day because of her associations with Columbia University, considered a "communist" institution, and with Franz Boas, whose research had been thrown into Nazi fires along with her own work on Black Jews in Harlem. She was suspected of being a spy from Moscow because she did research with 
"Negro folk in jungled suburbs." Vargas believed Candomblé communities were protecting and housing communists (Landes 1947:2, 9-13). Most Brazilians who studied in the U.S. went to the Teacher's College at Columbia, and the Bahians who did so were considered communists by the government (Landes 1939c, 1939e).

David Price emphasizes that it was Landes' association with suspected communists like her father, Joseph Schlossberg, and Franz Boas, her teacher at Columbia, that led to her academic exclusion during the McCarthy persecutions. An unnamed supervisor from the Gunnar Myrdal study (An American Dilemma), for which Landes wrote the never published "The Ethos of the Negro in the New World," 65 informed the FBI that Landes was "communistically inclined" citing her ideologies and even her manner of dress. Landes wrote in City of Women (1947) that people in Brazil thought she was a prostitute because of the shoes she wore (11)! Guy Johnson informed the FBI that Landes was "morally loose," known to associate with liberal radicals in New York, and had been forcibly removed from Brazil because of her radical perspectives regarding black Brazilians (Price 2004:228-30).

\footnotetext{
${ }^{65}$ Landes' study was never published because Guy B. Johnson received a negative review of Landes' work from white Brazilian anthropologist Arthur Ramos in March 1940. Ramos asserted that Landes presented "rushed" and "falsified" conclusions that he implied were not based on "prolonged observation" or "fieldwork" and would "pitifully confuse honest and carefully controlled studies of the black personality in the New World" (my translations into English). Of his many critiques of her theories based upon her fieldwork (with Edison Carneiro as her guide) was that "the best-known leaders of the black cult... are men" and that women were only "companheiras" (companions) and were "secondary" in importance to male Candomblé leaders. Ramos argued that women only became "relevant" later because of "new social conditions" (Ramos 1940:3, 6).
} 
Landes' significant other in Brazil and her research partner who accompanied her on almost all her "expeditions," was Edison Carneiro (Figure 43), a "mulato" of a "known family," who planned public utilities worker strikes before the dictatorship of 1937. (Note that her father was also a labor organizer.) Carneiro's work with Candomblés (which were viewed as "nests of Communism") was held in suspicion, leading to his arrest in 1938 (Landes 1947:61). ${ }^{66}$

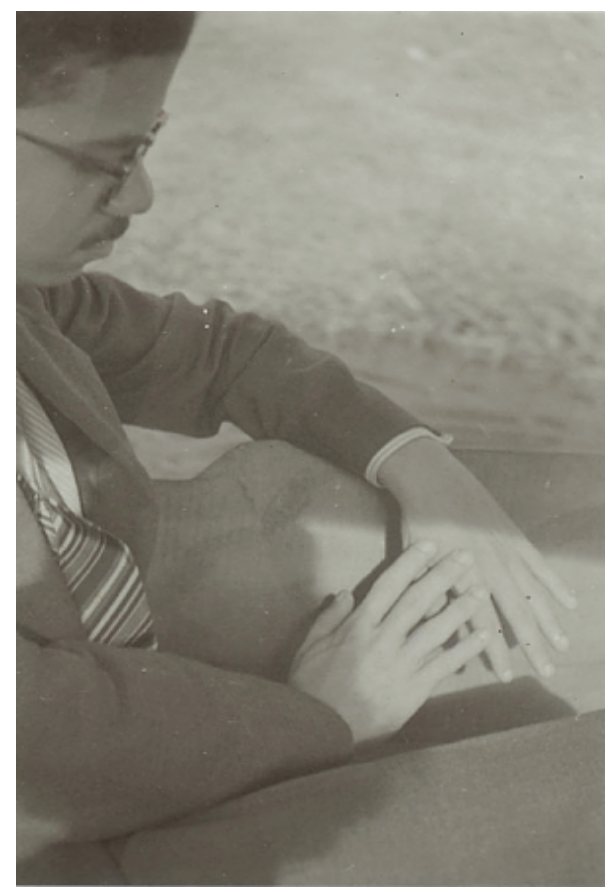

Figure 43. Edison Carneiro, photo taken by Ruth Landes in Bahia on a boat trip they took together, November 21, 1938. Image ID: landes_photo_brazil 91-4_0224, Box 62, Ruth Landes Papers

\footnotetext{
${ }^{66}$ Regarding Carneiro, Landes wrote to Benedict: "without him I could have gotten nowhere with the Negro studies for the cults are hidden and there are some 80 odd scattered around in the jungle and finally it is simply not safe for a woman and a white one to go around alone. He went with me on almost all expeditions..." (Landes 1939d).
} 
However, Landes emphasized that though Carneiro was a "liberal and a radical" she did not consider him a "man of the people" because of his aristocratic dress and demeanor (59). A photograph of Landes and Carneiro walking together in Salvador can be seen in Figure 44. What Landes did not write, was that Edison was a leader within the Brazilian Communist Party in Bahia since 1932-33, supported by his father and elder brother as well as fellow students in the law school who were opposed to the rise of fascism, in the form of Integralismo, in Brazil. ${ }^{67}$

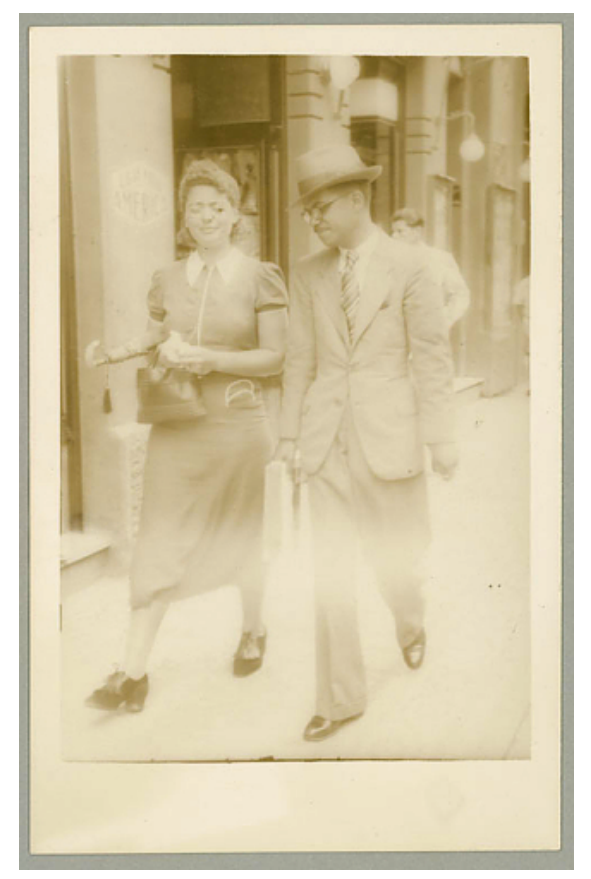

Figure 44. Ruth and Edison Carneiro in Salvador, September 14, 1938. Image ID: ruth_landes_02, Box 63, Ruth Landes Papers

${ }^{67}$ The Integralist movement was a Nazi-inspired, right wing political party that was "the fastest growing Brazilian party after its founding in 1932.” The Integralist party was formed in the context of an increase in Jewish immigration from Europe, a rise in antiSemitism in Europe, as well as increased anti-immigrant rhetoric in Brazil, especially against Jews, who were disliked by both rural and urban elites (Barroso 1999:182-83; Skidmore 1992). 
In fact, Edison's father's home in Barris, Salvador, was the site of the first meeting of the communist cell of Edison's law school (Rossi 2011:140). In his role as a youth and student communist leader, "the Old Teacher" (Mestre Antigo) according to his friend Aydano do Couto Ferraz, Edison took fellow Communist party members to visit Candomblé houses, which were in "popular" or "proletarian" neighborhoods that they normally would not have visited. Carneiro became a public spokesperson for the Candomblés, helping them to gain greater legitimacy, and they granted him access to the terreiros (houses of Candomblé) for his research, enabling Landes' research as well (Rossi 2011:139-144).

As the Yiddish press wrote about police brutality against black people, Landes called police "instruments for the enforcement of white domination" and critiqued police

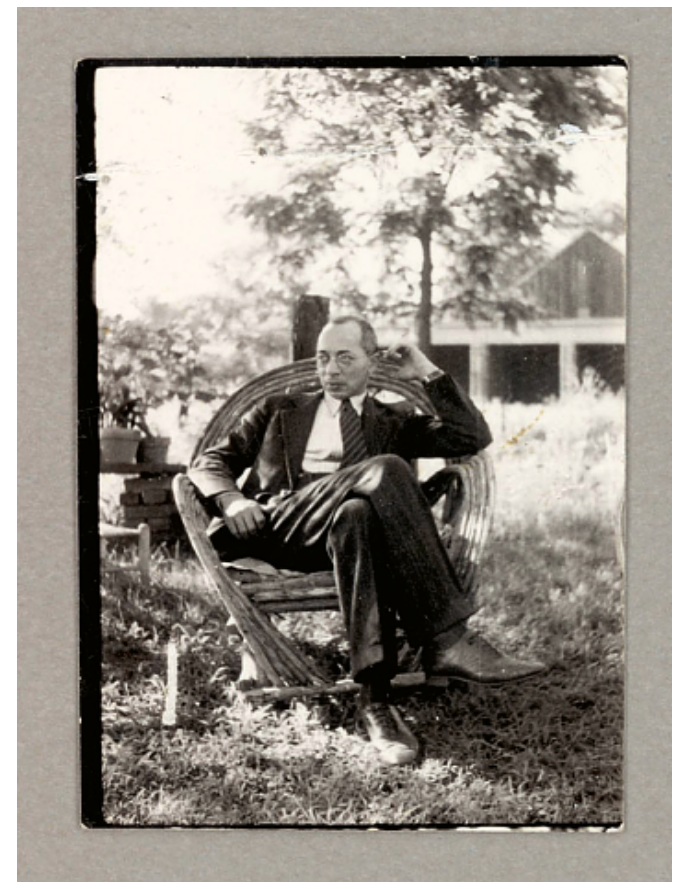

Figure 45. Elmer S. Imes on his lawn at Fisk University, 1937. Handwritten on verso by Ruth Landes: at Fisk on his lawn before my tow time in 1937. Image ID: landes_photo_family_friends_es_imes_07, Friends and Family: E.S. Imes, Box 62, Ruth Landes Papers, National Anthropological Archives, Smithsonian Institution 
harassment of Candomblé members in Salvador, Bahia (Diner 1995:37; Landes 1947:64, 1965:5, 62). Edison Carneiro's activism inspired her: "all characteristic Negro behavior is suffering now from the blight of Police suppression" (Landes 1938d:4). Edison “organized a 'union' of the cults to fight police persecution and preserve their traditions!" (Landes 1939d:2) Her second husband, Ignacio López, a Mexican American immigrant, also drew attention to police aggression toward Mexican American youth in his Spanish language newspaper, El Espectador (Garcia 2001:229, 299). In contrast, Ellen Hellmann did not question the authority of police or teachers to inculcate European values about appropriate citizenship.

Another example of the similarities between Landes' perspectives and those of the Yiddish papers, is her condemnation of Jewish racism. Hasia Diner reports that "AntiNegro sentiment among Jews was a subject of real pain to the Yiddish newspapers and they took every possible opportunity to expose and condemn it" because Yiddish writers felt a "deep psychological bond existed between the two groups" (1995:71, 73). While Landes was living at Fisk University, Joseph Schlossberg came to visit and stayed with Landes' friend and love interest, Elmer Imes (figure 45), a black physics professor. Landes expressed horror that a rabbi in Nashville segregated Elmer Imes in the living room, when Landes, Schlossberg and Elmer Imes visited the rabbi's home. The Yiddish papers pointed to three explanations for anti-black prejudice among Jews: (1) Jews learned racism from Americans and thus racism was "un-Jewish"; (2) Jews distanced themselves from a lower-status group to stabilize their own status in America; (3) since Jews tended to be small-scale merchants with black clientele, unequal economic relationships created Jewish racism, especially in the South (Diner 1995:71-72; Landes 
1986g:3). The connections between Joseph Schlossberg, and Imes, López and Carneiro are visualized in Figure $46 .^{68}$

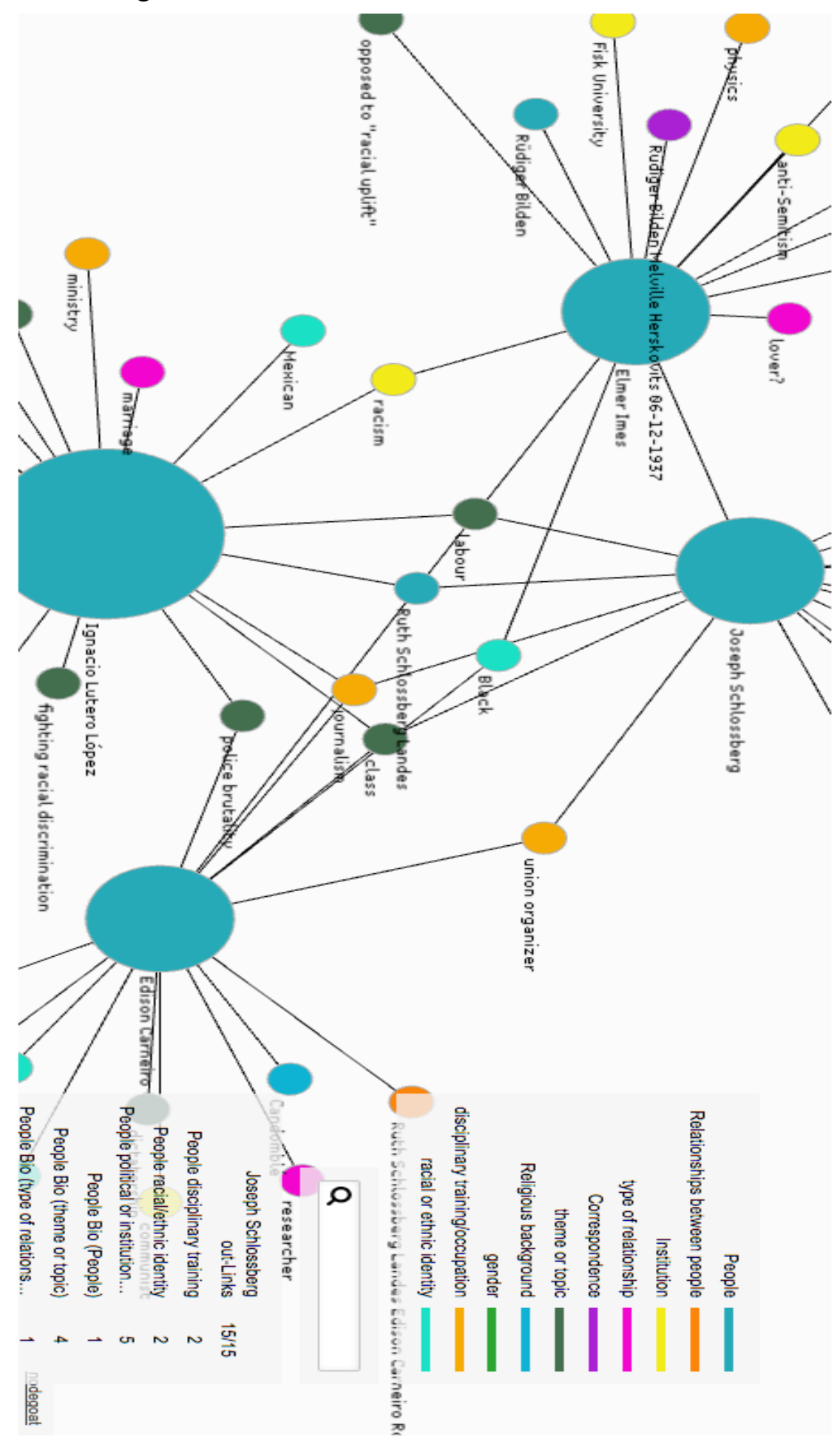

Figure 46. The intersections between Ruth Landes' father and her transracial romantic relationships. 
Resistance to oppression is another continuity between Landes' Jewish background and her theorizing about race. As the Yiddish press applauded those who resisted racial oppression, Ruth Landes viewed Jews and Blacks as the "two most vocal groups in the world" and it disturbed her that (from her perspective) neither black nor Jewish Canadians spoke out against racism (Diner 1995:45-51; Landes 1987e:1). Joseph Schlossberg expressed interest in labor rights in Mexico; he attended the inauguration of President Elías Calles at the invitation of the Mexican Federation of Labor in 1924. Landes investigated cases of racial discrimination and segregation in the workplace when she worked for the Fair Employment Practices Committee during World War II (Landes 1965:7). Through this work and subsequent research with Mexican American communities, influenced by her father's interest in Mexican labor rights, Landes and her husband Ignacio López disappointedly noted that Mexican Americans quietly accepted discrimination. Landes saw the only exception to this trend among the youth gangs called pachucos, which she portrayed positively, demonstrating the continuities between her perspective and that of the Yiddish press: both viewed resistance to subjugation as something to be praised (Garcia 2001:231; Landes 1965:7, 297).

\footnotetext{
${ }^{68}$ For simplicity, I excluded information about Ruth Landes in this visualization. She is pictured only in terms of how she relates to the other individuals.
} 
Landes portrayed American teachers as being primarily middle-class, urban, college-trained whites, and critiqued the American public education system as "the sanctioned practice of the dominant group, which transferred official knowledge through selected agents, called teachers...” (Landes 1965:192). In contrast, Hellmann praised education as a way to teach norms and conformity.

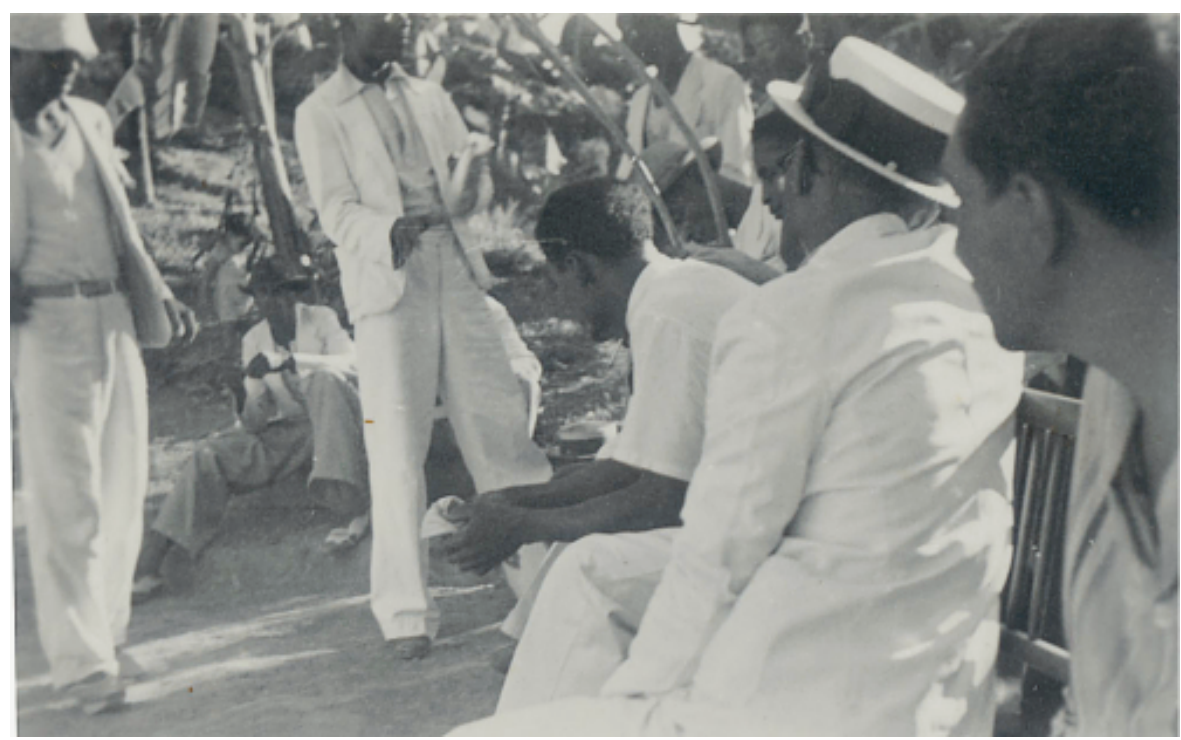

Figure 47. Capoeira musicians, 1938, Salvador, Bahia, Brazil. Image ID: landes_photo_brazil_914_0059, Box 62, Ruth Landes Papers

Landes also highlighted the resistance displayed by men who practiced capoeira (see Figure 47), an Afro-Brazilian martial art (Landes 1947:92, 106). Ruth Landes' emphasis on resistance to oppression, her alliance with socialists and communists, and her relationships with men of color (Edison Carneiro, Elmer Imes, Ignacio López) set her apart from Ellen Hellmann who emphasized social conformity, engaged solely in relationships with Jewish men, and was seen as an outsider "de yeke" (the German one) within the Zionist Socialist movement in Johannesburg. 
Ruth Landes is an excellent counter case to Ellen Hellmann because her theories and experiences were opposite of Hellmann's in various respects. Landes often venerated black women's leadership throughout the African Diaspora; even when her theorizations were over-generalized and to some degree inaccurate they still illustrate her

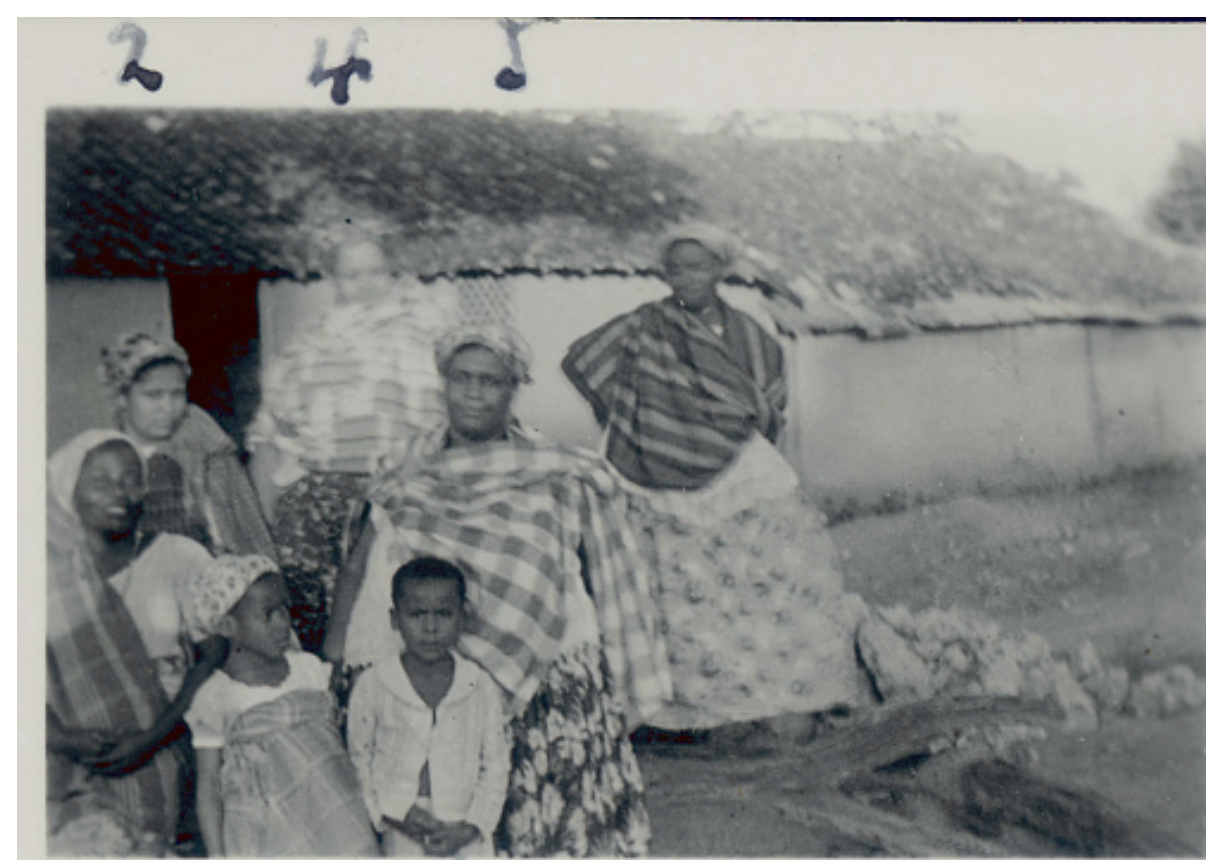

Figure 48. Mãe Menininha, Candomblé priestess of the terreiro called Gantois, in Salvador, Bahia with filhas do santo (daughters of the saint), September 1938. Image ID: landes_photo_brazil_91-4_0126 in Box 62 of RLP

emphasis on women's importance as leaders (Figure 48$)^{69}$ and the connection to her personal experiences of racialized sexism: "in ALL folk black worlds, women are the nurses, midwives, witches, doctors in Africa, West Indies, USA and Brazil” (Landes

${ }^{69}$ On the verso of the photograph Ruth Landes identified each person except for \#7 and in two cases her/his orixá (spirit/god): "2. America, 4. Celena, 5. Menininha Mãe Gantois, in arco-iris [rainbow], 3. Berenice - Omolu [orixa], 6. Xango? [orixa] Alexandre, 1. Adelziza." 
1986g:1-2). Throughout Part II, I present Landes's conclusions, not as accurate assessments of gender and sexuality within black communities, but rather as support for my argument that her theorization of gendered black cultural practices were informed by and linked to her experience of Eastern European Jewish practices and her relationships with black intellectuals and activists (which created a different set of networks than Ellen Hellmann's).

She praised the women-led "matriarchal" family structures and lack of formal marriage she encountered in Bahia, Brazil within Candomblé communities because she argued that marriage would have removed the priestesses' authority (Landes 1940b:261, 268-69, 1947:148, 1953:55-56). Landes' portrayal of black women's sexuality differed from Hellmann's because Ruth viewed sexuality as a form of power that Candomblé priestesses could use to gain increased spiritual authority and financial independence (1947:142-148). She was uninterested in the issues of economic national development that were central for Ellen Hellmann. Subsequently, Landes did not focus on the link between marital "instability," juvenile delinquency and economic underdevelopment as Hellmann did. Landes was more interested in issues of women's individual and community self-determination and resistance to governmental and sex/gender-based oppression. Hellmann was less interested in women as central actors and more preoccupied with the effects of women's behavior on their children, crime, and South African economic development.

As has been discussed previously, Landes viewed Jews and Blacks as "the two most vocal groups in the world" (Landes 1987a). Her emphasis on resistance to racial oppression and her use of analogies that allied anti-Semitism and racism against other 
marginalized groups were strategies frequently employed by Yiddish papers. Landes was an "Eastern Jew," (in Hellmann's terminology) and grew up in a family with strong ties to black intellectuals and activists through her father's labor organizing and Yiddish socialist journalism.

She received training in sociology at NYU (B.A. in 1928) and then social work (M.S.W. in 1929) and anthropology at Columbia with Franz Boas and Ruth Benedict. The life history method was central for Ruth Benedict, who was interested in individuals' experiences of cultural patterns, especially those whose experience deviated from governing cultural configurations and who would be perceived as "abnormal" within American society, especially shamans, gender non-conformers and homosexuals, who were granted unique authority and power within their own cultures (Cole 2002:535-536). Benedict investigated the life histories of those who were "culturally unprovided for" in diverse cultural groups demonstrating how normality and abnormality are contextually dependent (536). Sally Cole (2002) maintains that Ruth Landes built upon these ideological foundations in her work with Native American groups (Ojibwa, Potawatomi, Santee Dakota during 1932-1936) before her fieldwork in Brazil in 1938-1939. According to Cole, following Benedict's theorizations, Landes was highly captivated by individuals who were exceptions to societal patterns. However, Cole argues that Landes' fieldwork pushed Benedict's theories into the realm of studies of power and agency. Even before her Candomblé fieldwork, Landes analyzed the link between shamanism and gender/sexuality transgression (for both men and women) within Native American groups and she emphasized how religious expression could be a site of "resilience," "individual agency" and "cultural creativity" in resistance to the neglect and abuses of the American 
colonial government, including Indian agents, and the prejudice indigenous people experienced daily (536-539). Cole contends that rather than "salvage" anthropology, documenting acculturation and the death of traditions, Landes highlighted "agency and cultural production of people engaged in resistance" (Cole 2002:539). This network visualization of letters to Ruth Benedict from Ruth Landes (and one from Elmer Imes) reveals the content of the conversations between Landes and her teacher in 1938 when she was at Fisk and then in Brazil that I will elaborate upon within Part II (Figure 49). 


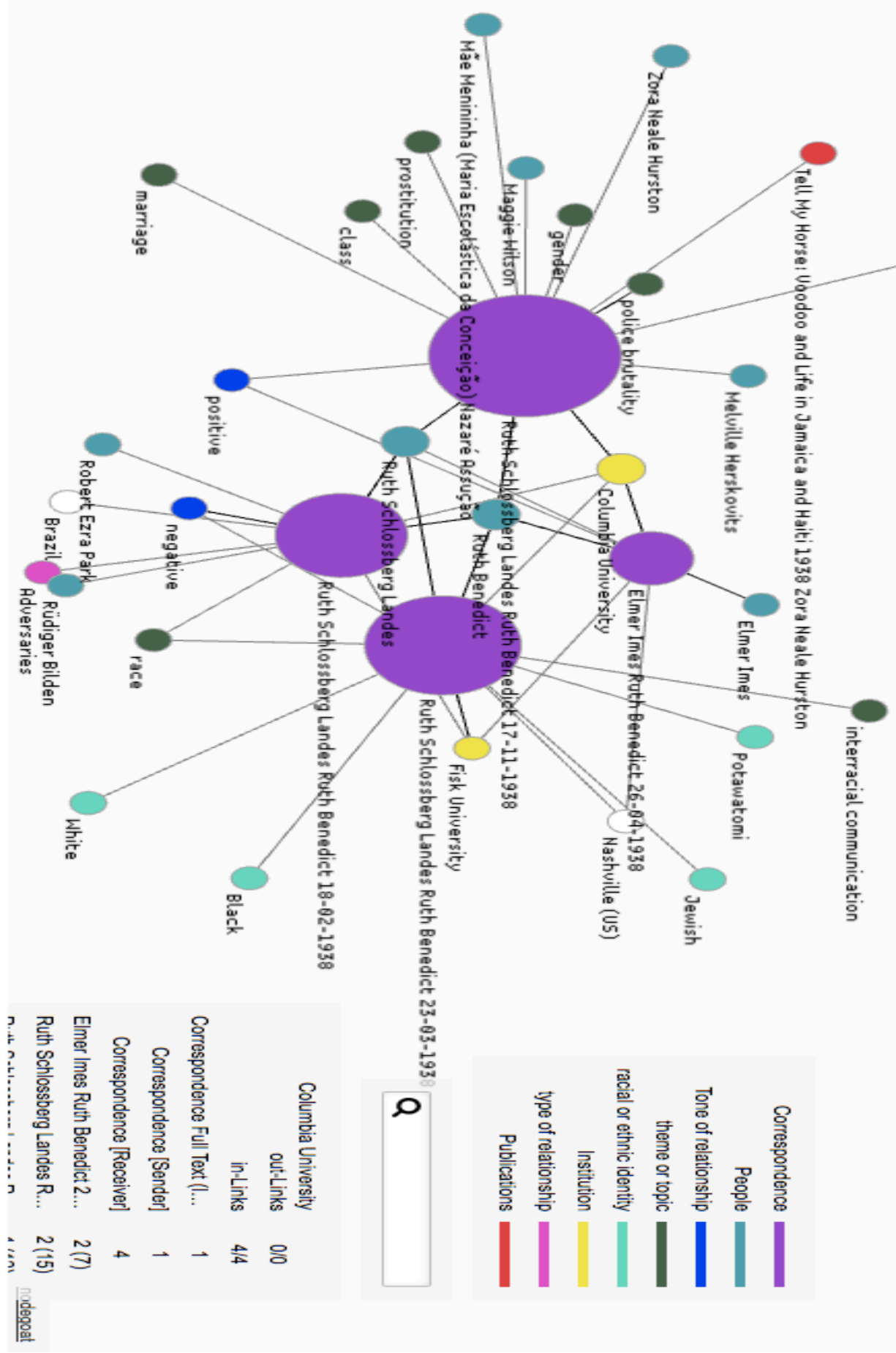

Figure 49. Ruth Landes' correspondence network with her teacher Ruth Benedict in 1938, while Landes was at Fisk and then in Brazil. This visualization reveals the content of Landes' letters including the people, themes, and racial/ethnic groups she discussed, as well as the institutions from which the letters were sent and received. 
After receiving her Ph.D. in 1935 Landes was unable to gain a stable academic position for thirty years until 1965 at McMaster University in Hamilton, Ontario, Canada. During those thirty years, she worked at a different university every few years (Glenn and Wang 2010:4-5).

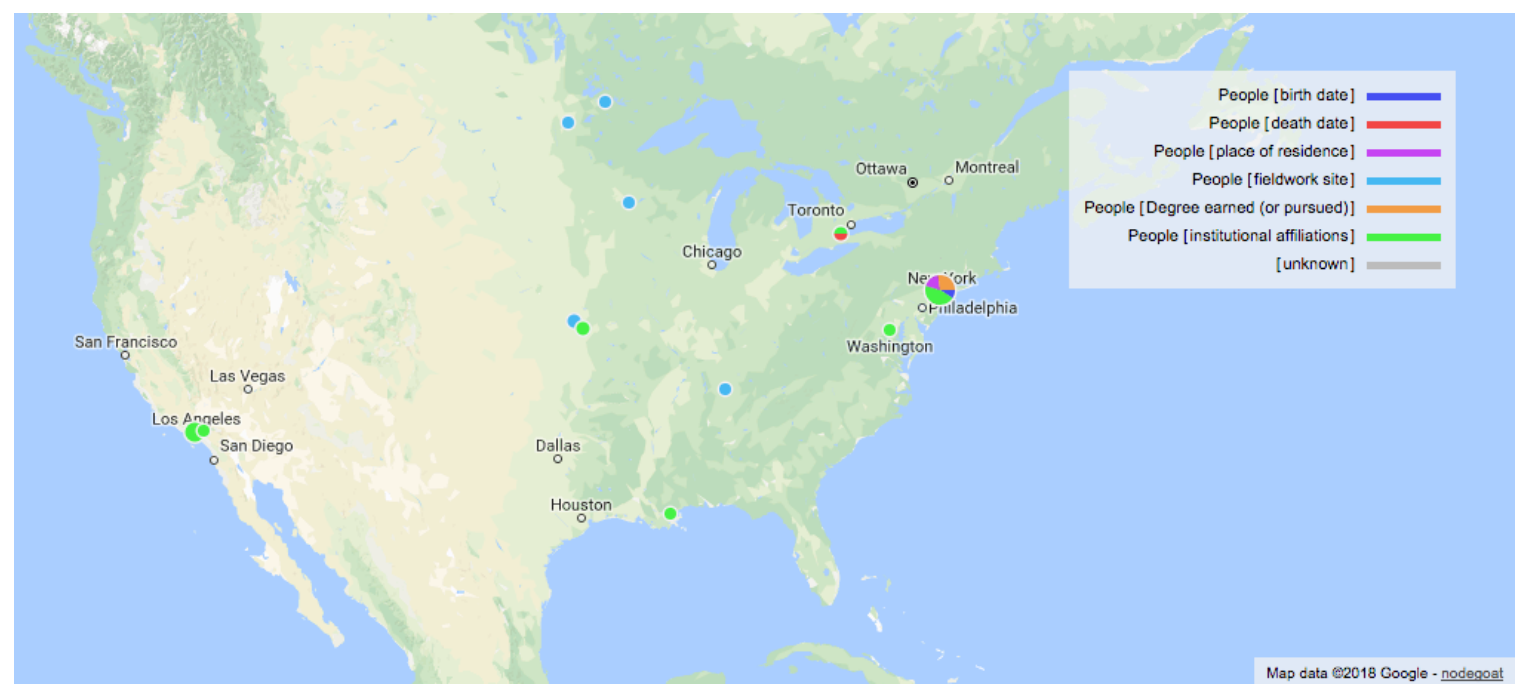

Figure 50. Ruth Landes' professional/institutional instability, represented through her multiple moves across the U.S. and Canada.

This professional and institutional instability (Figure 50) had multiple causes stemming from her divorced/unmarried status and her interracial relationships, her controversial theoretical stance that Candomblé was a matriarchal religion, and the subsequent sexualized and racialized gossip spread about her by a transnational white male network of established scholars including Melville Herskovits, Arthur Ramos and Rüdiger Bilden (Correa 2003:176; Price and Price 2003:84-85; Yelvington 2006:73). While Ellen Hellmann's arguments about black women's sexuality and family structures fell in line with typical stances of both white and black elites in South Africa at the time, Landes' theoretical positions stood in stark contrast with those of the renowned male theorists of the African Diaspora during that period. Her ties to individuals (her father, 
her teacher Franz Boas, and her partner, Edison Carneiro) but also institutions (like Columbia University) who/that were associated with communism and socialism, not only impacted her theorizing but also her ability to secure a stable academic position (Landes 1939c, 1939e; Price 2004:228-30).

I maintain that she did not emphasize marriage as an ideal in her ethnography City of Women (1947:193) because she herself was never in a happy or fulfilling marriage (Landes 1985b). In 1935 (at the age of 27), she divorced her first husband, Victor Landes, a family friend she had met through her family's summer trips to a socialist Jewish resort in upstate New York, because he did not approve of her professional academic aspirations (Landes 1970a:122; Sosnow 1991). This was only two years before she went to Fisk University in 1937 and met Elmer Imes. Landes' theoretical positions and subsequent marginalization were directly related to her own experiences as a divorced or unmarried woman (for the majority of her life) who engaged in interracial relationships, including marriage to Ignacio López and a life-long friendship with Edison Carneiro. She felt the effects of sexism and racism professionally to an extent that other Jewish women who were married to white Jewish men (like all the other women in this study) did not experience. Landes was able to clearly elucidate the impacts of class and color hierarchies on how marital status, extra-marital sexuality and childbearing were perceived both in black and white communities. In contrast to Hellmann, Landes did not apply a negative moral judgment to the unmarried black women she spent time with in Brazil. Since she was simultaneously involved in an extra-marital relationship with Edison Carneiro, she seemed to understand and appreciate their sexual decisions which she argued were based upon the history of slavery and their class positions. 
It is not only important that she was involved in these significant interracial relationships, but also that each of the men of color she became involved with shared and shaped her views about racial equality and justice. Both López and Carneiro were activist journalists like her father, and they both advocated for the rights of their communities (López for Mexican Americans and Carneiro for Afro-Brazilians). She also experienced sexism in each of these relationships (domestic violence with Ignacio and control of her behavior and movements with Edison), which she incorporated into her theorizing about gender in Mexican and Black communities(Landes 1947:196-201, n.d.; Nava 2013:38; A. Schlossberg 1959b:4). For example, in her depictions of Mexican American women from both the middle and lower classes, she revealed the similarities to Eastern European Jewish gendered practices regarding financial support of the family. Landes portrayed Mexican and Mexican American women as the providers of stability within Mexican families; the women were ultimately responsible while the men acted macho and even abused their wives and children (Landes 1949:4, 1965:299). Landes made connections between her research about male abuse of women in Mexican families and her own experiences of abuse in her marriage with Ignacio L. López. She used her experience with Ignacio as evidence for her assertions about Mexican American male aggression, bullying, machismo and dependence on their mothers, even when mothers were distant. She made a comparison between Jewish and Mexican males in how they looked for wives who were like their mothers (Landes n.d.; Nava 2013:38; A. Schlossberg 1959b:4).

Ruth Landes' relationships with black and indigenous women also substantially shaped her theorizations about sexuality and spirituality in the African Diaspora. Landes often referred to Zora Neale Hurston's experiences of sexism from black elite men and 
made comparisons between Zora's fieldwork in the Everglades and Haiti and her own regarding African-based religious practices in Brazil and Harlem (Landes 1938d:2, 1939g:10, 18-19, 31, 1985c).

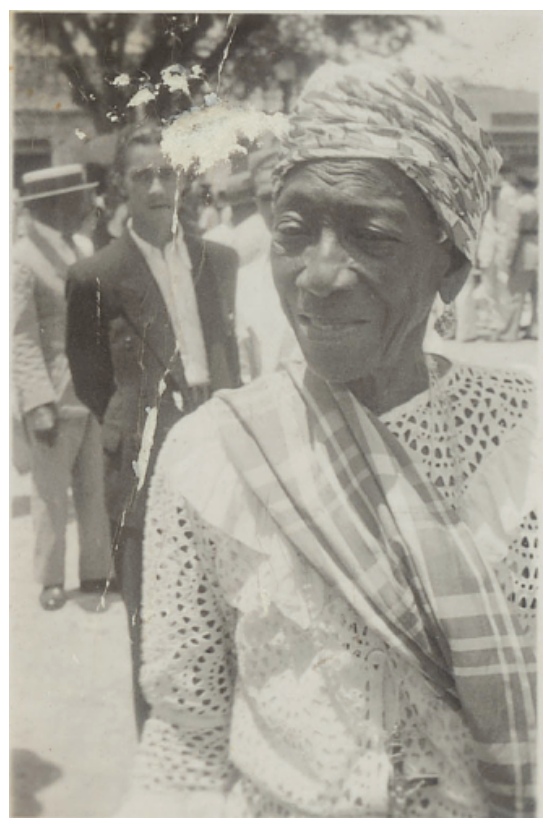

Black Matriarchy

Figure 51. Maria Julia, the most ancient priestess of her cult, said to be over 100 years of age. Lavagem do Bonfim (washing of the Bonfim church), Jan. 12, 1939. Photo ID: landes_photo_brazil_91-4_0001, Box 62, Ruth Landes Papers.

Hellmann's critiques of women-headed families were quite different from Ruth Landes' praiseful arguments about black matriarchy. Landes contended that black women's leadership (Figure 51) was common in the Caribbean, Africa and Brazil, although in Bahia there was a "true matriarchate" (Landes 1940b:269). Landes (1940) elucidated that the Candomblé priesthood was "made up almost exclusively of women and in any case controlled by women" (261). The "mothers" were "trained to rule independently" and have "developed into a type of matriarchy that is not only unique in 
modern times but is anachronistic in patriarchal Brazil” (268). Landes traced black women's leadership in Candomblé to both West Africa and the history of slavery in Brazil. She contrasted the history of "priestly 'mothers' of Bahia with their fierce prototypes of West Africa" (268). She argued that West African women acted as warriors and "rivaled and outdid male colleagues." But she also contended that it was slavery both in Brazil and in the U.S. that "facilitated the evolution of the matriarchal type of black woman, and thus the cult 'mother' continues certain slavery-time values" (268). In City of Women (1947) Landes maintained that a priestess's true affection for a man was shown when she called him "son," another piece of evidence of the matriarchal nature of Candomblés (146).

Ruth Landes referred to Bachofen ${ }^{70}$ in Ethos of the Negro in the New World (1939) in the context of her description of the black "matriarchate" in Bahia, Brazil:

The climax of female power is reached in Bahia, Brazil, where women have absolute control of the religious, and therefore of the political life (my ms. 'Creole Matriarchs'). This is precedented [sic] nowhere in history, and is paralleled only in the conjectures of Bachofen. I can surmise the conditions that led to the appearance of this true matriarchate in Bahia, and they rest chiefly on the constant devaluating of male Negroes during slavery (20-21).

Landes acknowledged that male devaluation during slavery occurred throughout the New World, yet women did not have this same position even elsewhere in Brazil, so "special local developments appear in Bahia" (Landes 1939g:20-21). Many of Landes' views about women's prominence in Candomblé were shared by Edison Carneiro: "In effect the

\footnotetext{
${ }^{70}$ Bachofen (1815-1887), a Swiss anthropologist, associated unbridled sexuality as well as matriarchal societies with an earlier and more "primitive" stage of human evolution. He argued that later, more advanced societies, were patriarchal, suppressing these earlier women-led societies (Gilman 1985:99; McGee and Warms 2008:46, note 71).
} 
spiritual and secular chiefdom of the cult house is in the hands of a woman (a mãe), who chooses her immediate assistant, her right hand, another woman (a mãe pequena), who directs the mass of women (as filhas)..." (Carneiro 1961:141-142). In contrast to Landes' belief that women's leadership in Candomblé was political and public (Healey 1998:102), Carneiro emphasized the private, domestic and feminine nature of women's involvement (Carneiro 1961:142). In the following sections, I will elaborate on Landes' interpretations of the assumed connections between matriarchy and "primitiveness."

\section{Sexuality}

Landes was opposed to the depictions of "primitiveness" and their associations with abnormal sexuality that journalists used to explain her research. Mark Healey writes that her work was often misinterpreted, for example The New York Times printed an article exclaiming: "women leaders of bizarre cults virtually rule the lives of 400,000 natives in the jungles surrounding Bahia, Brazil” (Healey 1998:109; Staff writer 1939). Landes disclosed to her teacher, Ruth Benedict, that she had to censor what the Hearst Syndicate - Kings' features - wrote, since they insisted, "for example that all Negroes have sexual orgies, and that the Negroes thought I was a reincarnated goddess of Love, and that if these things were not true they would have to put them in anyhow for the paper expected it" (Landes 1939f:1). In City of Women, she critiqued the commonly held belief among white Brazilians and Americans, that Candomblé was proof of black people's sexual otherness, backwardness and savagery (1947:130). She negatively evaluated a typical statement that she heard from whites: "The women, you know... they 
dance into a frenzy, then strip themselves naked in the woods and dance some more" (Landes 1947:139).

In The Ethos of the Negro in the New World (1939) Landes argued that the "superior position of women" and their importance in African-based religions was related to the

frequency of common-law marriages, of easy separation, of forms of concubinage, of easy sex, and of unstigmatized illegitimacy. This is reported from every part, even from Saramacca. It means of course that the women and their kin do not protest strenuously, nor do the kin of the offspring. Sexual intimacy and illegitimate motherhood are a woman's two most vulnerable points in our bourgeois white society, but this is not true of black peasantry; of course, assimilated Negroes assume the standards of the dominant group. Loose sexual and marital mores were encouraged by slave conditions and perpetuated by depreciated prestige and poverty ${ }^{71}$... Everywhere it is common for couples to marry for the first time in old age, surrounded by children and sometimes grandchildren; because there is prestige -of a luxury order - to marriage in the church according to white ways (Landes 1939g:29).

Landes clearly elaborated the differences based on race and class that impacted views about extra-marital sexuality. She also tied these different sets of values to "slave conditions" and poverty and highlighted that with class elevation came assimilation into white values, including those regarding sexuality and legal marriage.

However, Landes perpetuated the tendency among white Brazilians to sexualize black women because of her descriptions of sexual-economic transactions between

\footnotetext{
${ }^{71}$ In Frazier's “The Negro Famiy in Bahia, Brazil" (1942) and "The Black Matriarchate" (1939) in The Negro Family in the United States, he voiced a similar assessment of the power and authority of black priestesses in Bahia, but also of black mothers in the U.S. He attributed women's "important" position to "loose family ties," women's roles within Candomble (this is where he cited Landes), and the lack of institutional controls, such as legal or church marriage (Frazier 1942:476-77). He argued that this caused poor black families to assume a "primitive" and "natural organization" (Frazier 1939:125, 1942:477).
} 
priestesses and the men (ogans) who financially supported the women and their terreiros, houses of worship. It was common for ogans to have the sexual privileges of temporary husbands, but only during the periods of time when the priestesses were not "wives of the gods." The priestesses expected these wealthy men to provide admiration and financial backing. Ogans assumed they would receive sexual as well as spiritual services from the priestesses; they considered this more exciting than pursuing commercial prostitutes. Often the priestesses would not accept money directly but would utilize intermediaries for the purpose of collecting money for sexual services. Edison Carneiro said that many of the newer caboclo temples (the ones with male priests, who worshipped indigenous as well as African gods) did this regularly. Perhaps this accusation of the exchange of sex for money was a justification for judging these newer caboclo temples as unauthentic and impure (Landes 1947:145). In a letter to Ruth Benedict in 1938, Landes further explained this sexual exchange between upper class men and poor black women in Candomblé:

Candomble was persecuted dreadfully until a few years ago... But since it has been taken up by the educated and the wealthy in very curious ways. Partly for the amusement and easy women (not that Negro women are the prostitutes, but they are if possible, more independent than the men. So if a man or men pleases them, they take him; and it makes no difference to them whether or not they have children! ... Also the upper class women secretly become priestesses! Upper class men assume the male posts of 'protector'! But on the whole and officially candomble [sic] is scorned and no news or pictures of Negro life are supposed to get out (Landes 1938c).

Landes tried to contextualize the exchange of sex for money by talking about the "easy love-making" that she called typical in Bahia. She posited that it would be considered "brutish, and not virtuous to refuse it"; in fact, she said, even Catholic priests had sex (1947:145). This essentialization implied that Bahians were more sexual, a typical racialized stereotype of the region perpetuated by Gilberto Freyre (Freyre 1968). She 
argued that sexual customs for poor black Bahian women (Candomblé priestesses) were different than the customs among middle or upper-class women. Sex did not mean that a woman wanted a relationship with a man. "The black woman valued her company above rubies" (Landes 1947:193). Landes meant that black women would have sex without a relationship, but would only enter into a relationship with considerable thought.

The poor women she spoke with did not wish to marry legally; they also did not get into relationships lightly. Being in a relationship or in a marriage was not a prerequisite for a sexual relationship. Landes wished to illustrate how their value system operated differently from that of her readers, but she seemed to admire rather than look down upon these practices. "I smiled to see these women who did not care about being dainty. Their concern was to lay claim to where they sat" (1947:83). From her perspective, their sexual and intimate relationship value-system gave them freedom of movement and empowered them to make sexual and financial decisions that wealthier white women, like Landes, could not. She clearly saw how class and race differences created divergent gendered expectations (75-77, 141). For example, Edison Carneiro, who was also her significant other during her time in Brazil, reminded her that she must “act like a lady" and that she must not walk alone (1947:60, 200). Ruth Landes' portrayal of black women's sexuality differed from Hellmann's because Ruth viewed sexuality as a form of power that Candomblé priestesses could use to gain increased spiritual authority and financial success. 


\section{Black women as financial providers}

One reason priestesses did not legally marry was because then they would lose their authority. However, this was not the only reason: black men could not afford the cost of a legal marriage or the responsibilities of a family (Landes 1947:148). In fact, it was the black female Candomblé priestesses who provided for poor black men, who spent time on the terreiro grounds (Figure 52).

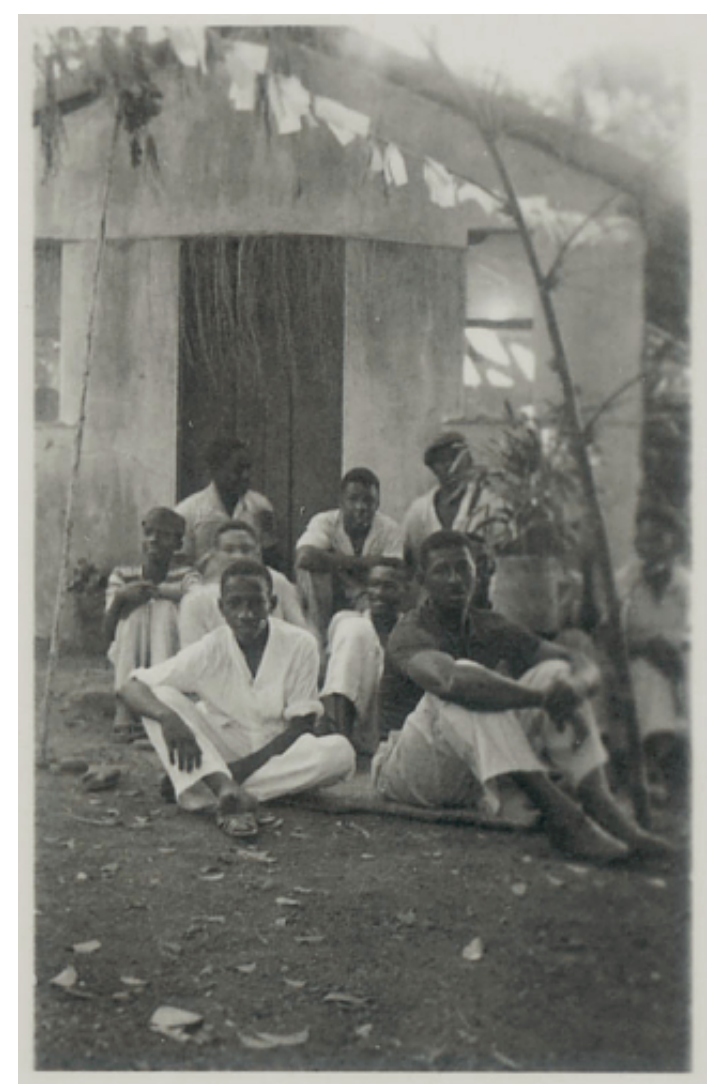

Figure 52. Men in front of the Ogum house (Ogum is one of the orixás, a warrior god) at Engenho Velho, one of the oldest Candomblé terreiros in Salvador, October 24, 1938. Photo ID: landes_photo_brazil_914_0577, Box 62, RLP

Landes called the terreiros "mutual aid societies" (146-147). In a separate essay, Landes (1953) traced the role of black women as providers to the slavery period. White slave owners preferred to name black women not black men as "heads of family" (thus de- 
privileging black men). White masters thus encouraged leadership traits in black women such as initiative, responsibility, endurance and charm (Landes 1953:55).

Thus, a slave family was regarded characteristically as having a responsible female parent but not a male parent, and a child was identified by his mother's given name and by the owner's surname, in a fair reflection of the relationships; a slave family's overtime wages were paid commonly to the woman as head, not to a man, especially in the United States (Landes 1953:55).

Her argument that black women sustained black men can also be seen in her fictionalized works about her experiences at Fisk University (1937-1938), the year before she traveled to Brazil. In A Chronicle of Bloods (n.d.), Landes focused on how men were able to pursue their educations and higher degrees through the tireless work of their women, both present and past, who hoped for marriage in return (Landes n.d.:4). In Color Cancer (1940), a clerk in the registrar's office at Fisk, Carolyn, received a man to her private room with "ostrich-like discretion" and eventually married him secretly. She supported him through medical school, a "frequent arrangement" Landes wrote, "among this class campus folk" (Landes 1985a:21-22).

Another example emerges from her research with a Black Jewish group in Harlem in the late 1920s. She depicted the black Caribbean female membership as being the financial "backbone" of the organization because the women were more steadily employed than their male partners. She also critiqued the ways that male church leaders used sex to "lure" the women into the organization and keep their faithful and lucrative membership (Landes 1933:26). In her descriptions of black women from both the middle and lower classes, she revealed her perceptions of the similarities to Eastern European Jewish gendered practices regarding financial support of the family. 
The continuities between Landes' family and her research can be seen in her analysis of gender roles in relation to class position. Landes argued that though the Eastern European Jewish family was patriarchal and patrilineal, women were the "actual heads of household" who were self-reliant and economically responsible for supporting the family. Yet this authority was contradictory since the wife's role was still "subordinate and dependent" to her husband and she was always under the "overall moral (i.e. talmudic-supported) supervision of male kin" (Landes 1951:10; Landes and Zborowski 1950:448-49, 452). Landes emphasized how class differences within the Eastern European Jewish group impacted gender roles (Landes and Zborowski 1950:448). Among the "upper bourgeoisie" women were not allowed to work independently outside of the home, as they were among the lower classes; this can be seen in the case of Landes' mother (Landes 1951:10). However, women in Landes' family financially supported their husbands for at least some period of time. Adele Pinski, Landes' maternal great aunt, supported her husband, David Pinski. Anna Grossman Schlossberg, Landes' mother, offered to support Joseph Schlossberg, Landes' father, through her work in her aunt Adele Pinski's medical massage practice. However, Landes felt that as a white, middle class Jewish woman she was quite restricted and viewed other women of her class as financially dependent (Cole 2003:22-23; Landes 1947:75-77, 1986g:2). Figure 53 demonstrates the thematic connections between Landes' writings about women in Eastern European Jewish families and black families in the African diaspora. 


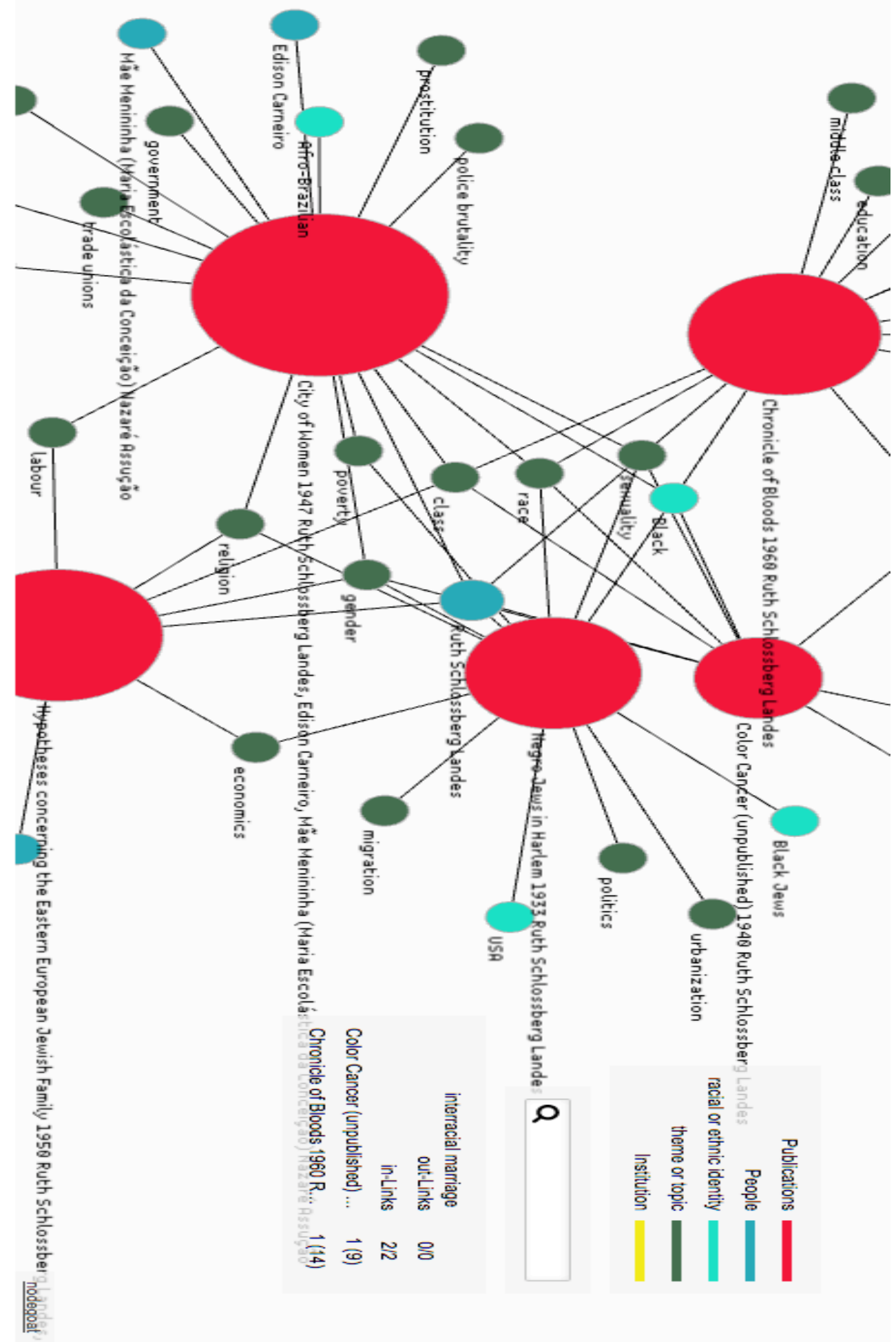

Figure 53. The connections between Landes' writings about Jewish and black families. 


\section{Modernization and women's loss of power}

Mark Healey argues that Landes was part of the typical primitivist stance of the interwar period, in which she saw black Bahian women as unchanging, stuck in the traditions of the past (Healey 1998:89). She, like Ruth Benedict and Margaret Mead, studied the primitive in order to critique the modern (90-91). Healey contends that Landes perpetuated the self/other split, thus she was not as radical as Sally Cole portrayed her to be (Healey 1998:108-109; Cole 2003). Healey further maintains that Landes could not see modernization, flexibility, and dynamism as empowering to women; she only saw modernization as weakening, degeneration, and a loss of women's power (105-106).

Landes' personal embodied experiences of the restrictions and dependence that accompanied her positionality as an ostensibly middle class white woman in Brazil are illuminated in her analysis of the link between modernization processes and women's loss of power in relation to men in Bahia. In City of Women, Landes described a "modern" social dance at the terreiro of Mãe Flaviana that she attended with Edison. This is the event to which Mark Healey directed his critique about Landes' "primitivist" position, though Healey does not consider how Landes' embodied gendered and racialized personal experience of the dance influenced her conclusions. At this event, according to Landes' narrative, priestesses dressed more "modern" in tight dresses and "uplift" bras that emphasized their curves. They also straightened their hair, typically forbidden during Candomblé ceremonies (1947:196). From Landes’ perspective, Carneiro emphasized how different gender interactions were at the social dances than during the ceremonial life of Candomblé because at these dances men had more power 
over the women through one-on-one dancing (198-199). Carneiro refused to dance with Landes because he feared that if the two of them danced together, they would become the objects of study and other men would ask Landes to dance. "You must act like a lady!" he scolded Landes (200).

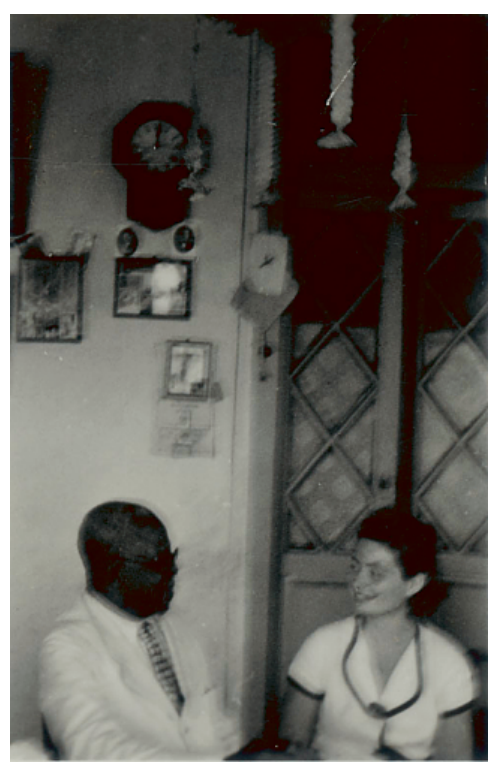

Figure 54. Ruth Landes with Martiniano Eliseu do Bonfim at his home in Salvador, Bahia, August 1938. Martiniano was a Babalorixá (Father of the Orixás), an Ifá diviner who received training in Lagos, Nigeria. Photo was taken by Edison. Photo ID: landes_photo_brazil_91-4_0315, Box 62, Ruth Landes Papers

Landes stated that she had "become African in my prejudices, as African as Martiniano (Figure 54), as Menininha and Luzía" [her key informants] so she perceived the way people dressed and danced as losing themselves. Her assessment, based upon this "African" epistemology, was that the kind of dance they did at this social was not authentically theirs, but was "borrowed from the aristocratic houses in which the women worked" (201). Landes pointed out how Carneiro "had this habit of putting people under a microscope so that they lost any individual uniqueness and suddenly became instead, a congeries of behavior" (197). She critiqued his "aristocratic" demeanor and his way of 
viewing Candomblé people from across a gap, common among Brazilian intellectuals of his class and color, but a stance that Landes called "patronizing and distasteful" (59-60). For example, he told Landes in her narrative, "Here you see them learning to become sophisticated... leaving Africa for the western world and the twentieth century. They are trying to think as we do" (197). With this statement, it is clear that (from Landes' point of view) Carneiro saw them as primitive, while Landes seemed to critique that mindset. Based upon the way Carneiro curtailed Landes' movements, she felt that "sophistication" and modernization weakened her own position, so that she and the priestesses had to become more physically restrained (tight dresses, uplift bras, hair straightened, only dancing with one man at a time) and were not permitted the typical liberties of selfexpression that the Candomblé priestesses experienced during their daily lives in their terreiros. The "modern" social dance created a hierarchical environment in which men disciplined women's bodies, including Landes' body. Carneiro's expectation that she behaved with an aristocratic demeanor caused her to feel resentful. Landes' conclusion that modernization weakened women's position emerged because she perceived her power to be diminished because of her racial and economic position. Landes selfethnographic style and her participation in (rather than just observation of) this "modern" social dance emphasizes Landes' first-person experience and her perceptions of how modernization or "Westernization" could weaken women's power and authority over their bodies and behavior.

In addition, Landes based her conclusions on her conversations with elders within the most established (and oldest) Candomblé houses (like Gantois). For example, Mãe Menininha, the head priestess, or mãe do santo, at Gantois, explained that the Candomblé 
traditions came straight from "old Africans" taught to Menininha by her aunt, Pulcheria, who learned from her aunt, Julia. Thus, according to the priestesses of these "traditional" houses, women's religious power within Candomblé emerged through women's familial historical lineages (1947:82). Interestingly, Landes made a connection to how leadership is passed within the family in Europe, but in the Bahian case, she highlighted how these roles were inherited through the women's line (perhaps this reminded her of the matrilineal inheritance of "Jewishness"). Landes also described how these "traditional" houses led by women perceived themselves to be under threat by new "caboclo" houses, led by men, (oftentimes homosexual) and interacting with $n o n$-Yoruba gods/spirits (37). ${ }^{72}$ Her valuation of Afro-Brazilian Candomblé elders' epistemologies indicates her contestation of typical perceptions of "African philosophies" as primitive, illogical, mystical and needing to be converted to more Western (and "rational") philosophies (Mudimbe and Appiah 1993:117-18).

Landes' depictions of Candomblé practitioners denote her strategy of comparison to her own Jewish family's inclusion of diverse class/culture histories, including her mother's refined musical abilities (invoking images of Central European Jewish

\footnotetext{
${ }^{72}$ By valuing certain "traditional" houses, others were devalued and made illegitimate, especially those with non-heterosexual priests (Healey 1998:89, 106). Bahian intellectuals like Carneiro and Arthur Ramos worked with Candomblé leaders from the "traditional" houses, to establish their superior "primitive African purity" in contrast to the newer, non-traditional houses (caboclo). Intellectuals could utilize this "purity" argument to advocate for the cultural power of Bahia in contrast to the more urbanized Southeast. Since these intellectuals believed that the African element would eventually be whitened, the focus on preserving the purity for these select houses could function simultaneously with the modern whitening project. Because most houses in Salvador were labeled non-traditional and impure, they were seen as needing state "guidance," and authoritarian policies, in order to be properly whitened (Healey 1998:94).
} 
“cultured" tastes) and her father's Eastern European peasant roots. At an axêxê ceremony (a ritual to cleanse the temple after an ogan had died), she compared one of the ogans to her mother: "he was a famed singer, with a repertoire as extensive as my mother's" (1947:228). And then when this same man revealed his comical side, she remarked "he resembled an eastern European peasant in his hearty interpretations and his full-mouthed smile" (229). Thus, the same man encompassed characteristics of both supposed modernity and non-modernity, West and non-West.

I agree with Healey that Landes portrayed Candomblé women as not modern (in some cases), however she articulated how the priestesses she spoke to explicitly claimed "tradition" as their source of female religious lineage and power. For example, when reminiscing about her time in Bahia after she was forced to leave after assumptions about her communist associations led to heightened police surveillance, she reflected on the Candomblé female children she was leaving behind: "These would be the women of Bahia, I thought, and they all would support the temple, mothering their men and their gods. They would know little else, and would keep those near them from joining the modern world. I missed them in Rio" (247). Landes' comment about becoming "African" in her prejudices, the analogy she made between European and Afro-Brazilian familial leadership lineages and between a Candomblé ogan and her own parents, and her critiques of her interpretation of Edison's "aristocracy" and patronizing attitude toward Candomble practitioners, indicate the ways that she contested the conceptual splits between modern and non-modern and West and not-West; she explicitly linked herself and her parents with Candomblé practitioners while simultaneously critiquing an Afro- 
Brazilian scholar (Edison) whom she perceived to be belittling people with whom she identified as coming from a similar peasant class/culture as her father.

\section{Transracial networks}

In a November 17, 1938 letter to Benedict, Landes cited an unnamed "junior experienced priestess" who is the "young head" of "one of the oldest and most famous cults" who was a key informant and research assistant (perhaps this was Mãe Menininha, who is a central character in City of Women and was the head of the terreiro called Gantois). Thus, Landes accentuated Afro-Brazilian women's central role in her research

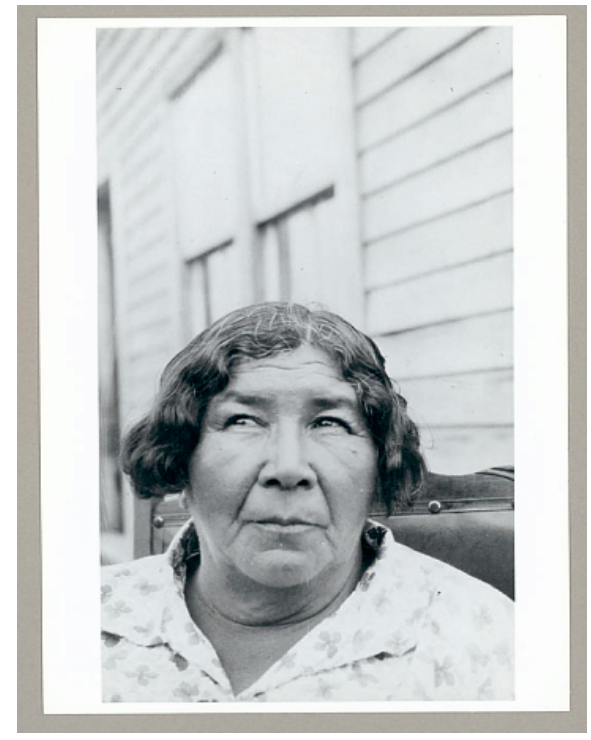

Figure 55. Maggie Wilson in front of her house in Manitou Rapids, near Emo, Ontario in 1933-4. Image ID: landes_photo_chippewa_people_09, Box 62, RLP

in Bahia, as well as the importance of indigenous women informants, like Maggie Wilson

(Figure 55), in Landes' previous fieldwork in Ontario.

She has decided that money is a good enough reason to tell all - tho [sic] it is forbidden to tell of the many elaborate and secret rites that go on in the organization. (I learned this sadly in the past few months, working with the cult 'mothers'; and looking vainly thru [sic] the very extensive Brazilian literature on the subject. This girl is both intelligent and literate, and does better work than 
Mrs. Wilson of the Ojibwa. ${ }^{73}$ She is giving marvelous material, every day. I should like to make the same story arrangement with her as we did with Mrs. W. and it would be cheaper).

This unnamed priestess was perhaps the author of some of the handwritten notes in Landes Brazil Notebooks II and XV (and maybe others too); I noticed a handwriting shift but did not know who took these notes (Landes 1938a, 1939a). Landes wrote of her notebooks: "I now live in daily fear that my mass of notebooks of this material will go astray - I've succumbed to the 'evil eye' dread." Landes also mentioned that she contracted all the illnesses of the girl's family ("colds and fleas and jigger and erysipelas"74 ) since "I all but sleep there" (Landes 1938c:2). Landes revealed to her teacher Ruth Benedict how deeply enmeshed she had become in the Candomblé household and with Candomblé philosophies (evil eye dread); she also indicated the key role this priestess played in creating the data in Landes' fieldwork notebooks that she utilized in her later writings.

\footnotetext{
${ }^{73}$ Maggie Wilson was Landes' primary informant during her research with the Ojibwa in Manitou Rapids in Northwest Ontario in 1933-1934 as part of Landes' dissertation research. Their collaboration led to Ojibwa Woman (1938). Landes paid Mrs. Wilson one dollar a day and then once Landes returned to New York she convinced Ruth Benedict to continue to pay Mrs. Wilson for her stories - fifteen cents per two-sided steno-pad page. "Landes considered Maggie Wilson one of her 'three great teachers of anthropology' along with Franz Boas and Ruth Benedict" (Cole 2009:xi-xiii). According to Sally Cole, Maggie's stories "are full of strong women characters. They document the resourcefulness of women as they overcome starvation, abandonment, abuse and loss" (xxxii).

${ }^{74}$ A jigger is a sand flea, and erysipelas is a bacterial skin infection.
} 
Initially trained in literature at Howard University (1918-1924) with the guidance of Alain Locke, in the years after Zora Neale Hurston started her anthropological training with Franz Boas at Barnard in 1925, she began to perceive herself as a "social analyst" whose focus on "Africanisms" "antagonized the black middle class" (Mikell 1983:28). In the "Introduction" to Mules and Men (1935), which was researched between 1927-28 and 1931-32, Hurston revealed what Sybil Cooksey calls Zora's “double consciousness" as both "Hurston the ethnographer and Hurston the informant" (2010:217):

I was glad when somebody told me 'You may go and collect Negro folklore.' In a way it would not be a new experience for me. When I pitched headforemost into the world I landed in the crib of negroism. From the earliest rocking of my cradle, I had known about the capers Brer Rabbit is apt to cut and what the Squinch Owl says from the house top. But it was fitting me like a tight chemise. I couldn't see it for wearing it. It was only when I was off in college, away from my native surroundings that I could see myself like somebody else and stand off and look at my garment. Then I had to have the spy-glass of Anthropology to look through at that (Hurston 1935:1).

According to Gwendolyn Mikell, the Boasian-influenced Mules and Men recounted black folklore and voodoo myths from Florida in which women guaranteed the "perpetuation of culture... settling scores through spiritualism and voodoo; yet, despite the abuse... struggle alongside their menfolk to survive" (1983:31). In the Ruth Benedict influenced, Tell My Horse, Hurston depicted the gender hierarchies within voodoo practice in Haiti through which female practitioners were at the bottom, while men were at the top. Hurston also emphasized the class critique evidenced through the manifestation of Guedé, the wholly Haitian "god of the common people" who belonged to the "uneducated blacks" and not to the mulattos. Guedé possessed market women and domestic servants who would come before their employers while "'mounted' by this 
god" and utilize the opportunity to "say many stinging things to the boss" (Hurston 1938:219). Hurston valued rural Southern black working-class culture and resented and rejected what she perceived to be the "bourgeoisification" she encountered among Howard students and the expectations that she fit into "New Negro" images of idealized "primordial Africanity," "feminine beauty" and "motherhood to African men" which deeply conflicted with her experiences interacting with black women in the South (Mikell 1999:55-58).

Ruth Landes discussed and cited Zora Neale Hurston frequently, often referring to Hurston's work in the Everglades and Haiti in order to support Landes' arguments about African-influenced religion in Brazil and Harlem. Landes also referred to Hurston's writings about color and class based differences within black communities. She always wrote of Hurston (whom she often referred to as "Zora") with high esteem: "the first Negro" admitted years before 1937 to Barnard, "a Boas protégée and a great black folklorist and novelist...We lost an immense talent to literature and posthumous fame" (Landes 1984c:350). Landes also seemed to identify with Hurston's position within the academy.

Ruth Landes mentioned Zora Neale Hurston in the context of a discussion of Ralph Linton becoming the chair of Anthropology at Columbia in 1937 since the Columbia administration did not want to accept a Jew or a woman (Ruth Benedict was passed over for the position). Landes remarked that she knew from experience that Linton “openly abused women as equal colleagues." It was in this atmosphere that Zora Neale Hurston left the department, "only days after receiving a Rockefeller grant for graduate study" because without Boas, "there was no one to approach about faculty indifference to 
Negro ('black' was offensive then) American Studies and race relations." Hurston asked Landes in a "horrified" tone: "Is this Anthropology?" (Landes 1984:350) According to Gwendolyn Mikell, Zora was forced to leave Columbia because the Rosenwald Foundation revoked her fellowship when Zora insisted on fieldwork-based (rather than library-centric) doctoral training (1999:61). I am unsure if Hurston and Landes were more than academic colleagues, but Sybil Cooksey writes that Hurston invited Landes to an annual writer's tea held in Hurston's honor at Barnard in February 1935 (Cooksey 2010:216).

Both Hurston and Landes struggled in two brief marriages, finding marriage incompatible with their self-directed intellectualism. Both used reflexivity and interpretive styles of ethnography (Cole 2003; Mikell 1999:59). Their sexuality was not confined to heterosexual marriage and thus they were threatening to the elite white male heterosexual patriarchal order. They were unable to be controlled, dominated or protected (Carroll 2011; Colwill 1998; Moloney 2005; Swarr 2012). They did not remain in the private, domestic sphere as middle class women were supposed to; they were not good wives and mothers (Chatterjee 1993).

Landes wrote of Hurston: "If I am right about the absence of black women figures in the university's [Fisk] history, I can suppose only a middle-class pressure against it, and the scorn of black folkways that afflicted the men of Racial Manhood (for which Zora Hurston paid a personal price)" (Landes 1985c). Landes likely associated herself with Hurston's position and treatment, since Landes (a Jew of Eastern European descent whose father had been a sweatshop worker and labor organizer) also paid a personal price 
for not submitting to certain men of her race like Melville Herskovits, a Jew of Central European descent.

Hurston and Landes shared a theoretical emphasis on the impact of race (color) and class on women of color. In Jamaica, Barbados and Haiti in 1936, Hurston noticed that being mulatta and middle class meant that women did not have to endure the hard physical labor that darker and poorer women had to (Hurston 1938:58; Mikell 1999:63). In A Chronicle of Bloods, Landes' unpublished fictionalized account of her experiences at Fisk University, Landes demonstrated her theoretical interest in how the internal color and class-based hierarchies in the black community impacted women (Landes 1960, 1985a). She referred to Zora Neale Hurston through the voice of her protagonist Hortense Crowe, a girl from a black family of "white Negroes" in DC (Landes 1960:1). In a section in which Hortense criticizes another light-skinned Black woman (named Samantha Burton), Landes wrote through Hortense's voice: "You can tell what's wrong [with Samantha] though from her eyes: they're black and long. She must have inspired Zora's cute mot about 'the eyes of Africa looking out of the face of Europe"' (12).

Hortense claims it was Samantha's hair and fairness that attracted Samantha's dark-skinned, "big, fat, low minded" and "woolly" haired husband (13) and that Samantha was with a darker-skinned man so she could feel like a "Southern belle" and would not have to compete with white girls (14). Landes' narrative reveals the competition for status between black women that E. Franklin Frazier discussed in The Black Bourgeoisie (Frazier 1957:218). Hortense's description of Samantha's husband underlines Frazier's and Hurston's point about the black middle-class effort to distance from dark skinned black people (Frazier 1957:226; Hurston 1938:6). 
Landes did not emphasize black women's fear that white women would try to marry black men (as Frazier did), but instead that light skinned black women chose to marry black men because they would confront too much competition with white women if they opted to pursue white men. I would also like to ponder the possibility that the character of Hortense represents Landes' own struggle with passing as white and her interest in the experience of bi-racialism, which she studied in the UK in the early 1950s (Landes 1954; Nava 2013:17-18).

In her writings on African Diasporic religion, Landes often referred to Hurston's fieldwork in the Everglades and Haiti in order to expand Landes' generalizations about African diasporic religious and cultural practices. She cited Hurston's "unpublished" fieldwork in the Everglades ${ }^{75}$ in relation to why African religious practice had not flourished in the U.S. as it had in the Caribbean and Brazil. Landes argued that perhaps studies in the U.S. had not been done in the right places and implied that Zora Hurston might have discovered such practices like "conjure" though Hurston "preferred not to discuss them" (Landes 1939g:10). In Part II of Mules and Men, entitled "Hoodoo," Hurston wrote: "Nobody knows for sure how many thousands in America are warmed by the fire of hoodoo, because the worship is bound in secrecy. It is not the accepted theology of the Nation and so believers conceal their faith" (1935:184-185). Hurston depicted the ritual work of Marie Leveau ("a hoodoo doctor" in New Orleans) through the words of Luke Turner, also a hoodoo doctor, who said he was Marie's nephew. Luke

\footnotetext{
${ }^{75}$ This is probably a reference to Mules and Men, published in 1935, though perhaps Landes did not know that it had been published and had read a pre-published version (Hurston 1935).
} 
Turner told Hurston: "white people say" they saw a "hoodoo dance," but Turner insisted that they only saw a "pleasure dance" because "Hoodoo is private... The white people come look on, and think they see all, when they only see a dance" (191-193). Hurston did describe several "conjure stories" (230-237). Conjuring utilized objects such as coins, candles, powders, or handkerchiefs soaked in blood, in order to somehow cause physical or psychological harm, typically as a form of revenge.

During a discussion of the universal "religious or magical behavior of new world Negroes" Landes stated: "Zora Hurston claims that Negroes universally dread the use of real poison. I know this to be true of instances in Harlem, and even in Bahia, where terrorism is reduced to a minimum. It fits into a sorcery psychology" (1939:18-19). ${ }^{76}$ Another common thread within African Diasporic religion according to Landes was "intimacy" with gods and ancestors. In Brazil, gods are "threatened, spanked, cajoled, starved, indulged, like children" and that this was true also in "Hurston's Haitian accounts" (1939:19). ${ }^{77}$

Within an explanation of the Candomblé initiation process for daughters to be "made" by becoming a "horse of the saint" (cavalho do santo), Landes said that she could not go through the process herself partly because she would not be in Bahia long enough, but she was able to witness the ceremonies as an officer of the Candomblé. This role was one that was taken up mostly by men but also by some women and involved taking care

\footnotetext{
${ }^{76}$ Hurston included a part on "Poisons" within Section IV "Prescriptions of Root Doctors" in the Appendix of Mules and Men (1935:247).

${ }^{77}$ In Tell My Horse Hurston described the importance of the feeding of Voodoo gods and goddesses, for example, during the initiation rites of Erzulie (Hurston 1938:124).
} 
of the altars and temples, protecting and financially supporting the Candomblé, playing instruments, singing and taking care of the possessed. She wrote that she would go through the "tedious ceremony and heavy expense of becoming one in the oldest candomble in Brazil." She made a comparison between the initiation ceremony in Brazil and what Hurston depicted in Florida: "The ceremony has certain resemblances with the one Zora described for herself in Florida" (Landes 1938d:2). In Mules and Men, Hurston described her initiation into hoodoo by Kitty Brown, "a well-known hoodoo doctor in New Orleans" (1935:239). During this ceremony Zora danced, though there was some debate at first about whether she had "gone far enough to dance" (in her training). She previously assisted in running errands, locating materials for medicines, handling patients, and "making 'hands"” - luck charms (240). Zora danced for forty minutes straight, dancers drank liquor to stimulate them, "but the fury of the rhythm more than the stimulant kept the dancers going...no one fell from exhaustion, though I know that even I, the youngest, could not have danced continuously on an ordinary dance floor unsupported by a partner for that length of time" (242). Figure 56 illustrates the thematic intersections between Hurston's ethnographies and Landes' unpublished writings about African diasporic religion. 


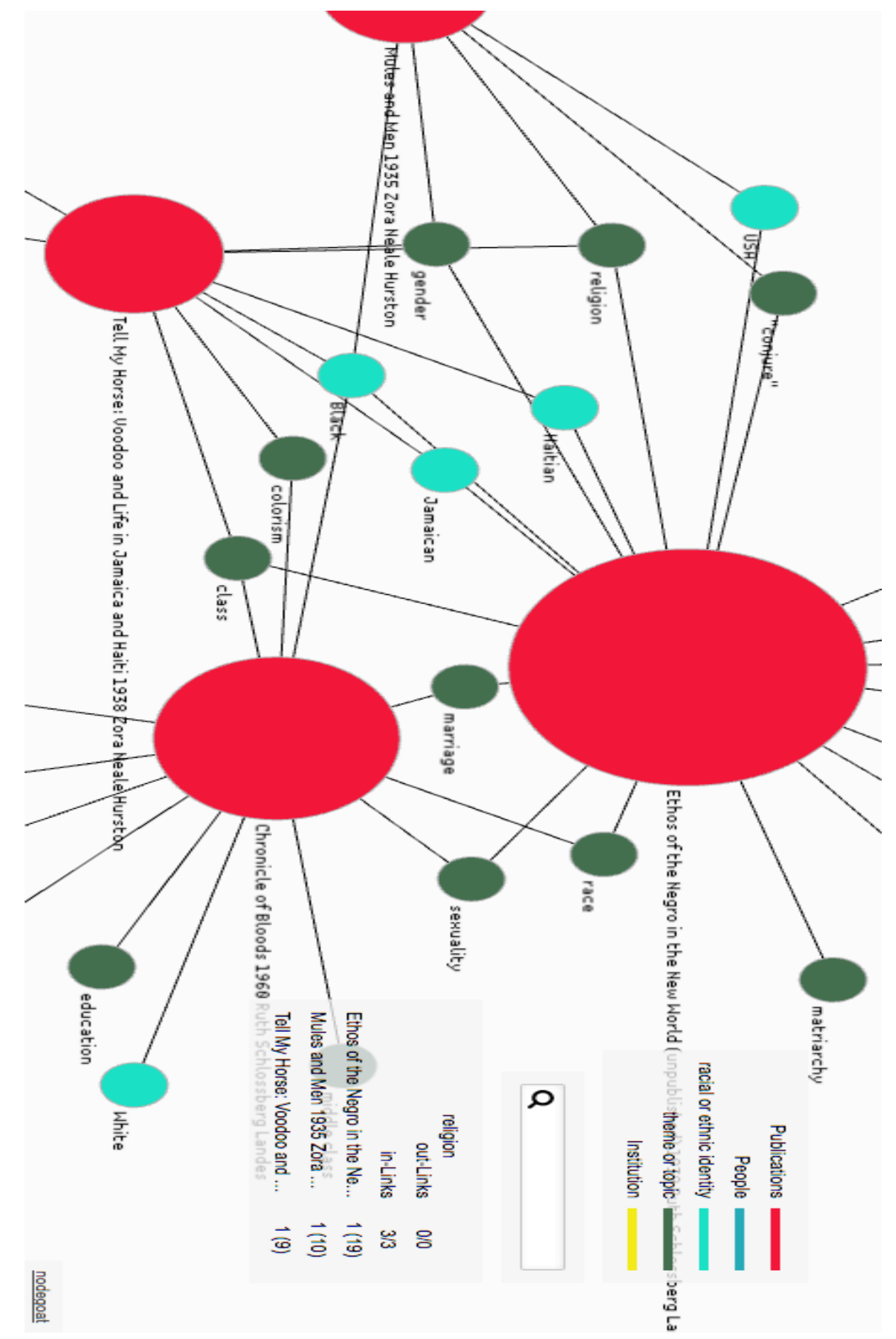

Figure 56. The highly interconnected thematic networks between Landes' unpublished works Ethos of the Negro in the New World (1939) and Chronicle of Bloods (1960) and Zora Neale Hurston's Mules and Men (1935) and Tell My Horse (1938). 
Though Landes did not often elaborate on her references to Zora Neale Hurston's work, she frequently used Zora's personal and research experiences as a reference point to substantiate her own fieldwork encounters and findings. In addition, the ways that Landes referred to Hurston, with a kind of shorthand, implied that Hurston's work was often in Landes' thoughts, as if they spoke the same anthropological/theoretical language and so Landes only had to use Zora's name to trigger certain associations for herself (and Landes assumed for her readers as well). Unfortunately, both women experienced similar negative reactions to their anthropological publications. Regarding Tell My Horse (published 1938), Mikell explains: "Many have accepted only [Hurston's] Haitian voodoo material as real anthropology and have shrugged off her observations in Jamaica and Barbados as impressionistic commentary and journalism because of her style of presentation" (1999:62). The same judgment was often targeted at Ruth Landes because of her informal and self-reflexive style in City of Women (1947), perceived by scholars like Melville Herskovits (1948), to be unscientific and inaccurate. Landes' references to Hurston underscore the central importance of the work of black social scientists to Landes' interpretations of African diasporic epistemologies.

\section{Marital Status}

Landes' perspectives about marriage reflected her own status as a divorced/unmarried woman for the majority of her life. Ruth Landes was married twice, to Alexander Victor Landes and then to Ignacio López, but had no children, though she implied that she had abortions (Nava 2013:18). She was married in her early twenties, but divorced because her husband forbade her to continue her graduate studies (Landes 
1970a:122, n.d.). The marriage began in 1929 and lasted until either 1931 or 1935 (Glenn and Wang 2010:7; Sosnow 1991). She married again in 1955 in California, to Ignacio López, a Mexican American activist journalist (Garcia 2001:229-33, 239, 299; Gurza 2008), but left the marriage in 1964/65 when she received a tenure track position at McMaster University (Landes 1968, 1985b; Schlossberg and Schlossberg 1955). Though it seems she did not pursue a legal divorce until 1970 (Landes 1970b). Ignacio was likely an alcoholic (Landes 1986b). In addition he possibly had a mental illness and was emotionally abusive towards her (A. Schlossberg 1959b, 1959c; J. Schlossberg and Schlossberg 1959; Schlossberg and Schlossberg 1958b). She experienced other disappointments from the men in her life. Her brother robbed her of her inheritance (Landes 1985b). Her research partner and significant other in Brazil, Edison Carneiro, told her he wanted to marry her but then married someone else. On June 8, 1939, Edison wrote: "In these ten months we lived together, working and amusing ourselves I learnt to love you and to appreciate your qualities: you are the woman I want" (Carneiro 1939b).

But by July 14, 1939 he disappointedly told her:

Our dream of marriage will remain only a dream, darling. London was the unique chance to accomplish it...You are the woman to whom I should like to give a child. I imagine the happiness I could give you with a boy or a girl - sons of our own blood, sons of our joy, sons of our mutual understanding. No we can't marry... I know I'll love you always. However, we have simply to be lovers anywhere we meet again (Carneiro 1939a).

By October 24, 1940 he was married to Magdalena Botelho, an "old friend from Bahia." He made it appear that he married Magdalena because of financial difficulties after he lost his job at the museum and his legs weakened (Carneiro 1940). She told her friend Boneta LeBeau Fite that she was "unlucky in love" (Landes 1985b). 
She admired the Bahian Candomblé priestesses because they did not emphasize marriage as an ideal, perhaps because she herself was never in a happy or fulfilling marriage. Also, she was marginalized by male academics because of her relationships with men of color. Kevin Yelvington explains, "Landes and Carneiro immediately formed a fieldwork partnership and ultimately a love affair. For whatever reason - sexual jealousy, racism, shock over a perceived lack of propriety, or a perceived lack of deference - this turn of events apparently riled [Arthur] Ramos... He began to spread rumors about Landes' supposed unethical fieldwork conduct and her supposed many sexual adventures" (73). Landes felt the gendered effects of internal colonization in a way that other Jewish women who were married to white Jewish men (like Ellen Hellmann) did not. In fact, her experiences could be compared to those of white women in Britain in the 1950s who were perceived as sexually and racially deviant because of their relationships with black migrants from the British colonies (see Chapter 5).

\section{Institutional instability}

While Ellen Hellmann became a "stalwart" of the "old guard," at the South African Institute of Race Relations, Landes only earned a stable academic post in 1965 at McMaster University in Hamilton, Ontario, Canada (see Figure 57). I argue that this was because Landes failed to be a "respectable" and "deserving" Jewish woman who followed the sexual and gender norms of white middle class Jewish society (Krut 1984:152, 159, n. 60-62). 
1928 Graduated from NYU, with a B.A. in sociology

1929 Graduated from Columbia University with a M.S.W. from New York School of Social Work

1929-1933 Research in Harlem with Black Jewish group

1931-1937 Columbia University: research with Ojibwa, Potawatomi, Santee

Dakota

1937-1938 Research at Fisk University, in preparation for Brazil

1938-1939 Research in Rio de Janeiro, and Salvador da Bahia, Brazil

1939 Gunnar Myrdal study "The Negro in America" - her work went unpublished because of Arthur Ramos

1941-1945 Representative for Negro and Mexican American Affairs, Fair

Employment Practices Committee (FEPC), President Franklin D. Roosevelt

Administration

1944 Interim Director, Committee Against Racial Discrimination, NY

1946-1947 Researcher, LA Metropolitan Council, study of Mexican American

youth, gangs and families

1948-1951 Researcher, American Jewish Congress, NY

1949-1951 Columbia University Research in Contemporary Cultures Project, study on Jewish families, NYC

1951-1952 Fulbright Scholar in UK, studying colored colonial immigration

1953-1954 Lecturer, William Alanson White Psychiatric Institution, NY

1953-1955 Lecturer, New School for Social Research, NY

1957 Visiting Professor, University of Kansas

1957-1958 Visiting Professor, University of Southern California

1957-1965 Consultant at various California agencies: Department of Social Work, Bureau of Mental Hygiene, Department of Education, Public Health Department, San Francisco Police Department

1958-1959 Director of Geriatrics Program, LA City Health Department

1959-1962 Visiting Professor Claremont Graduate School and Director of

Anthropology and Education Program

1962 Extension Lecturer at UCLA and UC Berkeley

1963 Extension Lecturer at Columbia University and LA State College

1963-1965 IBM Consultant

1964 Visiting Professor, Tulane University and University of Kansas

1965-1975 Professor at McMaster University

- from the Register to the Ruth Landes Papers (2010:7-9)

Ruth Landes is probably best known in the American anthropological literature

for her thirty-year exclusion from professional stability because of the "old boys"

network" of established male anthropologists that collaborated to block Landes' 
professional advancement. Landes was not alone in her fight to achieve academic security and promotion; even well-known women anthropologists like Margaret Mead and Ruth Benedict experienced similar challenges (Leonardo 1991:5). However, I want to highlight how this exclusion was not only a gendered process but also a racialized one, through which Jewish women were punished if they did not conform to white middleclass sexual behavior norms and were literally "cast out." The "old boys" network" (Figure 58) in Landes' case were (1) Melville Herskovits, (2) white Brazilian anthropologist Arthur Ramos (1903-1949) who was the self-appointed leader of AfroBrazilian studies, and (3) German non-Jewish immigrant Rüdiger Bilden (1893-1980) who considered himself an "expert” on race in Brazil. Bilden's writings were foundational for Gilberto Freyre's more famous theorizations about Brazil and racial mixture in Casa Grande e Senzala, published in 1933 (Pallares-Burke 2012:349-50).

Rüdiger Bilden: The gossip intermediary

"Landes is a damn fool and a disgrace to the Department of Anthrop. As far as I can see, she has done little or no Brazilian preparation here or anything else, except getting herself sexually involved with colored members of the faculty. Sex seems to be her forte, particularly in its practical aspects. The campus [Fisk University] is beginning to stink with all sorts of tales of her and the students have coined very uncomplimentary, but descriptive names for her. Why [Ruth] Benedict- she is B's child - ever took her up and mothered her is beyond me... What her conduct means for Fisk in view of Southern attitudes and Fisk's rather delicate position you can imagine. I have nothing to do with her. She has not attended my course, the primary purpose of her coming here, as Benedict told me. Fortunately, she is to be here only for a semester. But please keep all of this to yourself..." -Rüdiger Bilden (at Fisk University) to Melville Herskovits, December 6, 1937 


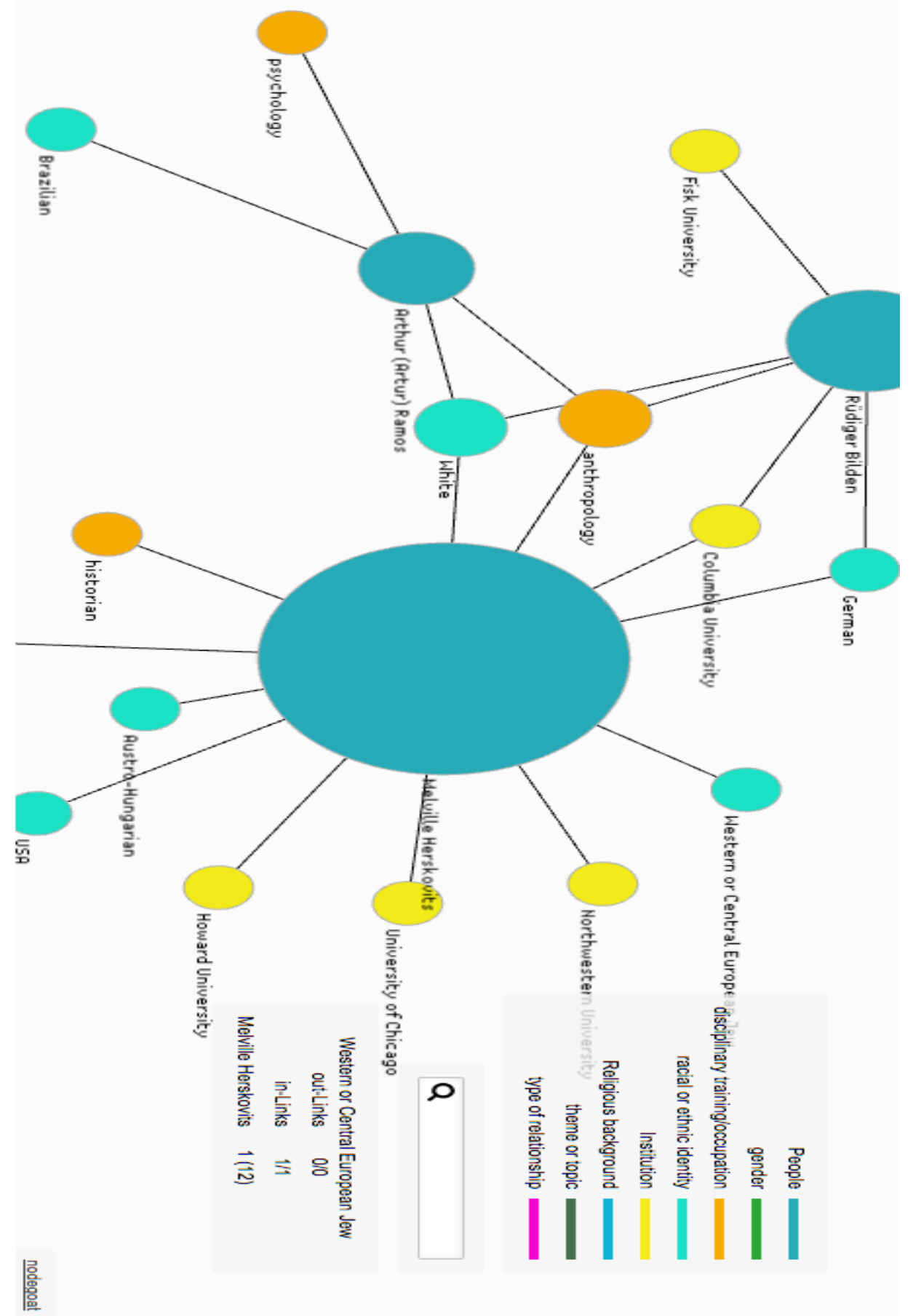

Figure 58. The white old boys' transnational network that circulated gossip and negative evaluations of Landes' research in Brazil, leading to her thirty-year institutional instability. 
According to Kevin Yelvington, Bilden knew about Landes' relationship with black physicist Elmer Imes at Fisk because Bilden informally trained Landes both in New York and at Fisk before she went to Brazil (Yelvington 2006:74). Unfortunately, Yelvington does not include the actual text of Bilden's letter to Herskovits villifying Landes. Also Bilden's letter does not refer specifically to Elmer Imes, but only to “coloured members of the faculty" (Bilden 1937:1). Landes wrote to her teacher, Ruth Benedict, about her detestation of Bilden fueled by what she felt was his exaggeration of his Brazilian training and knowledge. Landes depicted Bilden as pompous, "paranoid, unreliable, overbearing, scandal mongering" and unproductive; he gave "meandering" lectures which forced her to cease attendance. "I hate to write this way about him but you must know this in order to see why I am doing no work with him and avoid him as the others do too. I have to feel apologetic to [Charles S.] Johnson too for it was I who suggested Bilden to Johnson" (Landes 1937a:3-4, 1937b:2). Her dislike grew to hatred by February 1938:

The disease Bildensis is progressing. The University minister tells me that Bilden is to address students and faculty (on race relations) in chapel this morning and Bilden requests that he be introduced as 'Dr.' having spent eight years (this $\underline{\text { is }}$ cubing the root!) in Brazil and possessed of final information about all communities. [Robert E.] Park claims lately to be impressed by Bilden. A fantasy world with a vengeance. I wonder if Bilden believes all that I and others have heard him say (Landes 1938b:1).

Rüdiger Bilden originally provided a positive character reference for Landes to Arthur $\operatorname{Ramos}^{78}$ before she traveled to Brazil, but subsequently withdrew his recommendation

\footnotetext{
78 Though Ramos and Bilden were colleagues, Ramos disagreed with Bilden's (and Gilberto Freyre's) assessment that "the origins of evils attributed by some critics to the
} 
because he said he was unimpressed with her personality and her professional preparation but more likely it was because of what he considered her inappropriate interracial sexual relationships, based on his letter to Herskovits in 1937. Bilden decided that Landes was "incapable of developing" a study about blacks in Bahia because of her "superficial ability." Bilden also revealed to Ramos that his initial positive recommendation had been against the advice of Herskovits and "other anthropologists" who had expressed an “unfavorable impression" of Landes (Andreson 2014:16; Barros 2005:197-99). Bilden was possibly also responding to Landes' obvious dismissal of what he considered to be his Brazilian expertise. He likely expected her to be submissive and reverent since he was fifteen years older (44 years old) than she was ( 29 years old), yet according to her memoirs she spent most of her time with Elmer Imes "a colored member of the faculty" who was ten years older than Rüdiger was (54 years old)! Maria Lucia Pallares Burke contends that Bilden was not affiliated with Nazism or anti-Semitism, but was still discriminated against in the Latin American context because of his German nationality (Pallares-Burke 2013:189). Thus, it is unclear if his German affiliation had anything to do with his disgust for Landes. However, what is clear is that his retraction of his recommendation for Landes likely produced a highly negative impression of Ruth before her arrival in Brazil and contributed to the deleterious depictions of Landes' work by Herskovits and Ramos.

racial composition of Brazilian society should be blamed on slavery" (Carneiro and Ivy 1951:7). 
Melville Herskovits: The professional gatekeeper

Kevin Yelvington explains that Herskovits might have been jealous that Landes was able to go to Brazil before he was, fueling his ire (74). Landes told Mariza Corrêa that Herskovits was "furious because (1) I did not study with him and (2) he had wanted to do the Bahia cultos [houses of Candomblé religious practice] (I learned later)...” (Landes 1986c:2). In September 1939, she told Herskovits about some of the commonalities between her research in Brazil and his in Haiti (Landes 1939b:1). While in the field in Bahia, Landes made connections between her ethnographic observations and the findings of both Melville and Frances Herskovits in Dahomey in 1933 (Landes 1938a). Despite these overtures, Herskovits prevented Landes from getting tenured appointments; he told potential employers that she had "unorthodox" and "unscientific" field methods, code for what he considered her sexual improprieties (Price and Price 2003:84-85). In a letter to George and Alice Park, Landes explained: "Certainly you are correct in reminding me that it is overdue/proper to name MELVILLE HERSKOVITS as the one who set out to damage me, my life as a person, in the one sure strategy of the time: a woman who sells sexual services AND to Blacks!” (Landes 1985d:1)

In his review of her City of Women, Herskovits critiqued what he perceived as her lack of appropriate background knowledge of African and Brazilian studies (Herskovits 1948:124). He also explicitly stated that her "basic thesis is wrong" regarding the role of women within Candomblé since from his point of view, men were equally important in the religion (1948:124). In 1943 Herskovits portrayed patriarchy rather than matriarchy as the central organizing principle in Bahia. He maintained that African cultural survivals in Brazil came from the patrilineal practices of Dahomey and Yoruba in West Africa 
(Herskovits 1943:395). He depicted black Bahian communities as male centered, where wives and concubines catered to men and battled with each other for the attention of their male partners (Herskovits 1943:396).

Herskovits contended that the only reason that Landes saw more female than male leaders in the cult houses was that it is more difficult for men than women to take time from their productive labor (1948:125). Yet this neglects to consider that Afro-Bahian Candomblé women were engaged in "productive labor" as domestic workers, seamstresses, and street vendors selling food products and crafts in addition to their service to their religious communities (Gondek and Genoveva 2015; Gondek and Teixeira 2015; Landes 1947:85; Teixeira 2007:203). Additionally, Herskovits implied that Landes did not behave appropriately since anthropologists should know how to conduct themselves "in the capital as well as in the bush, told how to turn the corners of calling cards, when to leave them, and how to "sign the book." He also critiqued her lack of appropriate "detachment" within her fieldwork (125). These are veiled references to her relationship with Edison Carneiro (1938-1939) and her close relationships with Candomblé practitioners, which she detailed in City of Women, which was written in a self-ethnographic style. He was also likely referencing the letter from Bilden regarding Landes and her relationships with "colored faculty" and Arthur Ramos' accusations that she lacked the proper reverence for his authority in Afro-Brazilian Studies.

One unexplored explanation for Herskovits' hostility toward Landes is that she was the "wrong" kind of Jew, a trouble-making Jew. The wealthy German Uptown Jews of New York City were ashamed of the behavior, language, appearance, and political ideologies of Russian Jews: "aghast at their political ideologies, and terrified lest the 
world crumble by the mad act of a Jewish radical" (Lewis 2013:548). Though Gelya Frank discusses the differing professional experiences of Herskovits and Landes Herskovits was professionally accepted while Landes was rejected for espousing similar "Boasian views on race" - Frank does not discuss the possibility that Herskovits' Central European Jewish stance and Landes' Eastern European working-class position impacted these differing perceptions of them $(1997: 737,739)$. Central European Jews, like Melville Herskovits, viewed themselves as more sophisticated and enlightened than Eastern European Jews (like Landes' family) whom they considered poor, backward and prone to criminality. Herskovits felt ambivalence about his Jewishness, not supporting Zionism nor considering Jews a people (Brown 2014; Frank 2001:173, 180-83; Pinski 1999:4, 185). In order for elite Central European Jewish men, like Melville Herskovits, to gain disciplinary authority and acceptance into whiteness, they needed to demonstrate domination over Jewish women by ensuring these women sexually "behaved themselves." If not, these women's "improper" sexual behavior would reflect poorly on the elite Jewish community as a whole, indicating remnants of racialized, low-class "barbarity," emphasizing the already existent associations between Jewishness and blackness, from which elite Central European Jewish men desired to disassociate. Thus, Melville Herskovits made Ruth Landes, a Jewish woman of Eastern European descent, into an internal minority.

Arthur Ramos: Putting Landes in her place

Mariza Corrêa argues that Landes' "love affairs with black men" are the key explanation for her academic marginality, and weighed heavier than the "attack" of 
Ramos and Herskovits. Corrêa additionally compares Landes and Zora Neale Hurston's experiences of racialization (Correa 2003:176). I argue that her "love affairs," and "racialization" were two interrelated factors that led to the "attack" by Ramos and Herskovits and that this "attack" was mediated by the gossip spread by German anthropologist Rüdiger Bilden from Fisk University. In 1970, Landes argued that Arthur Ramos accused her of using sexual lures to obtain informants and running a brothel in Brazil; these rumors followed her to the US, UK and Africa (Landes 1970a:128-29). By portraying Landes as sexually abnormal, Ramos could more easily dismantle her theoretical arguments and establish himself as the authority on Afro-Brazilian religious practice.

Edison Carneiro discussed how Arthur Ramos claimed that Landes did not use the letters of reference Ramos had written for her, failed to write to Ramos when she was in Bahia, or return to see Ramos when she was again in Rio (Carneiro 1964:225). However, Landes wrote to Ramos three different times: she asked for his articles and opinions about her research, thanked Ramos for his help, inquired about his wife's well-being, asked about his future plans, and advised him of her publications (Barros 2005:201-4). Landes told Mariza Corrêa that she had heard from Dona Heloisa Alberto Torres, the head of the Brazilian National Museum in Rio when Landes was in Brazil in 1938-1939:

Ramos never went into the field to observe or talk, but called informants into his office. As Edison wrote, and everybody - including the police! - knew I was always in the field, a young woman under thirty, and conspicuously loura [blond]. Prof. Luis da Costa Pinto told me that Ramos - who had been his teacher - was furious that I had written about (discovered) the male homosexual priests (Landes 1986:2). 
Landes" findings about "matriarchal" Candomblé houses and the rival houses led by homosexual male priests (which were ideas she shared/inherited from Edison Carneiro), deeply bothered Arthur Ramos. According to Landes, in City of Women, newer caboclo houses (in which indigenous spirits were worshipped in addition to Yoruba spirits) had less stringent guidelines and allowed men to become priests. Landes argued that these men were primarily "passive" homosexuals; she looked down upon this development, which she saw as detracting from the woman-centered Yoruba traditions (Landes 1947:31-32,37). Landes' argument about homosexuality was a thread within her claim about matriarchy; she contended that men who became pais do santo (fathers of the saint) were homosexual men who had previously been "outcastes," prostitutes and vagrants, hounded by the police. By becoming like the "mothers" and acting as women, they could gain status and respect. Unfortunately, she portrayed these men negatively, calling them "foreign elements" and "a kind of terrorism" because of the way that they used sorcery and violence (Landes 1940a:386-87, 393-95). Her views on homosexual filhos do santo were highly influenced by Edison's perspectives, though he maintained that he neither agreed nor disagreed with her interpretations for why they existed within the religion (Carneiro 1964:226). Carneiro portrayed these homosexual male priests as being considered "immoral" by some, being more common in caboclo temples, and regarded as less important than priestesses, hurting Candomblé because these temples were "clandestine" and not "authentically" African, highlighting that homosexual caboclo priests had not undergone the seven years of training required in the more "traditional" houses of Candomblé. He also portrayed these male priests as imitating the priestesses in 
clothing and behavior and using "bad magic"/sorcery for financial benefit (1961:126-129, 142).

Ramos cited Herskovits' Dahomey, An Ancient West African Kingdom (1938) in order to support his conviction that Landes" "matriarchy" thesis had no basis in fact, and that in actuality Candomblé was male-dominant, tracing back to the Yoruba and Dahomey patrilineal tradition in West Africa. Ramos contended that Landes was not scientifically honest, made “dangerous generalizations" and errors of observation, falsified concepts and created an untrue picture of black religion in Brazil. He denied Landes' claim that homosexuality was related to the religious-cultural practice of Candomblé (Ramos 1942:185-92). In March 1940, Ramos wrote to Guy B. Johnson, Landes' supervisor for the Carnegie-Myrdal project, The Negro in America, in order to refute the validity of Landes' Ethos of the Negro in the New World (Landes 1939g). He also sent a copy to Herskovits and Landes' work was subsequently never published. Ramos asserted that Landes presented "rushed" and "falsified" conclusions that he implied were not based on "prolonged observation" or "fieldwork" and would "pitifully confuse honest and carefully controlled studies of the black personality in the New World" (my translations into English). One of his many critiques of her theories based upon her fieldwork (with Edison Carneiro as her guide) was that in stark contrast to Landes' arguments: "the best known leaders of the black cult... are men" and that women were only "companheiras" (companions) and were "secondary" in importance to male Candomblé leaders. Ramos argued that women only became "relevant" later because of "new social conditions" (Ramos 1940:3, 6). Just as he placed women in a secondary position within Candomblé, Ramos effectively demoted Landes to a secondary (or worse 
position) within Afro-Brazilian studies and prevented the publication of her work for the Carnegie-Myrdal project.

Ramos assumed Landes' assertions about homosexual priests and a “true matriarchate" would link Brazilianness with primitiveness and backwardness and he wished to project Brazil as a modern nation in the international realm. In his presentation to the First Afro-Brazilian Congress in 1934, he showed that "primitive mentalities" could co-exist in "modern" societies. In his position as the Secretary of Mental Hygiene in Rio de Janeiro's public schools he aimed to reform these "primitive" ways of thinking among the Afro-Brazilian population (Romo 2007:43-45). Thus, he perceived Landes' matriarchy and homosexuality thesis as threatening to the Brazilian national modernization project.

Landes' close networks, in 1938-1939 in Salvador, Bahia, with Afro-Brazilian Candomblé priestesses, who were generally stereotyped as hypersexual, and her intellectual and sexual partnerships with black men (Edison Carneiro, a scholar of AfroBrazilian culture, and Elmer Imes, a physicist at Fisk University in Nashville, where Landes worked in 1937-1938) that emerged through her family's black intellectualactivist networks provided the "evidence" to indict her "improper" sexuality, code her as not properly white by both white and black scholars ${ }^{79}$, and question the validity of her innovative methodologies and theoretical conclusions. Thus, even if she asserted her own

\footnotetext{
${ }^{79}$ Mariza Corrêa indicates this with her statement that Landes and Hurston were racialized in similar ways in the discipline of anthropology. Ruth Landes alluded to what she understood as an offence to her whiteness, when she was included against her consent in the Negro Who's Who or when Elmer Imes referred to Jews as non-white.
} 
whiteness as a Jew, others (including blacks, whites and Jews) labeled her as non-white and black. 


\section{CHAPTER 4 MORE SWAZI THAN AMERICAN: HILDA KUPER - SIMILAR}

\section{TRAINING, BUT DISTINCTIVE OUTCOMES}

"After awhile they began saying... 'there is our person' using the word that they used for an African person, for one of them" - Hilda Kuper in an interview with Gelya Frank, 1979

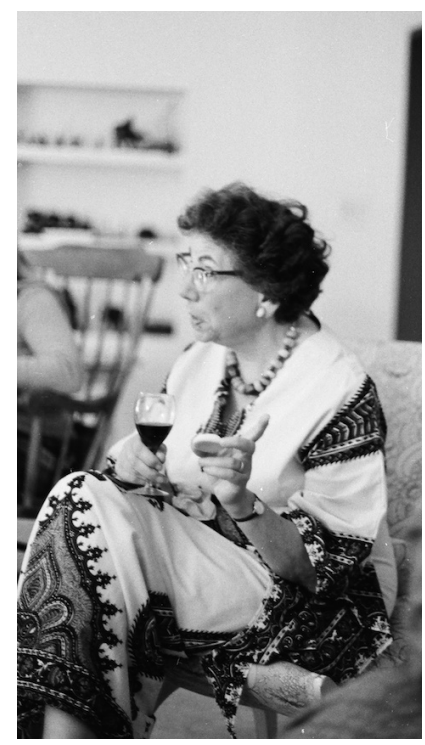

Figure 59. Hilda Kuper at her home in Los Angeles, 1974, at a party organized for her students, photo taken by Dawn Chatty and used with Dawn's permission.

Hilda Kuper (pictured in Figure 59) was of "mixed" Jewish heritage since her mother was from Vienna, Austria (Central Europe) and her father from Lithuania (Eastern Europe). She wrote infrequently about her Jewish identity or the topic of Jews (as compared to Ruth Landes and Ellen Hellmann). Her "assimilation" though was toward Swazi society rather than white society, as she became a Swazi citizen in 1970; however, non-aristocratic Swazis associated her with the Swazi nobility, causing some to "loathe" her. Her student, David Kuby, described her as a combination of "Jewish, British and African," thus her "mixed-ness" from her familial origins, led to an ability to blend different religious beliefs and cultures into her subjectivity. 
While Kuper and Hellmann began their research careers studying the impact of liquor laws on black women in Johannesburg under Winifred Hoernlé's guidance with affiliation through the South African Institute of Race Relations, Kuper's research sites expanded to Swaziland and later, Durban in Natal, South Africa. (Figure 60 provides a visualization of the connections between these three women.) In both of these subsequent field-sites she became fully immersed in the communities, forming life-long friendships and research partnerships. Margo Russell wrote: "Hilda seemed always at the centre of a bevy of educated Indian ladies in shimmering saris" during the Kupers' time in Durban in the 1950s (Russell 1994:145). In contrast, Hellmann maintained an "objective" distance from her fieldwork participants and continued with the same research institution, the South African Institute for Race Relations, for her entire career, eventually becoming an "ultra-conservative" member of this organization because of her "pragmatic" approach to apartheid politics.

Additionally, because of Hilda's marriage to Leo Kuper she became involved in non-violent apartheid protests as one of the founders of the Liberal Party. Eventually the couple and their children had to leave South Africa because of police persecution. In contrast, Ellen Hellmann's involvement in the Progressive Party meant that she publicly advocated the qualified franchise, requiring that voters have property and financial stability to prove they were "civilized" enough to exercise their vote. Hellmann promoted gradual change to the apartheid system through dispassionate research; thus, she never 
threatened the apartheid state enough to have to flee and lived in Johannesburg throughout her life.

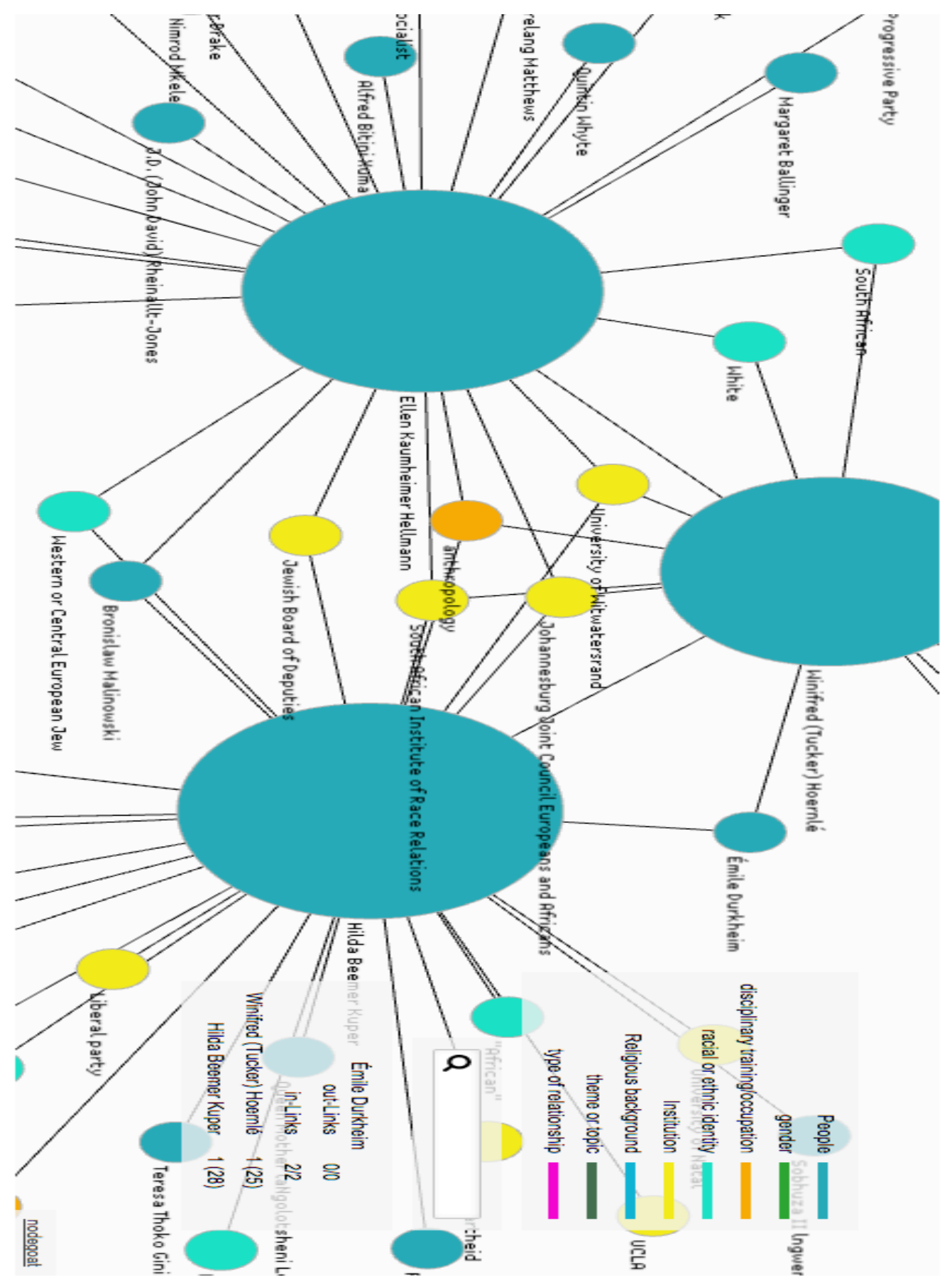

Figure 60. Hilda Kuper, Ellen Hellmann, and their teacher, Winifred Hoernlé: The intersections between their disciplinary training, institutional affiliations, racial/ethnic affiliations, and the people who influenced them. 
Kuper and Hellmann's positions were markedly different in terms of how they wrote about black women. Hilda took a Swazi point of view (based upon her networks with Swazi royalty), arguing that Westernization weakened women's position, so Swazi women should not assimilate into Western norms (perhaps more of a black nationalist position). She portrayed Swazi women and Indian South African women as the victims of colonization as well as patriarchal indigenous systems. In contrast, Ellen Hellmann took an assimilationist point of view, depicting black women in Johannesburg as the "problem" and cause of juvenile delinquency, and arguing that they should become more Western, white and middle-class in their familial structures.

In a few select places in this chapter, I discuss Ruth Landes, in terms of how she compares and contrasts with Hilda Kuper and Ellen Hellmann. The purpose of this is to bring all three women into conversation with each other in one place in order to accentuate their differences especially in regard to their representations of and transracial networks with women of color. Like Hilda, Ruth Landes identified with her research participants; they both distanced themselves from mixed-race or lighter-skinned members of the social elite who Kuper and Landes felt treated darker and poorer community members with condescension. They also academically supported women of color scholars who were denied effective mentorship from other white male and female scholars. Landes and Kuper additionally shared views regarding the negative effects of Westernization or modernization on women's access to power. Finally, while Hilda accentuated women's victimization, Landes underscored their agency, likely because of their differing disciplinary mentors and subsequent anthropological orientations and priorities. 


\section{Part I: A Mixed Jewish Heritage}

"I came to lead a strange dual life, loving my mother more than anyone in the world yet hating her for being 'one of the enemy,' boasting about my soldier father yet idolizing still my Austrian uncle." - Hilda Kuper, "Photograph"

Hilda Beemer was born in Bulawayo, Rhodesia on August 23, 1911 into a family divided by the differences between Eastern and Central European Jewish life (like Ruth Landes). Her Viennese mother, Antoinette Renner, had to stop speaking and singing German (with a Viennese dialect) at home with her children (because of anti-German sentiment during WWI) and lost her beloved brother, whom Antoinette talked about as if he were a Viennese prince, who fought on the German side during World War I. Hilda's father, Josef Beemer, was a Lithuanian Jewish trader who was fond of hiking in nature and proud to fight with the British in East Africa (Kuper 1993:99-100). Antoinette was from a well-off Viennese family. She met Josef when she came to her sister's wedding in Bulawayo. Antoinette's parents disapproved of the match. ${ }^{80}$ Unfortunately, when Hilda was six years old (in 1917), Josef Beemer died of influenza; his death caused economic strain for Antoinette, so she took her children (Hilda was the youngest) to Johannesburg to live with Josef's brother, Yoshie, who worked in a department store (Bank 2016:192193). Upon their move to the city of Johannesburg, Hilda became aware of anti-Semitism for the first time. Previously when they had lived in Bulawayo the family had non-Jewish friends, but upon arrival in Johannesburg she realized that all of her family's friends were

${ }^{80}$ Ellen Hellmann's maternal grandparents disapproved of their daughter, Ellen's mother, Chlothilde marrying Bernard, Ellen's father, because his family was poorer than Chlothilde's family. 
Jewish (but not Orthodox) because of the racial and cultural segregation in the city (Moran 1988:194). Unfortunately Uncle Yoshie died when he fell down a lift shaft, once again creating financial difficulties for her family (Bank 2016:193). She and her sister Ellie (whom she was quite close to) went to a girls' boarding school called Parktown in Johannesburg. As a fifteen year old, Hilda dated South African Jew of Russian-descent, Max Gluckman, who would also attend "Wits" (the University of Witwatersrand), receive training from Winifred Hoernlé, and become a social anthropologist at the Rhodes-Livingstone Institute in Rhodesia and later at the Manchester School (Bank 2016:193; Foreman 2013:1-2, 42, 72).

Hilda initially wanted to study French, English and History and become an actress in England or a criminal lawyer in South Africa on account of "'her increasing awareness of discrimination and the plight of innocent victims [in South Africa]: servants living in the backyard, the brutal treatment of blacks by whites, and her own Jewish heritage"” (Bank 2016:193; Kuper 1984:193; Moran 1988:194). Hilda had already been aware of racial injustice in Bulawayo where she witnessed an uncle, a farmer, beating his black workers (Bank 2016:193).

Of her South African anthropological colleagues (such as Meyer Fortes, Isaac Schapera, Max Gluckman, Ellen Hellmann and Jack Simons), Kuper said that they were all "non-orthodox Jews struggling to achieve a nonethnocentric ethical perspective.", 81

${ }^{81}$ Mary Kuper wrote to me: "I haven't really anything to add about Hilda's Jewishness, beyond what you will find in Andrew Banks's book. It was, of course, her background, and South Africa was such a divided society that these aspects of identity mattered a lot, but she was brought up without much knowledge of Jewish practice and apart from Passover, and Rosh Hashanah, not much was part of our home life. When she was older 
Kuper was the only one (out of Max Gluckman, Isaac Schapera, and Ellen Hellmann)

who fasted during a 1931 Yom Kippur fieldtrip to Mochudi, Bechuanaland (now

Botswana) led by their Jewish teacher of Eastern European descent, Isaac Schapera (who had taken over for Winifred Hoernlé). ${ }^{82}$ Kuper thought Schapera a boring lecturer, and critiqued his lack of participant observation methodology (Kuper 1984:193-196). ${ }^{83}$

Interestingly, in 1933, upon her return to South Africa from London, Hilda and Isaac Schapera became engaged for a brief period; their break-up was quite emotional for Hilda (Bank 2016:199). ${ }^{84}$ Hilda's Jewish South African network is depicted in Figure $61 .{ }^{85}$

she did fast on Yom Kippur, and I remember her reading the book of Job then, but this was something she arrived at very late and her practice was very individualistic" (e-mail communication, January 27, 2018).

${ }^{82}$ Though Kuper said she was the only one who fasted during that trip, it was Ellen Hellmann who would become far more involved in Jewish communal organizations in Johannesburg.

${ }^{83}$ Though Kuper thought Schapera a boring lecturer, Ellen Hellmann called him the only "readable" writer in contrast to Meyer Fortes and Siegfried Nadel (Hellmann 1952). Schapera introduced Kuper to theories of reciprocity (Malinowski) as Hoernlé introduced her to the similar concept of object exchanges (Marcel Mauss); both Malinowski and Mauss were Jewish (Kuper 1984:196).

${ }^{84}$ According to Adam Kuper, Isaac Schapera had no enduring love affairs in his life and remained a bachelor, an "eclectic" and a "loner," living solely in furnished rooms in boarding houses and hotels for the rest of his life (Kuper 2007:19-20,36).

${ }^{85}$ For simplicity, I excluded information about Hilda Kuper and Ellen Hellmann from this network visualization. This visualization reveals the commonalities between Kuper's Jewish South African colleagues in terms of institutional associations, disciplinary training/occupation, racial/ethnic identity, and mentors/colleagues. 


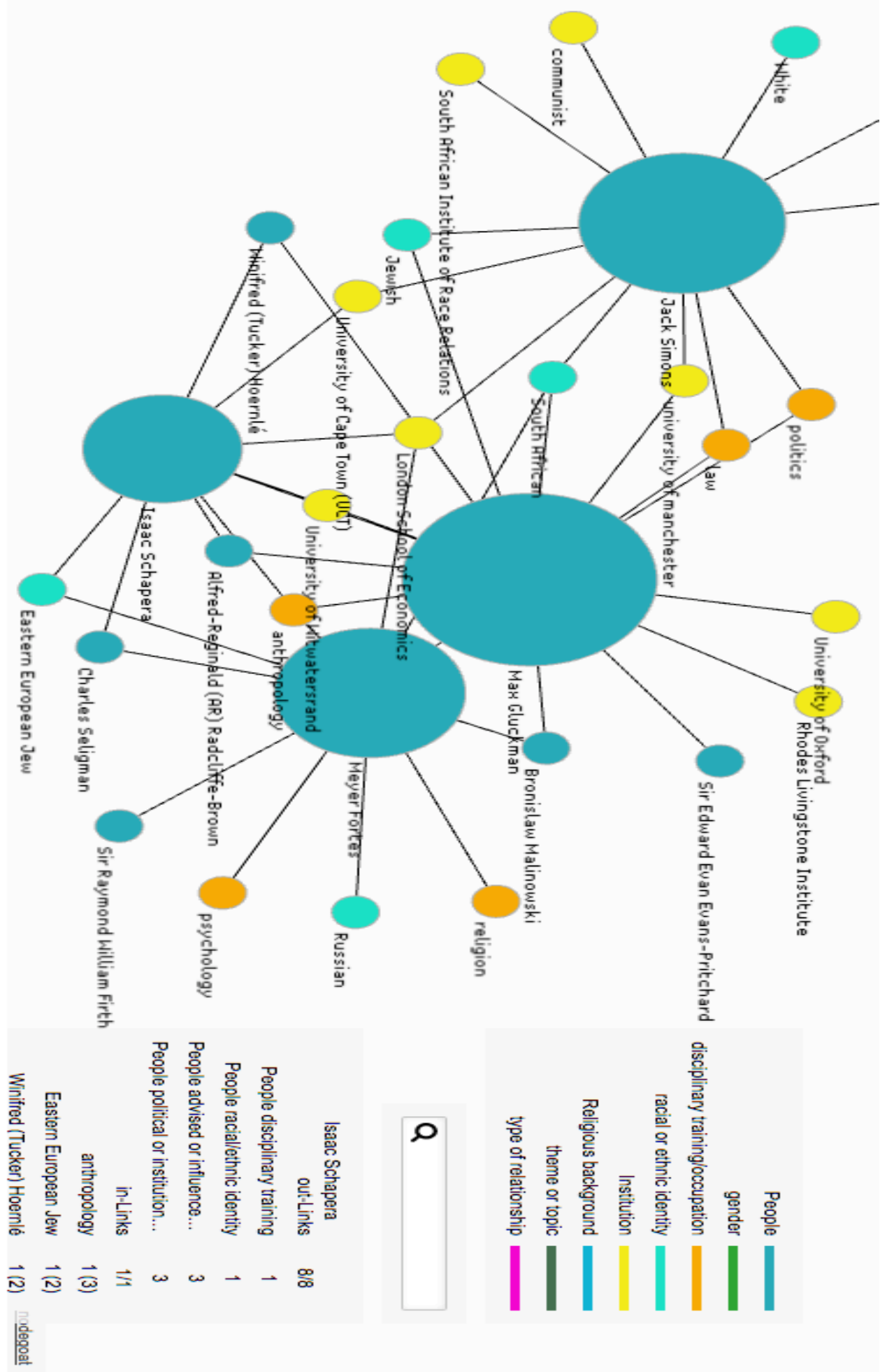

Figure 61. Hilda Kuper's Jewish South African network. 
In 1932 Kuper went to the London School of Economics and met Malinowski (who became her dissertation advisor) in addition to older students who were already there such as Raymond Firth, Meyer Fortes (South African Russian Jew), Sjoerd Hofstra, Siegfried Nadal (Austrian Jew), Audrey Richards, Evans-Pritchard, and Lucy Mair, who recorded the Malinowski seminars (1984:197-198). Kuper said that most of her friends in Britain were "aliens" discriminated against as "colonials" during a time when fascism and Nazism were on the rise, and Kuper described protest marches (Kuper 1984:199200). A network visualization of Hilda's LSE colleagues is pictured in Figure $62 .{ }^{86}$

\footnotetext{
${ }^{86}$ For simplification, this network visualization excludes information about Hilda Kuper;
} Kuper's London School of Economics anthropology network was highly interconnected. 


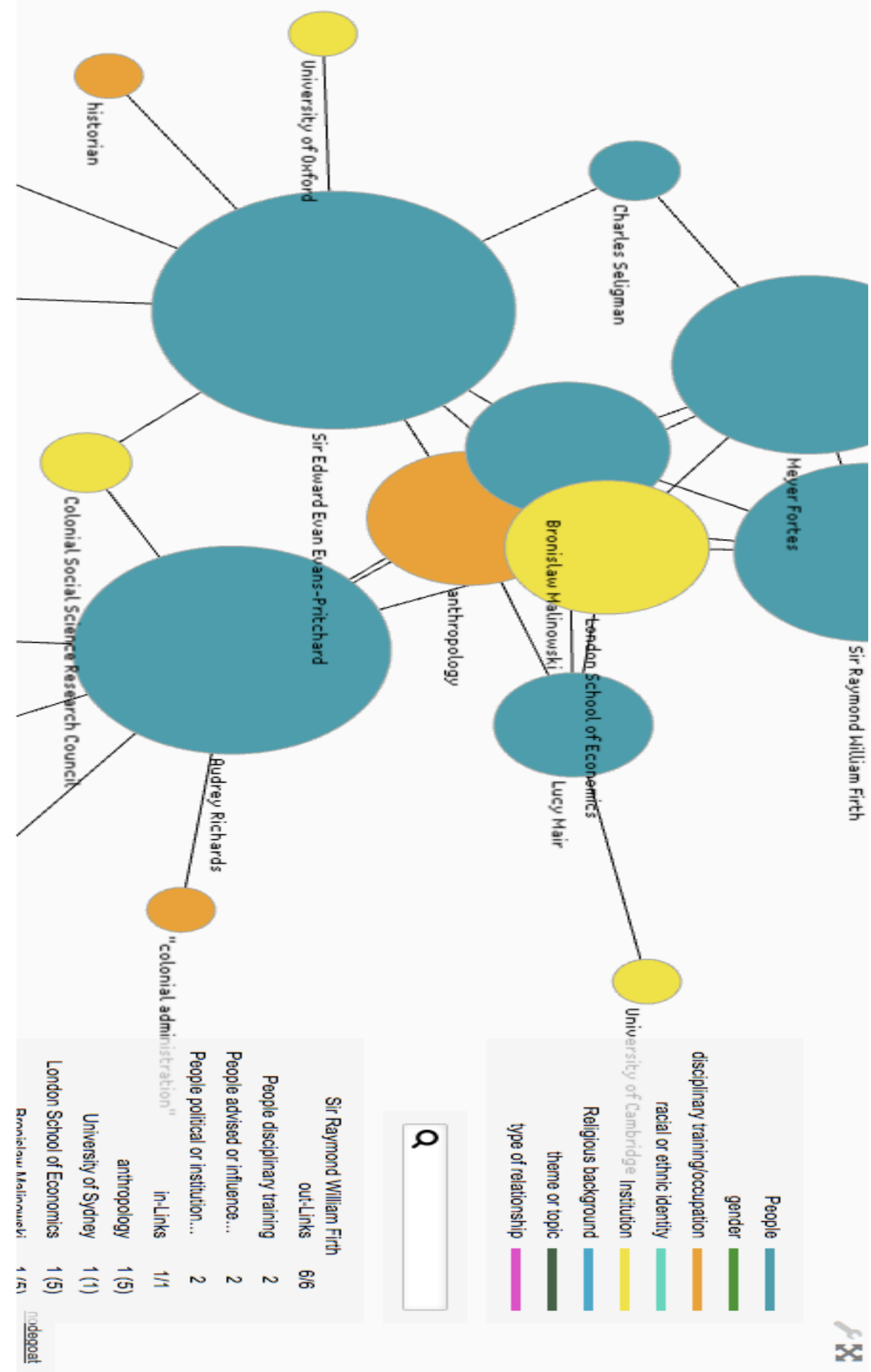

Figure 62. Hilda Kuper's London School of Economics network, 1932. 
Gelya Frank (who was Hilda's student in graduate school in Anthropology at UCLA and mentee, though not a dissertation advisee) explained that Hilda's husband, Leo Kuper (who came from an Orthodox Jewish background but did not want to be governed by it), experienced anti-Semitism, and "Jew-baiting” in Chapel Hill. (He began his doctoral training there in 1948). He also expressed concern when their daughter, Jenny, named her son "Sam," since in England to call a Jew a "Sammy" was a slur (Frank and Gondek 2017; Kuper 1994).

In Uniform of Colour (1947) based on her doctoral dissertation, Kuper elaborated the white European racist generalizations about Swazis (child-like, incapable of independent thought, ungrateful, violent, abusive), citing the deep historical roots of Nazi racial mythology leading to pogroms and crusades (Kuper 1947:29). Intriguingly, Kuper referred to those Swazis who the Europeans perceived as exceptions to their racist generalizations as "“pet Jews"” or "tame lions": "Individual Natives who do not conform to the white man's stereotype of the black man are considered exceptions that do not prove any rule; it is the old story of a few 'pet Jews' or tame lions" (31). Also, Kuper recounted how Swazis differentiated between whites, yet understood that whites united together. Swazis generalized English as those with law, Jews as those with money, and Boers as those who hated black people (1947:35). In Kuper's story "Bird of the Storm" (1975), a Jewish storeowner, simply called "the Jew," was disliked by the Swazi because he hurried his customers, did not permit them to touch the merchandise, and did not sell alcohol (Kuper 1975a:224).

In a story called "The Meal at a South African Guest House" which took place in 1944, the owner of the guesthouse and shop, Mr. Pugworth, espoused both racist and 
anti-Semitic views. Pugworth asserted, "kaffir bites" are poisonous... "if you hit a nigger on the mouth just be careful." When one of the British female guests, Helen, disagreed with him, Pugworth became angry because she was talking "dangerous nonsense about different races having similar abilities and the color of the skin being insignificant and the need to give all people similar opportunities... 'That's communism,", he declared. Soon afterward, his young son, Paul, loudly slurped his milk, and Pugworth commented: “Don't make such a noise, son. Only Jews drink coffee like that. You watch the Jews and hear how they drink." The story ends when Helen, who was Jewish, remarked to the little boy, "Yes, Paul, watch me" (Kuper 1993:90). The implication is that South Africans who were anti-black were likely also anti-Jewish. I also wonder if perhaps, Helen's character represented Hilda and if Hilda encountered these types of statements often. However, Kuper did not explicitly reflect upon these negative portrayals of Jews by both Swazis and Europeans.

\section{Hilda's primary alliance}

Hilda Kuper felt "more Swazi than American," proudly revealing that her children had been given Swazi names by Sobhuza II (the Swazi king), in an interview with Rand Daily Mail (Bank 2016:230; Staff 1981). “[Hilda] made an offer of traditional allegiance to Sobhuza in 1967 , and in 1970 she was personally granted Swazi citizenship”" (Golomski 2011). Perhaps she was drawn to elder male figures like Sobhuza and Malinowski because of the loss of her father and Uncle Yoshie at a young age. In a short story in which she is a principal character (a rarity in any of her fictional writing), "The Lord Will Provide" (1947), Hilda seemed to identify more with black Swazis than with a 
mixed-race girl named Eliza, whom Hilda found to be snobbish (Kuper 1993:83-86). Eliza's father was English, while her mother was black and Swazi; Hilda found Eliza crying on the side of the road as a storm approached. Hilda offered Eliza a ride, which Eliza accepted. Eliza knew of Hilda as the "lady who lives in Swazi huts." Unlike Hilda, who believed that the it would be best if the colors "went on mixing "til there was no sharp distinction," Eliza argued that, "The colors should not mix." Eliza was crying and walking by herself on the side of the road because the bus that had come along was full of whites and though there was room at the back with the "Blacks and luggage," Eliza stated that "a lady" like herself could not stand at the back since the Blacks "have no manners" (83). Eliza additionally explained that she could not stay with a white shopkeeper since he had a white wife. She also could not stay with (black) Swazis in a hut because "the Lord who made me as I am" would not permit her to sleep without a bed. Eliza decided that the "Lord will provide" and began to walk along the side of the road alone, until Hilda came along. Eliza believed that God had brought Hilda to her, which Hilda highly doubted (84). Once the storm began, and the rain flooded around them, Eliza commented "We are like Noah in his ark" and just then the car flipped onto its side. To make matters worse, the car slipped down a slope and Eliza's arm became pinned down by the car and Hilda was unable to free it (84).

Thankfully, a traditionally dressed Swazi man approached them but he refused to help once he saw Eliza; he was also "blind, stupid drunk" according to Kuper (85). In the hopes of pushing him to fetch help, Hilda utilized her knowledge of the Swazi belief system, "lost my temper and cursed him by all his ancestors and chiefs. I cursed in English and Swazi, threatening that unless he went to fetch help immediately he would be 
struck by all the furies, white and black.” Hilda yelled at him, “'Go or you'll die,' and ended with a final gesture drawing my finger across my throat and emitting an expressive guttural click" and finally this Swazi man left, eventually returning with eight other tribesmen. Hilda was appalled that Eliza not only called the men "lazy" but also accused them of causing the accident! The Swazi men succeeded in getting Eliza out of the car, and turning the car right side up. After the Swazi men were "liberally rewarded" by Hilda, the two women drove away. Hilda was again disturbed when Eliza commented that the men were "very dirty" and that she "could not have slept in a hut." Hilda wrote: " 'I am glad to be going back safe to my hut in the village tonight,' I retorted a little sharply, angered by her [Eliza's] snobbery, and pointed out that the men got dirty helping us out of the mud." After this, Eliza felt a bit embarrassed, so she conceded that "We are all children of God" but Eliza added that, "the Blacks are also alright if they keep in their place" (85). Hilda clearly did not agree with this statement, ending her story by telling her car, "I hope that the Lord will not always provide like that for me." It seems that she was referring to the entire encounter with Eliza, which Hilda found offensive. Interestingly, this phrase "The Lord will provide" is reminiscent of a phrase her mother often repeated "It is God's will," upon hearing expressions of sympathy after the death of Hilda's uncle, her mother's beloved brother who died during WWI; Hilda commented upon her mother's statement: "only God could have been responsible for such a catastrophe" $(1993: 100)$.

Hilda's representation of Eliza's condescension toward the Swazi men who helped her, is reminiscent of Ruth Landes' perception of Edison Carneiro's "aristocratic" and "patronizing" demeanor toward working-class Candomblé practitioners in Salvador. 
Like Hilda, Ruth Landes identified in this situation more with what she called the

"African prejudices" of her primary informants than with Edison's condescension. In an

interview with Gelya Frank in 1979 regarding ethics in life history work, Hilda revealed

how she came to feel that she was a Swazi, an African, belonging to the people among

whom she spent a lifetime working, as Figure $63^{87}$ reveals:

The fact that here I was a stranger and I was very young and ignorant and they had taken me in and treated me with such kindness and courtesy, and when I was ill, I was looked after - this queen, LaMatsebula was sort of given to me as my mother at that stage, and Sobhuza's mother, Lomawa, I stayed in her village...And I think an anthropologist owes it to the people who take her into confidence, reveal some of the things, some of the things were revealed in confidence and they said 'we don't want you to publish' these are ...'our hearts' ... 'our secrets' but we want you to know them, because we want you to know us. And this is a very moving experience. And initially they'd say... 'there's a white person.' After awhile they began saying... 'there is our person' using the word that they used for an African person, for one of them (Frank and Kuper 1979:10; Langness and Frank 1981:147; Moran 1988:196).

${ }^{87}$ All three women in this photograph are wearing "umhelwane" a Swazi cloth worn over garments by both sexes. There are several examples of these in the Thoko Ginindza collection at the UCLA Fowler Museum, Catalogue no. X76.378. Hilda is also wearing a ligcebesha necklace, see the following figure. Beth Rosen-Prinz deciphered the names of the wives of Makhosini from the verso of this photo. 
In a 1934 letter to her advisor, Malinowski, Hilda described how she intervened in a meeting between the Swazi National Council and the Resident Commissioner A.G. Marwick. She defended the Swazi right to kill a bull, by referring to her respect for tradition from her Jewish upbringing. "Well all my Jewish reverence for old tradition and respect for the laws of another race forced me, despite that cautiousness which is also an integral part of my heritage to contradict [Commissioner Marwick]." ${ }^{88}$ Then she pointed out that Europeans also killed animals, for sport, in hunting and bull-fighting (Bank 2016:204, n. 62).

Also, importantly, non-aristocratic Swazis associated her with the Swazi nobility:

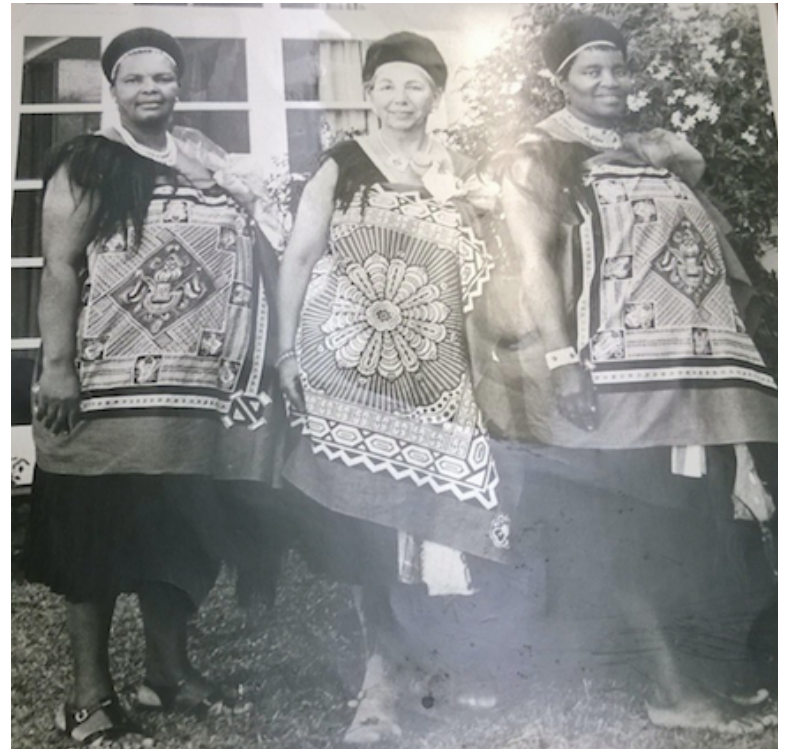

Figure 63. Hilda with the two wives of Prince Makhosini, the first Prime Minister of Swaziland: La Nldangamandla and La Mkhonta, 1974. Hilda Kuper Papers, Box 45, Folder 8.

"I was also given a very specialized position in the hierarchy and would have to stand with the queens, stand with the princesses." This caused some Swazi to "loathe" her

\footnotetext{
${ }^{88}$ Thanks to Gelya Frank for reminding me of this reference in Andrew Bank's chapter on Hilda Kuper.
} 
because she was "accepted in the inner circle" (Frank and Kuper 1979:11; Langness and Frank 1981:147-148). Even the assistant Hilda worked with in Swaziland, Umnyakaza, was assigned or "given" to her by Sobhuza, as her "umfana" or "boy" who was supposed to serve her as he would a member of the royal family. In An African Aristocracy (1947/1961) she wrote of her assistant, Umnyakaza: "The umfana becomes a member of the over-lord's intimate circle of dependents, regards him as a father and is treated much like a son. Umnyakaza, a warrior from Sobhuza's own bodyguard, acted as my teacher, interpreter, cook, and travelling companion" (2).

Sondra Hale (Hilda's graduate student at UCLA) described Hilda as "dignified" because of the "formal" way Hilda dressed, spoke and acted; for example, Hilda never cursed. Sondra felt "intimidated" because of the working-class background she came from. Sondra only learned later that Hilda had in fact grown up humbly and rather poor on a farm in Southern Rhodesia, but Sondra said she never would have known that by the way Hilda spoke and behaved (Hale and Gondek 2016). Sondra added: "Probably, also, the veneer of upper-classness was more theatrical than elitist or snobbish (which she was not). I think I recall that she did some acting and, of course, theater was very much in her life. I loved her somewhat exaggerated 'British' accent." 
David Kuby depicted Hilda as "Jewish, British and African"; she was able to combine these identities that would normally not fit together neatly (Kuby and Gondek 2017). Dawn Chatty, another student of Hilda's, described Hilda as "more British than the British," which Kuby echoed when he said that she was "quite British in her sensibilities" (Gondek and Chatty 2017). Kuby (2017) explained that Hilda was able to practice religions other than the one she was born into: "Hilda's religious sensitivity, empathy, respect for religious differences allowed her to 'suspend her disbelief' to enter into an unseen world charged with sacred power and vitality. She could participate in religious rituals that Orthodox Judaism would have prohibited her to do."

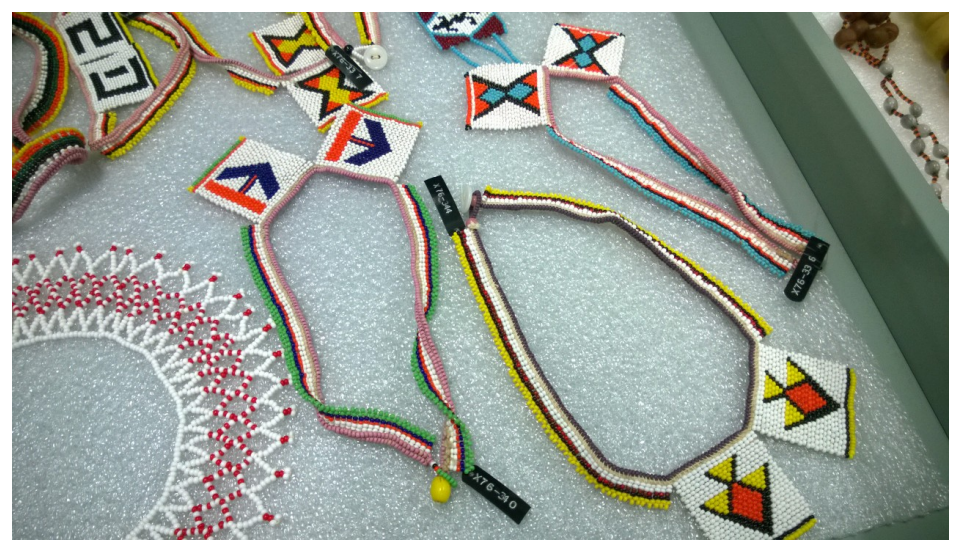

Figure 64. Ligcebesha Swazi necklaces in the Thoko Ginindza Collection at the UCLA Fowler Museum. Catalogue nos. X76.336, 340, 344, an everyday accessory worn by adults of both genders and children.

Gelya Frank described a unique gift she received from Hilda at a naming ceremony for Gelya's daughter, Rebecca S'manga Frank, in Spring $1988 .{ }^{89}$ During this

\footnotetext{
${ }^{89}$ Gelya created this naming ceremony as a Jewish feminist in which seven women among family members, friends and mentors were invited to speak and provide blessings. Rebecca's father was a Swazi, George Vilakazi, then a PhD student in Comparative Education at UCLA and later Minister of Tourism, Communication and the Environment in the Swazi government. Gelya met George through her friendship with Thoko Ginindza, whom she met while Thoko was living in Los Angeles with her son Martin
} 
naming ceremony, Hilda gave Rebecca a cloth coin bag tied with string and a Chinese coin that contained a traditional Swazi beaded choker, a "ligcebesha" (Figure 64) and another necklace strung with porcupine quills and red seeds - "umsinsi seeds" (Figure 65). Both types of necklaces are included in the Thoko Ginindza collection at the Fowler Museum (Fowler Museum 1976). The bag also contained an inexpensive and slightly tarnished chain and pendant that said "Shalom" in Hebrew (Frank and Gondek 2017). These symbolic gifts came from among Hilda's belongings. I argue that these gifts reveal how Hilda felt connected to both Swazi and Jewish identities.

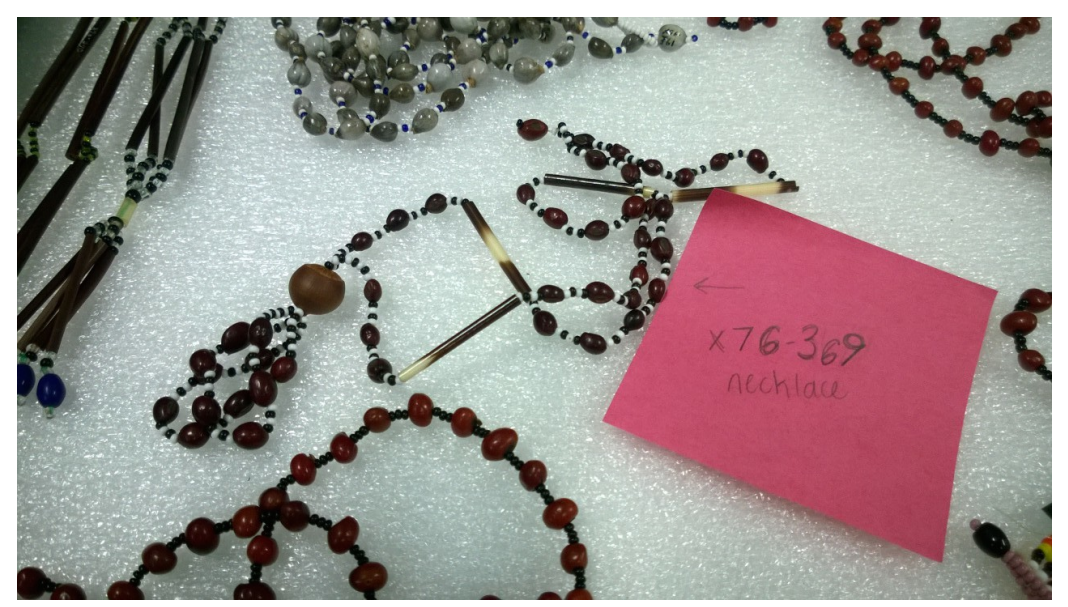

Figure 65. Swazi necklaces made from porcupine quills and umsinsi seeds in the Thoko Ginindza collection at the UCLA Fowler Museum. Catalogue no. X76.369.

Dlamini and doing PhD research with Hilda through International University (e-mail communication, March 18, 2018). 
Part II: Professional and Personal Networks

\section{Institutional Affiliations: The differential influence of Winifred Hoernlé and SAIRR on Kuper and Hellmann}

It was in the decade following the election of Afrikaner nationalist Hertzog (1929) that social anthropology students trained by Winifred Hoernlé (1885-1960) at the University of Witwatersrand, like Hilda Beemer Kuper and Ellen Kaumheimer Hellmann, engaged in localized, intensive, systematic, "scientific" participant observation, and wrote book-length manuscripts in order to detail the relationship between tradition and rapid social change in South Africa (Bank 2016:51). Andrew Bank portrays these ethnographies as working against the nationalistic government, through their political analysis of the complexities of "traditional and changing African cultures" (50).

Afrikaner-oriented anthropology, "volkekunde," which emerged from German ethnology, had a strong influence on apartheid policies; it emphasized "primordial cultural identities" which could be preserved through racial segregation of indigenous African cultures. Winifred Hoernlé strongly resisted volkekunde, along with Malinowski's too-similar culture contact theory that focused exclusively on rural rather than urban environments (Foreman 2013:35-37).

During the early 1930 s, poverty was seen as a social problem that needed to be scientifically studied in South Africa. In 1931, the South African Institute of Race Relations (SAIRR), of which Hellmann would eventually be president (1955-1956), began investigating the impacts of the liquor laws upon the "native" population (Bank 2016:105, 115). SAIRR, then under the direction of J.D. Rheinallt-Jones, avoided direct 
political involvement or commentary in favor of "factual presentation of issues" or "informal pressure on government ministers on an individual basis" (Rich 1984:30). ${ }^{90}$

Paul Rich argues that Rheinallt-Jones typically justified governmental actions, protecting them from attack (1984:66). This was because Rheinallt-Jones believed in the power of the state to alter social values and he aimed to overturn historical racial prejudices regarding a "primitive mentality" among "natives" by using "science" to create "interracial "harmony"” (Rich 1984:56-57).

Both Winifred Hoernlé and her husband Alfred Hoernlé were leaders within SAIRR. Alfred was the president from 1939 to 1943 when he died and Winifred took over the leadership (Bank 2016:60; Hoernlé 1939). In 1931, W. Hoernlé asked the director of SAIRR, Rheinallt-Jones to set up a project for Hilda Kuper to interview women beer-brewers, imprisoned because of the liquor laws (Kuper 1984:195-196; Bank 2016:115, 195). Hilda said that the prison was "soul destroying and dehumanizing" and

\footnotetext{
${ }^{90}$ SAIRR's position held steadfast in 1973, when Ellen Hellmann was one of the older, conservative, stalwarts of the organization. She believed that SAIRR had a legal duty to comply with the governmental investigation, called the Schlebusch Commission of Inquiry, into several multi-racial organizations (including SAIRR). Younger members of SAIRR felt that SAIRR should refuse to provide evidence or testify before the Commission of Inquiry, yet Hellmann argued that "if it is to maintain its integrity and uphold the principle of objective inquiry and its commitments to the rational, as opposed to the emotional approach, the Institute cannot, as a body, refuse to testify before a statutorily appointed commission." Hellmann felt that the SAIRR could not "put itself outside of the law or refuse to obey the law" even though it felt "dismay" at the banning of eight NUSAS -National Union of South African Students- leaders and the banning and house arrest of eight black leaders of the SASO- South African Student Organisation (Pringle 1973). Ellen's response and position on this issue reveals her fervent belief in the "rule of Law" and how it led her to take conservative positions in relation to apartheid policies and governmental commissions.
} 
that the women were resilient and returned to beer brewing when they got out of prison because they needed the money to pay for school fees and clothes for their children (1984:196). Ellen Hellmann took over the project from Hilda, when Kuper left for London to study with Malinowski in 1932, also arranged by W. Hoernlé (Bank 2016:115). Hellmann's master's thesis research in Rooiyard (1933-1934) emerged through this project.

Winifred Tucker Hoernlé: From measuring skulls to "politics not science"

Ellen believed her teacher Winifred Tucker Hoernlé emphasized: "the common humanity that all humans share is greater than the differences between them" (Bank 2016: 114). But W. Hoernlé did not always believe in this "common humanity." She began her anthropological training with A.C. Haddon at Cambridge (1908-1910), learning to perform measurements of human skulls as part of the physical anthropological study of "racial types" - thus emphasizing human differences rather than commonalities. However, later after her marriage to Alfred Hoernlé, Winifred began to work with Radcliffe-Brown (1922) and her research emphases drastically changed; she became interested in the negative impact of the colonial government on black Africans living in urban locations, material culture, historical change, as well as the intersections of age, gender, patriarchal kinship and lobola - themes that are clearly present in the work of her female students Hilda Kuper and Ellen Hellmann.

In a 1909 letter to her parents during the period in which she was working with Haddon on skull measurements, Winifred Tucker commented nonchalantly, "Then we all sit round amongst the skulls in the full view of any passers-by and drink our beverage" 
(Bank 2016:24). Her first fieldwork experience in German South West Africa (1912-

1913) was disastrous for her because Haddon's teaching had not taken into account the impact of colonialism on the area, which had become increasingly violent in the ten years before her arrival. Her Nama participants did not like their heads to be measured and did not understand what she meant by mental imaging of their dreams (which she had learned during her Gestalt psychology training). Potential Nama informants often avoided working with her by "feigning ignorance, incomprehension and ....an inability to concentrate" which she perceived to be laziness (Bank 2016:26-28).

Approximately ten years later, after she had married R.F. Alfred Hoernlé, ${ }^{91}$ a liberal philosopher of ethics who believed in territorial segregation of Africans (Bank 2016:17, 29), Winifred collaborated with Alfred Reginald Radcliffe-Brown (1881-1955), who had been a teacher at Cambridge when she studied there. He earned his PhD in 1908, the year Winifred Tucker arrived at Cambridge, and he was only four years older than she was. Radcliffe-Brown had been more influenced by W.H.R. Rivers than Haddon, and

\footnotetext{
${ }^{91}$ Ellen Hellmann wrote of Alfred Hoernlé's liberalism in April 1946 in Jewish Affairs, the journal of the Jewish Board of Deputies, that he felt that the concept of separated development was a Nazi-like ideology, yet he did believe that the ideal "liberal" solution for South African was territorial separation. However, he felt this was not economically practical or possible. Hellmann wrote that A. Hoernlé failed to realize the full economic implications of the Native Land and Trust Act of 1936; she clarified that in fact this "Land Act perpetuates the system of migratory labour upon which the mines depend; that it bases Bantu existence upon land-starvation and hence ensures the continuance of the Reserves as cheap labour reservoirs; that it prevents the emergence of a stabilised urban population on the one hand and on the other, of a full time peasantry" (Hellmann 1946). Note that the following month in May 1946, Ellen was elected to the editorial board of Jewish Affairs (J. B. of Deputies 1946).
} 
thus rather than physical anthropology and cranial measurements, Radcliffe-Brown highlighted kinship and the theories of Emile Durkheim, emphases that he imparted to Winifred Hoernlé when they re-met in Cape Town in 1922 (and that she taught to her students). Radcliffe-Brown shared Haddon's interest in material culture and so both Radcliffe-Brown and Winifred collected ethnographic objects for their respective museums (Bank 2016:32, 34-35).

Informed by her work with Radcliffe-Brown, Winifred Hoernlé's follow-up research with the Nama in South West Africa was different than her previous attempt because she listened to Nama complaints about the South African government appropriating their earnings. South African officials, who had taken control of South West African in 1915, were displeased with her "politics not science" because they had enlisted her assistance in tracking data regarding the Nama in rural areas in order to justify the creation of "native reserves" as they had done within South Africa. W. Hoernlé chose to study the appalling living conditions in the urban Windhoek location. Andrew Bank argues that her research contested the 1923 law that would promote Nama reserves (Bank 2016: 36-37). Winifred Hoernlé's anthropological networks are visualized in Figure 66. 


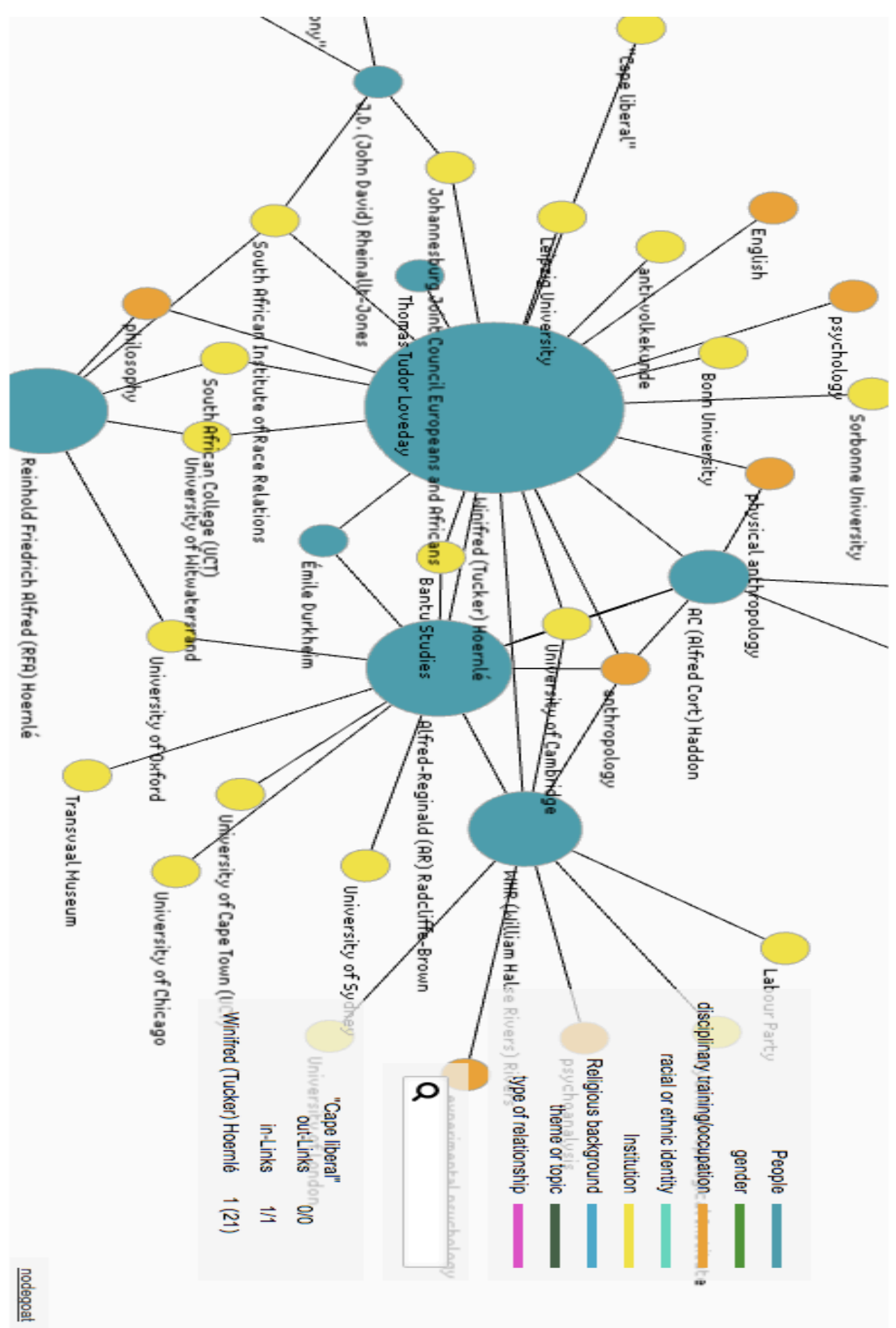

Figure 66. Winifred Hoernlé's network including A.R. Radcliffe-Brown, W.H.R. Rivers, A.C. Haddon, J.D. Rheinallt Jones, and Winifred's husband Alfred Hoernlé. This visualization includes shared institutional affiliations, advisors and advisees, and disciplinary training. 
There is a clear connection between W. Hoernlé's early 1920s research, emphasizing the negative impact of colonial governmental systems upon indigenous Africans in urban locations, as well as material culture, and the research of her students at Wits, Hilda Beemer Kuper and Ellen Kaumheimer Hellmann (Hellmann 1948c; Kuper 1973; Kuper and Ginindza 1976). For example, Ellen Hellmann wrote that native poverty prevented the acquisition of the European material culture that the "invading culture has to offer him" (1948:10). Hellmann emphasized that furniture (a form of material culture) was a sign of wealth and social status among "natives" who had lived in the urban setting longer. "The fittings of the rooms reveal the eagerness with which the material culture of Westernized civilization is being adopted"; newer arrivals to the urban environment demonstrated a "paucity of furniture" while those with more years of urban residence revealed a "comparative opulence of the fittings" (1948:9-10).

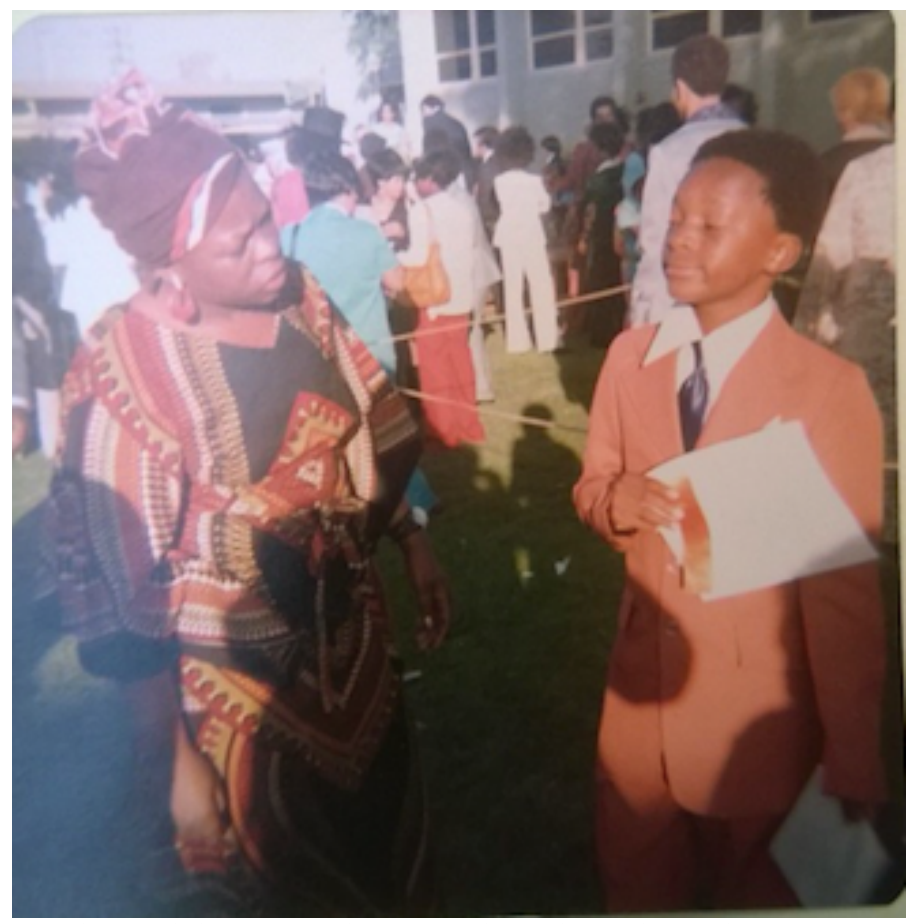

Figure 67. Thoko Ginindza with her son, Sibongo, at his 8th grade graduation, May 20, 1977, when he was 12 years old. From Box 45, Folder 20, HKP. Sibongo wrote letters to Hilda (January 6, 1974, Box 24, Folder 20, HKP). 
Hilda Kuper was also highly interested in material culture (probably influenced by her teacher Hoernlé), though for her the emphasis was on "traditional" Swazi culture, especially its patriarchal elements. Hilda's relationship with Swazi graduate student, Teresa Thoko Ginindza (1942-1996), emphasized this focus on gendered Swazi material culture. Thoko (as she was called, Figure $67^{92}$ ) knew Hilda from Swaziland and wrote to her in 1967 asking for Hilda's help to attend UCLA (Ginindza 1967). With Hilda's support, Thoko earned her M.A. in African Studies in 1972 (Kuper 1972). In Ginindza's 1971 paper "Dress in Swaziland" she focused on Swazi gendered clothing norms, and she spoke of a specific skirt that only married women wore called a sidvwaba, that was so heavy it "broke the waist"; Thoko noted that it was so stiff that it conquered "even the most stubborn woman" ensuring that she conformed to the demands of married life (Ginindza 1971:2). Teresa's research clearly influenced Hilda, since this description can be found in Kuper's 1973 article "Costume and Identity" (Kuper 1973:352). Also by 1975, Thoko and Hilda were coordinating the collection of Swazi artifacts for what became UCLA's Fowler Museum (Ginindza 1975; Kuper 1975b, 1975c).

Winifred Hoernlé was highly influenced by Brown's structural-functionalism, leading her in 1923 to view the Nama culture as an "intelligible" whole. Andrew Bank stresses that this type of language is now considered overly "harmonious," yet at that

\footnotetext{
${ }^{92}$ Gelya Frank explained that Sibongo goes by the name Martin Dlamini, studied journalism at Santa Monica College, when Thoko was doing PhD research with Hilda through International University, and that Martin is now the managing editor of the Times of Swaziland.
} 
historical moment, Bank insists, the view that an African society could be "cohesive" or "intelligible" countered the popular racist conceptions of black biological difference and inferiority, which were also held by Winifred's father, a miner, turned mayor of Johannesburg (1906-7), and senator for twenty years (Bank 2016:19, 42). In 1925, W. Hoernlé depicted a nuanced view of historical change in Nama society, precipitated not just by German colonialists (1884), but by other indigenous African groups such as the "Oorlams" (in the early $19^{\text {th }}$ century) and the "Herero" (in the mid-nineteenth century). This is important because it demonstrates how a society changes over time, rather than remaining "stuck" in the past, as African societies were typically depicted (Bank 2016:42; Hoernlé 1925b:3-7). In addition, W. Hoernlé's 1925 conclusions about the importance of age and gender, patriarchal kinship structures, and marriage customs that highly valued cattle, such as lobola, are all themes that emerge in the work of her students Kuper and Hellmann (Bank 2016:43-44; Hellmann 1935, 1940e; Hoernlé 1925a:482-84; Kuper 1947; Kuper et al. 1945).

The divergent paths of Kuper and Hellmann: The influence of Durkheim and Malinowski

Winifred Hoernlé was Hilda's advisor from 1927-1932 before Hilda attended the London School of Economics under the guidance of Bronislaw Malinowski (Bank 2016:193-197; Kuper 1984:193-195, 197-199). Ellen Hellmann also studied with Malinowski in London, although for only a few months in the fall of 1934 when she was writing up her master's thesis research about Rooiyard, after he had visited Johannesburg in July 1934 and given her a copy of Sexual Life of Savages; other students who were at 
LSE at the same time from South Africa were Max Gluckman, Jack Simons, P.J.

Schoeman, and Z.K. Matthews (Bank 2016:57, 121-122).

Hilda took Hoernlé's class with Ellen Hellmann and Max Gluckman. Hoernlé assigned Kuper to study and present Emile Durkheim (and French sociology) and Ellen Hellmann to J.J. Bachofen and Leo Frobenius (Kuper 1984:195; Bank 2016:114). Kuper passed her interest in Durkheim on to her students and assistants; Fatima Meer wrote about suicide rates in South Africa based upon the intersections of both race and gender, influenced by Durkheim (Meer 1976). Dawn Chatty told me that Hilda "brought Durkheim alive" (Gondek and Chatty 2017). Bachofen's influence can be detected in Hellmann's interest in women-led families and her association of an inferiority or primitiveness with this type of family organization. Ellen Hellmann inherited Frobenius' approach to African cultures as categorically different from Western civilizations, and as less advanced, including in their approach to parenting methods. ${ }^{93}$

\footnotetext{
${ }^{93}$ Frobenius (1873-1938), a self-trained German ethnologist, visited Africa twelve times between 1904 and 1935, collecting ethnographic objects and oral histories. His interest in Africa emerged through his childhood visits to "human zoos" at the Berlin Zoological Gardens during which he witnessed Africans performing as part of ethnological expositions. In 1934 he became the director of the anthropology museum in Frankfurt, Germany (Streck 2004). Hilda Kuper met Frobenius when he came to inspect ruins Kuper's uncle had found on his farm in Zimbabwe (Kuper was born in Bulawayo, Rhodesia). Kuper found the "museum approach" boring, though (Kuper 1984:194). Frobenius is often associated with championing the African cause; R.D. Cohen positions Frobenius as a figure who inspired German writers to valorize African civilization and styles of storytelling, and to contest racist conceptions of Africa and Africans held by the Nazis (Kohen 2014:110). In contrast, Seth Quartey maintains that Frobenius, like other colonial era ethnologists, failed to appreciate African art (Quartey 2010:262). Quartey contends that Frobenius could not conceptualize Africans as producing works of high aesthetic quality and thus Frobenius assumed that the ologun statue he excavated was of Greek rather than Nigerian Ife origin (264-265). Sarah Silva provides evidence that white Brazilian anthropologist Arthur Ramos (a friend of Melville Herskovits and one of the
} 
Winifred Hoernlé also likely initiated Kuper's interest in studying Indian South Africans. W. Hoernlé was the chair of the Indian Joint Council, and Hilda Beemer became the secretary. Hilda researched the housing and recreation of Indians who lived in Johannesburg slums in addition to her research with African women imprisoned for beer brewing (Kuper 1984:195).

In 1932 Kuper went to the London School of Economics and interviewed with Malinowski (a Polish Jew), before she was allowed into the doctoral program. Kuper recalled how Malinowski could be "cruel" to those students who opposed his views and who had training in other disciplines; for example he called Meyer Fortes, Siegfried Nadel and Sjoerd Hofstra, "Mandarins," a reference to Chinese scholar-bureaucrats; Kuper did not explain what this term meant to Malinowski, but it seems to be an implication that they were like "Easterners," similar to the distinctions Ellen Hellmann made between herself as a German Jew and "Eastern Jews" who she said were like "nonEuropeans" (Kuper 1984:197-98; Moran 1988:195). Hilda objected to Malinowski's focus on the "ethnographic present" and his de-emphasis on history; after working with the Swazi (and demonstrating W. Hoernlé's influence) she realized how important

men responsible for sexual rumors about Ruth Landes) used the theories of Frobenius in 1937 to posit black Candomblé practitioners' "pre-logical" and "primitive" thinking processes (Silva 2010:99-100). Frobenius believed that each culture had its own soul, and its own developmental process, like an organism, and like a human evolved from a child to an adult. This placed societies in certain stages of development (Silva 2010:110111). Even Aimé Césaire, the négritude writer, cited Frobenius in almost every piece of writing, bringing Frobenius' essentialist concept of an African soul into the heart of négritude philosophy, while at the same time critiquing the colonialism that enabled Frobenius to carry out his fieldwork in Africa (Arnold 2013). 
history, clanship and power were to the Swazi, and that they did not deem "function" important, in contrast to Malinowski's central preoccupation (Moran 1988:195-196; Kuper 1984:203-204). Kuper was drawn to political anthropology and away from studies of religion, magic and "the exotic"; she became interested in stratification, the hegemony of hierarchies, in both colonial systems but also within kingship, and the ruling clans (Kuper 1984:204). Yet her interest in institutions (rather than a focus on the individual, as Gelya Frank explained) was a preoccupation she shared with Malinowski (Kuper 1984:197-198). Hilda assisted Malinowski with two volumes of Coral Gardens and their Magic. Though psychology was influential for Malinowski, Hilda was more interested in Marxism, which Malinowski did not support (1984:199). Hilda remembered that both she and Godfrey Wilson, also a student of Malinowski (Godfrey became the husband of Monica Hunter Wilson), went to psychoanalysis, yet Hilda stopped after six months since she figured that music and theater would prove more useful (Kuper 1984:199). Hilda critiqued the psychological approach of Mead and Benedict, which emphasized a consistent pattern creating an oversimplification of an entire culture into an "individual personality" (Kuper 1984:205; Moran 1988:197). Hilda kept personal diaries in the field as part of her training with Malinowski but burned them when she became ill upon coming out of the field and feared she would die; she was worried what would become of her private information with secrets that the Swazi would not have wanted to be revealed. She later regretted destroying the diaries since "many of the anthropologists now would say that this is quite as important, the personal material. I turned some of it into a play, $A$ Witch in my Heart, and some I wrote as fiction" (Langness and Frank 1981:148). 
Though Marxism may have been influential for Hilda, Dawn Chatty stated that Hilda was not a Marxist. Dawn recalled that Hilda jumped in at Dawn's dissertation defense exclaiming, "You know we don't all have to be Marxists," to Gerry Hale, Sondra Hale's husband, who was on Dawn's dissertation committee (Gondek and Chatty 2017).

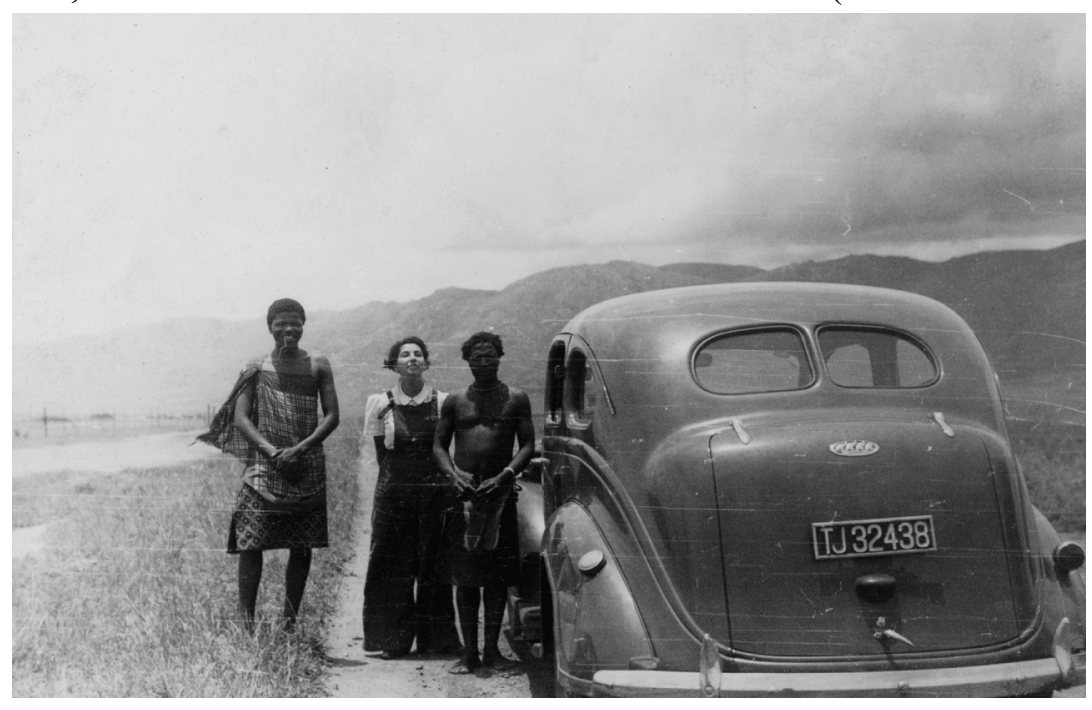

Figure 68. Hilda Kuper (center) with Sobhuza II (left) in September 1934. Photo likely taken by Leo Kuper before Hilda's departure for three-month tour of Swaziland. Hilda's assistant (right) is unnamed in the photo, but in African Aristocracy (1961) she said his name was Umnyakaza. Car's license plate was from Transvaal, Johannesburg (TJ). Hilda Kuper Papers, Box 60, Folder 2.

Kuper's networks in Swaziland and with the Queen Mother began through Malinowski, who bonded with the Queen Mother while they both soaked their injured feet in hot water and Epsom salt multiple times a day (the Queen Mother had stepped on a thorn, while Malinowski had his foot stomped on by a horse). Thus, as Malinowski's student, Hilda had an immediate connection with the Swazi royal family, which created protection but also suspicion and jealousy (Kuper 1984:200-201). In 1935, King Sobhuza II (Figure 68) defended Hilda Beemer's representation of the Swazi rain ceremony, when Hilda critiqued an Afrikaner anthropologist P.J. Schoeman whose depiction of the rain ceremony she found to be inaccurate, incomplete, and insulting. Beemer maintained that Schoeman's information and informants were unreliable, since he had not been 
physically present and they were not the key participants in the ceremony and thus were incapable of accessing the secret knowledge of the event only held by the Queen Mother, her son, the King, and a few select other individuals (Kuper 1984:202; Beemer 1935:274275). Beemer also emphasized (in direct contrast to Schoeman) that it was the Queen Mother and not the King who was the "main personality" within the rain ceremony (1935:275). Sobhuza wrote "The following critical comments on Dr. P.J. Schoeman's article have been written after consultation with the Indlovukazi [Queen Mother], myself and other authorities on tribal lore, by another anthropologist who is at present working in Swaziland [Hilda Beemer]. I have read through the criticism and I corroborate the corrections" (Beemer 1935:273). Beemer emphasized the responsibility anthropologists should have to check their findings with educated and literate authorities within the indigenous culture, as she did with Sobhuza (279). She also highlighted values she learned from Sobhuza II and carried with her throughout her career: the importance of looking at a society through a holistic lens, studying religious ceremonies in their intersections with the economic and political context and the history of colonialism and its effects. Since Schoeman neglected to do this, his analysis overemphasized and simplified magical beliefs and created a "distorted picture of Swazi mentality" that portrayed them as if they were children and "pre-logical" (279). Hilda's writings about Swazi people were highly influenced by her close affiliations with the Swazi royal family (see Figure 69). In addition, Malinowski's emphasis on institutions was influential for her and distinguished her from Ruth Landes, who was highly influenced by Ruth Benedict, and thus was more intrigued by individual expressions of agency. 


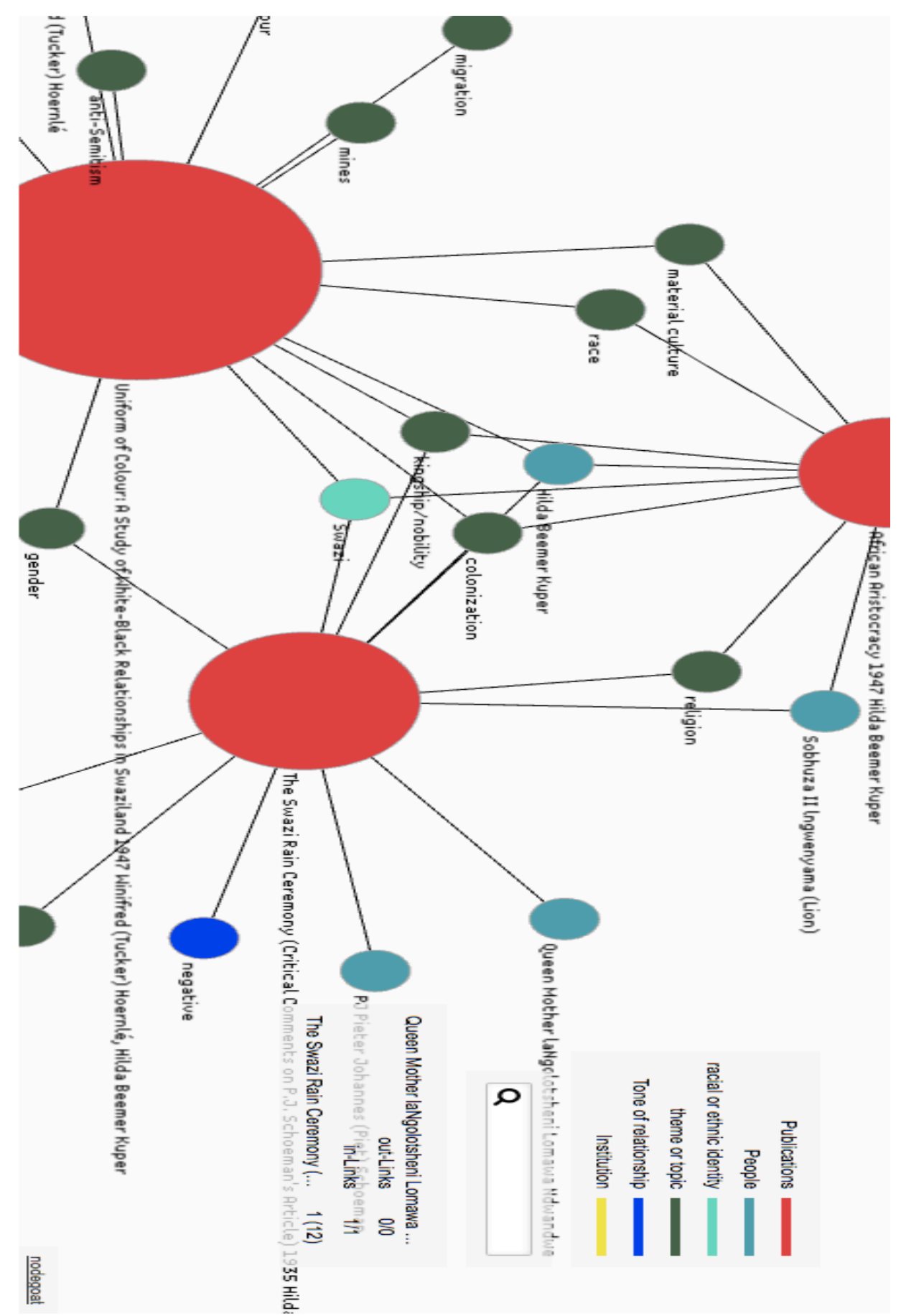

Figure 69. Kuper's publications about Swaziland, connections with Swazi royalty, and research themes investigated. 


\section{Political orientations and marital status}

Many of Hilda's subsequent institutional affiliations after her research with SAIRR and through Malinowski's doctoral program were facilitated through her romantic relationships with Jewish men. She shared her political orientations with her husband, Leo Kuper, whom she married in January 1935; Leo was a criminal lawyer who became a sociologist of genocide. I heard from many of Hilda's students that Hilda had a "traditional" or "conventional" marriage (Bank 2016:211); she deferred to Leo (RosenPrinz and Gondek 2016), "doted" or "catered" to him, and did everything for him (Hale and Gondek 2016). Gelya Frank articulated how Leo and Hilda "adored each other" (Frank and Gondek 2017).

Leo came from an Orthodox Jewish family, but he did not want to be governed by this orthodoxy. When Leo's co-author brought his own food and utensils to a meeting about their genocide book in order to maintain the rules of kashrut, Leo thought it was a bit excessive (Bank 2016:199; Gondek and Frank 2017). According to Adam Kuper, Leo's nephew, Leo received his law degree from the "University of the Witwatersrand and practised law until the outbreak of the Second World War, acting in human-rights cases for African clients and representing one of the first non-racial trade unions..." (Kuper 1994). Adam Kuper also depicted his uncle Leo Kuper as a liberal who advocated non-violence and passive resistance rather than violent revolution; Leo believed that civil organizations provided the best option for addressing racism. These were the foundational philosophies of the Indian elite intellectual community in Durban, and the Liberal Party, which Leo and Hilda helped to found in 1953. Yet the official history of 
the Liberal Party neglects to mention Hilda's involvement (Bank 2016:217-18; Golomski 2011:3-4; Russell 1994:146).

The Kuper home was a central site for anti-apartheid solidarity across racial lines. On November 9, 1952, Leo collaborated with the joint ANC-Indian Congress political rally at Red Square in Durban; he wrote about his experiences in Passive Resistance in South Africa (1955). Leo was arrested in 1956 with Alan Paton and four Indian Congress members for their participation in the "assembly of the Native" in the Gandhi Library Hall in Durban; this is where they launched a defense fund for the 156 Treason Trialists. Hilda was arrested earlier in 1956 with Fatima Meer at a women's march protesting new laws that extended the pass system to "non-European" women (Bank 2016:217-18). Hilda was "combative with non-progressive colleagues" and was excluded from a departmental research trip to Swaziland, despite her expertise (Russell 1994:146). By the late 1950s, the apartheid police increasingly harassed Leo and Hilda, spies attended their lectures, and Leo was threatened with a banning order; eventually Hilda instigated their departure from South Africa (Golomski 2011:4; Moran 1988:198). Hilda and Leo’s intersecting organizational affiliations are depicted in Figure 70. 


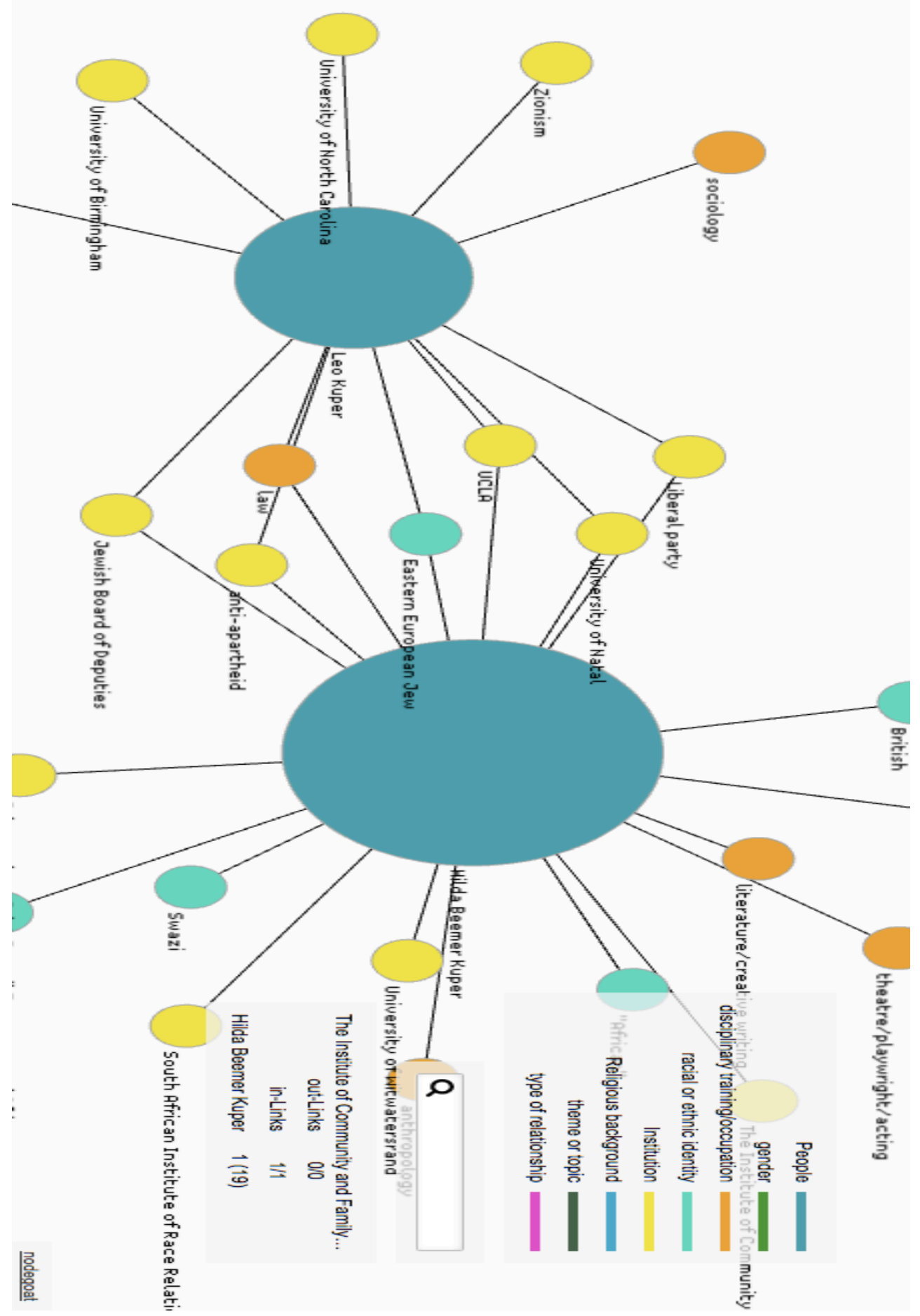

Figure 70. The institutional associations that Hilda Kuper and Leo Kuper shared.

Andrew Bank writes (and I agree): "[Hilda] also always seemed to put Leo's career above her own, from the time of their moves to North Carolina, Coventry and 
Birmingham, when he established his career, to her insistence in private communications with the editor of his festschrift, Pierre van den Berghe, that the celebration be about him rather than her" (2016:236). Between 1947 and 1952, Hilda followed Leo to four different cities. First, they went to Chapel Hill, North Carolina so he could pursue a doctorate in sociology. Then they went to Birmingham University where Leo studied with Charles Madge, conducting his doctoral research on urban planning in Coventry, England (Living in Towns); Hilda felt academically isolated there (Kuper 1984: 207; Bank 2016:216-217; Kuper 1994).

Hilda moved to Durban, Natal in 1952 when Leo was awarded the chair position in the Department of Sociology at the University of Natal. In 1958, Hilda received a Simons Fellowship to complete the writing of her Indians in Natal manuscript at the University of Manchester organized by her former boyfriend, Max Gluckman (Bank 2016:217, 224; Kuper 1984:208-9; Russell 1994:146). Hilda received a Senior Lecturer

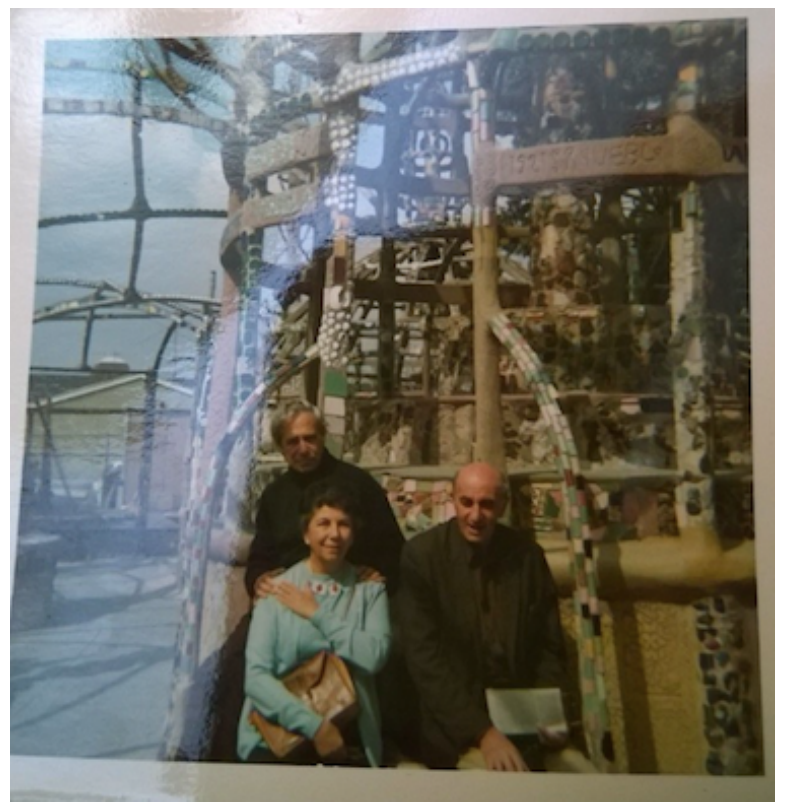

Figure 71. Hilda Kuper (center) with Leo Kuper (behind) and Max Gluckman (right) at Watts Towers, Los Angeles. Hilda Kuper Papers, Box 45, Folder 20. 
position in the Social Anthropology Department at the University of Natal after Jack Krige's sudden death in 1959 (Bank 2016:229). However, because of the aforementioned police surveillance, she and Leo fled to UCLA in October 1961 where Leo got a position in the Anthropology/Sociology department (Figure 71). ${ }^{94}$ However, Hilda could not teach in that department until 1963, because of nepotism rules, so she had to wait until the Anthropology department separated from Leo's Sociology department (Kuper 1984:209). Eventually she became the chair of the Department of Anthropology, retiring in 1977 (Bank 2016:230). Gelya Frank explained that Hilda was at a structural disadvantage within the department because she did not have funding and consequently lost promising $\mathrm{PhD}$ students to those, like Clement Meighan, an archaeologist in the department, who could offer funded positions. Before Gelya started at UCLA in the early 1970s, Hilda was the only female professor in the Anthropology department, but the year Gelya began her graduate studies, there were at least two female hires (e-mail communication, March 18, 2018)..$^{95}$

Leo and Hilda shared their political affiliation in the Liberal Party and Leo's career took precedence in their relationship; Hilda often received academic positions based upon Leo's existing appointments. Her life-long marriage gave her a certain degree

\footnotetext{
${ }^{94}$ Gelya Frank thinks that this photograph was likely taken in the early or mid-1970s when Gluckman came to UCLA to give a lecture. Hilda is wearing a Swazi ligcebesha necklace. Examples of these necklaces can be found at the UCLA Fowler Museum, Thoko Ginindza Swazi collection, catalogue numbers: X76.336-345.

${ }^{95}$ The two female hires were: Claudia Mitchell (Kernan) - African American Linguistic studies - and Fadwa El Guindi - visual Egyptian ethnographer, participatory research relating to the Zapotec, Islam and gender.
} 
of stability that Ruth Landes did not experience. However, because of nepotism rules, Hilda was not able to work in the same department as Leo, placing her at a gender-based disadvantage.

\section{Divergent Political Beliefs - Ellen Hellmann, the Progressive Party and the qualified}

\section{franchise}

While Hilda was a founder of the Liberal Party starting in 1953, Ellen was a founding executive member of the Progressive Party from 1959-1971. Despite Ellen's continued interest in black representation in politics and labor unions, ${ }^{96}$ she did not promote unqualified voting rights or "one man, one vote" but instead she backed the qualified or "progressive" franchise:

Dr. Hellmann herself would not be party to the call for 'one man one vote', whereas many young Jews would be satisfied with no less. She feels that a qualified vote is an acceptable alternative which some would say was discriminatory. One cannot bind Jews any more than any other communities to a particular line of action (Deputies 1976:4).

\footnotetext{
${ }^{96}$ In 1945 Hellmann critiqued the lack of black political representation in recognized trade unions and the inability for "non-Europeans" to vote (Hellmann 1945b). In a 1944 article in Pioneer Woman about Labor Zionism she explained that though the majority of South African workers were "non-Europeans," who would normally make leftist parties strong, they were denied the vote making them "politically impotent" (6). She deplored the fact that "non-Europeans" had no political representation, and that though they provided the country with un-skilled labor, their unions were unrecognized (Hellmann 1945e). In 1976 she remarked to the Jewish Board of Deputies that after the 1973 unrest in Durban, black workers could strike but their trade unions still lacked legal status, and blacks were not permitted to join recognized [white] trade unions (Deputies 1976:2). At the end of her life, in an interview with journalist Pat Schwartz, she reiterated this theme: "if we had recognized African trade unions or at least thrown open the unions to all groups in 1948, things would look different" (Schwartz 1981).
} 
A "qualified" vote was one of the principle tenets of Hellmann's Progressive Party: "to enable suitably qualified citizens of a defined degree of civilisation belonging to any population group to participate in the government of the country..." (Party 1959). Thus black (and also white) people had to prove that they had a sufficient degree of "civilization" - property, education, wealth - in order to be eligible to vote: only those who "are sufficiently educated to have an understanding of politics, and who have a sufficient economic stake in the country to make them desire its stability" (Mitchell 1962). The Progressive Party (and Hellmann) were concerned that the "one man, one vote" policy advocated by the Liberal Party (of which Hilda Kuper was a founding member) would cause the black population to overtake the white one: "lead inevitably to the exploitation of illiterate voters and probably to the triumph of a purely sectional Black nationalism” (Mitchell 1962:6-7). Through my conversation with Ruth Runciman, I discovered that it was possible that Hellmann privately believed in "one man, one vote" but that she likely decided that sponsoring this overly "radical" political platform was impractical and unlikely to achieve the necessary "progress" to dismantle apartheid "stepby-step.” Ruth's husband, Garry Runciman, a British historical sociologist, explained Ellen's position on black voting rights: "She was wary about the granting of immediate universal suffrage because of a fear that it would result in a one-party state and consequent risk of abuse of power: I have often said that if she could have foreseen what the ANC became under the leadership of Jacob Zuma, she would have been disappointed but far from wholly surprised" (March 7, 2018).

Hilda Kuper and Ellen Hellmann's different public positions on the issue of voting is significant, demonstrating their divergent approaches to South African politics 
and perhaps also their perceptions of black capabilities for self-rule. Hilda's primary long-term fieldwork was in Swaziland working with the royal family, so she observed first-hand black self-governance and understood the necessity for "one man, one vote." Also, in Durban, Hilda's colleagues and friends (like Fatima Meer) were actively pursuing more "radical" approaches to the apartheid state. In contrast, one of Hellmann's closest friends, Helen Suzman (who was of Jewish Lithuanian descent), was the only M.P. (member of parliament) for the Progressive Party and the only anti-apartheid voice (Suttner 1997:423). Though Suzman, like Hellmann, was fairly conservative or moderate, she was the only "liberal" M.P. during 1961-1974. Hellmann was the chairman for Suzman's constituency in the Houghton neighborhood (Gondek and Runciman 2018).

During the Treason Trials, Hellmann took a primarily fundraising role (Figure 72), serving as the chair for the committee that organized an art auction (Staff Writer 1959). Ellen was never arrested and did not experience police persecution in the way that Hilda Kuper and her husband Leo, did. Hellmann contended that the Progressive Party's

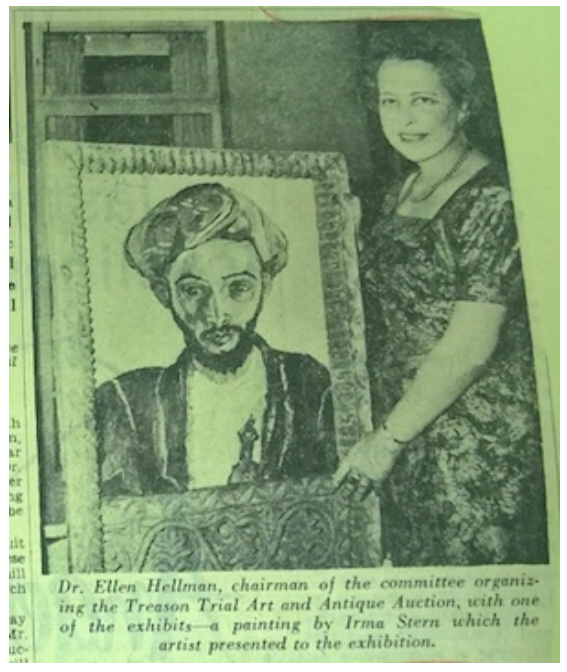

Figure 72. People Ransack Their Attics: Ellen Hellmann fundraising for the Treason Trial Art Auction. Hellmann is pictured with Irma Stern painting, February 19, 1959, The Star. Ellen Hellmann Box of Clippings, Jewish Board of Deputies Archives, Beyachad Community Center 
policies were "securely based on reason and on faith in human progress and I believe it is our commitment to these abiding values of western civilisation that will rescue us from the turmoil and afflictions of today." She maintained that the racial system of South Africa created an embarrassing image to outside nations, making South African seem uncivilized; the Progressive Party would "restore South Africa's honour in the outside world" (Hellmann 1962b). Ellen Hellmann's and Hilda Kuper's differential political stances point to the potential for diverse perspectives about black electoral rights within the South African Jewish community of social scientists as well as indicate potential explanations for their differing representations of women of color in their writings. In addition, the previous two sections have illustrated the reciprocal relationship between political and personal networks, though it is not possible to establish a causal relationship; Kuper and Hellmann belonged to political parties in which their friends (and in Hilda's case, also her husband) simultaneously participated, thus reinforcing their beliefs and strengthening the relationships which further influenced their theorizing.

Transracial Networks: Fatima Meer

Hilda met Fatima Meer in 1952 when Hilda moved to Durban, where her husband Leo Kuper, received a Sociology chair position at the University of Natal. It was Leo, the new head of the department, who allowed Fatima to rewrite her sociology honors exam (after she had been failed by a racist Afrikaner Nationalist lecturer); she passed with “flying colours” (Meer 2017:150-151). Fatima was Hilda's research assistant for Kuper's book Indian People in Natal (Kuper 1960:x). The Institute of Community and Family 
Health ${ }^{97}$ in the Newlands neighborhood in Durban funded this research (Meer 2017:155).

Fatima's fieldwork notebooks in the Hilda Kuper Papers, elaborate the effect of Indian immigration to South Africa upon caste affiliation, marriage traditions, legally required medical care, and labor strikes. Meer also tracked and summarized the ship logs by sex, age, caste, religion, village, and marriage status (Kuper et al. 1953). In her autobiography, Fatima refers to "filling in dozens of these reporter's notebooks" but unfortunately, she was dismissed after only a year from this position at the Institute of Community and Family Health because of her anti-apartheid activism and radicalism; Hilda and Fatima were both shocked (2017:158). Hilda clearly used Fatima's notes in Indian People in Natal in Chapter 1 regarding migration and Chapter 2 on changes in caste affiliation postmigration. Fatima is pictured with Hilda in Figure 73.

${ }^{97}$ Hilda conducted fieldwork in Durban in three Indian suburbs from 1953-1957 with funding from the Council for Social and Industrial Research. She worked with Indian health educators who were trained by the Institute of Community and Family Health including four women Miss N. Perumal, Mrs. Padmini Govindoo, Sally Naidoo and Violet Padayachee. In addition to Fatima Meer, Mrs. Radhi Singh assisted Hilda (Bank 2016:218-221; Kuper 1960:x). 


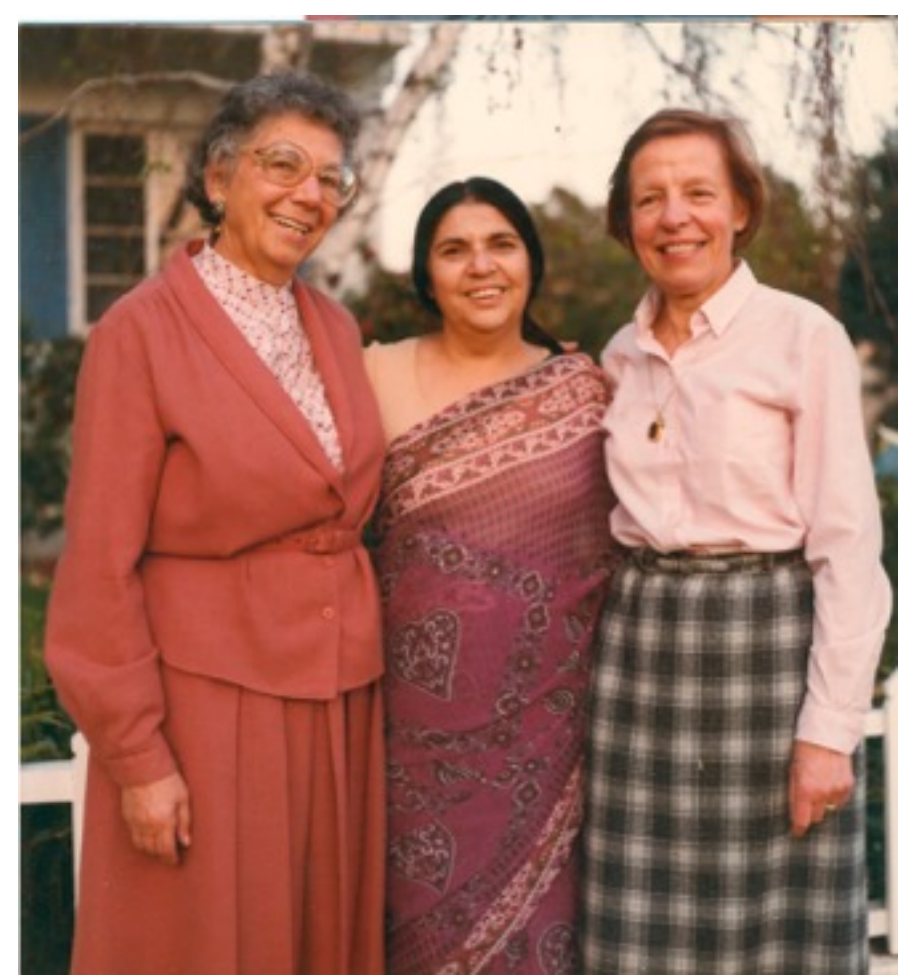

Figure 73. Hilda Kuper with Fatima Meer and Gisele Maquet, in front of Hilda's home on Warner Ave. in Los Angeles, 1984/5. Mary Kuper personal collection. Fatima's daughter, Shamim, posited that Fatima must have come to visit Hilda during 1985 when Fatima was a Visiting Lecturer at Swarthmore. Gisele Maquet's husband Jacques Maquet was an anthropologist at UCLA (with Hilda).

In 1970, Hilda wrote to Fatima from Los Angeles to express that she was "so delighted" with Fatima's book (Portrait of Indian South Africans, 1969) that she and Leo felt Fatima should submit it for a Ph.D. "The photographs are fascinating and the text is rich in perception." In closing, Hilda wrote, "There is so much to talk about that cannot be expressed in letters. We think of you very often and send you much, much love" (Kuper 1970). In her autobiography, Fatima wrote that Hilda Kuper "considered the manuscript so good that she canvassed the head of department to award me a doctorate for it” (2017:186).

In the fall of 1970, Fatima wrote to Hilda to tell her about an infuriating population conference she had attended and also about the resistance she was confronting 
from her department in response to her efforts to get approved for a Ph.D. based upon her book publication. Fatima explained:

I found the population explosion conference so depressing- the gathering of the privileged...to complain bitterly about the primitive... and living habits of the underprivileged, and their threat to swallow them up. Most nauseating of all, of course, was to see the extent to which white 'liberalism' had leaned backwards to accommodate...the new Afrikaner intellectuals from the Afrikaans universities. I said what I could, as long as I couched what I said in careful sociological jargon (Meer 1970:1).

Fatima told Hilda that a man in her department called "Hamish" did not think her book, Portrait of Indian South Africans, merited a Ph.D. because it lacked "sufficient theory" (a commonly used argument against women social scientists). Then Fatima added that Eileen [Krige?] agreed with him, stating that it was poorly documented! Meer commented, "Frankly, I don't know what she means by this." Also "Hamish" suggested that Hilda's "enthusiasm" for the book was based on her close relationship with Fatima and Hilda's supposed softness (Meer 1970:2). 


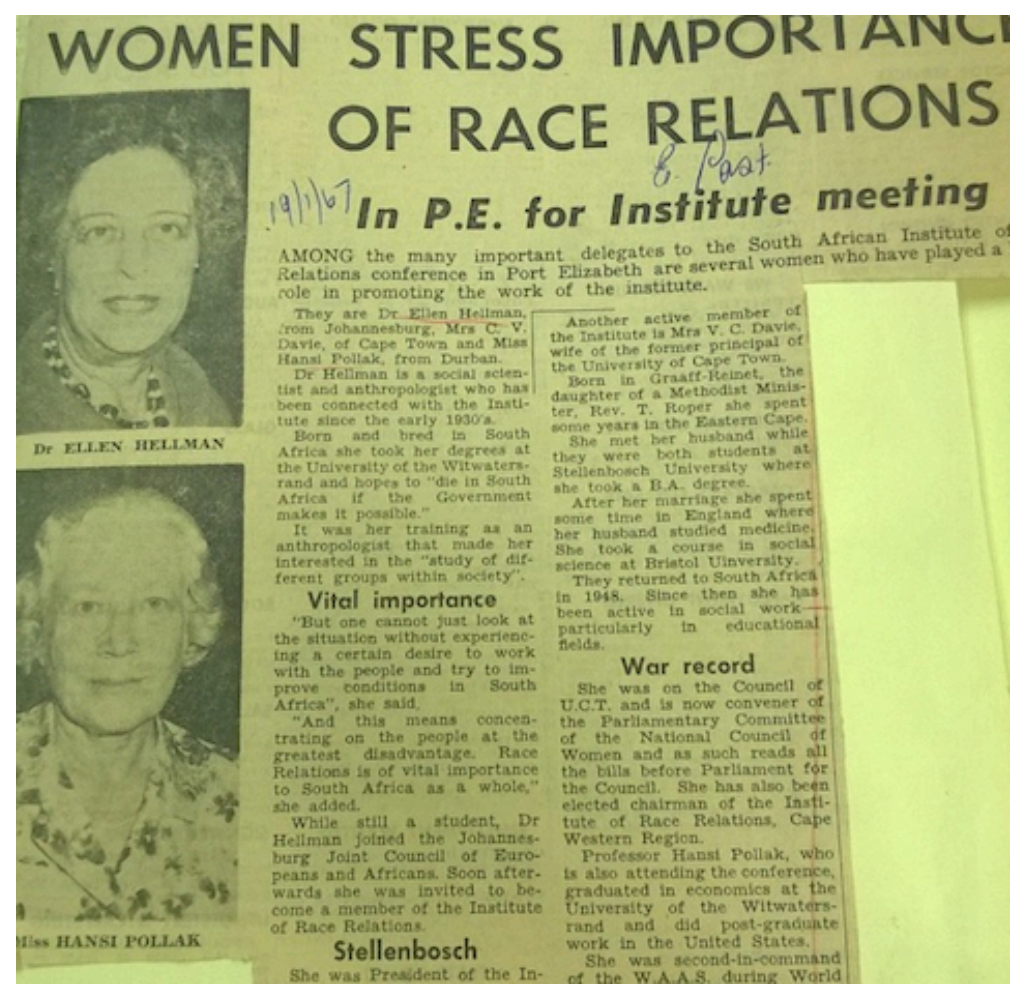

Figure 74. Hansi Pollak pictured with Ellen Hellman (sic) regarding their work with SAIRR, January 19, 1967. Ellen Hellmann Box of Clippings, Jewish Board of Deputies Archive, Beyachad Community Center

In her autobiography, Fatima notes that another professor, Hansi Pollak (Figure 74), the head of her department at the University of Natal, was "disparaging about the book." Hansi had also cut Fatima's salary because having black staff was a "problem" when Hansi took over for Leo at the University of Natal. Pollak additionally blocked Fatima's submission of her thesis for a year $(2017: 169,186)$. If that was not enough, Ellen Hellmann "rejected publication of the book on grounds that my Indian characters spoke bad English!” (Meer 2017:186)

While Hilda sided with Fatima, Ellen Hellmann was often named along with Hansi Pollak in newspaper articles because of their association with the South African Institute of Race Relations. In both 1962 and 1967 Hellmann and Pollak served as delegates for the SAIRR in Port Elizabeth (Pitman 1962; Writer and Jewish Board of 
Deputies Archive 1967). According to Ruth Runciman, Hansi was one of Ellen's best friends.

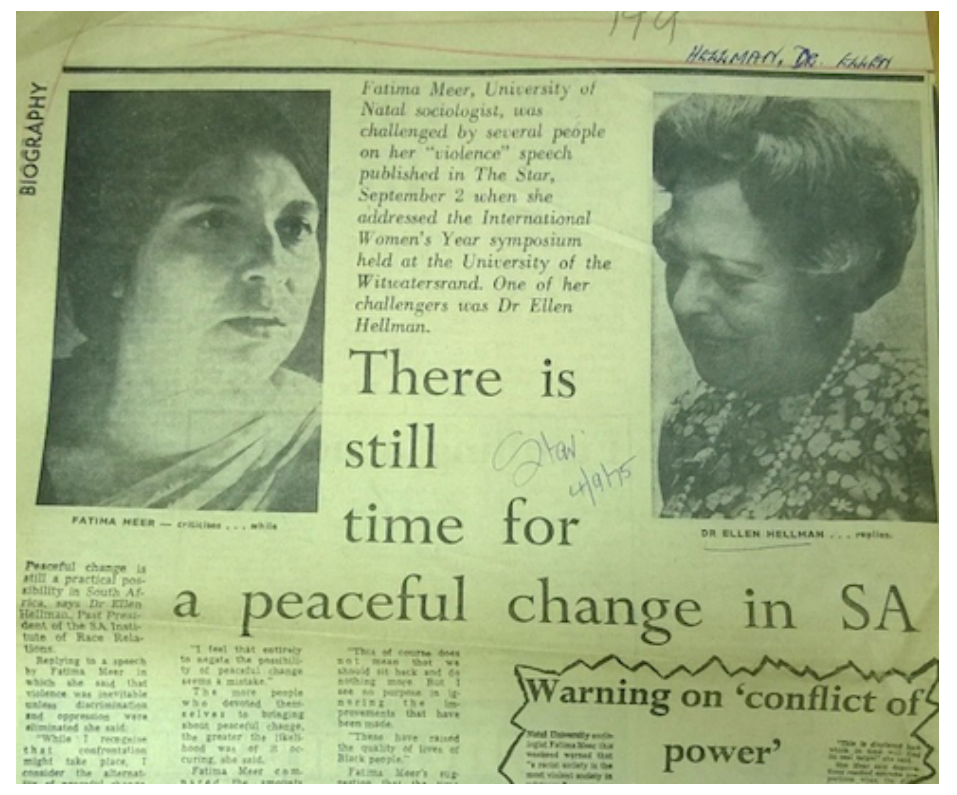

Figure 75. Fatima Meer and Ellen Hellmann Debate, September 4, 1975, The Star. Ellen Hellmann Box of Clippings, Jewish Board of Deputies Archive, Beyachad Community Center

The 1975 debate between Ellen Hellmann and Fatima Meer (Figure 75) regarding the use of violence to fight apartheid provides another example of the political differences between Hellmann and Meer (and by association, Hilda Kuper). Hellmann challenged Fatima Meer's position that "violence was inevitable unless discrimination and oppression were eliminated" which Fatima expressed at the International Women's Year Symposium held at the University of Witwatersrand; Ellen responded that it would be a mistake to "entirely negate the possibility of peaceful change." When Fatima critiqued the discrepancy between defense and education spending, Ellen commented that black education had increased, even if it was still not enough, "But one mustn't ignore efforts to improve the situation. To only look at the negative is not particularly helpful." Ellen commonly argued that it was important to look at the "efforts being made" 
(Hellmann and Meer 1975). ${ }^{98}$ Meer pointed out the "big pudding" of economic development that solely benefitted whites. Then Hellmann countered that black wages had increased at a faster rate than white wages. Rather than emphasizing evidence of racial discrimination as Meer did, Hellmann typically stressed the improvements that had been made, likely because she had been working to effect measured change in South Africa since the 1930s. However, the outward impression created by Hellmann's statements was that she was minimizing and dismissing the legitimate concerns expressed by activists of color, like Fatima Meer. It is important to note that in this article, Ellen Hellmann was referred to with the title "Dr." while Fatima Meer, though a sociologist at the University of Natal, was not acknowledged with any comparable title such as "Professor."

Just as Hilda encouraged Fatima's academic career, Ruth Landes advocated for Keewaydinoquay (Kee) Peschel, an Anishinaabeg ethnobotanist. Fatima's experiences of racism and sexism at the University of Natal were similar to Kee Peschel's experiences in the Biology department at the University of Michigan where she was pursuing a doctoral degree in ethnobotany. Kee added Ruth Landes to her dissertation committee in revolt against the male chair of her department who had not allowed Kee to select her own

\footnotetext{
${ }^{98}$ In 1980, Ellen wrote a letter to the editor of the Sunday Express in response to an article by Carol Lazar regarding the Bantu education system. Hellmann disagreed with Lazar's contention that the Bantu education system had remained unchanged since 1956. Ellen insisted that the new Education and Training Act of 1979 was markedly different from the Bantu Education Act of 1953. Hellmann argued that there had been an improvement in policy because the government had created the same standards for black and white groups (Hellmann 1980).
} 
committee (Peschel 1978). When Peschel confronted the chair of her department about the lack of female committee members, he remarked: "if women were in the field they either weren't women or if they were then they weren't anthropologists." In response, Kee wrote "the names of the only three women I know whose position in anthropology cannot be denied" including Ruth Landes and Margaret Mead. In response to the name Margaret Mead, one of the male professors in the room exclaimed, "we do Mrs. Peschelle [sic] an injustice; she is not one of Those Women. Her culture has taught her the wisdom of accepting a woman's role" (Peschel 1978:6).

Like Hilda did with Fatima, Ruth expressed intense admiration for Kee's work (Landes 1978) and advocated for a "special curator" position for Kee at the Milwaukee Public Museum (in correspondence with Nancy Lurie, Head Curator), so that Kee could organize and administer a collection of Landes' Ojibwa artifacts and notebooks (Landes 1984a, 1984b). "[Kee] is the one knowing Ojibwa... who has an imminent $\mathrm{PhD}$, practices and believes in the traditional life, identifies with 'ancestors' and is extremely bright, besides being original in the mischievous Ojibwa way. She is a latter-day match for my extremely gifted Maggie Wilson, long gone to her fathers" (Landes 1984b). Though Landes did advocate for and praise Peschel, she also conveyed this esteem in a slightly condescending manner; Landes had an invested interest in Kee receiving this curator position since she needed someone to organize her Ojibwa collection, and Landes also used the possessive pronoun "my" to refer to Maggie Wilson (which she often did when referencing the groups with which she had worked in her fieldwork). 
Ellen Hellmann taught black students at the Jan Hofmeyr School of Social Work (whom she referred to as "kids"); she wrote to her colleague and friend Colin Legum in June 1955:

I'm sitting in the Jan Hofmeyr school classroom, on guard over fifty of the kids writing their mid year exams. This sort of job - you know what you're doing, why $\&$ for how long - which is hardly applicable to anything else in the unhappy country - Colin, dear, I've never felt so clueless and ineffective and dumb as now. Everything one is connected with involves different decisions and weighing up a new set of considerations and one ends up by wondering whether one has any integrity left at all. And even if one has it's unimportant and for something called 'The Record' (E. K. Hellmann 1955).

This letter reveals Hellmann's battle with maintaining her "integrity" in an "unhappy country" in which she felt ineffective and likely a certain degree of hopelessness, likely leading to her long-term depression. Hellmann engaged in transracial interactions but they typically kept her in the role of helper, philanthropist, or teacher (rather than positioning herself as being the receiver of teachings). Because of her dedication to gradually reforming the existing apartheid system, she did not engage in transracial relationships that focused on a revolutionary change to the racial hierarchy. Her political stances held her in a position which required her to constantly compromise with the Afrikaner-dominant epistemologies (as Fatima Meer wrote in her letter to Hilda Kuper in 1970: "white 'liberalism' had leaned backwards to accommodate" the Afrikaner intellectuals) and led Hellmann to feel that her integrity was disintegrating.

\section{Part III: Theorizing about black women}

In contrast to the commonly employed colonizing portrayals of black partnerships in Rooiyard and in townships and locations in Johannesburg that Ellen Hellmann also 
utilized, Hilda Kuper (1945) described "town-style" unions in Western Native Township in a non-judgmental way that emphasized their low frequency. ${ }^{99}$ From 1941-1946, Hilda was lecturing at the University of Witwatersrand, where she had taken over from Audrey Richards, when Richards returned to England (Kuper 1984:206; Bank 2016:208). ${ }^{100}$ With her female co-authors and graduate students at the University of Witwatersrand ${ }^{101}$ Kuper argued that town-style unions, illegitimacy, divorce, desertion and adultery were rare and family stability was higher than officials estimated in Western Native Township, especially among the "more stable registered tenant class" though she contended that town-style unions were possibly more prevalent among the younger generations of "lodgers" (Kuper et al. 1945).

In the concluding section of this unpublished study, Kuper summarized her overall findings, which are in marked contrast to those of Hellmann,

...marriage would appear to be very stable. Both tribal and intertribal marriages, among a sample group composed in many cases of members of the older generation, were of long duration; divorce and desertion, adultery on the part of both men and women, townstyle unions and illegitimacy, as associated phenomena appeared to be rare...marital instability may be more marked among the younger generation (Kuper et al. 1945).

\footnotetext{
${ }^{99}$ If men and women lived together without some form of recognized marriage, it was called "living townstyle."

${ }^{100}$ When Winifred Hoernlé left the University of Witwatersrand in 1938, Audrey Richards was the preferred candidate to take over for her because she was not Jewish or leftist, as Hilda Kuper was. Audrey ensured that Hilda took over for her after Audrey left Wits in 1941 and Leo Kuper went to North Africa to fight in the war (Bank 2016:151, 178). A similar situation occurred when Heloisa Torres refused to hire William Lipkind (a Jewish anthropologist from Columbia) at the National Museum in Rio because she was concerned about the impact of rising anti-Semitism (Landes 1939d).

${ }^{101}$ Her student co-researchers were Ruth First, Kay Theron, Myrtle Canan, and Selma Kaplan. She co-wrote "Voluntary Associations in an Urban Township" with Selma Kaplan in 1944 (Kuper and Kaplan 1944).
} 
Hilda Kuper posited marriage as stable, of long duration, and contended that adultery, illegitimacy and informal unions were rare. Hilda's in-depth immersion in Swazi marital customs likely impacted her less judgmental views about relationship patterns in Western Native Township; thus, she de-emphasized and de-problematized practices of "adultery" and "illegitimacy."

\section{Lobola and stability of marriage in Western Native Township, a contrast to}

\section{Hellmann's conclusions}

Kuper utilized Hellmann's study of Rooiyard to show how the process of lobolo (cattle exchanged for a wife) was changing (Kuper et al. 1945). Ellen Hellmann wrote in 1935: "The conception that lobola is purchase, a conception which anthropologists have hitherto strenuously combated, is now rapidly becoming current among the natives themselves" (Hellmann 1935:53). Hilda Kuper and her female collaborators noted that it was common that a woman with "two or three illegitimate children fathered by the same man" (my emphasis) would stay "unmarried because the man was not yet in a position to meet the lobolo ${ }^{102}$ required by the [woman's] father" (Kuper et al. 1945).

Originally lobola had been a transaction between two fathers-in-law, who were heads of their respective homesteads. But it had become an individual-based monetary transaction between a son-in-law and his father-in-law. Kuper provided a comparison between the number of lobolo (cattle-based) versus money payments in her study of the

\footnotetext{
${ }^{102}$ Kuper spelled lobolo with an "o" in this text while Hellmann spelled it with an "a"; it can be spelled either way, in another text Kuper used the spelling "lobola" (Kuper 1965:209).
} 
Western Native township and contrasted these statistics with the studies of Ellen Hellmann in Rooiyard, and Eileen Krige in the "long established location" of Pretoria. Kuper explained that there were the most money-based payments in Pretoria since residents had lost more of their ties with the rural areas. There were the least moneybased payments in Rooiyard, where ties to the rural area were stronger; residents of Rooiyard were more likely to use the cattle-based exchange process (lobola). The number of monetary payments in the Western Native Township, where Kuper and her students had completed their study, fell in between the other two sites (Kuper 1945).

Kuper's discussion of lobola emerged as part of a larger analysis of the types of marriage residents entered into within the Western Native Township. The marriages of 204 couples were categorized based on whether they utilized a Native Customary Union (property or money exchange), Civil Union and/or Christian religious ceremony, either separately or in combination with each other. Kuper and her student collaborators found that 200 out of 204 of the "registered tenant class in the location" had entered into "one or more forms of recognized marriage": 49 used Native Customary Union (involving partial or full lobolo payment), 18 used both Civil and Christian Unions, 115 used Native Customary Union, Civil AND Christian Unions, and only 4 were "irregular." In 96 cases the marriage took place in the country and in 79 cases the husband sent for his wife who was living in the countryside to come to the city to be with him. Native customary union (both alone and in combination) was the most frequent type of union. In the 21 cases when it was not used the couple said it was because they believed it to be old fashioned: "we no longer believe in these things" (Kuper et al. 1945). 
All of this statistical data was used to underscore Kuper's primary finding, which was that marriages were in fact quite stable in the Western Native Township, in contrast to the assertions of many other writers including Ellen Hellmann who conducted research in Rooiyard (1933-1934), and also in Orlando location, Alexandra Township and the married quarters of two mine compounds (1937-1938). In Rooiyard, the percentage of unmarried couples was a minority, only twenty percent, but Hellmann chose to emphasize this fact. Hellmann seemed quite bothered by this, as well as by the lack of concern expressed by other residents. "[The unmarried couples] were not, however, regarded as different in any way from the married couples, nor was the illegitimacy of their own estate or of their children made the subject of reproach or abuse" (Hellmann 1935:51).

In a later section entitled "Stability of Marriage" of the unpublished study, Kuper maintained that though there might have been high rates of adultery, this did not mean that there were necessarily unstable marriages, contesting Hellmann's argument (though not explicitly mentioning her name). Kuper considered divorce, desertion or marriage length to be better measures of instability. She emphasized that divorce rates were quite low in the Western Native Township. More than two-thirds of the marriages were longer than ten years though "inter-tribal marriages are reported to be less successful than tribal marriages." Out of 204 sample families, only 16 men and 13 women had previously been married (29 total people). Neither the men nor the women had been married more than twice (only the women were interviewed so it is possible that the men had actually been married more times but their wives did not know about it). In 26/29 cases the reason for the end of the first marriage was death and only 3 were divorced. Desertions were 
commonly believed to be frequent in town-style unions. Yet among Kuper's sample only 4 out of 204 "admitted to having been deserted by their husbands." Divorce was too expensive, so desertion was more common or couples could just live their own lives separately. There were only 4 cases of civil divorce out of 204 total couples. Kuper used these low desertion and divorce rates to accentuate her point that Western Native Township unions were stable, rather than unstable. Instead of using adultery as a measure of stability, she chose to use length of marriage as the measure of stability. Hilda's ability to recognize different perspectives or explanations for same phenomenon likely emerged because of her early childhood exposure to the conflicts between her parents during World War I, when her father fought on the British side, while her mother's beloved brother fought for the Germans. Kuper felt ambivalent emotions simultaneously: love for her mother, yet hatred because her mother was "one of the enemy." Hilda also expressed multiple identities that might otherwise be perceived as incompatible: Jewish, British, African. Additionally, because of her fieldwork in Swazi communities where polygyny was a conventional facet of Swazi custom, Kuper did not use "adultery" as a measure of stability of marriage, but instead focused on the length of the marital relationship.

\section{Chauvinism and Westernization}

When Hilda explicitly discussed "chauvinism," she linked it not with Swazi "traditional" culture, but with colonization and the effects of Westernization. ${ }^{103}$ Similarly,

${ }^{103}$ Casey Golomski reveals that what Hilda viewed as "traditional" Swazi customs were likely recent re-introductions that Sobhuza initiated in the 1920s and '30s (and that Hilda helped to reinstate as "traditions" through her writings) in order to revive the "militaristic regimental age system" called emabutfo, which served to bolster his own royal power and 
Ruth Landes linked modernization and Westernization with the loss of Candomblé priestesses' power. However, in Kuper's creative writing about both Swazi and Indian South African women, the female characters emerge as the victims of not only the colonial authorities but also indigenous societies. These underlying messages oftentimes stand in direct contrast with Kuper's explicit arguments in her academic writings that direct the blame to the European colonial systems. As Kerry Vincent illustrates: Kuper was part of a "literature of protest" written by other South African "white liberals," to contest "colonial fantasies" but also to "alert Swazis to the violence of some of their own traditional practices" (Vincent 2011:96). In contrast, Hellmann's writing about black women typically represented them as the cause of family instability and youth delinquency rather than victims of the colonial system. Ruth Landes depicted black women as the matriarchal financial supporters and leaders of their communities, emphasizing their agency rather than their victimhood. She perceived women-led households as an asset rather than a weakness.

In an interview with her student, Gelya Frank, Kuper maintained that Westernization caused the deterioration of women's position in Swazi society: "The westernized Swazi man retains the most terrible chauvinist attitude toward women."

control over national consciousness (Golomski 2011:8-9). Hugh MacMillan (1995) maintains that while Kuper believed in the importance of studying history and social change, she still did not emphasize discontinuities within Swazi so-called "traditions" because she wanted to support "the Swazi point of view" which was a royal/elite perspective (Macmillan 1995:559-61). Leroy Vail and Landeg White (1991) contend that Hilda's writings about Sobhuza served to promote his propaganda campaign to promote Swazi "tradition" in support of his monarchy (Golomski 2011:9; Vail and White 1991:179, 192). 
Hilda highlighted that she felt more chauvinism from white males in Swaziland "who nearly went mad that I was there - I was quite a nice looking young woman, and there they were all those Swazi..." Kuper explained to Frank that polygamy was part of the Swazi respect for women (1979:18). Kuper also contended in 1975 that "co-wives in a traditional polygamous African society were more socially secure than the modern woman in their alienated, overly competitive American society" (Bank 2016:226, n. 134). Additionally, Kuper argued that Swazi women were treated better than Zulu women because of the institutionalization of the Queen Mother in Swazi society. Hilda recounted to Gelya how Sobhuza II (the King of Swaziland who had authorized her research and publications on the Swazi from 1934-1978) had to sit on the ground when his elder sister entered the dwelling where Hilda sat with the king. Hilda explained that age, rank and sex all played an integral role; thus, Hilda asserted, it could not be argued that women were necessarily inferior within Swazi society and instead she used the term “complementarity” (Frank and Kuper 1979:17-18). ${ }^{104}$

Kuper's perspectives were highly influenced by her identification with Swazi culture and especially her affiliation with the Swazi royal family. Thus, her argument that

${ }^{104}$ Gelya Frank responded to this anecdote: "the complementarity argument was a key underpinning of social anthropology's structural-functionalism, which has long since been characterized for its uncritical acceptance of the status quo in traditional societies, and which had come under feminist critique by the time I was having these conversations with Hilda. Needless to say, I didn't 'buy' the complementarity argument because of the disparities in power between women and men. She asked me what I had observed in this regard when I had done my first fieldwork, on the Tule River Indian Reservation, over a period of nine months, in 1972-1974. I said that I saw it this way: 'The men at Tule River had been kicked around by mainstream society like the dog. And the dog went home and kicked the cat"' (e-mail communication, March 18, 2018). 
Swazi women were better treated rested upon an example from the royal family, rather than reference to non-elite Swazi gender relations. Also, her ties of obligation to Sobhuza necessitated her adoption of a Swazi elite male point of view regarding women's position in Swazi society, at least in her "academic writings." Hilda's emphasis on "complementarity" also likely related to her "traditional" or "conventional" relationship with her husband, Leo. In her creative writings, it is possible that Hilda felt she could represent gender relations in Swazi society with more criticism than she could through her "scientific writings." As Andrew Sparkes (2002) explains, narrative and autoethnographic writing creates a different type of relationship between storyteller and reader/audience, one that is relational and emotionally expressive, in contrast with "scientific writing" in which the reader is expected to take a "passive" position $(210,218$ 219). Hilda's fictional writing created characters and situations that could be discussed and debated dialogically, thus encouraging contemplation and deliberation about gender relations rather than simply positing her point of view in a didactic manner. Subsequently, A Witch in My Heart was translated into siSwati in 1978 as Inhlitiyo Ngumtsakatsi (though without her knowledge, according to Nancy Schmidt) and used in secondary schools in Swaziland as a way to discuss "intersections between tradition and modernity" (Vincent 2011:101). Hilda explained how fictional writing enabled the writer to access both "social conditions" and individual "idiosyncrasies"; she asserted that sociological and anthropological writing took these individual eccentricities out of the picture in order to portray generalizations, norms, and values of a society, "a picture of social life without life" and a "structure and process without flexibility or recognition of the unexpected to which the individual must respond" (Schmidt 1993:3, n.11). 
Dawn Chatty, one of Hilda's graduate students, detailed Hilda's influence on her thinking about gender "complementarity." Hilda encouraged Dawn to look at women's roles within the pastoral Bedouin economy. Dawn found that women were in a complementary role not in a subaltern one. Hilda always said, "it's not just about women, it's about men," and emphasized the importance of looking at the whole society (Gondek and Chatty 2017). Gelya highlighted Hilda's emphasis on the impact of institutions and the "social" on the "self" as a kind of corrective to Frank's initial interest in psychological anthropology and the life history method (Frank e-mail communication, March 18, 2018). In the Swazi society that Kuper observed, conformity was of the utmost importance in order to prevent jealousy and rivalry between co-wives: "individual exhibitionism was still restrained by wider identification. A conservative (and wise) polygamist bestows on all his wives identical prints and blankets so as not to awaken jealousy; though each woman may impart her own distinctive quality and express herself in small part by the ornaments she herself makes" but to an outsider the prints all looked the same (Kuper 1973:353).

Kuper understood conformity as a necessary component in the maintenance of polygamy. She viewed polygamy as a form of social organization that created security for women. Yet, through her creative writings, she also revealed the negative effects of these indigenous or "traditional" social systems on Swazi women who did not obey the expected norms. Perhaps because of her emphasis on systems and hierarchies and conformity rather than on individual agency and resistance (in contrast to Ruth Landes), Hilda tended to portray women as victims rather than as empowered and creative resistors to hierarchical and patriarchal structures. As Kuper depicted in A Witch in my 
Heart, Swazi wives, who were considered outsiders in their husband's patrilocal family, were required to conform to strict rules. If they demonstrated any extraordinary talents including cooking, gardening or being overly artistic, and if a tragedy befell the family (such as the death of a co-wife's child), they were deemed a witch (and murderer of the child) by male diviners. Fathers-in-law were responsible for hiring these male diviners and if the non-conforming co-wife was found guilty of witchcraft she was banished to her natal home, where she continued to be dreaded and feared. Even if the woman's husband did not want her banished, he was forced to obey his father, who was the ultimate head of power; the father-in-law maintained the stability of the male controlled family and protected co-wives from what were considered non-conforming and aberrant wives (Kuper and Institute 1970:xiv-xxvi). ${ }^{105}$

Typically, in Kuper's academic writings, the European colonial authorities were clearly identified as the cause of social injustice for Swazi people, especially Swazi men. In Uniform of Colour (1947) in which Kuper discussed Swazi women quite infrequently, Kuper critiqued the European authorities and the Christian church for their claims that Swazi women were "drudges and chattel" as well as the European failure to abolish the colonial tax; if abolished, this would have protected Swazi women's marriages (Kuper 1947:153). ${ }^{106}$ The colonial imposition of taxes on Swazi men required them to become

${ }^{105}$ According to Andrew Bank (2016:223), Witch in my Heart was written from 19561958 while Hilda was living in Durban, Natal, and performed by African medical students at the University of Natal, but published in 1970.

${ }^{106}$ Colonial authorities accused colonized men of abusing their women in order to establish European civility and African barbarity and justify colonial interventions in order to "save" oppressed African women (Schmidt 2015; Sebastiani 2005:76). As in the 
migrant unskilled laborers, leave their rural farms and their wives for extended periods, to travel to mines, where they earned only enough to sustain their families on the farm, but not to bring their families with them to Johannesburg (1947:18-20). Kuper revealed that Swazi men felt effeminized by the European legal system, remarking that they had become the "women of the Europeans" (Kuper 1947:152). Swazi men also perceived the European colonial system as protecting women and witches (1947:70-71) and Swazi male leaders no longer sentenced accused witches to death because of fear of the white man's punishments (1970:53-55). However, Kuper did not elaborate this history of witchcraft accusations, or how they shifted throughout Swazi history before European intervention. She only presented one point in Swazi history, in which accused witches were sentenced to death, and the post-European colonial intervention period in which Swazi men feared European men's punishments and felt that they had become the "women of the Europeans."

Kuper explicated that, "A Swazi woman, like most women, values her family life more than economic independence or equality before the law," and that Swazi women preferred being beaten to being celibate or lonely; even though Swazi women might have seemed "frustrated," they were "complete" within their society (1947:152). However these aspects of Kuper's argument are contradicted by Kuper's explanation that Swazi women sought out the European courts when they were accused of witchcraft and in

Spanish colonies in the Americas (Overmyer-Velázquez 2005; Powers 2005), colonial authorities in Swaziland dramatically altered the gendered power system. 
domestic disputes with their husbands (Kuper 1947:70-71; Kuper and Institute 1970:35). Swazi women who sought European legal remedies wanted equality before the law, clearly displaying their dissent to certain "traditional" patriarchal Swazi customs, which as Casey Golomski (2011) points out, may not have always been the "traditions," since Sobhuza initiated re-introductions of "traditions" in order to bolster his rule in the 1920 s and '30s. It is possible that through her writings about Swazi "traditions" she actually bolstered certain oppressive practices towards Swazi women that had been part of Sobhuza's program of royal consolidation of power through re-inventions of "traditions." In $A$ Witch in My Heart (1970), Kuper implied that the accusation of witchcraft and the banishment of the co-wife, Bigwapi, after the death of a co-wife's baby, was partly caused by the fact that her husband had gone to Johannesburg so he could make enough money to buy medicines for her infertility. He was detained in the city after hearing of the death of his newborn son, because he was arrested for drinking beer, in a police raid of an illegal bar (45). Commercial beer brewing by African women was prohibited so that white authorities could control the production and sale in municipal beer halls (controlled by the government) and use the profits to fund police surveillance of black communities; police constantly raided slums to enforce these laws (La Hausse 1988:22-23, 35, 42). Thus, Bigwapi's banishment can be partly explained by the colonial system that no only forced Swazi men to journey to cities for access to money, but also imprisoned them unjustly for drinking beer in privately-run bars. Yet, the Swazi motherin-law character in Kuper's play A Witch in My Heart, seemed to blame the Swazi patriarchy for Bigwapi's exile when she stated "the law of our people is hard on women" (Kuper and Institute 1970:56). Kuper created a text in which there are multiple 
intertwining reasons for non-conforming co-wives' exile that include both the colonial system but also the "traditional" Swazi patriarchy, even if Hilda did not name it as such. Yet the women in her stories never win the battle or even fight back against either the men of their culture or European men/colonial authorities.

In another of Kuper's stories, called "Bird of the Storm" (1975) published in a festschrift for Isaac Schapera, a similar complicated pattern of colonial and indigenous or "traditional" causes for women's victimization emerges. A young Swazi girl, Umqubelo, was betrothed to a man, Mona (whose name means "jealousy"), who went to the mines in order to pay his tax to the colonial government (222-223). During Mona's time away, Umqubelo was lent to her mother's brother to care for his ill wife along the Portuguese border (223). There she met and fell in love with a Portuguese shop-owner, Alfonso, causing her to lose her Swazi fiancé (Mona), become a prostitute, contract a venereal disease and die (224-227). In this case it was the colonial system (forcing men to go to mines to pay their taxes) but also the patriarchal system (that lent girls to their uncles' families) that caused this tragic outcome. Additionally, Kuper implied that it was the hierarchical racial system (a part of internal colonialism) that disadvantaged Swazi girls in relationships with white men, who preferred to marry white girls (as did Alfonso in the story), thus leading Swazi girls who got involved with white men to become prostitutes rather than wives (226). The reader could also wonder why Mona and his family were unable to forgive Umqubelo's relationship with Alfonso and take her back (225). This aspect of the story emphasizes the "traditional" patriarchy of the Swazi system (Kuper 1975a). After Umqubelo's second miscarriage (with Alfonso's child) her mother visited her and begged her to return home, but Umqubelo refused. Her mother exclaimed: "the 
sufferings of women!" (266). This is reminiscent of Bigwapi's mother-in-law's statement: "the law of our people is hard on women" (1970:56). Yet the women are never portrayed resisting this oppression.

The Decision (1957) is a similarly tragic Kuper play in which the female lead character is punished through death, for the patriarchal and racist hierarchical structure of her society. In this play, Savitree, a girl from a high caste Hindi speaking family in Durban, in Natal province, South Africa, fell in love with a Tamil Christian boy, Siva, whose family was from Southern India. Their different ethnicities and religions, as well as the fact that Siva was active in the Indian National Congress and the passive resistance movement, marked Siva as "other" and unmarriageable (61). One version of the story closed when Savitree set fire to herself and died because her family forbade her to be with Siva (Kuper 1993:63). In a different version of the play, Savitree sacrificed herself by marrying the man her family decided she should marry (Kuper 1957:30-31). Directly before Siva heard the news of Savitree's suicide (in the 1993 version) he told his activist friends that Indian South African families imprison their daughters in domestic roles, preventing their freedom. Siva's friend Rajid Naidoo argued: "African women are a major force in African politics, but few Indian women are active in political affairs," implying that the problem was within Indian culture, rather than South African culture as a whole. Siva's friend Chetty remarked that the women should "free themselves" rather than waiting for men to do so, upon which Siva discovered that Savitree killed herself, causing the reader to wonder if this was Savitree's way of "freeing herself" (Kuper 1993:63). In the 1957 version of the play, Siva's words close the play; "all I wanted is to be myself and let others be themselves." He contended that Savitree should not have had 
to sacrifice herself for her family out of the "strength of her affection for others, for those who had brought her up." Siva emphasized that her loyalty should not lie with her family alone but with the "family of the people of the world" (31). Perhaps, this was Kuper's message for unity rather than separation between not only Indian South Africans, but also all South Africans. Intriguingly, Kuper revealed that she had never published the play because a few Indian couples confronted her after a performance of the play in Durban (by Indian medical students) to inform her they would sue her for writing about their families. Though she did not know these families she "realized that I had struck a very vulnerable center and Indians were already scapegoated for much of the antagonisms so sadly I put the manuscript aside" but she was revising it for publication in the months before her death (Schmidt 1993:1, n.5).

The Decision echoes some of the findings from a paper about Indian elites in Natal, co-written by Fatima Meer and Hilda Kuper (1956). They described two primary elite groups: the protest and compromise elites. ${ }^{107}$ "The protest elites, led mainly by intellectuals, identify with Non-Europeans and 'oppressed people' in general; the compromise elites operate as a defensive and exclusive minority" (Kuper and Meer

\footnotetext{
${ }^{107}$ This article about Indian elites echoes (thought does not cite) Violaine Junod's findings from 1952 about protest and compromise leaders among the "coloured" social elite in Britain. Compromise leaders were the intermediaries between white and black groups, serving as non-political token "coloured" spokespeople "on show" in a "zoo situation" within white organizations, which were "sympathetic" to "colonial" issues. Compromise leaders had no direct ties to either colonial nationalist governments or to policy makers and were seen as "acting white" (Banton 1960:151-153). In contrast, protest leaders had close links with colonial nationalist movements, denounced white racism, and held defiant attitudes toward whites supposedly "sympathetic" to the cause. Protest leaders were esteemed by "coloured" community members but disliked by whites (Banton 1960:152).
} 
1956:145). Siva was part of the protest elite, while Savitree's family represented the compromise elites. Meer and Kuper found that original caste differences between Indian immigrants were fading because of the "upward mobility of the ex-indentured and the downward pressure from the Europeans, and it appears that the Indian elite of the future will relate more to the Non-Europeans in general than to specific sectional groups" (145). Interestingly, despite caste distinctions fading, ethnic differences were not, for example between Tamil, Telegu and Hindustani, which are clearly displayed in Hilda's play since Savitree's Hindustani family disapproved of Siva because he was Tamil (Kuper 1957; Kuper and Meer 1956:130). Even though Hilda's female protagonists did not exemplify feminine resistance or empowerment, Kuper challenged canonical dichotomies such as modern/non-modern, West/non-West, and social/structure through her fiction. For example, in A Witch in My Heart, Bigwapi's "personal” struggles within the Swazi cultural system are intertwined with public and structural constraints such as patriarchal control of non-conforming wives, the European colonial system's responses to witchcraft accusations, the economic push for Swazis to go to Johannesburg to access money, as well as the Europeans' unjust liquor laws. "The Lord Will Provide" contests the West/non-West and modern/non-modern splits because Hilda identifies more with the Swazi characters who come to Eliza's rescue than with Eliza herself, who is half-white and views black Swazis with disdain. While Eliza sees herself and her belief system (presumably Christianity) as more "civilized," and thus modern and Western than that of the Swazi men who save her, Kuper clearly indicates that it was the Swazi men who saved Eliza, not God. 


\section{Summary}

Even though Hellmann and Kuper grew up in Johannesburg and were trained by the same woman, Winifred Hoernlé, they expressed divergent views about Jews, and about the communities of color they worked with in their research. This was a result of their differing fieldwork experiences, institutional affiliations, and political orientations. While Kuper grew up in an environment in which she was required to accept ambivalence because of the conflicts between her parents' Jewish origins, Hellmann was raised with a sense of superiority as a German Jew but also with a pervasive sense of guilt, for her privilege because of her whiteness and also for not helping "her own kind." Subsequently, Hellmann became a leader in Jewish communal protection and advocacy efforts. While Kuper identified overlaps between anti-Semitism and anti-black racism, her writing and activism did not center on Jewishness. Their early affective orientations deeply impacted each scholar's approaches to fieldwork communities: while Hellmann remained separate from the people with whom she conducted research and did not fully acknowledge her "assistants" in her published manuscripts, Kuper was able to eventually overcome Swazi suspicions and become a Swazi citizen, though non-royal Swazi still associated her with the royal family. Hilda was endorsed by King Sobhuza II as the authorized Swazi anthropologist, and she opposed an Afrikaner anthropologist (P.J. Schoeman) because of his depictions of "primitive" and "pre-logical" Swazi consciousness. While Kuper defended the Swazi point of view, contributing to Sobhuza's program of re-invigoration of "tradition" in support of the expansion of his monarchy, Hellmann adopted a commonly-held position among both white and black elites that 
black women's "laxness of sexual morality" led to juvenile delinquency and the inhibition of national economic development. Thus, they both adopted "established" ideas, however these conventional beliefs were advocated by divergent groups.

This was also the case with their political affiliations since they held leadership positions in their respective political parties (Ellen Hellmann with the Progressive Party and Hilda Kuper with the Liberal Party) and these political orientations were accompanied by friendship networks with individuals who shared their views. In Hilda's case, this meant transracial friendship and collaboration with Fatima Meer, whose research assistance influenced Hilda's writings about Indian South Africans. In contrast, Ellen's participation in the Progressive Party and the SAIRR connected her with other white "liberals" like Helen Suzman and Hansi Pollak. Hilda's ally-ship with Fatima Meer set her in opposition to Hellmann and Pollak, who hindered Fatima's academic career.

Though Kuper moved frequently and held positions at multiple academic institutions throughout her life, she was able to maintain financial stability and access to academic positions through her connections with Jewish men (like her husband, Leo Kuper, and former boyfriend, Max Gluckman). Hellmann lived in Johannesburg and maintained her affiliation with the same core organizations throughout her life, and her financial and institutional stability was guaranteed by her father, husbands, and directors of SAIRR (J.D. Rheinallt Jones, Quintin Whyte, and Fred van Wyk). Kuper and Hellmann's political beliefs were divergent, yet they both benefitted from being married heterosexual women and thus conforming to gendered and sexualized behavioral norms. Even in Kuper's creative writing which revealed the ways that "indigenous" or 
"traditional" systems, in addition to colonial ones, subjugated women, she did not create female characters that could resist or challenge these normative structures.

In contrast, Ruth Landes' political orientations because of her familial background, affiliations with men of color, including sexual relationships outside of marriage, her status as a divorced woman from 1935-1955, and her subsequent theorizing about black women's religious and financial leadership and power in Candomblé, led her to be outside of normative expectations academically, politically and personally and caused her to experience institutional and financial instability from 1935-1965.

Thus, this chapter has illustrated how a complex set of factors influenced how Jewish women social scientists theorized about black women and understood their Jewish subjectivities. Solely analyzing one of these factors (for example, national context) in isolation would not reveal the full complexity of the relationships between Jewish subjectivity, transracial networks and theorizing. Hilda Kuper and Ellen Hellmann were raised in the same national context and also experienced a similar initial anthropological training, however these circumstances alone are not enough to explain their differential theorizing about women of color. The quality of transracial networks they developed through their fieldwork research, institutional (including political) affiliations and interpersonal relationships deeply affected their theoretical perspectives. Another key intervention in this chapter has been to emphasize how marital status and deference to heterosexual gendered and sexualized norms profoundly mattered to not only Jewish women's theorizing but also their institutional stability and placement within disciplinary hierarchies. 


\section{CHAPTER 5 THE CRITIQUE OF COLOUR CALCULUS: RUTH GLASS AND}

\section{GERMAN JEWISH OPPOSING VIEWS OF BLACK URBAN MIGRATION}

"In an earlier age, she would have been burnt at the stake as a witch." - Arthur Tattersall, then-Secretary to University College London, speaking about Ruth Glass
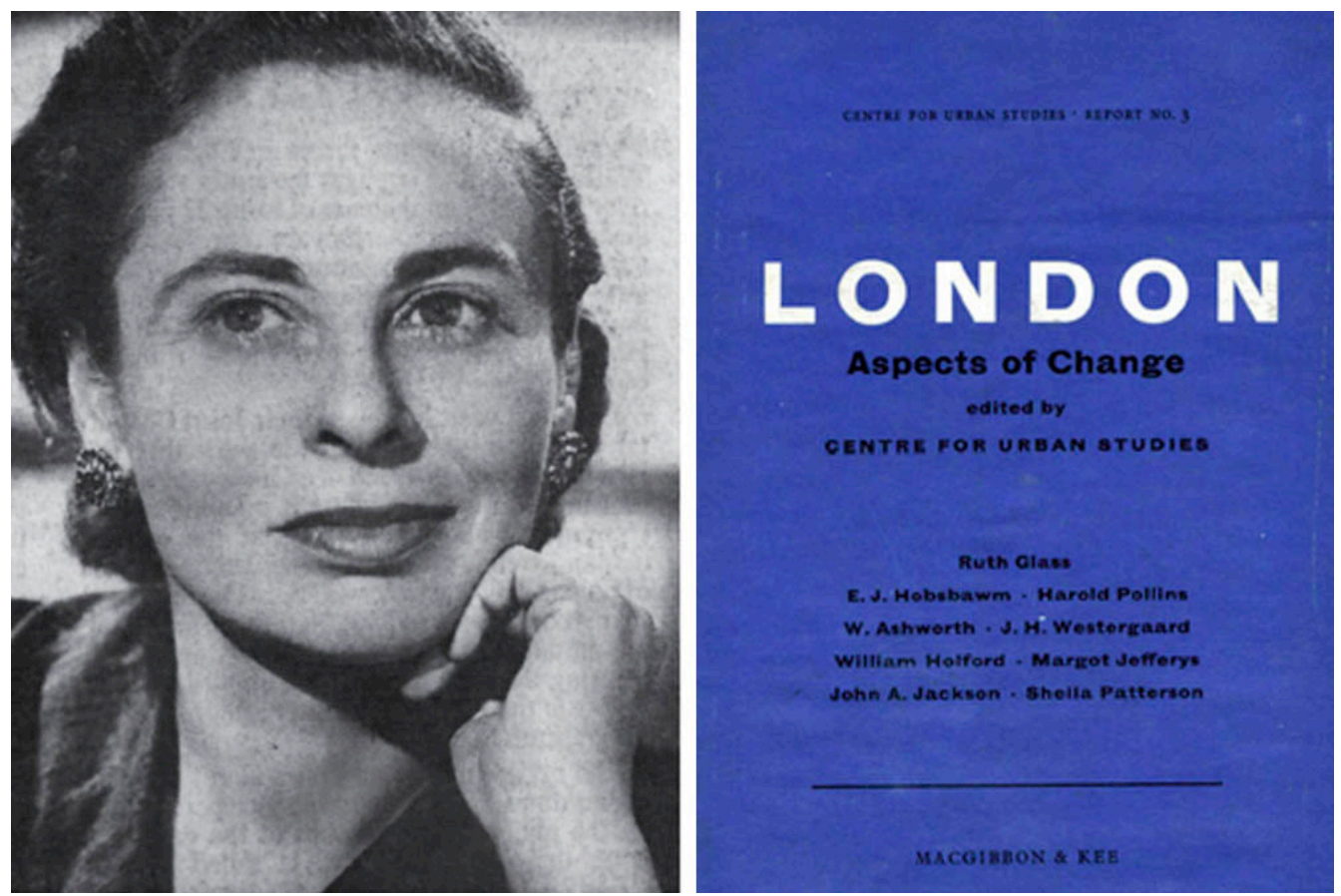

Figure 76. Ruth Glass and the cover for her book, London: Aspects of Change (1964). This image comes from the following site: https://www.brownstoner.com/brooklyn-life/what-isgentrification-definition-causes-effects/

While Ruth Glass (Figure 76) and Ellen Hellmann were both of German Jewish descent, their histories of immigration were divergent. Ruth Glass (1912-1990) left the University of Berlin in 1932, fleeing the rise of Nazism, traveling to Prague (apparently to interview a politician for a students' journal she worked for in Germany), then to Geneva (where she studied at the University of Geneva), and Wien, Austria, before fleeing to England and enrolling at the London School of Economics in the mid 1930s.

Enzo Mingione recalled that "Ruth mentioned various times that her parents phoned her 
in Prague and asked her not to return to Germany because the Nazi repression had begun." She was opposed to visiting Germany until the 1980s when she returned for a brief visit (Mingione and Gondek 2017; Pimlott Baker 2004). In contrast, Ellen Hellmann's parents emigrated from Germany (her father in 1894, and her mother in 1906) but Hellmann herself was born (1908), raised and lived her whole life in Johannesburg, South Africa (with short term trips to other cities in South Africa, as well as transnationally).

Glass seemed to maintain her leftist orientations throughout her career. Hellmann was affiliated with the Zionist Socialist Party in South Africa in the 1930s and 40s, but later in her career was considered an "ultra-conservative" part of the "old guard" at the South African Institute of Race Relations (Hellmann 1974:2; Laurence 1973; Pringle 1973; Schwartz 1981).

They also had different disciplinary training. Glass was a sociologist and Hellmann was trained as an anthropologist. Glass and Hellmann used "science" in opposite ways: Glass mobilized her research to activate profound policy changes, while Hellmann viewed "objectivity" as a value that prevented radical social activism. They were both urban studies scholars, even attending a conference together, where they voiced opposing views about trends of urbanization. Hellmann emphasized the "problems" while Glass critiqued the clichés associated with urban growth voiced by scholars like Hellmann. Glass explicitly linked the Jewish and Black experience; she critiqued "native" white Londoners, who used Nazi-like tropes to discuss the increasing migration of black migrants to London, while Hellmann placed the onus of responsibility on black migrants to adapt "civilized" white modes of behavior. 
In another contrast in their theorizations, Glass portrayed black women migrants primarily as workers and did not discuss their sexuality or family structures. This also differentiates her writing from that of other social scientists who studied black migration to the United Kingdom during the same time period.

Part of the reason for their differing approaches to the relationship between black and Jewish communities was the divergent placement of Jews within the racial hierarchy in these two national contexts. In London, where whites were in the majority, Jews were not needed to bolster the white community, and German Jews like Glass, who fled the Nazis, were recent refugees in London who could relate to the experiences of black migrants from the British colonies. However, in South Africa, where whites were in the minority, Jews were needed to form a larger white group to counter the black majority, which was viewed as a threat. Yet, their differing national affiliations cannot completely explain their differences, since Hilda Kuper and Ellen Hellmann were both raised in Johannesburg and lived many years in South Africa, yet they held divergent views about black migrants to Johannesburg.

The dichotomy between Eastern European Jews as politically "radical," working class, criminally inclined, and separatist and Western/Central European Jews as more "civilized," middle or upper class, and assimilationist is too simplistic. The contrasts between Glass and Hellmann serve to challenge the assumption that German Jews were necessarily assimilationist and conservative as compared to Eastern European Jews. There was variation within these two groups and cases in which divergences from this pattern occurred. Ruth Glass is evidence of this deviation from the "norm," thus putting that norm into question. 
Thus, Chapter 5 analyzes the intersections of Jewish Studies, African Diaspora Studies and Migration/Urban Studies in Johannesburg and London. I emphasize how the Jewish position in relation to whiteness based on the national racial context impacted Jewish women social scientists' theorizations of urbanization and the migration of racialized and marginalized peoples. I accomplish this through contrasting Ruth Glass and Ellen Hellmann, two German Jewish women social scientists with differing immigration/familial histories, disciplinary training and political affiliations. Subsequently their representations of black women migrants diverged.

\section{Ruth Glass' Jewish origins}

Ruth Lazarus Glass came from a line of rabbis (Hobsbawn 1990), and was the daughter of a "factory burner," Eli Lazarus and his wife, Lilly Leszczynska (Oxford Dictionary of National Biography 2004). Ruth Glass was a "non-doctrinaire" Marxist throughout her life (Rubinstein, Jolles, and Rubinstein 2011:324), "a woman of leftish sympathies" (Clapson 2006:262). “...She brought the leftwing convictions of a lifetime” but not "those of the Communist Parties"; she also carried with her "assumptions about women's freedom common in intellectual Mitteleuropa long before they became so in Britain” (Hobsbawn 1990). Hilary Rose (a feminist sociologist studying at LSE during the time that David Glass was a senior professor in the department) elaborated: "Ruth and David [Glass] were on the left but this was not publicly evident" (Rose and Gondek 2017). Ruth Glass served as a radical journalist in pre-Nazi Berlin, and according to Eric Hobsbawn, "claimed to have lost her virginity, on her own initiative, to a prominent 
figure from the tables of the Romanische Café."108 David Glass (1911-1978), Ruth's second husband, was from a Russian Jewish family and was raised in the East End of London. The couple shared their political views: David was a "man of the radical left" and believed in applying empirical inquiry of social inequalities, such as class structure and social mobility, to public policy. He argued in 1935 that a Socialist state was the only path to the needed society (Westergaard 1979:173-75).

Unfortunately, despite my attempts to discover more about Glass’ Jewish background, her family, and her experiences as a refugee, no one I asked (even those who worked directly with her) could tell me any additional information or details about these topics other than the little biographical information that is already available. I asked Michael Edwards and Hilary Rose, who wrote publicly about their memories of her. I also asked Nigel Harris, Harold Pollins and Enzo Mingione who worked with her at the Centre for Urban Studies. Nigel Harris told me: "she spoke little of her early days except, at the age of six, being taken to see the giant statue of Frederick the Great in Berlin, rising up on a horse - and being fascinated by the giant size of the horse's genitals!" (Gondek et al. 2017) The sexual connotations in the recollections of the male colleagues of Ruth Glass is a theme that will be elaborated in this chapter.

Ruth Glass completed a study of youth unemployment at the University of Berlin but was unable to finish her degree before fleeing Germany in 1932. Hellmann also studied urban youth and employment (in Johannesburg) in her dissertation in the late 1930s but especially reprimanded black mothers for their children's disobedience. In

108 This was a café-bar in Berlin known for the meetings of artists. 
Glass' 1932 study of youth unemployment, she found that $25 \%$ of employable youngsters in January 1932 were without work and of those who left school in March 1932, 60\% or more remained without work. This created not only "deterioration in health and living conditions" but also "daily guerilla warfare in families" and an "existence devoid of dignity." These youth "vent all their pent-up desperation and irritability on their nearest and dearest," including verbal and physical abuse (Glass 1989:2-3). This desolate situation led to youth gangs or "cliques" as she termed them, including "Nazi cliques." In some of the "cliques" girls were "shared one to eight boys" (4). Also, she found that 30,000 boys engaged in prostitution either "occasionally or habitually," similar to the number of girls engaged in the sex trade. "It has been proved repeatedly that for boys in need, street-walking is an easier decision than for girls in the same situation." Glass argued that boys resorted to this form of work because they were hungry and unemployed (1989:5). She emphasized that the presence of cliques and prostitution in Berlin were just the most obvious signs of "neglect and deprivation" as well as individual moral disintegration (Glass 1989a:6). In contrast to Hellmann, Glass did not blame urban youth desperation, irritability, verbal and physical abuse, the Nazi-cliques, sex work, or sexual abuse of girls on urban mothers or families. Glass' interest in employment in the urban environment would continue later with her research regarding West Indian migrants. Also, her exploration of the desperation of unemployed youth in Berlin and the rise of Nazi "cliques" would inform her analysis of white "racialists" in London in the 1950s and $60 \mathrm{~s}$. 


\section{Ruth Glass' analogies between anti-Semitism and anti-black racism}

In her empirical study, London's Newcomers: The West Indian Migrants (1960),

Glass frequently used Jews and anti-Semitism as a comparison for the prejudice experienced by "coloured" migrants. ${ }^{109}$ She often made the point that anti-Semitism was more socially acceptable than anti-color prejudice. This was especially true after the race riots in Nottingham and Notting Dale in 1958 during which mobs of 300-400 white supremacist working-class men from "Keep Britain White" groups brutally attacked West Indian migrants as a form of "nigger-hunting" (Travis 2002). Glass explained, "colour prejudice had become a social stigma. Antisemitism on the other hand, has been a part of the general ideology and terminology in all social strata for so long - without causing political embarrassment - that it is much more taken for granted" (Glass 1989a:189, n. 3; Glass and Pollins 1960:217, n. 3). She contended that white men's clubs in England were more anti-Semitic than they were prejudiced by color. "Coloured" royalty from the

${ }^{109}$ In an e-mail exchange with Harold Pollins (age 93), who was a research assistant to London's Newcomers, I learned that Harold felt that Glass should have given him coauthor status. She refused and even threatened to sue a newspaper that listed him as coauthor. He did not remember who had developed the comparisons between anti-Semitism and anti-black racism, whether it was Ruth or Harold. Glass stated explicitly in her acknowledgements to the book (1960) that Harold Pollins wrote the original draft, "collected a good deal of the material" and also additional notes that she used to expand his report (ix). Harold wrote to me: "I told her I thought I ought to be joint author. She then asked me to meet her, which I did in her office one evening. She then started to go through the book saying. 'Who wrote this? You or me?' After a bit, I got fed up and told her she had written the book. We left it there. She took over my stuff but expanded it. I don't recall who inserted the business of Jews and West Indians. I think I might have told her about the Jews in the East End, which I knew about and she didn't (although she had done research on part of the East End earlier)" (Pollins and Gondek 2017). 
colonies would be accepted into white "high society" once they arrived in England, while being rejected from the same types of white men's clubs in India or Africa (109).

In an essay called "Insiders-Outsiders: The Position of Minorities" (1962), she developed a similar argument; she illustrated how minorities are treated in an "ambiguous, ambivalent and erratic" way. Discrimination can be transferred from one group to another and can return to an older group, like the Jews: "in Britain when the colour bar agitators, having found some satisfaction in the passing of the Commonwealth Immigrants Act of 1962, turned from the Blacks, as their primary target, back to their original one, the Jews" (Glass 1989a:226). In another example, she highlighted antiSemitism's predominance in schools and de-emphasized anti-color prejudice: she maintained that though "segregation is unknown" for West Indian children as of 1959, Jewish children were formerly harassed in East End schools and in the streets, and there were juvenile gang wars between "goys and yids" (Glass 1960:63).

She implied that the solution to the problems of anti-black racism could be found in returning to laws created to address anti-Semitism in the 1930s and 1940s. In a section where she discussed the legal approach to discrimination cases, she showed how at the time of the writing of London's Newcomers, there was no real legal remedy for "Group Defamations" cases. When the Committee on the Law of Defamation met in 1948, "coloured people" were not yet the major targets of "Group Defamation" while Jews were. She clearly linked the inability for the court system to address anti-Semitism with its inability to address "racialism" against West Indians and other "coloured" residents of England (1960:113-114). 
“Keep Britain White" groups, especially the 1959 campaign of the Union Movement's Sir Oswald Mosley in North Kensington, were not only "racialist" but also anti-Semitic: there was a rise in both swastikas and anti-Semitic slogans painted on synagogues directly opposite Mosley's office. This led several Labor MPs to write a Private Members' bill, which would make it an offense to use race or religion as a basis for public insults in speech and in writing (170-171). This was an expansion of the Public Order Act of 1936 passed during rising fascist organizing in the East End of London (where many Jews lived). The 1936 Act made it illegal to use threatening public speech that intended to provoke violence, but did not apply to the written word (170). In 1959 Mosley's Union Movement advocated sending West Indian immigrants back to the West Indies (176), but also used anti-Semitic rhetoric in their paper Action including phrases such as "concealed Jewish control," while claiming that the Union Movement was not anti-Semitic. The Action article blamed any anti-Semitism on Jews themselves who had “sought revenge after the war" (1960:191, note 91).

Directly before this discussion of anti-Semitic themes employed by Mosley's group, Glass emphasized how the female Action vendors attempted to dissuade [white] women from associating with black men: "Go home you young ladies who love the Negroes" (1960:190). In a 1959 article in The Guardian, Mosley told stories about "coloured" people "assaulting, raping, keeping brothels." Glass explained that opponents to Mosley's Union Movement would be called 'Nigger lovers' and 'Jews' - clearly emphasizing the links between anti-black racism and anti-Semitism, as well as pointing out the sexualized nature of these racial stereotypes (Glass and Pollins 1960:184-85). 
Though Glass emphasized that anti-color prejudice was less socially acceptable than anti-Semitism, in a 1958 Gallup Poll that she cited, voters expressed more prejudice against atheists and "coloured" people than they did towards Jews or [white] women. While $51 \%$ of respondents said they would not vote for an atheist even if this person were well qualified, $36 \%$ said they would not vote for a "coloured" person, $27 \%$ said they would not vote for a Jew and 21\% said they would not vote for a woman (1960:248). The race of this hypothetical "woman" was not stated.

She also found that if respondents were opposed to "coloured" candidates, they were also likely opposed to other "out-group" candidates. Thus "overtly expressed colour bias is often associated with general prejudice against other 'minority groups"” (1960:249-250). Interestingly though "the opposition expressed in the Gallup Poll to women or Jewish candidates, for example, seems not to be reflected in actual voting, where such candidates stand" (250, n. 4).

Even if at times she seemed to minimize "anti-colour" prejudice, she also pointed out that black people have never been compensated for their suffering and loss of life as Jews have been. In "The Ashes of Discontent: Jamaica Today" (1962) she wrote:

Nor has there ever been an Eichmann trial of the slave traders, the slave owners, the masters of indentured labour (who were secure in their position until 1917, when the system of indenture was at last outlawed). After abolition, the slave owners were compensated for the loss of their human property; the slaves were not compensated for the carnage, the torture, for the expatriation from human society, which many millions of them had suffered. All that history, so lucrative for Britain, so disastrous to Africa and the West Indies, has been conveniently filed away (Glass 1989a:216).

It is clear that Glass' German refugee status marked her perspective on the experiences of migrants of African descent, even if she never explicitly stated what she personally 
experienced. She frequently used analogies with anti-Semitism in order to contextualize and understand anti-black racism. In 1978 Glass expressed her alarm at recent antiimmigrant rhetoric that struck her as quite similar to what had been said about the Jews. She argued that the blame should never be placed on the immigrants (Jews or "coloured"); and disputed the commonly raised argument that it was the "influx of strangers" that caused increased anti-Semitism or "racialism." As Ruth Landes did when she used the term "concentration camps" to refer to Native American reservations or Fisk University, a historically black college, Glass utilized the same strategy as the Yiddish newspapers when she employed the term "final solution" (that also clearly triggers images of the concentration camps) to criticize anti-color legislation. "Various proposals are in the offing: to reduce them to the status of second-class citizens, or simply to expel them. Perhaps the talk will shift from 'illegal immigrants' to 'illegal natives'? Wherever along this road will be 'the final solution'?'(Glass 1978)

Glass' rhetorical technique of frequently developing analogies between anti-black racism and anti-Semitism creates a different effect than Ellen Hellmann's often separate discussion of Jewish political rights and the need for social services for black populations. Hellmann's guiding emotion - guilt - led her to work with her "own" people, Jews, during the rise of Nazism. This affective response also fueled her work with black migrants to Johannesburg since she felt she "owed" those with less privileges. Ruth Glass' emotional motivations deviated sharply; though Glass did not explicitly discuss her refugee history either in her public writings or in her conversations with her male colleagues, the tone of her writings about West Indian migrants and her use of terms like "the final solution" in order to describe the proposals to expel or strip citizenship 
rights from black migrants, indicate emotions such as horror, terror, distress and disgust. For example, Glass was so incensed by governmental policies toward "coloured" immigrants, even in the Labour Party, that she believed that "radicals had no place in any political party in Britain" (Oxford Dictionary of National Biography 2004). Ruth Glass' personal experience of being a Jewish refugee in Britain who had directly experienced Hitler's genocidal policies positioned her completely differently in relation to the British government and to other migrants than Ellen Hellmann was positioned in relation to the Afrikaner government and black migrants to Johannesburg.

\section{Institutional affiliation}

While both Glass and Hellmann worked at a single institution for a significant tenure, Glass's Centre for Urban Studies was more institutionally unstable. In contrast, Ellen Hellmann worked at SAIRR for four decades as a "stalwart" of the "old guard." Michael Edwards explains that the Centre for Urban Studies was physically mobile, shifting its office location and departmental sponsorship several times within the campus of University College London (UCL). In the 1960s William Holford housed Ruth Glass'

Centre within the Department of Town Planning in Flaxman Terrace. ${ }^{110}$ In approximately 1970, Richard Llewelyn-Davies ejected her from that spot, and the Centre moved to 87 Gower Street at "the corner diagonally opposite Mrs. Dillon's shop" sponsored by Bill

\footnotetext{
${ }^{110}$ Ruth Glass' letters to the editor of The Times show that the Centre was at Flaxman house in 1960-1963 (Glass 1960, 1963). From 1962-1971, Glass listed her address as 10 Palace Gardens Terrace W8 (Glass 1962, 1971).
} 
Meade, from the department of Geography, yet the Centre was not housed within the Geography department. ${ }^{111}$ Later she had to move again when UCL wanted to sell the house on Gower St. This time she moved to "one big room (by then I think with no other staff). It was the ground floor room in an old house in Tavistock/Torrington Place immediately adjoining the side elevation of 26 Bedford Way" (Edwards 2012) ${ }^{112}$

Figure 77. Ruth Glass’ Institutional Affiliations, 1932-1986

1932 Forced to leave the University of Berlin "mid-1930s" attended the University of Geneva and London School of Economics 1935-1941 married to Henry Durant, "pioneer" of public opinion surveys like the Gallup Poll

1939 published Watling about the new London City Council cottage estate in Hendon in the outskirts of London 1940-1942 Senior Research Officer at the Bureau of Applied Social Research at Columbia University, received her M.A.

1942 Married David Glass, demographer

1943 returned to London, lecturer and researcher at the Association for Planning and Regional Reconstruction 1947-1948 Research officer for Political and Economic Planning 1948-1950 Ministry of Town and Country Planning 1950 University College London, returned to academic life 1951 Director of the Social Research Unit, UCL, founded Centre for Urban Studies 1958 Director of Research at UCL 1958-1975 Chair of the Urban Sociology Research Committee, International Sociological Association 1972-1985 Visiting Professor at University College 1980-1986 Visiting Professor at University of Essex (Hobsbawn 1990; Oxford Dictionary of National Biography 2004; Pimlott Baker 2004)

${ }^{111}$ Based upon the letters to the editor of The Times the Centre was at 87 Gower St. from 1969-1981 (Glass 1969, 1981).

112 In 1983, the Centre was housed at 55 Gordon Square, WC1, which is next to 26 Bedford Way (Glass 1983). 
Many of the men who worked with Glass argued that her institutional precariousness (Figure 77) was because of her personality. Nigel Harris (September 29, 2017 and December 20, 2017) explained that her husband's position as "the head of the only Department of Sociology in Britain and center of a global network of sociological luminaries" was a key factor that permitted her to continue with the Centre: "David gave Ruth and the Centre enormous status." Nigel indicated that the Centre folded in 1980, only two years after David Glass' death in 1978 (Gondek et al. 2017). Based upon Ruth Glass' letters to the editor of The Times, the Centre was still in existence in 1981 (at 87 Gower St.) and 1983 (at 55 Gordon Square). Hilary Rose explained that Ruth could not work at the London School of Economics because of nepotism rules - her husband was a senior professor in Sociology (Rose 1990); Hilda Kuper suffered from the same rules at UCLA. Rose (1990) elaborated that women academics during the sixties, especially those who were beautiful and clever like Ruth Glass, became "special targets" of sexual harassment and "rubbishing" and were perceived to be "difficult."

I heard the theme of Ruth Glass' "difficult" personality from multiple sources even from Hilary Rose herself. Ruth apparently had the tendency to utilize a condescending or belittling demeanor, which caused embarrassment and the sense that one was not good enough for her standards. Hilary recounted an "awful" job interview she had with R. Glass:

I hugely admired her work and put in for a job she was advertising. She asked me what I had read. I muttered, feeling embarrassed as it sounded like I was ingratiating myself, 'Everything you have written' (should have added 'in English'). I had also read almost everything on the LSE undergraduate multipage Modern Britain course but was too embarrassed to say so. I thought she was going to ask about housing newcomers (September 27, 2017). 
Rose said that more experienced sociologists told Hilary: "[Ruth] like her husband David were not easy with people" (Rose and Gondek 2017). When I asked Rose to elaborate what she meant by "not easy with people," Hilary wrote: “... she was seen as 'difficult' that term so readily given to any woman who refused to be bullied and insisted on being recognised as a professional"' (September 28, 2017).

Harold Pollins (October 18, 2017), who was Ruth Glass' research assistant for London's Newcomers, explained: "It was said that she never got an academic post for which she was well qualified, because people did not get on with her" (Pollins and Gondek 2017). Nigel Harris, who became the Deputy Director of the Centre in 1968, elaborated on this idea (September 29, 2017): "Ruth had a reputation for ferocity, cantankerousness (the then-secretary to University College, Tattersall, was overheard to say - 'in an earlier age, she would have been burnt at the stake as a witch')... Ruth found it very difficult to recruit and hold staff or create a cadre that might have given her Centre more substance" (Gondek, Harris and Harris 2017). Michael Edwards reported: "Ruth was a cornery [sic] and ungovernable person, incapable of arse-licking. My feeling always was that this, as much as her radicalism within her work, always made heads of departments keep her (and sociology) rather at arms-length” (Edwards 2012).

Most of her employees were men, and neither Nigel Harris nor Harold Pollins remembered her positively; both felt that she had treated them poorly and unjustly. Nigel was hired to create and teach a one-year post-graduate diploma program for public servants from developing countries, which was funded by the British aid program. "I assumed she had a conception of what a course on urbanization in developing countries might be (I was a complete novice, learning on the job) but she was not a teacher and did 
not think in terms of teaching courses - so I found myself on my own. But that did not stop her trying to control the process, to defend her authority, with micro-management" (September 27, 2017). He added: "With the rows, it was all I could do to stop resigning and I congratulated myself on being able to complete my 4-year contract (1967-71) without resigning. She made no effort to renew my contract...” (September 29, 2017). Also, Nigel remembered that Ruth Glass asked him to drive and type for her on the weekends since "we had weekend cottages nearby in Suffolk... Ruth never learned to type (or to drive), she constantly summoned me at the weekend to type her letters to The Times" (September 25, 2017; December 20, 2017).

One of Harold Pollin's memories of Ruth seemed to have a particularly sexualizing undertone: "She was a mixture of a flirtatious nature towards men - as I recall she wore light blue stockings (tights?) and a garter below the knees" (October 18, 2017). ${ }^{113}$ It seems that Ruth Glass was deemed "difficult" because she behaved in "masculine" ways: she was assertive, controlling, condescending, and demanding. She did not treat the men who worked for her in the ways that they felt they should have been treated or perhaps in the ways they were accustomed to being treated by women during that particular era. Interestingly, the depictions of her masculine-like behavioral traits were paired with allusions to her sexuality, whether it was her blue stockings and garter belt, or her references to the genitals on a horse statue, or how she lost her virginity.

${ }^{113}$ Pollins wrote this in response to my question: "Did she ever talk about how she saw herself as a woman in a male dominated professional environment? What was her relationship with male colleagues like? What were your experiences working with her? (I have heard that she was "difficult" to work with and I am wondering what your views of her are?)" 
These sexualized references could be a way for her male colleagues/employees to put her back in a woman's "proper" place, since (from their perspectives) she often treated them in ways which left them feeling powerless. However, Hilary Rose's experience reveals that women could also feel belittled or demeaned by Ruth Glass' demeanor. Thus, it is unclear how much of the reports about Ruth Glass' workplace deportment might be influenced by sexist perspectives of women's "proper" place and behavior at that time and/or how much is founded upon Ruth's no-nonsense professional (and perhaps personal) style, that could leave employees/colleagues feeling devalued and even disrespected. However, what I most want to emphasize is how her challenge to gender normative workplace performances was directly connected to the institutional instability of her Centre for Urban Studies. Whereas Ellen Hellmann collaborated with male colleagues in the various organizations where she served in a leadership capacity, Ruth Glass was perceived to be unable to collaborate effectively with male colleagues/employees (making Glass more similar to Ruth Landes in regard to her institutional/disciplinary positionality.

\section{Differential uses of science}

Ruth Glass believed that objective scientific research should be used to enact significant governmental policy changes. She also argued that in order for scientific research to proceed, public policies needed to be free from racial discrimination. She saw the liberating potentials of objective fact-finding; from her perspective empiricism was on the side of activism rather than status quo politics. For example, in 1960 she wrote in a letter to the editor of The Times: 
At present public authorities cannot compile statistics about coloured people for fear that this may be regarded as a symptom of discrimination, and that it may lead to segregation. But if we had an unequivocal policy of racial equality, expressed also in specific legislation, we could collect facts about coloured people as we do about any other social group, without apprehension that our intentions may be misinterpreted and that adverse consequences will follow. We could then obtain the information necessary to assess systematically the difficulties of mutual adjustment and to take practical measures for their solution (Glass 1960).

In 1976, she critiqued "urban improvements" in Third World cities, that provided ornamental fountains in elite enclaves rather than water taps in poor districts, or that focused on private rather than public transport. She was outraged that urban planners were more motivated by politics than by "plain facts." She believed that true empiricism could be much more liberating than this type of politics (Glass 1976). Though both Hellmann and Glass revered scientific study, they understood its purposes completely differently.

Hellmann equated the scientific objectivity of the SAIRR with following the apartheid laws because they were laws (even if they were unjust); in contrast, the activist “emotional approach" advocated by younger members of SAIRR like Michael Savage and Clive Nettleton went against the "rule of Law." Thus, in Hellmann's conception empiricism was allied with the maintenance of the apartheid government (even if she advocated for gradual step-by-step progress) and in opposition to activism and revolutionary social change. Hellmann described the SAIRR as a "middle of the road body" centered upon the "pursuit of truth," and "objective fact-finding" (Hellmann 1974:1). Regarding the Schlebusch Commission of Inquiry, Hellmann believed that the SAIRR was legally required to provide testimony in the apartheid government's investigation into interracial organizations. 
If it is to maintain its integrity and uphold the principle of objective inquiry and its commitments to the rational, as opposed to the emotional approach, the institute cannot, as a body, refuse to testify before a statutorily appointed commission... We have pinned our faith on the instrumentality of reason, believing that the pursuit of objective facts and a rational approach to our problems can induce peaceful change (Pringle 1973).

Because SAIRR was an objective fact-finding organization it could not "put itself outside of the law or refuse to obey the law" even though it felt "dismay" at the banning of 8 NUSAS (National Union of South African Students) leaders and the banning and house arrest of 8 black leaders of SASO (South African Student Organisation) and the Black People's Convention. Even though she admitted that these governmental actions were an "abuse of power" and represented a "silencing of the voice of the emerging black leadership" by the Minister of Justice that was "bound further to increase the deep resentment of racial discrimination felt by the Black people," she still adamantly argued that the SAIRR had to obey the law by testifying before this commission of inquiry into multi-racial organizations (Pringle 1973). While Hellmann's emphasis on scientific objectivity tied her to the apartheid government's status quo, Ruth Glass employed "science" to challenge racist governmental policies.

\section{Theories of the urban}

Glass and Hellmann interacted at a conference on urbanization at Nuffield College in 1959 (Hellmann et al. 1959). Glass tended to be more optimistic and less judgmental, while Hellmann was more pessimistic and moralistic about the negative effects of growing urbanization. Glass often critiqued the rhetorical clichés employed to bemoan the development of cities - like "devouring cities" and "threats of impending 
catastrophe" (Glass 1976). Glass found that thinking of cities in terms of the "wrong size" was unhelpful (1959:11). Hellmann disagreed with this assessment: she felt that the size of the city was of "considerable importance" and she advocated limiting city size because "beyond a certain limit it became a monstrosity in terms of cost, inconvenience, and human dislocation" (Hellmann et al. 1959:13). As evidence of the "problems" of urbanization Hellmann cited "indices of illegitimacy, juvenile delinquency," in both European and African groups in South Africa (1959:18). Glass (in an article called "Clichés of Urban Doom," 1976) critiqued this type of perspective, that "the city is the scapegoat for our troubles" because when this approach was taken, "the blame gets shifted... to the people who are supposed to swell the crowds and problems of cities migrants from rural areas, or immigrants from abroad" (Glass 1989a:128); yet, black rural migrants to Johannesburg were the people whom Hellmann spent the majority of her time bemoaning in her conference talks and articles.

\section{Depictions of migrants}

Ruth Glass critiqued the commonly expressed belief that black immigrants were to blame for increased racial tensions or that increases in these immigrant populations led to increased racial discrimination (Glass 1965). She objected to this "colour calculus"that " $\mathrm{X}$ number of coloured people are tolerable, but X plus one tips the balance and sets off an explosion of hostility" (Glass 1978). She argued that "racialism" had nothing to do with the size of the minority population. She made an analogy with the rise of Nazism, maintaining that the number of Jews was not responsible for increasing anti-Semitism. She disagreed with Professor Hayek who maintained that the "“sudden influx of large 
numbers of Galician and Polish Jews' into Vienna caused antisemitism (in Vienna) which 'led' to the Fascist takeover (in Berlin)." She was angered by the fact that there were governmental proposals to reduce native-born "coloured" people (the children of black immigrants) to "second class citizens or to simply expel them." $60 \%$ of the "coloured" population in Britain would be native-born by 1999. Proposals to reduce citizenship status or expel native "coloured" people reminded her of "the final solution": she asked, “Perhaps the talk will shift from 'illegal immigrants' to 'illegal natives'?" This was a reference to the proposal to eject native-born "coloured" children of immigrants (1978). Glass made it clear that the "blame" should not be placed on the black immigrants but on those whites who lived in London and considered themselves "natives" (Glass 1989b). While Glass shifted the causes of racism from black immigrants to "native" Britons, Hellmann placed the onus for change on black migrants who needed to adapt to "civilized" ways. Hellmann critiqued the negative effects of the colonial system on "native" Africans including poverty and unsanitary living conditions (1948:7-9), yet her goal was for them to "adopt such elements of European culture as may enable them to attain to an ordered and economically secure social life" (1935:61). In 1955, she Hellmann spoke to the Cape Zionist Club, arguing that acceptance into Western society could be achieved when middle-class Africans became properly civilized and adopted Western ways of living (E. Hellmann 1955b). Her view was that culture contact in South Africa "is a process of westernization in the course of which Africans, living their lives within a western economic, political, legal and religious framework, are adopting and assimilating this whole western way of life, not only its knowledge and techniques, but its standards and values" (Hellmann 1962a:11). Unlike Ruth Glass, Ellen Hellmann did not 
demand that white South Africans change their perspectives, but instead she required "natives"/"non-Europeans" to adapt their behaviors to the "civilized" Western standard.

Glass and Hellmann did overlap in their findings that middle class Africans and West Indians viewed the British middle class as a model. Glass cited Vera Rubin's 1957 Caribbean Studies: A Symposium regarding "colour snobbery" and class consciousness among West Indian migrants. The middle class and intellectuals were lighter-skinned, "light pigmentation conveys social prestige," and subsequently, West Indians desired to "marry fair." Overall, the West Indian middle class had more in common with the English middle class than with the West Indian working class (Glass and Pollins 1960:94, n.1; Rubin 1971). In 1955 Hellmann cited black sociologists St. Clair Drake and Horace Cayton, the authors of Black Metropolis (1945), in order to support her contention that "middle class status and family stability go together" and that Black middle class norms for behavior, "respectability," and "morality," are those of the white middle class (Drake and Cayton 1962). She maintained that as the African middle class advanced it became more Westernized and European rather than undermining "Western civilization" (E. Hellmann 1955a:11-12).

Representations of black women within race relations social science -1950s

Ruth Glass did not sexualize black women migrants or discuss their sexual or family relationships in London's Newcomers in contrast to the four other Jewish women social scientists in this study. Other social scientists writing about black migrants in the U.K. during the same time period such as Michael Banton, Kenneth Little, Anthony 
Richmond, Sydney Collins, Joyce Egginton, and Sheila Patterson ${ }^{114}$ specifically discussed black women's sexual and familial relationships. Banton, Richmond, Collins, and Patterson, in addition to Eyo Ndem, Sheila Webster, and Violaine Junod ${ }^{115}$ worked with Kenneth Little at the University of Edinburgh's Department of Social Anthropology in the 1950s to study "British race relations" in terms of specific geographic sites (cities in the U.K. and neighborhoods in London), white attitudes toward black migrants (influenced by class), as well as class and ethnic differentiation and stratification within and between black migrant groups. This research was funded by the Nuffield Foundation, UNESCO, and the Colonial Social Sciences Research Council (Little 1960). Ruth Glass cited Banton (1959), Richmond (1954), Little (1948), Egginton (1957), Junod (1952) and Patterson but not to discuss black women's experiences. She

${ }^{114}$ Sheila Patterson and Ellen Hellmann were friends (Patterson 1983). Hellmann had a plan to see Sheila (Patterson) Horko when Ellen visited England (Hellmann 1967). Apparently the two became friends when Sheila came to South Africa and researched the history of the Cape Coloured (Banton 1998). In 1973, Sheila Patterson reviewed Ellen Hellmann's work: "Ellen Hellman [sic], in her survey of social change among urban Africans, points out that the white middle-class is the normative reference group for Africans and that the degree of Westernization is in itself an attribute of status. This has come about despite the lack of any systematic efforts to promote cultural assimilation in the past, and despite the government's endeavours to reactivate ethnic values and divisions in the town" (Patterson 1973:177). Paul Rich presents Sheila Patterson as advocating assimilation and integration of West Indian migrants into British society. Rich argues that Patterson supported governmental "intervention" in anti-discrimination legislation, educational programs combatting racial prejudice, and "integrative social action" for migrants' involvement in their communities (Rich 1990:199).

${ }^{115}$ Violaine Junod was close to both Hilda Kuper and Fatima Meer. There are at least three letters from Violaine to Hilda in the Hilda Kuper Papers; Violaine spent time with Hilda's daughter Jenny, who lived in London (Junod n.d.). Fatima Meer described the Kupers and Violaine Junod as her "most constant friends" during the Treason Trials (Meer 2017:169). 
contested Banton's claim that while "colour prejudice" was not widespread, discrimination was "undeniable"; she found the opposite to be true (Banton 1960:210; Glass and Pollins 1960:217-18, 255). She utilized Richmond's work to discuss the ambiguity of the racial situation in England, which caused anxiety, uneasiness, and a sense of un-belonging for black migrants, leading to mental breakdowns and even suicide (Glass and Pollins 1960:121, n. 33; Richmond 1954:99, 122). Glass additionally argued that there were no "serious difficulties" in social relationships within professional and university circles between white and "coloured" peers; in contrast to what Violaine Junod found in her unpublished study Report on a Study of the Coloured 'Social Elite' in London (Junod 1952; Glass 1960:107, n. 10). Glass mentioned Little's analysis of the Cardiff race riots in 1919 (Glass 1960:128, n. 44; Little 1948:57-60) and Joyce Egginton's description of a group of Jamaican immigrant men who shared tea with the mayor of Brixton after arrival on the Windrush in 1948 (Glass 1960:46-47; Egginton 1957:65-66). Glass cited Anthony Richmond to explore employers' discrimination against West Indian workers because of their supposed lack of "skills"; Richmond found that West Indian workers were as objectively highly "skilled" as they subjectively assessed themselves to be (Glass 1960:72, n. 26; Richmond 1954:33-34). He also found that the worst white employers were those who had worked as bosses in the colonies and treated West Indian workers in the U.K. as they had treated unskilled workers from the “bush” (Glass 1960:87-88, n. 45-46; Richmond 1954:41-44). Overall, Ruth Glass utilized these authors to provide foundational information about white racialist attitudes, the racialized experience of migration, and racial discrimination in the workplace, but not black women's specific experiences. 
Glass briefly alluded to black men's sexuality, as it related to interracial relationships with white women. Glass clearly thought that the "folklore" about "coloured men's sexual behavior" was "hearsay" that was "overlaid with meaningless distortions"; these images about black men and white male sexual competition with black men "strongly affects attitudes to coloured people" but she did not think that these ideas were necessarily transferred to the workplace - one of her primary sites of interest (86). She cited a study by Senior and Manley from 1955 that found that white workers were more reluctant to accept "coloured" colleagues in workplaces where both women and men worked, but she did not think that attitudes outside the workplace were necessarily transferred into the place of work $(1960: 86, n .44)$. Thus, she seemed to not be able to accept the possibility that "racialism" could spread between what she seemed to view as the public and private spheres.

When black women are mentioned in London's Newcomers, it is in the context of demographics (the number of West Indian women and children who migrated to London) and employment. Before 1957, there were more male migrants, however there were more women and children migrants than male migrants in 1958 and '59 (1960:5-6). Seventy percent of these women migrants were from Jamaica (15). Glass concluded that this meant that men were asking their wives and children to join them in London (17). 56\% of these female migrants were between the ages of 15 and 29,24\% were in their $30 \mathrm{~s}$, and only $20 \%$ were over 40 years old (18).

One of the primary themes in Glass' discussion of black women and employment was their experience of "downgrading" in profession between their employment in the West Indies and in London post-migration (29). 50\% of women migrants (versus $1 / 4$ of 
men) had been in the "non-manual trades" in the West Indies. Only 1/5 of both genders had been in a "rather low occupational grade" such as semi-skilled, unskilled or farm labor. Higher proportions of "black coated and skilled workers" immigrated to London from the West Indies, and fewer were agricultural workers. Thus, there was a "selective migration" from the West Indies to London of those in the more educated and skilled classes (22). Glass explained that upon arrival in London, more women than men worked as typists, clerks and nurses. The women who worked in "manual" trades were "domestic and kitchen assistants in restaurants, hotels, hospitals and canteens" or "machinists and finishers in the clothing industry" (29). To highlight the "downgrading" in occupation, Glass wrote:

In London, 60 per cent of the men and 66 per cent of the women had semi-skilled and unskilled manual jobs. In the West Indies, in their previous occupations, only 21 per cent of the men and 23 per cent of the women in the Sample had been in these rather low categories (29).

Another topic that Glass addressed regarding West Indian women migrants was the "problems" they experienced after migration (45). Problems relating to employment made up $62 \%$ of the complaints filed by women migrants, compared to $75 \%$ for men (45). As an example of racialist attitudes that black immigrant women faced in the work environment, one firm in Willesdin (in Middlesex) reported that, "coloured women workers were 'dirty"” (92). "Family and personal" problems made up 12\% of women's complaints, compared to $6 \%$ for the men (45). However, overall, Black women's experiences are not a dominant theme in London's Newcomers. "Family and personal" problems are not an area which Glass explored; instead she focused on problems in 
housing, schools, and employment - within the traditionally defined "public" realm, informed by her disciplinary training in urban planning.

\section{Interracial relationships}

Interracial marriage was a topic briefly addressed in London's Newcomers, yet black women were not specifically mentioned. "Mixed marriage" was the issue that provoked the "strongest disapproval” from survey respondents (Glass 1960:251). Glass cited the Gallup Poll (which her former husband Dr. Henry William Durant conducted) from September 1958 during the "disturbances" in Nottingham and Notting Dale; $71 \%$ of respondents objected to marriages between whites and "coloured" people (1960:248).

The reason that black women were not specifically mentioned is that these "mixed" relationships were primarily between black men and white women. Mica Nava explains that white male scholars, primarily Michael Banton (a widely cited sociologist of race relations in the 1950s and 60s) and secondly Anthony Richmond (a social anthropologist), tended to emphasize the sexuality of black men and white women and the immoral and deviant nature of white women who engaged in interracial relationships (Nava 2007:111, 114-17). This is reminiscent of Ann Laura Stoler's argument about the Dutch colonial context, where white women who chose to be with native men "were neither well-bred nor deserving of European standing” (Stoler 2002:103).

Anthony Richmond explained the tendency for interracial marriages in Britain to take place between white women and black men.

The interesting fact about inter-marriage in Britain, from the sociological point of view, is that it takes place principally between coloured men and white women. This is in contrast with the situation in South Africa, the West Indies, or the U.S.A., where the large majority of coloured people of mixed descent trace their 
ancestry to the relations-between a white man and a coloured woman (Richmond 1955:279-80).

Sydney Collins, a Jamaican social anthropologist who worked at the University of Edinburgh with Kenneth Little, pointed out that white men married to non-white women were much less ostracized than white women married to non-white men (Collins 1957:25). Ruth Landes (1952) reported to the Royal Anthropological Institute that the English "resented the sight of a black man with a white woman, reacting rivalrously [sic], sometimes violently... to the thought that an alien man was being admitted to the closed society, through a woman violating her social trust." ${ }^{, 16}$ Landes contended that the root of the problem was with the Englishman rather than the black immigrants, and she celebrated black difference (unfortunately through the use of exotification and negrophilic essentializations). Yet her theorizations stand in contrast with those of her colleagues from the University of Edinburgh because of the way that she reframed the tendency toward negative moral judgments about black migrants, instead portraying black people with positive adjectives that emphasized their inclusion rather than exclusion of those outside of their community, and especially because she contested the assumption that black or brown men oppressed their wives. Landes stated that the Englishman was primarily affected by "the Negro's incomprehensible and perhaps theatrical zest and spontaneity; it challenged the English at some vulnerable level..."

\footnotetext{
${ }^{116}$ Ruth Landes received a Fulbright grant to study at the University of Edinburgh with Kenneth Little from 1951-1952. Charles S. Johnson connected her with Kenneth Little, who had been on sabbatical at Fisk in 1949-1950 before arriving at the University of Edinburgh in 1950 (Bailkin 2012:27; Landes 1987c:1; Rich 1990:191).
} 
threatening to break their self-discipline. ${ }^{117}$ "It was possibly that responsiveness of the Negro, so warm and friendly, that entertained Englishwomen." Landes emphasized “"that Negro men everywhere from Dahomey to New York, take women into their lives much more entirely than do most other peoples, and elevate them institutionally, whether in the Congo or in the Americas"” (Landes 1952). Perhaps she was speaking of her own experiences with Elmer Imes at Fisk and Edison Carneiro in Salvador, Bahia, Brazil. Landes' disciplinary training with Ruth Benedict who was interested in individuals who did not fit into the norms of their society, along with her personal experiences in interracial relationships, likely informed her emphasis on "personality and culture" in her theorizing about black men and white women's relationships in the U.K. In contrast, Ruth Glass, trained as an urban sociologist and town planner, was more interested in overtly or traditionally "political" and "public" issues like citizenship, housing and employment rights.

Anthony Richmond (1955), like other social scientists who tried to understand why interracial marriages occurred in Britain, posited that "mixed marriages usually occur where the girl or woman is in certain respects a deviant from the norms of her own culture" (280). Michael Banton argued that these white women were outsiders, coming to Stepney from "other parts of the country, Northern towns and ports, the Birmingham area, Glasgow and Ireland" (1955:153). In 1960, Banton called these white women "outcasts" who came from a "background of deprivation" and were "personally unstable"

\footnotetext{
${ }^{117}$ Michael Banton (1960) cited Landes' findings in order to argue that "the coloured man" in Britain was the "archetypal stranger" (84).
} 
(Banton 1960:127). Richmond hypothesized that only lower class white girls would marry a "coloured" man in order to improve their "material circumstances"; because of the stigma associated with such a marriage, only white girls who were in some way desperate would marry a black man. Social scientists such as Richmond (1955), Kenneth Little (1948), and Michael Banton (1955) listed similar reasons for these white girls' supposed desperation including quarrels with family, running away from home, illegitimate pregnancy by white men who subsequently deserted them, hiding from the police after committing crimes, unemployment, or lack of supportive friend networks (Richmond 1955:281; Little 1972:137; Banton 1955:152-153). Sydney Collins repeated the commonly used explanations that white female partners of "coloured" men were living "illicit sex lives" or had "illegitimate" children by either white or "coloured" men who had deserted them, their parents had "forsaken" them, and thus they found "security... with a coloured man." However, Collins added that: "But more often mutual affection may bring the couple together" (1957:45).

Adding to this view of "deviant" white female partners of black men, Kenneth Little (1948) described white female prostitutes in Cardiff's Bute Street, who engaged in relationships with multiple men including their "coloured" husbands: "the woman continues her attempt to make the best of both worlds, and carries on her old profession more or less sporadically by accommodating 'visitors' in the house during her husband's absence, sometimes even, with his consent or connivance, when he is at home" (Little 1972:136); this of course is reminiscent of Ellen Hellmann's description of "back-door husbands" at Rooiyard (informed, of course, by the knowledge of John Chawafambera) . Michael Banton went so far as to say that "Some of the women attracted to coloured men 
appear to be nympho-maniacs..." a shocking statement which Mica Nava also critiques (Banton 1955:153; Nava 2007:114).

Sheila Patterson incorporated the same link between "coloured" men and white female prostitutes, but she contended that the "majority of recent West Indian male migrants in Brixton form permanent or temporary liaisons with West Indian women," not white women. However, she clearly stated that there were "a certain number [of West Indian men] who have casual and short-lived affairs with white girls" whom she referred to as 'casuals,' not-locally born, some of whom were "ageing, low-class, professional prostitutes." The young girls among the 'casuals' were from rural areas in England, Ireland or from the European continent, who came to Britain as domestic workers, thus highlighting these white girls' foreignness to authentic Britishness (287). Figure 78 visualizes the intersections between Ruth Glass's London's Newcomers and writings by Sheila Patterson, Violaine Junod, Ruth Landes and Kenneth Little. ${ }^{118}$

${ }^{118}$ Note the connection between Violaine Junod's "Report on a Study of the Coloured 'Social Elite' in London" (1952) and Hilda Kuper and Fatima Meer's "Indian Elites in Natal” (1954). Ruth Glass cited Vera Rubin's Caribbean Studies: A Symposium (1957) and acknowledged Claudia Jones, the editor of the West Indian Gazette. Sheila Patterson cited Edith Clarke's My Mother Who Fathered Me (1957). 


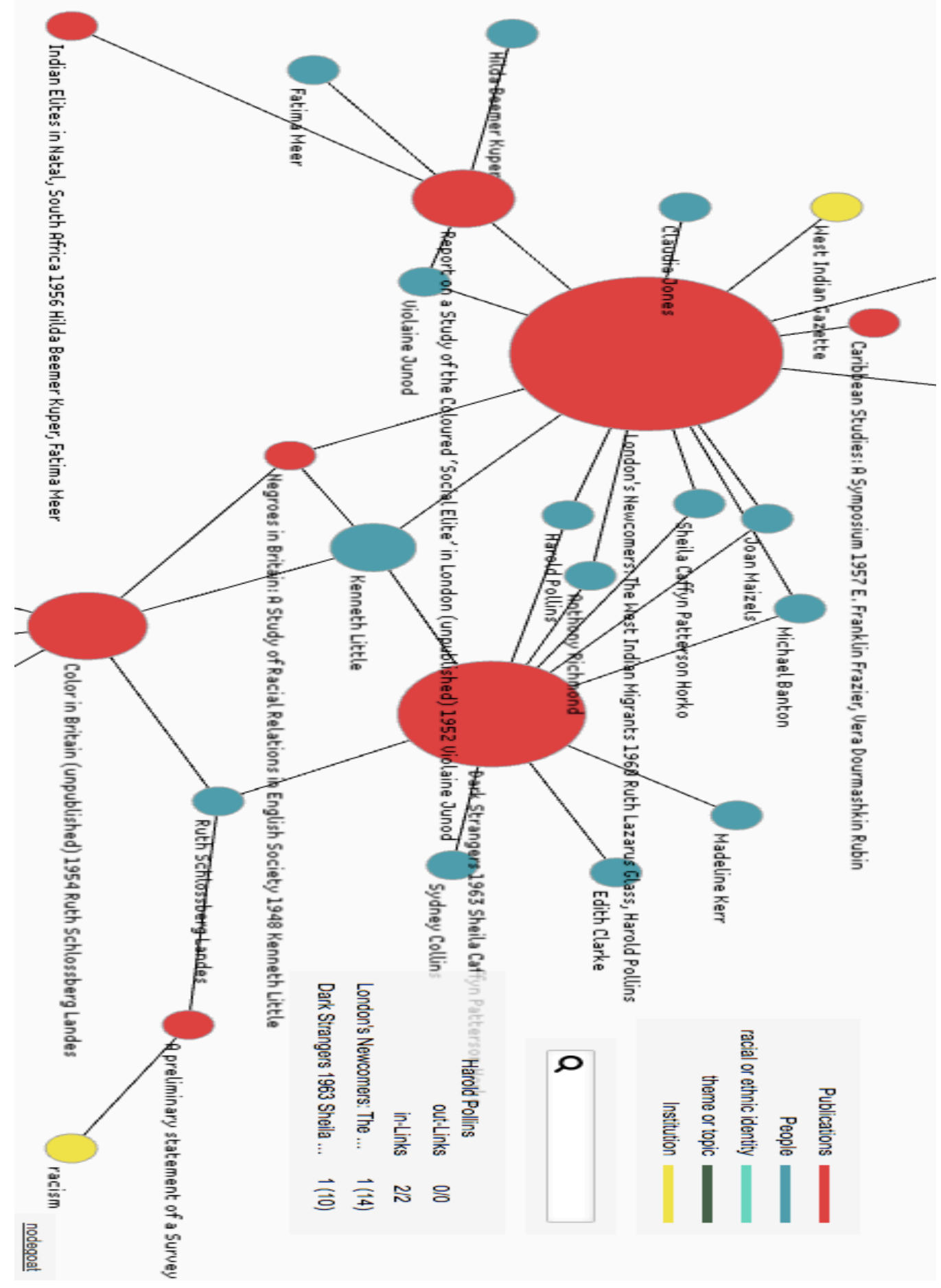

Figure 78. London's Newcomers (1960) and the publications in its network (including the female authors). 
The children of these interracial couples experienced ostracism from both whites and "coloured" immigrants. Sydney Collins explained that there was twice as many "illegitimate" "coloured" children as there were "illegitimate" white children in Lancashire, and that these were the offspring of "common law" couples. "The Anglocoloured does not mix easily with the immigrant, and one often feels the opposition between them" because the recently arrived "sophisticated" immigrants in Lancashire refused to accept white women, whom they considered to be "deviants" (1957:131).

Landes described the 'mulatto' daughter of a black American man and a white Scottish woman in Edinburgh (the Motley family) as filled with "self-hate" because of the daughter's hair texture and skin color (Landes 1954:168; Nava 2013:27). In Black Skin White Masks, originally published in 1952 using evidence from French speaking authors of Caribbean descent, Franz Fanon depicted black Caribbean men in France as self-hating, valuing the colonizer culture over their own, and being extremely conscious of their bodies (Fanon 1967:23, 50, 110-11).

Ruth Glass included an interview with a group of "Teddy Boys" from Shepherd's Bush (one large estate) in which they derided "half-castes." The "teddy boys" were seen as the "main culprits" in the 1958 Notting Hill "disturbances" that began when groups of white boys attacked "coloured" residents of Shephard's Bush; one of the boys interviewed by Barry Carman of the BBC stated the following regarding "half-castes": "we don't want a lot of half-castes running around, do we... you don't want a lot of foreigners in here, especially black anyway. In my opinion, they ought to be shot-the whole lot of them" (1960:261-262). Since this is an appendix, Glass did not elaborate, but 
it seems possible that she made a connection to the Nazi working class youth cliques that she had studied in Germany in 1932.

\section{Images of illegitimacy, instability and matri-central black families}

Ruth Glass' omission of any discussion of black women's sexuality or family structures emerged as significant considering that other scholars studying West Indian migration in Britain at that time utilized themes such as "illegitimacy" and "instability" to discuss West Indian women's sexuality and families. In his chapter entitled "The aftermath of slavery in the West Indies" Anthony Richmond cited both T.S. Simey Welfare and Planning in the West Indies (1946) and E. Franklin Frazier The Negro Family in the U.S. (1940) within a discussion of "illegitimate" births in the West Indies, and "maternal" family structures.

Marriage in church or by any other legally recognized procedure is the exception rather than the rule, and is the mark of 'middle and upper class' status. Strictly speaking, around $70 \%$ of births in the West Indies are illegitimate, if this term can be said to have any meaning in such a situation. The instability is not quite as marked as it may seem at first sight, because many women practise a 'faithful concubinage' with one man over a period of years, and the couple are at least as faithful to one another as many British and Americans in the present day. The West Indian family tends to be 'maternal' without being 'matriarchal' because although the status of women is low, they tend to take the leading role in the family owing to the frequent absence and occasional change of husband (221, n.26, my emphasis).

Sheila Patterson (1963) associated the "matri-central unit" with increased "female emancipation" among the lower-classes and called this family formation "unstable." She accused West Indian women of depending upon nurseries, schools, migrant neighbors, and the National Assistance Board, as they would have relied upon the "matrilineal, matrilocal unit" in the West Indies. She also associated lower-class West Indian women's 
financial independence from men with their reliance upon the National Assistance Board including "tax free payments for such services as baby-minding, rent-collecting, home dressmaking, caretaking for a landlord, acting as a hire-purchase company's agent, arranging weddings, or catering" (304). ${ }^{119}$ Thus she depicted black women as gaining their financial emancipation through cheating the system, using language that evoked "welfare queen"-type stereotypes.

Though Mica Nava portrays Joyce Egginton, the author of They Seek a Living, as a radical political activist and civil rights era journalist, I found that Egginton used the same rhetorical patterns in her descriptions of black women's sexuality and family structures as her male contemporaries. She cited the same average "illegitimacy rate" $70 \%$ and commented: "This appallingly high figure is due, not so much to lack of

\footnotetext{
${ }^{119}$ Laura Longmore (1959) also invoked this association between female emancipation, matri-central families and instability in Johannesburg, South Africa. Longmore researched the sexual lives of Bantu women in Eastern Native Township from 19501957. She found that not only were men in the township disinclined from making permanent unions with women, but that urban women were self-reliant and selfsufficient, and "no longer accepted the patriarchal authority" of their former lives in the rural environment (Bonner 1988:397; Longmore 1959:118). When an African woman won an election for the Bethlehem Native Township Native Advisory Board in 1950, another woman commented to Longmore that this was a "smashing triumph' for African women in their struggle for equality with their menfolk"; thus, it was common for urban women to "claim the same rights and privileges of their man" because of their status as wage earners and this had "undermined the authority of the father" giving women "independence and authority" (119). Interestingly, Longmore tied women's growing independence in the urban setting, with increasing family instability, and tensions because of the wives' greater contribution to household income than their husbands' contributions and also their interactions with male beer customers, igniting the ire of their husbands (120).
} 
standards as to an entirely different moral outlook for which past British administration must take much blame..." Egginton argued that since West Indians were only five generations out of slavery "the marriage habit is not yet formed; marriage is still regarded as a social ambition rather than a moral obligation." Then she added condescendingly, in a tone similar to Ellen Hellmann's: "That it is a sacrament of the church in which they worship escapes many West Indians' minds" (Egginton 1957:125). Egginton proceeded to describe the lack of morality that West Indians demonstrated through cheating or stealing from their bosses, and argued that the same "easy going" approach applied to their "sexual morality," thus implying that they were morally lacking. She reported: "West Indians have little sense of shame about illegitimacy" and explained that they did not marry because of the expense. She gave a description similar to Ruth Landes' in The Ethos of the Negro in the New World (1939): "So it sometimes happens that a devoted couple marry after years of living together, because they have at last saved sufficient money, and their children are bridal attendants, among the honoured guests. The thought behind the action is not just a desire to be conventional, but also to climb a little higher up the social scale" (Egginton 1957:127). Egginton emphasized that it was "the West Indian way of life" for a West Indian woman to have "several illegitimate children" and thus employers must accept this difference in "moral standards" (128). However, even if this description was couched in terms of a difference in morality or culture, it did not challenge the assumption that the European white middle-class standard was the one with moral superiority and correctness.

Kenneth Little, in his study of the Cardiff community, found that within the area close to the docks (where approximately 1 in 3 inhabitants were "coloured") "a number 
of households are run on more or less 'polyandrous' lines. In addition to either a legal or socially recognized husband, such a woman may have one or even two other temporary 'husbands', whom she accommodates in her house on their return from sea” (159). Though he clarified that sexual and marital relations in this community were similar to whites of the same class background, he still included the fact that in 41 out of 60 cases of "coloured people living in London and Cardiff" in the unpublished study of Nancie Sharpe (1932), children were born before the couple married (Little 1972:160, n. 2).

Sydney Collins (1957) described West Indian girls' loneliness, causing them to become "unmarried mothers"; while in the West Indies, extended families could have provided support, in Britain this situation presented "problems for the welfare workers and for charitable organizations" (253). Sheila Patterson discussed immigrant women's requests for birth control from almoners and welfare workers, after bearing "more than one illegitimate child in this country"; Patterson reflected that this was a "great change in attitudes" since there was an "almost universal desire for children felt by West Indians, and of the woman's usual view that child-bearing is her natural function and that any attempts at prevention are unnatural, unhealthy and wrong" (338). Patterson cited Edith Clarke's 1957 study My Mother Who Fathered Me, in which Clarke (a Jamaican anthropologist trained at the London School of Economics by David Glass ${ }^{120}$ ) argued that because of the economic burden that additional children bring, especially without male

\footnotetext{
${ }^{120}$ In addition to David Glass, she received support from Raymond Firth, Isaac Schapera, Audrey Richards and Lucy Mair through funding from the Colonial Social Science Research Council. E. Franklin Frazier, Kenneth Little and M.G. Smith (among others) provided additional assistance (Clarke 1999:xvi).
} 
financial support, Jamaican women sought "bush" medicines to avoid additional children after their first birth, though men disapproved of this practice. Thus, Clarke found that contraceptive use was rare, except in "Sugartown," where men only used contraceptives to prevent the contraction of venereal disease from prostitutes (Clarke 1999:66; Patterson 1963:338, n. 4).

Michael Banton also contributed to the association between black women and prostitution. He described the difficulty that "coloured women" had in gaining employment in the inter-war period. "Most of the United Kingdom-born coloured women in Stepney suffer from personal instability; if they go on the streets they often do very good trade with white men-especially middle-class whites" (1955:158). Then Banton quoted one of his "coloured" male informants who described "all the types of women" in the "coloured quarter" including what he termed the "utilities," who were young women (late teens-twenties) with "nowhere to go." Since both white and "coloured" women reside in the "coloured quarter" it is unclear how to racially classify the "utilities." Yet this discussion directly follows the description of "coloured women" who became prostitutes, crafting an association between "utilities" and "coloured women." The "utilities" shared the following characteristics: "almost always a family background of deprivation and rejection, who are personally unstable and have no settled residence," and "mentally and educationally sub-normal" (1955:158). In addition, Banton depicted this group of women as thieves and liars who were known to steal the money and possessions of the male immigrants who housed them (159). Banton cited "someone living in the heart of the coloured quarter" who described nine of "the better known prostitutes": one of these was a "West Indian girl" with a day-job, who "makes no profit 
from men but likes different ones to sleep with"; two others were mixed race, with a white mother and a father of African descent; and one was mixed race, with a white mother and an Arab father. The description of the third woman in this list, "W," reveals how gender, sexual and psychological abnormality were linked with racial difference: "No chance from birth; born in Canada of a white mother and a coloured man. Mother was a legalized prostitute. W. goes with both sexes, is still young but very disillusioned with life and once attempted suicide; prefers whites" (Banton 1955:160).

In an exploration of a different theme, Sydney Collins commented positively upon "the arrival of coloured women" to Lancashire since white men became "reassured" when sexual competition was "allayed by the presence of coloured women"; white men became "more friendly towards coloured men" once they could develop friendships with "coloured girls" (137). In this scenario, black women are represented as useful to the improvement of relations between black and white men in addition to serving as “companions" for “coloured" men's "problems of adjustment." Sheila Patterson argued that black women brought "stability" (rather than "instability") and facilitated black male migrants' assimilation into white British society.

The presence of so many West Indian women, most of them obviously highly respectable, has not only helped to allay local apprehensions about the potential threat to respectable white women; it has also furthered the processes of accommodation on the migrant side. These women have helped to improve living standards and have brought a certain order and stability into migrant life (Patterson 1963:289). 
Black women, marriage, class and color hierarchies

Regarding black women's marriage prospects, Kenneth Little remarked that black women had to marry within their "colour" because even the "lightest skinned girls" would not be offered the opportunity to marry a white man. In contrast, black men had "wider opportunities and choice"; Little reported that "they [black men] deliberately seek out and marry, when they can, white girls in preference to girls of their own colour" (1948:139-140). In contrast, Sheila Patterson found that black women who married white men tended to be "lighter-coloured girls of some social standing who are fairly acceptable to the receiving [white] group." Also, Patterson found that these women "adapt themselves to their husband's environment" and the [white] man and his children are not "lost to or rejected by the group" in contrast to what typically occurred when white women married black men (284).

Within a section entitled "Ango-coloured wives," Sydney Collins wrote that it was not difficult for "coloured girls on Tyneside" to find husbands because there were so few of them. There was great competition among the girls of the highest social status, and their mothers discouraged them from associating with "coloured men of low social status." If "coloured" girls married white men they left the "coloured" community (58). Collins found that recent immigrants who married "Anglo-coloured" women experienced disappointment because they expected her to "behave like a coloured woman of his homeland" but she behaved more like "a white English woman" (61). 


\section{Final thoughts}

Since Ruth Glass clearly knew about the work of many of these other social scientists of race relations in the U.K., she would have read their descriptions of black women. Yet Ruth Glass did not comment upon, critique or include any of these common representations of black women as "illegitimate" mothers, and prostitutes, who lacked sexual morality. One possible explanation is that she maintained a focus on what she considered the legitimate realm of sociological study - the traditionally defined public sphere. However, Michael Banton was also a sociologist, and he discussed both white and black women's sexuality disparagingly within his studies of race relations. Social anthropology was the discipline that explicitly studied issues such as family life, sexuality, and child-rearing practices, so the fact that those scholars affiliated with Kenneth Little and his anthropological studies of race at the University of Edinburgh analyzed these themes is unsurprising; however their derision of black women's sexual patterns, family structures and parenting practices was not a universally adopted stance (as Ruth Landes demonstrated in her Brazil research) though it was a widespread set of theories espoused by social scientists across the African Diaspora.

It is possible that Ruth Glass explicitly chose not to engage in this type of vilification of black women. I do not know for certain why she omitted these tropes. But this fact distinguishes her writing from not only Ellen Hellmann, but also other "race relations" social scientists studying the same geographical region at the same time. Glass' approach was also different from Sydney Collins, who like Glass was an immigrant (Collins was Jamaican); yet Glass was a refugee who had been forced to immigrate from 
Germany because of the rise of Nazism. Perhaps Glass was also responding to her own experiences of sexualization as a woman who was "ferocious" and "cantankerous"; it is possible that she did not want to attach the same negative labels onto West Indian women migrants as she experienced for herself.

I wondered if her work on West Indian migrants was also unique in its utilization of analogies between anti-Semitism and anti-black racism. Michael Banton was the only other scholar (among the group of race-relations social scientists writing about "coloured" migrants to the U.K. analyzed in this chapter) who frequently referred to Jews and anti-Semitic sentiments in order to understand the experiences of "coloured" migrants (he used the word "Jew" 59 times in The Coloured Quarter, 1955). Perhaps this could be partially explained by the fact that his study (1955) was based in Stepney, where West Indian settlement occurred in traditionally Jewish neighborhoods in East London, especially because Jewish landlords were more likely than non-Jewish whites to rent to “coloured" tenants (Banton 1955:20, 90, 106-8). Additionally, in Banton's 1960 text White and Coloured, 29 out of the 46 mentions of the word "Jew" were placed within sections that discussed the unpublished work of two women also affiliated with the University of Edinburgh's Social Anthropology department: Sheila Webster and Violaine Junod.

One of the white girls that Sheila Webster interviewed at an "Oxbridge" residential women's college stated: "Marrying a Jew would be very much like marrying a 
black man. Just as different" (Banton 1960:142). Sheila Webster ${ }^{121}$ found that white girls would not realize that girls were Jewish "even though they may have a characteristically Jewish appearance" and would not treat Jewish girls with distaste as long as they did not present a source of competition for potential marriage partners for the elite white girls. If a Jewish girl presented competition, she was portrayed as "typically Jewish" (Banton 1960:139-40; Webster 1955). This is of course similar to Ruth Landes' letter to Ruth Benedict regarding her colleague Lipkind in Brazil; Landes found that his Jewishness was associated with all his "unlikeable" traits.

In the case of Violaine Junod, Banton utilized her findings that "coloured" elites resented "patronage" (such as statements like "isn't he good, for an African?") to craft a parallel with the writings of Jean Paul Sartre about the Jews in Nazi-occupied France who were forced to wear yellow stars. The French were then free to treat the Jews with either abuse or patronizing demonstrations of their French virtue. Either way, the Jews (like the "coloured" elites) had no choice and became "objects" for white men to prove their virtuousness (Banton 1960:154-56; Junod 1952).

Banton's use of both Webster's and Junod's studies, emphasized the interpersonal aspects of both anti-Semitism and racism, in the realm of social relations. Ruth Glass' incorporation of analogies between anti-Semitism and anti-black racism primarily related to legal actions, white racialist groups, survey findings and rhetorical analysis, rather than ethnographic observations of interactions between individuals that simultaneously

${ }^{121}$ Mica Nava (2013) notes that Sheila Webster married Uwe Kitzinger, a German Jewish refugee who became a political theorist (11). 
represented larger social patterns. This reflects her overall investment in utilizing empirical social science data collection to fuel policy changes and address ingrained ways of thinking about migrants that she found disturbing because of the ways that these rhetorical strategies followed Nazi-era thinking. 


\section{CHAPTER 6: DISCUSSION/CONCLUSION}

The events in Charlottesville, Virginia on August 11, 2017, highlighted the contemporary necessity of scrutinizing anti-Semitism in order to understand white supremacy and anti-black racism. The white nationalist march that night claimed to be a protest of the removal of a statue honoring Confederate general, Robert E. Lee from a city park (Spencer and Stolberg 2017). Commentators revealed their surprise to hear antiSemitic, Nazi-era chants such as "Jews will not replace us" at a white nationalist march that was expected to be anti-black (Glanton 2017). As Ruth Glass prophetically wrote in 1962, "Hidden minorities cannot rely on remaining hidden" because in times of "social stress" they can become re-stigmatized, as she explained was the case with Jews in Europe and Indians in Africa and the Caribbean (Glass 1989a:226).

Eric Ward (2017) emphasizes the importance of acknowledging "the centrality of anti-Semitism to White nationalist ideology" in order to fully comprehend the racism within our contemporary society (2). Ward explains that white nationalist thought, "positions Jews as the absolute other, the driving force of white dispossession - which means the other channels of its hatred cannot be intercepted without directly taking on anti-Semitism." Within this ideology, Jews are still the "arch-nemesis" of the "White race" because they are "diabolical evil" "manipulating the social order" through a "secret cabal" effecting radical social changes like LGBTQ and feminist rights, socialism, racial equality including the election of the first black president in the U.S., and even the rise in popularity of Islam (2). Thus, Ward articulates, "the notion that Jews long ago and 
uncontestably became White folks in the US - became, in effect, post-racial - is a myth that we must dispel" (Ward 2017:3). ${ }^{122}$

My research intervenes in the silence about anti-Semitism as a central aspect of white supremacy, but also analyzes how European Jews in diaspora were in some cases conditionally able to pass into whiteness and how certain groups of Jews asserted their own whiteness in relation to their representations of blackness. Jewish social scientists have often been portrayed as (1) "marginal intellectuals" who necessarily applied their experiences of anti-Semitism to their anti-racist theorizing or (2) examining antiSemitism through "remote control" in order to understand their otherness through "the most other." My dissertation has complicated this picture by accentuating how the Jewish women in this study (1) did not necessarily link advocacy for Jews and Blacks (Ellen Hellmann) and (2) were explicit in their examination of Jews as a marginalized group, rather than operating through "remote control" and discussing racism with a hidden agenda to address anti-Semitism. All four women explicitly addressed anti-Semitism and Landes, Kuper and Glass often showed how anti-Semitism and anti-black racism were linked and expressed by the same individuals and groups. However, it is too simplistic to argue that Jewish social scientists always acted as "marginal intellectuals" who were necessarily always anti-racist because (1) Ellen Hellmann proves this generalization to be untrue and (2) this ignores the ways that some Jewish women sometimes relied upon assimilation and conformism and were not always radical or revolutionary.

\footnotetext{
122 Thank you to Penny Rosenwasser, from the Jewish caucus of the NWSA, for this article recommendation.
} 
White supremacist views of concealed Jewish control and links to anti-racism and

communism

Depending upon the national context, Jews could become temporarily white or semi-white, but this position could easily shift based upon transracial associations, especially interracial relationships, which were linked with communist agitation, as Eric Ward articulates in the contemporary context. This association between Jews-blackscommunism can be seen in the cases of all four women in this study from 1903-1960. In 1951, Ellen Hellmann discussed the persistence of an anti-Semitic cartoon within the Afrikaner Party's literature, the "Hoggenheimer caricature," which emerged in 1903 and was reinvigorated in 1922, that linked Jewish mine owners' improved treatment of black workers with bolshevism. Ruth Landes engaged in romantic partnerships with men of color (like Edison Carneiro who was a leader in the Communist Party in Salvador, Bahia, Brazil). Even if she self-identified as white, she was oftentimes assigned to the racial category of non-white and marginalized in ways that were reminiscent of what occurred to black women anthropologists, like Zora Neale Hurston. In one of Hilda Kuper's short stories (1944), she depicted a racist and anti-Semitic guesthouse owner who associated anti-racist views with communism, and then proceeded to scold his son for drinking his coffee like a Jew. Ruth Glass (1960) revealed that Mosley's Union Movement (which was a "Keep Britain White" group) called its opponents both "Nigger lovers" and "Jews." Mosley's organization encouraged the proliferation of swastikas and anti-Semitic slogans on synagogues, and used terms such as "concealed Jewish control" in its newspaper. 
Thus, even during a period when Jews were "becoming white" there was still evidence that they were not seen as being white especially in relation to class-based politics.

\section{Jewish gendered internal colonization}

This dissertation has underscored the contradictions and tensions that Jews, and especially Jewish women faced, since Jewish women have often been glossed over in previous histories of Jewish social scientists. I have demonstrated how systems of internal colonization promote gendered and sexualized social conformism and how Jewish women have often been the targets or scapegoats for Jewish ambivalence regarding whiteness. Central European or German Jews (like Melville Herskovits) used assessments of "abnormal" gender and sexuality linked to lower-class status, to create internal minorities out of Eastern European Jewish women like Ruth Landes. However, "Western" Jews, like Ellen Hellmann, also perpetrated these value judgments on people of color, especially women.

Even Landes, who was a victim of this gendered internal colonization process, was not immune to replicating this practice by asserting her own whiteness and Western European-ness. She praised black women's leadership throughout the African Diaspora, expressed criticism of Edison Carneiro's snobbery toward black working-class people, and revealed horror that black people like Elmer Imes could demonstrate what she considered anti-Semitism. Yet she still struggled to come to terms with the fact that black people might consider her to be non-white and include her in the Negro Who's Who and that as a "semite" she belonged "in the same abstraction of the damned" as other Jews in the Brazilian context, even while she hid her Jewishness from her Brazilian colleagues. 
This evidence challenges the assumption that all Jews had already become white or that "choosing" whiteness meant that they were actually perceived as white by all others, including other Jews, black and white people, who perceived themselves to be more sophisticated, Westernized and subsequently, gender normative and sexually moral, than Jews of certain class and political orientations who engaged in interracial relationships (like Ruth Landes).

These contradictions and tensions between alliance or identification with other marginalized racial groups and disassociation from personal identification with those groups is the epitome of the experience of European Jewishness in diaspora. However, other racially marginalized groups similarly encounter these processes of ambivalence and disunity along class lines that are represented through measures of "aberrant" gender and sexuality performances. For example, both in the South African and British context, there were divisions within black communities between "deserving" or "respectable" women and those who were seen as low-class, deviant, and associated with prostitution and criminal activity. In South Africa, I demonstrated how these divisions also applied within the Jewish community (in 1907) between the more established "Western" Jews who led the Jewish Board of Deputies, and the more recent Eastern European Jewish women migrants who were linked with prostitution and illegal liquor trading, just as black African women would be by the time Ellen Hellmann and Hilda Kuper began their research about the effects of liquor laws on black immigrant women with Winifred Hoernlé and the SAIRR in 1931. Thus, this dissertation utilized Jewishness in order to disrupt conceptions of uniform or unified racial identity and assignment, especially 
through an analysis of how gender and sexuality "deviance" were used to signify lowclass status and racial otherness within racial groups.

\section{Questioning canonical theoretical dichotomies}

One of my primary goals in this dissertation was to express how Jewish women social scientists theorized uniquely, informed by their Jewishness, in its gendered and racialized aspects, and their transracial and transnational networks. I wanted to challenge what counts as "canonical" by including the theories of women who are not typically included in sociological or anthropological canons, revealing how their theories were a result of their Jewish subjectivities and epistemological networks, and underscoring how these theories reconfigured canonical splits between private/public, social/structure, nonWest/West, and non-modern/modern.

"Personal" experiences of gendered and racialized Jewishness deeply affected how these four Jewish women social scientists understood the composition of their "public" social world. In addition, "public" divisions are also necessarily inflected by the intersections of supposedly "social" or "private" experiences of gender, sexuality and race. For example, Ellen Hellmann's German Jewish father made her feel ugly in a family of otherwise "lovely" women and called her a "communist." At the age of six, she was physically humiliated in the playground at school for being German. These "private" or "personal" experiences of shame deeply influenced her later "public" theories. She would later critique what she considered to be the overly strict parenting style of African migrant parents to the cities which she felt exacerbated juvenile delinquency. She also joined the Zionist Socialists, but was known as "de yeke" - the German one - an outsider 
in an organization of mostly Eastern European Jews, and affirmed her superior values and capabilities as a "Western Jew." It is possible that she internalized and then reproduced the gendered critiques she experienced from her father, becoming critical of black women as her father had been critical of her.

Because of Ruth Landes' familial ("personal" or "private") collaboration with black activist intellectuals, she engaged in interracial relationships including her second marriage with a Mexican-American activist journalist, Ignacio López, and a life-long research relationship and friendship with Edison Carneiro. These "personal" experiences deeply affected her "public" career trajectory. Melville Herskovits' public disparagement of her research methodologies and scholarly knowledge, was of course intricately interwoven with his censure of her "personal" interracial relationship choices and "aberrant" sexuality but also of his own "personal" desire to advance his "public" position in the discipline of anthropology and his belonging in whiteness as a Central European Jewish elite male.

Both Ruth Landes and Hilda Kuper challenged the supposed split between modern/non-modern through their critiques of the assumed "liberal" qualities of modernity. They both theorized how modernization or Westernization actually weakened women's positions and created alienation rather than security. In Landes' case, she not only depicted this phenomenon among the Candomblé women she observed at the "modern" social dance, but also for herself and other women of her social class, since her movements and body were restricted and surveilled by men, including Edison. Hilda Kuper challenged the assumption that "modernity" was superior through her contention that male "chauvinism" became worse with Westernization, in defiance of colonial 
authorities' supposition that Swazi men oppressed Swazi women. Yet she complicated the modern/non-modern split even more when she demonstrated through her female protagonists how hard Swazi laws were on women. Though she never stated this explicitly, it was as if she spotlighted that neither "modernity" nor "tradition"//"nonmodernity" held the solution to the oppression of women, since both were to blame. The modern/non-modern split presupposes that gender norms and sexual practices determine a society's level of modernity. However, Kuper revealed that this invented dichotomy actually meant nothing for women's treatment, since women were punished within both societal formulations.

Hilda also confronted both personally and publically the West/non-West contradiction by becoming a Swazi citizen, calling herself "more Swazi than American," and identifying more with traditionally-dressed Swazi men than with a mixed-race Swazi-British woman (Eliza) she met on the road (as depicted in the story "The Lord Will Provide," 1947). At the same time, her students called her "more British than the British" (Dawn Chatty) and "Jewish, British and African” (David Kuby). If such a separation as West and non-West exists, how can one person embody both (all) sides at once? Similarly, Ruth Landes identified with her Afro-Brazilian Candomblé informants Martiniano and Menininha, exclaiming that she had "become African in her prejudices" and agreed with them that the Candomblé women at the "modern" social dance were becoming in-authentic and "losing themselves." Simultaneously, she critiqued Edison, who was also Afro-Brazilian but who was "mulato," "aristocratic" and from a wellknown family because of his "patronizing and distasteful" demeanor toward the Candomblé women at the "modern" dance whom he portrayed as primitive, "leaving 
Africa for the western world and the twentieth century." Thus, she associated herself with African (non-Western) epistemologies, and placed those values as superior to those of Edison who likely perceived himself to be "Western" and "modern" and looked down upon the "primitive" and "non-Western" Candomblé women.

Ruth Glass also challenged these dichotomies between modern/non-modern, and West/non-West when she created analogies between racialism toward black West Indian migrants to London in the 1950s and "60s in the form of "colour calculus" and the "final solution" enacted by the Nazis in the 1930s and "40s. Rather than portraying black immigrants to cities like London as the "problem" of urbanization and modernization, she emphasized that it was the "native" white Londoners (the supposedly "modern" and "Westernized" citizens) who were the problem. Thus, she questioned the assumption that "native" Londoners were more "modern" or "Western" than West Indian migrants.

Each of these women witnessed the effects of anti-Semitism, that made Jews who may have felt as if they were Western and modern, into non-moderns and non-Western others. This likely influenced the way they viewed and acted on these conceptual dichotomies, causing them to simultaneously identify with both sides and to question the legitimacy of the divisions. In Hilda Kuper's 1944 story, a guesthouse owner sequentially claimed that "kaffir bites are poisonous" and "only Jews drink coffee like that." In 1938, Ruth Landes heard "Heil Hitler!" and talk of Jews being removed from Germany on the same boat trip as she heard "I feel for you, stuck up there in Bahia with all those blacks!" Ruth Glass was horrified to hear about British government proposals to either expel native-born "coloured" people or to reduce them to second-class citizenship status, which 
of course reminded her of what happened to Jews - "the final solution" - in her home country, Germany.

Landes perfectly demonstrated the way that Jews who might have thought of themselves as part of the white group, became shocked to discover that actually whites thought of Jews as "others" and she struggled to accept the fact that Jews were in fact considered part of the "othered" group: "neither [Dona Heloisa Torres] nor anyone else imagines that I too am a 'semite' and the effect on me has worn so deep that I have to remind myself as they talk, including me with them and excluding the 'others,' that I too belong in the strange abstraction of the damned."

Ellen Hellmann was the only woman in this study who did not seem to have personally experienced anti-Semitism, though she said she became involved in Jewish communal organizing because of the "guilt" she felt with the rise of Nazism. Though, there was a rise in anti-Semitism and anti-communism in the 1930s in South Africa, she explicitly stated that she had not experienced anti-Semitism personally, but only "generally." Also because of her positionality as a "Western Jew" and her perceptions of German Jewish superiority to "Eastern Jews" and non-Europeans, she did not seem to have experienced Jewishness in the same way that the other three women in this study did. 
Argument was the spice of life: A closer examination of the diverse positionalities and perspectives of Jewish women social scientists in relation to their theories about black women's sexuality

My central critiques of histories of Jewish communal conflicts, Jewish social scientists and Jewish involvement in anti-black racism movements, are that these histories tend to posit that (1) familial origin point in Europe (either Central/Western or Eastern) alone is enough to explain differences in class and political orientations and (2) Jewish social scientists were either "radical"/anti-racist or "colonizing"/assimilationist in their orientations toward black populations. These explanations for European Jewish difference are too clear-cut to fully explain the complex divergences between Jewish women social scientists' theorizing about black women's sexuality in the African diaspora. One of my central goals was to demonstrate how each woman's Jewish subjectivity was relational in that it was interconnected and dependent upon how she understood blackness and black women in her research. In the following five sections I summarize my significant findings for five areas of influence on Jewish women's theorizing: (1) Jewish family background; (2) transnational networks; (3) political and institutional affiliations; (4) marital/romantic relationships; and (5) transracial networks.

\section{Influence 1: Jewish family background}

First, I analyzed the familial origin points, class status, occupational histories, political backgrounds and immigration histories of each of the women (Table 1). I did this because I wanted to intervene in the tendency among histories of women social scientists who were Jewish, to either gloss over, ignore or de-emphasize the gendered and 
racialized Jewishness of their theorizing or to romanticize and simplify the influence of their Jewishness on their relationships with communities of color. In this and subsequent tables, the names of each woman are represented with her first and last initial.

\begin{tabular}{|c|c|c|c|c|c|}
\hline \multicolumn{6}{|c|}{ Parental info } \\
\hline Factor & & EH & RL & HK & RG \\
\hline \multirow{2}{*}{$\begin{array}{l}\text { Parental } \\
\text { country of }\end{array}$} & Father & \multirow[t]{2}{*}{ Germany } & \multirow{2}{*}{ Russia } & \begin{tabular}{|l|} 
Lithuania \\
\end{tabular} & \multirow{2}{*}{ Germany } \\
\hline & Mother & & & Austria & \\
\hline \multirow[t]{2}{*}{$\begin{array}{l}\text { Parental class } \\
\text { (occupational) } \\
\text { background }\end{array}$} & Father & $\begin{array}{l}\text { poor, became } \\
\text { wealthy trader }\end{array}$ & $\begin{array}{l}\text { poor, sweatshop } \\
\text { worker, became } \\
\text { labor organizer }\end{array}$ & poor trader & \begin{tabular}{|l} 
"factory \\
burner" and \\
from a line of \\
rabbis \\
\end{tabular} \\
\hline & Mother & \begin{tabular}{|l} 
petit- \\
bourgeoisie
\end{tabular} & $\begin{array}{l}\text { well-off and } \\
\text { educated }\end{array}$ & well-off & unknown \\
\hline \multirow[t]{2}{*}{$\begin{array}{l}\text { Parental } \\
\text { political } \\
\text { orientation }\end{array}$} & Father & $\begin{array}{l}\text { critiqued EH for } \\
\text { being a } \\
\text { "communist" }\end{array}$ & \begin{tabular}{|l} 
socialist Yiddish \\
joumalist, trade \\
union organizer, \\
Labor Zionist
\end{tabular} & $\begin{array}{l}\text { proud to fight } \\
\text { with British in } \\
\text { East Africa in } \\
\text { WWI }\end{array}$ & \multirow[t]{2}{*}{ unknown } \\
\hline & Mother & unknown & $\begin{array}{l}\text { Pioneer Women's } \\
\text { Organization } \\
\text { (Labor Palestine) }\end{array}$ & $\begin{array}{l}\text { brother fought on } \\
\text { German side } \\
\text { during WWI }\end{array}$ & \\
\hline $\begin{array}{l}\text { Parental } \\
\text { immigration to: }\end{array}$ & Both parents & $\begin{array}{l}\text { Johannesburg, } \\
\text { South Africa }\end{array}$ & $\begin{array}{l}\text { New York City, } \\
\text { U.S. }\end{array}$ & $\begin{array}{l}\text { Bulawayo, } \\
\text { Rhodesia, then } \\
\text { Johannesburg, } \\
\text { South Africa } \\
\text { after father's } \\
\text { death } \\
\end{array}$ & $\mathrm{N} / \mathrm{A}$ \\
\hline \multirow{2}{*}{$\begin{array}{l}\text { Year of } \\
\text { immigration }\end{array}$} & Father & 1894 & 1888 & unknown & \multirow[t]{2}{*}{$\mathrm{N} / \mathrm{A}$} \\
\hline & Mother & 1906 & 1900 & \begin{tabular}{|l} 
Joburg - 1917 \\
\end{tabular} & \\
\hline
\end{tabular}

Table 1: Parental information for each of the four women: country of origin, class, political orientation, immigration history

As evidenced in this table and from the previous chapters, though Ellen Hellmann and Ruth Glass both had German Jewish parents, their families had different immigration histories, since Hellmann's parents immigrated to South Africa in the late $19^{\text {th }}$ century/early $20^{\text {th }}$ century, while Glass' parents did not leave Germany, and it was Glass herself who was a refugee to England because of the rise of Nazism. Also, the South African and British racial contexts were quite divergent as has already been discussed. Though both Ellen's and Hilda's fathers were poor traders, Hilda's father was from 
Lithuania (Eastern Europe) and died when Hilda was only six years old, causing the family to have to move to Johannesburg, where Hilda's uncle also died, again leaving her family in financial distress. Landes' father was also poor; he worked in a sweatshop upon arrival in New York City. However, he ended up being a labor organizer, while Hellmann's father became so wealthy that he built a mansion in Houghton, Johannesburg. Thus, neither country of origin nor initial class background is enough to establish each woman's eventual social location and theorizing. Another layer of analysis that could help to explain their social theorizing is to explore their relationships with each parent (Table 2).

\begin{tabular}{|c|c|c|c|c|c|}
\hline Factor & & EH & RL & HK & RG \\
\hline \multirow[t]{2}{*}{$\begin{array}{l}\text { Relationship to } \\
\text { parents }\end{array}$} & Father & $\begin{array}{l}\text { her father } \\
\text { emotionally } \\
\text { abused her, } \\
\text { making her feel } \\
\text { like an "ugly } \\
\text { duckling" }\end{array}$ & $\begin{array}{l}\text { she called her } \\
\text { father "genteel } \\
\text { and gracious" and } \\
\text { chose partners } \\
\text { with similar } \\
\text { political beliefs }\end{array}$ & $\begin{array}{l}\text { her father died } \\
\text { when she was } \\
\text { six, he liked } \\
\text { going for hikes } \\
\text { in nature }\end{array}$ & \multirow[b]{2}{*}{$\begin{array}{l}\text { her parents } \\
\text { phoned her } \\
\text { while she was in } \\
\text { Prague to tell } \\
\text { her not to return } \\
\text { to Germany }\end{array}$} \\
\hline & Mother & $\begin{array}{l}\text { EH and Bodo } \\
\text { Koch moved } \\
\text { into the } \\
\text { "parental } \\
\text { mansion" after } \\
\text { her father's } \\
\text { death in } 1956 \text { so } \\
\text { her mother } \\
\text { could continue } \\
\text { living there }\end{array}$ & $\begin{array}{l}\text { criticized Ruth's } \\
\text { appearance and } \\
\text { relationship } \\
\text { choices }\end{array}$ & $\begin{array}{l}\text { she remembered } \\
\text { her mother } \\
\text { speaking and } \\
\text { singing to the } \\
\text { children in } \\
\text { German with a } \\
\text { Viennese dialect, } \\
\text { her mother } \\
\text { viewed Hilda's } \\
\text { uncle as a } \\
\text { Viennese fairy- } \\
\text { tale prince }\end{array}$ & \\
\hline
\end{tabular}

Table 2. Relationship between each woman and her parents

Though Ellen grew up wealthy in Johannesburg, she had a strained relationship with her father who preferred her younger sister. In contrast, Ruth Landes deeply admired her father who worked as a union organizer, calling him "genteel and gracious," and found romantic partners who mirrored his political stances. However, Landes' mother was hypercritical of Ruth's appearance, just as Hellmann's father was of hers. Landes 
theorized that Jewish mothers perceived their daughters as competition within a patriarchal family structure and she subsequently sought out women who "did not care about being dainty." It is possible that Hellmann reproduced the patriarchal critiques she received from her father by becoming hypercritical of black women in Johannesburg. Hilda emphasized the differences between her parents, since her father was a soldier fighting for the British, while her mother's brother fought on the German side during WWI. She felt torn between their differing personalities; her father liked hiking in nature, while her mother preferred telling romantic tales about her brother, whom her mother depicted as if he were Viennese royalty. Throughout her life, Kuper was in-between worlds, accustomed to blending belief systems and cultures. Yet, she was often connected to the elites of each of the cultures she studied, as was true in Swaziland and in Durban, Natal perhaps showing the life-long influence of her mother's romanticism regarding Viennese royalty. She also seemed to seek out father-like figures (Malinowski and Sobhuza) perhaps because she lost her father at such a young age. In the future, I would like to further investigate how the emotional tone and gendered nature of relationships between Jewish women theorists and their parents (including evidence of internalized colonization in the form of gendered critiques of physical appearance), in addition to factors such as parental origin, class and political orientation, influenced each woman's eventual theoretical positions.

\section{Influence 2: Transnational networks}

A second important influence on Jewish women's theorizing and subjectivities was the amount and nature of transnational migrations (Table 3) and fieldwork (Table 4). 
Transnational relationships and "connected histories" mattered to me because I wished to explore how national boundaries were often crossed through social science fieldwork and how these women challenged the existence of conceptual and physical boundaries between nations and between West/non-West. I also wanted to underscore the ways that theory creation was not centered in the U.S. or Western Europe because it was a result of these transnational collaborations. Ruth Glass was a German refugee and lived in six different countries between 1932-1942 including Germany, England, the U.S., Czech Republic, Switzerland and Austria. She also lived in India for two months every year after 1958. Hilda Kuper was forced to leave South Africa in 1961 and seek refuge in Los Angeles, because of police surveillance. Before that she had already lived and/or conducted research in Rhodesia, two different provinces in South Africa, Swaziland, the U.S. and England.

\begin{tabular}{|l|l|l|l|l|}
\hline Self-information & EH & RL & HK & RG \\
\hline Factor & $\begin{array}{l}\text { Johannesburg, South } \\
\text { Africa }\end{array}$ & New York City, U.S. & Bulawayo, Rhodesia & Berlin, Germany \\
\hline $\begin{array}{l}\text { Place of birth } \\
\begin{array}{l}\text { Transnational } \\
\text { immigration } \\
\text { (permanent change } \\
\text { of residence) to } \\
\text { and year }\end{array}\end{array}$ & n/a & $\begin{array}{l}\text { Hamilton, Ontario, } \\
\text { Canada -1965 }\end{array}$ & $\begin{array}{l}\text { Los Angeles, } \\
\text { California, USA -1961 }\end{array}$ & $\begin{array}{l}\text { London, U.K. - "mid } \\
\text { 1930s" }\end{array}$ \\
\hline $\begin{array}{l}\text { Temporary changes } \\
\text { of residence and } \\
\text { time periods }\end{array}$ & n/a & $\begin{array}{l}\text { Los Angeles, } \\
\text { California, USA 1946 } \\
7,1957-1965 ; \\
\text { Edinburgh, UK 1951- } \\
1952, \text { Kansas 1957, } \\
1964\end{array}$ & $\begin{array}{l}\text { Coventry, England } \\
1947-1952, \\
\text { Manchester, England } \\
1958 ; \text { Durban, Natal } \\
1952-1958,1959-1961\end{array}$ & $\begin{array}{l}\text { Wing, Austria 1932-"mid- } \\
\text { 1930s"; New York City } \\
1940-1942\end{array}$ \\
\hline
\end{tabular}

Table 3. Self- information regarding birth place, and transnational immigration 
New York was Landes' home-base, but she also lived in other states like California and Kansas, and in 1965 (at age 57) took a position in Hamilton, Ontario in Canada. She conducted fieldwork in Minnesota, Tennessee, Louisiana (in the U.S.), Salvador, Bahia, Brazil, and South Africa, in addition to other international locations. The fact that Landes, Kuper and Glass lived in so many different countries, that Kuper and Glass were refugees/exiles, and that Landes researched such diverse cultural groups, was likely influential in their less judgmental views of women of color.

\begin{tabular}{|c|c|c|c|c|}
\hline Factor & EH & RL & HK & RG \\
\hline $\begin{array}{l}\text { Ficldwork sites, } \\
\text { groups studied }\end{array}$ & $\begin{array}{l}\text { Johannesburg, South Africa: rural- } \\
\text { urban migration; Umtata, Transkei: } \\
\text { agriculture/farming; Congo, French } \\
\text { Equatorial Africa, the Caribbean } \\
\text { and New York on behalf of J.D. } \\
\text { Rheinallt Jones; Nairobi, Kenya } \\
\text { with Rheinallt Jones; Abidjan, } \\
\text { Ivory Coast: UNESCO conference } \\
\text { on urbanization }\end{array}$ & $\begin{array}{l}\text { Blacks Jews in Harlem, NYC; Ojibwa in } \\
\text { Emo, Manitou Rapids, Ontario, Canada; } \\
\text { Santee Dakota in Red Wing, Minnesota; } \\
\text { Potawatomi in Mayetta, Kansas; Black- } \\
\text { white relations at Fisk University and in } \\
\text { the U.K.; Candomblé in Salvador, Bahia, } \\
\text { Brazil; Mexican Americans in Los } \\
\text { Angeles; multi-lingualism in South } \\
\text { Africa }\end{array}$ & $\begin{array}{l}\text { Swaziland; black } \\
\text { families in } \\
\text { Johannesburg and } \\
\text { Indians in Durban, } \\
\text { South Africa }\end{array}$ & $\begin{array}{l}\text { youth unemployment, } \\
\text { Berlin; West Indian } \\
\text { migrants and city planning } \\
\text { in London, UK; } \\
\text { development projects in } \\
\text { India }\end{array}$ \\
\hline
\end{tabular}

Table 4. Fieldwork sites, groups studied

Ellen Hellmann was the only woman in this study who centered her primary fieldwork and writings on one geographic location and topic - urbanization in Johannesburg, where she lived for her entire life. Though Hellmann traveled as part of her work at SAIRR (for example her trip in 1944-45 to the Congo, French Equatorial Africa, the Caribbean and New York on behalf of J.D. Rheinallt Jones in addition to other transnational trips to Nairobi, Kenya in 1947 with Rheinallt Jones, and Abidjan, Ivory Coast in September-October 1954 for an UNESCO conference on urbanization), she did not experience forced migration or residential instability. 


\section{Influence 3: Political and institutional affiliations}

\begin{tabular}{|c|c|c|c|c|}
\hline Factor & EH & RL & HK & RG \\
\hline $\begin{array}{l}\text { political } \\
\text { affiliations }\end{array}$ & $\begin{array}{l}\text { leader in Progressive Party } \\
\text { (qualified franchise) }\end{array}$ & $\begin{array}{l}\text { affiliated with communism/socialism } \\
\text { because of her father, her ties with } \\
\text { Columbia University and Edison } \\
\text { Carneiro }\end{array}$ & $\begin{array}{l}\text { Founder of Liberal Party } \\
\text { (one man, one vote), ties } \\
\text { with the Indian intellectual } \\
\text { elite in Durban, not a } \\
\text { Marxist though had been } \\
\text { interested in Marxism at } \\
\text { LSE }\end{array}$ & $\begin{array}{l}\text { "non-doctrinaire" Marxist, } \\
\text { "a woman of leftish } \\
\text { sympathies" but not "those } \\
\text { of the Communist Parties"; } \\
\text { she worked for a radical } \\
\text { paper as a student in Berlin }\end{array}$ \\
\hline $\begin{array}{l}\text { Institutional } \\
\text { affiliations }\end{array}$ & $\begin{array}{l}\text { Wits (1929-1938), SAIRR (1932- } \\
\text { 1974), Zionist Socialists (1930s- } \\
\text { 1948), Johannesburg Joint Council } \\
\text { of Europeans and Africans (1940- } \\
\text { 1948), Jewish Board of Deputies } \\
(1940-1950) \text {, Jan Hofmeyr School } \\
\text { of Social Work (1955) }\end{array}$ & \begin{tabular}{|l|} 
NYU (1928), Columbia University \\
(1929-1937), Fisk University (1937- \\
1938), FEPC (1941-1945), University of \\
Edinburgh (1951-1952), University of \\
Kansas (1957, 1964), Consultant at \\
various California agencies: Department \\
of Social Work, Bureau of Mental \\
Hygiene, Department of Education, \\
Public Health Department, San \\
Francisco Police Department (1957- \\
1965), Claremont Graduate School \\
(1959-1962), McMaster University \\
(1965-1991)
\end{tabular} & $\begin{array}{l}\text { Wits (1927-1932, 1941- } \\
\text { 1946), SAIRR (1931- } \\
\text { 1932), LSE (1932-1942), } \\
\text { Joint Council and Jewish } \\
\text { Board of Deputies } \\
\text { (1945/6), Institute of } \\
\text { Community and Family } \\
\text { Health, Durban (1953- } \\
\text { 1957), University of } \\
\text { Manchester (1958), } \\
\text { University of Natal (1959- } \\
\text { 1961), UCLA (1963-1977) }\end{array}$ & $\begin{array}{l}\text { University of Berlin } \\
\text { (1932), University of } \\
\text { Geneva, LSE (mid-1930s), } \\
\text { Bureau of Applied Social } \\
\text { Research, Columbia } \\
\text { University (1940-1942), } \\
\text { Association for Planning } \\
\text { and Regional } \\
\text { Reconstruction (1943), } \\
\text { Political and Economic } \\
\text { Planning (1947-1948) UCL } \\
\text { Centre Urban Studies } \\
\text { (1950-1983) }\end{array}$ \\
\hline $\begin{array}{l}\text { Disciplinary } \\
\text { training }\end{array}$ & Urban anthropology & $\begin{array}{l}\text { Sociology B.A., M.S.W., PhD } \\
\text { Anthropology }\end{array}$ & Anthropology & Sociology, urban planning \\
\hline Graduate advisors & $\begin{array}{l}\text { Winifred Hoernle; short period of } \\
\text { time with Malinowski }\end{array}$ & Ruth Benedict, Franz Boas & $\begin{array}{l}\text { Winifred Hoernlé, } \\
\text { Bronislaw Malinowski }\end{array}$ & $\begin{array}{l}\text { Paul Lazarsfeld at } \\
\text { Columbia }\end{array}$ \\
\hline
\end{tabular}

Table 5. Political and institutional affiliations, disciplinary training

Other sources of difference between the women in this study were their political orientations, the number and type of institutional affiliations (a measure of institutional stability/instability), and their disciplinary training (whether sociology or anthropology).

Table 5 organizes this information. Ruth Landes and Ruth Glass were the most "left."

Landes was associated with communism because of her involvement with Carneiro and socialism through her father, though she did not necessarily explicitly self-identify this way. Ruth Glass was a leftist and Marxist, though never a communist. She became disenchanted even with the Labour Party for its concessions regarding "coloured" immigration and she felt that there was no place for "radicals" (like herself) in British 
politics. Though Hilda was not a Marxist, she was interested in Marxism during her time at the London School of Economics. Ellen Hellmann was clearly the most divergent from the other women's politics because of her affiliation and leadership in the Progressive Party which advocated for the qualified franchise.

Ruth Landes had the highest number of different institutional affiliations (27), not all of which are included in the above table, while Hellmann had the fewest (6). Hilda Kuper had nine, four of which were facilitated either by her relationship with her husband, Leo Kuper (a well-respected sociologist) or her former boyfriend Max Gluckman (a famous anthropologist). Ruth Glass had ten institutional affiliations (not all are listed in the above table), five of which were in applied sociological research and town/urban planning. Her husband, David Glass, gave prominence and longevity to her Centre for Urban Studies. Hilda was the only woman in this study who was primarily affiliated with academic institutions and anthropology departments. Ellen Hellmann worked with a research (and explicitly non-activist) organization, the South African Institute of Race Relations, as well as the Council of Europeans and Africans which lobbied city agencies for basic social services for "Africans"/"non-Europeans." She also worked for Jewish communal organizations like the Jewish Board of Deputies and the Zionist Socialists. Hellmann recruited Kuper to be a member of the Joint Council and the Jewish Board of Deputies during the time that the Kupers lived in Johannesburg in 19456, before they left for Leo's graduate schooling in the U.S. Landes worked as a researcher for the American Jewish Congress from 1948-1951, not nearly as long as Hellmann's Jewish communal involvement. Both Landes and Glass worked for governmental agencies. Glass primarily worked with five urban planning organizations, while Landes 
worked with nine different agencies relating to a hugely diverse range of social issues including: racial discrimination in employment, social work, mental health, geriatrics, education, public health and policing.

Landes had graduate training in both sociology (social work) and anthropology, while the other women had training only in one or the other. Ruth Glass' training was in sociology and urban planning. Both Kuper and Hellmann received training at the University of Witwatersrand with Winifred Hoernlé, but Kuper continued her anthropological training with Malinowski at the London School of Economics and then in Swaziland (Hellmann studied with Malinowski for only a brief period in the fall of 1934). Hilda Kuper had a more "traditional" anthropological career, probably because of her husband's academic ties, which enabled most of Kuper's academic placements, though she did suffer from nepotism rules which prevented her from receiving permanent posts in departments where her husband worked. In contrast, Hellmann, Landes and Glass had non-traditional careers, more like what women social scientists of their age cohort typically experienced, since women were often unable to obtain tenure-track and stable academic positions until the mid-1960s. While Hellmann's forty-year affiliation with a non-academic institution, SAIRR, was explicitly focused on non-activist oriented research, Glass adamantly believed that research must be in the service of policy change that was socially just. She ran a research-policy organization, the Centre for Urban Studies for over thirty years, though this organization was much less institutionally stable than the SAIRR, likely because of Glass' refusal to follow gendered norms that would require her to compromise or cooperate with men. Like Glass, Landes was committed to making anthropology applicable to pressing social justice issues. However, the breadth of 
Landes' interests went beyond one field (urban planning) to improving racialized social interactions in fields as diverse as education and policing. As has already been discussed, Landes was the most institutionally unstable out of all the women in this study, which was linked to her assumed political orientations, her theorizing and her romantic relationships.

\section{Influence 4: Marital/romantic relationships}

\begin{tabular}{|c|c|c|c|c|}
\hline \multicolumn{5}{|c|}{ Romantic Partners' information } \\
\hline Factor & EH & RL & HK & RG \\
\hline marital status & \begin{tabular}{|l|} 
married twice; Joseph \\
Hellmann 1932-1941 \\
(Suicide); Bodo Koch \\
1946/1948-1982 (her \\
death)
\end{tabular} & $\begin{array}{l}\text { married twice; Victor } \\
\text { Landes 1929-1931/1935 } \\
\text { (divorce); Ignacio López } \\
\text { 1955-1964/1965/1970 } \\
\text { (divorce); relationship with } \\
\text { Edison Carneiro 1938-1939 } \\
\text { and life-long friendship } \\
\text { with some breaks, until } \\
1972 \text { (Edison's death) } \\
\end{array}$ & $\begin{array}{l}\text { dated Max Gluckman } \\
\text { (1926); engaged to Isaac } \\
\text { Schapera (1933); married } \\
\text { Leo Kuper (1935-1992 - } \\
\text { Hilda's death) }\end{array}$ & $\begin{array}{l}\text { married twice: Henry Durant } \\
\text { 1935-1941 (divorce); David } \\
\text { Glass 1942-1978 (David's } \\
\text { death) }\end{array}$ \\
\hline $\begin{array}{l}\text { partner's } \\
\text { ethnic/racial } \\
\text { identity }\end{array}$ & \begin{tabular}{|l|} 
JH: Eastern European \\
(Lithuanian) Jew; \\
BK: German Jewish \\
refugee
\end{tabular} & $\begin{array}{l}\text { VL: family friend (Jewish); } \\
\text { IL: Mexican American; EC: } \\
\text { Afro-Brazilian }\end{array}$ & $\begin{array}{l}\text { all three men were } \\
\text { Eastern European Jews }\end{array}$ & $\begin{array}{l}\text { HD: white; DG: Eastern } \\
\text { European Jew }\end{array}$ \\
\hline $\begin{array}{l}\text { partner's } \\
\text { class } \\
\text { background }\end{array}$ & $\begin{array}{l}\text { Bodo received an } \\
\text { "expensive and } \\
\text { thorough medical } \\
\text { training" } \\
\end{array}$ & $\begin{array}{l}\text { VL: unknown; IL: Ignacio's } \\
\text { father was a Protestant } \\
\text { minister; EC: well-known } \\
\text { family in Salvador } \\
\end{array}$ & unknown & $\begin{array}{l}\text { HD: unknown; DG: working- } \\
\text { class in East London }\end{array}$ \\
\hline $\begin{array}{l}\text { partner's } \\
\text { occupation }\end{array}$ & $\begin{array}{l}\text { JH: lawyer; BK: } \\
\text { surgeon }\end{array}$ & $\begin{array}{l}\text { VL: unknown; IL: activist } \\
\text { joumalist; EC: journalist, } \\
\text { Afro-Brazilian studies } \\
\text { scholar and folklorist }\end{array}$ & $\begin{array}{l}\text { Leo was a criminal } \\
\text { lawyer and then a } \\
\text { sociologist of genocide }\end{array}$ & $\begin{array}{l}\text { HD:"pioneer" of public } \\
\text { opinion surveys like the } \\
\text { Gallup Poll; DG: } \\
\text { demographer, chair of } \\
\text { Sociology at LSE }\end{array}$ \\
\hline $\begin{array}{l}\text { partner's } \\
\text { political } \\
\text { affiliation }\end{array}$ & $\begin{array}{l}\text { BK: served "poor } \\
\text { community" of } \\
\text { mostly Indians as a } \\
\text { general practitioner, } \\
\text { perhaps this shaped } \\
\text { his political views } \\
\end{array}$ & $\begin{array}{l}\text { VL: unknown; IL: fought } \\
\text { discrimination against } \\
\text { Mexican Americans in So } \\
\text { Cal; EC: leader in } \\
\text { Communist Party in } \\
\text { Salvador, Bahia } \\
\end{array}$ & $\begin{array}{l}\text { Leo was a Liberal Party } \\
\text { founder, arrested for anti- } \\
\text { apartheid protests with } \\
\text { ANC-Indian Congress }\end{array}$ & David was a socialist \\
\hline $\begin{array}{l}\text { partner's } \\
\text { Jewish } \\
\text { subjectivity } \\
\text { (if } \\
\text { applicable) }\end{array}$ & \begin{tabular}{|l|} 
BK: victim of Nazi \\
persecution, \\
imprisoned and \\
tortured, his Jewish \\
mother was killed by \\
Nazis, his father \\
reduced to 90 lbs
\end{tabular} & $\begin{array}{l}\text { VL: unknown; other } \\
\text { partners n/a }\end{array}$ & $\begin{array}{l}\text { Leo was raised Orthodox } \\
\text { but did not want to be } \\
\text { governed by it, } \\
\text { experienced anti- } \\
\text { Semitism and "Jew- } \\
\text { baiting" in Chapel Hill }\end{array}$ & unknown \\
\hline
\end{tabular}

Table 6. Marital and other romantic relationships: marital status, class, race, politics and Jewish subjectivity of partners 
Table 6 illustrates the details of each woman's romantic relationship(s). Hilda Kuper was the only woman in this study who was only married once. Both Ruth Glass and Ruth Landes were divorced; Landes was twice divorced. Ellen Hellmann's first husband committed suicide, but the effect this had on her is unknown. She did say that one of the troubles with this marriage was that he was an "Eastern Jew" and that this was "not good." Both Ellen and Hilda were survived by their husbands, while David Glass died before Ruth Glass did, which caused her to fall into a depression. Ellen and Ruth Glass were without husbands for fairly short periods of time. Ellen's first husband committed suicide in 1941, and she met Bodo Koch in 1946. Ruth Glass divorced Durant in 1941 and married David Glass in 1942. All the women except Ruth Landes were married during their thirties and forties. Hilda was married from the time she was 24 until she died. Ruth Glass was married from age 23-29, and then again from age 30-66 when David Glass died. Ellen was married from age 24-33, and then from age 38 until her death. In contrast, Ruth Landes married early at age 21, but was divorced by either 23 or 27. She did not marry again until 47 , and then was separated by age 57 . Thus, Landes lived the majority of her adult life as a divorced/unmarried woman. I argue that this significantly impacted her theorizing about unmarried sexuality and contributed to her institutional instability.

In addition, while all four women were married to Eastern European Jewish men at one time, Ellen ended up with a German Jewish man (matching her German Jewish background), and Ruth Landes never had a significant relationship with a Jewish man again after her first husband, and instead mostly engaged in interracial relationships. While Ruth Glass' first husband was not Jewish, both she and Hilda Kuper ended up 
staying married to an Eastern European Jewish man until death. Ruth Landes was also different from the other three women since Ignacio and Edison worked as activist journalists who actively advocated against racial discrimination through their work. Kuper and Glass were married to academics/researchers, like themselves, and both Leo Kuper and David Glass were sociologists, though in different sub-fields (Leo was a sociologist of genocide, while David was a demographer). Ellen married a lawyer - her first husband Joseph Hellmann - (as Leo Kuper was initially) and then a surgeon - Bodo Koch. All of these fields of work - law, medicine, and academics/research, were (are) common occupations for Jewish men. Also, Jewish intra-marriage (endogamy) was typical during that time. While Hilda's and Ellen's fathers were initially poor traders, they married well-educated men. Landes married and dated men who were journalists and activists like her father. Landes' romantic partners also tended to share her father's political views - socialist and anti-racist. Hilda Kuper and Ruth Glass shared their politics with their husbands. Both Ruth and David Glass identified with leftist or socialist positions. Hilda and Leo Kuper were both arrested for their involvement in anti-apartheid Liberal party organizing in collaboration with the elite Indian community in Durban.

\section{Influence 5: Transracial networks and theorizing about black women}

Finally, I analyzed the racialized colleague networks that influenced each woman (Table 7). I asked whether each woman had significant and influential relationships with scholars and participants of color. I emphasized transracial networks because I wanted to accentuate how the social theorizing created through fieldwork depended upon diasporic 
networks across racial lines, rather than being the result of individual women's thinking in isolation.

\begin{tabular}{|c|c|c|c|c|}
\hline Factor & EH & RL & HK & RG \\
\hline transracial networks & $\begin{array}{l}\text { two black assistants: } \\
\text { John } \\
\text { Chawafambera/Chav } \\
\text { afambira and } \\
\text { Conference } \\
\text { Setlogelo, also she } \\
\text { sometimes cited } \\
\text { black scholars } \\
\text { regarding African } \\
\text { middle class, but } \\
\text { mostly her } \\
\text { connections were } \\
\text { with white men (JD } \\
\text { Rheinallt-Jones, } \\
\text { Quintin Whyte, Fred } \\
\text { Van Wyk) and } \\
\text { women through } \\
\text { SAIRR (Hansi } \\
\text { Pollak) and her } \\
\text { political } \\
\text { involvements } \\
\text { (Margaret Ballinger, } \\
\text { Helen Suzman). } \\
\end{array}$ & \begin{tabular}{|l|} 
often cited black \\
intellectuals beginning \\
in her 1933 writing \\
about black Jews in \\
Harlem, collaborated \\
with Edison Carneiro \\
in Brazil, formed close \\
relationships with \\
indigenous women \\
who were her key \\
informants: Maggie \\
Wilson, Louise Masha \\
Nocktonick, Kee \\
Peschel, Mãe \\
Menininha.
\end{tabular} & $\begin{array}{l}\text { became a Swazi } \\
\text { citizen, identified with } \\
\text { Swazi royalty, worked } \\
\text { with Thoko Ginindza } \\
\text { and Fatima Meer, and } \\
\text { collaborated with other } \\
\text { Swazis and Indian } \\
\text { South Africans } \\
\end{array}$ & $\begin{array}{l}\text { As Director of the Centre } \\
\text { for Urban Studies she } \\
\text { worked with many } \\
\text { students from the "Third } \\
\text { World", visited India for } \\
\text { two months every year } \\
\text { after 1958, a good friend } \\
\text { was Dharma Kumar, an } \\
\text { economic historian }\end{array}$ \\
\hline $\begin{array}{l}\text { theorizations about } \\
\text { black women }\end{array}$ & $\begin{array}{l}\text { moralizing/ } \\
\text { judgmental stance } \\
\text { toward "unstable" } \\
\text { families, } \\
\text { "illegitimate" } \\
\text { children, } \\
\text { grandmother-led } \\
\text { families }\end{array}$ & \begin{tabular}{|l|} 
celebrated black \\
women's leadership, \\
spiritual and economic \\
power, theorized \\
Candomblé as a \\
"black matriarchy"; \\
modernization and \\
formal marriage \\
increased male control \\
over women's bodies
\end{tabular} & $\begin{array}{l}\text { Westernization } \\
\text { worsened male } \\
\text { chauvinism, black } \\
\text { families were more } \\
\text { stable than EH } \\
\text { theorized in } \\
\text { Johannesburg, women } \\
\text { were victims of both } \\
\text { colonial system and } \\
\text { "traditional" } \\
\text { patriarchies }\end{array}$ & $\begin{array}{l}\text { did not discuss black } \\
\text { women's sexuality, wrote } \\
\text { about black women as } \\
\text { working women, } \\
\text { critiqued those who } \\
\text { blamed black migrants } \\
\text { for racism, resisted } \\
\text { "clichés" of urban doom }\end{array}$ \\
\hline
\end{tabular}

Table 7. Transracial networks and theorizing black women's sexuality

Landes, Kuper and Glass all had significant working relationships with men and women of color. Though Hellmann worked with women and men of color during her research, to some extent in her social service work at the Joint Council for Europeans and Africans (where Alfred B. Xuma was the Chair when she was the Honorary Secretary in 1940) and sometimes cited black scholars when she discussed the African middle class, overall her closest and most influential connections were with white male and female 
colleagues in the SAIRR and the Progressive Party. These connections likely influenced her conservative views, which were common among whites and black elites at that time in South Africa.

Landes' relationships with men of color (which were a result of her family's political values), the influence of her partners' political perspectives on her own, and her experience of being an unmarried/divorced woman, all contributed to her positive views of black women as spiritual and economic leaders and providers who used sexuality to access power, and her insights that modernization and Westernization actually decreased women's control over their own bodies and sexuality.

Hilda Kuper's immersion in the communities she studied, and the close friendships and ties of obligation she formed in Swaziland, impacted her views about the negative impact of colonization and Westernization on women's position. However, this immersion also allowed her to portray in her creative writings the ways that "traditional" indigenous systems were simultaneously oppressive for women. Her experience in a lifelong marriage and her ties with the royal family in Swaziland (which was highly invested in maintaining prestige and status) likely impacted her understanding of why women were likely to remain in marriages that disadvantaged them in some ways but also provided them certain privileges. Hilda's functionalist training under Malinowski that emphasized the importance and interworking of the entire social system likely influenced her theorizing about women's victimization (rather than agency) within social structures (in both Swaziland and Durban, Natal) that required conformity. In contrast, Landes' training with Ruth Benedict emphasized the study of individuals who were outliers in their societies. Subsequently, Landes accentuated religious leaders who displayed gender 
and sexuality non-conformity, agency and resilience in their resistance to colonial power structures. This in combination with Landes' personal experience as a social outlier and rejecter of gender and sexuality norms, resulted in her differing theorizations about black women's sexuality.

Perhaps because of Ruth Glass' disciplinary training, gender and sexuality were not her central interests, and black women only entered her analysis in relation to her primary research questions which revolved around demography (an interest she shared with David Glass), employment, housing and racialist attitudes especially in terms of their similarity with anti-Semitic perspectives.

\section{An offering for the future}

Though I only researched the lives of six women in depth, and only included analysis of four women in this dissertation (Viola Klein and Vera D. Rubin are only briefly mentioned, though I collected data for each of them), my findings illuminate a potential process for investigations of other Jewish women social scientists. In this way, this dissertation serves as a kind of "pilot study" for future analysis and the construction of an entire network of women social scientists working during this time period. I know the types of patterns and connections that I would seek and the aspects of their lives into which I would delve. For example, how does each female theorist write about antiSemitism and anti-black racism? How does she understand the relationships between gender, sexuality, race, class, nation, and colonization? How did her specific Jewish background, transnational and transracial relationships, disciplinary training, marital status and romantic relationships influence her theorizing? Rather than the similarities or 
generalizations which I expected to find, I observed many more differences between the women. The writing process pressed me to consider the reasons for the differences. This revealed the importance of a grounded theory approach, an iterative process through which I returned to the data, reformulated and questioned with Dr. Patil my central themes - which factors or elements of divergence between the women made the most difference?

The research method that I would like to employ more in the future is the oral history-type interviews I conducted with students of Hilda Kuper. Gelya Frank said she felt grateful to me for interviewing her about Hilda because it was a way of honoring Hilda and subsequently Gelya felt honored. By speaking about Hilda, we were bringing her into the room and "reckoning" with her. All of the interviews I had with Hilda's students felt like this, an offering to an important female ancestor, a "communing with the dead." I felt especially close to Hilda since she advised Sondra Hale and Sondra advised my friend Dalal, from my Women's Studies M.A. program. Since I consider teachers to be a kind of kin, in a way I have a slightly removed kinship-type relationship with Hilda since she was the teacher of the teacher of my very close friend. Also, the interviews with Hilda's students caused me to think about my own Jewish subjectivity in relation to Hilda's. Because Hilda's Jewishness did not seem to be as central of a concern for her as it is for my own sense of identity, these interviews facilitated the opportunity for me to reflect on the process of my Jewish subjectivity formation including the familial and personal experiences that led me to this particular point (and that I elaborate on in Chapter 1). This brought me back to some of my initial research interests in studying the process of relationship development between researcher 
and the subjects of her research (whether they are human, non-human or no-longer-living but formerly human) and how this affective space impacts the kinds of ideas and theories created.

This dissertation project has been an "academic" endeavor but I argue that these "scholarly" or "scientific" practices are also inherently embodied and affective experiences. For me, this dissertation has been a kind of "exo-autoethnography" an opportunity to understand Jewish women's experiences of anti-Semitism and gendered internal colonization, like what my mom experienced; their stories are not my stories, but they are the stories of my female Jewish ancestors, and they affect me "by proxy." Though I am no longer in direct physical contact with their archival materials, I still feel the ties of "reciprocal obligation" to ensure that these women's words carry forward to be further debated and analyzed, because - as Hilda said in 1979 about how Swazi people eventually began to speak about her - they are my people, I am one of them. I have written about their hearts, their secrets and my own. I depend upon them and they depend upon me. This interconnectedness between researcher and research subjects and between researcher and her collaborators is of course a theme I have explored throughout this dissertation. An idea I continue to struggle with and that is exemplified in the work of each of the woman in this dissertation is how can one feel simultaneously connected to but also different from or even offended or disturbed by the behaviors or words of the women she studies? How can researchers contain and balance such ambivalent emotions or affective reactions? I think the key is in Uma Narayan's (1997) suggestion: instead of looking down on "others" or looking up to them, we should look at each other "face-toface" (156). This is what I have endeavored to do in this dissertation, by placing the 
women in conversation with each other and with other social scientists of their time/place and with my own experiences. 


\section{REFERENCES}

Adas, Michael. 2004. "Contested Hegemony: The Great War and the Afro-Asian Assault on the Civilizing Mission Ideology." Pp. 78-99 in Decolonization: Perspectives from Now and Then, Rewriting Histories, edited by Prasenjit Duara. London: Routledge.

Africans, Johannesburg Joint Council of Europeans and. 1939. Letter Dated August 16, 1939, to Mrs. H. Kuper at 26 Westcliffe Drive, Parktown, Johannesburg, Regarding Joint Council Meeting to Be Held August 21, 1939 at the Bantu Men's Social Centre, Eloff St. Johannesburg, South Africa: AD1433 Johannesburg Joint Council, Correspondence, Box 20 1938-1939 Cj 2.1.19 File 2, July-Dec. 1939, Historical Papers Archive, University of Witwatersrand.

Africans, Johannesburg Joint Council of Europeans and. 1947. List of Members Who Paid Subscriptions, 1945/6, Including H. Kuper and A.W. Hoernle. Johannesburg, South Africa: AD1433 Box 23, Cj 2.1.24-2.1.28 Johannesburg Joint Council Correspondence, 1944-1948; Cj 2.1.27, 1947 Correspondence, Historical Papers Archive, University of Witwatersrand.

Africans, Joint Council of Europeans and. 1939. Proposed Employment of Women Beersellers in Municipal Beer Halls, Misc. 30/39 "Confidential" - The Joint Council's Critique of the Municipal Native Affairs Department's Proposal Regarding Women Beersellers. Johannesburg, South Africa: AD1433 Joint Council Europeans and Africans, Box 20, 1938-1939, Cj 2.1.19 File 2, July-Dec. 1939, Historical Papers Archive, University of Witwatersrand.

Africans, Joint Council of Europeans and. 1946. List of Office Bearers for 1946 of the Joint Council, Cj 2.1.27, 1947 Correspondence. Johannesburg, South Africa: AD1433, Box 23, Cj 2.1.24-2.1.28 Johannesburg Joint Council Correspondence, 1944-1948, Historical Papers Archive, University of Witwatersrand.

Albert, Katelin. 2014. "Towards a New Normal: Emergent Elites and Feminist Scholarship." The American Sociologist 46(1):29-39.

Aldridge, Delores P. 2009. Imagine a World: Pioneering Black Women Sociologists. Lanham, MD: University Press of America.

Alexander, M.Jacqui. 2006. Pedagogies of Crossing: Meditations on Feminism, Sexual Politics, Memory and the Sacred. Duke University Press.

Andreson, Jamie. 2014. "Ruth Landes E a Sua Experiência Etnográfica Na Bahia." Faculdade de Filosofia e Ciências Humanas Universidade Federal da Bahia, Estudos Étnicos e Africanos do Centro de Estudos Afro-Orientais.

Andrews, George Reid. 1991. Blacks and Whites in São Paulo Brazil 1888-1988. Madison: University of Wisconsin Press.

Arnold, A.James. 2013. “Césaire, Aimé 1913 - 2008." Encyclopedia of Race and Racism. 
Bacchetta, P., F. El-Tayeb, and J. Haritaworn. 2015. "Queer of Colour Formations and Translocal Spaces in Europe." Environment and Planning D: Society and Space 33(5):769-78.

Bacchetta, Paola. 2010. "The (Failed) Production of Hindu Nationalized Space in Ahmedabad, Gujarat." Gender, Place \& Culture 17(5):551-72.

Bailkin, Jordanna. 2012. The Afterlife of Empire. University of California Press.

Baldwin, James. 1984. “On Being White... and Other Lies.” Essence, April.

Bank, Andrew. 2016. Pioneers of the Field: South Africa's Women Anthropologists. London, England: Cambridge University Press, International African Institute.

Banton, Michael. 1955. The Coloured Quarter: Negro Immigrants in an English City. London: Jonathan Cape.

Banton, Michael. 1960. White and Coloured: The Behavior of British People towards Coloured Immigrants. 2nd ed. New Brunswick, N.J.: Rutgers University Press.

Banton, Michael. 1998. "Obituary: A Woman of Colour: Sheila Patterson.” The Guardian (London, England), July 1, 18.

Barraclough, Geoffrey. 2004. "The Revolt Against the West." Pp. 118-30 in Decolonization: Perspectives from Now and Then, Rewriting Histories, edited by Prasenjit Duara. London: Routledge.

Barros, Luitgarde Oliveira Cavalcanti. 2005. "Três Polêmicas Da Antropologia No Rio de Janeiro." Pp. 168-212 in Arthur Ramos e As Dinâmicas Sociais de Seu Tempo. Maceió: Universidade Federal de Alagoas.

Barroso, Gustavo. 1999. “The Paulista Synagogue.” Pp. 182-83 in The Brazil Reader: History, Culture, Politics, edited by Robert M. Levine and John Crocitti. Durham: Duke University Press.

Beemer, Hilda. 1935. "The Swazi Rain Ceremony (Critical Comments on P.J. Schoeman's Article)." Bantu Studies: a journal devoted to the scientific study of Bantu, Hottentot, and Bushman 9:273-80.

Behar, Ruth. 1995. "Introduction: Out of Exile." in Women Writing Culture, edited by Ruth Behar and Deborah Gordon. Berkeley: University of California Press.

Behar, Ruth. 1996. The Vulnerable Observer: Anthropology That Breaks Your Heart. Boston: Beacon Press.

Behar, Ruth. 2009. "Folklore and the Search for Home (American Folklore Society Presidential Invited Plenary Address, October 2008)." Journal of American Folklore 122(485):251-66.

Bell, Joshua A. 2009. "“For Scientific Purposes a Stand Camera Is Essential': Salvaging Photographic Histories in Papua." Pp. 143-70 in Photography, Anthropology and History: Expanding the Frame, edited by C. Morton and E. Edwards. Ashgate.

Bennett, Jane. 2010. Vibrant Matter: A Political Ecology of Things. Durham: Duke 
University Press.

Berger, Karen. 2010. “'In Search of the Thing Itself': Animals and Africans in the Art of Three Jewish Women: Maya Deren (1917-1961), Clarice Lispector (1920-1977) and Helene Cixous (1937-).” Australian Journal of Jewish Studies 24:23-36.

Bhambra, Gurminder K. 2007. "Sociology and Postcolonialism: Another 'Missing' Revolution." Sociology 41(5 Special Issue on Sociology and Its Public Face(s)):871-84.

Bhambra, Gurminder K. 2010. "Chapter 2: Sociology after Postcolonialism: Provincialized Cosmopolitanisms and Connected Sociologies." Pp. 33-48 in Decolonizing European Sociology: Transdisciplinary Approaches, edited by Encarnación Gutiérrez Rodríguez, Manuela Boatca, and Sérgio Costa. Farnham, Surrey, England: Ashgate Publishing Co.

Bhambra, Gurminder K. 2014. "A Sociological Dilemma: Race, Segregation and US Sociology.” Current Sociology Monograph 62(4):472-92.

Bhaskaran, Suparna. 2004. Made in India: Decolonizations, Queer Sexualities, Trans/national Projects. edited by Chandra Talpade Mohanty. Comparative Feminist Studies: Palgrave MacMillan.

Bilden, Rüdiger. 1937. Rüdiger Bilden to Melville Herskovits, December 6, 1937 Regarding Ruth Landes. Evanston, Illinois: Melville Herskovits Papers, Series 35/6, Folder 26, Box 3, Rüdiger Bilden, Northwestern University Archives.

Blasi, Anthony J. 2005. Diverse Histories of American Sociology. edited by History of Sociology Section of the American Sociological Association. Leiden: Brill.

Bloul, Rachel. 2013. "Do I Look Jewish in This? A Phenomenological Approach to Intercorporeality and Racism." Identities 1-22.

Blumen, Orna. 2002. "Women's Professional Choice in Geography: National Sentiments and National Exclusion." Women's Studies International Forum 25(5):555-71.

Blumer, Herbert. 1969. Symbolic Interactionism: Perspective and Method. Berkeley: University of California Press.

Carby, Hazel V. 1992. "Policing the Black Woman's Body in an Urban Context." Critical Inquiry 18(4 (Identities, Summer)):738-55.

Du Bois, W. E. B. 1994. The Souls of Black Folk. Dover Thrift Editions.

Bonilla-Silva, Eduardo. 2012. "The Invisible Weight of Whiteness: The Racial Grammar of Everyday Life in America." Michigan Sociological Review 26(Fall):1-15, 82.

Bonner, Philip L. 1988. "Family, Crime and Political Consciousness on the East Rand, 1939-1955*." Journal of Southern African Studies 14(3):393-420.

Braidotti, Rosi. 2014. "Writing as a Nomadic Subject." Comparative Critical Studies 11(2-3):163-84.

Brettell, Caroline B. 1997. "Blurred Genres and Blended Voices: Life History, 
Biography, Autobiography, and the Auto/Ethnography of Women's Lives.” Pp. 223-46 in Auto/Ethnography: Rewriting the Self and the Social, edited by Deborah E. Reed-Danahay. Oxford: Berg.

Brockman, Norbert C. 2006. "Oppenheimer, Harry Frederick (South Africa, 19082000)." An African Biographical Dictionary.

Brodkin, Karen. 1998a. How Jews Became White Folks and What That Says about Race in America. New Brunswick, New Jersey: Rutgers University Press.

Brodkin, Karen. 1998b. "Introduction." in How Jews Became White Folks and What That Says about Race in America. New Brunswick, New Jersey: Rutgers University Press.

Brondo, Keri Vacanti, Linda Bennett, Harmony Farner, Cindy Martin, and Andrew Mrkva. 2009. Work Climate, Gender, and the Status of Practicing Anthropologists: Report Commissioned by the Committee in the Status of Women in Anthropology. Committee on the Status of Women in Anthropology.

Broschart, Kay Richards. 2005. "The Neglected Contributions of Female Sociologists in the American South." Pp. 59-73 in Diverse Histories of American Sociology, edited by Anthony J. Blasi. Leiden: Brill.

Brown, Jay M. 2014. "From The Shtetl To The Tenement: The East European Jews and America, A Social History 1850-1925." Yale-New Haven Teachers Institute: Themes in Twentieth Century American Culture. Retrieved August 20, 2014 (http://www.yale.edu/ynhti/curriculum/units/1979/2/79.02.02.x.html).

Brown Lavitt, Pamela. 1999. "First of the Red Hot Mamas: 'Coon Shouting' and the Jewish Ziegfeld Girl." American Jewish History 87(4):253-90.

Burton, Antoinette. 1994. "The Politics of Recovery: Historicizing Imperial Feminism, 1865-1915." Burdens of History: British Feminists, Indian Women, and Imperial Culture 1-19.

Burton, Antoinette. 2003. "Chapter One: Memory Becomes Her, Women, Feminist History and the Archive." Pp. 3-30 in Dwelling in the archive: women writing house, home, and history in late colonial India. Oxford: Oxford University Press.

Calhoun, Craig. 2007. Sociology in America: A History. Chicago: University of Chicago Press, An ASA Centennial Publication.

Cantres, James G. 2014. "Migrants in the Metropole: Patterns of Caribbean Identification in Post-War London." New York University.

Carneiro, Edison. 1939a. Edison Carneiro to Ruth Landes, July 14, 1939, from São Clemente, Botafogo, Rio. Washington, D.C.: Box 2 Letters Received, Ruth Landes Papers, National Anthropological Archives, Smithsonian Institution.

Carneiro, Edison. 1939b. Edison Carneiro to Ruth Landes, June 8, 1939 from São Clemente, Botafogo, Rio. Washington, D.C.: Box 2 Letters Received, Ruth Landes Papers, National Anthropological Archives, Smithsonian Institution. 
Carneiro, Edison. 1940. Edison Carneiro to Ruth Landes, October 24, 1940. Washington, D.C.: Box 2 Letters Received, Ruth Landes Papers, National Anthropological Archives, Smithsonian Institution.

Carneiro, Edison. 1946. Letters from Edison Carneiro to Ruth Landes Dating from September 28, 1938 to March 14, 1946. Washington, DC: Box 2 Ruth Landes Papers, National Anthropological Archives, Smithsonian Institution.

Carneiro, Edison. 1947. Edison Carneiro to Ruth Landes, July 28, 1947, upon Receiving City of Women. Washington, D.C.: Box 2, Ruth Landes Papers, National Anthropological Archives, Smithsonian Institution.

Carneiro, Edison. 1961. Candomblés Da Bahia. Third. Rio de Janeiro, Brazil: Conquista.

Carneiro, Edison. 1964. Ladinos E Crioulos: Estudos Sóbre O Negro No Brasil. Rio de Janeiro, Brazil: Editora Civilização Brasileira, S.A.

Carneiro, Edison. 1968. Edison Carneiro Letters to Ruth Landes: Dec. 22, 1966; June 1, 1967; August 7, 1967; January 28, 1968. Washington, DC: Box 2 Letters Received, Ruth Landes Papers, National Anthropological Archives, Smithsonian Institution.

Carneiro, Edison de Souza, and James W. Ivy. 1951. "Arthur Ramos : Brazilian Anthropologist (1903-1949)." Phylon (1940-1956) 12(1):73-81.

Carroll, Hamilton. 2011. Affirmative Reaction: New Formations of White Masculinity. New Americ. edited by Donald E. Pease. Durham \& London: Duke University Press.

Celarent, Barbara. 2012. "Rooiyard: A Sociological Survey of an Urban Native Slum Yard by Ellen Hellmann.” American Journal of Sociology 118(1):274-80.

Chakrabarty, Dipesh. 2000. Provincializing Europe: Postcolonial Thought and Historical Difference. Princeton: Princeton University Press.

Chatterjee, Partha. 1993. "The Nation and Its Women.” Pp. 116-34 in The Nation and Its Fragments: Colonial and Postcolonial Histories. Princeton University Press.

Chivallon, Christine. 2002. "Beyond Gilroy's Black Atlantic: The Experience of the African Diaspora.” Diaspora: A Journal of Transnational Studies 11(3):359-82.

Clapson, Mark. 2006. "The American Contribution to the Urban Sociology of Race Relations in Britain from the 1940s to the Early 1970s." Urban History 33(2):25373.

Clarke, Edith. 1999. My Mother Who Fathered Me: A Study of the Families in Three Selected Communities of Jamaica. Revised Ed. Barbados, Jamaica, Trinidad and Tobago: The Press University of the West Indies.

Clifford, James. 1994. "Diasporas.” Cultural Anthropology 9(3):302-38.

Coggin, Theo. 1982. "Tribute Is Paid to Top Institute Stalwarts." Race Relations News; Ellen Hellmann Box of Clipppings, Jewish Board of Deputies Archive, Beyachad Community Center 44(9):1. 
Cole, Sally. 2002. "“Mrs. Landes Meet Mrs. Benedict': Culture Pattern and Individual Agency in the 1930s." American Anthropologist 104(2):533-43.

Cole, Sally. 2003. Ruth Landes: A Life in Anthropology. Lincoln: University of Nebraska Press.

Cole, Sally. 2009. Rainy River Lives: Stories Told by Maggie Wilson. edited by Sally Cole. Lincoln: University of Nebraska Press.

Collins, Patricia Hill. 1986. "Learning from the Outsider Within: The Sociological Significance of Black Feminist Thought." Social Problems 33(6):S14-32.

Collins, Sydney. 1957. Coloured Minorities in Britain: Studies in British Race Relations Based on African, West Indian and Asiatic Immigrants. London: Lutterworth Press.

Colwill, Elizabeth. 1998. "Sex, Savagery and Slavery in the Shaping of the French Body Politic." Pp. 198-224 in From the Royal to the Republican Body: Incorporating the Politic in 17th and 18th century France, edited by Sara Melzer and Kathryn Norberg. Berkeley, CA: University of California Press.

Congress, Library of. 2013. "The Gibson Girl's America: Drawings by Charles Dana Gibson." Library of Congress Exhibitions. Retrieved August 14, 2014 (http://www.loc.gov/exhibits/gibson-girls-america/).

Cooksey, Sybil J. 2010. "Being Black : Reading Obscurity in Afro-American Cultural Practice and Performance.” New York University.

Correa, Mariza. 2003. "Introdução: A Natureza Imaginária Do Gênero Na História Da Antropologia \& Capítulo V: O Mistério Dos Orixás E Das Bonecas: Raça E Gênero Na Antropologia Brasileira.” Pp. 19-32, 163-84 in Antropologas e Antropologia. Belo Horizonte: Editora UFMG.

Crooks, Deborah L., and Geraldine Moreno-Black. 2012. "Slowly Rising Waters: Women in Human Biology." Voices: A Publication of the Association for Feminist Anthropology 12(1):9-14.

Cubé, Caroline, and Lilace Hatayama. 2011. Finding Aid for the Hilda Kuper Papers, Ca. 1930-1992. Los Angeles: Charles E. Young Research Library, Special Collections.

Cuddihy, John Murray. 1974. Ordeal of Civility: Freud, Marx, Lévi-Strauss and the Jewish Struggle with Modernity. New York, NY: Basic Books Inc.

da Cunha, Olívia Maria Gomes. 2004. "Tempo Imperfeito: Uma Ethnografia Do Arquivo." Mana 10(2):287-322.

da Cunha, Olívia Maria Gomes. 2006. "Imperfect Tense: An Ethnography of the Archive." Mana 1:1-28.

Damon, Maria. 1996. "Gertrude Stein's Jewishness, Jewish Social Scientists and the 'Jewish Question."' MFS: Modern Fiction Studies 42(3):489-506.

Davis, Geoffrey. 2009. “A Deeper Silence: Dan Jacobson's Lithuania.” Pp. 39-66 in Africa Writing Europe: Opposition, Juxtaposition, Entanglement/Cross Cultures- 
Readings in the Post-Colonial Literatures in English, No. 105, edited by Maria Olaussen and Christina Angelfors. Amsterdam: Rodopi.

Deegan, Mary Jo. 2005. "Chapter Ten: Women, African Americans and the ASA, 19052005.” Pp. 178-206 in Diverse Histories of American Sociology, edited by History of Sociology Section of American Sociological Association. Leiden: Brill.

Denejkina, Anna. 2017. "Exo-Autoethnography: An Introduction.” Forum Qualitative Sozialforschung / Forum : Qualitative Social Research 18(3).

Deputies, Jewish Board of. 1944. "Jewish Board of Deputies, Public Relations Committee Minutes, March 27, 1944.” P. PR 214 in Jewish Board of Deputies, Public Relations Committee Minutes, 1944-1950, ARCH809. Johannesburg, South Africa: South African Jewish Board of Deputies Archive, Beyachad Jewish Community Center.

Deputies, Jewish Board of. 1945a. "Jewish Board of Deputies, Public Relations Committee Minutes, October 4, 1945." in Jewish Board of Deputies, Public Relations Committee Minutes, 1944-1950, ARCH809. Johannesburg, South Africa: South African Jewish Board of Deputies Archive, Beyachad Jewish Community Center.

Deputies, Jewish Board of. 1945b. "Jewish Board of Deputies Public Relations Committee Minutes, September 13, 1945.” P. PR 238-239 in Jewish Board of Deputies, Public Relations Committee Minutes, 1944-1950, ARCH809. Johannesburg, South Africa: South African Jewish Board of Deputies Archive, Beyachad Jewish Community Center,.

Deputies, Jewish Board of. 1946. "South African Jewish Board of Deputies, Public Relations Committee Minutes, May 9, 1946." P. PR281-283 in South African Jewish Board of Deputies, Public Relations Committee Minutes, 1944-1950, ARCH 809. Johannesburg, South Africa: Jewish Board of Deputies Archive, Beyachad Community Center.

Deputies, Jewish Board of. 1949. "Jewish Board of Deputies, Public Relations Committee Minutes, September 1947-June 1949.” P. PR431-441 in Jewish Board of Deputies, Public Relations Committee Minutes, 1944-1950, ARCH809.

Deputies, Jewish Board of. 1950. "Jewish Board of Deputies, Public Relations Committee, December 18, 1950 Meeting." P. PR 529-530 in Jewish Board of Deputies, Public Relations Committee Minutes, 1944-1950, ARCH809. Johannesburg, South Africa: South African Jewish Board of Deputies Archive, Beyachad Jewish Community Center.

Deputies, Jewish Board of. 1976. Address given at the S.A. Jewish Board of Deputies Meeting on 29 August 1976. Johannesburg, South Africa: Jewish Board of Deputies Archive, Beyachad Community Center, Ellen Hellmann Box of Clippings, No. 199.

Deputies, South African Jewish Board of. 1946. South African Jewish Board of Deputies, Public Relations Committee Minutes, September 4 and 23, 1946, Regarding Involvement of Leo and Hilda Kuper. Johannesburg, South Africa: Jewish Board of 
Deputies Archive (PR committee minutes 1944-50), Beyachad Community Center.

Desai, Ashwin. 2010. "Fatima Meer: From Public to Radical Sociologist." South African Review of Sociology 41(2):121-27.

Diner, Hasia R. 1995. In the Almost Promised Land: American Jews and Blacks, 19151935. Westport, CT: Greenwood Press; The Johns Hopkins University Press.

Drake, St.Clair, and Horace R. Cayton. 1962. Black Metropolis: A Study of Negro Life in a Northern City. New York: Harper and Row.

Edwards, Brent Hayes. 2003. “Chapter 3 Feminism and L'Internationalisme Noir: Paulette Nardal.” Pp. 119-86 in The Practice of Diaspora Literature, Translation, and the Rise of Black Internationalism. Harvard University Press.

Edwards, Michael. 2012. "Ruth Glass at UCL (University College London)." Michael Edwards Blog, UCL Reminiscences: "Planning. ” Retrieved February 14, 2016 (http://michaeledwards.org.uk/?p=953).

Egginton, Joyce. 1957. They Seek a Living. London: Hutchinson \& Co. Ltd.

Elazar, Dahlia S. 2002. ""Engines Of Acculturation": The Last Political Generation of Jewish Women in Interwar East Europe.” Journal of Historical Sociology 15(3):366-94.

Emerson, Robert M., Rachel I. Fretz, and Linda L. Shaw. 1995. "Chapter 5: Pursuing Members' Meanings and Chapter 6: Processing Fieldnotes: Coding and Memoing." in Writing Ethnographic Fieldnotes, edited by Robert M. Emerson, Rachel I. Fretz, and Linda L. Shaw. Chicago: University of Chicago Press.

Erickson, Bonnie H. 1997. "Social Networks and History: A Review Essay." Historical Methods: A Journal of Quantitative and Interdisciplinary History 30(3):149-57.

Von Eschen, Penny. 1997. "Introduction and Conclusion." in Race against Empire: Black Americans and Anticolonialism, 1937-1957.

Fanon, Frantz. 1967. Black Skin, White Masks. New York, N.Y.: Grove Press.

Fanon, Frantz. 2003. “5: Algeria Unveiled.” Pp. 42-55 in Decolonization: Perspectives from Now and Then, Rewriting Histories, edited by Prasenjit Duara. New York: Routledge.

Farge, Arlette. 2013. The Allure of the Archives. edited by Thomas Scott-Railton. New Haven: Yale University Press.

Feinstein, Amy. 2005. “Goy Interrupted: Mina Loy’s Unfinished Novel and Mongrel Jewish Fiction.” MFS Modern Fiction Studies 51(2):335-53.

Fernandes, Leela. 2013. Transnational Feminism in the United States: Knowledge, Ethics and Power. New York: New York University Press.

Few, Martha. 2007. “That Monster of Nature': Gender, Sexuality, and the Medicalization of a 'Hermaphrodite' in Late Colonial Guatemala." Ethnohistory 54(1):159-76. 
Foreman, Grahame Philip. 2013. "Horizons of Modernity: British Anthropology and the End of Empire." University of California Berkeley.

Fowler Museum. 1976. Description of Thoko Ginindza Swaziland Object Donation to UCLA Fowler Museum. Los Angeles: UCLA Fowler Museum.

Frank, Gelya. 1997. "Jews, Multiculturalism and Boasian Anthropology." American Anthropologist 99(4):731-45.

Frank, Gelya. 2001. "Melville J. Herskovits on the African and Jewish Diasporas: Race, Culture and Modern Anthropology." Identities 8(2):173-209.

Frank, Gelya, and Abby Gondek. 2017. Abby Gondek Interview with Gelya Frank, August 6, 2017, Regarding Hilda Kuper. Santa Monica, CA: University of Southern California.

Frank, Gelya, and Hilda Kuper. 1979. Rough Transcript Interview Conducted by Gelya Frank with Hilda Kuper Re: Ethics/Morality of Life History Work and Hilda's Biography of Sobhuza II, June 28, 1979. Los Angeles: Hilda Kuper Papers, Box 16, Folder 5, UCLA Special Collections, Charles E. Young Research Library.

Franzosi, Roberto, and John W. Mohr. 1997. "New Directions in Formalization and Historical Analysis." Theory and Society 26(2/3):133-60.

Frazier, E.Franklin. 1939. “The Black Matriarchate.” Pp. 125-45 in The Negro Family in the United States. Chicago, Illinois: The University of Chicago.

Frazier, E.Franklin. 1942. "The Negro Family in Bahia, Brazil." American Sociological Review 7(4):465-78.

Frazier, Franklin. 1957. Black Bourgeoisie. Simon and Schuster.

Freidenreich, Harriet Pass. 2002. Female, Jewish and Educated: The Lives of Central European University Women. Bloomington: Indiana University Press.

French, Brigittine M. 2005. "Partial Truths and Gendered Histories: Ruth Bunzel in American Anthropology.” Journal of Anthropological Research 61(4):513-32.

Freyre, Gilberto. 1968. The Masters and the Slaves (Casa Grande E Senzala) A Study in the Development of Brazilian Civilization. New York: Knopf.

Fuchs, Thomas. 2012. "The Phenomenology of Body Memory.” Pp. 9-22 in Body Memory, Metaphor and Movement, edited by Sabine C. Koch, Thomas Fuchs, Michela Summa, and Cornelia Müller. Amsterdam: John Benjamins.

Fuentes, Alejandro de la. 2001. A Nation for All: Race, Inequality and Politics in Twentieth Century Cuba. University of North Carolina Press.

Gacs, Ute, Aisha Khan, Jerrie McIntyre, and Ruth Weinberg. 1989. Women Anthropologists: Selected Biographies. Urbana: University of Illinois Press.

Garcia, Matt. 2001. A World of Its Own: Race, Labor and Citrus in the Making of Greater Los Angeles, 1900-1970. Chapel Hill: University of North Carolina Press.

Garner, Steve. 2004. Racism in the Irish Experience. Pluto Press. 
Gewald, Jan-Bart. 2007. "Researching and Writing in the Twilight of an Imagined Conquest: Anthropology in Northern Rhodesia 1930-1960." History and Anthropology 18(4):459-87.

Gibson, Charles Dana. n.d. "Drawings." Pp. 3-31 in The Best of Charles Dana Gibson. Washington, DC: Box 60 Clippings, Ruth Landes Papers, National Anthropological Archives, Smithsonian Institution.

Gillespie, Kelly. 2011. "Containing the 'Wandering Native': Racial Jurisdiction and the Liberal Politics of Prison Reform in 1940s South Africa." Journal of Southern African Studies 37(3):499-515.

Gilman, Sander. 1985. "The Hottentot and the Prostitute: Toward an Iconography of Female Sexuality." Pp. 76-108 in Difference and Pathology: Stereotypes of Sexuality, Race and Madness, vol. 1877, edited by Sander Gilman. Ithaca, NY: Cornell University Press.

Gilman, Sander L. 1993. Freud, Race and Gender. Princeton, N.J.: Princeton University Press.

Gilroy, Paul. 2003. "The Black Atlantic as a Counterculture of Modernity." Pp. 49-80 in Theorizing Diaspora: A Reader, edited by J.E. Braziel and A. Mannur. Malden, MA: Blackwell Publishing.

Ginindza, Teresa Thoko. 1967. Teresa Thoko Ginindza to Hilda Kuper, November 28, 1967, Stating Her Interest in Attending UCLA. Los Angeles, CA: Hilda Kuper Papers, Box 24 folder 20, Special Collections, Charles E. Young Research Library, UCLA.

Ginindza, Teresa Thoko. 1971. Dress in Swaziland. Los Angeles, CA: Hilda Kuper Papers, Box 24, Folder 20, UCLA Special Collections, Charles E. Young Library.

Ginindza, Teresa Thoko. 1973. Teresa Thoko Ginindza to Hilda Kuper, November 30, 1973. Los Angeles, CA: Hilda Kuper Papers, Box 24, Folder 20, UCLA Special Collections, Charles E. Young Research Library.

Ginindza, Teresa Thoko. 1974. Statement of Purpose. Los Angeles, CA: Hilda Kuper Papers, Box 24, Folder 20, UCLA Special Collections, Charles E. Young Research Library.

Ginindza, Teresa Thoko. 1975. Letter to Hilda Kuper, in March or April 1975 Regarding Swazi Material Culture Artifacts Collected for the Fowler Museum. Los Angeles, CA: Hilda Kuper Papers, Box 24 folder 20, Special Collections, Charles E. Young Research Library, UCLA.

Ginindza, Thoko. 1989. Swazi Women: Sociocultural and Economic Considerations, Final Report March - May 1989. Labat-Anderson Incorporated; US Agency for International Development.

Glanton, Dahleen. 2017. "Column: Neo-Nazis, Anti-Semitism and the Cycle of Hatred in America." Chicago Tribune, August 28. 
Glaser, Clive. 2000. Bo-Tsotsi: The Youth Gangs of Soweto, 1935-1976. Portsmouth, NH: Heinemann.

Glass, Ruth. 1960. "Stubborn Prejudice, Letter to the Editor." The Times, July 19, 17.

Glass, Ruth. 1962. "Cuba, Letter to the Editor.” The Times, October 10, 13.

Glass, Ruth. 1963. "The Rachman Affair: Story Not New, Letter to the Editor.” The Times, July 20, 9.

Glass, Ruth. 1965. "The Dark Million: Keeping Issue out of Politics, Letter to the Editor." The Times, February 1, 13.

Glass, Ruth. 1969. "Immigration Issues, a Letter to the Editor." The Times, August 4, 9.

Glass, Ruth. 1971. "World Aid for Bengal's Refugees: Letter to the Editor." The Times, June 3, 15.

Glass, Ruth. 1976. "Planners and Devouring Cities.” The Times, June 8, 15.

Glass, Ruth. 1978. "The Politics of Race and Immigration, Letter to the Editor." The Times, February 16, 13.

Glass, Ruth. 1981. "Long Term Destiny of Inner Cities, Letter to the Editor." The Times, August 6, 1-2.

Glass, Ruth. 1983. "Tory Pledge to Abolish GLC, Letter to the Editor." The Times, May $24,13$.

Glass, Ruth. 1989a. Clichés of Urban Doom and Other Essays. Oxford: Basil Blackwell.

Glass, Ruth. 1989b. "London: Aspects of Change.” Pp. 133-58 in Clichés of Urban Doom and Other Essays. Oxford: Basil Blackwell.

Glass, Ruth, and Harold Pollins. 1960. London's Newcomers: The West Indian Migrants. Harvard University Press.

Glenn, James. 1991. Undated Note (Feb. 25, 1991) from James Glenn (Archivist) from His Visit to Ruth Landes' Home in Hamilton, Ontario to Pick up Her Papers. Washington DC: Accession File, Ruth Landes Papers, National Anthropological Archives, Smithsonian Institution.

Glenn, James R., and Lorain Wang. 2010. Register to the Papers of Ruth Landes. Washington, DC: National Anthropological Archives, Smithsonian Institution.

Gold, David L. 1981. “The Etymology of Yiddish Yeke.” Zeitschrift für Dialektologie und Linguistik 48(Jahrgang, Heft 1):57-59.

Goldberg, Chad Alan. 2012. "Robert Park's Marginal Man: The Career of a Concept in American Sociology." Laboratorium: Russian Review of Social Research 4(2):199_ 217.

Goldberg, Harvey E. 1995. "The Voice of Jacob: Jewish Perspectives on Anthropology and the Study of the Bible." Jewish Social Studies 2(1):36-71.

Goldstein, Eric L. 2006. The Price of Whiteness: Jews, Race, and American Identity. 
Princeton and Oxford: Princeton University Press.

Golomski, Casey. 2011. "Hilda Kuper, Anthropology, History." P. 21 in University of Swaziland, UNISWA, History Staff Seminar Series. University of Swaziland, Department of Theology and Religious Studies.

Goluboff, Sascha L. 2001. "The Savage in the Jew: Race, Class, and Nation in Postsoviet Moscow." Identities 8(2):283-312.

Gondek, Abby, and Dawn Chatty. 2017. Interview with Dawn Chatty, Former Graduate Student of Hilda Kuper, July 20, 2017. Miami and Oxford: University of Oxford, Refugee Studies Center.

Gondek, Abby, and Isaura Genoveva. 2015. Abby Gondek Interview with Isaura Genoveva, Lawyer and Ekede at Casa Branca, January 6, 2015. Salvador, Bahia, Brasil: Casa Branca.

Gondek, Abby, and Sondra Dungan Hale. 2016. E-Mail Correspondence between Sondra Hale and Abby Gondek, 2016. Los Angeles, CA; Miami, FL: UCLA; FIU.

Gondek, Abby, Nigel Harris, and Tirril Harris. 2017. Correspondence with Nigel and Tirril Harris, Regarding Ruth Glass, September and December 2017. Miami and London: Florida International University.

Gondek, Abby, and Mica Nava. 2015. Mica Nava Interview, February 27, 2015. Miami and London: Florida International University, Department of Global and Sociocultural Studies, University of East London.

Gondek, Abby, and Linda Perkins. 2015. E-Mail Correspondence between Abby Gondek and Linda Perkins, February 3, 6, 7, 2015. Pasadena, California and Miami, Florida: Claremont Graduate University, Florida International University.

Gondek, Abby, and Ruth Runciman. 2018. Abby Gondek Interview with Ruth Runciman, Regarding Her Mother, Ellen Hellmann, January 29, 2018. London and Miami: Florida International University.

Gondek, Abby Suzanne. 2008. "Afro-Brazilian Jewish Women: Female Centaurs Transgressing the Borderlands." San Diego State University.

Gondek, Abby, and Maria das Graças de Souza Teixeira. 2015. Abby Gondek Interview with Graça Teixeira, Director of MAFRO, the Museu Afro-Brasileiro of UFBA, January 6, 2015. Salvador, Bahia, Brasil: Museu Afro Brasileiro of Universidade Federal da Bahia.

Goodwin, John, and Henrietta O'Connor. 2015. "Pearl Jephcott: The Legacy of a Forgotten Sociological Research Pioneer." Sociology 49(1):139-55.

Gordon, Beverly. 2006. The Saturated World: Aesthetic Meaning, Intimate Objects, Women's Lives, 1890-1940. Knoxville, TN: University of Tennesee Press.

Gordon, Linda. 2005. “The Imperial Within: Internal Colonialism and Gender.” Labrys: Estudos Feministas/Études Féministes Agosto/Dez:1-24.

Gordon, Robert. 1998. "The Rise of the Bushman Penis: Germans , Genitalia and 
Genocide." African Studies 57(1):27-54.

Graczyk, Ulla, Bastian Heimrath, and Susanne Eisen. 2013. "The Gabriel Theilheimer Family." Jüdisches Leben in Gunzenhausen 1-5. Retrieved February 13, 2015 (http://jl-gunzenhausen.de/en/theilheimer-gabriel.html).

Grant, Nicholas. 2014. "Crossing the Black Atlantic: The Global Antiapartheid Movement and the Racial Politics of the Cold War." Radical History Review Spring(119):72-93.

Gurza, Agustin. 2008. "El Espectador." Pomona College Magazine Online 45(3):1-5.

Gutsche, T. 1952. A Letter from Silver Leaf Books PTY LTD to Ellen Hellmann, October 28, 1952 and an Untitled, Anonymous Story Attached. Johannesburg, South Africa: Ellen Hellmann Papers, Box 7, File 50 Women 1945-1978, Historical Papers Archive, University of Witwatersrand.

Hale, Sondra Dungan, and Abby Gondek. 2016. Sondra Hale Interview, November 23, 2016, Regarding Her Teacher, Hilda Kuper. Los Angeles, CA.

Hall, Jacquelyn Dowd. 2005. "The Long Civil Rights Movement and the Political Uses of the Past." The Journal of American History 91(4):1233-63.

Hall, Stuart. 2001. "Negotiating Caribbean Identities." Pp. 24-39 in New Caribbean Thought: A reader, edited by B Meeks and F Lindahl. Kingston: University of West Indies Press.

Hancock, Ange-Marie. 2016. Intersectionality: An Intellectual History. Oxford: Oxford University Press.

Hanneman, Robert A., and Mark Riddle. 2005. Introduction to Social Network Methods. Riverside: University of California Riverside.

Harden, J. 2011. "Native like Me: Confessions of an Asiatic Black Anthropologist." Critique of Anthropology 31(2):139-55.

Harley, Kirsten, and Gary Wickham. 2014. "Introduction: The Main Themes and the Structure of the Book." Pp. 1-18 in Australian Sociology: Fragility, Survival, Rivalry, edited by Kirsten Harley and Gary Wickham. Houndmills, Basingstoke, Hampshire and New York, NY: Palgrave MacMillan.

Harrison, Ira E., and Faye V. Harrison. 1999. African-American Pioneers in Anthropology. Urbana: University of Illinois Press.

Hart, Mitchell B. 1999. "Racial Science, Social Science and the Politics of Jewish Assimilation." Isis 90(2):268-97.

La Hausse, Paul. 1988. Brewers, Beerhalls and Boycotts: A History of Liquor in South Africa. Johannesburg, South Africa: Ravan Press.

Healey, Mark Alan. 1998. “'The Sweet Matriarchy of Bahia': Ruth Landes' Ethnography of Race and Gender." Disposition: The Cultural Practice of Latinamericanism II 23(50):87-116. 
Helg, Aline. 2000. "Black Men, Racial Stereotyping, and Violence in the U.S. South and Cuba at the Turn of the Century." Society for Comparative Study of Society and History 42(3):576-604.

Hellmann, Ellen. 1935. "Native Life in a Johannesburg Slum Yard." Africa: Journal of the International African Institute 8(1):34-62.

Hellmann, Ellen. 1939. Original Report on Causes of Early School Leaving and Occupational Opportunities for Juveniles, 1938-1939. Johannesburg, South Africa: Ellen Hellmann Papers Box 1, File 6 Part 2, Historical Papers Archive, University of Witwatersrand.

Hellmann, Ellen. 1940a. EH as Honorary Secretary to The System Manager at Western Transvaal System SA Railways and Harbours, Johannesburg, September 17, 1940. Johannesburg, South Africa: AD1433 Joint Council Europeans and Africans, Box 21, 1940-1941, Cj 2.1.20 File 2, 1940-July-Dec, Historical Papers Archive, University of Witwatersrand.

Hellmann, Ellen. 1940b. Letter from EH as Honorary Secretary to The Secretary of the Office of the Minister of Railways and Harbours and of the Railway Board, Union Buildings in Pretoria, October 19, 1940. Johannesburg, South Africa: AD1433 Joint Council Europeans and Africans, Box 21, 1940-1941, Cj 2.1.20 File 2, 1940-JulyDec, Historical Papers Archive, University of Witwatersrand.

Hellmann, Ellen. 1940c. Letter from EH as Honorary Secretary to The Town Clerk, Johannesburg, PO Box 1049, October 18, 1940. Johannesburg, South Africa: AD1433 Joint Council Europeans and Africans, Box 21, 1940-1941, Cj 2.1.20 File 2, 1940-July-Dec, Historical Papers Archive, University of Witwatersrand.

Hellmann, Ellen. 1940d. Letter from Ellen Hellmann as Honorary Secretary of the Joint Council on Europeans and Africans to The Secretary of the Sub-Committee on Rationalisation of Consumption, Anti-Waste Campaign, Johannesburg, September 17, 1940. Johannesburg, South Africa: AD1433 Joint Council Europeans and Africans, Box 21, 1940-1941, Cj 2.1.20 File 2, 1940-July-Dec, Historical Papers Archive, University of Witwatersrand.

Hellmann, Ellen. 1940e. Problems of Urban Bantu Youth: Report of an Enquiry into the Causes of Early School Leaving and Occupational Opportunities Amongst Bantu Youth in Johannesburg. Johannesburg, South Africa: South African Institute of Race Relations.

Hellmann, Ellen. 1943. Ellen Hellmann to Colin Legum, January 7, 1943 from Umtata, Transkei. Cape Town: BC1329 Colin Legum Papers, B11.48 Letters from Dr. Ellen Koch, University of Cape Town Libraries.

Hellmann, Ellen. 1944a. Ellen Hellmann to Colin Legum, November 11, 1944 from Trinidad and Tobago on Her Way to New York. Cape Town: BC1329 Colin Legum Papers, B11.48 Letters from Dr. Ellen Koch, University of Cape Town Libraries.

Hellmann, Ellen. 1944b. "Labour Zionism in South Africa." The Pioneer Woman, Women's Labor Zionist Organization of America December:5-6. 
Hellmann, Ellen. 1945a. "America Strives for Democracy, in Ellen Hellmann Papers, Box 1, File 4." Common Sense, 309-11.

Hellmann, Ellen. 1945b. "Ellen Hellmann Looks at America: Trade Unions Wage Bitter Fight." Illustrated Bulletin; Ellen Hellmann Papers, Historical Papers Archive, William Cullen Library, University of Witwatersrand, Box 1, File 4 “America” 1945, 1970, December 5, 19.

Hellmann, Ellen. 1945c. "Interesting Women with Interesting Careers: I. Margaret Ballinger." The Bluestocking; Ellen Hellmann Papers, Box 7, File 50 "Women," November, 14-16.

Hellmann, Ellen. 1945d. Letter from Ellen Hellmann to Rheinallt Jones, Jan 23, 1945, Regarding Her Trip to the U.S. Johannesburg, South Africa: AD843RJ Box 26 Aa 3.3.5 SAIRR Head Office Correspondence: Subjects, Visits by SAIRR staff File 6, 1944-1945, Historical Papers Archive, University of Witwatersrand.

Hellmann, Ellen. 1945e. "South African Canvas." Pioneer Woman; Ellen Hellmann Papers, Box 7, File 50, “Women” 1945-1978 March:7-9.

Hellmann, Ellen. 1946. "Heartbreak House: A Liberal Look at South African Native Policy." Jewish Affairs, Jewish Board of Deputies, Johannesburg, South Africa April:9-10.

Hellmann, Ellen. 1947. "Non-European Problems in British East Africa." The Outspan; EH Box of Clippings, Jewish Board of Deputies Archive, February 28, 17, 97.

Hellmann, Ellen. 1948a. “Apartheid Cannot Work.” Jewish Affairs; Ellen Hellmann Papers, Box 1, File 5 July:4-9.

Hellmann, Ellen. 1948b. Ellen Hellmann as Chairman of the Joint Council Letter to the Editor of the Star Regarding the Issue of Demolition of Shacks in Sophiatown, October 8, 1948. Johannesburg, South Africa: AD1433, Box 23, Cj 2.1.24-2.1.28 Johannesburg Joint Council Correspondence, 1944-1948, File Cj 2.1.28 No. 2, 1948 July-Dec., Historical Papers Archive, University of Witwatersrand.

Hellmann, Ellen. 1948c. Rooiyard: A Sociological Survey of an Urban Native Slum Yard. First. Cape Town; Livingstone, Northern Rhodesia: Oxford University Press; The Rhodes-Livingstone Institute.

Hellmann, Ellen. 1950. "Plea Against Jewish 'Isolationism." Jewish Affairs, Jewish Board of Deputies, Johannesburg, South Africa 5(10):4-6.

Hellmann, Ellen. 1951. "The Jew's Problems Cannot Be Isolated.” Jewish Affairs, Jewish Board of Deputies, Johannesburg, South Africa 6(5):8-10.

Hellmann, Ellen. 1955a. "African Culture, Old and New." in 31st annual Congress of National Union of South African Students, at the University of Witwatersrand, July 3-14, 1955. Johannesburg, South Africa: Ellen Hellmann Papers Box 2, File 16 Conferences, Congresses \& Symposiums, 1955-1968, Historical Papers Archive, University of Witwatersrand.

Hellmann, Ellen. 1955b. “Dr. Ellen Hellmann on Race Relations: Lecture to Cape Zionist 
Club." South African Jewish Times; Ellen Hellmann Box No. 199 Newspaper Clippings, Jewish Board of Deputies Archive, January 25.

Hellmann, Ellen. 1956. Comments on the Sociological Aspects of the Tomlinson Report. Johannesburg, South Africa: Ellen Hellmann Papers Box 2, File 15 Commissions 1956 Tomlinson Commission Report, Historical Papers Archive, University of Witwatersrand.

Hellmann, Ellen. 1960. "The African Woman in the Change from Traditional to Modern Life." National Council of Women News; Ellen Hellmann Papers, Box 1, File 11: Black Women 1947-1975, June 11.

Hellmann, Ellen. 1961a. "90 Justinas; 40 Mandlas: Sixty Bursaries for Native Applicants." The Star; Ellen Hellmann Box of Clippings 199, Jewish Board of Deputies Archive, Beyachad Jewish Community Center, December 26.

Hellmann, Ellen. 1961b. “'Preserve Jewish Background' Dr. Ellen Hellmann Appeals L60,000 Target for Women's UCF Campaign." Southern African Jewish Times; Ellen Hellmann No.199 Box of Newspaper Clippings, Jewish Board of Deputies Archive, Beyachad Jewish Community Center, February 10.

Hellmann, Ellen. 1962a. Education for a Common Culture. Johannesburg, South Africa: Ellen Hellmann Papers, A1419, Box 1, File 6, University of Witwatersrand, Historical Papers Archive, William Cullen Library.

Hellmann, Ellen. 1962b. Letter to Voters upon Running for Office, February 1962, in Preparation for the Municipal Elections in Johannesburg, Ward 18. Johannesburg, South Africa: Ellen Hellmann Papers Box 5, File 32, Historical Papers Archive, University of Witwatersrand.

Hellmann, Ellen. 1963a. "Take off That Apron, Mr. Botha." The Star; Ellen Hellmann Box of Clippings 199, Jewish Board of Deputies Archive, Beyachad Jewish Community Center, June 11.

Hellmann, Ellen. 1963b. The Impact of City Life on Africans. Johannesburg, South Africa: Institute for the Study of Man in Africa, ISMA-Uitgawe; Ellen Hellmann Papers, Box 7, File 50, Historical Papers Archive, University of Witwatersrand.

Hellmann, Ellen. 1964. “Johannesburg's African Community in File 49, Urban Blacks and Urban Studies, 1948-1981." Pp. 1-16 in Urban Areas "Workshop" of the Interdenominational African Ministers' Association of Southern Africa, November 24-27, 1964. Johannesburg, South Africa: Ellen Hellmann Papers, A1419, Box 7, File 49, University of Witwatersrand, Historical Papers Archive, William Cullen Library.

Hellmann, Ellen. 1967. From Ellen Hellmann to Quintin Whyte, 24 July 1967, from London Where Hellmann Was on Vacation Visiting Her Daughter, Ruth. Johannesburg, South Africa: AD 1158 SAIRR, Series B History of the Institute, File B2.2 Ellen Hellmann, Historical Papers Archive, University of Witwatersrand.

Hellmann, Ellen. 1968. Ellen Hellmann Letters to Ruth Landes, 1956, 1968, 4 Letters. 
Washington DC: Box 3, Ruth Landes Papers, National Anthropological Archives, Smithsonian Institution.

Hellmann, Ellen. 1970. "The South African Community: Its Peoples, Problems and Priorities." in Union of Jewish Women of South Africa, Joburg Branch, August/September 1970, Service Leadership Training Institute. Johannesburg, South Africa: Ellen Hellmann Papers, Box 7, File 49, Urban Blacks and Urban Studies, Historical Papers Archive, University of Witwatersrand.

Hellmann, Ellen. 1973a. Letter from Ellen Hellmann to HW van Der Merwe. Johannesburg, South Africa: Ellen Hellmann Papers Box 2, File 15 Commissions Schlebusch Commission, 1973, Security Police Seizure, Historical Papers Archive, University of Witwatersrand.

Hellmann, Ellen. 1973b. Letter to Fred Van Wyk, Director of SAIRR Regarding the Behavior of Clive Nettleton, and the Schlebusch Commission, November 17, 1973. Ellen Hellmann Papers Box 2, File 15 Commissions Schlebusch Commission, 1973, Security Police Seizure, Historical Papers Archive, University of Witwatersrand.

Hellmann, Ellen. 1974. Reflections on the Report of the Schlebusch (Now Le Grange) Commission: Fifth Interim Report RP 62/1974 of the SA Institute of Race Relations. Johannesburg, South Africa: Ellen Hellmann Papers Box 2, File 15 Commissions Schlebusch Commission, 1973, Security Police Seizure, Historical Papers Archive, University of Witwatersrand.

Hellmann, Ellen. 1980. Letter to the Editor of the Sunday Express from Hellmann on 9 June 1980 Regarding an Article That Had Been Published on June 8, 1980 called "Racial Education in Black and White" by Carol Lazar in the Section Called Better Living-Talking Point. Johannesburg, South Africa: Ellen Hellmann Papers Box 1, File 6 Bantu Education, Historical Papers Archive, University of Witwatersrand.

Hellmann, Ellen. n.d. “Chapter Three: Economic Life.” Pp. 38-91 in Rooiyard Manuscript. Johannesburg, South Africa: Ellen Hellmann Papers Box 5, File 35, Historical Papers Archive, University of Witwatersrand.

Hellmann, Ellen, Ruth Glass, and Alva Myrdal. 1959. "Conference on Urban Growth, June 25-26, 1959 at Nuffield College." in Box 2, Com-Con, File 16 Conferences, Congresses and Symposiums, 1955-1968, in Ellen Hellmann Papers. Johannesburg, South Africa: Ellen Hellmann Papers, A1419, University of Witwatersrand, Historical Papers Archive, William Cullen Library.

Hellmann, Ellen Koch. 1952. Ellen Koch Hellmann Letter to Ruth Landes, March 25, 1952. Washington DC: Box 3, Ruth Landes Papers, National Anthropological Archives, Smithsonian Institution.

Hellmann, Ellen Koch. 1955. Ellen Hellmann to Colin Legum, June 15, 1955. Cape Town: BC1329 Colin Legum Papers, B11.48 Letters from Dr. Ellen Koch, University of Cape Town Libraries.

Hellmann, Ellen, and Riva Krut. 1982. Transcript of Interview Side A with Ellen Hellmann, by Riva Krut, June 3, 1982 and My Notes on Untranscribed Side B. 
Johannesburg, South Africa: BC949 Kaplan Centre Archive, University of Cape Town Libraries, Special Collections.

Hellmann, Ellen, and Fatima Meer. 1975. "There Is Still Time for a Peaceful Change in South Africa." The Star; Ellen Hellmann Box of Clippings 199, Jewish Board of Deputies Archive, Beyachad Jewish Community Center, September 4.

Hellmann, Ellen, and Alfred Xuma. 1940. Series of Letters Involving Ellen Hellmann, Alfred Xuma, the Chairman of the Joint Council of Europeans and Africans, and the Editor of the Star Newspaper, September 1940.

Herskovits, Melville J. 1943. "The Negro in Bahia, Brazil: A Problem in Method." American Sociological Review 8(4):394-404.

Herskovits, Melville J. 1948. "Review of The City of Women." American Anthropologist 50(1):123-25.

Hesse, Isabelle. 2014. "Colonizing Jewishness? Minority, Exile and Belonging in Anita Desai's Baumgartner's Bombay and Caryl Phillips's The Nature of Blood." Textual Practice 28(5):881-99.

Hier, Sean, and Candace Kemp. 2002. "Anthropological Stranger: The Intellectual Trajectory of Hortense Powdermaker.” Women's History Review 11(2):253-72.

Hintzen, Percy, and Jean Muteba Rahier. 2010. "Introduction Theorizing the African Diaspora: Metaphor, Miscognition, and Self-Recognition." Pp. ix-xxv in Global Circuits of Blackness: Interrogating the African Diaspora, edited by Jean Muteba Rahier, Percy Hintzen, and F. Smith. Urbana-Champaign: University of Illinois Press.

Hobsbawn, Eric. 1990. "Obituary of Ruth Glass: A Passionate Sociologist.” The Guardian (London, England), March 9, 39.

Hodder, Ian. 2014. "The Entanglements of Humans and Things: A Long-Term View." New Literary History 45(1):19-36.

Hoernlé, A.Winifred. 1925a. "The Importance of the Sib (Clan) in the Marriage Ceremonies of the South-Eastern Bantu." South African Journal of Science 22:48192.

Hoernlé, A.Winifred. 1925b. "The Social Organization of the Nama Hottentots of Southwest Africa." American Anthropologist 27(1):1-24.

Hoernlé, RF Alfred. 1939. Letter from RF Alfred Hoernlé to Ellen Hellmann, December 27, 1939 Regarding the Conflict between Mr. Ballinger and Mr. Saffery/Hoernlé. Johannesburg, South Africa: AD843RJ Box 23, Aa 3.2.9.2 SAIRR Head Office Corresp. w/Individuals re: Al Saffery, Friends of Africa, Historical Papers Archive, University of Witwatersrand.

Hurston, Zora Neale. 1935. Mules and Men. New York: Harper Collins.

Hurston, Zora Neale. 1938. Tell My Horse: Voodoo and Life in Haiti and Jamaica. New York: Harper Collins. 
Hutchinson, George. 2006. In Search of Nella Larsen: A Biography of the Color Line. Cambridge, MA: The Belknap Press of Harvard University Press.

Hviding, Edvard, and Cato Berg. 2014. The Ethnographic Experiment: A.M. Hocart and W.H.R. Rivers in Island Melanesia 1908. Oxford: Berghahn Books.

Hyatt, Marshall. 1990. Franz Boas, Social Activist: The Dynamics of Ethnicity. New York: Greenwood Press.

Imes, Elmer, Elizabeth Wallace Imes, and Ruth Landes. 1941. Correspondence from Elmer and Elizabeth Wallace Imes to Ruth Landes, 1938, 1940, 1941. Washington, D.C.: Ruth Landes Papers, Box 3, Letters Received, “I”, National Anthropological Archives, Smithsonian Institution.

Imes, Elmer, and Ruth Landes. 1940. "Letter from Elmer Imes to Ruth Landes, October 10, 1940, and Landes' Commentary on the Bottom, October 10, 1941."

Jansen, Willy. 2000. "Women Anthropologists in the Arab World: Recognizing the Pioneers." History and Anthropology 12(1):37-63.

Jephcott, Pearl. 1964. A Troubled Area: Notes on Notting Hill. London, England: Faber and Faber.

Jewish Board of Deputies Archive, Beyachad. 1954. "A Woman About Town." Evening Post; Ellen Hellmann Box of Clippings, February 25.

Johnson, Charles S. 1957. "A Southern Negro's View of the South.” The Journal of Negro Education 26(1):4-9.

Johnson, Charles S., and Ruth Landes. 1946. Correspondence between Charles S. Johnson and Ruth Landes, 1944-1946. Nashville, TN: Fisk University Archives; Charles S. Johnson Collection; Box 7; Folder 15; March 1944-June 1946.

Junod, Violaine. 1952. "Report on a Study of the Coloured 'Social Elite' in London." University of Edinburgh.

Junod, Violaine. n.d. Violaine Junod Letters to Hilda Kuper, Correspondence from 1970s-80s. Los Angeles, CA: Hilda Kuper Papers, Box 52, Folder 7, UCLA Special Collections, Charles E. Young Research Library.

Kamel, Rachael. 2014. "Women and the Transformation of Jewish Studies: An Oral History of the Association of Jewish Studies Women's Caucus: The Paula Hyman Oral History Project." Nashim: A journal of Jewish Women's Studies and Gender Issues 27:129-58.

King, Karen Ann Russell. 2000. "Surviving Modernity: Jewishness, Fieldwork and the Roots of American Anthropology in the 20th Century." University of Texas at Austin.

Klein, Viola. 1946. The Feminine Character: History of an Ideology. Routledge.

Klein, Viola. 1960. "Married Women in Employment." International Journal of Comparative Sociology 1(2):254-61. 
Koch, Ellen Hellmann. 1953. Ellen Koch to Colin Legum, November 3, 1953. Cape Town: BC1329 Colin Legum Papers, B11.48 Letters from Dr. Ellen Koch, University of Cape Town Libraries.

Koch, Ellen Hellmann, and Colin Legum. 1971. Correspondence between Dr. Ellen Koch and Colin Legum, 1943-1971. Cape Town: BC1329 Colin Legum Papers, B11.48 Letters from Dr. Ellen Koch, University of Cape Town Libraries.

Kohen, Robert Dean. 2014. "Dreaming Empire: European Writers in the Fascist Era." Harvard University Graduate School of Arts and Sciences.

Krut, Riva. 1984. "The Making of a South African Jewish Community in Johannesburg, 1886-1914.” Pp. 135-59 in Class, Community and Conflict, South African Perspectives, History Workshop 3, edited by Belinda Bozzoli. Johannesburg, South Africa: Ravan Press.

Kuby, David, and Abby Gondek. 2017. David Kuby and Abby Gondek Email Correspondence, December 2016 and January 2017. Thousand Oaks, CA.

Kuper, Adam. 1994. “Obituary Leo Kuper.” The Independent, May 27.

Kuper, Adam. 2007. "Isaac Schapera (1905-2003) His Life and Times.” Pp. 19-42 in Picturing a Colonial Past: The African Photographs of Isaac Schapera, edited by John L. Comaroff, Jean Comaroff, and Deborah James. Chicago: The University of Chicago Press.

Kuper, Hilda. 1947. The Uniform of Colour; a Study of White-Black Relationships in Swaziland. New York: Negro Universities Press.

Kuper, Hilda. 1957. The Decision: A Contemporary South African Indian Play. Los Angeles, CA: Sondra Hale Personal Collection, UCLA Anthropology Department.

Kuper, Hilda. 1960. Indian People in Natal. Durban, Natal, South Africa: The University Press in Natal.

Kuper, Hilda. 1961. An African Aristocracy: Rank among the Swazi. Published for the International African Institute by the Oxford University Press.

Kuper, Hilda. 1965. Bite of Hunger: A Novel of Africa. Harcourt, Brace \& World.

Kuper, Hilda. 1970. Hilda Kuper to Fatima Meer and Ismail Meer, March 20, 1970. Los Angeles, CA: Hilda Kuper Papers, Box 41, Folder 9, UCLA Special Collections, Charles E. Young Research Library.

Kuper, Hilda. 1972. Memo to the "Gentlemen" of the African Studies Center M.A. Program at UCLA, June 8, 1972, to Recommend That Teresa Thoko Ginindza Be Awarded Her M.A. in African Studies. Los Angeles, CA: Hilda Kuper Papers, Box 24, Folder 20, UCLA Special Collections, Charles E. Young Library.

Kuper, Hilda. 1973. "Costume and Identity." Comparative Studies in Society and History 15(3):348-67.

Kuper, Hilda. 1975a. "Bird of the Storm." Pp. 221-28 in Studies in African Social Anthropology: Essays presented to Isaac Schapera, edited by Meyer Fortes and 
Sheila Patterson. London, England: Academic Press, subsidiary of Harcourt Brace Jovanovich.

Kuper, Hilda. 1975b. Hilda Kuper to Teresa Thoko Ginindza, April 26, 1975 Regarding Cost of Object Collections. Los Angeles, CA: Hilda Kuper Papers, Box 24 folder 20, Special Collections, Charles E. Young Research Library, UCLA.

Kuper, Hilda. 1975c. Hilda Kuper to Teresa Thoko Ginindza, March 13, 1975 Regarding the Museum Collections. Los Angeles, CA: Hilda Kuper Papers, Box 24, Folder 20, UCLA Special Collections, Charles E. Young Library.

Kuper, Hilda. 1978. Sobhuza II, Ngwenyama and King of Swaziland: The Story of an Hereditary Ruler and His Country. New York, N.Y.: Africana Publishing, Holmes \& Meier.

Kuper, Hilda. 1984. "Function, History, Biography: Reflections on Fifty Years in the British Anthropological Tradition.” Pp. 192-213 in Functionalism Historicized: Essays on British Social Anthropology, edited by George W. Jr. Stocking. University of Wisconsin Press.

Kuper, Hilda. 1993. A Witch in My Heart: Short Stories and Poems. edited by Nancy Schmidt. Madison: African Studies Program, University of Wisconsin--Madison.

Kuper, Hilda, Ruth First, Kay Theron, Myrtle Canan, and Selma Kaplan. 1945. Marriage. Los Angeles, CA: Hilda Kuper Papers, Box 41, Folder 6, UCLA Special Collections, Charles E. Young Research Library.

Kuper, Hilda, and Teresa Thoko Ginindza. 1975. Correspondence between Hilda Kuper and Teresa Thoko Ginindza, March and April 1975 Regarding Swazi Material Culture Collection. Los Angeles, CA: Hilda Kuper Papers, Box 24 folder 20, Special Collections, Charles E. Young Research Library, UCLA.

Kuper, Hilda, and Teresa Thoko Ginindza. 1976. Box 24 Teresa Thoko Ginindza Correspondence Folder 20, Also Folders 9 and 11. Los Angeles, CA: Hilda Kuper Papers, UCLA Special Collections, Charles E. Young Research Library.

Kuper, Hilda, and International African Institute. 1970. A Witch in My Heart: A Play Set in Swaziland in the 1930s. Oxford U.P.

Kuper, Hilda, and Selma Kaplan. 1944. "Voluntary Associations in an Urban Township." African Studies 3(4):178-86.

Kuper, Hilda, and Fatima Meer. 1956. "Indian Elites in Natal, South Africa.” Pp. 129-45 in Social Science Conference, University of Natal, Institute for Social Research. Durban, Natal, South Africa: University of Natal, Institute for Social Research.

Kuper, Hilda, Fatima Meer, R. Singh, and Regina Twala. 1953. Hilda Kuper Papers, Boxes 14 (Fatima Meer and R. Singh Fieldnotes), 19 (Folder 2: Regina Twala Manuscript). Los Angeles: UCLA Special Collections.

Landes, Ruth. 1933. Negro Jews in Harlem. Washington, DC: Box 49, Ruth Landes Papers, National Anthropological Archives, Smithsonian Institution. 
Landes, Ruth. 1937a. Ruth Landes to Ruth Benedict, October 7, 1937 from Fisk University. Poughkeepsie, NY: Ruth Fulton Benedict Papers, Folder 31.3, Correspondence with Ruth Landes, 1934-1937; Archives and Special Collections Library, Vassar College Libraries.

Landes, Ruth. 1937b. Ruth Landes to Ruth Benedict December 2, 1937 from Fisk University. Poughkeepsie, NY: Ruth Fulton Benedict Papers, Folder 31.3 Correspondence with Ruth Landes, 1934-1937, Archives and Special Collections Library, Vassar College Libraries.

Landes, Ruth. 1938a. Ruth Landes Brazil Notebook II. Washington, DC: Box 9 Brazil Notebooks, Ruth Landes Papers, National Anthropological Archives, Smithsonian Institution.

Landes, Ruth. 1938b. Ruth Landes to Ruth Benedict, February 18 [1938] from Fisk University. Poughkeepsie, NY: Ruth Benedict Papers Folder 31.3 Correspondence with Ruth Landes, 1934-1937, Archives and Special Collections Library, Vassar College Libraries.

Landes, Ruth. 1938c. Ruth Landes to Ruth Benedict, November 17, 1938 Regarding Fieldwork in Bahia with Assistance of a Female Priestess from One of the Oldest and Most Famous Cults. Poughkeepsie, NY: Ruth Benedict Papers Folder 31.4 Correspondence with Ruth Landes, 1938-1939, Archives and Special Collections Library, Vassar College Libraries.

Landes, Ruth. 1938d. Ruth Landes to Ruth Benedict, September 22, 1938, Comparisons between Bahia, Fisk, Harlem, and Native American Fieldwork, Discusses the Work of Edison Carneiro, Zora Neale Hurston. Poughkeepsie, NY: Ruth Benedict Papers Folder 31.4 Correspondence with Ruth Landes, 1938-1939, Archives and Special Collections Library, Vassar College Libraries.

Landes, Ruth. 1939a. Ruth Landes Brazil Notebook XV. Washington, DC: Box 9 Brazil Notebooks, Ruth Landes Papers, National Anthropological Archives, Smithsonian Institution.

Landes, Ruth. 1939b. Ruth Landes to Melville Herskovits, September 30, 1939. Evanston, Illinois: Northwestern University Archives; Melville Herskovits Papers; Series 35/6; Box 12; Folder 13, Correspondence between Herskovits and Ruth Landes, 19391940.

Landes, Ruth. 1939c. Ruth Landes to Ruth Benedict, February 15, 1939, Regarding Forced Exile from Bahia. Poughkeepsie, NY: Ruth Benedict Papers Folder 31.4 Correspondence with Ruth Landes, 1938-1939, Archives and Special Collections Library, Vassar College Libraries.

Landes, Ruth. 1939d. Ruth Landes to Ruth Benedict, Undated but Probably April 1939, Regarding Anti-Semitism and Heloisa Torres' Antipathy toward Lipkind, Landes Praises Edison Carneiro. Poughkeepsie, NY: Ruth Benedict Papers Folder 31.4 Correspondence with Ruth Landes, 1938-1939, Archives and Special Collections Library, Vassar College Libraries. 
Landes, Ruth. 1939e. Ruth Landes to Ruth Benedict, Undated Letter, Probably End of February or Beginning of March 1939, Regarding Why Columbia University Viewed with Suspicion in Bahia. Poughkeepsie, NY: Ruth Benedict Papers Folder 31.4 Correspondence with Ruth Landes, 1938-1939, Archives and Special Collections Library, Vassar College Libraries.

Landes, Ruth. 1939f. Ruth Landes to Ruth Benedict Undated, August 1939. Poughkeepsie, NY: Ruth Benedict Papers Folder 31.4 Correspondence with Ruth Landes, 1938-1939, Archives and Special Collections Library, Vassar College Libraries.

Landes, Ruth. 1939g. The Ethos of the Negro in the New World: A Research Memorandum Under the Direction of Guy B. Johnson. Washington DC: Carnegie Myrdal Study, The Negro in America, Box 48 Ruth Landes Papers, National Anthropological Archives.

Landes, Ruth. 1940a. "A Cult Matriarchate and Male Homosexuality." The Journal of Abnormal and Social Psychology 35(3):386-97.

Landes, Ruth. 1940b. "Fetish Worship in Brazil." The Journal of American Folklore 53(210):261-70.

Landes, Ruth. 1944. Letter to Charles S. Johnson, Regarding Zionist Uses of Race, March 6, 1944. Nashville, TN: Fisk University Archives; Charles S. Johnson Collection; Box 7; Folder 15; March 1944-June 1946.

Landes, Ruth. 1947. The City of Women. New York: The MacMillan Company.

Landes, Ruth. 1949. Mañana, A Cultural Study in American Liberties: Chapter OneConfusion \& Outline of Chapters Four-Thirteen. Washington, DC: Box 49, Mañana Folder 1, Ruth Landes Papers, National Anthropological Archives, Smithsonian Institution.

Landes, Ruth. 1951. Memorandum Regarding Jewish National Character. Washingtion DC: Box 49, Ruth Landes Papers, National Anthropological Archives, Smithsonian Institution.

Landes, Ruth. 1952. "A Preliminary Statement of a Survey of Negro-White Relationships in Britain.” Man: Royal Anthropological Institute Proceedings 52:133.

Landes, Ruth. 1953. "Negro Slavery and Female Status.” African Affairs 52(206):54-57.

Landes, Ruth. 1954. Manuscript Entitled Color in Britain: A Study of Emerging Biracialism. Washington, D.C.: Ruth Landes Fund, Reed Foundation; Ruth Landes Papers Box 48, National Anthropological Archives, Smithsonian Institution.

Landes, Ruth. 1957. Ruth Landes to Louise Nocktonick, September 5, 1957. Washington DC: Box 1 Letters Sent 1957-58 and 1977-79, Ruth Landes Papers, National Anthropological Archives, Smithsonian Institution.

Landes, Ruth. 1958. Holiday Card from Ruth Lopez to Luz, December 25, 1958. Washington, DC: Box 1 Letters Sent, Ruth Landes Papers, National Anthropological Archives, Smithsonian Institution. 
Landes, Ruth. 1960. A Chronicle of Bloods Folder One, Part One. Washington, DC: A Chronicle of Bloods Folder 1, Box 47, Ruth Landes Papers, National Anthropological Archives, Smithsonian Institution.

Landes, Ruth. 1965. Culture in American Education: Anthropological Approaches to Minority and Dominant Groups in the Schools. New York: John Wiley and Sons, Inc.

Landes, Ruth. 1967. Letter from Ruth Landes to Ruth Sawtell Wallis, July 10, 1967. Washington DC: Box 1, Folder: Letters Sent 1966-69, Ruth Landes Papers, National Anthropological Archives, Smithsonian Institution.

Landes, Ruth. 1968. Letter to Ellen Hellman from Ruth Landes, 20 February 1968. Washington, DC: Box 1 Letters Sent, Ruth Landes Papers, National Anthropological Archives, Smithsonian Institution.

Landes, Ruth. 1970a. "A Woman Anthropologist in Brazil." Pp. 119-42 in Women in the Field: Anthropological Experiences, edited by Peggy Golde. Chicago, Illinois: Aldine Publishing Company.

Landes, Ruth. 1970b. Letter from Ruth Landes to Audrey Richards, 20 November 1970. Washington DC: Box 1: Letters Sent, Folder 1970-72, Ruth Landes Papers, National Anthropological Archives, Smithsonian Institution.

Landes, Ruth. 1970c. Letter from Ruth Landes to Audrey Richards, 9 October 1970. Washington DC: Box 1: Letters Sent, Folder 1970-72, Ruth Landes Papers, National Anthropological Archives, Smithsonian Institution.

Landes, Ruth. 1970d. The Prairie Potawatomi: Tradition and Ritual in the Twentieth Century. Madison: University of Wisconsin Press.

Landes, Ruth. 1977. Ruth Landes to Kurt Mayer 8 December 1977. Washington DC: Box 1, Letters Sent, Ruth Landes Papers, National Anthropological Archives, Smithsonian Institution.

Landes, Ruth. 1978. Ruth Landes to Kee Peschel, November 16, 1978. Washington DC: Box 1 Letters Sent 1957-58 and 1977-79, Ruth Landes Papers, National Anthropological Archives, Smithsonian Institution.

Landes, Ruth. 1980. Afrikanerdom and the English-Speaking. Washington, DC: Box 54, Folder 2: Afrikanerdom and the English Speaking, Ruth Landes Papers, National Anthropological Archives, Smithsonian Institution.

Landes, Ruth. 1983. Ruth Landes to Zvi Gitelman, 18 May 1983. Washington DC: Box 1 Letters Sent 1980-1984, Ruth Landes Papers, National Anthropological Archives, Smithsonian Institution.

Landes, Ruth. 1984a. Letter to Nancy O. Lurie, February 25, 1984 Regarding Kee Peschel and Landes Object Collection. Washington, D.C.: Ruth Landes Papers Box 1 Letters Sent 1980-1984, National Anthropological Archives, Smithsonian Institution.

Landes, Ruth. 1984b. Letter to Nancy O. Lurie Regarding Keewaydinoquay Peschel as 
Curator of Landes Ojibwa Objects, February 6, 1984. Washington, D.C.: Ruth Landes Papers Box 1 Letters Sent 1980-1984, National Anthropological Archives, Smithsonian Institution.

Landes, Ruth. 1984c. "Review of Ruth Benedict: Patterns of a Life, by Judith S. Modell." American Journal of Orthopsychiatry 54(2):348-50.

Landes, Ruth. 1984d. Ruth Landes Letters Sent, Box 1, Folder 1980-1984. Washington DC: Box 1 Letters Sent, Ruth Landes Papers, National Anthropological Archives, Smithsonian Institution.

Landes, Ruth. 1985a. Color Cancer 1940, Edited in 1985. Washington, DC: Color Cancer Folder, Box 47, Ruth Landes Papers, National Anthropological Archives, Smithsonian Institution.

Landes, Ruth. 1985b. Letter from Ruth Landes to Boneta LeBeau Fite, July 1, 1985. Washington, DC: Box 1 Letters Sent, 1985-1986, Ruth Landes Papers, National Anthropological Archives, Smithsonian Institution.

Landes, Ruth. 1985c. Letter from Ruth Landes to Dr. Bettye Collier-Thomas, Director of the Bethune Museum-Archives, National Archives for Black Women's History, August 7, 1985. Washington, DC: Box 1, Folder Letters Sent 1985-1986, Ruth Landes Papers, National Anthropological Archives, Smithsonian Institution.

Landes, Ruth. 1985d. Letter from Ruth Landes to George and Alice Park, Anthropology Department, Memorial University of Newfoundland, August 31, 1985. Washington, DC: Box 1, Folder: Letters Sent 1985-1986, Ruth Landes Papers, National Anthropological Archives, Smithsonian Institution.

Landes, Ruth. 1985e. Letter to Julian Bach from Ruth Landes May 12, 1985. Washington, DC: Box 1 Letters Sent, Ruth Landes Papers, National Anthropological Archives, Smithsonian Institution.

Landes, Ruth. 1986a. Landes Letter to Joe Richardson, June 23, 1986, Pages 1-3. Washington, DC: Box 1 Letters Sent, Ruth Landes Papers, National Anthropological Archives, Smithsonian Institution.

Landes, Ruth. 1986b. Letter from Ruth Landes August 24, 1986 Regarding Ignacio's Alcoholism and Feminism Pre-Civil War. Washington, DC: Box 1 Letters Sent, Ruth Landes Papers, National Anthropological Archives, Smithsonian Institution.

Landes, Ruth. 1986c. Letter from Ruth Landes to Mariza Correa, April 6, 1986. Washington, DC: Ruth Landes Papers, Box 1 Letters Sent 1985-6, National Anthropological Archives, Smithsonian Institution.

Landes, Ruth. 1986d. Letter from Ruth Landes to Professor Levinstein, September 7, 1986 (Includes Both Pages). Washington, DC: Box 1 Letters Sent, Ruth Landes Papers, National Anthropological Archives, Smithsonian Institution.

Landes, Ruth. 1986e. Letter to Professor Levinstein from Ruth Landes September 7, 1986. Washington, DC: Box 1 Letters Sent, Ruth Landes Papers, National Anthropological Archives, Smithsonian Institution. 
Landes, Ruth. 1986f. Ruth Landes Letter to Dr. Joe Richardson July 17, 1986. Washington, DC: Box 1 Letters Sent 1985-1986, Ruth Landes Papers, National Anthropological Archives, Smithsonian Institution.

Landes, Ruth. 1986g. Ruth Landes Letter to Eli Marks, November 8, 1986 Pages 1-4. Washington, DC: Box 1 Letters Sent 1985-1986, Ruth Landes Papers, National Anthropological Archives, Smithsonian Institution.

Landes, Ruth. 1986h. Ruth Landes Letter to Eli Marks on November 8, 1986. Washington, DC: Ruth Landes Papers, Box 1 Letters Sent 1985-86, National Anthropological Archives, Smithsonian Institution.

Landes, Ruth. 1987a. Letter from Landes to John Hope Franklin, September 20, 1987. Washington, D.C.: Folder: Letters sent 1987-1990, Ruth Landes Papers, National Anthropological Archives, Smithsonian Institution.

Landes, Ruth. 1987b. Letter from Ruth Landes to Alan Pifer of the Carnegie Corporation in New York, 3 May 1987. Washington, D.C.: Ruth Landes Papers, Box 1 Letters Sent, Folder 1987-1990, National Anthropological Archives, Smithsonian Institution.

Landes, Ruth. 1987c. Letter from Ruth Landes to Edgar Thompson, Duke Emiritus Professor of Sociology, 20 January 1987. Washington, DC: Box 1: Letters Sent 1987-1990; Ruth Landes Papers, National Anthropological Archives, Smithsonian Institution.

Landes, Ruth. 1987d. Letter from Ruth Landes to John Hope Franklin, August 20, 1987. Washington, DC: Ruth Landes Papers, National Anthropological Archives, Smithsonian Institution.

Landes, Ruth. 1987e. Ruth Landes Letter to Professor Franklin, September 20, 1987. Washington, DC: Box 1 Letters Sent, Ruth Landes Papers, National Anthropological Archives, Smithsonian Institution.

Landes, Ruth. 1990. Ruth Landes Letters Sent 1987-1990. Washington, DC: Box 1: Letters Sent 1987-1990; Ruth Landes Papers, National Anthropological Archives, Smithsonian Institution.

Landes, Ruth. 2010. Ruth Landes Accession File No. 1048265. Washington, DC: National Museum of Natural History Collections Records Room, Anthropology Department, Smithsonian Institution.

Landes, Ruth. n.d. A Chronicle of Bloods Folder 3, a Separate Version than Folders 1 and 2. Washington, DC: Box 47, Folder 3, Ruth Landes Papers, National Anthropological Archives, Smithsonian Institution.

Landes, Ruth. n.d. Seminar Notes for Culture and Personality (Mexican Male). Washington DC: Ruth Landes Papers, Box 60, Series 4 Teaching Materials, National Anthropological Archive, Smithsonian Institution.

Landes, Ruth. n.d. The Magician and the Girl. Washington, DC: Box 49, Ruth Landes Papers, National Anthropological Archives, Smithsonian Institution. 
Landes, Ruth, and Sally Cole. 1997. The Ojibwa Woman. University of Nebraska Press.

Landes, Ruth, and Mark Zborowski. 1950. "Hypotheses Concerning the Eastern European Jewish Family.” Psychiatry 13:447-64.

Langness, L. L., and Gelya Frank. 1981. “An Interview with Hilda Kuper, June 1979.” Pp. 143-54 in Lives: An Anthropological Approach to Biography. Novato, CA: Chandler \& Sharp.

Lapkin, Alexandra. 2015. "Rabbi Pesner Goes to Washington; Local Rabbi Takes a Leadership Role in the Reform Movement." The Jewish Advocate (Boston, MA) 206(4):1.

Laslett, Barbara, and Barrie Thorne. 1997. "Life Histories of a Movement: An Introduction." Pp. 1-27 in Feminist Sociology: Life Histories of a Movement, edited by Barbara Laslett and Barrie Thorne. New Brunswick, N.J.: Rutgers University Press.

Latour, Bruno. 1990. On Actor-Network Theory A Few Clarifications plus More than a Few Complications. Paris and San Diego.

Laurence, Patrick. 1973. "Division among the Unifiers." The Star; Ellen Hellmann Box of Clippings, No. 199, Jewish Board of Deputies Archive, Beyachad, May 11, 25.

Legum, Colin. 1946. Colin Legum November 9 and 10, 1946 Diary Entries Regarding Ellen Hellmann and Bodo Koch. BC1329 Colin Legum Papers, F1.1.1 November 1946 Diaries, November 9 and 10, 1946, University of Cape Town Libraries.

Leonardo, Micaela di. 1991. "Gender, Culture and Political Economy: Feminist Anthropology in Historical Perspective." in Gender at the Crossroads of Knowledge: Feminist Anthropology in the Postmodern Era, edited by Micaela di Leonardo. Berkeley: University of California Press.

Leveson, Marcia. 2000. "Insiders on Outsiders: Some South African Jewish Writers.” Pp. 60-75 in Memories, Realities and Dreams: Aspects of the South African Jewish Experience, edited by Milton Shain and Richard Mendelsohn. Johannesburg, South Africa: Jonathan Ball Publishers.

Lewis, David Levering. 2013. "Parallels and Divergences : Assimilationist Strategies of Afro-American and Jewish Elites from 1910 to the Early 1930s." Journal of American History 71(3):543-64.

Lewis, Herbert S. 2008. "Franz Boas: Boon or Bane?” Reviews in Anthropology 37(23):169-200.

Little, Kenneth. 1960. "Research Report No. 2 Department of Social Anthropology, The University of Edinburgh.” The Sociological Review 8(2):255-66.

Little, Kenneth. 1972. Negroes in Britain: A Study of Racial Relations in English Society. 2nd editio. London and Boston: Routledge \& Kegan Paul.

Longmore, Laura. 1959. The Dispossessed: A Study of the Sex-Life of Bantu Women in Urban Areas and Around Johannesburg. London: Jonathan Cape. 
Lovisek, Joan A., Tim E. Holzkamm, and Leo G. Waisberg. 1997. "Fatal Errors: Ruth Landes and the Creation of the "Atomistic Ojibwa."' Anthropologica 39(1):133.

Lynn, Denise. 2014. "Socialist Feminism and Triple Oppression: Claudia Jones and African American Women in American Communism." Journal for the Study of Radicalism 8(2):1-20.

Lyon, E.Stina. 2007. "Viola Klein: Forgotten Émigré Intellectual, Public Sociologist and Advocate of Women." Sociology 41(5):829-42.

Macmillan, Hugh. 1995. “Administrators, Anthropologists, and 'Traditionalists' in Swaziland: The Case of the 'AmaBhaca' Fines." Africa 65(4):545-64.

Magubane, Zine. 2014. 'Science, Reform, and the 'Science of Reform': Booker T Washington, Robert Park, and the Making of a 'Science of Society.'" Current Sociology 62(4):568-83.

Maor, Maya. 2012. "Fat Women: The Role of the Mother-daughter Relationship Revisited." Women's Studies International Forum 35(2):97-108.

Marshall, Jennifer L.Freeman. 2008. "Constructions of Literary and Ethnographic Authority, Canons, Community and Zora Neale Hurston.” Emory University.

Masha, Louise. 1936. Louise Masha to Ruth Landes, July 1, 1936. Washington DC: Box 4, Letters Received from Louise Masha (maiden name), Folder Mas-May, Ruth Landes Papers, National Anthropological Archives, Smithsonian Institution.

Matsumoto, Mio. 2005. “E. Franklin Frazier on W.E.B. Du Bois: Sociologist, Critic, and Friend." Souls 7(3-4):55-71.

Mbembe, Achille. 1992. "Provisional Notes on the Postcolony." Africa 62(1):3-37.

McBee, Richard. 2004. "The Last Jew: A Tragedy By David Pinski.” The Jewish Press, June 9.

McClaurin, Irma. 2001. Black Feminist Anthropology. New Brunswick, N.J.: Rutgers University Press.

McClaurin, Irma. 2009. "Walking in Zora's Shoes or 'Seek [ Ing ] Out de Inside Meanin' of Words': The Intersections of Anthropology, Ethnography, Identity, and Writing." Pp. 119-33 in Anthropology off the Shelf: Anthropologists on Writing, edited by Alisse Waterston and Maria D. Vesperi. Blackwell Publishing Ltd.

McClintock, Anne. 1991. “'No Longer in a Future Heaven': Women and Nationalism in South Africa." Transition/Position (51):104-23.

McDowell, Linda. 1993. "Space, Place and Gender Relations: Part I. Feminist Empiricism and the Geography of Social Relations." Progress in Human Geography 17(2):157-79.

McGee, R.Jon, and Richard L. Warms. 2008. Anthropological Theory: An Introductory History. Fourth Edi. Boston: McGraw Hill.

Meer, Fatima. 1970. Letter to Hilda Kuper. Los Angeles, CA: Hilda Kuper Papers, Box 
41, Folder 10, UCLA, Charles E. Young Research Library, Special Collections.

Meer, Fatima. 1976. Race and Suicide in South Africa. London: Routledge \& Kegan Paul.

Meer, Fatima. 2017. Fatima Meer: Memories of Love and Struggle. edited by Shamim Meer. Cape Town: Kwela Books.

Messer, Ellen. 1986. "Franz Boas and Kaufmann Kohler: Anthropology and Reform Judaism.” Jewish Social Studies 48(2):127-40.

Meyer, Leisa D. 2012. “'Strange Love': Searching for Sexual Subjectivities in Black Print Popular Culture during the 1950s." Feminist Studies 38(3):625-57.

Mickens, Ronald E. 2017. Letter to Abby Gondek Regarding Ruth Landes and Elmer Imes, December 29, 2017. Atlanta, GA: Clark Atlanta University.

Mikell, Gwendolyn. 1983. "The Anthropological Imagination of Zora Neale Hurston." The Western Journal of Black Studies 7(1):27-35.

Mikell, Gwendolyn. 1999. "Feminism and Black Culture in the Ethnography of Zora Neale Hurston." Pp. 51-69 in African American Pioneers in Anthropology, edited by Ira E. Harrison and Faye V. Harrison. Urbana: University of Illinois Press.

Mingione, Enzo, and Abby Gondek. 2017. Correspondence between Enzo Mingione and Abby Gondek, Regarding Ruth Glass, September and December 2017. Miami and Milan: University of Milano-Bicocca, Florida International University.

Mitchell, M. K. 1962. Safeguard Your Future: Principles and Policies of the Progressive Party of South Africa. Johannesburg, South Africa: Ellen Hellmann Papers Box 5, File 32, Historical Papers Archive, University of Witwatersrand.

Mohanram, Radhika. 1999. "2: The Embodiment of Blackness.” Pp. 23-55 in Black Body: Women, Colonialism and Space. Minneapolis, MN: University of Minnesota Press.

Moloney, Pat. 2005. "Savages in the Scottish Enlightenment's History of Desire." Journal of the History of Sexuality 14(3):237-65.

Moran, Katy. 1988. "Hilda Beemer Kuper (1911- ).” Pp. 194-201 in Women Anthropologists: Selected Biographies, edited by Ute Gacs, Aisha Khan, Jerrie McIntyre, and Ruth Weinberg. Urbana: University of Illinois Press.

Morris-Reich, Amos. 2008. The Quest for Jewish Assimilation in Modern Social Science. New York: Routledge.

Morris, Aldon D. 2007. "Sociology of Race and W.E.B. Du Bois: The Path Not Taken." Pp. 503-34 in Sociology in America: A History, edited by Craig Calhoun. Chicago: University of Chicago Press.

Moustakas, Clark. 1990. Heuristic Research: Design, Methodology, and Applications. Newbury Park, CA: Sage Publications, Inc.

Mudimbe, VY, and Kwame Anthony Appiah. 1993. "The Impact of African Studies on 
Philosophy." Pp. 113-38 in Africa and the Disciplines: The Contributions of Research in Africa to the Social Sciences and Humanities, edited by JF O'Barr, RH Bates, and VY Mudimbe. Chicago: University of Chicago Press.

Mufti, Aamir. 2007. Enlightenment in the Colony: The Jewish Question and the Crisis of Postcolonial Culture. Princeton University Press.

Mufti, Aamir R. 1995. "Secularism and Minority: Elements of a Critique." Social Text 45(Winter):75-96.

Mufti, Aamir R. 1998. "Auerbach in Istanbul: Edward Said, Secular Criticism, and the Question of Minority Culture." Critical Inquiry 25(1):95-125.

Narayan, Uma. 1997. Dislocating Cultures: Identities, Traditions and Third World Feminism. New York: Routledge.

Nava, Mica. 2007. Visceral Cosmopolitanism: Gender, Culture and the Normalisation of Difference. Oxford: Berg.

Nava, Mica. 2013. American Anthropologist Ruth Landes and Race Relations Research in Postwar Britain. University of East London Open Access Repository.

Del Negro, Giovanna P. 2010. "The Bad Girls of Jewish Comedy: Gender, Class, Assimilation and Whiteness in Postwar America." Pp. 144-59 in A Jewish Feminine Mystique? Jewish Women in Postwar America, edited by Hasia R. Diner, Shira Kohn, and Rachel Kranson. New Brunswick, N.J.: Rutgers University Press.

Nettleton, Clive. 1973. SAIRR RR 64/73, SM 8/5/73 (8 May 1973) The Young Person's Guide to the Road Ahead. Johannesburg, South Africa: Ellen Hellmann Papers Box 2, File 15 Commissions Schlebusch Commission, 1973, Security Police Seizure, Historical Papers Archive, University of Witwatersrand.

Nocktonick, Louise Masha. 1966. Louise Nocktonick to Ruth Landes, March 8, 1958 December 14, 1966, 5 Letters. Washington DC: Box 5 Letters Received, Folder No$\mathrm{Nu}$, Letters from Louise Masha Nocktonick, Ruth Landes Papers, National Anthropological Archives, Smithsonian Institution.

Nocktonick, Louise Masha, and Ruth Landes. 1975. Louise Nocktonick to Ruth Landes: December 11, 1967, March 26, 1969, December 12, 1969, January 2, 1975 (Final Angry Letter); Ruth Landes to Louise Nocktonick June 5 1969. Washington DC: Box 5 Letters Received, Folder No-Nu, Letters from Louise Masha Nocktonick, Ruth Landes Papers, National Anthropological Archives, Smithsonian Institution.

Okely, Judith, and Helen Callaway. 1992. Anthropology and Autobiography. edited by Judith Okely and Helen Callaway. London, England: Routledge.

Omi, Michael, and Howard Winant. 2014. Racial Formation in the United States. Routledge.

Online, South African History. 2015. "Ellen Phyllis Hellman Biography." South African History Online: towards a people's history 1-2. Retrieved January 21, 2016 (http://www.sahistory.org.za/people/ellen-phyllis-hellman). 
Overmyer-Velázquez, Rebecca. 2005. "Christian Morality in New Spain: The Nahua Woman in the Franciscan Imaginary." Bodies in Contact: Rethinking Colonial Encounters in World History 67-83.

Oxford Dictionary of National Biography. 2004. "Glass [Née Lazarus; Other Married Name Durant], Ruth Adele (1912-1990).” Oxford Dictionary of National Biography.

Padilla, Mark. 2013. "Syndemics Project Funded Grant.” NSF Grant.

Pallares-Burke, Maria Lucia. 2013. "BRASIL, LABORATÓRIO DE CIVILIZAÇÃO: A Importância de Rüdiger Bilden.” Politica e Trabalho 39:179-94.

Pallares-Burke, Maria Lúcia. 2012. "Epilogo: Vencedores E Perdedores: Gilberto Freyre E Rudiger Bilden." in O Triunfo do Fracasso: Rudiger Bilden, o Amigo Esquecido de Gilberto Freyre. Editora UNESP.

Palmer, Phyllis M. 1989. Domesticity and Dirt: Housewives and Domestic Servants in the United States 1920-1945. Temple University Press.

Parezo, Nancy J. 1993. Hidden Scholars: Women Anthropologists and the Native American Southwest. Albuquerque: University of New Mexico Press.

Party, The Progressive. 1959. The Progressive Party - Main Principles and Politics, Adopted at the Inaugural Congress, November 13-14, 1959. Johannesburg, South Africa: Ellen Hellmann Papers Box 5, File 32, Historical Papers Archive, University of Witwatersrand.

Patel, Sujata. 2011. "Introduction: Ruminating on Sociological Traditions in India." Pp. xi-xxxviii in Doing Sociology in India: Genealogies, Locations and Practices, edited by Sujata Patel. New Delhi: Oxford University Press.

Patil, Vrushali. 2008. Negotiating Decolonization in the United Nations: Politics of Space, Identity, and International Community. 1st ed. Routledge.

Patil, Vrushali. 2016. "Chapter Seven: Sex Gender and Sexuality in Colonial Modernity: Towards a Sociology of Webbed Connectivities." Pp. 139-55 in Global Historical Sociology, edited by Julian Go and George Lawson. Cambridge: Cambridge University Press.

Patterson, Sheila. 1963. Dark Strangers: A Sociological Study of the Absorption of a Recent West Indian Migrant Group in Brixton, South London. Bloomington: Indiana University Press.

Patterson, Sheila. 1973. "Review of South Africa: Sociological Perspectives. Ed. by Heribert Adam. London: Oxford University Press, 1971. Pp. Xii-340. L3.50.” Africa: Journal of the International African Institute 43(2):177-78.

Patterson, Sheila. 1983. "In Memorium: Ellen Hellmann, Hansi Pollak, Monica Wilson." New Community 10(3):505-7.

Patterson, Tiffany, and Robin. Kelley. 2000. "Unfinished Migrations: Reflections on the African Diaspora and the Making of the Modern World." African Studies Review 43(1):11-45. 
Perkins, Linda M. 2011. Final Report of Landes Grant. Claremont.

Perkins, Linda M., Sally Cole, and Mica Nava. 2013. Correspondence Regarding Ruth Landes and Elmer Imes, November 2013. Miami, Pasadena, London, Montreal: Florida International University, Claremont Graduate University, University of East London, Concordia University,.

Peschel, Keewaydinoquay. 1978. Kee Peschel to Ruth Landes, Nov 21, 1978. Washington DC: Box 5 Letters Received, Folder Pa-Pe, Letters from Kee Peschel, Ruth Landes Papers, National Anthropological Archives, Smithsonian Institution.

Peschel, Keewaydinoquay. 1988. Kee Peschel to Ruth Landes, 1980-88, 8 Letters. Washington DC: Box 5 Letters Received, Folder Pa-Pe, Letters from Kee Peschel, Ruth Landes Papers, National Anthropological Archives, Smithsonian Institution.

Phillips, Danielle Taylor. 2013. "Moving with the Women: Tracing Racialization, Migration and Domestic Workers in the Archive." Signs 38(2):379-404.

Pierre, Jemima. 2004. "Black Immigrants in the United States and the 'Cultural Narratives' of Ethnicity." Identities 11(2):141-70.

Pimlott Baker, A. 2004. "Ruth Glass." Oxford Dictionary of National Biography. Retrieved July 14, 2017 (http://www.geos.ed.ac.uk/homes/tslater/ruthglass.pdf).

Pinski, David. 1918. Three Plays. edited by Isaac Goldberg. New York: BW Huebsch.

Pinski, David. 1999. “The Treasure.” Pp. 184-260 in God, Man and the Devil: Yiddish Plays in Translation, edited by Nahma Sandrow. Syracuse University Press.

Pitman, Elsa. 1962. "Four Women with Big Jobs.” Evening Post; Ellen Hellmann Box of Clippings at Beyachad, January 20.

Polimis, Kivan. 2012. "Junk in the Trunk: Evaluating the Relationship between BodyMass Index and Interracial Dating for White Adolescent Females." University of North Carolina at Chapel Hill.

Pollins, Harold, and Abby Gondek. 2017. E-Mail Correspondence between Harold Pollins and Abby Gondek Regarding His Work with Ruth Glass, October 18-19, 2017. Miami and Oxford: Florida International University.

Powers, Karen Vieira. 2005. "Chapter 2: The Spanish Invasion of the Americas: A Gendered Collision." Pp. 39-67 in Women in the Crucible of Conquest: The Gendered Genesis of Spanish American Society, 1500-1600. Albuquerque, New Mexico: University of New Mexico Press.

Prahlad, Sw.Anand. 2005. "Getting Happy: An Ethnographic Memoir.” Journal of American Folklore 118(467):21-44.

Price, David H. 2004. Threatening Anthropology: McCarthyism and the FBI's Surveillance of Activist Anthropologists. Duke University Press.

Price, Richard, and Sally Price. 2003. The Root of Roots, Or, How Afro-American Anthropology Got Its Start. Chicago: Prickly Paradigm. 
Price, Sally. 1993. Co-Wives and Calabashes. 2nd ed. Ann Arbor, MI: University of Michigan Press.

Pringle, Lambert. 1973. "Should Race Institute Testify Before Schlebusch Inquiry?" Sunday Express; Ellen Hellmann Box of Clippings, No. 199, Jewish Board of Deputies Archive, April 1.

Probyn, Elspeth. 1993. Sexing the Self: Gendered Positions in Cultural Studies. London: Routledge.

Puri, Jyoti. 2015. "Postcolonial Feminisms and Introducing Sociology in the Imperium." Radical Teacher: A Socialist, Feminist, and Anti-Racist Journal on the Theory and Practice of Teaching (101):63-70.

Puri, Shalini. 2004. The Caribbean Postcolonial: Social Equality, Post-Nationalism, and Cultural Hybridity. Palgrave MacMillan.

Quartey, Seth. 2010. "Rewriting African Art: Viktor Leo Frobenius and his 'Ologun.'” Journal of Cultural Studies 8(2):259-70.

Ramos, Arthur. 1940. Copy of Letter That Arthur Ramos Sent to Guy B. Johnson, March 14, 1940, Sent to Melville Herskovits. Evanston, Illinois: Melville Herskovits Papers, Series 35/6, Box 19, Folder 14, Northwestern University Archives.

Ramos, Arthur. 1942. "Pesquisas Estrangeiras Sobre O Negro Brasileiro." Pp. 185-95 in A Aculturação Negra no Brasil. São Paulo, Brazil: Companhia Editora Nacional.

Rheinallt Jones, J. D. 1944. Letter of Introduction for Ellen Hellmann, from JD Rheinallt Jones to Emory Ross, September 27, 1944. Johannesburg, South Africa: AD843RJ Box 26 Aa 3.3.5 SAIRR Head Office Correspondence: Subjects, Visits by SAIRR staff File 6, 1944-1945, Historical Papers Archive, University of Witwatersrand.

Rich, Paul B. 1984. White Power and the Liberal Conscience: Racial Segregation and South African Liberalism, 1921-1960. Manchester and New York: Manchester University Press.

Rich, Paul B. 1990. Race and Empire in British Politics. 2nd editio. Cambridge University Press.

Richmond, Anthony H. 1954. Colour Prejudice in Britain: A Study of West Indian Workers in Liverpool, 1941-1951. Routledge and Paul.

Richmond, Anthony H. 1955. The Colour Problem: A Study of Racial Relations. Harmondsworth, Middlesex: Penguin Books Ltd.

Rodríguez, Encarnación Gutiérrez, Manuela Boatca, and Sérgio Costa. 2010. Decolonizing European Sociology: Transdisciplinary Approaches. edited by Encarnación Gutiérrez Rodríguez, Manuela Boatca, and Sérgio Costa. Farnham, Surrey, England: Ashgate.

Roediger, David. 1994. "Whiteness and Ethnicity in the History of 'White Ethnics' in the United States." Pp. 181-98 in Toward the Abolition of Whiteness: Essays on Race and Working Class History. London: Verso. 
Rollins, Judith. 1985. Between Women: Domestics and Their Employers. Temple University Press.

Romo, Anadelia A. 2007. "Rethinking Race and Culture in Brazil's First Afro-Brazilian Congress of 1934." Journal of Latin American Studies 39(1):31-54.

Rose, Hilary. 1990. "Gender Politics at LSE: Appreciation of Ruth Glass.” The Guardian (London, England), March 17, 21.

Rose, Hilary, and Abby Suzanne Gondek. 2017. Hilary Rose and Abby Gondek Correspondence, Regarding Ruth Glass, September 28-29, 2017. London and Miami: Bradford University, Florida International University.

Rosen-Prinz, Beth. 1972. Beth Rosen-Prinz Letter to Hilda Kuper, 19 December 1972 from Swaziland Regarding Hilda's Sister's Death. Los Angeles, CA: Hilda Kuper Papers, Box 23, Folder 8, UCLA Special Collections, Charles E. Young Research Library.

Rosen-Prinz, Beth. 1978. Beth Rosen Prinz Letters Part 2, 1976-1978. Los Angeles, CA: Hilda Kuper Papers, Box 41, Folder 3, UCLA Special Collections, Charles E. Young Research Library.

Rosen-Prinz, Beth, and Abby Gondek. 2016. Beth Rosen-Prinz Interview, December 20, 2016, Regarding Her Teacher, Hilda Kuper. Los Angeles, CA.

Rossi, Luiz Gustavo Freitas. 2011. “O Intelectual 'Feiticeiro': Édison Carneiro E O Campo de Estudos Das Relações Raciais No Brasil.” Universidade Estadual de Campinas, Department of Social Anthropology.

Rubin, Vera. 1971. Caribbean Studies: A Symposium, Monograph 34, The American Ethnological Society, Verne F. Ray, Editor. Third. edited by University College of the West Indies and the Research Institute for the Study of Man Institute of Social and Economic Research. Seattle: University of Washington Press.

Rubin, Vera D. 1960. "Colonialism, Nationalism and Parochialism in the West Indies." in AAAS Symposium on the Development of New Nations. New York City: The Vera D. Rubin Professional Papers, Series VI, Box 1, Folder 8, The Reed Foundation.

Rubinstein, William D., Michael Jolles, and Hilary L. Rubinstein. 2011. The Palgrave Dictionary of Anglo-Jewish History. Palgrave Macmillan.

Russell, Margo. 1994. “OBITUARY: Hilda Kuper, 1911-92.” Africa 64(1):145-49.

Ryan, Gery W., and H.Russell Bernard. 2003. "Techniques to Identify Themes." Field Methods 15(1):85-109.

Sachs, Wulf. 1947. Black Hamlet. Boston: Little, Brown and Company.

Safran, William. 1991. "Diasporas in Modern Societies: Myths of Homeland and Return.” Diaspora: A Journal of Transnational Studies 1(1):83-99.

Saldaña, Johnny. 2013. The Coding Manual for Qualitative Researchers. Second. London, Thousand Oaks: SAGE Publications. 
Sanjek, Roger. 1990. “A Vocabulary for Fieldnotes.” Pp. 92-138 in Fieldnotes: The makings of anthropology. Ithaca, NY: Cornell University Press.

Scheper-Hughes, Nancy. 1991. "Hortense Powdermaker, the Berkeley Years (19671970): A Personal Reflection.” Journal of Anthropological Research 47(4):457-71.

Schiff, Ellen. 2003. "Sinners, Scandals, Scoundrels, and Scamps on the American Jewish Stage.” American Jewish History: an American Jewish History Society quarterly publication (Baltimore, MD) 83.

Schlossberg, Anna. 1959a. Letter from Anna Schlossberg to Ruth Landes, April 11, 1959. Washington, DC: Box 7, Ruth Landes Papers, National Anthropological Archives, Smithsonian Institution.

Schlossberg, Anna. 1959b. Letter from Anna Schlossberg to Ruth Landes, April 29, 1959. Washington, DC: Box 7 Letters from Landes' parents, Ruth Landes Papers, National Anthropological Archives, Smithsonian Institution.

Schlossberg, Anna. 1959c. Letter from Anna Schlossberg to Ruth Landes, March 9, 1959. Washington, DC: Box 7 Letters from Landes' parents, Ruth Landes Papers, National Anthropological Archives, Smithsonian Institution.

Schlossberg, Anna. 1970. Letter from Anna Schlossberg to Ruth Landes, May 16, 1970, Re: Ellen Hellmann. Washington, D.C.: Box 8: Letters from Ruth Landes' parents, Folder 1970-1973, Ruth Landes Papers, National Anthropological Archives, Smithsonian Institution.

Schlossberg, Anna, and Joseph Schlossberg. 1956. February 13, 1956 Letter from Anna and Joseph Schlossberg to Their Daughter, Ruth Landes. Washington, DC: Box 7: Letters from Joseph and Anna Schlossberg, Ruth Landes Papers, National Anthropological Archives, Smithsonian Institution.

Schlossberg, Anna, and Joseph Schlossberg. 1959. Letter from Joseph and Anna Schlossberg to Ruth Landes, April 25, 1959. Washington, DC: Box 7 Letters from Landes' parents, Ruth Landes Papers, National Anthropological Archives, Smithsonian Institution.

Schlossberg, Joseph. 1935a. "Foreword.” Pp. 3-4 in Strikes under the New Deal, edited by Maurice Goldbloom. New York City: League for Industrial Democracy.

Schlossberg, Joseph. 1935b. The Workers and Their World: Aspects of the Workers' Struggle at Home and Abroad: Selected Essays. New York: ALP Committee.

Schlossberg, Joseph. 1942. "The Bill of Rights Then and Now." Pp. 6-7 in The Rights of Man Are Worth Defending. New York City: League of Adult Education INC.

Schlossberg, Joseph. 1947. "Foreword." Pp. ix-xvii in Cooperative Palestine: The Story of Histadrut, edited by Samuel Kurland. New York: Sharon Books for the National Committee for Labor Palestine.

Schlossberg, Joseph. 1948. "Reawakening of Jewish Spirituality." Religious Education 43(5):267-68. 
Schlossberg, Joseph. 1959a. February 27, 1959 Letter from Joseph Schlossberg to Ruth Landes. Washington, DC: Box 7, Ruth Landes Papers, National Anthropological Archives, Smithsonian Institution.

Schlossberg, Joseph. 1959b. Letter from Joseph Schlossberg to Ruth Landes, April 11, 1959. Washington, DC: Box 7, Ruth Landes Papers, National Anthropological Archives, Smithsonian Institution.

Schlossberg, Joseph. 1959c. March 16, 1959 Letter from Joseph Schlossberg to Ruth Landes. Washington, DC: Box 7, Ruth Landes Papers, National Anthropological Archives, Smithsonian Institution.

Schlossberg, Joseph, and Anna Schlossberg. 1955. February 6, 1955 Letter to Ruth Landes from Her Parents, Joseph \& Anna Schlossberg. Washington, DC: Box 7: Letters from Anna and Joseph Schlossberg, Ruth Landes Papers, National Anthropological Archives, Smithsonian Institution.

Schlossberg, Joseph, and Anna Schlossberg. 1958a. December 12, 1958 Letter from Anna and Joseph Schlossberg to Their Daughter, Ruth Landes. Washington, DC: Box 7: Letters from Anna and Joseph Schlossberg, Ruth Landes Papers, National Anthropological Archives, Smithsonian Institution.

Schlossberg, Joseph, and Anna Schlossberg. 1958b. Letter from Joseph and Anna Schlossberg to Their Daughter, Ruth Landes, April 10, 1958. Washington, DC: Box 7 Letters from Landes' parents, Ruth Landes Papers, National Anthropological Archives, Smithsonian Institution.

Schlossberg, Joseph, and Anna Schlossberg. 1959. Letter from Joseph and Anna Schlossberg to Ruth Landes, July 13, 1959. Washington, DC: Box 7 Letters from Landes' parents, Ruth Landes Papers, National Anthropological Archives, Smithsonian Institution.

Schmidt, Benjamin. 2015. "Chapter Three: Exotic Bodies Sex and Violence Abroad.” P. 448 pages in Inventing Exoticism: Geography, Globalism and Europe's Early Modern World. Philadelphia, PA: University of Pennsylvania Press.

Schmidt, Nancy J. 1993. "Introduction.” Pp. 1-3 in A Witch in my Heart: Short stories and poems. Madison: African Studies Program, University of Wisconsin--Madison.

Schumaker, Lyn. 2001. Africanizing Anthropology: Fieldwork, Networks, and the Making of Cultural Knowledge in Central Africa. Durham: Duke University Press.

Schwadron, Hannah Sarah. 2013. "White Nose, (Post) Bawdy Bodies and the Un/dancing Sexy Jewess.” UC Riverside.

Schwartz, Pat. 1981. "A View from Both Sides of the Fence." Rand Daily Mail; Beyachad Community Center Jewish Board of Deputies Archive, Ellen Hellmann Box of Clippings No. 199, July 10.

Schwartz, Pat. 1982. "A Tribute to a Fighter for Justice." Rand Daily Mail, November 15.

Sebastiani, Silvia. 2005. "'Race,' Women and Progress in the Scottish Enlightenment." Pp. 75-96 in Women, Gender and the Enlightenment, edited by Sarah Knott and 
Barbara Taylor. New York: Palgrave MacMillan.

Secretary, Honorary. 1940. Letter from the Honorary Secretary of the Joint Council to the Manager of the Native Affairs Department, July 8, 1940. Johannesburg, South Africa: AD1433 Joint Council Europeans and Africans, Box 21, 1940-1941, Cj 2.1.20 File 2, 1940-July-Dec, Historical Papers Archive, University of Witwatersrand.

Shain, Milton. 1994. The Roots of Anti-Semitism in South Africa. Charlottesville, NC: University Press of Virginia.

Shain, Milton. 2016. "From Hoggenheimer to the Guptas." Politics Web, April 20, 1-8.

Shain, Milton, and Richard Mendelsohn. 2000. "Introduction.” Pp. 7-14 in Memories, Realities and Dreams: Aspects of the South African Jewish Experience, edited by Milton Shain and Richard Mendelsohn. Johannesburg, South Africa: Jonathan Ball Publishers.

Shalin, Dmitri N. 2010. “Goffman's Self-Ethnographies.” Pp. 1-38 in American Sociological Association. Atlanta, Georgia.

Shapiro, Edward S. 1992. "Brandeis University and the Jews: Brandeis Rose Quickly to Academic Excellence, but the Nature of Its Jewish Character Remains Ambiguous." My Jewish Learning. Retrieved April 28, 2015 (http://www.myjewishlearning.com/article/brandeis-university-and-the-jews/).

Sherman, Joseph. 2000. "Serving the Natives: Whiteness as the Price of Hospitality in South African Yiddish Literature.” Journal of Southern African Studies 26(3):50521.

Shimoni, Gideon. 1996. "Review of The Roots of Antisemitism in South Africa by Milton Shain.” Modern Judaism 16(2):185-88.

Shimoni, Gideon. 2000. "Accounting for Jewish Radicals in Apartheid South Africa.” Pp. 163-86 in Memories, Realities and Dreams: Aspects of the South African Jewish Experience, edited by Milton Shain and Richard Mendelsohn. Johannesburg, South Africa: Jonathan Ball Publishers.

Shohat, Ella. 1992. "Notes on the 'Post-Colonial."' Social Text (31):99-113.

Shusta, Shielagh R. 1994. "Relationships between Childhood Abuse, Dissociation and Body Image Disturbance in Eating Disordered Women.” Adelphi University.

Sillar, Bill. 2009. "The Social Agency of Things? Animism and Materiality in the Andes." Cambridge Archaeological Journal 19(3):367-77.

Silva, Antonio Jose Bacelar da. 2012. "Voicing Race and Anti-Racism: Rethinking Black Consciousness among Black Activists in Salvador, Brazil.” University of Arizona.

Silva, Sarah Calvi Amaral. 2010. “Africanos E Afro-Descendentes Nas Origens Do Brazil: Raça E Relações Raciais No II Congresso Afro-Brasileiro de Salvador (1937) E No III Congresso Sul-Rio-Grandense de História E Geografia Do IHGRS (1940)." Universidade Federal do Rio Grande do Sul. 
Simmons, Lakisha Michelle. 2012. “"To Lay Aside All Morals': Respectability, Sexuality and Black College Students in the United States in the 1930s." Gender and History 24(2):431-55.

Skidmore, Thomas. 1992. Black into White: Race and Nationality in Brazilian Thought. 2nd ed. Durham: Duke University Press.

Slabodsky, Santiago. 2014. Decolonial Judaism: Triumphal Failures of Barbaric Thinking. Palgrave Macmillan US.

Soltes, Mordecai. 1969. The Yiddish Press: An Americanizing Agency. Second. New York, NY: Arno Press and The New York Times.

Sosnow, Emily. 1991. Affidavit of Kinship. New York: Ruth Landes Fund Principal Papers, Reed Foundation, Research Institute Study of Man.

Sparkes, Andrew C. 2002. "Auto-Ethnography: Self-Indulgence or Something More?" Pp. 209-31 in Ethnographically Speaking: Autoethnography, Literature, and Aesthetics, edited by Arthur P. Bochner and Carolyn Ellis. Walnut Creek, CA \& Lanham, MD: Rowman Altamira.

Spencer-Wood, Suzanne M. 2011. "Introduction: Feminist Theories and Archaeology." Archaeologies 7(1):1-33.

Spencer, Hawes, and Sheryl Gay Stolberg. 2017. "White Nationalists March on University of Virginia." New York Times, August 11.

Staff, Rand Daily Mail. 1981. "It's a Fine Finale for Hilda." Rand Daily Mail; Hilda Kuper Papers, Box 23, Folder 9 "Biographical” UCLA Special Collections, August 6.

Staff writer. 1954. "Premier of Gold Coast, 'understands South African Problems." The Star; Ellen Hellmann Box of Clippings, Jewish Board of Deputies Archive, October 19.

Staff writer, New York Times. 1939. "PRIESTESSES RULE 400,000 IN BRAZIL Women of Cults Dominate Jungle, Anthropologist Reports." New York Times, July $10,21$.

Staff Writer, The Star. 1959. "People Ransack Their Attics." The Star; Ellen Hellmann Box of Clippings 199, Jewish Board of Deputies Archive, Beyachad Jewish Community Center, February 19.

Steedman, Carolyn. 2008. "Romance in the Archive." Pp. 1-10 in Network for Methodological Innovation, Seminar 1: The Ontology of the Archive, Session 2. Manchester: ESRC National Centre for Research Methods.

Steedman, Carolyn Kay. 2002. Dust: The Archive and Cultural History. New Brunswick, New Jersey: Rutgers University Press.

Steinmetz, George. 2013. "A Child of the Empire: British Sociology and Colonialism, 1940s-1960s." Journal of the history of the behavioral sciences 49(4):353-78.

Steinmetz, George. 2014. "The Sociology of Empires, Colonies, and Postcolonialism." 
Annual Review of Sociology 40(1):77-103.

Stocking, George W. 1992. "The Ethnographer's Magic: Fieldwork in British Anthropology from Tylor to Malinowski." Pp. 12-59 in The Ethnographer's Magic and Other Essays in the History of Anthropology. Madison: University of Wisconsin Press.

Stoler, Ann Laura. 2002. Carnal Knowledge and Imperial Power: Race and the Intimate in Colonial Rule. Berkeley: University of California Press.

Stoler, Ann Laura. 2009. Along the Archival Grain: Epistemic Anxieties and Colonial Common Sense. Princeton: Princeton University Press.

Strauss, Anselm, and Juliet Corbin. 1998. Basics of Qualitative Research: Techniques and Procedures for Developing Grounded Theory. Second. Thousand Oaks, CA: Sage Publications.

Streck, Bernhard. 2004. "Frobenius, Leo b.1873, Berlin, Germany D. 1938, Biganzolo, Italy." Biographical Dictionary of Social and Cultural Anthropology.

Subrahmanyam, Sanjay. 1997. "Connected Histories: Towards a Reconfiguration of Early Modern Eurasia." Modern Asia Studies Special Issue: The Eurasian Context of the Early Modern History of Mainland South East Asia, 1400-1800 31(3):735-62.

Subrahmanyam, Sanjay. 2001. "A Tribute to Dharma Kumar (1928-2001).” Economic and Political Weekly 36(45):4251-54.

Suttner, Immanuel. 1997. Cutting Through the Mountain: Interviews with South African Jewish Activists. edited by Immanuel Suttner. London, New York, Ringwood, Toronto, Auckland, Parktown, Sandton: Viking Press.

Swarr, Amanda Lock. 2012. Sex in Transition: Remaking Gender and Race in South Africa. Albany, NY: SUNY Press.

Tabili, Laura. 2013. "Race Is A Relationship, And Not A Thing." Journal of Social History 37(1):125-30.

Teixeira, Maria das Graças de Souza. 2007. "INFÂNCIA, SUJEITO BRINCANTE E PRÁTICAS LÚDICAS NO BRASIL OITOCENTISTA.” Universidade Federal da Bahia.

Thomas, Lynn M. 2009. "Love, Sex, and the Modern Girl in 1930s Southern Africa." Pp. 31-57 in Love in Africa, edited by Jennifer Cole and Lynn M. Thomas. Chicago and London: The University of Chicago Press.

Thorne, Barrie. 2006. "How Can Feminist Sociology Sustain Its Critical Edge?" Social Problems 53(4):473-78.

du Toit, Marijke. 2005. "The General View and Beyond: From Slum-Yard to Township in Ellen Hellmann's Photographs of Women and the African Familial in the 1930s." Gender and History 17(3):593-626.

Travis, Alan. 2002. "After 44 Years Secret Papers Reveal Truth about Five Nights in Notting Hill." The Guardian, August 24. 
Trubowitz, Lara. 2012. Civil Antisemitism, Modernism, and British Culture, 1902-1939. Palgrave Macmillan.

UNESCO, United Nations Educational Scientific and Cultural Organisation. 1954. "Ellen Hellmann's Participation as an 'expert' September 29-October 7, 1954." in English Conference of Social Scientists on the Social Impact of Industrialisation and Urban Conditions in Africa. Abidjan, Ivory Coast: Ellen Hellmann Papers, Box 7, File 49, Urban Blacks and Urban Studies, Historical Papers Archive, University of Witwatersrand.

Vail, Leroy, and Landeg White. 1991. Power and the Praise Poem: Southern African Voices in History. University Press of Virginia.

Vincent, Kerry. 2011. "Literature as Laboratory: Hilda Kuper's Factional Representations of Swaziland." African Studies 70(1):89-102.

Ward, Eric K. 2017. "Skin in the Game: How Antisemitism Animates White Nationalism." The Public Eye: Political Research Associates, Challenging the Right, Advancing Social Justice, June, 1-8.

Webster, Sheila. 1955. "Negroes at Bluebrick: An Analysis of the Problems of Assimilation of African and West Indian Students in the Universities of Oxford and Cambridge." University of Edinburgh Archive and Manuscript Collections, Special Collections.

Wekker, Gloria. 1999. “'What's Identity Got to Do With It?' Rethinking Identity in Light of the Mati Work in Suriname." Pp. 119-38 in Female Desires: Same-sex Relations and Transgender Practices Across Cultures. New York: Columbia University Press.

Westergaard, John. 1979. "In Memory of David Glass." Sociology 13(2):173-77.

Wetherell, Charles. 1998. "Historical Social Network Analysis." International Review of Social History 43(supplement):125-44.

Williams, Brackette F. 1989. "A Class Act: Anthropology and the Race to Nation Across Ethnic Terrain." Annual Review of Anthropology 18(1):401-44.

Wilson, Kathleen. 2003. "Breasts, Sodomy and the Lash: Masculinity and Enlightenment Aboard the Cook Voyages." Pp. 169-200 in The Island Race: Englishmen, Empire and Gender in the 18th Century, edited by Kathleen Wilson. London: Routledge.

Woollacott, Angela. 2006. "Chapter Five: Women and Gender in Anti-Colonial and Nationalist Movements." Pp. 104-21 in Gender and Empire. Houndmills, Basingstoke, Hampshire and New York, NY: Palgrave MacMillan.

Writer, Staff. 1954a. "Individual Worth Counts in Gold Coast." Friend?; Ellen Hellmann Box of Clippings No. 199, Jewish Board of Deputies Archives, Beyachad, November 16.

Writer, Staff. 1954b. "Visit to the Gold Coast." Star; Ellen Hellmann Box of Clippings, Jewish Board of Deputies Archive, September 22.

Writer, Staff. 1955. “Cameo- Dr. Ellen Hellmann.” Friend?; Ellen Hellmann Box of 
Clippings No. 199, Jewish Board of Deputies Archives, Beyachad, January 24.

Writer, Staff, and Beyachad Jewish Board of Deputies Archive. 1967. "Women Stress Importance of Race Relations in Port Elizabeth for Institute Meeting." Evening Post; Ellen Hellmann Box of Clippings at Beyachad, January 19.

Yelvington, Kevin A. 2006. "Chapter 2: The Invention of Africa in Latin America and the Caribbean." Pp. 35-82 in Afro-Atlantic Dialogues: Anthropology in the Diaspora. Santa Fe: School of American Research Press.

Yue, Liang. 2012. "Searching for a Place Beyond Modern Chinese History: A Study of the Sociologist Lei Jieqiong." Pp. 89-108 in Sociology and Anthropology in Twentieth Century China: Between Universalism and Indigenism, edited by Arif Dirlik, Guannan Li, and Hsiao-pei Yen. Hong Kong: The Chinese University Press. 


\section{APPENDICES}

Appendix A: Archives Visited or Accessed Digitally

\section{Format of entries}

Title of collection

Name of Archive, Location

Dates visited

Types of materials accessed

People responsible (archivists, librarians)

\section{Archives related to Ruth Landes}

\section{Ruth Landes Papers}

National Anthropological Archives (NAA)

National Museum of Natural History, Museum Support Center, Suitland, Maryland June-August 2014, August 2016

Personal and professional correspondence, fieldwork notebooks, unpublished

manuscripts, photographs, accession file

Jake Homiak, Director of the NAA

Lorain Wang, Processing Archivist

Caitlin Haynes, Reference Archivist

Adam Minakowski, Reference Archivist

Ruth Fulton Benedict Papers

Archives and Special Collections Library

Vassar College, Poughkeepsie, NY

Accessed at the Reed Foundation, NYC

June-July 2016

Correspondence between Ruth Landes and her teacher, Ruth Benedict, 1932-1947

David Latham, Reed Foundation, Director of Programs

Charles S. Johnson Papers

Fisk University Archives, Nashville, TN

Accessed at the Reed Foundation, NYC

June-July 2016

Correspondence between Ruth Landes and Charles S. Johnson, 1944-1946

David Latham, Reed Foundation, Director of Programs

\section{Edison Carneiro Papers}

Biblioteca Amadeu Amaral, Centro Nacional de Folclore e Cultura Popular, IPHAN

Rio de Janeiro, Brazil

Accessed at the Reed Foundation, NYC

June-July 2016

Letters from Ruth Landes to Edison Carneiro 1946-1970 
David Latham, Reed Foundation, Director of Programs

Melville Herskovits Papers

Northwestern University

Evanston, Illinois

Accessed digitally through e-mails sent by archivist, and at the Reed Foundation, NYC

June-July 2016, July 2017

Correspondence between Ruth Landes and Melville Herskovits, Rüdiger Bilden and MH, and Arthur Ramos and $\mathrm{MH}$

Janet C. Olson, Assistant Archivist, Special Collections

\section{Archives related to Hilda Kuper}

Hilda Kuper Papers

UCLA, Charles E. Young Research Library, Special Collections

May-June, November-December 2016

Professional correspondence, unpublished manuscripts, fieldwork notebooks, photographs

Cesar Reyes, Reader Services and Post-cataloguing coordinator

Julianna Jenkins, Public Services, Special Collections

Sondra Hale private collection of Hilda Kuper creative writing

Accessed at UCLA

November-December 2016

published and unpublished creative writings in draft form

Sondra Hale, Professor Emeritus, Gender Studies and Anthropology, UCLA

Archives related to Vera D. Rubin

Research Institute Study of Man (RISM) research collections and archives 1943-1985

Held at NYU Special Collections, NYC

September 2017

Published conference proceedings

Janet Bunde, University Archivist

Vera D. Rubin Professional Papers

Being organized at the Reed Foundation, NYC

June-July, November 2016

professional correspondence, conference talks, published and unpublished manuscripts Sara P. O'Neill, was in the process of organizing, indexing, and creating finding aids for the Vera D. Rubin Professional Papers 


\section{Archives related to Ellen Hellmann}

University of Cape Town Special Collections

Accessed digitally

Clive Kirkwood, Special Collections Librarian

Materials originally held at the Kaplan Centre Archive

January 2017

Digitized tape-recorded interview with Ellen Hellmann by Riva Krut, 3 June 1982 in

Johannesburg, item no. BC949, transcript of "side A" only

Colin Legum Papers

February 2017

Colin Legum diaries, correspondence between Legum and Hellmann (Koch)

\section{$\underline{\text { Historical Papers Archive }}$}

University of Witwatersrand, William Cullen Library, Johannesburg, South Africa Dates accessed: February-March 2017

Archivists:

Gabriele Mohale

Zofia Sulej

Ellen Hellmann Papers; Collection A1419

Newspaper articles, conference talks, published and unpublished manuscripts

AD1158 South African Institute of Race Relations, Series B: History of the Institute

Professional correspondence, pamphlets

AD843RJ Records of the South African Institute of Race Relations Part II

Professional correspondence, memos

AD1433 Joint Council of Europeans and Africans

Professional correspondence, meeting minutes, lists of executive members

\section{Beyachad Jewish Community Center}

Jewish Board of Deputies Archive

Johannesburg, South Africa

February-March 2017

Minutes of the Public Relations Committee 1944-1950 "ARCH 809"

Box of Clippings related to Ellen Hellmann "199" 
Naomi Musiker, Archivist, Jewish Board of Deputies

Maxine Fine, Librarian, South African Zionist Federation Isie Maisels Library 


\section{Appendix B: Museums Visited}

\section{Format of entries}

Title of collection

Name of Archive, Location

Dates visited

Types of materials accessed

Museum professionals responsible

\section{Collections related to Ruth Landes}

Ruth Landes Ethnographic Object Collection

National Museum of Natural History, Museum Support Center, Suitland, Maryland

Collections Storage Area

June-July 2014

Ethnographic objects including 4 bahiana dolls from Salvador, Bahia (1938-1939), object accession file

Candace Greene, Director of the Smithsonian Institute in Museum Anthropology (SIMA)

Suzanne Godby Ingalsbe, SIMA Program Manager

David Rosenthal, Collections Manager, NMNH

Susan Crawford, Registrar NMNH

Kasia Ahern, Intern, SIMA

Lorenzo Dow Turner collection

Anacostia Community Museum in Anacostia, Maryland

June-July 2014

Lorenzo Dow Turner bahiana doll, photographs

Alcione Amos, Curator

Joshua M. Gorman, Head of Collections

Popular Art Museum, Feminine Institute of Bahia

Salvador, Bahia, Brazil

December 2014-January 2015

Bahiana doll collection

Ilma Vila Boas, Curator

Museu Afro-Brasileiro of the Federal University of Bahia

Salvador, Bahia, Brazil

December 2014-January 2015

Orixá dolls, photographs of bahiana dolls being repaired

Graça Teixeira, Museum Director

Marcelo Cunha, Curator of the Estácio de Lima Collection 


\section{Collections related to Hilda Kuper}

Swaziland ethnographic object collection

Collected by Teresa Thoko Ginindza in collaboration with Hilda Kuper

UCLA Fowler Museum

November 2016

Swazi jewelry and textiles, object accession file

Erica P. Jones, Assistant Curator, African Art

Rachel Raynor, Director of Exhibitions and Collections

Isabella Kelly-Ramirez, Collections Manager

Jeanette Saunders, Registrar

Women's Gaol

Johannesburg South Africa

March 2017

Fatima Meer paintings from her time at the jail 


\section{Format is as follows:}

Name

Title

Method of communication: E-mail, phone, in-person

Format of interaction: Consultation, informal conversation, interview (recorded, notes)

Date(s) completed

Type of relationship with core woman, brief summary of content of interview

\section{Regarding Ruth Landes}

\section{Sally Cole}

Professor of Sociology and Anthropology, Concordia University, Montreal

E-mail

Consultation

June 2014, January 2015

Biographer of RL

\section{Jamie Andreson}

Doctoral Student, Anthropology and History, University of Michigan

E-mail

Consultation

February, October-November 2014, February 2015

B.A. and M.A. about Landes' research in Bahia

Mica Nava

Emeritus Professor of Cultural Studies, University of East London

e-mail, skype

recorded interview

February 2015

Researched RL UK race study

\section{Linda Perkins}

Associate University Professor History, Education, Director of Applied Women's

Studies, Claremont Graduate University

E-mail, in-person interview in Pasadena California

Informal conversation with notes

February and May 2015

Researched RL Fisk University related writings and relationship with Elmer Imes 
Ron Mickens

Callaway Professor of Physics at Clark Atlanta University; formerly professor of Physics at Fisk University until 1982

E-mail and phone

Informal conversation with notes

September-October 2015, June-July, December 2017

Elmer Imes' biographer; historian of Fisk University black physicists

Kevin Yelvington

Professor of Anthropology, University of South Florida

E-mail

Consultation

February 2015

Historian of transnational anthropological networks between Herskovits, Ramos and

Price-Mars

\section{Diana Brown}

Professor Emeritus of Anthropology, Bard College

Washington D.C. at the AAA meeting

Informal conversation

November 30, 2017

She met RL in Brazil in 1966 when Ruth had come back to Rio for the first time since leaving in 1939. Ruth was dismissive of Diana's project because she was studying Umbanda which RL looked down upon as an impure form of Candomblé. Diana was there for the reunion of Ruth and Edison Carneiro. Diana told me that she attended an event with both Ruth and Edison, who seemed afraid of Ruth and asked Diana to sit in between them, but then on the way home, dropped off Diana first and then Edison and Ruth went off together.

\section{Mario Bick}

Professor Emeritus of Anthropology, Bard College

Washington D.C. at the AAA meeting Informal conversation

November 30, 2017

He knew RL when she taught summer sessions at Columbia after she retired (which I did not know about).

\section{Leni Silverstein}

Applied anthropologist specializing in sustainable reproductive health, formerly conducted research in Bahia with Candomblé terreiros

Washington D.C. at the AAA meeting Informal conversation

November 30, 2017 
Leni interviewed RL in 1976 and created an audio tape of the interview. Leni brought Ruth yellow flowers which delighted her considering this was the color of Ruth's orixá, Oxum. Ruth immediately guessed that Leni's orixá was Iemanjá.

$\underline{\text { Brazil interviews }}$

\section{Fábio Lima}

public school teacher and filho do santo, Ilê Axé Opô Afonjá; studied at Centro de

Estudos Afro-Orientais

Salvador, Bahia, Brazil

interview, notes

December 23, 2014

According to Fábio, he introduced City of Women to his Candomblé house and

advocated for its inclusion in courses at UFBA

\section{Lindinalva Barbosa}

Administrative Assistant at Centro de Estudos Afro-Orientais (CEAO), and filha do santo at Casa do Cobre

Salvador, Bahia, Brazil

informal conversation, notes

December 22, 2014

Barbosa presented Ch. 18 of Landes' City of Women to her house as way to educate her community about Mãe Flaviana, the mãe do santo during Landes' time in Salvador

\section{Isaura Genoveva}

Lawyer and Ekede at Casa Branca

Salvador, Bahia, Brazil

interview, audio-note

January 6, 2015

Learned about Landes through the film City of Women; she told me about women's sewing skills in Candomblé houses historically-related to my bahiana dolls research

\section{Claudio Luiz Perreira}

Former professor of CEAO, now the Director of the Museum of Anthropology of the Federal University of Bahia

Salvador, Bahia, Brazil

informal conversation, notes

December 28, 2014

Specialist of the history of Candomble studies in Salvador; written about Arthur Ramos and Vivaldo da Costa Lima

J.B.

Professor at CEAO

E-mail and phone 
consultation, notes

Dec. 2014-Jan. 2015

He said that Ruth Landes has become an "exotic object" within the field and that her book is popular for "folklore" reasons

Márcia Souza

Administrator at CEAO

Salvador, Bahia, Brazil

consultation, audio-note

December 17, 2014

According to Souza, Landes had no importance at all within the Gantois house, since so many people had conducted research there already. Ironically, this is the central house discussed in City of Women.

\section{Maria Rosário do Carvalho}

Vice Coordinator, Graduate Program in Anthropology, UFBA

E-mail consultation

December 30, 2014

Utilized City of Women in methodology course focusing on Brazilian anthropology at CEAO

\section{Livio Sansone}

Professor at CEAO

Salvador, Bahia, Brazil

consultation

December 16, 2014

Wrote about Landes as part of an article discussing Lorenzo Dow Turner and Franklin E. Frazier's trip to Salvador the year after Landes was there

\section{Solange Matos}

Head Librarian, CEAO

Salvador, Bahia, Brazil

consultation

December 2014

Gave me contact info for Claudio Perreira and Fábio Lima

Jenny Kuper

Lawyer and human rights researcher

E-mail

consultation 
September 2016, December 2017-January 2018

Daughter of Hilda Kuper

\section{Sondra Hale}

Professor Emeritus, Gender Studies and Anthropology, UCLA

Los Angeles, CA

E-mail and recorded interview

November 2016

Graduate student of Hilda Kuper; highlighted class differences between Hilda and herself and told me about the differing relationships Hilda had with each of her students

\section{Beth Rosen-Prinz}

Former Deputy Director (Housing) and Regional Administrator (Housing) at the

California Department of Fair Employment \& Housing (DFEH)

Los Angeles, CA

recorded interview

December 20, 2016

Graduate student of Hilda Kuper; did fieldwork in Swaziland with Thoko Ginindza;

thought of Hilda as being a mother to her

\section{Dawn Chatty}

Emeritus Professor of Anthropology and Forced Migration and former Director of the

Refugee Studies Centre, University of Oxford

E-mail \& skype

consultation $\&$ informal interview

Dec. 2016, July 20, 2017

Graduate student of Hilda Kuper; HK "brought Durkheim alive"; she was "more British than the British"; she was not a Marxist- jumping in at Dawn's defense saying "you know we don't all have to be Marxists" to Gary Hale, Sondra's husband, who was a committee member for Dawn; Hilda encouraged Dawn to look at women in the pastoral economy, Dawn found that women were in a complementary role not a subaltern one, HK always said "it's not just about women, it's about men" looking at the WHOLE society

\section{David Kuby}

Trinity Counseling Center Supervisor; Therapist; Master's in Divinity

E-mail

consultation

Dec. 2016-Jan. 2017

Graduate student of Hilda Kuper; described Hilda's Jewish identification as "deep concern for empowering those who had been disempowered, loving broadly, deeply and authentically"

\section{Gelya Frank}

Professor of Anthropology and Occupational Science and Therapy, USC

E-mail \& in-person, Los Angeles, CA 
Consultation, recorded interview, notes

Dec. 2016-Jan. 2017, August 6, 2017, March 18, 2018

Graduate student of Hilda Kuper; interviewed Hilda about her biography of Sobhuza II

Mary Kuper

Artist, Daughter of Hilda Kuper

E-mail

Consultation

January 2018

Mary sent me photographs of Hilda and Leo Kuper with Fatima Meer and Thoko

Ginindza from 1984-5

Regarding Thoko Ginindza and Hilda Kuper

Nolwazi Mkhwanazi

Medical Anthropologist at Wits Institute for Social and Economic Research

E-mail

consultation

Jan.-Feb. 2017

Introduced me (electronically) to Casey Golomski

Casey Golomski

Assistant Professor of Anthropology, University of New Hampshire

E-mail

consultation

January 2017

Historian of anthropology of Swaziland and conducts contemporary material culture fieldwork in Swaziland; gave me article he wrote about Hilda Kuper and resources for Thoko Ginindza's work at the National Museum in Swaziland

$\underline{\text { Regarding Fatima Meer and Hilda Kuper }}$

\section{Sharad Chari}

Associate Professor of Geography, Berkeley; at the time I visited him he was at the Centre for Indian Studies at Wits

E-mail; Johannesburg, South Africa

consultation

Jan.-Mar. 2017

Gave me contact info for Shamim Meer; recommended I speak to Kelly Gillespie and Shireen Hassim; he researches Indian communities and black activism in Durban, South Africa where Hilda Kuper and Fatima Meer collaborated in the 1950s

Shamim Meer 
Daughter of Fatima Meer

Phone, E-mail

consultation

March 2017, January 2018

Edited Fatima Meer's autobiography (2017); told me about few mentions of Hilda Kuper as a family friend in the autobiography; also explained that Fatima likely came to Los Angeles in 1985 because she had a visiting lectureship at Swarthmore that year.

\section{Regarding Ellen Hellmann}

\section{Jill Weintroub}

Honorary Research Fellow, Rock Art Research Institute, Wits

E-mail; Johannesburg, South Africa

informal conversation and site visit

Jan.-Mar. 2017

Did research on Hellmann for Andrew Bank's book, helped me track down the Ellen Hellmann resources at the Jewish Board of Deputies and showed me Ellen Hellmann's mansion in Houghton, Johannesburg

Kelly Gillespie

Chair of the Anthropology Department at Wits

E-mail; Johannesburg, South Africa

consultation, notes

March 9, 2017

Knew of my earlier dissertation project re: Ruth Landes and bahiana dolls because she reviewed and recommended it for a SSRC grant. She gave me recommendations for readings on the history of Anthropology in South Africa. She's written about Winifred Hoernlé, Ellen Hellmann's teacher at Wits.

\section{Shireen Hassim}

Political Scientist at WISER: Wits Institute for Social and Economic Research

E-mail; Johannesburg, South Africa

consultation, notes

March 9, 2017

She gave me suggestions of Jewish leftist women in the history of South African antiapartheid activism to compare to Ellen Hellmann.

\section{Claudia Gastrow}

Lecturer, Department of Anthropology and Development Studies, University of

Johannesburg

Johannesburg, South Africa

consultation, notes

March 9, 2017 
With Shireen Hassim, Claudia told me about the debated relationships between Jewishness and anti-apartheid activism; mainstream Jewish community rejected radical Jewish anti-apartheid activists, later used their activism to claim that Jews were antiapartheid

\section{Isak Niehaus}

Social anthropologist, Brunel University, London

E-mail

consultation

March, May 2017

Recommended to me by Kelly Gillespie; Isak has researched Winifred Hoernlé and her opposition to Afrikaner nationalist anthropology

\section{Ruth Runciman}

Daughter of Ellen Hellmann, Chair of Central and NorthWest London NHS Foundation

Trust, and Deputy Chair of the Prison Reform Trust until 2013. From 1974-95, Ruth was a member of the Advisory Council on the Misuse of Drugs where she chaired several Working Groups including those that looked at AIDS and drug misuse, and the criminal justice system. From 1994-1998 she was Chair of the Mental Health Act Commission. She also worked part-time for twenty years at the Citizens Advice Bureau, in Hackney (East London) and North Kensington, which she described as "areas with a high proportion of black and minority ethnic residents and significant deprivation."

E-mail, phone

Formal interview, audio recording, and notes

January 29, 2018 and follow up e-mails in March 2018

Ellen's close relationship with her sister Inez, her friendships with Helen Suzman, Margaret Ballinger, and Hansi Pollak, in addition to Quintin Whyte, Hilda and Leo Kuper, Isaac Schapera, and Winifred Hoernlé. Ruth also told me about the mixed-race parties she used to have at her mother's house at a time when these kinds of social gatherings were illegal. Ruth explained that perhaps the reason for the seeming contradiction between Ellen's early advocacy for black representation in unions and voting and her later support for the qualified or "progressive" franchise (as Ruth called it) was rooted in Ellen's "pragmatism," "realism" and her belief in the need for "progress," and a step-by-step approach to reform of the apartheid system. Ruth said that her mother "believed in the absolute rights of black people, passionately" and in "social justice" so even if Ellen thought that there should be "one man, one vote" she may have concluded that this was too radical of a position to be realistically achieved at the time (a belief she shared with her friend Helen Suzman). Ruth agreed that compared to the Liberal Party, her mother was more conservative and apparently Ruth's husband, Garry Runciman, (a British sociologist who had known Ellen) agreed, but she said her mother was conservative with a lower case "c"; similarly, Ruth said her mother was liberal with a lower case "l" because she was philanthropic and "loathed racism of any kind." Ellen valued rationality, remarking that Ruth's husband, Garry, was "the most rational man I've ever met" which was the utmost of compliments from Ellen. Ruth described herself and 
her mother as a: "Very privileged person, owed it to those who were not privileged, to give something back. That's the strongest of all the things that she has embedded in me. That's why I have been involved in so many unpopular causes, I suppose." Regarding gender roles in marriage, Ruth said that her mother did not have dogmatic beliefs about what women should do, since Ellen was "much more open-minded than that." Regarding Ellen's Jewish subjectivity, Ruth said that her mother may have withdrawn from her Zionism somewhat because of the "passionate nationalism" that evolved, but she was always to some degree a Zionist (even if less so than Inez, her sister). Also, though Ellen did not attend synagogue on Shabbat, she "urged" her daughter to go every Saturday until Ruth was 15, when Ruth developed a reasonable enough excuse not to go. Ruth explained that this was during the time she was at Roedean, a girls' boarding school in Johannesburg with only Jewish students in the entire school, and therefore attending Shabbat services was more attractive to her than if she had not been a boarder. Ellen was very much a Jew, and also committed to being a South African, in the broader sense of a "decent society."

\section{Garry Runciman}

Historical Sociologist, Cambridge, husband of Ruth Runciman, son-in-law of Ellen Hellmann

E-mail

Ruth Runciman sent me Garry's response to the excerpts from my dissertation that I had sent to Ruth for her comments.

March 10, 2018

Garry wrote the following statement, most of which I have incorporated throughout the

dissertation: "Ellen was fundamentally conservative in her temperament and attitudes, but both moderately and pragmatically so. She detested apartheid, but was neither a socialist nor an egalitarian. She was wary about the granting of immediate universal suffrage because of a fear that it would result in a one-party state and consequent risk of abuse of power: I have often said that if she could have foreseen what the ANC became under the leadership of Jacob Zuma, she would have been disappointed but far from wholly surprised. She was entirely comfortable with the workings of capitalism provided that they are subject to the rule of law, and admired men like her father who rose to riches from rags. She had no reservations about the employment of domestic servants by welloff private employers, but deplored that restrictions imposed on them under apartheid and their effect on their family lives. She was a firm believer in the conventional European norms of marriage and childrearing, but equally firmly believed that the failure of the black population to conform to them was due not to their innate psychology but to sociological influences beyond their control. She was excessively modest about her own career and achievements, and would have been astonished to see a photograph of herself reproduced in the pages of The Times Literary Supplement in a review about women anthropologists including herself. Her reservations about Zionism were not in contradiction with pride in her Jewishness." 


\section{Regarding Ruth Glass}

Mica Nava

Emeritus Professor of Cultural Studies, University of East London

E-mail

consultation

September 2017

Gave me Hilary Rose's e-mail after I told her that Hilary Rose knew RG. Also, I initially heard of Nigel Harris through Mica Nava who had read his name in the acknowledgements section of Clichés of Urban Doom. She said she wanted to interview him for a project which she eventually discontinued (about RG and other women social scientists studying race).

Hilary Rose

Feminist sociologist of science, Emeritus Professor at Bradford University

E-mail

consultation

September 2017

Hilary tried to get a job with RG but I gathered that Ruth was not easy to get along with because she came across as condescending and belittling. Hilary wrote to me: "I hugely admired her work and put in for a job she was advertising. She asked me what I had read. I muttered, feeling embarrassed as it sounded like I was ingratiating myself, 'everything you have written' (should have added in English). I had also read almost everything on the LSE undergraduate multipage Modern Britain course but was too embarrassed to say so. I thought she was going to ask about housing newcomers. It was awful” (Sept. 27, 2017).

\section{Enzo Mingione}

Sociology professor at University of Milano-Bicocca

E-mail

consultation

September \& December 2017

Mica Nava mentioned him as someone who worked with RG. He is mentioned in the acknowledgements to Clichés of Urban Doom. He described "her sudden flight from Prague (where she had gone for a short visit as young journalist of a students' journal in order to interview some politician) to Wien and then to England in order to avoid persecutions."

\section{Michael Edwards}

UCL Teaching Fellow, The Bartlett School of Planning Faculty of the Built Environment E-mail consultation

September 2017

He wrote a blog post about RG at UCL; he also spoke at the UCL Urban Lab event that included a panel about RG; he connected me with Andrew Harris 


\section{Andrew Harris}

Co-Director of the UCL Urban Laboratory, convener of the Urban Studies MSc and

Senior Lecturer in the UCL Department of Geography

E-mail and phone

Consultation, informal interview/conversation, written notes

September 2017 \& April 17, 2018

He wrote me: "I draw on her writing in research I've done on both London and Bombay

(she also studied both cities). I also run a Masters module called 'London: Aspects of

Change' referencing her essay from $1964 . .$. I did manage to talk to several people who

knew her (although John Westergaard was unfortunately too ill to speak for very long)

and after much effort was able to contact her family but it hasn't been a straightforward process."

Nigel Harris

Economist and specialist in Urban and Economic Development and the Economics of Migration. He was Emeritus Professor of the Economics of the City at University College London. Formerly Research Fellow, Indian Statistical Institute, Calcutta; Deputy Director, Centre for Urban Studies, UCL. Research Fellow at Queen Elizabeth House, Oxford. Director of the DPU 1982-89. Policy Consultant to World Bank, to UNDP on the urban environment

E-mail

Consultation

September \& December 2017

RG was difficult to work with, controlling, micro-managing, uninterested in teaching or developing curricular materials, smoked a lot, was passionate, "obsessed" about her work in India and even went there against medical advice in the hot season and had to return to London with a severe case of heat stroke/exhaustion and she ended up in the hospital. She never learned to type or to drive so he would go over to her house on weekends and type up her letters to The Times (I found 35 articles/letters to the editor that she wrote between the ' 50 s and ' 80 s). Andrew Harris may have interviewed him as part of the UCL Urban Lab event.

\section{Tony Kushner}

Marcus Sieff Professor of the History of Jewish/non-Jewish Relations at Univ. of Southampton, Parkes Institute for the Study of Jewish/non-Jewish Relations and History Department; formerly historian for the Manchester Jewish Museum

E-mail

Brief consultation

October 17, 2017

Mica Nava forwarded me an email she had received from Tony Kushner, asking Mica if she would like to speak to Harold Pollins about his work with RG, after Tony had read Mica's article in Ethnicities (2013) "Ardently Sympathetic"; Mica sent me her e-mail exchange with Tony and suggested that I follow up with Tony. I then emailed Tony to 
ask him if I could correspond with Harold Pollins and then Tony connected me with Harold.

\section{Harold Pollins}

Anglo-Jewish historian especially modern Jewish history of Oxford, assisted (coauthored) London's Newcomers

E-mail

consultation

October 18, 2017

Harold Pollins (age 93) told me that RG never discussed her refugee background or her time in Germany. He also said that she was "flirtatious" toward men, wearing blue stockings with a garter below the knees. He felt that she had taken over his work with West Indians and refused to give him co-authorship. When a newspaper later called Pollins a co-author she said she would sue if they wrote that. He also told me that it was often said that she didn't get the posts she was qualified for because people did not "get on" with her. He also doesn't remember her saying anything about feminism (but he knew her in the late ' 50 s early ' 60 s so he says the movement wasn't really starting yet). Also, according to Pollins, RG didn't interact with West Indian women; Harold Pollins met Claudia Jones since he was assigned to the project on West Indians. 
VITA

\section{ABBY SUZANNE GONDEK}

Born, Fontana, California

2000-2004

B.A., Women's Studies and Psychology

Brandeis University

Waltham, Massachusetts

2006-2008

M.A., Women's Studies

San Diego State University

San Diego, California

2011-2013

M.S. Education, Teaching Urban Adolescents with Disabilities

Long Island University-Brooklyn

Brooklyn, New York

2013-2015

M.A. African and African Diaspora Studies

Florida International University

Miami, Florida

2016-2018

Ph.D. Candidate, Global and Socio-cultural Studies

Florida International University

Miami, Florida

\section{PUBLICATIONS AND PRESENTATIONS}

Gondek, Abby. 2017. "Book Review: Red Diaper Daughter: Three Generations of Rebels and Revolutionaries." Fat Studies 7(1):107-9.

Gondek, Abby. 2017. “Text Box 2: Does Black Matriarchy Exist in Brazil? Histories of Slavery and African Cultural Survivals in Afro-Brazilian Religion in Gender and Sexuality Chapter." Pp. 26-28 in Perspectives: An Open Invitation to Cultural Anthropology, edited by Nina Brown, Laura Tubelle De González, and Thomas McIlwraith. Arlington, VA: American Anthropological Association: Society for Anthropology in Community Colleges.

Gondek, Abby. 2017. "Ruth Landes, Candomblé Priestesses, and the Multiple Meanings of Afro-Bahiana Cloth Dolls, April 30, 2017." in Panel: Blackness, Identity, and African-derived Religion in Cuba and Brazil, organized by Norma Luisa Vasallo 
Barrueta. Lima, Peru: Latin American Studies Association International Congress, Theme: Diálogos de Saberes.

Gondek, Abby. 2017. "Intersectional Jewish Subjectivities: Jewish Women Social Scientists' 'Oppositional Culture' in Colonial Contexts, 1920-1970, February 11, 2017." in Table 13: Intersectionality Research. Albuquerque, New Mexico: Sociologists for Women in Society Winter Meeting, Theme: "Intersectionality and Privilege: Inclusive Feminist Praxis."

Gondek, Abby. 2016. "Gendered Late Style: Decolonized Relationships between Memory, History and Form in the Archive of Jewish American Anthropologist, Ruth Landes, November 12, 2016." in Panel: Jewish Perspectives on Decolonizing Ageism, organized by Sharon Leder. Montreal, Quebec: National Women's Studies Association Annual Conference: Decoloniality.

Gondek, Abby. 2016. "Race and Gender Hierarchies of Knowledge in Social Science Networks: Ruth Landes and the Debates about 'black Matriarchy' in Salvador, Bahia, Brazil 1938-1942, August 21, 2016." in Panel: Neglected Figures in the History of Sociology, organized by Martin Bulmer. Seattle, WA: American Sociological Association Annual Conference: Rethinking Social Movements.

Gondek, Abby. 2015. “Disappearing Objects at the Smithsonian's National Museum of Natural History Ethnology Department: What Happened to the Ruth Landes Ethnographic Object Collection? November 22, 2015." in Panel: Afterlives: Interventions in Museum Collections and Ethnographic Contexts, organized by Catherine Nichols. Denver, Colorado: American Anthropological Association: 114th annual meeting "Familiar/Strange."

Gondek, Abby. 2012. "Female Centaurs Transgressing the Borderlands: Race, Judaism and Gender in Brazil." Journal of Spanish, Portuguese and Italian Crypto Jews 4(Spring):115-34.

Gondek, Abby. 2009. “Identity Crisis: Integrating a Brazilian Women's Union in a Global Political Movement." Critical Half: Bi-annual Journal of Women for Women International 7(1):34-40.

Gondek, Abby. 2008. “I Am Black and Jewish: Black Jewish Women's Experiences in 'White' Jewish Communities in Brazil." P. 11 pages in UCLA Center for the Study of Women, Thinking Gender Papers. Los Angeles, CA: UCLA Center for the Study of Women.

Gondek, Abby. 2007. “The Same Taste.” Gender on Our Minds, A Journal of Southern Connecticut State University's Graduate Program in Women's Studies 1(1):11. 